\title{
Hanford Immobilized LAW Product Acceptance: Initial Tanks Focus Area Testing Data Package
}

\author{
J. D. Vienna \\ B. M. Jorgensen \\ A. Jiricka \\ D. E. Smith \\ B. P. McGrail \\ B. R. Allen \\ Pacific Northwest National Laboratory, Richland, Washington 99352 \\ J. C. Marra \\ K. G. Brown \\ D. K. Peeler \\ I. A. Reamer \\ Savannah River Technology Center, Aiken, South Carolina 29808 \\ W. L. Ebert \\ Argonne National Laboratory, Argonne, Illinois 60439
}

February 2000

Prepared for the U.S. Department of Energy

under Contract DE-AC06-76RLO 1830 


\title{
DISCLAIMER
}

This report was prepared as an account of work sponsored by an agency of the United States Government. Neither the United States Government nor any agency thereof, nor Battelle Memorial Institute, nor any of their employees, makes any warranty, expressed or implied, or assumes any legal liability or responsibility for the accuracy, completeness, or usefulness of any information, apparatus, product, or process disclosed, or represents that its use would not infringe privately owned rights. Reference herein to any specific commercial product, process, or service by trade name, trademark, manufacturer, or otherwise does not necessarily constitute or imply its endorsement, recommendation, or favoring by the United States Government or any agency thereof, or Battelle Memorial Institute. The views and opinions of authors expressed herein do not necessarily state or reflect those of the United States Government or any agency thereof.

\section{PACIFIC NORTHWEST NATIONAL LABORATORY operated by \\ BATTELLE MEMORIAL INSTITUTE for the \\ UNITED STATES DEPARTMENT OF ENERGY under Contract DE-AC06-76RLO 1830}

\author{
Printed in the United States of America \\ Available to DOE and DOE contractors from the \\ Office of Scientific and Technical Information, P.O. Box 62, Oak Ridge, TN 37831; \\ prices available from (615) 576-8401.
}

Available to the public from the National Technical Information Service, U.S. Department of Commerce, 5285 Port Royal Rd., Springfield, VA 22161 


\title{
Hanford Immobilized LAW Product Acceptance: Initial Tanks Focus Area Testing Data Package
}

\author{
$\begin{array}{lll}\text { J. D. Vienna } & \text { B. M. Jorgensen }\end{array}$ \\ A. Jiricka \\ D. E. Smith \\ B. P. McGrail \\ B. R. Allen
}

Pacific Northwest National Laboratory, Richland, Washington 99352

J. C. Marra

K. G. Brown

D. K. Peeler

I. A. Reamer

Savannah River Technology Center, Aiken, South Carolina 29808

W. L. Ebert

Argonne National Laboratory, Argonne, Illinois 60439

February 2000

Prepared for the U.S. Department of Energy

under Contract DE-AC06-76RLO 1830

Pacific Northwest National Laboratory

Richland, Washington 99352 


\section{Summary}

A matrix of 55 glasses was developed and tested with the aim to identify the impact of glass composition on long-term corrosion behavior and to develop an acceptable composition region for Hanford LAW glasses. Of the 55 glasses, 45 were designed to systematically vary the glass composition and 10 were selected because large and growing databases on their corrosion characteristics had accumulated. The targeted compositions of these glasses are listed in Section 3.1. All glasses were fabricated according to standard procedures and heat treated to simulate the slow cooling that occurs to a portion of the glass to be fabricated in the future vitrification plant at Hanford. The homogeneity of test glasses, characterized with electron and optical microscopy and X-ray diffraction, are discussed in Section 3.1. The densities of these glasses were measured with gas pycnometry and are reported in Section 3.2. The performance of these 55 glasses in the product consistency test (PCT) and the vaporhydration test (VHT) were characterized in Sections 3.5 and 3.6.

PCT series were performed at $90^{\circ} \mathrm{C}$ with glass surface area to solution-volume ratios (S/Vs) of $2000 \mathrm{~m}^{-1}$ for 7 days and $\mathrm{S} / \mathrm{V}$ values of $20,000 \mathrm{~m}^{-1}$ for 10,100 , and $1000 \mathrm{~h}$. The PCT corrosion extents, determined as functions of time from solution-composition analyses, are listed in Section 3.5. The normalized releases for the 1000 -h tests range from 0.1 to $6.3 \mathrm{~g} / \mathrm{m}^{2}$ for boron and from 0.1 to $7.2 \mathrm{~g} / \mathrm{m}^{2}$ for sodium. Based on the boron releases, the estimated release rates for these glasses range up to 1.0 and 0.1 $\mathrm{g} / \mathrm{m}^{2} / \mathrm{d}$ for periods of 1 and $1000 \mathrm{~h}$, respectively. The glasses with the highest boron release rates were HLP-31, -02, -39, -41, and -27 at $10 \mathrm{~h}$ and HLP-51, -41, -33, and -39, and -31 at $1000 \mathrm{~h}$. For the sodium data, the release rates range up to 0.7 and $0.2 \mathrm{~g} / \mathrm{m}^{2} / \mathrm{d}$ for periods of 1 and $1000 \mathrm{~h}$, respectively. The glasses with the highest sodium release rates were HLP-31, -02, -41, -39, and -27 at $1 \mathrm{~h}$ and HLP-52, -33, -41, 42 , and -31 at $1000 \mathrm{~h}$. Insufficient information concerning the alteration products formed during PCT was available to make a comparison to the VHT or other data.

VHTs were performed at temperatures between $150^{\circ} \mathrm{C}$ and $300^{\circ} \mathrm{C}$ for times up to 280 days. The preliminary alteration rates of most glasses have been determined at $200^{\circ} \mathrm{C}$. These rates, listed in Section 3.6.2, are preliminary and are expected to change as further data are generated. Rates measured at higher and lower temperatures were also reported in Section 3.6.4 for selected glasses. The glasses with high resistance to VHT (e.g., alteration rates $\leq 14 \mathrm{~g} / \mathrm{m}^{2} / \mathrm{d}$ ) take long times to corrode sufficiently for an accurate measurement of rate. For these glasses, the rates are likely to change when more data have been collected. The preliminary glass alteration rates ranged from 0.0 to $1219 \mathrm{~g} / \mathrm{m}^{2} / \mathrm{d}$ at $200^{\circ} \mathrm{C}$ and cover at least three orders of magnitude. The rates of only four glasses exceeded $100 \mathrm{~g} / \mathrm{m}^{2} / \mathrm{d}-\mathrm{HLP}-52$, HLP-53, HLP-02, and HLP-46. The remaining test matrix glasses are highly resistant to the VHT, possibly indicating high durability. The alteration products formed during VHT of selected glasses were characterized with XRD. Section 3.6.3 summarizes the phases found to form during the alteration of selected test glasses. Most tested samples altered to form analcime and sodium aluminum silicate hydrate, which are frequently formed also in other alteration tests.

The precision and accuracy of test methods were in Section 1.0 with data found in literature on the behavior of selected test matrix glasses in the PCT and VHT and with a series of glasses with the same targeted composition (repeated glasses) added to the test matrix. A comparison of results from PCT and VHT is discussed briefly in Section 1.0. 


\section{Glossary}

Accelerated tests tests conducted to attain certain conditions faster than it would be possible under natural conditions or tests conducted under conditions that increase the reaction rate

AES

AGCR

Alteration

products

Amount of glass dissolved

ANL

ASTM

Behavior

Corrosion

Corrosion layer

Corrosion rate

Dissolution

DIW

DOE

$\mathrm{E}_{\mathrm{a}}$

EDS

HLP

HLW

HVV

IA

ICP

ILAW

LAW

LRM

$\mathrm{m}_{\mathrm{d}}$

$\mathrm{OM}$

PA

PCT

PCT-A atomic emission spectroscopy

acceptable glass composition region

thermodynamically more stable phases formed during glass corrosion. These phases may incorporate constituents from glass and other species from the solution, atmosphere, and barrier materials.

mass of glass dissolved, calculated from the thickness of glass reacted, which is determined by subtracting the remaining glass layer thickness (determined by $\mathrm{OM} / \mathrm{IA}$ ) from initial glass thickness

Argonne National Laboratory

American Society for Testing and Materials

the response of a material to its environment, specifically to the temperature and solution chemistry

the process of glass dissolution and conversion to alteration products

layer of corrosion products formed on the surface of bulk glass

the rate at which glass is dissolved or converted to alteration products

the process of dissolving solid material into the solution

deionized water

U.S. Department of Energy

apparent activation energy

energy dispersive spectroscopy

Hanford LAW product acceptance (glass nomenclature)

high-level waste

Hanford Vitrification Vendor

image analysis

inductively coupled plasma

immobilized low-activity waste

low-activity waste

low-activity waste reference material

mass of glass altered in $\mathrm{g} / \mathrm{m}^{2}$

optical microscopy

performance assessment

Product Consistency Test

method A of the PCT as defined in ASTM (1998) 
PCT-B method B of the PCT as defined in ASTM (1998)

PDF powder diffraction file

Performance the ability of the burial system, primarily waste form in this work, to meet regulatory limits on release of radioactive and hazardous components

PNNL Pacific Northwest National Laboratory

$\mathrm{r} \quad$ alteration rate in $\mathrm{g} / \mathrm{m}^{2} / \mathrm{d}$

repeated glasses multiple glasses with the same target composition, fabricated and tested separately

S/V glass surface area to solution volume ratio

SEM scanning electron microscopy

SRTC Savannah River Technology Center

SRTC-ML SRTC mobile laboratory

t time

TBD to be determined

TFA Tanks Focus Area

VHT Vapor Hydration Test

XRD X-ray diffraction 


\section{Acknowledgments}

The authors would like to acknowledge the following individuals for their contribution to this work:

- P. Hrma and D. M. Strachan for assistance in crafting the vapor-hydration test procedure and frequent, helpful discussions and advice

- $\quad$ E. W. Holtzscheiter for management and guidance

- C. A. Babel, P. Hrma, J. M. Perez, L. M. Peurrung, G. F. Piepel, D. M. Strachan, and G. Wicks for careful review and suggestions on this document

- D. E. Clark, P. M. Dove, J. A. Gentilucci, P. Hrma, J. D. Rimstidt, J. H. Simmons,

D. M. Strachan, T. Weber, M. C. Weinberg, and F. E. Woolley for project review and guidance

- Y. Su for assitance in VHT phase identification

- M. J. Schweiger and J. V. Crum for help in the laboratory

- B. W. Arey, J. S. Young, and J. E. Coleman for help with scanning electron microscopy/energydispersive spectroscopy of vapor-hydration test samples

- W. C. Cosby for assistance in editing this document.

This study was funded by the U.S. Department of Energy's Offices of Science and Technology through the Tanks Focus Area and River Protection. Pacific Northwest National Laboratory is operated for DOE by Battelle under Contract DE-AC06-76RLO 1830. Westinghouse Savannah River Company is operated for DOE under Contract DE-AC09-89SR 18035. Argonne National Laboratory is operated for DOE by the University of Chicago under Contract W-31-108-ENG-38. 


\section{Contents}

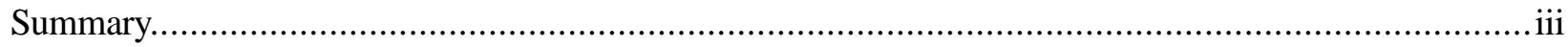

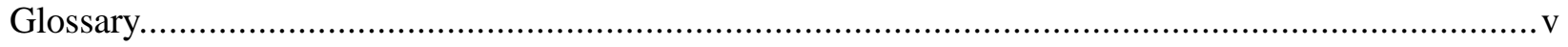

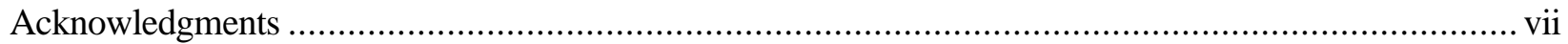

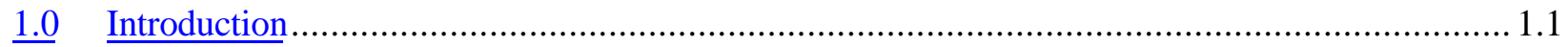

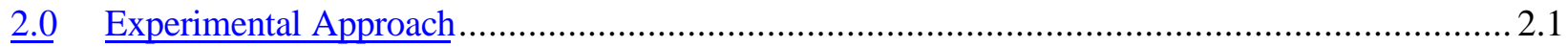

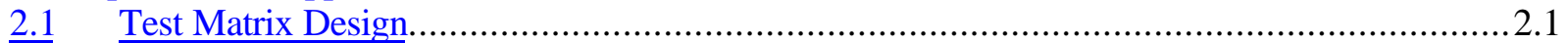

2.2 Glass Fabrication and Heat Treatment......................................................................... 2.5

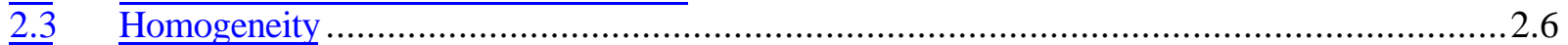

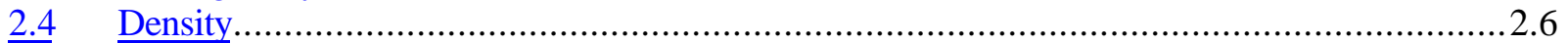

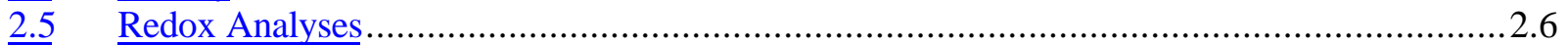

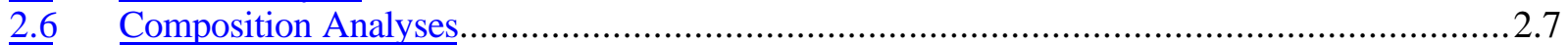

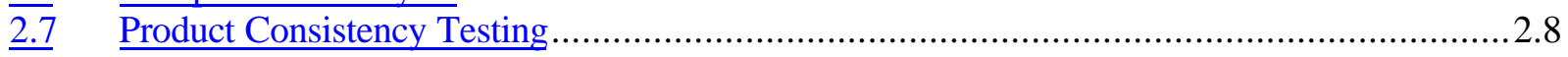

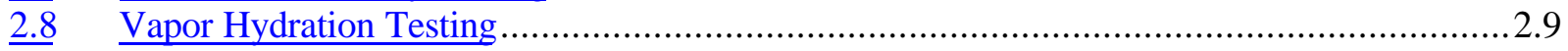

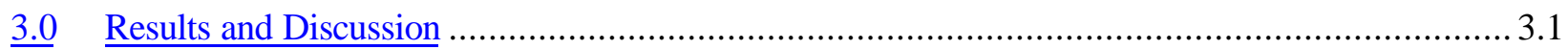

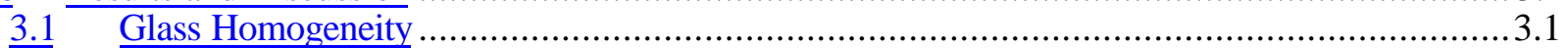

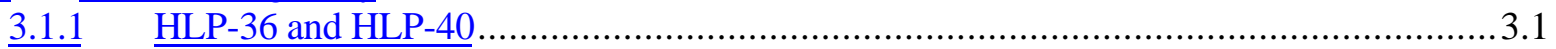

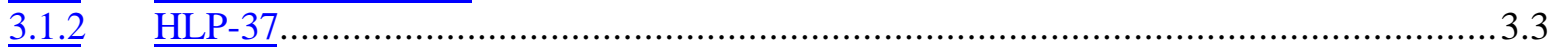

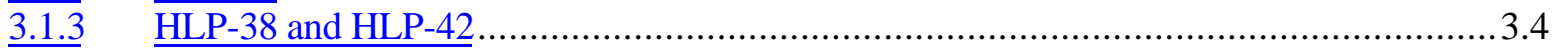

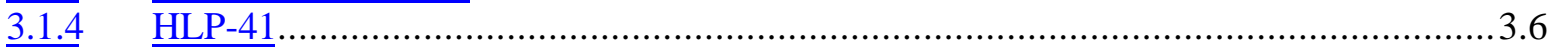

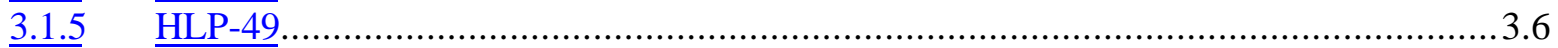

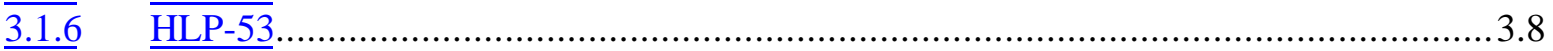

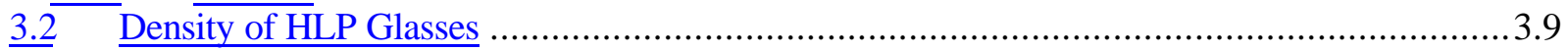

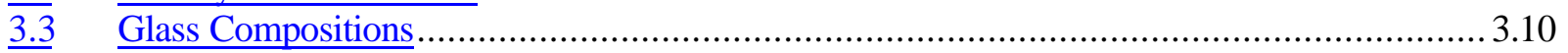

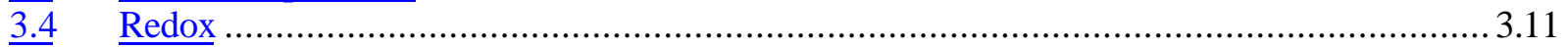

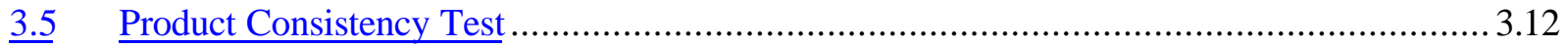

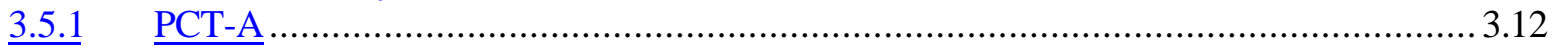

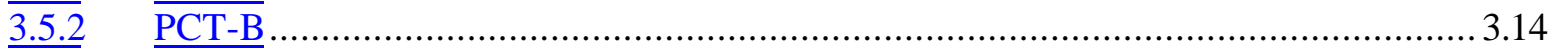

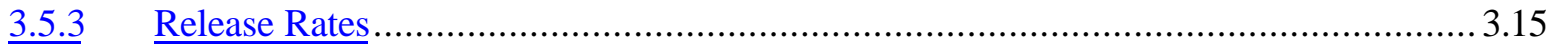

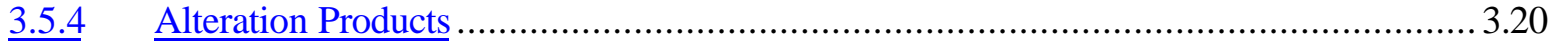

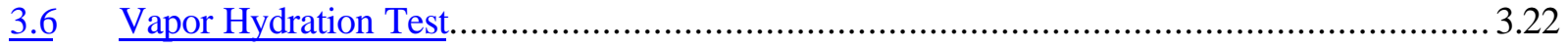

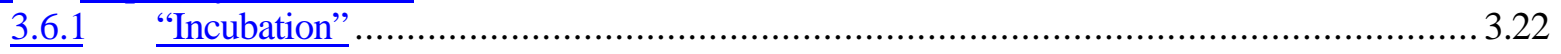

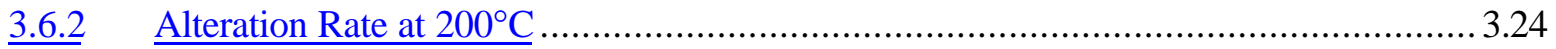

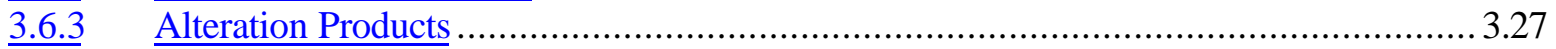

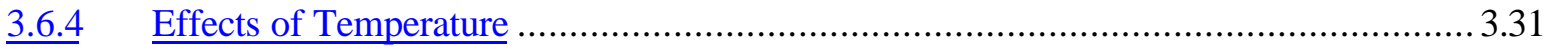

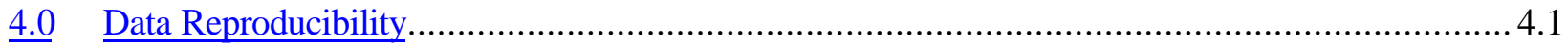

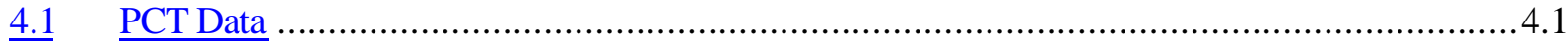

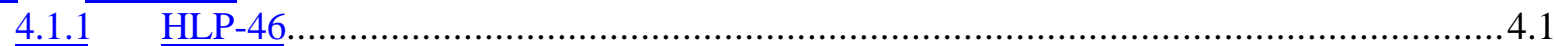

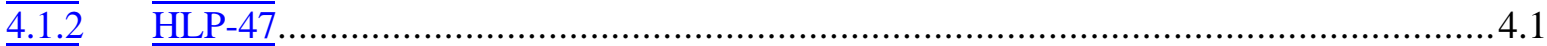

4.1.3 $\quad$ HLP-48

4.1.4 $\quad$ HLP-54

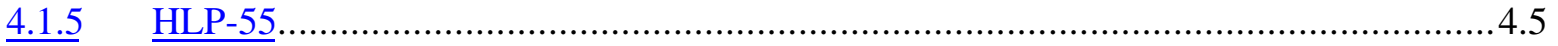

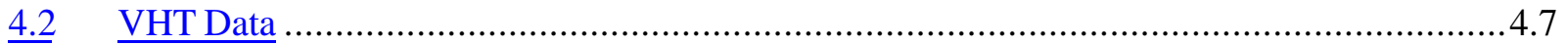

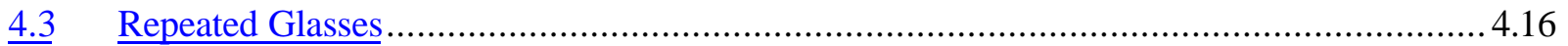

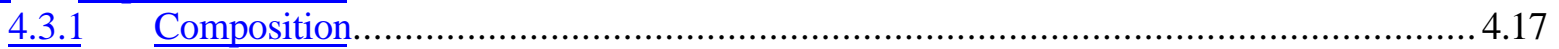

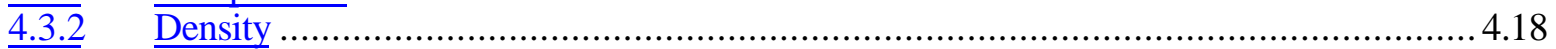

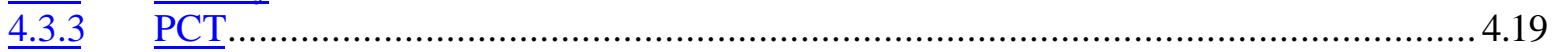


$\underline{5.0}$ Comparison Between Test Methods ….................................................................... 5.1

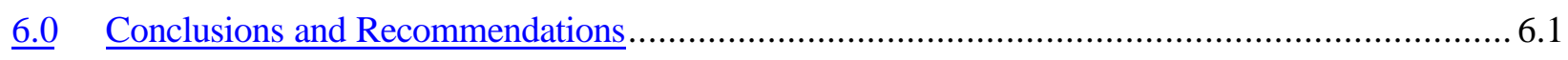

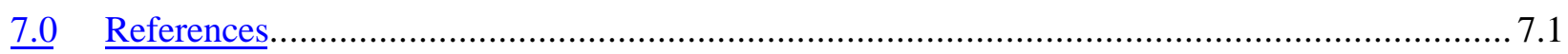

Appendices

A Target and Measured Composition Information for the HLP Glasses.......................... A.1

B PCT-A, PCT-B, and Corrosion Information for the HLP Glasses ........................... B.1

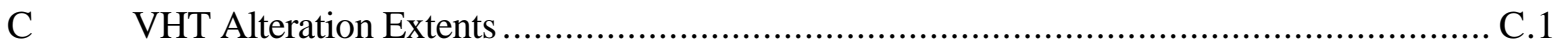

D VHT Alteration Extent as a Function of Time (plots) ............................................. D. 1

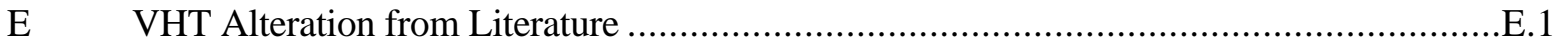

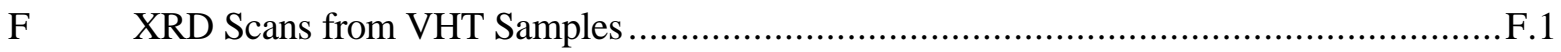

\section{Figures}

Figure 2-1. Computed Thermal Cooling Curve for $1.2 \times 1.2 \times 1.8 \mathrm{~m}$ Waste Package ........................2.5

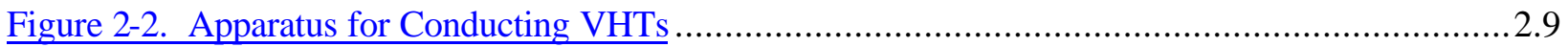

Figure 2-3. Measurement of Remaining Glass Layer in Transmitted Light OM (lengths of remaining glass layer are listed above each measurement) ….......................................................... 2.10

Figure 3-1. XRD Pattern of Inhomogeneous Glasses (with the "amorphous hump" subtracted) ............3.1

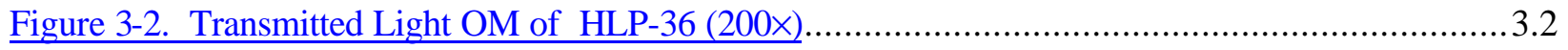

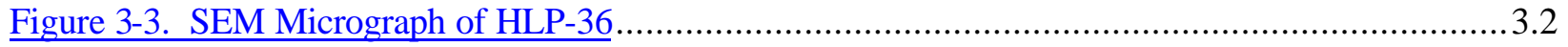

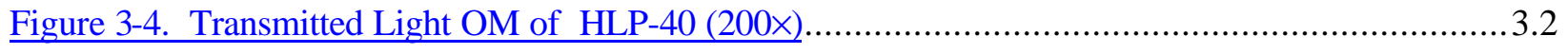

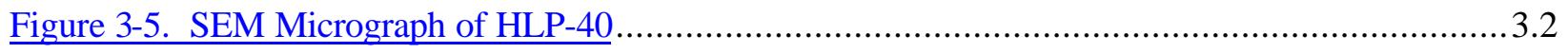

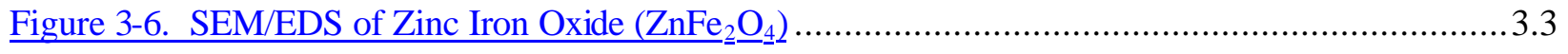

Figure 3-7. SEM/EDS of Hematite $\left(\mathrm{Fe}_{2} \underline{\mathrm{O}}_{3}\right.$ ), where Iron is Substituted by Ti.................................3.3

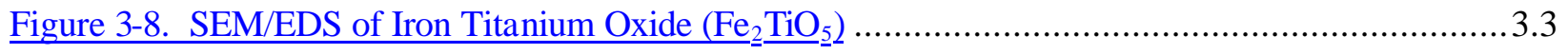

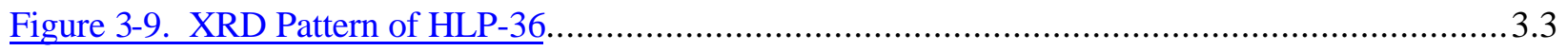

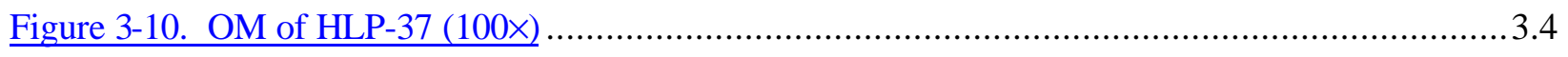

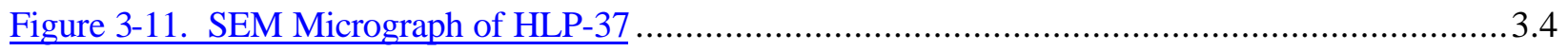

Figure 3-12. SEM/EDS of Carnegieite Low $\left[\mathrm{Na}\left(\mathrm{AlSiO}_{4}\right)\right]$ - Dark Gray Phase …............................. 3.4

Figure 3-13. SEM/EDS of Carnegieite Low $\left[\mathrm{Na}\left(\mathrm{AlSiO}_{4}\right)\right]$ - Light Gray Phase ............................... 3.4

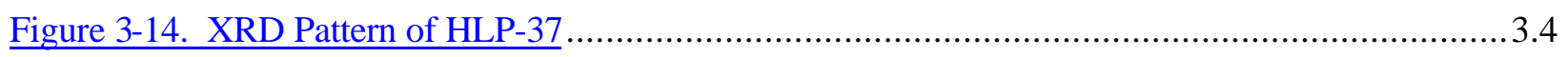

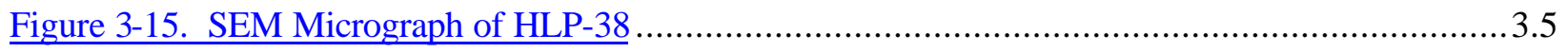

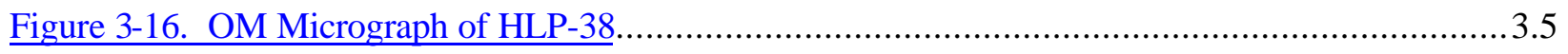

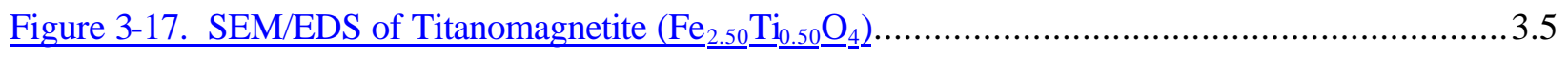

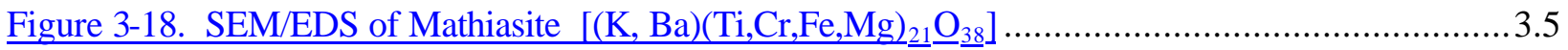




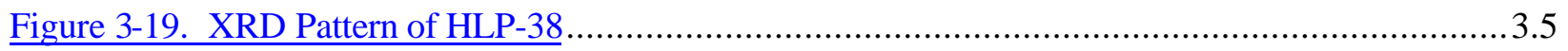

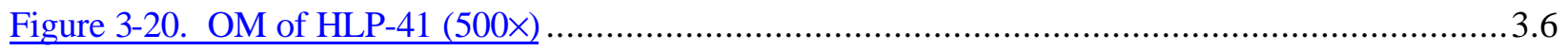

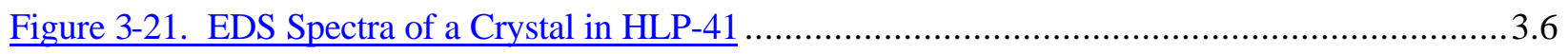

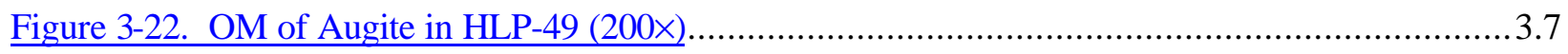

Figure 3-23. SEM Micrograph of Augite and Zinc Iron Oxide (on top) in HLP-49 …........................ 3.7

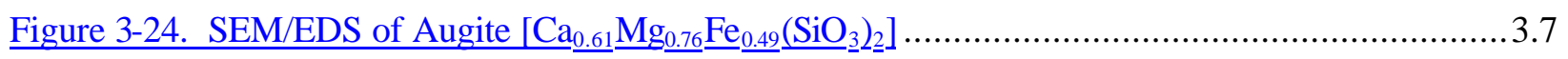

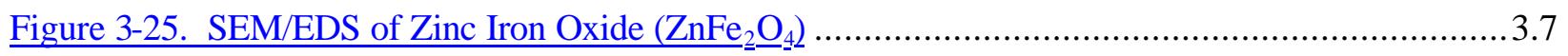

Figure 3-26. SEM Micrograph of Pt, Augite (background), and Zinc Iron Oxide in HLP-49 ............... 3.7

Figure 3-27. EDS Spectra of a Pt particle in HLP-49 ......................................................... 3.7

Figure 3-28. Photograph of HLP-53 Glass Monolith after Heat Treatment....................................... 3.8

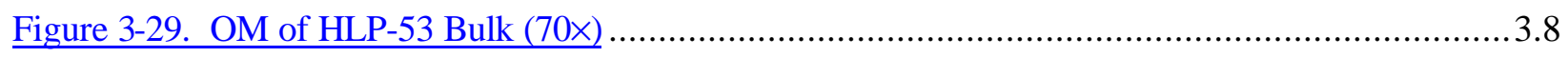

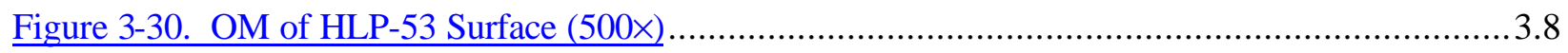

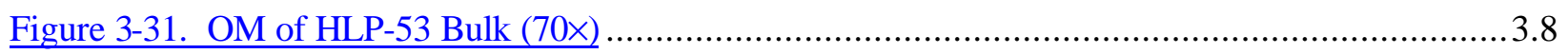

Figure 3-32. Effect of $\mathrm{p}_{02}$ on Measured Glass Redox............................................................ 3.12

Figure 3-33. Log-Log Plot Illustrating the Normalized Sodium versus Boron Releases for the

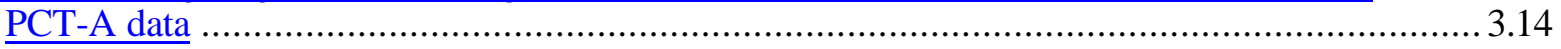

Figure 3-34. Log-Log Plot Illustrating the Normalized Sodium versus Boron Releases for the

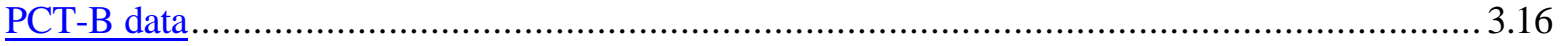

Figure 3-35. Illustration of the Relationship Between the Boron and Sodium Normalized Releases, $\mathrm{NL}_{\mathrm{i}}$ in $\mathrm{g} / \mathrm{m}^{2}$, and Time, $\mathrm{t}$ in $\mathrm{h}$, for the HLP-01 Glass. .................................................... 3.17

Figure 3-36. Boron Release Rate Estimates for the HLP-01 Glass.............................................. 3.18

Figure 3-37. SEM Images of Reacted HLP-39 Glass from PCT Conducted $1000 \mathrm{~h}$ at $90^{\circ} \mathrm{C}$ and $\underline{20,000 \mathrm{~m}^{-1} \text {. (a) Moderate magnification showing uniform size and appearance of particles }}$ and (b) High magnification showing pristine appearance of surface.

Figure 3-38. VHT Tests on HLP- 46 Glass at $175^{\circ} \mathrm{C}$ up to 12 Days; Triangles Represent Data in the Incubation Time that Were Excluded from Linear Regression .............................................. 3.23

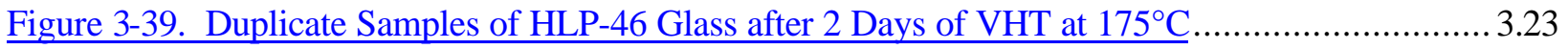

Figure 3-40. Photograph of a Sample of HLP-46 Glass after 3 Days of VHT at $175^{\circ} \mathrm{C}$ (a) and Optical Micrograph of the Cross Section of the Same Sample (b) ................................................ 3.24

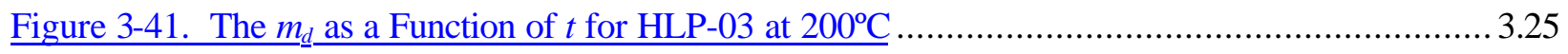

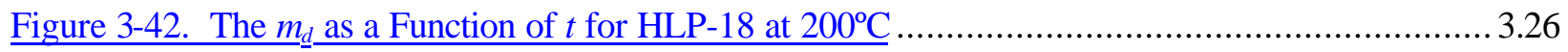

Figure 3-43. SEM Micrograph of Analcime Formed During the Alteration of HLP-48 at $175^{\circ} \mathrm{C}$

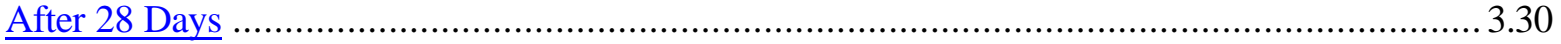

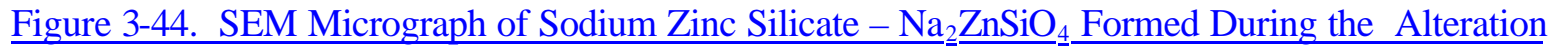

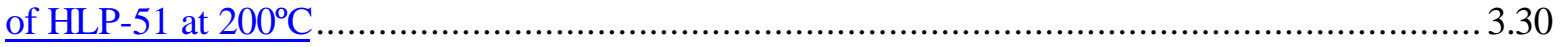

Figure 3-45. Amount of HLP-46 Dissolved in VHT at $150^{\circ} \mathrm{C}, 175^{\circ} \mathrm{C}$, and $200^{\circ} \mathrm{C}$ as Functions of $t \ldots 3.32$

Figure 3-46. Amount of HLP-48 Dissolved in VHT at $150^{\circ} \mathrm{C}, 175^{\circ} \mathrm{C}, 200^{\circ} \mathrm{C}$, and $250^{\circ} \mathrm{C}$ as

Functions of $t$..... 
Figure 3-47. Amount of HLP-51 Dissolved in VHT at $200^{\circ} \mathrm{C}, 250^{\circ} \mathrm{C}, 275^{\circ} \mathrm{C}$, and $300^{\circ} \mathrm{C}$ as

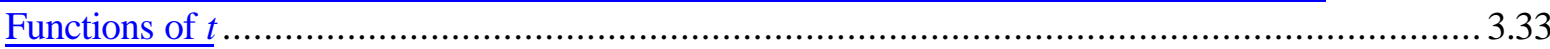

Figure 3-48. Effect of Temperature on rate for HLP-46, HLP-48, HLP-51................................... 3.34

Figure 3-49. Comparison of XRD Patterns for HLP-46 Subjected to VHT at Different Temperatures. 3.35

Figure 3-50. Comparison of XRD Patterns for HLP-46 Subjected to VHT at $200^{\circ} \mathrm{C}$ for $1,2,3$, and

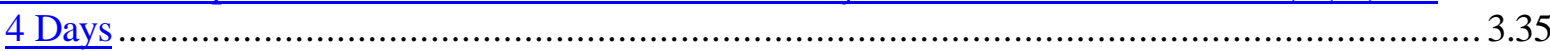

Figure 3-51. XRD Pattern of HLP-46 Subjected to VHT at $200^{\circ} \mathrm{C}$ for 4 Days .....................................3.36

Figure 3-52. Comparison of XRD Patterns for HLP-48 Subjected to VHT at Different Temperatures. 3.37

Figure 3-53. Comparison of XRD Patterns for HLP-48 Subjected to VHT at $200^{\circ} \mathrm{C}$ for 3,11 , and

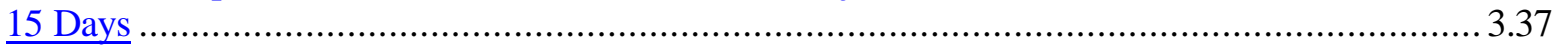

Figure 3-54. XRD Pattern of HLP-48 Subjected to VHT at $200^{\circ} \mathrm{C}$ for 20 Days .................................3. 38

Figure 4-1. Relationships Between the Boron and Sodium Releases, $\mathrm{NL}_{\mathrm{i}} \mathrm{in} \mathrm{g} / \mathrm{m}^{2}$, and Time for

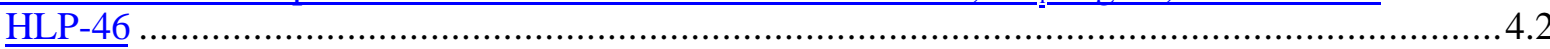

Figure 4-2. Boron (on the left) and Sodium (on the right) PCT-A Measurements for HLP-47

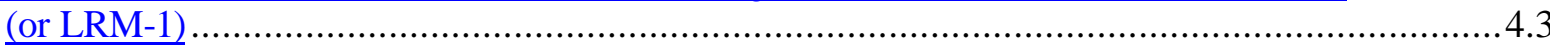

Figure 4-3. Relationships Between Normalized Boron and Sodium Rele ases, $\mathrm{NC}_{\mathrm{i}}$ in $\mathrm{g} / \mathrm{L}$, as Functions

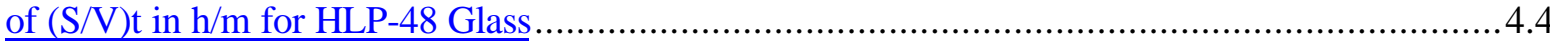

Figure 4-4. Relationships Between Normalized Boron and Sodium Releases, $\mathrm{NC}_{i}$ in g/L, as Functions

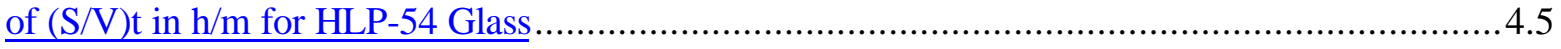

Figure 4-5. Relationships Between Normalized Boron and Sodium Releases, $\mathrm{NC}_{\mathrm{i}}$ in g/L, as Functions of (S/V)t in h/m for HLP-55 Glass .................................................................. 4.6

Figure 4-6. The $m_{d}$ of HLP-48 as a Function of Volume of Water in the Vessel...............................4.8

Figure 4-7. The rate of HLP-48 as a Function of Volume of Water in the Vessel...............................4.8

Figure 4-8. The $m_{d}$ of HLP-48 as a Function of $t$ for Different Volumes of Water ............................4.9

Figure 4-9. The $\mathrm{m}_{\mathrm{d}}$ of HLP-51 as a Function of Volume of Water in the Vessel.............................. 4.10

Figure 4-10. HLP-51 Glass after 1.5 Days at $300^{\circ} \mathrm{C}$ with (a) $0.9 \mathrm{~mL}$ and (b) $1.4 \mathrm{~mL}$ of Water ......... 4.10

Figure 4-11. The Rate of HLP-51 as a Function of Volume of Water in the Vessel........................ 4.11

Figure 4-12. The $m_{d}$ of HLP-51 as a Function of $t$ for Different Volumes of Water ….................... 4.11

Figure 4-13. The $\mathrm{m}_{\mathrm{d}}$ as a Function of $\mathrm{t}$ for HLP-46 at $175^{\circ} \mathrm{C}$ Tested at PNNL in May 1999 and

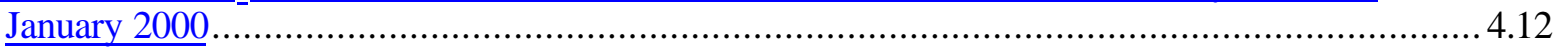

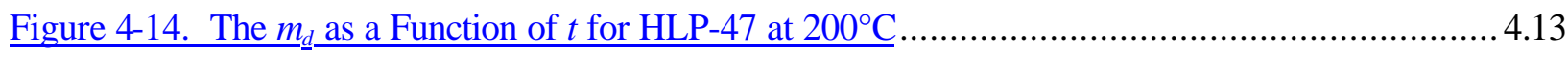

Figure 4-15. The $\mathrm{m}_{\mathrm{d}}$ as a Function of $\mathrm{t}$ for HLP- 48 at $200^{\circ} \mathrm{C}$ Tested at PNNL in May 1999 and

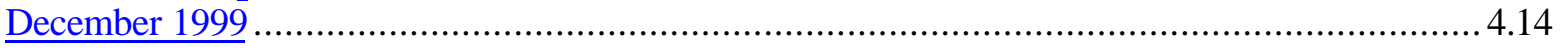

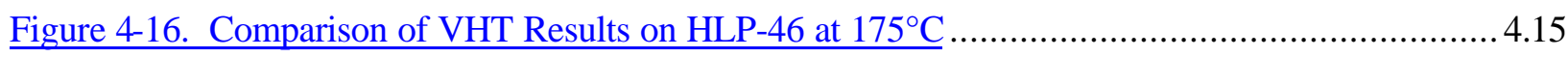

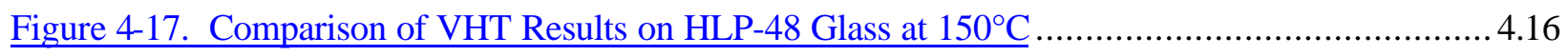

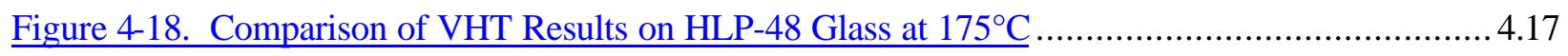

Figure 4-19. Density Range (2 standard deviations) for Repeated Glasses .................................. 4.19 
Figure 4-20. PCT-A Results for the Four HLP Glasses (i.e., HLP-01, -25, -26, and -43) Batched by

PNNL and SRTC to the Same Target Composition ................................................................ 4.20

Figure 4-21. Normalized PCT-A Results, $\mathrm{NL}_{\mathrm{i}}$ in $\mathrm{g} / \mathrm{m}^{2}$, for the Four HLP Glasses (i.e., HLP-01, -25,

-26, and -43) Batched by PNNL and SRTC to the Same Target Composition.............................. 4.21

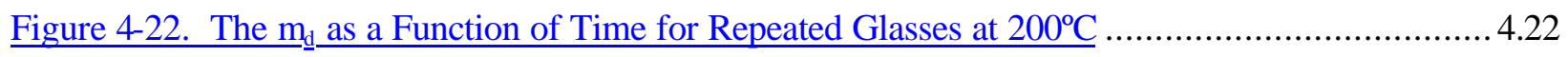

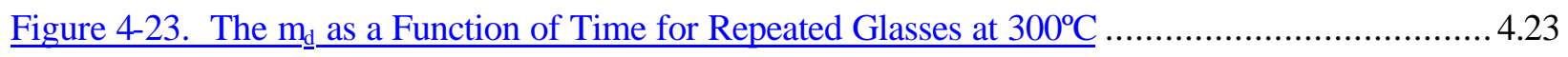

Figure 5-1. Comparison of 1000-h PCT Release to $200^{\circ} \mathrm{C}$ VHT Alteration Rate ..............................5.3

\section{Tables}

Table 2-1. Target Compositions (in mass\% of oxides) of the Hanford LAW Product-Acceptance

Glasses.

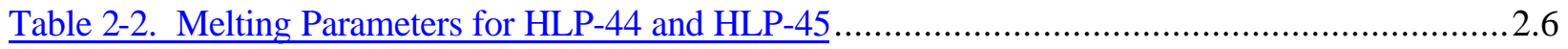

Table 2-3. Elemental Analysis Based on Dissolution Procedure and Analytical Technique .................2.8

Table 3-1. List of Phases Identified in HLP-36 and -40 With XRD ..................................................

Table 3-2. List of Phases Identified in HLP-37 .............................................................................. 3.3

Table 3-3. Phases Identified in HLP-38 and HLP-42 With XRD .................................................... 3.5

Table 3-4. List of Phases Identified in HLP-49 with XRD ............................................................. 3.6

Table 3-5. Comparison of Composition for Different Samples of HLP-53 (mass \%) ........................... 3.9

Table 3-6. Density of HLP Glasses (heat treated and powdered unless otherwise noted) ................... 3.10

Table 3-7. Melting Oxygen Partial Pressure and Measured Redox of HLP-26, -44, and -45.............. 3.11

Table 3-8. Comparison of Mean $\mathrm{NC}_{\mathrm{B}}$ for Selected Glasses Calculated with the Assumptions of Lognormal and Normal Distributions of Data 3.13

Table 3-9. Estimated Relative Percent Standard Deviations in Release Estimates............................. 3.19

Table 3-10. Rank Ordering of Release Rates for the HLP Glasses Based Upon PCT-B Data.............. 3.20

Table 3-11. Preliminary VHT Alteration Rates and Major Alteration Products at $200^{\circ} \mathrm{C} \ldots \ldots \ldots \ldots \ldots \ldots . . . . . . .3 .25$

Table 3-12. HLP Glasses Listed in Order of rate and Grouped into Three Categories ....................... 3.27

Table 3-13. Crystalline Phases Identified in VHT Samples with XRD .......................................... 3.28

Table 3-14. Crystalline Phases from Table 3-13 and Their Content (\%) in Analyzed VHT Samples ... 3.28

Table 3-15. Preliminary $r \mathrm{~s}$ (in $\mathrm{g} / \mathrm{m}^{2} / \mathrm{d}$ ) of Test Glasses Subjected to VHT at Various Temperatures... 3.32

Table 4-1. PNNL PCT-B Test Results for HLP-46 ................................................................. 4.2

Table 4-2. PNNL PCT-B Test Results for HLP-54 .................................................................. 4.4

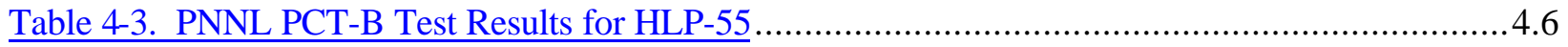

Table 4-4. Comparison of Test Parameters ......................................................................... 4.14 
Table 4-5. Target Compositions (in mass $\%$ of oxides) and Measured Compositions (in mass $\%$ of oxides) for the Replicate Hanford LAW Product-Acceptance (HLP) "Center" Glasses ( $\mathrm{Li}_{2} \underline{\mathrm{O}, \mathrm{Cl}, \mathrm{SO}_{3}} \underline{\mathrm{P}}_{2} \underline{\mathrm{O}}_{2}$, $\underline{\mathrm{F}, \mathrm{ReO}_{2}}$, and $\mathrm{MoO}_{3}$, not included here, can be found in Table A-1) …................................... 4.18

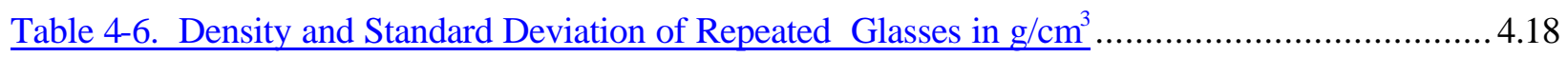

Table 4-7. PCT-A Variance Components Estimates for the PNNL "Replicate" Glasses..................... 4.21

Table 4-8. Comparison of Rates (in $\mathrm{g} / \mathrm{m}^{2} / \mathrm{d}$ ) and Test Durations for Repeated Glasses...................... 4.22

Table 5-1. Summary of Results from PCT $\left(\mathrm{NL}_{\mathrm{i}}\right.$ in $\left.\mathrm{g} / \mathrm{m}^{2}\right)$ and VHT of Heat-Treated Glasses ................5.1 


\subsection{Introduction}

The Hanford Site's mission has been to produce nuclear materials for the U.S. Department of Energy (DOE) and its predecessors. A large inventory of radioactive and mixed waste, largely generated during plutonium production, exists in 177 underground single- and double-shell tanks. These wastes are to be retrieved and separated into low-activity waste (LAW) and high-level waste (HLW) fractions. The total volume of LAW requiring immobilization will include the LAW separated from the tank waste, as well as new wastes generated by the retrieval, pretreatment, and immobilization processes. Per the TriParty Agreement (1994), both the LAW and HLW will be vitrified. It has been estimated that vitrification of the LAW waste will result in over 500,000 metric tons or 200,000 $\mathrm{m}^{3}$ of immobilized LAW (ILAW) glass.

DOE is proceeding with an approach to privatize the treatment and immobilization of Hanford's LAW and HLW. DOE will deliver these wastes to a private contractor for treatment and immobilization and will receive the products (immobilized waste) for storage and ultimate disposal. The ILAW glass is to be disposed of onsite in a near-surface burial facility. It must be demonstrated that the disposal system will adequately retain the radionuclides and prevent contamination of the surrounding environment. Waste-form performance is the first line of defense against releases of contaminants after disposal and an integral part of the multiple engineered barrier system. Mann et al. (1998) found that the release of radionuclides from the waste form via interaction/reaction with water is the prime threat to the environment surrounding the disposal site. The two major dose contributors in Hanford ILAW glass that must be retained are ${ }^{99} \mathrm{Tc}$ and ${ }^{79} \mathrm{Se}$ (Mann et al. 1998).

McGrail et al. (1998) describe the strategy for testing and modeling to determine/assess the radionuclide release rates from ILAW glass. This strategy requires extensive testing and modeling for each glass considered. The program includes, for example, in situ testing, tests with waste-package components, tests that simulate the hydrology and geochemistry of the burial site, and coupled flowreaction modeling. The resources required to perform such a thorough study on a large number of glasses are not practical. The Tanks Focus Area (TFA) Immobilization Program, DOE-EM Office of Science and Technology, has outlined a task to help reduce DOE's risk of accepting an ILAW glass that will not meet performance expectations. The TFA task is highly integrated with the Performance Assessment (PA) task described by McGrail et al. (1998). The goal of the PA task is to determine the long-term performance of the Hanford vitrification vendor (HVV) glass to be buried in the Hanford Site near a surface-disposal facility. The goal of the TFA task is to relate the long-term performance to glass composition and to provide a means for screening glass compositions proposed by the HVV.

In this study (the TFA task), a team from Pacific Northwest National Laboratory (PNNL) and Savannah River Technology Center (SRTC) is measuring the impacts of systematic glass-composition variation on the responses from accelerated laboratory corrosion tests of representative LAW glasses. A committee of experts, assembled to identify the appropriate testing program, determined that no single short-term test or pair of short-term tests was capable of determining the long-term performance of a waste glass (Vienna et al. 1999). However, the committee did conclude that the combination of two tests, the product consistency test (PCT) and vapor-hydration test (VHT), could give valuable indications of the relative rate at which a glass could be expected to corrode in the burial scenario. ${ }^{a}$ These data are being generated and will be used to

\footnotetext{
${ }^{\text {a }}$ To fully understand the long-term performance of a glass additional testing is required. McGrail et al. (1998 and 1999) discuss how this information is being gathered for a few selected glasses.
} 
- quantify the effect of glass composition on response to PCT and VHT

- supply selected glass compositions to the PA Program for further testing (along with PCT and VHT results)

- help identify the appropriate glass-acceptance specifications for the HVV in concert with other DOE activities

- supply a database to support glass-acceptance specifications and support the PA by giving an indication of the range of test responses and possibly identify an irregularities in glass behavior.

This is planned to be a two-stage task; the first stage, described in this report, is nearing completion. The second stage will be planned based on the knowledge gained from the first stage and concurrent work on the Hanford PA study (described by McGrail et al. 1998) and the glass development program of the HVV. In the second stage, a second tier of glass compositions will be designed and tested to account for any additional components introduced by the HVV and to better cover the initial composition region. Additional tests may also be performed on existing glasses, if needed, to better understand glass behavior. This report provides the status for the first stage of testing and recommends possible approaches for the next stage. 


\subsection{Experimental Approach}

Fourty-five glasses with systematically varying compositions were fabricated along with ten additional glasses, including glasses similar to those being considered by the HVV. The glasses were heat treated to simulate slow cooling that is expected to occur during plant operation. The homogeneity, density, and chemical composition of test glasses were measured. The responses of each glass to the VHT and the PCT were measured.

\subsection{Test Matrix Design}

A matrix of 55 glasses was developed and tested with the aim to identify the relationship between glass composition and response to the PCT and VHT (Vienna et al. 1999). The target compositions of these Hanford LAW product-acceptance (HLP) glasses are listed in Table 2-1. They are split into four groups of glasses:

1. The first 24 glasses contained variations in nine components- $\mathrm{SiO}_{2}, \mathrm{Al}_{2} \mathrm{O}_{3}, \mathrm{~B}_{2} \mathrm{O}_{3}, \mathrm{Fe}_{2} \mathrm{O}_{3}, \mathrm{TiO}_{2}, \mathrm{ZnO}$, $\mathrm{ZrO}_{2}, \mathrm{MgO}$, and waste (primarily $\mathrm{Na}_{2} \mathrm{O}$ ) —one-at-a-time (HLP-01 through -24) from a central composition (HLP-01). These glasses give a direct indication of the impact of each of these oxides on the behavior of glasses in the testing program. Glasses HLP-44 and -45 have the same target composition as HLP-01, but were melted and heat treated under reducing atmospheres to increase the ratio of two valent to total iron $(\mathrm{Fe}(\mathrm{II}) / \mathrm{Fe})$.

2. Four glasses (HLP-01, -25, -26, and -43) have the same target composition and were fabricated and tested separately to assess the reproducibility of the glass fabrication and test procedures.

3. Sixteen glasses (HLP-27 through -42) varied four components at a time- $-\mathrm{SiO}_{2}, \mathrm{Al}_{2} \mathrm{O}_{3}, \mathrm{~B}_{2} \mathrm{O}_{3}$, and waste (primarily $\mathrm{Na}_{2} \mathrm{O}$ ) - to assess the interactive effects of the components expected to have the largest effect on glass behavior in corrosion testing.

4. The final 10 glasses (HLP-46 through -56) (see below) were included because large and growing databases on their corrosion characteristics had accumulated:

- HLP-46 is the LD6-5412 glass that was characterized by Kim et al. (1995), Feng et al. (1996), and McGrail et al. (1997a,b). ${ }^{a}$ This glass expands the composition ranges of test glasses to higher concentrations of $\mathrm{SiO}_{2}, \mathrm{CaO}$, and $\mathrm{K}_{2} \mathrm{O}$.

- HLP-47 is the low-activity waste reference material (LRM) glass that was characterized by Wolf et al. (1998) and Ebert and Wolf (1999). This glass increases the range of $\mathrm{SiO}_{2}, \mathrm{~K}_{2} \mathrm{O}$, $\mathrm{Cl}^{-}$, and $\mathrm{F}$ concentrations in the test glasses.

- HLP-48 is the LAW-A33 glass that was characterized by McGrail et al. (1999). This glass represents a composition that may be processed by the HVV.

- HLP-49 is the LAW-B, also known as LAW-B29, that was characterized by Ferrara et al. (1998). It expands the composition ranges of the study to lower $\mathrm{Na}_{2} \mathrm{O}$ concentrations and higher $\mathrm{CaO}$ and $\mathrm{Li}_{2} \mathrm{O}$ concentrations and represents a composition that may be processed by the HVV.

- HLP-51 is the LAW-ABP1 glass that was characterized by McGrail et al. (1998 and 1999). This glass introduces $\mathrm{La}_{2} \mathrm{O}_{3}$ as a glass component.

\footnotetext{
${ }^{a}$ W. L. Ebert, A. J. Bakel, D. M. Strachan, and S. F. Wolf. 1998. Laboratory Testing of LD6-5412 Glass, DRAFT, Argonne National Laboratory, Argonne, Illinois.
} 
- HLP-52 is the Han-28 glass that was characterized by McGrail et al. (1999). This glass expands the composition ranges to lower $\mathrm{B}_{2} \mathrm{O}_{3}$ and $\mathrm{Fe}_{2} \mathrm{O}_{3}$ concentrations and higher $\mathrm{Na}_{2} \mathrm{O}$ and $\mathrm{P}_{2} \mathrm{O}_{5}$ concentrations.

- HLP-53 is the LAW-A23 glass that was characterized by McGrail et al. (1998 and 1999). This glass represents a composition that may be processed by the HVV and expands the range of composition to higher $\mathrm{CaO}$ concentrations.

- HLP-54 is the L4-912 glass that was characterized by Kim et al. (1995) and Feng et al. (1996). ${ }^{\text {a }}$ This glass expands the composition ranges to higher concentrations of $\mathrm{Al}_{2} \mathrm{O}_{3}$ and $\mathrm{SiO}_{2}$ and lower concentrations of many glass components.

- HLP-55 is the L4-99 glass that was characterized by Kim et al. (1995) and Feng et al. (1996). ${ }^{\mathrm{a}}$ This glass expands the composition ranges to higher $\mathrm{SiO}_{2}$ concentration and lower concentrations of many glass components.

- HLP-56 is the LAW-A44 glass that was characterized by McGrail et al. (1999). The composition of this glass is proprietary.

${ }^{a}$ W. L. Ebert, A. J. Bakel, D. M. Strachan, and S. F. Wolf. 1998. Laboratory Testing of LD6-5412 Glass, DRAFT, Argonne National Laboratory, Argonne, Illinois. 
Table 2-1. Target Compositions (in mass\% of oxides) of the Hanford LAW Product-Acceptance Glasses

\begin{tabular}{|c|c|c|c|c|c|c|c|c|c|c|c|c|c|c|c|c|c|c|c|c|c|c|}
\hline Glass ID $^{\mathrm{a}}$ & Description $^{b}$ & $\mathrm{SiO}_{2}$ & $\mathbf{A l}_{2} \mathbf{O}_{3}$ & $\mathbf{B}_{2} \mathbf{O}_{3}$ & $\mathrm{e}_{2} \mathrm{O}_{3}{ }^{\mathrm{i}}$ & $\mathrm{TiO}_{2}$ & ZnO & $\mathrm{ZrO}_{2}$ & MgO & $\mathbf{L i}_{2} \mathbf{O}$ & $\mathrm{Na}_{2} \mathrm{O}$ & $\mathrm{K}_{2} \mathrm{O}$ & $\mathrm{CaO}$ & $\mathrm{Cl}^{-}$ & $\mathrm{SO}_{3}$ & $\mathbf{P}_{2} \mathrm{O}_{5}$ & $\mathrm{Cr}_{2} \mathrm{O}_{3}$ & $\mathbf{F}$ & $\mathrm{ReO}_{2}$ & $\mathrm{MoO}_{3}$ & $\mathrm{La}_{2} \mathrm{O}_{3}$ & Total \\
\hline HLP-01 & Center & 49.07 & 7.00 & 10.00 & 5.50 & 3.00 & 1.50 & 1.50 & 1.50 & 0.00 & 20.00 & 0.41 & 0.01 & 0.28 & 0.07 & 0.06 & 0.08 & 0.01 & 0.01 & 0.00 & 0.00 & 100.00 \\
\hline & $\mathrm{L} \mathrm{Si}$ & 5.00 & 8.79 & .57 & 6.92 & 3.77 & 1.8 & 1.88 & 1.88 & 0.00 & & 0.52 & 0.02 & 0.35 & 0.09 & 0.07 & & 0.01 & & & 0.00 & 99.99 \\
\hline & $\mathrm{HS}$ & & 6.60 & 9.43 & 5.19 & 2.82 & 1.41 & 1.41 & 1.41 & 0.00 & & 0.39 & 0. & 0.26 & 0.07 & 0.05 & & 0.01 & & & .00 & 99.99 \\
\hline & I Si & 00 & 8.24 & 11.78 & 6.48 & 3.53 & 1.77 & 1.77 & 1.77 & 0.00 & & 0.49 & 0. & 0.33 & 0.09 & 0.07 & & 0.01 & & & 00 & 100.01 \\
\hline LP-05 & $\mathrm{L} \mathrm{Al}$ & 0.65 & 4.00 & 0.32 & 5.68 & 3.09 & 1. & 1.55 & 1.55 & 0.00 & 20.65 & 0.43 & 0.01 & 0.29 & 0.08 & 0.06 & 08 & 0.01 & 0.01 & 00 & & 100.01 \\
\hline P-06 & $\mathrm{HA}$ & 5.46 & 11.94 & 9.47 & 5.21 & 2.84 & 1.42 & 1.42 & 1.42 & 0.00 & 18.94 & 0.39 & 0.01 & 0.26 & 0.07 & 0.05 & 0.07 & 0.01 & 0.01 & .00 & 0.00 & \\
\hline-07 & I A & .01 & 9.00 & 9.79 & 5.38 & 2.93 & 1.47 & 1.47 & 1.47 & 0.00 & 19.57 & 0.40 & 0.01 & 0.27 & 0.07 & 0.05 & 0.07 & 0.01 & 0.01 & .00 & 0.00 & \\
\hline-08 & L B & .25 & 7.31 & 6.00 & 5.75 & 3.13 & 1.57 & 1.57 & 1.57 & 0.00 & .89 & 0.43 & 0.01 & 0.29 & 0.08 & 0.06 & .08 & 0.01 & .01 & 00 & 0.00 & \\
\hline LP-09 & H B & .98 & 6.84 & 12.00 & 5.38 & 2.93 & 1. & 1.47 & 1.47 & 0.00 & 56 & 40 & 0.01 & 0.27 & 0.07 & 0.05 & .07 & 0.01 & 0.01 & 00 & .00 & \\
\hline LP-10 & I B & & 7.15 & 8.00 & 5.63 & 3.06 & 1. & 1.53 & 1.53 & 0.00 & 45 & 42 & 0.01 & 0.28 & 0.07 & 0.06 & .08 & 0.01 & .01 & 00 & 0.00 & \\
\hline LP-11 & $\mathrm{L} \mathrm{Fe}$ & & 7.41 & 10.58 & 0.00 & 3.17 & 1.59 & 1.59 & 1.59 & 0.00 & 17 & 44 & 0.01 & 0.29 & 0.08 & 0.06 & 0.08 & 0.01 & 0.01 & .00 & 0.00 & \\
\hline HLP-12 & $\mathrm{HFe}$ & .25 & 6.74 & 9.63 & 9.00 & 2.89 & 1.44 & 1.44 & 1.44 & 0.00 & 19.26 & 0.40 & 0.01 & 0.27 & 0.07 & 0.05 & 0.07 & 0.01 & 0.01 & .00 & 0.00 & .98 \\
\hline & I Fe & .37 & 7.18 & 10.27 & 3.00 & 3.08 & 1.54 & 1.54 & 1.54 & 0.00 & 20.53 & 0.42 & 0.01 & 0.28 & 0.08 & 0.06 & .08 & 0.01 & 0.01 & .00 & 0.00 & 0.00 \\
\hline & $\mathrm{L} \mathrm{Ti}$ & & 7.21 & 10.31 & 5.67 & 0.00 & 1. & 1.55 & 1.55 & 0.00 & & 0.43 & 0.01 & 0.29 & 0.08 & 0.06 & .08 & 0.01 & 0.01 & 00 & 0.00 & 0.02 \\
\hline & $\mathrm{H} \mathrm{Ti}$ & & 6.78 & 9.69 & 5.33 & 6.00 & 1. & 1.45 & 1.45 & 0.00 & & 0.40 & 0.01 & 0.27 & 0.07 & 0.05 & 07 & 0.01 & 01 & 00 & 0.00 & 99.98 \\
\hline & L Zn & & 7.10 & 10.15 & 5.59 & 3.04 & 0.00 & 1.52 & 1.52 & 0.00 & & 0.42 & 0.01 & 0.28 & 0.07 & 0.06 & .08 & 0.01 & 0.01 & 0.00 & 0.00 & 99 \\
\hline LP-17 & H Zn & & 6.82 & 9.75 & 5.36 & 2.92 & 4.00 & 1.46 & 1.46 & 0.00 & & 0.40 & 0.01 & 0.27 & 0.07 & 0.05 & .07 & 0.01 & 0.01 & 0.00 & 0.00 & 99.98 \\
\hline HLP-18 & $\mathrm{L} \mathrm{Zr}$ & .82 & 7.10 & 10.15 & 5.59 & 3.04 & 1.52 & 0.00 & 1.52 & 0.00 & 20.31 & 0.42 & 0.01 & 0.28 & 0.07 & 0.06 & .08 & 0.01 & 0.01 & 0.00 & 0.00 & 99.99 \\
\hline HLP-19 & $\mathrm{H} \mathrm{Zr}$ & 5.83 & 6.68 & 9.55 & 5.25 & 2.86 & 1.43 & 6.00 & 1.43 & 0.00 & 19.09 & 0.39 & 0. & 0.26 & 0.07 & 0.05 & 0.07 & 0.01 & 0.01 & 0.00 & 0.00 & 99.99 \\
\hline HLP-20 & L M & 82 & 7.10 & 10.15 & 5.59 & 3.04 & 1.52 & 1.52 & 0.00 & 0.00 & 20.31 & 0.42 & 0.01 & 0.28 & 0.07 & 0.06 & 0.08 & 0.01 & 0.01 & 0.00 & 0.00 & 99.99 \\
\hline-21 & $\mathrm{H} \mathrm{M}$ & & 6.82 & & 5.36 & 2.92 & 1.46 & 1.46 & 4.00 & 0.00 & & 0.40 & 0. & 0.27 & 0.07 & 0.05 & 0.07 & 0.01 & 0.0 & 0.00 & 0.00 & 99.98 \\
\hline-22 & L N & & 7.37 & 10.53 & 5.79 & 3.16 & 1.58 & 1.58 & 1.58 & 0.00 & 16.00 & 0.33 & 0.01 & 0.22 & 0.06 & 0.04 & 0.06 & 0.01 & 0.01 & 0.00 & 0.00 & 100.00 \\
\hline-23 & $\mathrm{H} \mathrm{Na}$ & 13 & 6.72 & 9.61 & 5.29 & 2.88 & 1.44 & 1.44 & 1.44 & 0.00 & 23. & 0.47 & 0.01 & 0.32 & 0.08 & 0.06 & 0.09 & 0.01 & 0.01 & 0.00 & 0.00 & 100.00 \\
\hline & I Na & & 7.18 & 10.27 & 5.65 & 3.08 & 1.54 & 1.54 & 1.54 & 0.00 & & 0.37 & 0.01 & 0.25 & 0.07 & 0.05 & 0.07 & 0.01 & 1 & & 0.00 & 100.01 \\
\hline & & & 7.0 & .00 & 5. & 3.00 & 1. & 1.50 & 1.50 & 0.00 & & 0.41 & 0. & 0.28 & 0.07 & 0 . & 0.08 & 0.01 & 0.0 & & 0.00 & 100.00 \\
\hline HLP-26 & Center & .07 & 7.00 & 10.00 & 5.5 & 3.00 & 1.50 & 1.50 & 1.50 & 0.00 & 20.00 & 0.41 & 0.01 & 0.28 & 0.07 & 0.06 & 0.08 & 0.01 & 0.01 & .00 & 0.00 & 100.00 \\
\hline HLP-27 & $\mathrm{HHHH}^{\mathrm{c}}$ & 2.00 & 1.94 & 12.00 & 0.00 & 0.00 & 0.00 & 0.00 & 0.00 & 0.00 & 23.00 & 0.47 & 0.01 & 0.32 & 0.08 & 0.06 & 0.09 & 0.01 & 0.01 & 0.00 & 0.00 & \\
\hline HLP-28 & $\mathrm{HHHL}^{\mathrm{c}}$ & 52.00 & 11.94 & 12.00 & 3.10 & 1.69 & 0.84 & 0.84 & 0.84 & 0.00 & 16.00 & 0.33 & 0.01 & 0.22 & 0.06 & 0.04 & 0.06 & 0.01 & 0.01 & 0.00 & 0.00 & 99.99 \\
\hline HLP-29 & $\mathrm{HHLH}^{\mathrm{c}}$ & 52.00 & 11.94 & 6.00 & 2.54 & 1.38 & 0.69 & 0.69 & 0.69 & 0.00 & 23.00 & 0.47 & 0.01 & 0.32 & 0.08 & 0.06 & 0.09 & 0.01 & 0.01 & 0.00 & 0.00 & 99.98 \\
\hline HLP-30 & HHLL $^{\mathrm{c}}$ & 52.00 & 11.94 & 6.00 & 5.64 & 3.07 & 1.54 & 1.54 & 1.54 & 0.00 & 16.00 & 0.33 & 0.01 & 0.22 & 0.06 & 0.04 & 0.06 & 0.01 & 0.01 & 0.00 & 0.00 & 100.01 \\
\hline & $\mathrm{HLHH}^{\mathrm{c}}$ & 52.00 & 4.00 & 12.00 & 3.36 & 1.83 & 0.92 & 0.92 & 0.92 & 0.00 & 23.00 & 0.47 & 0.01 & 0.32 & 0.08 & 0.06 & 0.09 & 0.01 & 0.01 & 0.00 & 0.00 & 100.00 \\
\hline HLP-32 & HLHL $^{\mathrm{c}}$ & 52.00 & 4.00 & 12.00 & 6.46 & 3.52 & 1.76 & 1.76 & 1.76 & 0.00 & 16.00 & 0.33 & 0.01 & 0.22 & 0.06 & 0.04 & 0.06 & 0.01 & 0.01 & 0.00 & 0.00 & 100.00 \\
\hline
\end{tabular}




\begin{tabular}{|c|c|c|c|c|c|c|c|c|c|c|c|c|c|c|c|c|c|c|c|c|c|c|}
\hline 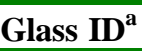 & Description $^{\text {b }}$ & $\mathrm{SiO}_{2}$ & $\mathrm{Al}_{2} \mathrm{O}_{3}$ & $\mathbf{B}_{2} \mathbf{O}$ & $\mathrm{Fe}_{2} \mathrm{O}_{3}{ }^{\mathrm{i}}$ & $\mathrm{TiO}_{2}$ & $\mathrm{ZnC}$ & $\mathrm{ZrO}_{2}$ & MgO & $\mathbf{L i}_{2} \mathbf{O}$ & $\mathrm{Na}_{2} \mathrm{O}$ & $\mathbf{K}_{2} \mathbf{O}$ & $\mathrm{CaO}$ & $\mathrm{Cl}^{-}$ & $\mathrm{SO}_{3}$ & $\mathbf{P}_{2} \mathbf{O}$ & $\mathrm{Cr}_{2} \mathrm{O}_{3}$ & $\mathbf{F}$ & $\mathrm{ReO}_{2}$ & $\mathrm{MoO}_{3}$ & $\mathrm{La}_{2} \mathrm{O}_{3}$ & Total \\
\hline HLP-33 & HLLH $^{\mathrm{c}}$ & 2.00 & 4.00 & 6.00 & 5.90 & 3.21 & 1.61 & 1.61 & 1.61 & 0.00 & 23.00 & 0.47 & 0.01 & 0.32 & 0.08 & 0.06 & 0.09 & 0.01 & 0.01 & 0.00 & 0.00 & 99.99 \\
\hline HLP-34 & HLLL $^{\mathrm{c}}$ & 52.00 & 4.00 & 6.00 & 9.00 & 4.90 & 2.45 & 2.45 & 2.45 & 0.00 & 16.00 & 0.33 & 0.01 & 0.22 & 0.06 & 0.04 & 0.06 & 0.01 & 0.01 & 0.00 & 0.00 & 99.99 \\
\hline HLP-35 & $\mathrm{LHHH}^{\mathrm{c}}$ & 36.00 & 11.94 & 12.00 & 6.77 & 3.69 & 1.85 & 1.85 & 1.85 & 0.00 & 23.00 & 0.47 & 0.01 & 0.32 & 0.08 & 0.06 & 0.09 & 0.01 & & 0.00 & 0.00 & 100.00 \\
\hline HLP-36 & $\mathrm{LHHL}^{\mathrm{c}}$ & 36.00 & 11.94 & 12.00 & 9.87 & 5.38 & 2.69 & 2.69 & 2.69 & 0.00 & 16.00 & 0.33 & 0.01 & 0.22 & 0.06 & 0.04 & 0.06 & 0.01 & 0.01 & 0.00 & 0.00 & 100.00 \\
\hline HLP-37 & $\mathrm{LHLH}^{\mathrm{c}}$ & 36.00 & 11.94 & 6.00 & 9.31 & 5.07 & 2.54 & 2.54 & 2.54 & 0.00 & 23.00 & 0.47 & 0.01 & 0.32 & 0.08 & 0.06 & 0.09 & 0.01 & 0.01 & 0.00 & 0.00 & 9.99 \\
\hline HLP-38 & LHLL $^{\mathrm{c}}$ & 36.00 & 11.94 & 6.00 & 12.41 & 6.76 & 3.38 & 3.38 & 3.38 & 0.00 & 16.00 & 0.33 & 0.01 & 0.22 & 0.06 & 0.04 & 0.06 & 0.01 & 0.01 & 0.00 & 0.00 & 99.99 \\
\hline HLP-39 & $\mathrm{LLHH}^{\mathrm{c}}$ & 36.00 & 4.00 & 12.00 & 10.13 & 5.52 & 2.76 & 2.76 & 2.76 & 0.00 & 23.00 & 0.47 & 0.01 & 0.32 & 0.08 & 0.06 & 0.09 & 0.01 & 0.01 & 0.00 & 0.00 & 99.98 \\
\hline HLP-40 & LLHL $^{c}$ & 36.00 & 4.00 & 12.00 & 13.23 & 7.21 & 3.61 & 3.61 & 3.61 & 0.00 & 16.00 & 0.33 & 0.01 & 0.22 & 0.06 & 0.04 & 0.06 & 0.01 & 0.01 & 0.00 & 0.00 & 100.01 \\
\hline HLP-41 & LLLH $^{\mathrm{c}}$ & 36.00 & 4.00 & 6.00 & 12.67 & 6.90 & 3.45 & 3.45 & 3.45 & 0.00 & 23.00 & 0.47 & 0.01 & 0.32 & 0.08 & 0.06 & 0.09 & 0.01 & 0.01 & 0.00 & 0.00 & 99.97 \\
\hline HLP-42 & LLLL $^{\mathrm{c}}$ & 36.00 & 4.00 & 6.00 & 15.77 & 8.59 & 4.30 & 4.30 & 4.30 & 0.00 & & 0.33 & 0.01 & 0.22 & 0.06 & 0.04 & 0.06 & 0.01 & 0.01 & 0.00 & 0.00 & 100.00 \\
\hline HLP-43 & Center & 49.07 & 7.00 & 10.00 & 5.50 & 3.00 & 1.50 & 1.50 & 1.50 & 0.00 & 20.00 & 0.41 & 0.01 & 0.28 & 0.07 & 0.06 & 0.08 & 0.01 & 0.01 & 0.00 & 0.00 & 100.00 \\
\hline HLP-44 & reduced $^{\mathrm{d}}$ & 49.07 & 7.00 & 10.00 & 5.50 & 3.00 & 1.50 & 1.50 & 1.50 & 0.00 & 20.00 & 0.41 & 0.01 & 0.28 & 0.07 & 0.06 & 0.08 & 0.01 & 0.01 & 0.00 & 0.00 & 100.00 \\
\hline HLP-45 & reduced $^{\mathrm{d}}$ & 49.07 & 7.00 & 10.00 & 5.50 & 3.00 & 1.50 & 1.50 & 1.50 & 0.00 & 20.00 & 0.41 & 0.01 & 0.28 & 0.07 & 0.06 & 0.08 & 0.01 & 0.01 & 0.00 & 0.00 & 100.00 \\
\hline HLP-46 & LD6-5412 $2^{\mathrm{f}}$ & 55.91 & 12.00 & 5.00 & 0.00 & 0.00 & 0.00 & 0.00 & 0.00 & 0.00 & 20.00 & 1.46 & 4.00 & 0.35 & 0.21 & 0.19 & 0.04 & 0.29 & 0.00 & 0.15 & 0.00 & 99.60 \\
\hline HLP-47 & LRM $^{\mathrm{g}}$ & 55.00 & 10.00 & 8.00 & 1.00 & 0.10 & 0.00 & 1.00 & 0.10 & 0.10 & 20.00 & 1.50 & 0.50 & 0.80 & 0.20 & 0.50 & 0.20 & 1.00 & 0.00 & 0.00 & 0.01 & 100.01 \\
\hline HLP-48 & LAW-A $33^{\mathrm{e}}$ & 38.25 & 11.97 & 8.85 & 5.77 & 2.49 & 4.27 & 2.49 & 1.99 & 0.00 & 20.00 & 3.10 & 0.00 & 0.5 & 0.10 & 0.08 & 0.02 & 0.04 & $0 .($ & 0.00 & 0.00 & 100.00 \\
\hline HLP-49 & LAW-B & 43.93 & 8.03 & 8.07 & 8.03 & 0.00 & 3.99 & 3.04 & 3.00 & 4.08 & 10.00 & 0.36 & 7.03 & 0.29 & 0.02 & 0.01 & 0.10 & 0.00 & 0.00 & 0.00 & 0.00 & 99.98 \\
\hline HLP-51 & LAW-A & 41.89 & 10.00 & 9.25 & 2.50 & 2.49 & 2.60 & 5.25 & 1.00 & 0.00 & 20.00 & 2.20 & 0.00 & 0.58 & 0.10 & 0.08 & 0.02 & 0.04 & 0.00 & 0.00 & 2.00 & 100.00 \\
\hline HLP-52 & HAN $-28^{\mathrm{e}}$ & 44.46 & 10.15 & 0.00 & 2.53 & 0.38 & 0.00 & 5.00 & 1.18 & 0.00 & 28.62 & 1.96 & 2.59 & 0.13 & 0.30 & 1.90 & 0.08 & 0.31 & 0.00 & 0.00 & 0.00 & 99.59 \\
\hline HLP-53 & $\mathrm{LAW}-\mathrm{A} 23^{\mathrm{e}}$ & 40.15 & 9.86 & 4.23 & 7.30 & 0.00 & 3.28 & 2.99 & 2.04 & 2.04 & 20.00 & 3.10 & 4.38 & 0.36 & 0.04 & 0.08 & 0.01 & 0.12 & 0.00 & 0.00 & 0.00 & 99.98 \\
\hline HLP-54 & L4-912 & 56.78 & 12.00 & 9.00 & 0.00 & 0.00 & 0.00 & 0.00 & 0.00 & 0.00 & 20.00 & 0.33 & 0.00 & 0.09 & 0.32 & 1.19 & 0.04 & 0.21 & 0.00 & 0.00 & 0.01 & 99.97 \\
\hline HLP-55 & L4-99 & 59.78 & 9.00 & 9.00 & 0.00 & 0.00 & 0.00 & 0.00 & 0.00 & 0.00 & 20.00 & 0.33 & 0.00 & 0.09 & 0.32 & 1.19 & 0.04 & 0.21 & 0.00 & 0.00 & 0.01 & 99.97 \\
\hline
\end{tabular}

-56 LAW-A44,

\footnotetext{
(a) Glass HLP-50 is reserved for a suitable natural analog glass to be tested once identified.

(b) Levels of glass components are given as $\mathrm{L}$ - low, I - intermediate, and $\mathrm{H}$ - high for the components following the level.

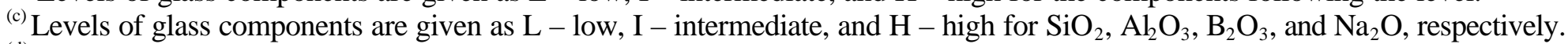

(d) HLP-44 and -45 were melted and heat treated under a reducing atmosphere to increase the ratio of two valent to total iron (Fe(II)/Fe).

(e) Preliminary Hanford LAW glasses developed by the Vitreous State Laboratory at the Catholic University of America for the HVV. Target composition was normalized to $100 \%$ during fabrication.

(f) HLP-46, or LD6-5412, contains additional components (target mass\%): SrO (0.11), I (0.13), $\mathrm{Cs}_{2} \mathrm{O}(0.15)$, and MnO (0.002), see Feng et al. (1996) for details.

(g) HLP-47, or LRM, contains additional components (target mass \%): $\mathrm{BaO}(0.005), \mathrm{CdO}(0.2), \mathrm{I}(0.002), \mathrm{MnO}(0.1), \mathrm{NiO}(0.1)$, and PbO (0.1), see Ebert and Wolf 1999 for details.

(h) Proprietary glass composition.

(i) The entire Fe concentration is listed as $\mathrm{Fe}_{2} \mathrm{O}_{3}$; except where otherwise noted, no attempt was made to control the oxidation state of Fe.
} 


\subsection{Glass Fabrication and Heat Treatment}

Matrix glasses were batched from single metal oxide or carbonate precursors for all components except $\mathrm{SO}_{3}, \mathrm{P}_{2} \mathrm{O}_{5}, \mathrm{~F}$, and $\mathrm{Cl}$, which were added as sodium salts, and $\mathrm{B}_{2} \mathrm{O}_{3}$, which was added as $\mathrm{H}_{3} \mathrm{BO}_{3}$. Batches sufficient to produce $500 \mathrm{~g}$ of glass were melted in covered $\mathrm{Pt} / \mathrm{Rh}$ crucibles for $1 \mathrm{~h}$, quenched on a steel plate, ground in a tungsten carbide mill, and remelted in a covered Pt/Rh crucible for $1 \mathrm{~h}$. After the second melt, a portion of the melt was quenched on a steel plate. The remainder of the melt was transferred directly into a preheated furnace (in Pt or Pt/Rh containers) and heat-treated according to the HVV box interior cooling schedule shown in Figure 2-1. ${ }^{a}$ This cooling schedule was used to simulate the slowest cooling that can be expected during plant operation. Glasses HLP-46, $-47,-52,-54$, and -55 were not heat treated (to maintain the same thermal history of the glasses previously tested with the same compositions), but bars were cast and annealed for $2 \mathrm{~h}$ at roughly $10^{\circ} \mathrm{C}$ above the glass transition temperature and slow cooled to room temperature. Glasses HLP-44 and -45 were batched with a targeted ratio of $\mathrm{FeO}$ to $\mathrm{Fe}_{2} \mathrm{O}_{3}$ and melted and heat treated in a controlled atmosphere furnace with $\mathrm{CO} / \mathrm{CO}_{2}$ ratios described in Table 2-2. This procedure was used at SRTC to fabricate glasses HLP-13 to HLP-25 and at PNNL to fabricate the remaining glasses.

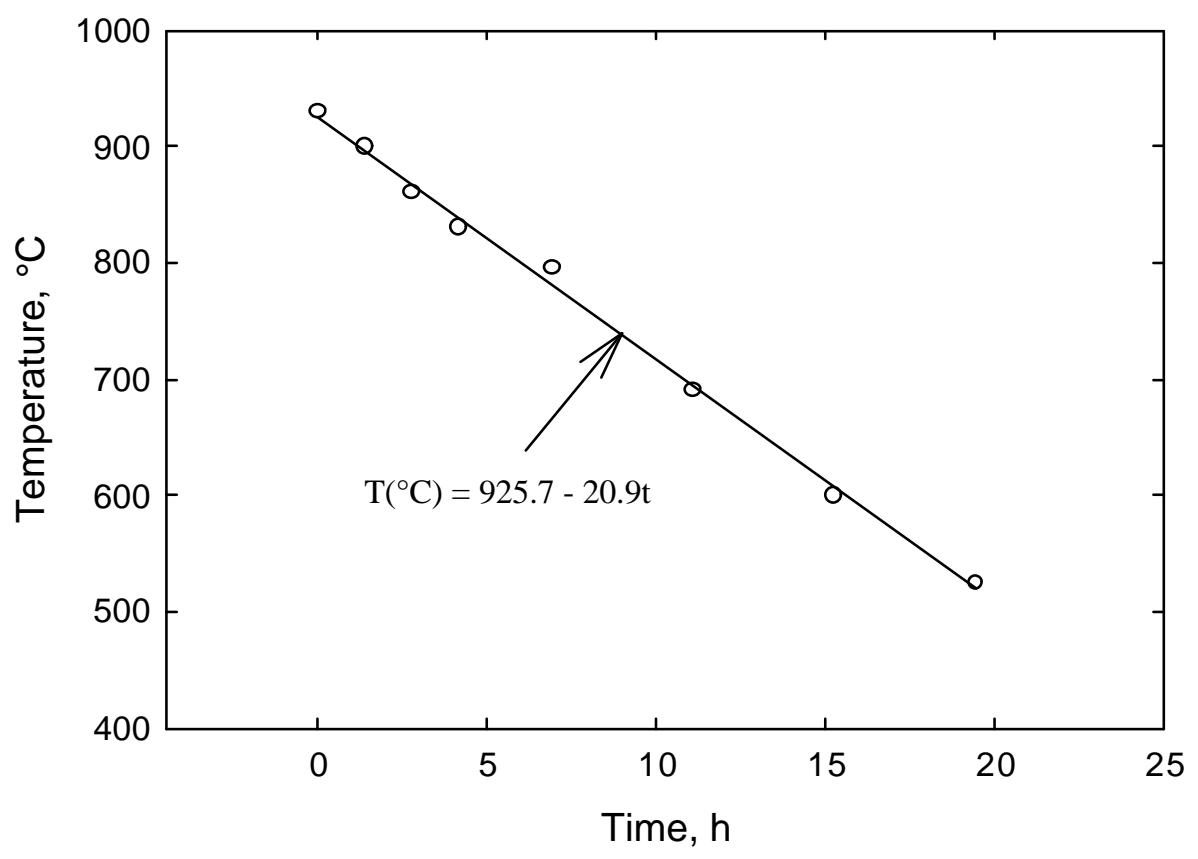

Figure 2-1. Computed Thermal Cooling Curve for $1.2 \times 1.2 \times 1.8 \mathrm{~m}$ Waste Package

${ }^{a}$ Although the HVV no longer plans to cast glass into a box, an updated cooling schedule was not available at the time of this testing. The impacts of a different cooling schedule will have to be assessed after the final schedule is available. However, the impacts are not expected to be significant. 
Table 2-2. Melting Parameters for HLP-44 and HLP-45

\begin{tabular}{lccc}
\hline Fabrication Step & Ratio & HLP-44 & HLP-45 \\
\hline Batching & $\mathrm{FeO} / \mathrm{Fe}_{2} \mathrm{O}_{3}$ & $1.65 / 3.67$ & $3.87 / 1.23$ \\
Melting & $\mathrm{CO} / \mathrm{CO}_{2}$ & $0.64 / 99.36$ & $16.66 / 82.7$ \\
Heat Treatment & $\mathrm{CO} / \mathrm{CO}_{2}$ & $0 / 100$ & $0.02 / 99.97$ \\
\hline
\end{tabular}

\subsection{Homogeneity}

Heat-treated glasses were examined in transmitted-light optical microscopy (OM) at magnifications up to $70 \times$. Selected glasses were examined at high magnification (up to $1000 \times$ ) OM, scanning electron microscopy (SEM) with energy dispersive spectroscopy (EDS), and X-ray diffraction (XRD). Crystalline fractions of any glass in which secondary crystalline phases were identified with OM were obtained by semiquantitative XRD according to the direct comparison method (Cullity 1978). This method is estimated to have a relative accuracy of $\pm 50 \%$.

\subsection{Density}

Densities of all glasses were measured with a gas pycnometer AccuPyc 1330, which uses ultra pure Helium and is equipped with a $1-\mathrm{cm}^{3}$ cell. Heat-treated glass samples were ground in a tungsten carbide mill for 1 min to reduce the impact of bubbles on density. The device was calibrated with a tungsten carbide calibration ball before each set of measurements to check the calibration and exclude possible contamination of the instrument by glass powder. ${ }^{\mathrm{a}}$

Once the sample was loaded, ten purge cycles were performed in roughly $30 \mathrm{~min}$. The average of 10-volume-displacement measurements on the same sample was used to calculate the density of each glass. A standard deviation was calculated from the 10 -volume-displacement measurements. This procedure was found to yield a precision from 0.04 to $0.01 \%$ (relative) when multiple measurements of the same glass were made over a period of roughly 4 months, which is consistent with the reported precision for this instrument.

\subsection{Redox Analyses}

The Fe(II)/Fe ratio or redox of selected matrix glasses (HLP-26, -44, and -45) were measured according to the colorimetric method. The redox of both quenched and heat-treated samples was measured. For the measurement, roughly $0.1 \mathrm{~g}$ of powder (ground in a tungsten carbide mill) was mixed with $2.5 \mathrm{~mL}$ of concentrated $\mathrm{H}_{2} \mathrm{SO}_{4}(95-98 \%)$ and then with $7.5 \mathrm{~mL}$ of concentrated $\mathrm{HF}(48-51 \%)$. Within $15 \mathrm{sec}$ after the powder was mixed with HF, a $250 \mathrm{~mL}$ reagent solution composed of phenanthroline, boric acid, and potassium hydrogen phthalate, was immediately added to stabilize the Fe(II). The solution was diluted to $500 \mathrm{~mL}$ with DIW and the absorbance of Fe(II) was measured using an ultra-violet/visible/near infrared spectrophotometer. The spectrophotometer was calibrated, and an $\mathrm{Fe}$ (II) concentration was calculated from calibration data. The total iron was determined by inductively coupled plasma-emission spectroscopy of the solution.

${ }^{\text {a }}$ Certificate of Calibration, 98-046490, traceable to NIST Test No. 821 25B 592-97 according to ANSI/NCSL 2640-1-94 and ISO 10012-1-92, Precision Ball \& Guage Co., Alvadore, Oregon (1998). 


\subsection{Composition Analyses}

To confirm that the "as-fabricated" glass compositions corresponded to the defined targeted compositions (see Table 2-1), a sample from each HLP glass was submitted to the SRTC Mobile Laboratory (SRTC-ML) for chemical analysis. Due to limited quantities of glass, fines (-200 mesh powder) produced during the PCT sample-preparation procedure were submitted for analysis. Concentrations (as mass \%) for the cations of interest were measured using inductively coupled plasma-atomic emission spectroscopy (ICP-AES) after preparing the samples using one of two fusion techniques: 1) $\mathrm{Na}_{2} \mathrm{O}_{2} / \mathrm{NaOH} / \mathrm{HCl}$ or 2) $\mathrm{LiBO}_{2} / \mathrm{HNO}_{3}$. Table 2-3 identifies the elements analyzed, methods of analysis, and typical reportable limits ${ }^{\mathrm{a}}$. The target and measured concentrations will be compared below.

Glass standards were not run with these samples as this practice is not required in the SRTC Mobile Laboratory (SRTC-ML) procedures. Instead, a matrix-matched calibration standard was run at the beginning and end of the test blocks as well as after each ten samples. For the analyses of the calibration standard, the expected differences are $\pm 5 \%$ (although the SRTC-ML procedure allow for differences up to $\pm 10 \%$ ).

\section{$\mathrm{Na}_{2} \mathrm{O}_{2} / \mathrm{NaOH} / \mathrm{HCl}$ Fusion Preparation}

Approximately $0.25 \pm 0.01 \mathrm{~g}$ of crushed glass was fused with $1.5 \mathrm{~g} \mathrm{Na}_{2} \mathrm{O}_{2}$ and $1.0 \mathrm{~g} \mathrm{NaOH}$ at $600^{\circ} \mathrm{C}$ for $15 \mathrm{~min}$ in a Pt crucible. The fused sample was dissolved in water and $25 \mathrm{~mL}$ of $\mathrm{HCl}$ acid. The fused sample was diluted to $250 \mathrm{~mL}$ with deionized water.

ICP-AES was used to measure the concentrations of $\mathrm{B}, \mathrm{Si}, \mathrm{Al}$, and $\mathrm{Li}$ in the $\mathrm{Na}_{2} \mathrm{O}_{2} / \mathrm{NaOH} / \mathrm{HCl}$ fusion preparation. Before running the solution through the ICP-AES, a 1/10 dilution on the final $250-\mathrm{mL}$ solution was performed. Calibration standards were matrix matched.

\section{$\mathrm{LiBO}_{2} / \mathrm{HNO}_{3}$ Fusion Preparation}

Approximately $0.1 \pm 0.01 \mathrm{~g}$ of crushed glass was fused with $0.3 \mathrm{~g}$ of $\mathrm{LiBO}_{2}$ at $900^{\circ} \mathrm{C}$ for $15 \mathrm{~min}$ in a Pt crucible. The fused sample was dissolved in a $4 \% \mathrm{HNO}_{3}$ solution. The dissolved sample was diluted to a final volume of $250 \mathrm{~mL}$. No further dilutions were made before running this solution through the ICP-AES. Again, calibration standards were matrix matched.

\footnotetext{
${ }^{\mathrm{a}}$ The reportable limits are obtained from a two-point calibration, followed by the analyses of a blank five times with five replicates. The average standard deviation for each element, or detection limit, is then calculated from these results. The reportable limit is the detection limit multiplied by 10 .
} 
Table 2-3. Elemental Analysis Based on Dissolution Procedure and Analytical Technique

\begin{tabular}{|c|c|c|c|}
\hline Element & Dissolution Technique & $\begin{array}{l}\text { Analytical } \\
\text { Technique }\end{array}$ & $\begin{array}{c}\text { Typical Reportable } \\
\text { Limit }(\mu \mathrm{g} / \mathbf{m L})\end{array}$ \\
\hline $\mathrm{Al}$ & $\mathrm{Na}_{2} \mathrm{O}_{2} / \mathrm{NaOH} / \mathrm{HCl}$ & ICP-AES & $<0.200$ \\
\hline $\mathrm{B}$ & $\mathrm{Na}_{2} \mathrm{O}_{2} / \mathrm{NaOH} / \mathrm{HCl}$ & ICP-AES & $<0.180$ \\
\hline $\mathrm{Ca}$ & $\mathrm{LiBO}_{2} / \mathrm{HNO}_{3}$ & ICP-AES & $<0.010$ \\
\hline $\mathrm{Cr}$ & $\mathrm{LiBO}_{2} / \mathrm{HNO}_{3}$ & ICP-AES & $<0.030$ \\
\hline $\mathrm{Fe}$ & $\mathrm{LiBO}_{2} / \mathrm{HNO}_{3}$ & ICP-AES & $<0.020$ \\
\hline $\mathrm{K}$ & $\mathrm{LiBO}_{2} / \mathrm{HNO}_{3}$ & ICP-AES & $<0.600$ \\
\hline $\mathrm{Li}$ & $\mathrm{Na}_{2} \mathrm{O}_{2} / \mathrm{NaOH} / \mathrm{HCl}$ & ICP-AES & $<0.020$ \\
\hline $\mathrm{Mg}$ & $\mathrm{LiBO}_{2} / \mathrm{HNO}_{3}$ & ICP-AES & $<0.001$ \\
\hline $\mathrm{Na}$ & $\mathrm{LiBO}_{2} / \mathrm{HNO}_{3}$ & ICP-AES & $<0.530$ \\
\hline $\mathrm{Ni}$ & $\mathrm{LiBO}_{2} / \mathrm{HNO}_{3}$ & ICP-AES & $<0.060$ \\
\hline $\mathrm{Si}$ & $\mathrm{Na}_{2} \mathrm{O}_{2} / \mathrm{NaOH} / \mathrm{HCl}$ & ICP-AES & $<0.180$ \\
\hline $\mathrm{Ti}$ & $\mathrm{LiBO}_{2} / \mathrm{HNO}_{3}$ & ICP-AES & $<0.001$ \\
\hline $\mathrm{Zn}$ & $\mathrm{LiBO}_{2} / \mathrm{HNO}_{3}$ & ICP-AES & $<0.400$ \\
\hline $\mathrm{Zr}$ & $\mathrm{LiBO}_{2} / \mathrm{HNO}_{3}$ & ICP-AES & $<0.080$ \\
\hline
\end{tabular}

\subsection{Product Consistency Testing}

Both PCT-A and PCT-B were performed on each test-matrix glass to assess chemical durability as defined in American Society for Testing and Materials (ASTM) C 1285 (ASTM 1985). The PCT-A was conducted in triplicate for each of the LAW glasses. Duplicate blank tests with ASTM Type I water were also run within each test block. Samples were ground, washed, and prepared according to procedure. For PCT-A, $15 \mathrm{~mL}$ of ASTM water was added to $1.5 \mathrm{~g}$ of glass in stainless steel vessels resulting in a surface area to volume ratio $\mathrm{S} / \mathrm{V}$ of approximately $2000 \mathrm{~m}^{-1}$. (For this initial examination of the data, small variations in $\mathrm{S} / \mathrm{V}$ resulting from minor density differences were not considered.) The vessels were closed, sealed, and placed into an oven at $90 \pm 2^{\circ} \mathrm{C}$ where they remained for 7 days. After the 7-day test, vessels were removed from the oven and allowed to cool to room temperature. The final masses of each vessel and the solution $\mathrm{pH}$ were recorded on the data sheet. Test solutions were then filtered through a $0.45-\mu \mathrm{m}$ pore size filter. Six $\mathrm{mL}$ of each test solution was then acidified with $4 \mathrm{~mL}$ of $0.4 \mathrm{M} \mathrm{HNO}_{3}$ to ensure that the cations remain in solution. Test solutions and blanks were then analyzed in the SRTC-ML for Si, B, Na, and Li concentrations using ICP-AES. A multi-element solution standard was also submitted with the PCT solutions for control purposes. Data sheets were used to record the vessel identification number, sample ID, mass of vessel (empty), mass of vessel with glass, and the mass of vessel with glass and water.

The PCT-B series was conducted at an S/V value of approximately $20,000 \mathrm{~m}^{-1}$ and a temperature of $90^{\circ} \mathrm{C}$ in Teflon ${ }^{\circledR}$ vessels ${ }^{a}$ as defined by Vienna et al. (1999). The durations for the PCT-B tests were: $10,100,1000,5000$ (or a time to be determined [TBD]), and 10,000 h (or a time TBD). Samples were ground, washed, and prepared according to procedure. Ten $\mathrm{mL}$ of ASTM water was added to $10.0 \mathrm{~g}$ of glass in Teflon vessels, resulting in an S/V value of approximately $20,000 \mathrm{~m}^{-1}$. The vessels were closed,

\footnotetext{
${ }^{a}$ When Teflon ${ }^{\circledR}$ vessels are used, $\mathrm{CO}_{2}$ diffuses into the test solution so that secondary reactions are not limited by $\mathrm{CO}_{2}$ concentration. Also for these long test durations, the vessel mass must be tracked and water added when the water mass loss exceeds $10 \%$.

b A sixth sample was initiated and will be used as a "pulse-flow" test in which solution concentrations are monitored on, at least, a monthly basis to determine the appropriate times to pull the two TBD tests. Samples will be terminated at a time determined upon review of initial data.
} 
sealed, and placed into an oven at $90 \pm 2{ }^{\circ} \mathrm{C}$. After the specified test duration, the vessels were removed from the oven and were allowed to cool to room temperature. The final mass of each vessel and the solution $\mathrm{pH}$ were recorded on the data sheet. Test solutions were then filtered through a $0.45-\mu \mathrm{m}$ pore size filter. Generally, $6 \mathrm{~mL}$ of each test solution was then acidified with $4 \mathrm{~mL}$ of $0.4 \mathrm{M} \mathrm{HNO}_{3}$ to ensure that the cations remain in solution. Test solutions and blanks were then analyzed in the SRTC-ML for Si, $\mathrm{B}, \mathrm{Na}$, and Li concentrations using ICP-AES. A multi-element solution standard was also submitted with the PCT solutions for control purposes. Data sheets were used to record the vessel identification number, sample ID, mass of vessel (empty), mass of vessel with glass, and the mass of vessel with glass and water. Selected glass samples from the PCT-B tests are being evaluated for the formation of secondary phases via electron microscopy.

\subsection{Vapor Hydration Testing}

In the VHT, monolithic samples are exposed to saturated water vapor at elevated temperatures (typically $100^{\circ} \mathrm{C}$ to $300^{\circ} \mathrm{C}$ ) in a sealed vessel as shown schematically in Figure 2-2. This environment greatly accelerates the progression of glass corrosion by water and can result in the formation of alteration phases. The principal uses of the test are 1) as a screening tool to quickly determine if a glass is likely to corrode at an extreme rate, 2) as a convenient means of generating alteration phases for analysis within a short period, and 3) for a measure of the alteration rate at elevated temperatures.

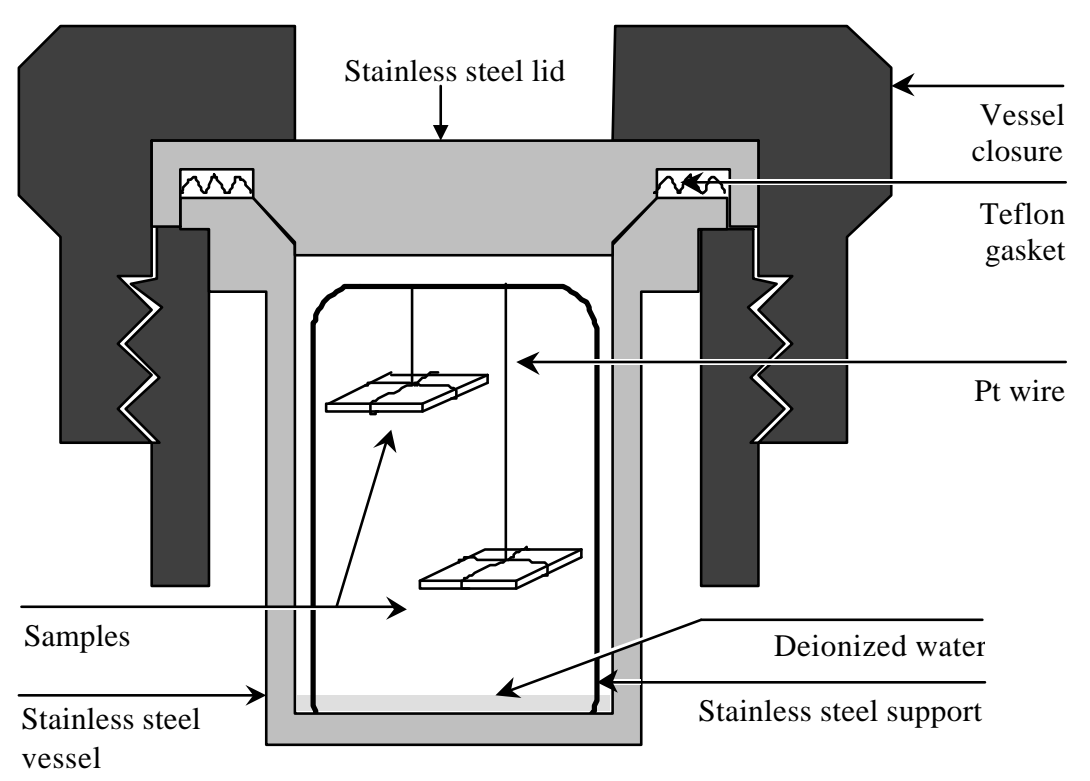

Figure 2-2. Apparatus for Conducting VHTs

The VHTs were performed according to a PNNL technical procedure. ${ }^{\text {a }}$ Samples with dimensions of $10 \times 10 \times 1.5 \mathrm{~mm}$ are prepared from heat-treated glass bars with a diamond-impregnated saw. All sides are polished to 600-grit surface finishes with silicon carbide paper. Samples, stainless steel vessels, lids, and supports are cleaned, and samples are suspended from stainless steel supports on Pt wire. An

\footnotetext{
${ }^{a}$ Vapor-phase Hydration Test Procedure, GDL-VHT, Rev. 1, Pacific Northwest National Laboratory, Richland, Washington (1999).
} 
amount of deionized water (DIW), predetermined to be appropriate for the vessel size, the temperature, and the number of samples in the vessel, is added to the vessel. The sealed vessel is held at constant temperature in a convection oven for a preset time, removed, weighed, and quenched in water. After the test termination, samples are removed from the vessel and examined for the presence of alteration products with OM. The alteration products are identified with XRD and SEM with EDS.

The amount of altered glass was calculated from the difference between initial glass thickness and remaining glass thickness determined from sample cross sections with OM and image analysis (IA). The thickness of remaining glass layer, $d_{r}$, is determined by performing 10 measurements equally distributed across the specimen as shown in Figure 2-3.

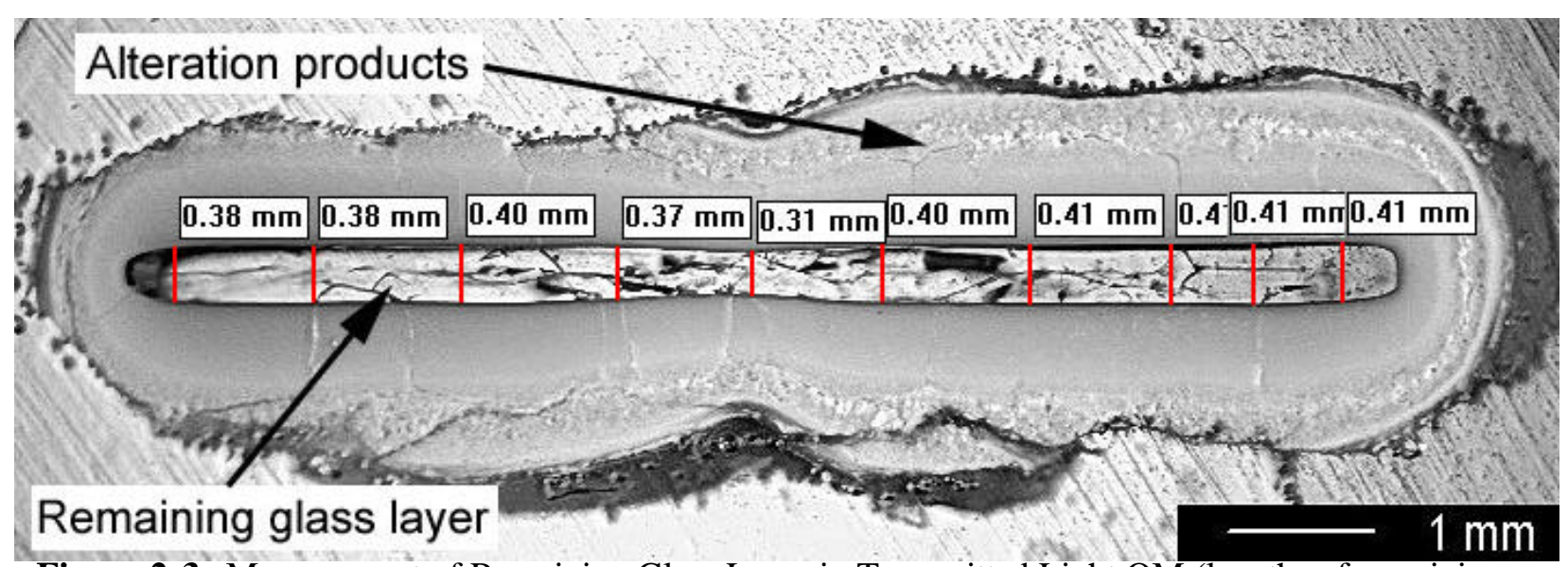

Figure 2-3. Measurement of Remaining Glass Layer in Transmitted Light OM (lengths of remaining glass layer are listed above each measurement)

The alteration extent or the amount of glass converted into alteration products $\left(m_{d}\right)$ per unit surface area, is given by

$$
m_{d}=\frac{m_{i}}{2 w_{i} l_{i}}\left(1-\frac{d_{r}}{d_{i}}\right)
$$

where $m_{i}$ is the initial sample mass, $w_{i}$ and $l_{i}$ are sample width and length, respectively, $d_{r}$ is the thickness of remaining glass layer, and $d_{i}$ is the initial glass layer thickness. The alteration rate, $r$, is then given by

$$
r=\frac{\partial m_{d}}{\partial t}
$$

where $t$ is time, and the rate is calculated by regression over the linear portion of the $m_{d}-t$ curve as discussed in Section 3.6.1. This rate is that describing the alteration process, which is known to include leaching (ion exchange), corrosion (matrix dissolution), and precipitation of multiple alteration products. We do not yet know if one of the reactions limits the rate of the overall process or if so, which reaction. This will be a topic of further study. 


\subsection{Results and Discussion}

The testing program described above is still in progress. This section summarizes the current, preliminary results. The final results from this testing program will be reported in a subsequent report.

\subsection{Glass Homogeneity}

Eight of the 55 matrix glasses formed significant amounts of a crystalline phase during the heat treatment. All other glasses appeared to be homogeneous or single phased by OM. However, additional phases that were not detectable by OM could have formed. Selected glasses were examined with SEM and XRD to confirm their homogeneity (which is still not considered adequate to rule out the presence of additional phases). Of the glasses that formed additional phases-HLP-36, -37, -38, -40, -41, -42, -49, and -53 - six were four-component-at-a-time change glasses with low $\mathrm{SiO}_{2}$, and two were proposed $\mathrm{HVV}$ glasses. Examination of the XRD traces of each glass, shown in Figure 3-1, suggests that they all contain crystalline inclusions with the possible exception of HLP-41. Further examination suggests that glasses HLP-38 and -42 have similar patterns. The phase characterization for each of these glasses is described in Sections 3.1.1 through 3.1.6.

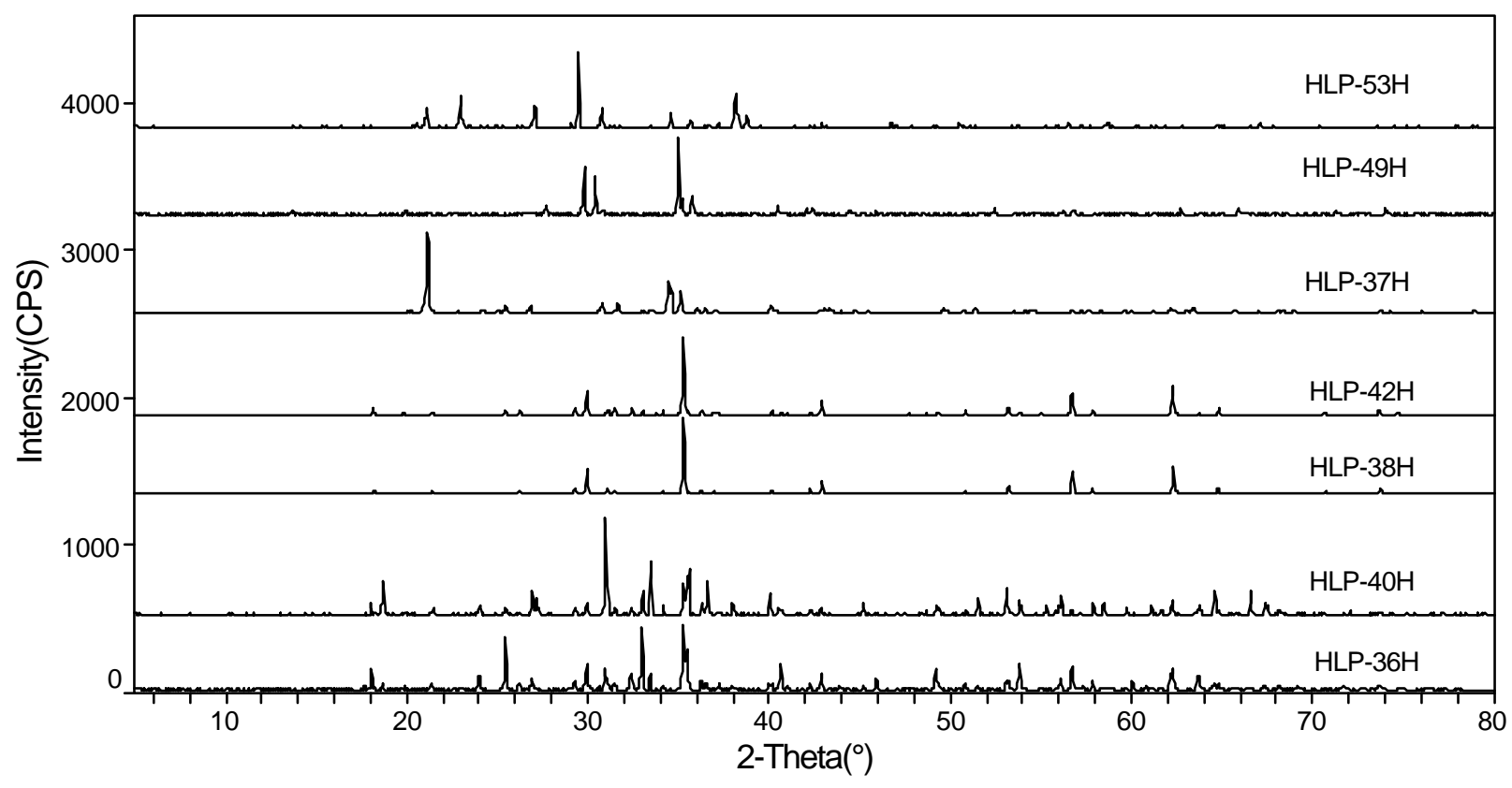

Figure 3-1. XRD Pattern of Inhomogeneous Glasses (with the "amorphous hump" subtracted)

\subsubsection{HLP-36 and HLP-40}

Glasses HLP-36 and -40 have the same target concentrations of $\mathrm{SiO}_{2}, \mathrm{Na}_{2} \mathrm{O}$, and $\mathrm{B}_{2} \mathrm{O}_{3}$ with a different concentration of $\mathrm{Al}_{2} \mathrm{O}_{3}$ and form the same crystalline phases. The phases identified in these glasses along with their estimated concentrations are listed in Table 3-1. Hematite was found in two modifications with a different content of Ti substituting for Fe. Micrographs of these phases, both OM 
and SEM, are shown in Figure 3-2 and Figure 3-3 for HLP-36 and Figure 3-4 and Figure 3-5 for HLP-40. Both zinc iron oxide and iron titanium oxide form smaller crystals located usually on the surface of hematite. An additional phase was found in HLP-36 with SEM/EDS; this phase has a high concentration of Ti and a smaller concentration of Mg. It likely accounts for the Loveringite structure found with XRD with Mg substituted for Ca (Figures 3-6 through 3-9).

Table 3-1. List of Phases Identified in HLP-36 and -40 With XRD

\begin{tabular}{llcc}
\hline$\#^{\text {a) }}$ & \multicolumn{1}{c}{ Phase } & Concentration in HLP-36 & Concentration in HLP-40 \\
\hline 1 & Zinc Iron Oxide $\left(\mathrm{ZnFe}_{2} \mathrm{O}_{4}\right)$ & 1.74 mass\% & 0.44 mass\% \\
2 & Hematite $\left(\mathrm{Fe}_{2} \mathrm{O}_{3}\right)$ & 2.40 & 1.52 \\
3 & Iron Titanium $\mathrm{Oxide}_{\left(\mathrm{Fe}_{2} \mathrm{TiO}_{5}\right)}$ & 2.09 & 10.32 \\
4 & Loveringite $\left(\mathrm{CaTi}_{21} \mathrm{O}_{38}\right)$ & 4.85 & 1.02 \\
\hline
\end{tabular}

a) Numbers refer to the labels in figures.

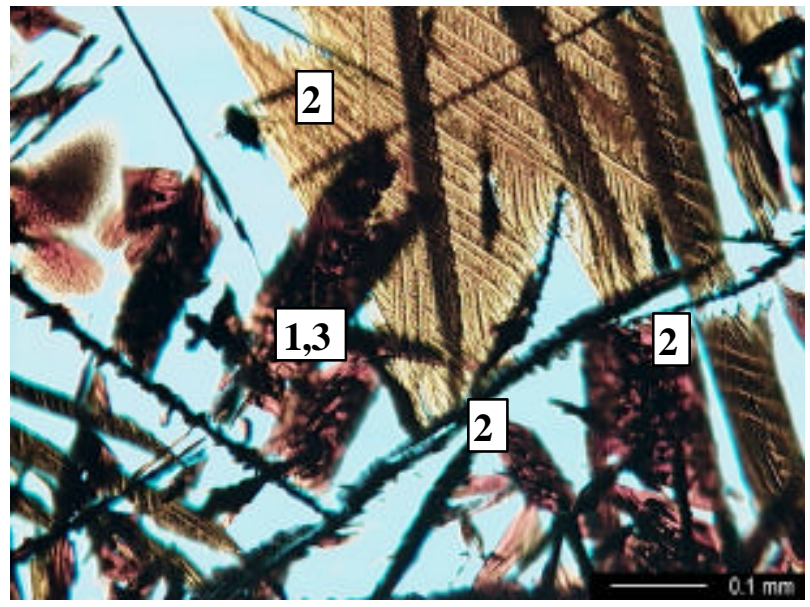

Figure 3-2. Transmitted Light $\mathrm{OM}$ of HLP-36 (200x)

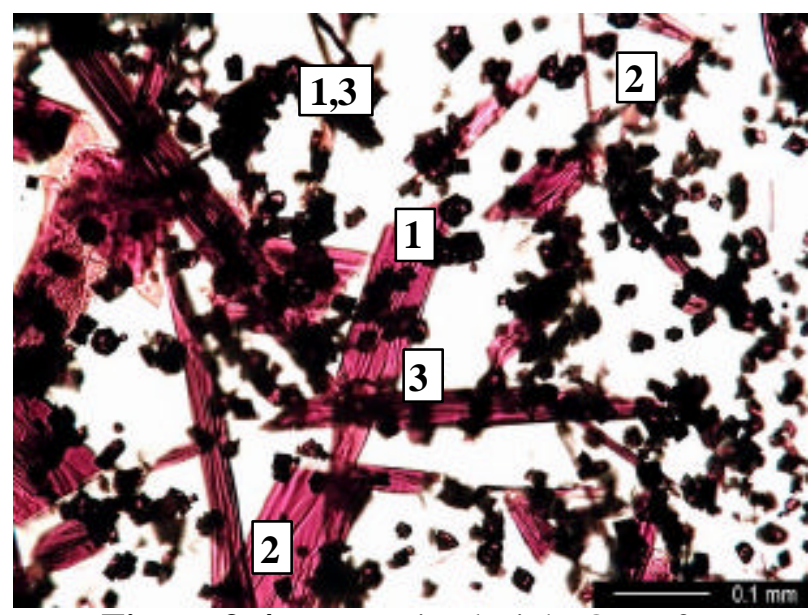

Figure 3-4. Transmitted Light $\mathrm{OM}$ of HLP-40 (200×)

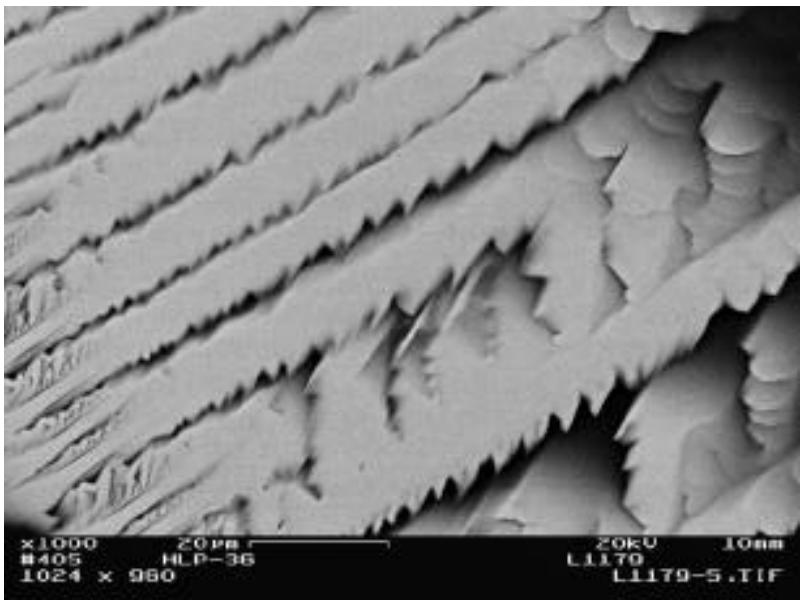

Figure 3-3. SEM Micrograph of HLP-36

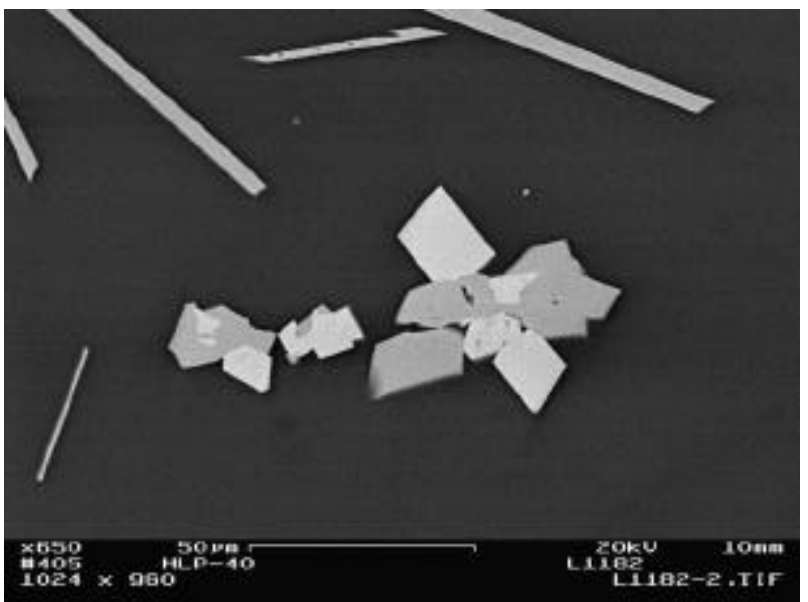

Figure 3-5. SEM Micrograph of HLP-40 


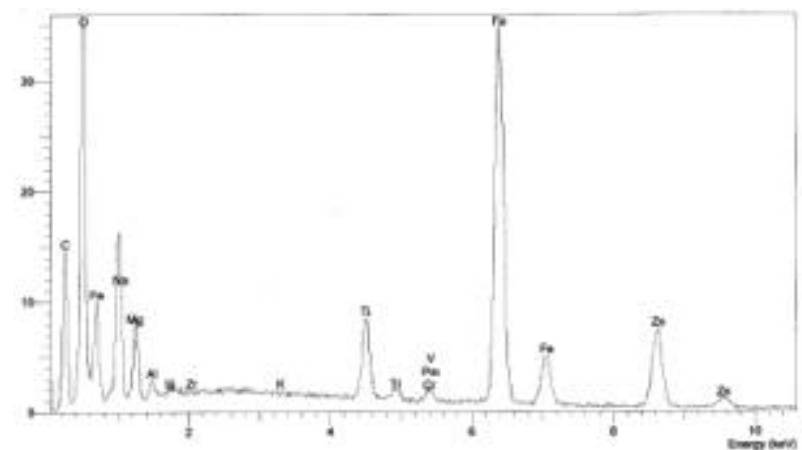

Figure 3-6. SEM/EDS of Zinc Iron Oxide $\left(\mathrm{ZnFe}_{2} \mathrm{O}_{4}\right)$

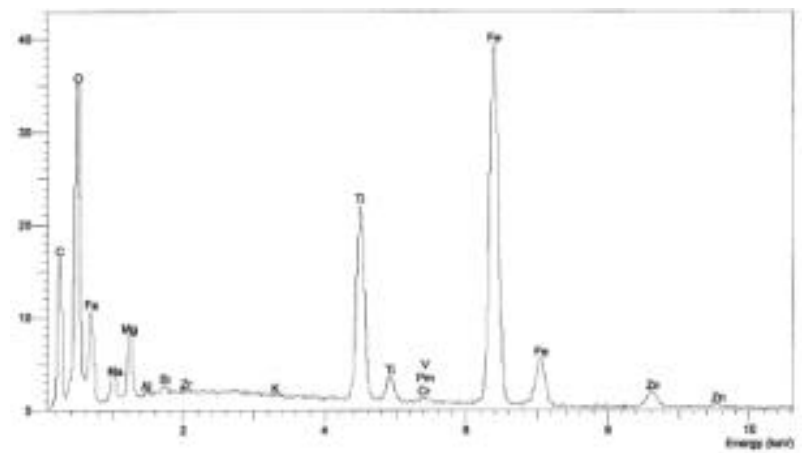

Figure 3-8. SEM/EDS of Iron Titanium Oxide $\left(\mathrm{Fe}_{2} \mathrm{TiO}_{5}\right)$

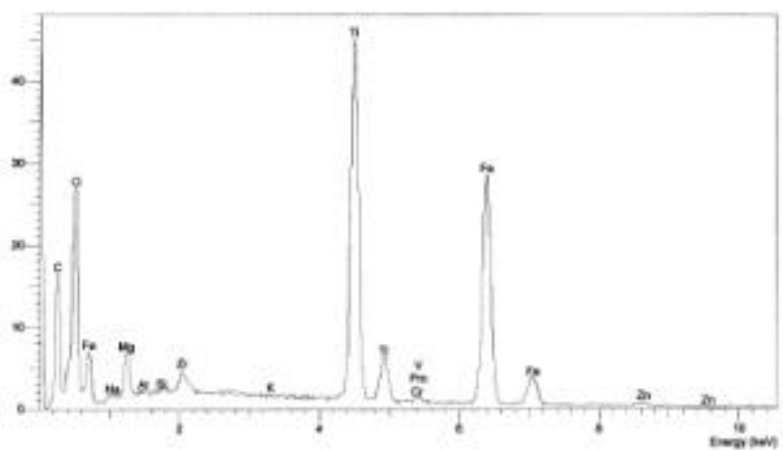

Figure 3-7. $\mathrm{SEM} / \mathrm{EDS}$ of Hematite $\left(\mathrm{Fe}_{2} \mathrm{O}_{3}\right)$, where Iron is Substituted by $\mathrm{Ti}$

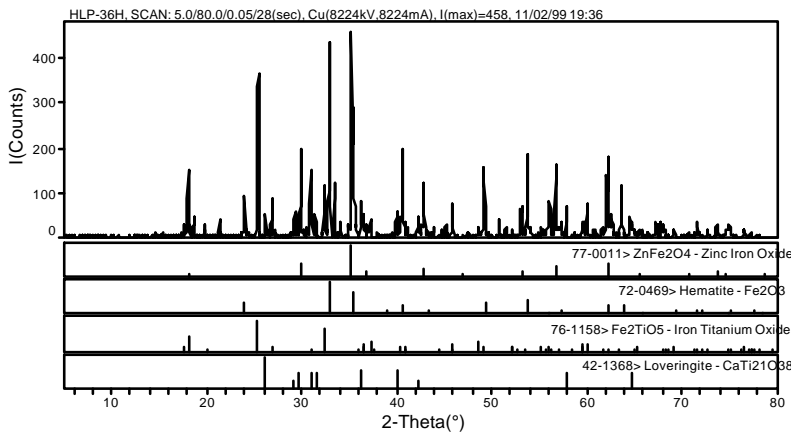

Figure 3-9. XRD Pattern of HLP-36

\subsubsection{HLP-37}

Carnegeite and chromite were identified in HLP-37 glass, with concentrations listed in Table 3-2. The leaf-like crystals in Figure 3-10 were identified as two distinct carnegieite phases. The light gray phase in Figure 3-11 has higher Si concentration, while the darker phase has higher concentrations of $\mathrm{Al}$ and Na. The second phase was identified with OM as spinel. An EDS spectra of this phase indicates high concentrations of $\mathrm{Cr}$ and $\mathrm{Fe}$, likely chromite. This structure cannot be verified by XRD because of its minor content in glass (Figures 3-12 through 3-14).

Table 3-2. List of Phases Identified in HLP-37

\begin{tabular}{ccc}
\hline$\#^{\text {a) }}$ & \multicolumn{1}{c}{ Phase } & Concentration \\
\hline 1 & Carnegieite low $\left(\mathrm{Na}\left(\mathrm{AlSiO}_{4}\right)\right)$ & 49.28 mass\% \\
2 & Chromite $\left(\mathrm{FeCr}_{2} \mathrm{O}_{4}\right)$ & $\geq 0.5$ \\
\hline \multicolumn{2}{c}{ a) Numbers refer to the labels in figures. }
\end{tabular}




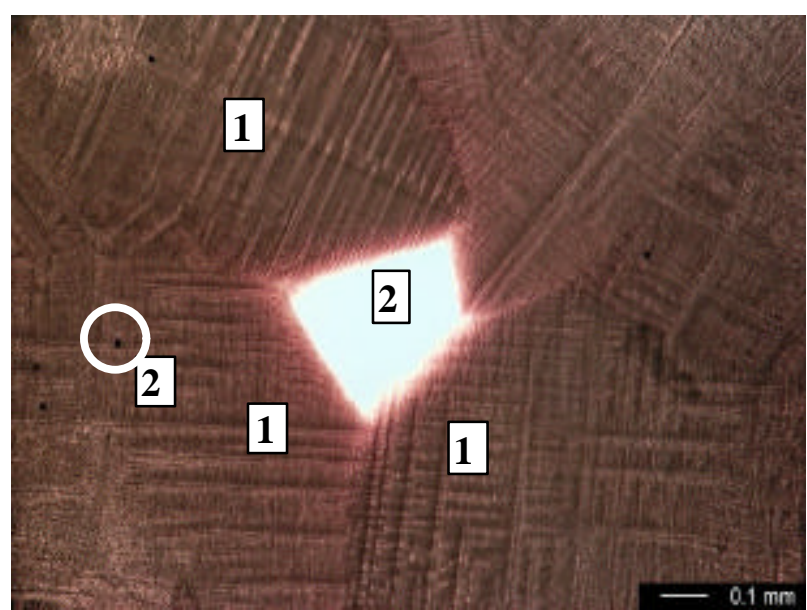

Figure 3-10. OM of HLP-37 (100×)

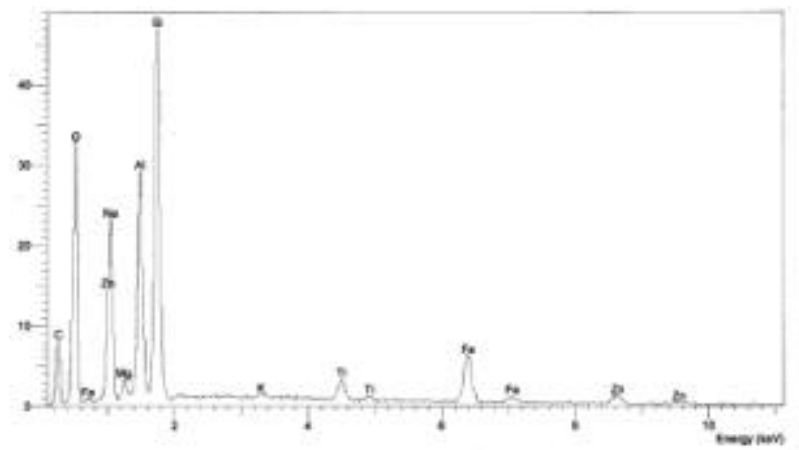

Figure 3-12. SEM/EDS of Carnegieite Low $\left[\mathrm{Na}\left(\mathrm{AlSiO}_{4}\right)\right]$ - Dark Gray Phase

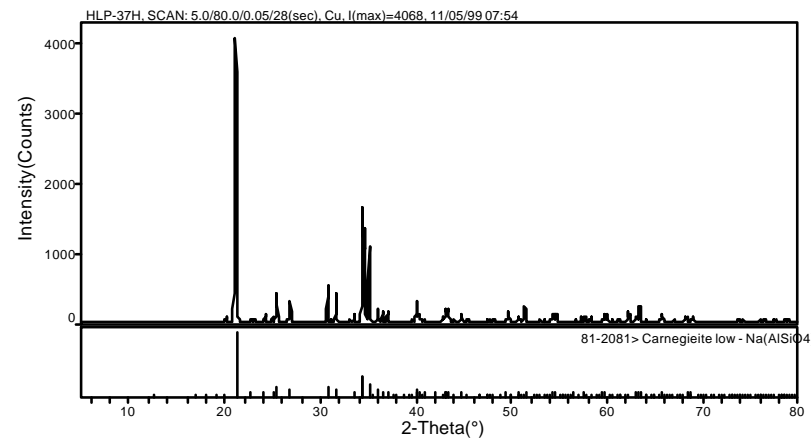

Figure 3-14. XRD Pattern of HLP-37

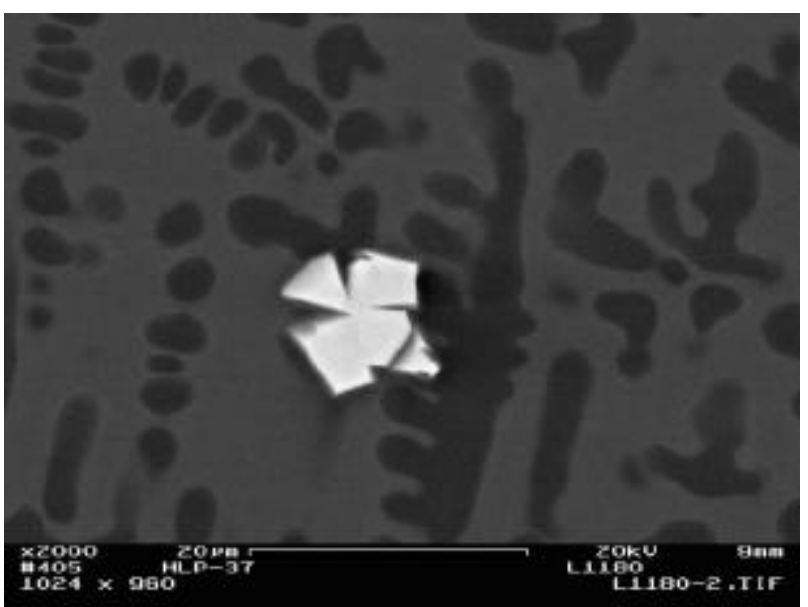

Figure 3-11. SEM Micrograph of HLP-37

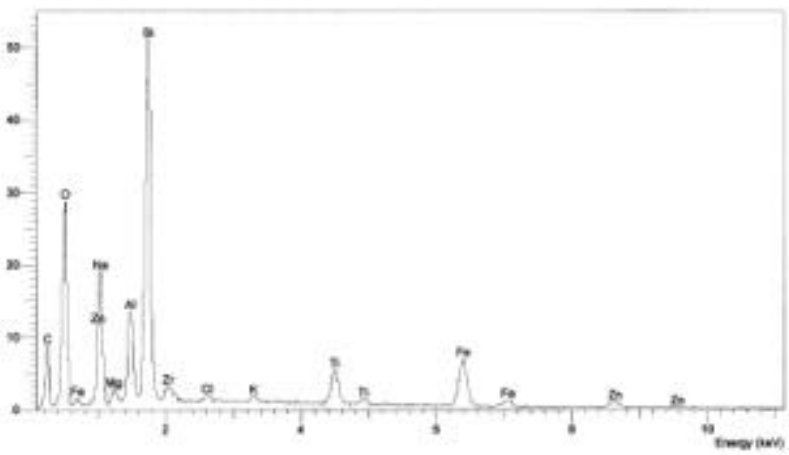

Figure 3-13. SEM/EDS of Carnegieite Low $\left[\mathrm{Na}\left(\mathrm{AlSiO}_{4}\right)\right]$ - Light Gray Phase

\subsubsection{HLP-38 and HLP-42}

Like glasses HLP-36 and -40, HLP-38 and -42 have the same target concentrations of $\mathrm{SiO}_{2}$, $\mathrm{Na}_{2} \mathrm{O}$, and $\mathrm{B}_{2} \mathrm{O}_{3}$ with a different concentration of $\mathrm{Al}_{2} \mathrm{O}_{3}$ and form the same crystalline phases.

Titanomagnetite and mathiasite were identified in these glasses with their estimated concentrations listed in Table 3-3. Figure 3-15 and Figure 3-16 show SEM micrographs of these phases in HLP-38 (Figures 3-17 through 3-19). 
Table 3-3. Phases Identified in HLP-38 and HLP-42 With XRD

\begin{tabular}{cccc}
\hline$\#^{\text {a) }}$ & Phase & Concentration in HLP-38 & Concentration in HLP-42 \\
\hline 1 & Titanomagnetite $\left(\mathrm{Fe}_{2.50} \mathrm{Ti}_{0.50} \mathrm{O}_{4}\right)$ & $\sim 12.78$ mass $\%$ & 13.41 mass\% \\
2 & Mathiasite $\left[(\mathrm{K}, \mathrm{Ba})(\mathrm{Ti}, \mathrm{Cr}, \mathrm{Fe}, \mathrm{Mg})_{21} \mathrm{O}_{38}\right]$ & 6.04 & 5.42 \\
\hline
\end{tabular}

a) Numbers refer to the labels in figures.

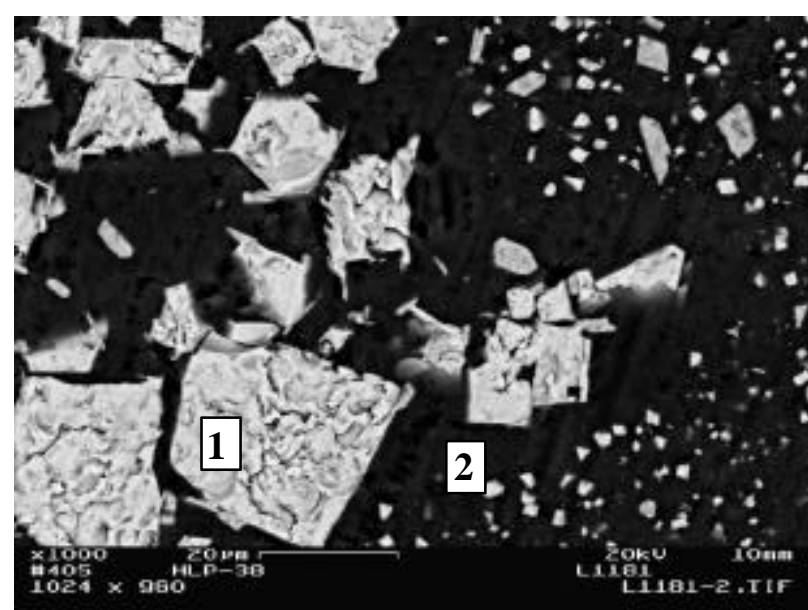

Figure 3-15. SEM Micrograph of HLP-38

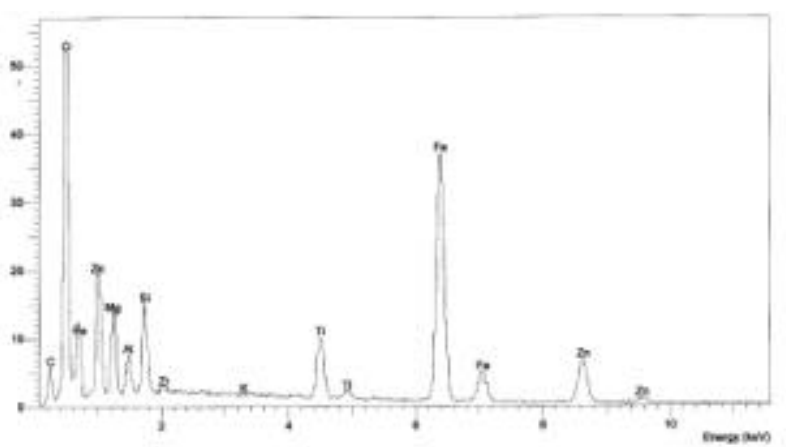

Figure 3-17. SEM/EDS of Titanomagnetite $\left(\mathrm{Fe}_{2.50} \mathrm{Ti}_{0.50} \mathrm{O}_{4}\right)$

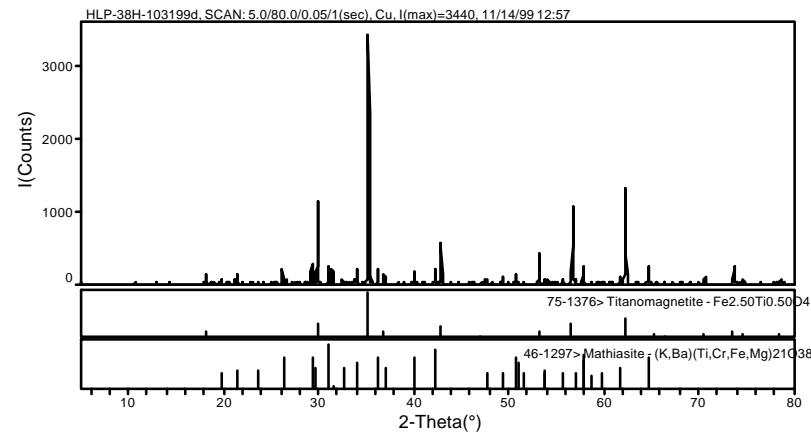

Figure 3-19. XRD Pattern of HLP-38

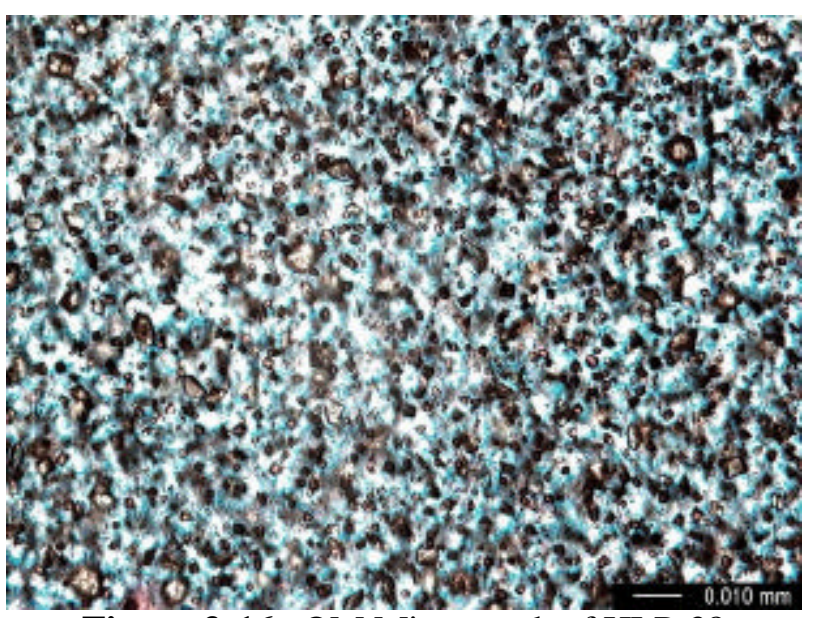

Figure 3-16. OM Micrograph of HLP-38

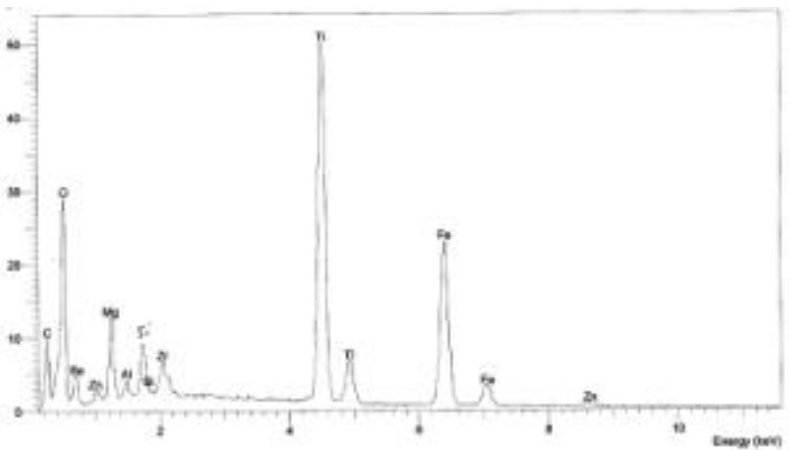

Figure 3-18. SEM/EDS of Mathiasite $\left[(\mathrm{K}, \mathrm{Ba})(\mathrm{Ti}, \mathrm{Cr}, \mathrm{Fe}, \mathrm{Mg})_{21} \mathrm{O}_{38}\right]$ 


\subsubsection{HLP-41}

Zinc Iron Oxide $\left(\mathrm{ZnFe}_{2} \mathrm{O}_{4}\right)$ was identified in HLP-41 with a combination of OM (which showed spinel like crystals as shown in Figure 3-20) and EDS (which showed high concentrations of Fe and $\mathrm{Zn}$ as shown in Figure 3-21). We were not able to identify the crystalline phases with XRD because of the low concentration of crystals. The detection limit of crystalline phases by the XRD method used is estimated at roughly 0.5 mass $\%$.

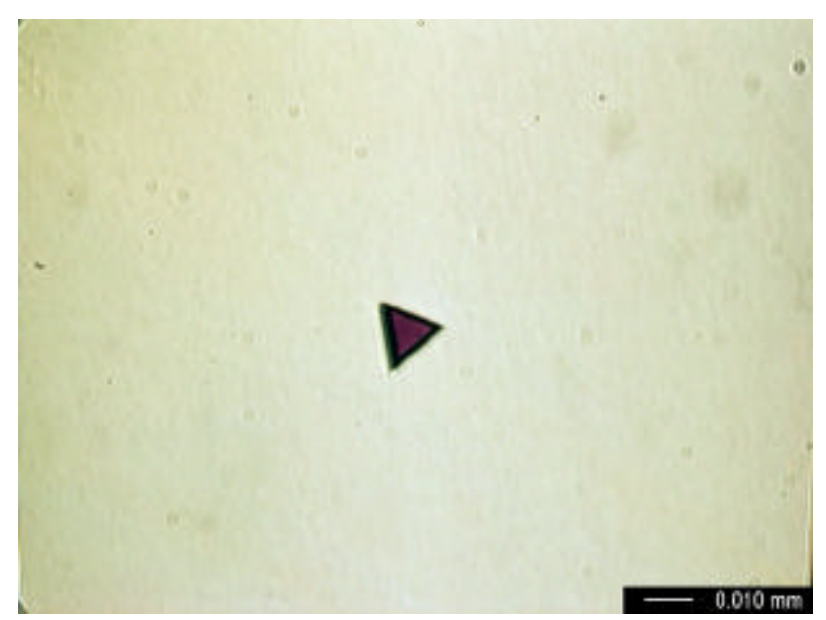

Figure 3-20. OM of HLP-41 (500×)

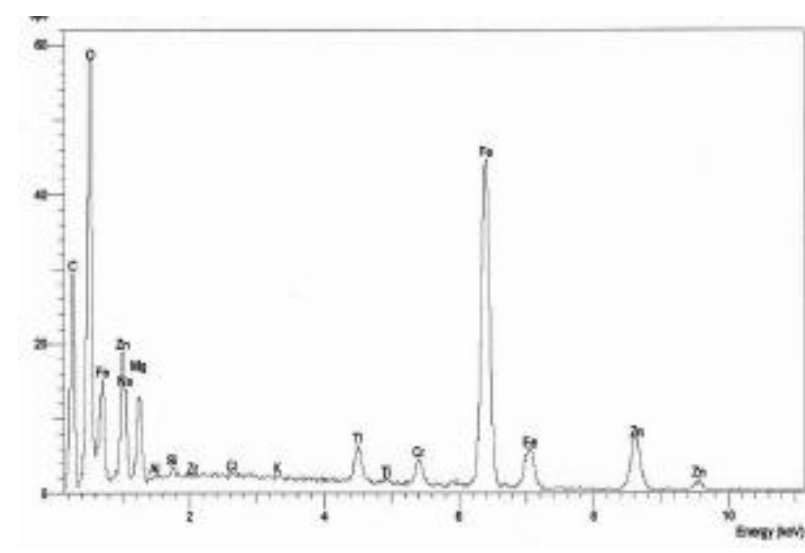

Figure 3-21. EDS Spectra of a Crystal in HLP-41

\subsubsection{HLP-49}

The phases identified in HLP-49 glass with XRD are listed in Table 3-4. Only one type of crystal was identified in HLP-49 with OM as shown in Figure 3-22 through Figure 3-25. The composition of the crystal was calculated with $\mathrm{SEM} / \mathrm{EDS}$ to be $\mathrm{Ca}_{0.88} \mathrm{Mg}_{0.49} \mathrm{Fe}_{0.49}\left(\mathrm{SiO}_{3}\right)_{2}$, which is very close to a Caclinopyroxene named augite. Some $\mathrm{Zr}$ impurities were also found via SEM/EDS of these crystals. XRD identified two types of these clinopyroxene with a different ratio of Fe substituting for Mg. Further SEM investigation identified chromite at the center of a clinopyroxene crystal and $\mathrm{Pt}$ in the center of one chromite crystal (see Figure 3-26 and Figure 3-27). Platinum was introduced into the glass, probably during the melting process, and may have served as a nucleation center for growth of the chromite, which in turn may have served as a nucleation site for the growth of clinopyroxene.

Table 3-4. List of Phases Identified in HLP-49 with XRD

\begin{tabular}{clc}
\hline$\#^{\text {a) }}$ & \multicolumn{1}{c}{ Phase } & Concentration \\
\hline 1 & Calcium Magnesium Silicate $\left[\mathrm{Ca}_{0.8} \mathrm{Mg}_{1.2}\left(\mathrm{SiO}_{3}\right)_{2}\right]$ & 2.24 mass\% \\
2 & Augite $\left[\mathrm{Ca}_{0.61} \mathrm{Mg}_{0.76} \mathrm{Fe}_{0.49}\left(\mathrm{SiO}_{3}\right)_{2}\right]$ & 3.51 \\
3 & Zinc Iron Oxide $\left(\mathrm{ZnFe}_{2} \mathrm{O}_{4}\right)$ & $\leq 0.5$ \\
\hline
\end{tabular}

a) Numbers refer to the labels in figures. 


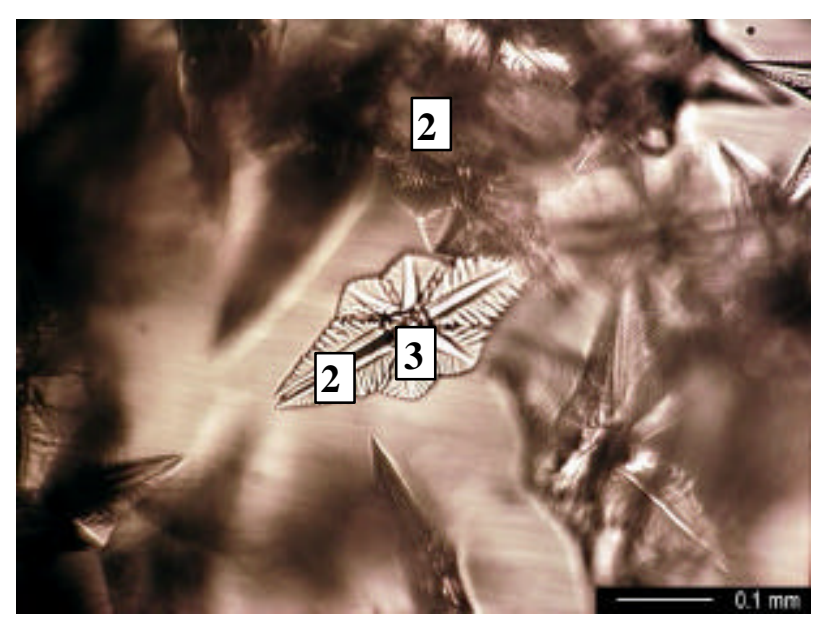

Figure 3-22. OM of Augite in HLP-49 (200×)

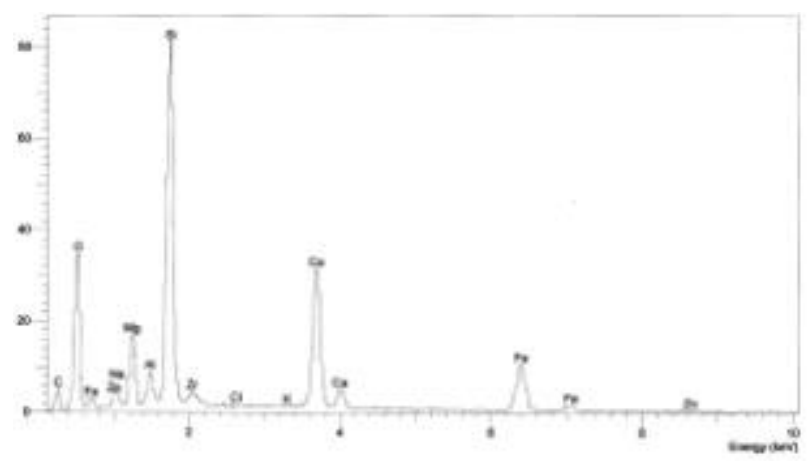

Figure 3-24. SEM/EDS of Augite $\left[\mathrm{Ca}_{0.61} \mathrm{Mg}_{0.76} \mathrm{Fe}_{0.49}\left(\mathrm{SiO}_{3}\right)_{2}\right]$

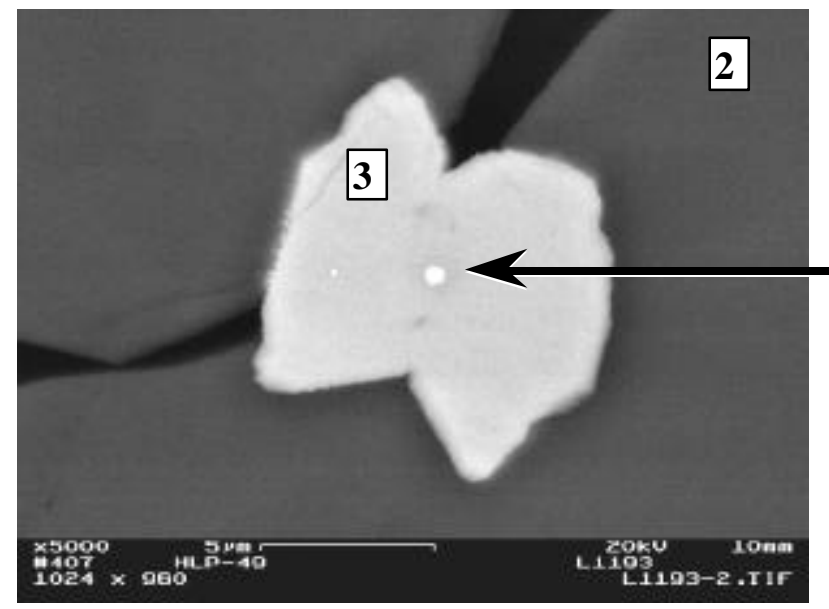

Figure 3-26. SEM Micrograph of Pt, Augite (background), and Zinc Iron Oxide in HLP-49

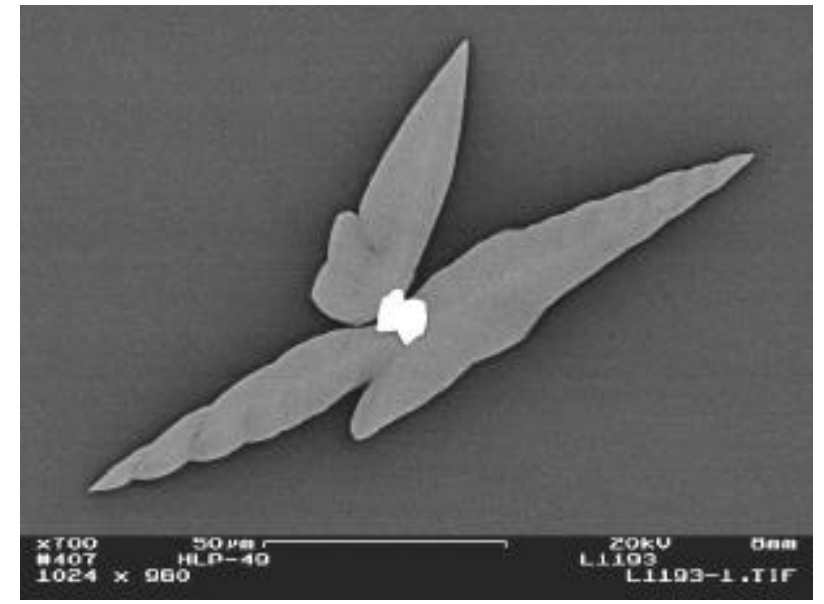

Figure 3-23. SEM Micrograph of Augite and Zinc Iron Oxide (on top) in HLP-49

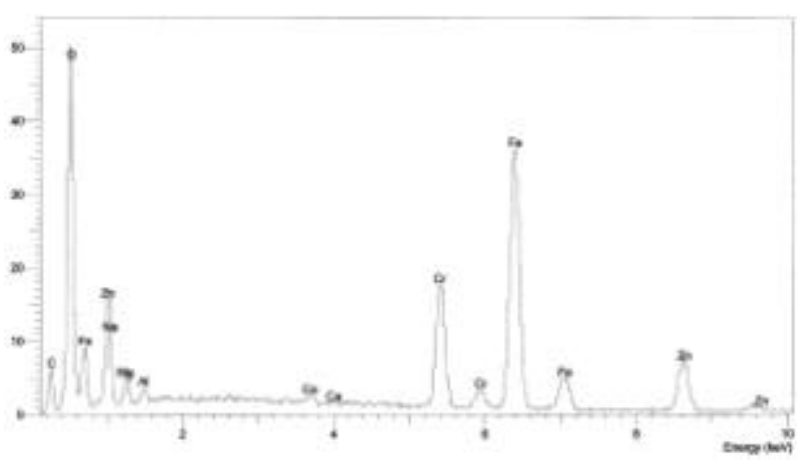

Figure 3-25. SEM/EDS of Zinc Iron Oxide $\left(\mathrm{ZnFe}_{2} \mathrm{O}_{4}\right)$

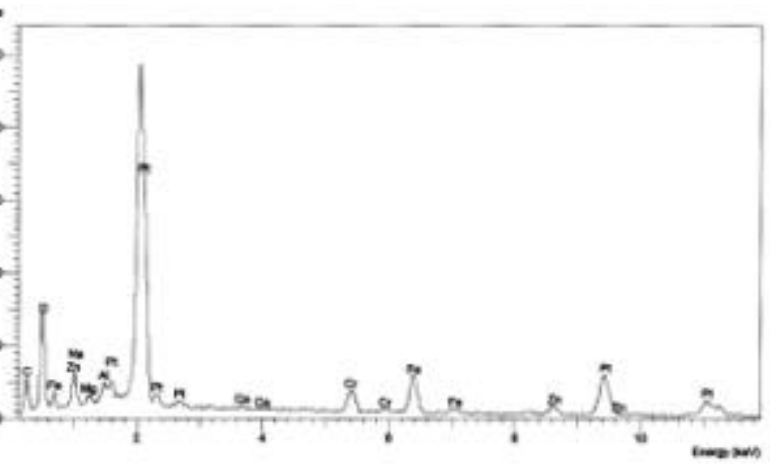

Figure 3-27. EDS Spectra of a Pt particle in HLP-49 


\subsubsection{HLP-53}

During the heat treatment of HLP-53, a second phase appeared to segregate on all surfaces of the melt (for example, see Figure 3-28 and Figure 3-29). The segregated materials or "phases" were easy to mechanically separate. OM analyses of each individual "phase" (given in Figure 3-30 and Figure 3-31) showed densely packed small crystals on the surface phase and a few large crystals in the bulk phase. XRD analyses identified only nepheline $\left(\mathrm{NaAlSiO}_{4}\right)$ in both the surface and bulk. The measured compositions of the bulk-quenched glass and the surface layer and bulk layer of the heat-treated glass are compared in

Table 3-5. The differences are too small to suggest that the two layers are of different composition. These data suggest massive surface crystallization of nepheline in HLP-53 during heat treatment. The inhomogeneity of this sample precluded the testing of heat-treated samples by VHT; however, a sample representative of the material was ground and used for PCT along with a quenched sample. The content of nepheline measured in HLP-53 glass with XRD was 2.11 mass\%.

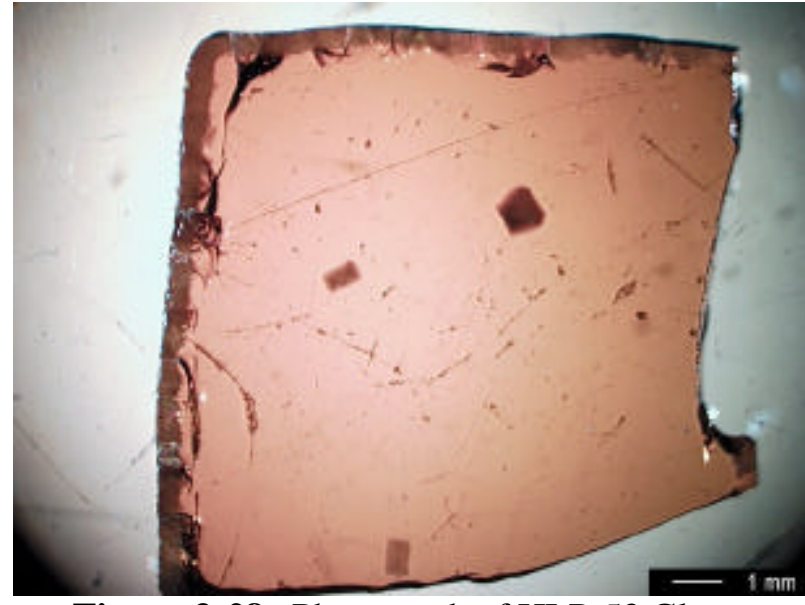

Figure 3-28. Photograph of HLP-53 Glass Monolith after Heat Treatment

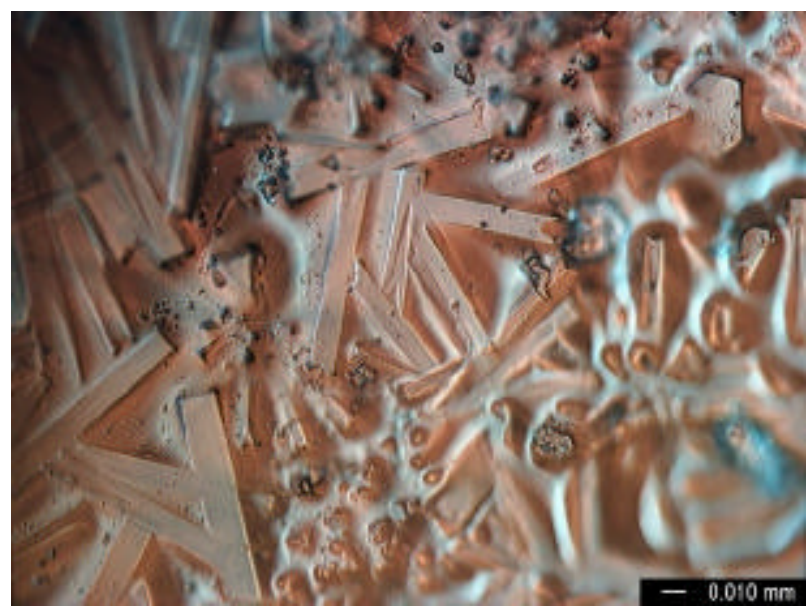

Figure 3-30. OM of HLP-53 Surface (500x)

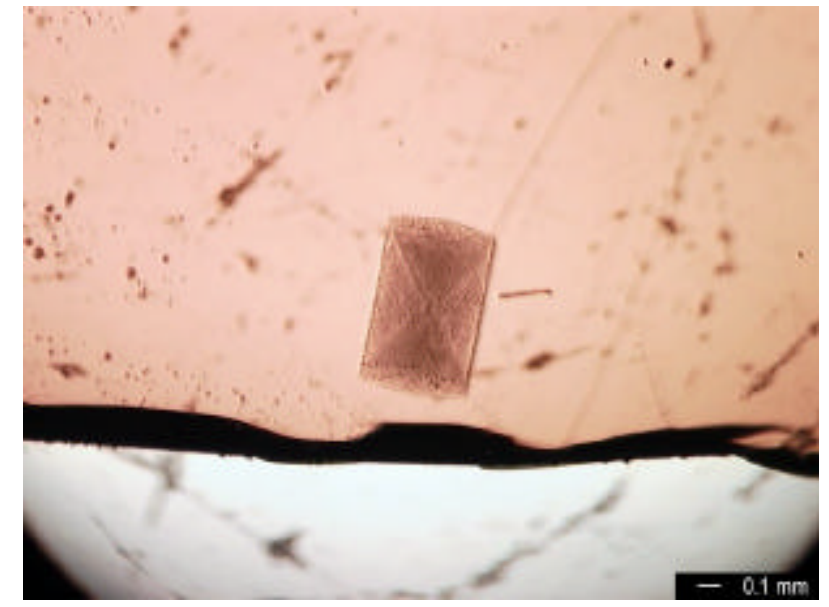

Figure 3-29. OM of HLP-53 Bulk (70×)

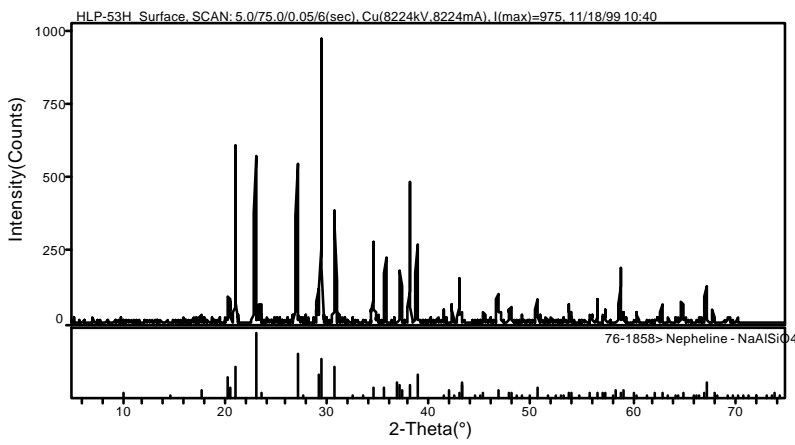

Figure 3-31. OM of HLP-53 Bulk (70x) 
Table 3-5. Comparison of Composition for Different Samples of HLP-53 (mass \%)

\begin{tabular}{|c|c|c|c|c|c|}
\hline & Target & Quench & T (PCT) & Bulk & Surface \\
\hline $\mathrm{SiO}_{2}$ & 40.15 & 40.8 & 39.5 & 42.2 & 43.5 \\
\hline $\mathrm{Al}_{2} \mathrm{O}_{3}$ & 9.86 & 9.79 & 9.31 & 9.59 & 9.49 \\
\hline $\mathrm{B}_{2} \mathrm{O}_{3}$ & 4.23 & 4.54 & 5.46 & 4.34 & 4.26 \\
\hline $\mathrm{Fe}_{2} \mathrm{O}_{3}$ & 7.30 & 7.52 & 7.67 & 7.99 & 8.12 \\
\hline $\mathrm{ZnO}$ & 3.28 & 3.24 & 3.09 & 3.07 & 3.26 \\
\hline $\mathrm{ZrO}_{2}$ & 2.99 & 2.82 & 2.76 & 2.79 & 2.67 \\
\hline $\mathrm{MgO}$ & 2.04 & 1.84 & 1.93 & 1.85 & 1.89 \\
\hline $\mathrm{Li}_{2} \mathrm{O}$ & 2.04 & 2.13 & 2.29 & 2.11 & 2.09 \\
\hline $\mathrm{Na}_{2} \mathrm{O}$ & 20.00 & 20.4 & 18.6 & 18.7 & 19.3 \\
\hline $\mathrm{K}_{2} \mathrm{O}$ & 3.10 & 3.08 & 2.75 & 2.98 & 2.93 \\
\hline $\mathrm{CaO}$ & 4.38 & 4.33 & 4.21 & 4.27 & 4.32 \\
\hline $\mathrm{Cl}^{-}$ & 0.36 & NM & NM & NM & NM \\
\hline $\mathrm{SO}_{3}$ & 0.04 & NM & NM & NM & NM \\
\hline $\mathrm{P}_{2} \mathrm{O}_{5}$ & 0.08 & NM & NM & NM & NM \\
\hline $\mathrm{Cr}_{2} \mathrm{O}_{3}$ & 0.01 & $\mathrm{BD}$ & 0.14 & $\mathrm{BD}$ & BD \\
\hline $\mathrm{F}^{-}$ & 0.12 & $\mathrm{NM}$ & NM & NM & NM \\
\hline Total & 99.98 & 100.49 & 97.71 & 100.19 & 101.83 \\
\hline
\end{tabular}

\subsection{Density of HLP Glasses}

The measured glass densities $(\rho)$ are listed in Table 3-6 along with standard deviations. The densities of all matrix glasses range from $2.45 \mathrm{~g} / \mathrm{cm}^{3}$ to $2.95 \mathrm{~g} / \mathrm{cm}^{3}$. ${ }^{\text {a }}$ However, on average, the crystallized glasses have higher densities, ranging from $2.71 \mathrm{~g} / \mathrm{cm}^{3}$ to $2.95 \mathrm{~g} / \mathrm{cm}^{3}$ as compared to the homogeneous glasses, which range in density from $2.45 \mathrm{~g} / \mathrm{cm}^{3}$ to $2.81 \mathrm{~g} / \mathrm{cm}^{3}$.

${ }^{a}$ The units of $\mathrm{g} / \mathrm{cm}^{3}$ are used in this report to allow direct comparison with existing data on glass density. To convert to the SI units of $\mathrm{kg} / \mathrm{m}^{3}$, the reader can multiply reported values by 1000 . 
Table 3-6. Density of HLP Glasses (heat treated and powdered unless otherwise noted)

\begin{tabular}{lllllllll}
\hline Glass $^{\mathbf{a}} \boldsymbol{\rho}\left[\mathbf{g} / \mathbf{c m}^{3}\right]$ St.Dev. & Glass $^{\mathbf{a}}$ & $\left.\boldsymbol{\rho} \mathbf{\rho} \mathbf{g} / \mathbf{c m}^{3}\right]$ St.Dev. & Glass $^{\mathbf{a}}$ & $\boldsymbol{\rho}\left[\mathbf{g} / \mathbf{c m}^{3}\right]$ St.Dev. \\
\hline HLP-01 & 2.6493 & 0.0020 & HLP-24 & 2.6087 & 0.0006 & HLP-21 & 2.6148 & 0.0009 \\
HLP-02 & 2.7022 & 0.0020 & HLP-25 & 2.6409 & 0.0018 & HLP-22 & 2.5900 & 0.0018 \\
HLP-03 & 2.6364 & 0.0011 & HLP-26 & 2.6418 & 0.0018 & HLP-23 & 2.6285 & 0.0033 \\
HLP-04 & 2.6828 & 0.0009 & HLP-27 & 2.5048 & 0.0008 & HLP-43 & 2.6354 & 0.0026 \\
HLP-05 & 2.6756 & 0.0002 & HLP-27QP & 2.4869 & 0.0008 & HLP-44 & 2.6391 & 0.0018 \\
HLP-06 & 2.5609 & 0.0025 & HLP-28 & 2.5165 & 0.0021 & HLP-45 & 2.6572 & 0.0024 \\
HLP-07 & 2.6027 & 0.0015 & HLP-29 & 2.5691 & 0.0028 & HLP-46 & 2.5389 & 0.0006 \\
HLP-08 & 2.6915 & 0.0030 & HLP-30 & 2.5990 & 0.0006 & HLP-47 & 2.5233 & 0.0015 \\
HLP-09 & 2.6014 & 0.0009 & HLP-31 & 2.6244 & 0.0011 & HLP-48 & 2.6872 & 0.0014 \\
HLP-10 & 2.6229 & 0.0009 & HLP-32 & 2.6249 & 0.0010 & HLP-48HG & 2.6556 & 0.0007 \\
HLP-11 & 2.5630 & 0.0025 & HLP-33 & 2.6351 & 0.0018 & HLP-48QP & 2.6515 & 0.0015 \\
HLP-12 & 2.6819 & 0.0018 & HLP-34 & 2.6729 & 0.0031 & HLP-48QG & 2.6428 & 0.0009 \\
HLP-13 & 2.6074 & 0.0011 & HLP-35 & 2.6437 & 0.0060 & HLP-49 & 2.7712 & 0.0006 \\
HLP-14 & 2.588 & 0.003 & HLP-36 & 2.7437 & 0.0011 & HLP-51 & 2.7218 & 0.0006 \\
HLP-15 & 2.6275 & 0.0032 & HLP-37 & 2.7056 & 0.0010 & HLP-51HG & 2.6751 & 0.0011 \\
HLP-16 & 2.5919 & 0.0034 & HLP-38 & 2.7828 & 0.0020 & HLP-52 & 2.6539 & 0.0007 \\
HLP-17 & 2.6574 & 0.0039 & HLP-39 & 2.7304 & 0.0018 & HLP-53 & 2.7258 & 0.0007 \\
HLP-18 & 2.5997 & 0.0027 & HLP-40 & 2.8250 & 0.0005 & HLP-54 & 2.4897 & 0.0030 \\
HLP-19 & 2.6692 & 0.0012 & HLP-41 & 2.8140 & 0.0015 & HLP-55 & 2.4545 & 0.0025 \\
HLP-20 & 2.6258 & 0.0002 & HLP-42 & 2.9520 & 0.0012 & HLP-56 & 2.6804 & 0.0015 \\
\hline
\end{tabular}

(a) $\mathrm{H}=$ Heat-treated, $\mathrm{Q}=$ Quenched, $\mathrm{P}=$ Powdered, $\mathrm{G}=$ Grain (i.e., not powdered)

\subsection{Glass Compositions}

The targeted and measured glass compositions are shown in Table A-1. Comparison of the targeted and measured compositions indicates that there were no gross batching errors. That is, the differences between the target and measured concentrations for most of the major components (i.e., $\mathrm{SiO}_{2}$, $\mathrm{Al}_{2} \mathrm{O}_{3}, \mathrm{~B}_{2} \mathrm{O}_{3}, \mathrm{TiO}_{2}$, and $\mathrm{Na}_{2} \mathrm{O}$ ) were less than 5\%. Furthermore, the initial review of these data suggested that no gross laboratory-to-laboratory variation in glass preparation appeared to have occurred. (Glasses HLP-13 to HLP-25 were prepared at SRTC while the remainder of the glasses were fabricated at PNNL.) A more detailed statistical analysis (including appropriate components of variance) of the composition data is planned for the final Hanford ILAW data package.

It should be noted that the $\mathrm{Fe}_{2} \mathrm{O}_{3}$ and $\mathrm{Cr}_{2} \mathrm{O}_{3}$ measured values were higher than the targeted values for all the glasses. Since a significant amount of glass was needed for testing (i.e., VHT, PCT-A, and PCT-B), only ground PCT fines (-200 mesh) were available for composition analyses. Therefore, contamination from the stainless steel grinding vessel is suspected to be the primary cause of the elevated $\mathrm{Fe}_{2} \mathrm{O}_{3}$ and $\mathrm{Cr}_{2} \mathrm{O}_{3}$ values. This contamination has the effect of relatively decreasing the other measured concentrations for the glass. A number of the glasses may be resubmitted for nickel analyses so that the glass concentrations can be corrected for the suspected stainless steel contamination.

The sum of the oxides was greater than $95 \%$ a for all but one glass (i.e., HLP-46). For another four glasses (HLP-9, HLP-11, HLP-26 and HLP-32), the sum of the oxides was approximately 95\%. The

\footnotetext{
${ }^{a}$ A sum of oxides greater than $95 \%$ is a heuristic metric used at SRTC to ensure that the measured glass compositions are valid.
} 
resulting lower-than-expected sums of oxides may be either the result of an analytical bias or normal random variation in the measured concentrations.

In almost all cases, the measured $\mathrm{Na}_{2} \mathrm{O}$ values were lower than targeted. The maximum deviation was observed in HLP-11 where the measured $\mathrm{Na}_{2} \mathrm{O}$ value was $14 \%$ lower than targeted. There is currently insufficient data to resolve the source(s) of these differences; further examination is necessary.

Batching and analytical errors were further examined by comparing the chemical composition data for the repeated glasses. This analysis will be discussed in Section 4.17.

\subsection{Redox}

Glasses HLP-44 and -45 have the same target composition as the center glass (HLP-01). However, they were melted and heat treated under reducing conditions to progressively increase the redox (ratio of two valent to total iron-Fe(II)/Fe) as discussed in Section 2.2. The measured redox of these glasses is compared to that of HLP-26 in Table 3-7. The redox of these heat-treated glasses ranges from $1 \%$ to nearly $59 \%$, which is expected to bracket the redox of glasses to be produced by the HVV.

Figure 3-32 shows the relationship between the natural logarithm of oxygen partial pressure above the glass melt and the measured redox of the quenched glasses. Our measurements show that $\ln [\mathrm{Fe}(\mathrm{II}) / \mathrm{Fe}(\mathrm{III})]$ is related to $\ln \left[\mathrm{p}_{\mathrm{O} 2}\right]$ by a straight line with slope of 0.253 , which closely matches the expected slope of 0.25 . This relationship allows the reader the ability to interpolate the effects of $\mathrm{p}_{\mathrm{O} 2}$ on corrosion characteristics of the glass.

Table 3-7. Melting Oxygen Partial Pressure and Measured Redox of HLP-26, -44, and -45

\begin{tabular}{|c|c|c|c|c|}
\hline Sample $^{a}$ & $-\ln \left(\mathbf{p}_{02}\right)$ & $\mathrm{Fe}(\mathrm{II}) / \mathrm{Fe}$ & $\mathrm{Fe}(\mathrm{II}) / \mathrm{Fe}$ & ave. \\
\hline HLP-26Q & 1.56 & 0.0115 & 0.0119 & 0.0117 \\
\hline HLP-26H & & 0.0099 & 0.0102 & 0.0101 \\
\hline HLP-44Q & 13.8 & 0.195 & 0.1856 & 0.1903 \\
\hline HLP-44H & & 0.2029 & 0.2066 & 0.2048 \\
\hline HLP-45Q & 20.7 & 0.6199 & 0.5924 & 0.6062 \\
\hline HLP-45H & & 0.581 & 0.59 & 0.5855 \\
\hline SRM-278 & & 0.711 & 0.686 & 0.6985 \\
\hline
\end{tabular}

(a) $\mathrm{Q}=$ quenched and $\mathrm{H}=$ heat treated

(b) Obsidian Rock with certified $\mathrm{Fe}(\mathrm{II}) / \mathrm{Fe}=0.74 \pm 0.01^{\mathrm{a}}$

\footnotetext{
a Standard Reference Material \#278 - Obsidian Rock, National Bureau of Standard, Washington, D. C., 1992.
} 


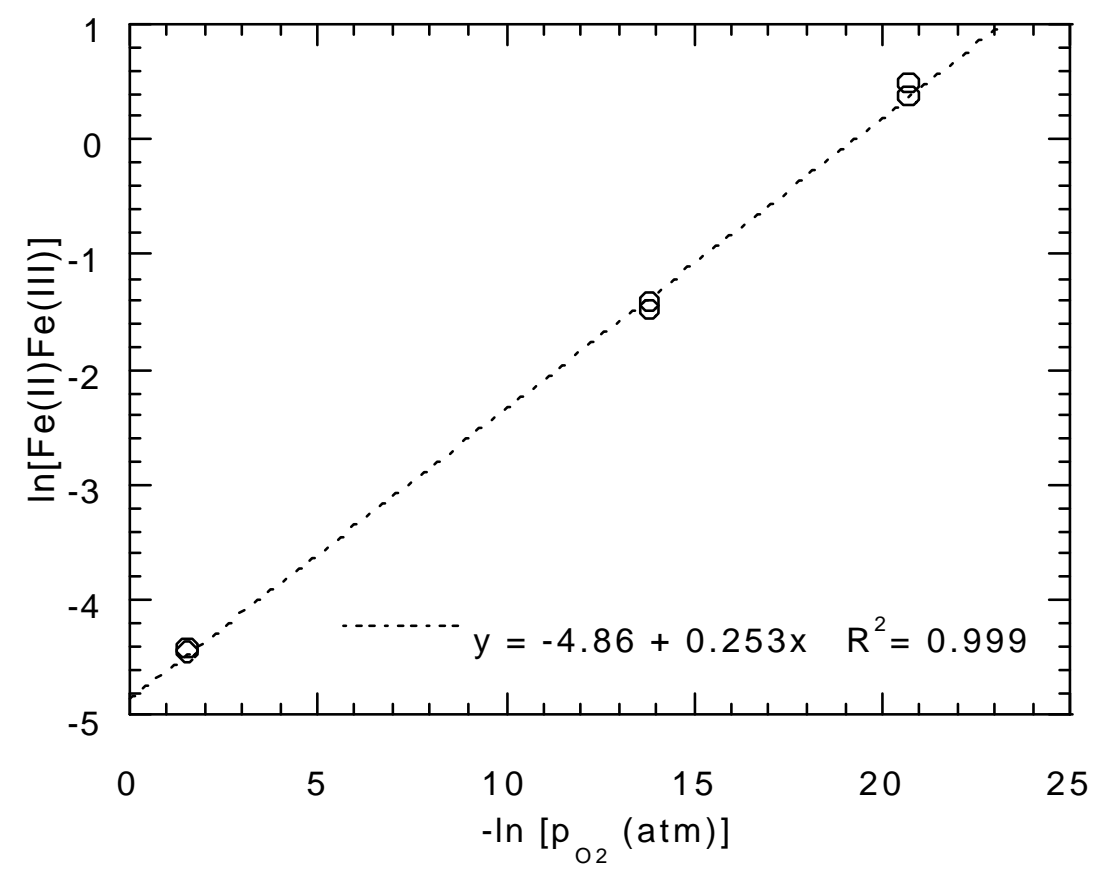

Figure 3-32. Effect of $p_{02}$ on Measured Glass Redox

\subsection{Product Consistency Test}

\subsubsection{PCT-A}

A PCT-A series (i.e., 7 day, $90^{\circ} \mathrm{C}, 2000 \mathrm{~m}^{-1}$ ) was run in triplicate on the glasses whose compositions are provided in Table 2-1. The raw, measured concentrations resulting from these tests are provided in Table B-1. (Those for the PCT-B series are provided in Table B-2 through Table B-4.) The release values corresponding to these PCT-A results (and the appropriate target concentrations from Table 2-1) are provided in Table B-5. The expression for the normalized release, $\mathrm{NC}_{\mathrm{i}}$ in $\mathrm{g} / \mathrm{L}$, is normally given as

$$
\mathrm{NC}_{\mathrm{i}}=\frac{\mathrm{p}_{\mathrm{i}}}{10 \mathrm{x}_{\mathrm{i}}}
$$

where $\mathrm{p}_{\mathrm{i}}$ is the test solution concentration in $\mathrm{mg} / \mathrm{L}$ (adjusted for dilution), and $\mathrm{x}_{\mathrm{i}}$ is the target cation concentration in grams of $\mathrm{i}$ per 100 grams glass for the cation in question. A lognormal distribution was assumed appropriate for the data. ${ }^{a}$ Under this assumption, the normalized release value, or $\mathrm{NC}_{\mathrm{i}}$ in $(\mathrm{g} / \mathrm{L})$, for a glass is

$$
\mathrm{NC}_{\mathrm{i}}=\exp \left[\overline{\ln \left(\mathrm{p}_{\mathrm{i}}\right)}-\ln (10)-\ln \left(\mathrm{x}_{\mathrm{i}}\right)\right]
$$

\footnotetext{
${ }^{a}$ A lognormal distribution was assumed, since the test solution concentrations cannot be less than zero and many are close to zero in terms of expected errors, the assumption is made that the measured test solution concentrations, $\mathrm{p}_{\mathrm{i}}$, and thus $\mathrm{NC}_{\mathrm{i}}$, will likely follow a lognormal distribution. In addition, some experience from PCT data suggested lognormal behavior.
} 
where the term $\overline{\ln \left(\mathrm{p}_{\mathrm{i}}\right)}$ represents the mean of the three $\ln \left(\mathrm{p}_{\mathrm{i}}\right)$ results for a glass. The data in Appendix $B$ can be used to recalculate the average release assuming a normal distribution if desired. The difference in average releases calculated under the two assumptions is considered to be of little practical consequence as shown in Table 3-8.

Table 3-8. Comparison of Mean $\mathrm{NC}_{\mathrm{B}}$ for Selected Glasses Calculated with the Assumptions of Lognormal and Normal Distributions of Data

\begin{tabular}{ccc}
\hline Glass ID & Normal & Lognormal \\
\hline HLP-01 & 10.13 & 10.13 \\
HLP-10 & 10.47 & 10.46 \\
HLP-20 & 14.30 & 14.21 \\
HLP-30 & 3.51 & 3.51 \\
HLP-40 & 40.23 & 40.21 \\
\hline
\end{tabular}

These values were measured for an $\mathrm{S} / \mathrm{V}$ value of approximately $2000 \mathrm{~m}^{-1}$. (For this initial data examination, small differences in $\mathrm{S} / \mathrm{V}$ resulting from minor density and other differences were not considered.) The release values obtained from Equation 3.2 were normalized by this test parameter to provide releases, $\mathrm{NL}_{\mathrm{i}}=\mathrm{NC}_{\mathrm{i}} /(\mathrm{S} / \mathrm{V})$, with units of $\mathrm{g} / \mathrm{m}^{2}$. The $\mathrm{B}$ and $\mathrm{Na}$ release values for the PCT-A tests are provided in Table B-5.

\subsubsection{Gross Check of the PCT-A Release Data}

For PCT-A data (i.e., at seven days), the more soluble constituents (e.g., boron and sodium) often release into the test solution at comparable rates. Accordingly, a comparison of these releases can provide a rough check on the analytical errors in the PCT data. Figure 3-33 provides such a comparison for the PCT-A releases computed using Equation 3.2. From this figure, only glass HLP-46 appears to deviate appreciably from the $45^{\circ}$ line shown on the figure; however, sodium ion exchange from this glass is known, and this result is not surprising and no additional tests on this glass are warranted. The gross check in Figure 3-33 indicates no obvious errors in the PCT-A analytical data provided in Table B-5. However, such a check may be even more important for the PCT-B data from this study where only a single measurement is available for each glass at each time. 


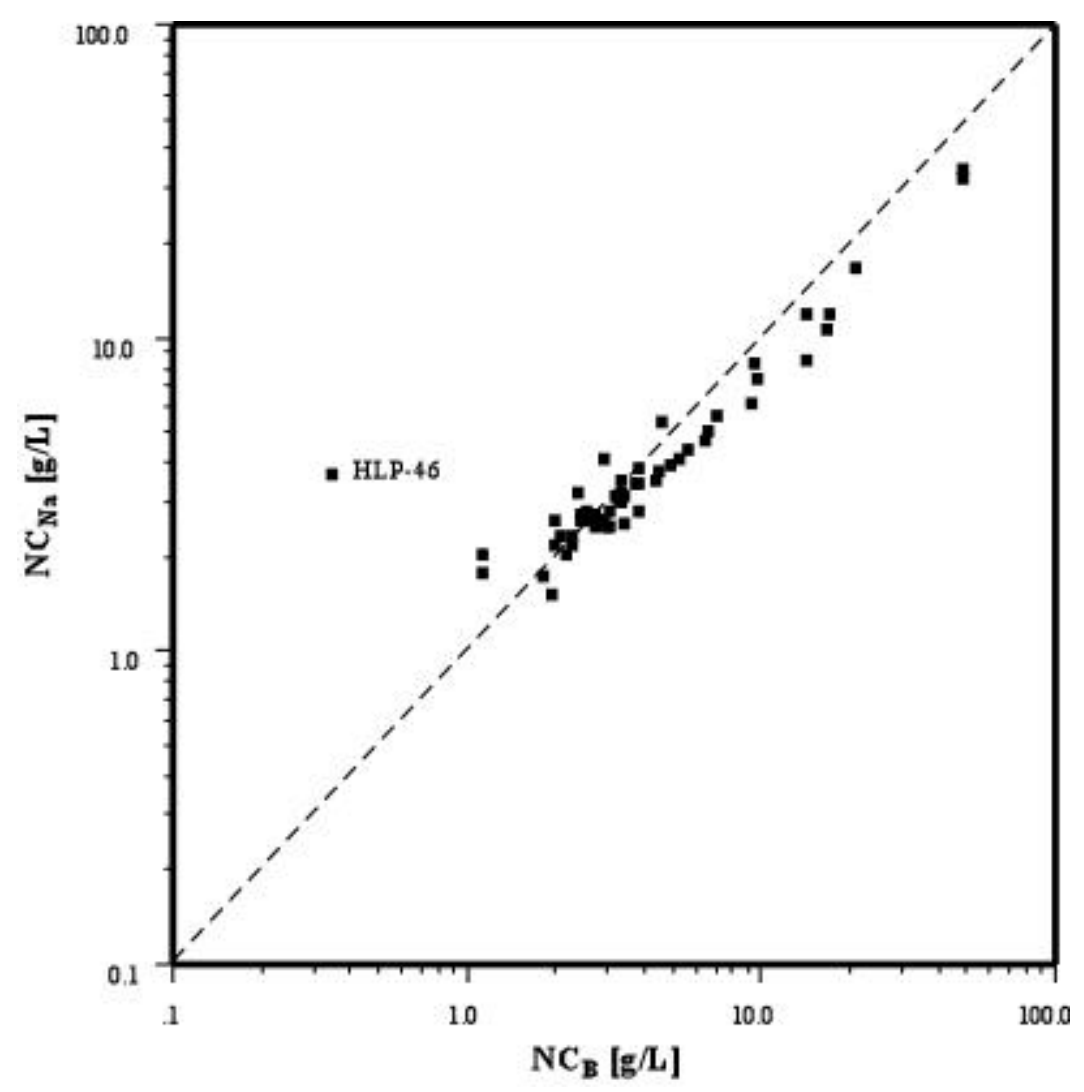

Figure 3-33. Log-Log Plot Illustrating the Normalized Sodium versus Boron Releases for the PCT-A data. Note that glass HLP-46 exhibits known sodium ion exchange. (The dotted line is the $45^{\circ}$ line representing a one-to-one correspondence between the test results.)

\subsubsection{PCT-B}

A PCT-B series was also run on the HLP glasses whose compositions are provided in Table 2-1. These tests differed from the aforementioned PCT-A series in that S/V was increased from $2000 \mathrm{~m}^{-1}$ to 20 $000 \mathrm{~m}^{-1}$, and the tests were carried out at intervals of 10,100 , and $1000 \mathrm{~h}$. However, due to budgetary constraints, only single tests were performed for the PCT-B experiments (vis-à-vis the triplicate tests run for the PCT-A series). Thus the random variations in the PCT-B results for a glass are likely higher than those in the PCT-A values (which are based upon the means of three replicate tests) for the same glass. The PCT-B release data for boron and sodium are provided in Table B-6. These PCT-B values were computed using Equation 3.1 because only a single test-solution measurement was available for each glass for each set of conditions.

\subsubsection{Gross Check of the PCT-B Release Data}

Figure 3-34 shows the relationship between the log-normalized releases for sodium and boron for the PCT-B data collected at 10, 100, and $1000 \mathrm{~h}$. The three lines provided on this figure represent the least-squares fits for the data at each time. (The uncertainties in the parameters describing these lines suggest that these lines are indistinguishable from each other.) Figure 3-34 indicates that only the 10-h values for glasses HLP-04 and HLP-46 may need to be reevaluated based upon this gross examination. 
Similar plots will be used to identify glasses for additional testing. Thus the gross checks illustrated in Figure 3-33 and Figure 3-34 suggest that the PCT data can be used for further short-term examinations.

The differences in the $\mathrm{NC}_{\mathrm{B}} / \mathrm{NC}_{\mathrm{Na}}$ with corrosion extent are generally consistent with the currently accepted model of glass corrosion. At short times the values of $\mathrm{NC}_{\mathrm{Na}}$ are higher than the values $\mathrm{NC}_{\mathrm{B}}$ because ion exchange occurs to some depth in the glass surface. After longer times, $\mathrm{NC}_{\mathrm{B}}$ values approach the $\mathrm{NC}_{\mathrm{Na}}$ values because the amount of additional $\mathrm{Na}$ in solution from ion exchange becomes a progressively lower fraction of the total $\mathrm{Na}$ in solution.

\subsubsection{Release Rates}

The PCT releases were measured for four different time intervals (i.e., 7 days and 10, 100, and $1000 \mathrm{~h}$, respectively). Figure 3-35 shows the relationship between the release, $\mathrm{NL}_{\mathrm{i}}=\mathrm{NC}_{\mathrm{i}} /(\mathrm{S} / \mathrm{V})$, and time, $\mathrm{t}$, in hours for the HLP-01 glass. When a log-log transformation of these data is made, the relationship for the resulting HLP-01 values (i.e., that for the 10, 100, and 1000-h data) appears to be fairly linear over the range of time considered for this glass. ${ }^{\mathrm{a}}$ That is, the relationship between the normalized concentrations and time (up to $1000 \mathrm{~h}$ ) can be described by

$$
\mathrm{NL}_{\mathrm{i}}=\mathrm{NC}_{\mathrm{i}} /(\mathrm{S} / \mathrm{V}) \approx \exp \{\mathrm{a}+\mathrm{b} \ln (\mathrm{t})\}=\exp (\mathrm{a}) \mathrm{t}^{\mathrm{b}}
$$

for the HLP-01 glass. Using the data in Table B-6, this relationship appears reasonable for many of the HLP glasses for times up to $1000 \mathrm{~h}$. However, because there are PCT-B data at only three time intervals for each glass, any release rates estimated based upon the expression in Equation 3.3 will have very large uncertainties associated with them, and any comparisons made using these release-rate estimates will also be fraught with uncertainty. Finally, because the relationship in Equation 3.3 cannot be shown to be fundamental to the short-term PCT-B behavior, release rates will instead be estimated using the PCT-B release information in Table B-6. However, because Equation 3.3 appears to be descriptive for many of the short-term HLP data, further examination of this relationship may become warranted when more data become available.

\footnotetext{
${ }^{a}$ The PCT-A NL $\mathrm{L}_{\mathrm{i}}$ values in $\mathrm{g} / \mathrm{m}^{2}$ exceed the corresponding values that would be predicted from the PCT-B values for the same cation and glass. This behavior is well-known, and thus only the PCT-B data are used to estimate short-term corrosion rates for the HLP glasses.
} 


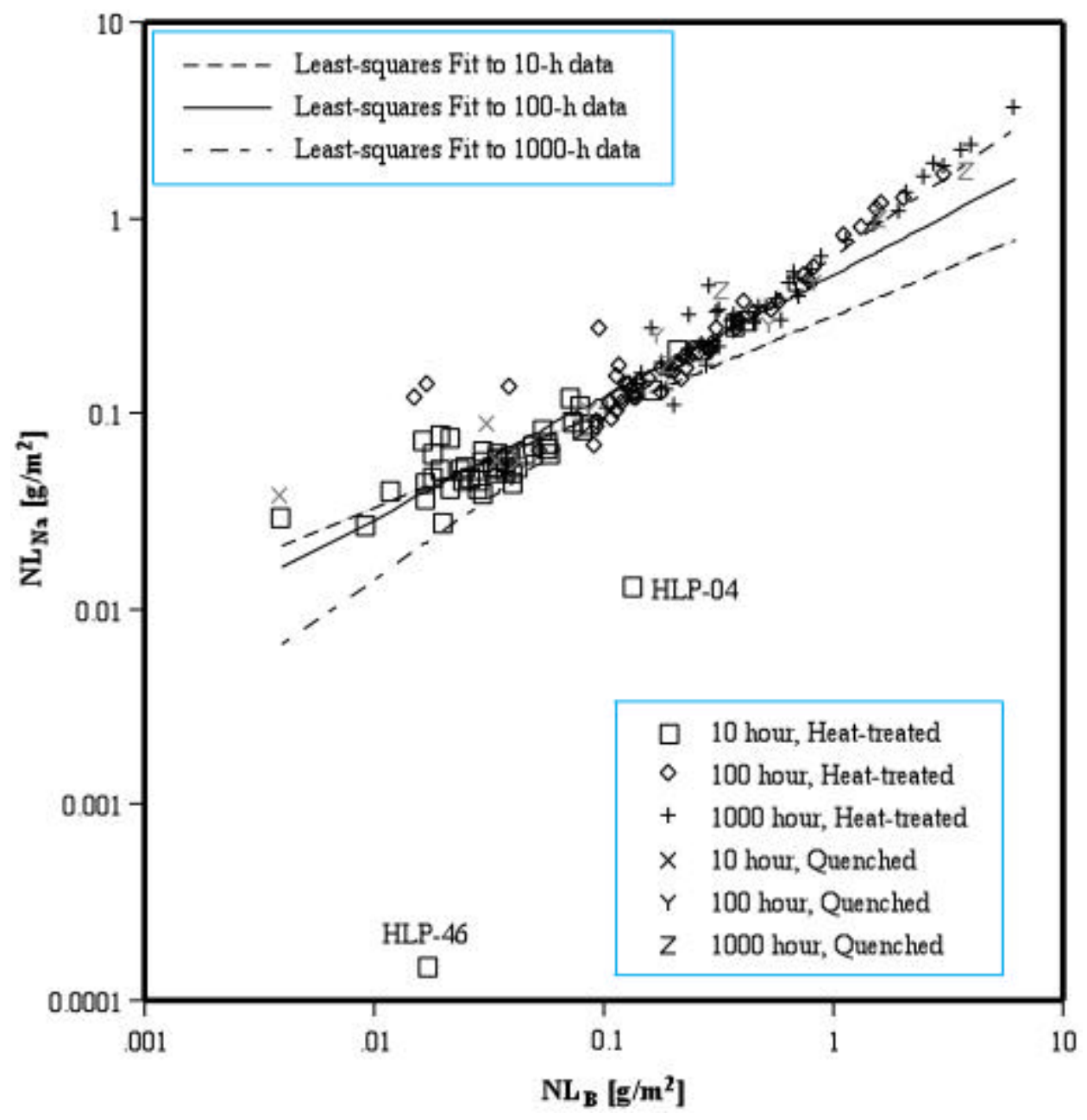

Figure 3-34. Log-Log Plot Illustrating the Normalized Sodium versus Boron Releases for the PCT-B data. This gross examination suggests that the 10-h tests for HLP-04 and HLP-46 may need to be measured again. The lines represent the three least-squares fits through the 10, 100, and 1000-h data (excluding the 10-h values for HLP-04 and HLP-46). 


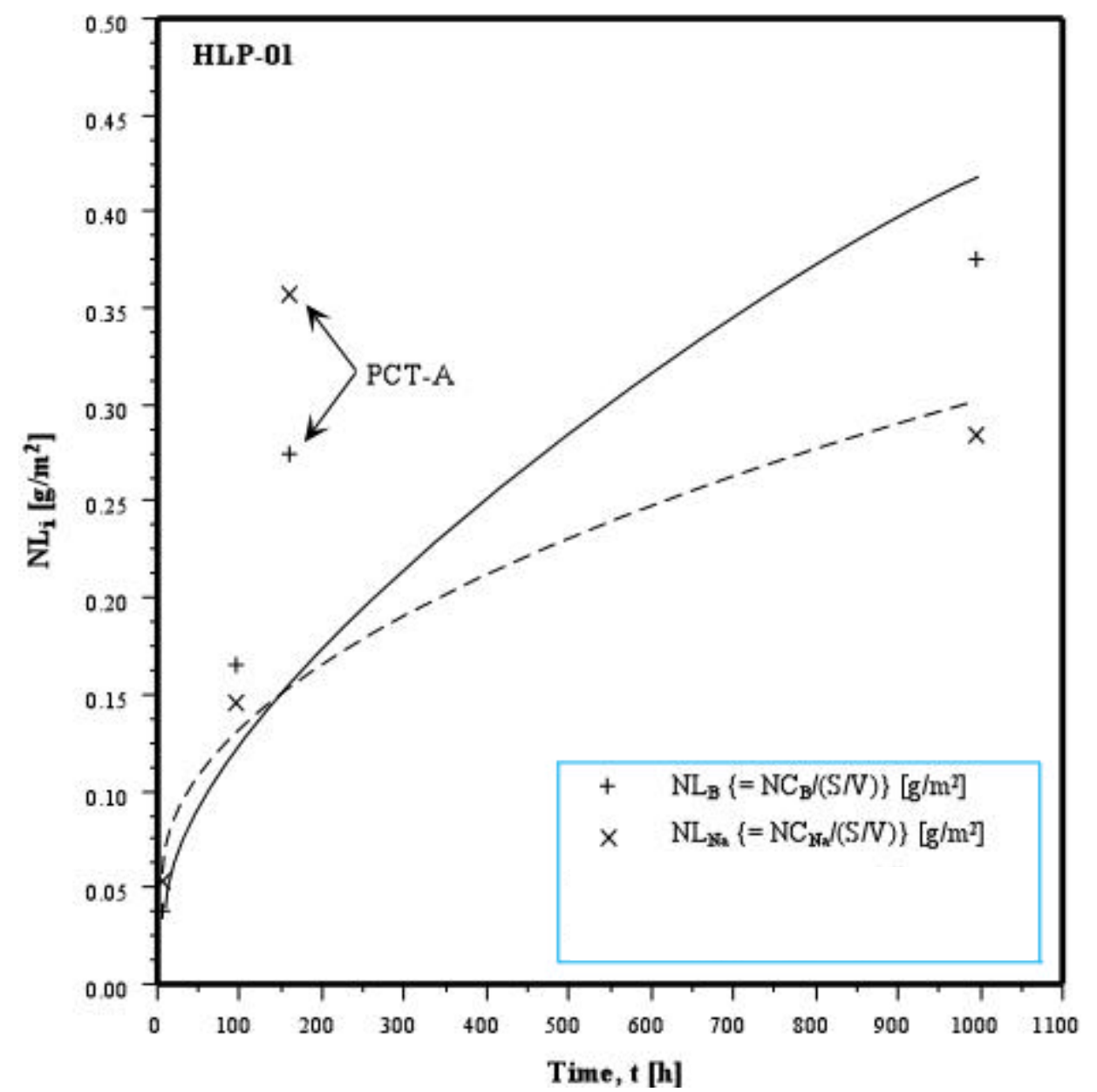

Figure 3-35. Illustration of the Relationship Between the Boron and Sodium Normalized Releases, $\mathrm{NL}_{\mathrm{i}}$ in $\mathrm{g} / \mathrm{m}^{2}$, and Time, $\mathrm{t}$ in $\mathrm{h}$, for the HLP-01 Glass. The PCT-A results are indicated; the remaining data are the PCT-B results. Lines on this figure indicate the least-squares fits between $\ln \left(\mathrm{NL}_{\mathrm{i}}\right)$ and $\ln (\mathrm{t})$ (i.e., from Equation 3.3) for the PCT-B data and are for indication only.

At any given time, the release, $\mathrm{NL}_{\mathrm{i}}$ in $\mathrm{g} / \mathrm{m}^{2}$, represents the concentration of constituent $\mathrm{i}$ in the test solution at time $\mathrm{t}$ in hours. Thus a release rate, $r$ in $\mathrm{g} / \mathrm{m}^{2} / \mathrm{d},{ }^{\mathrm{a}}$ can be obtained by dividing the measured $\mathrm{NL}_{\mathrm{i}}$ value (at the time tested) by the time tested, $t$, or

$$
r=24\left(\frac{\mathrm{NL}_{\mathrm{i}}(\mathrm{i})}{\mathrm{t}}\right)
$$

where $\mathrm{t}$ is in hours. A differential release rate, $r_{\Delta}$ in $\mathrm{g} / \mathrm{m}^{2} / \mathrm{d}$, can also be computed by taking differences in measured values at successive times, or

\footnotetext{
${ }^{a}$ The units of $\mathrm{g} / \mathrm{m}^{2} / \mathrm{d}$ are used in this report to allow direct comparison with existing data on glass alteration rates. To convert to the SI units of $\mathrm{kg} / \mathrm{m}^{2} / \mathrm{s}$, the reader can multiply reported values by $1.1574 \times 10^{-8}$.
} 


$$
r=24\left(\frac{\mathrm{NL}_{\mathrm{i}}\left(\mathrm{t}_{\mathrm{i}+1}\right)-\mathrm{NL}_{\mathrm{i}}\left(\mathrm{t}_{\mathrm{i}}\right)}{\mathrm{t}_{\mathrm{i}+1}-\mathrm{t}_{\mathrm{i}}}\right)=24\left(\frac{\Delta\left(\mathrm{NL}_{\mathrm{i}}\right)}{\Delta \mathrm{t}}\right) .
$$

The bases for the release rates are presented in Figure 3-36. ${ }^{\mathrm{a}}$

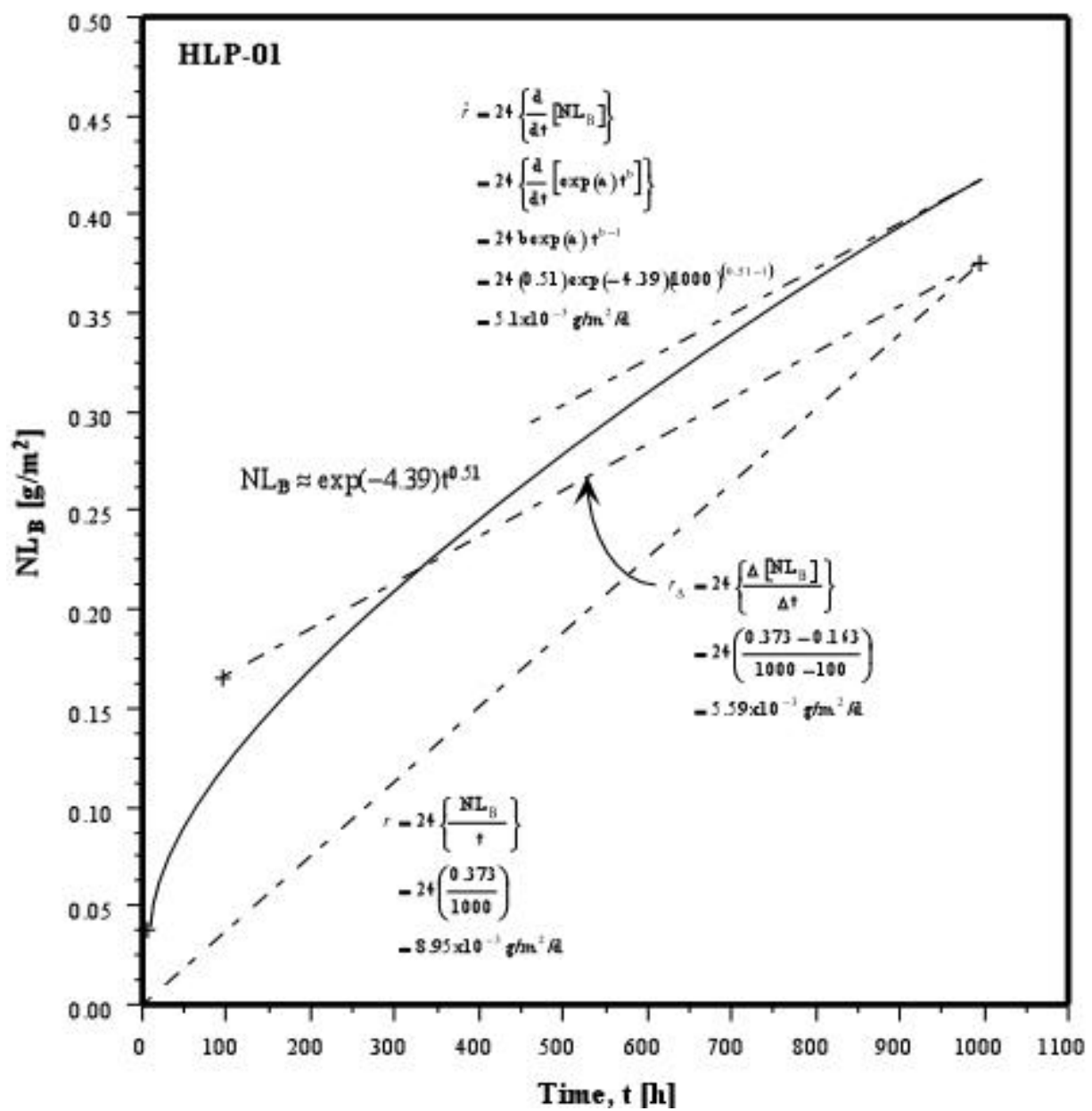

Figure 3-36. Boron Release Rate Estimates for the HLP-01 Glass. The solid line represents the fit from the boron data based upon Equation 3.3 (as shown in). The three dotted lines in this figure represent the estimated boron release rates for the HLP-01 glass, based upon the relevant PCT-B data.

There are errors associated with the values obtained from any of the proposed methods of estimating the release rate from PCT-B data. For example, the errors for the boron release rates obtained from Equation 3.3 for the HLP-01 glass would be large and would make any sort of comparison amongst glasses difficult. The errors in the release-rate estimates from either Equation 3.4 or Equation 3.5 (assuming that the error in $t$ is negligible) are functions of the errors in the $\mathrm{NL}_{\mathrm{i}}$ values. However, the $\mathrm{NL}_{\mathrm{i}}$ values are computed from various measured and assumed values, and the components of variance for the

${ }^{\mathrm{a}}$ For completeness, the least-squares fit line (i.e., the solid line) and corrosion rate, $\hat{r}$ in $\mathrm{g} / \mathrm{m}^{2} / \mathrm{d}$, that would be obtained from the expression in Equation 3.3 has been provided on Figure 3-36. 
terms used to compute the $\mathrm{NL}_{\mathrm{i}}$ values are confounded and cannot be estimated from the PCT-B data in this study. In addition, no single rate can be determined from PCT-B glass because the corrosion extent (as measured by $\mathrm{NL}_{\mathrm{i}}$ ) is not a linear function of time.

Some insight may be obtained by inspecting the PCT-A data (as provided in Table B-1), which were collected in triplicate. It is true that these data were from samples with $\mathrm{S} / \mathrm{V}$ values different from those of the PCT-B data and that the ranges of measured PCT-A concentrations did not completely cover those of the PCT-B data; however, the tests were carried out by the same personnel, and the resulting testsolution concentrations were measured in the same laboratory as those used to compute the PCT-B data. As illustrated in Exhibit B-1,the PCT-A data suggest that the magnitude of the errors in the measured boron and sodium concentrations in the test solutions are relative to the magnitude of the corresponding concentrations. As also illustrated in this exhibit, there does not appear to be a similar trend in these PCT-A values under the natural logarithm transformation (i.e., for $\ln [\mathrm{p}]$ where $\mathrm{p}_{\mathrm{i}}$ is the concentration in ppm). The PCT-A error estimates, obtained from components of variance analysis, were used for this initial examination of the release-rate estimates from PCT-B data.

Using error propagation and assuming that the errors in the various glass composition and $\mathrm{S} / \mathrm{V}$ terms are negligible (for this initial examination of the data), the error in an $\mathrm{NL}_{\mathrm{i}}$ value, represented by $\mathrm{s}_{\mathrm{NL}_{1}}$, is estimated from the error in the corresponding $\ln (\mathrm{p})$, represented by $\mathrm{s}_{\ln }\left(\mathrm{p}_{\mathrm{i}}\right)$, using the following:

$$
\mathrm{S}_{\mathrm{NL}_{\mathrm{i}}} \approx\left(\mathrm{NL}_{\mathrm{i}}\right) \mathrm{s}_{\ln \left(\mathrm{p}_{\mathrm{i}}\right)}
$$

where $\left(\mathrm{NL}_{\mathrm{i}}\right)$ is computed from a release measurement (as in the PCT-B data).

Equation 3.6 indicates that the error obtained from the transformed concentrations is an estimate of the relative error in the $\mathrm{NL}_{\mathrm{i}}$ value. Using the PCT-A data in Table B-1, the relative errors in the $\mathrm{NL}_{\mathrm{B}}$ and $\mathrm{NL}_{\mathrm{Na}}$ values are approximately 17.5 and $8.7 \%$, respectively. Furthermore, the correlations between successive $\mathrm{NL}_{\mathrm{i}}$ (or $\ln \left[\mathrm{NL}_{\mathrm{i}}\right]$ ) values were very large and positive (i.e., all are greater than 0.70 ). These results will be used to examine likely errors in the release rates estimated from PCT-B data. Additional examinations of the likely error structure will be made when additional data have been collected and analyzed.

Using Equation 3.4, Equation 3.5, and Equation 3.6, the release rates, $r$ and $r_{\Delta}$, and their relative errors were estimated for the HLP glasses. These release-rate estimates, $r$ and $r_{\Delta}$, based upon the boron and sodium release data, are provided in Table B-7 and Table B-8, respectively. Using estimates of 17.5 and $8.7 \%$ relative errors in the $\mathrm{NL}_{\mathrm{B}}$ and $\mathrm{NL}_{\mathrm{Na}}$ values, respectively (and assuming the error in measured time is negligible), the relative percent errors in the release rates were estimated and placed in Table 3-9.

Table 3-9. Estimated Relative Percent Standard Deviations in Release Estimates

\begin{tabular}{ccccc}
\hline & \multicolumn{2}{c}{ Boron } & \multicolumn{2}{c}{ Sodium } \\
Time (h) & $\boldsymbol{r}$ & $\boldsymbol{r}_{\boldsymbol{\Delta}}$ & $\boldsymbol{r}$ & $\boldsymbol{r}_{\boldsymbol{\Delta}}$ \\
\hline 10 & 42 & 42 & 20.8 & 20.8 \\
100 & 4.2 & 6.6 & 2.08 & 3.28 \\
1000 & 0.42 & 0.66 & 0.21 & 0.33 \\
\hline
\end{tabular}

\footnotetext{
${ }^{\mathrm{a}}$ The errors for the corrosion rates, $r_{\Delta}$, obtained from successive differences, were estimated, neglecting the correlations between successive $\mathrm{NL}_{\mathrm{i}}$ values; this should provide conservative estimates of the errors.
} 
For the boron release rates, $r$, represented in Table B-7, the glasses with the five largest values at $10 \mathrm{~h}$ were HLP-31, $-02,-39,-41$, and -27 . The glasses with the five smallest boron release rates at $10 \mathrm{~h}$ were HLP-30, -38Q (or the quenched HLP-38 glass), -22, -34, and -29. For the sodium release rates presented in Table B-8, the five glasses with the largest values at $10 \mathrm{~h}$ were HLP-31, -02, -41, -39, and 27, which agrees with the five largest boron release rates at $10 \mathrm{~h}$. For the sodium release rates, the glasses with the five smallest values at $10 \mathrm{~h}$ were HLP-46, -04, -52, -22, and -28. Thus, the same five HLP glasses have the largest boron and sodium release rates at $10 \mathrm{~h}$; however, this is not the case for the glasses with the lowest release rates at $10 \mathrm{~h}$. This could be due to a number of possible reasons, including the large analytical error expected (as suggested in Table 3-9).

The glasses with the five largest and smallest release rates, $r$ and $r_{\Delta}$, from the boron and sodium PCT-B data are presented in Table 3-10 for 10, 100, and $1000 \mathrm{~h}$. As illustrated in this table, the rank ordering of the boron and sodium release rates appears to be fairly consistent. One exception is glass HLP-52, which for $10 \mathrm{~h}$ has some of the smallest release rates, whereas at $100 \mathrm{~h}$ and $1000 \mathrm{~h}$, this glass has one of the largest release rates. This may be due to the large relative errors expected at short leach times and low test-solution concentrations. These results may be confirmed with further experiments.

From the information in Table 3-10, no clear delineation in composition space (as presented in Table 2-1) can be made between glasses tending to have large short-term release rates from those tending to have small release rates. It appears that the target sodium concentrations in those HLP glasses that tend to have the largest short-term release rates based upon the PCT-B data have relatively high $\operatorname{target~} \mathrm{Na}_{2} \mathrm{O}$ concentrations in glass. However, many of the glasses that tend to have low short-term release rates also have relatively high sodium concentrations. More work will be needed to make such a distinction based upon glass compositions.

Table 3-10. Rank Ordering of Release Rates for the HLP Glasses Based Upon PCT-B Data

\begin{tabular}{cccccc}
\hline & & \multicolumn{4}{c}{$\begin{array}{c}\text { Release Rate Rank Ordering by HLP Glass Number } \\
\text { Release rates, } \boldsymbol{r}\end{array}$} \\
Release rates, $\boldsymbol{r}_{\boldsymbol{\Delta}}$ \\
Time (h) & Cation & Largest Five & Smallest Five & Largest Five & Smallest Five \\
\hline \multirow{2}{*}{10} & $\mathrm{~B}$ & $31>02>39>41>27$ & $30<38 \mathrm{Q}<22<34<29$ & $31>02>39>41>27$ & $30<38 \mathrm{Q}<22<34<29$ \\
& $\mathrm{Na}$ & $31>02>41>39>27$ & $46<04<52^{\dagger}<22<28$ & $31>02>41>39>27$ & $46<04<52^{\dagger}<22<28$ \\
\multirow{2}{*}{100} & $\mathrm{~B}$ & $41>39>33>31>05$ & $44<45<51<30<38 \mathrm{Q}$ & $41>39>33>05>31$ & $44<45<51<30<28$ \\
& $\mathrm{Na}$ & $52^{(\mathrm{a})}>41>39>33>31$ & $30<28<22<06<49$ & $52^{(\mathrm{a})}>41>33>39>31$ & $30<28<54<06<49$ \\
& $\mathrm{~B}$ & $33>41>42 \mathrm{Q}>42>05$ & $30<06<49<08<38$ & $51>41>33>39>31$ & $30<28<54<06<49$ \\
& $\mathrm{Na}$ & $52^{(\mathrm{a})}>33>41>42>31$ & $30<28<22<06<49$ & $52^{(\mathrm{a})}>33>42>42 \mathrm{Q}>05$ & $30<28<22<06<34$ \\
\hline
\end{tabular}

(a)There was no boron added to glass HLP-52.

\subsubsection{Alteration Products}

Reacted grains of glass from the PCT conducted for $1000 \mathrm{~h}$ with glass HLP-39 at 20,000 $\mathrm{m}^{-1}$ was examined with SEM to determine if alteration phases had formed during the test. Representative photomicrographs are shown in Figure 3-37. No alteration of the glass could be detected during examination of a large number of grains. The surface of the glass appeared unreacted, with no evidence of alteration phases or pitting of the surface. This is consistent with the very low values of $N_{B}$ and $N L_{N a}$ measured in the test: $\mathrm{NL}_{\mathrm{B}}=2.52$ and $\mathrm{NL}_{\mathrm{Na}}=1.56 \mathrm{~g} / \mathrm{m}^{2}$ (see Table B-6). The amount of glass dissolved (in terms of thickness) can be calculated from the measured values of $\mathrm{NL}_{\mathrm{i}}$ and glass density. The density of HLP-39 was measured to be 2.73 (see Table 3-6). The amount of glass that must have dissolved to generate the measured solution concentration is $\left(2.52 \mathrm{~g} / \mathrm{m}^{2}\right) /\left(2.73 \mathrm{~g} / \mathrm{cm}^{3}\right)=0.923 \mu \mathrm{m}$ based on the boron 


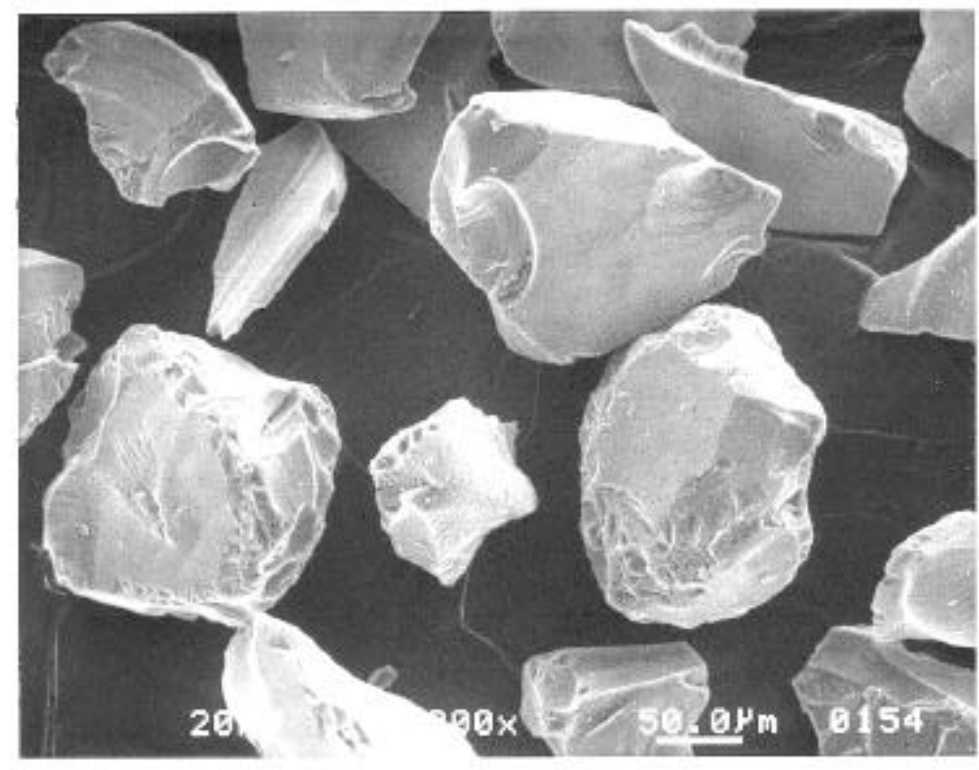

a.

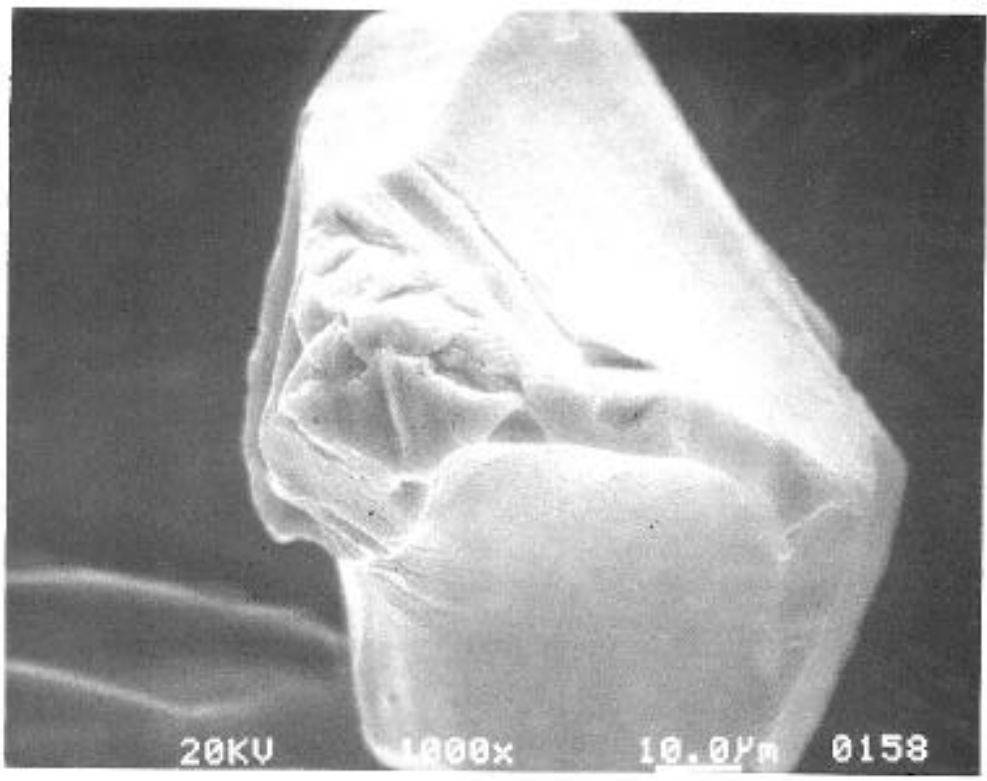

b.

Figure 3-37. SEM Images of Reacted HLP-39 Glass from PCT Conducted $1000 \mathrm{~h}$ at $90^{\circ} \mathrm{C}$ and $20,000 \mathrm{~m}^{-1}$. (a) Moderate magnification showing uniform size and appearance of particles and (b) High magnification showing pristine appearance of surface. 
concentration and $\left(1.56 \mathrm{~g} / \mathrm{m}^{2}\right) /\left(2.73 \mathrm{~g} / \mathrm{cm}^{3}\right)=0.571 \mu \mathrm{m}$ based on the sodium concentration. The appearance of the reacted particles in the photomicrographs suggests that the actual amount of glass that dissolved from the surface is much less than $1 \mu \mathrm{m}$ and that a significant proportion of dissolved material may result from the dissolution of fines.

\subsection{Vapor Hydration Test}

The resistance of matrix glasses to corrosion in the VHT was measured over the temperature range from $150^{\circ} \mathrm{C}$ to $300^{\circ} \mathrm{C}$. Preliminary rates at $200^{\circ} \mathrm{C}$ are reported for most glasses in Section 3.6.2. The initial plan (Vienna et al. 1999) called for measuring the rate at $150^{\circ} \mathrm{C}$. However, after initial scoping tests, it became clear that the time required to sufficiently alter most matrix glasses to estimate rate would be prohibitively long. In other words, most of the matrix glasses were far more resistant to the VHT than initially expected. The impact of this temperature increase, or the use of elevated temperatures in general, on the reaction mechanisms is not yet well understood. The alteration products are reported for many VHT samples in Section 3.6.3, and the impacts of temperature on rate are discussed in Section 3.6.4 for selected glasses.

\subsection{1 "Incubation"}

An incubation time is a time needed for the hydration process to establish suitable conditions for precipitation of secondary alteration phases. These phases start to form on the surface of samples from nucleation centers, usually at the Pt wire-sample interface (in samples polished to a 600 grit finish), and extend across the sample, eventually forming a continuous layer, typically $50 \mu \mathrm{m}$ to $300 \mu \mathrm{m}$ thick. A characteristic dissolution curve of LAW glasses is displayed in Figure 3-38. The process of conversion of glass to alteration products by VHT can be divided into three stages: 1) incubation time, 2) precipitation of first alteration products indicated by a dramatic increase in rate, and 3) a linear $m_{d}-t$ region with constant rate. In Figure 3-38, the incubation time is roughly $10 \%$ of the total dissolution time (the time to dissolve the entire sample which is at roughly $1950 \mathrm{~g} / \mathrm{m}^{2}$ in Figure 3-38). The incubation time was found to range from $2 \%$ to $10 \%$ of the total dissolution time for all matrix glasses for which both values could be obtained. However, due to lack of data measured during the incubation time, the comparison was made only for 12 glasses form the entire test matrix. Although the incubation time presumably depends on test temperature and glass composition, it was not possible to predict these effects, due to lack of experimental data. 


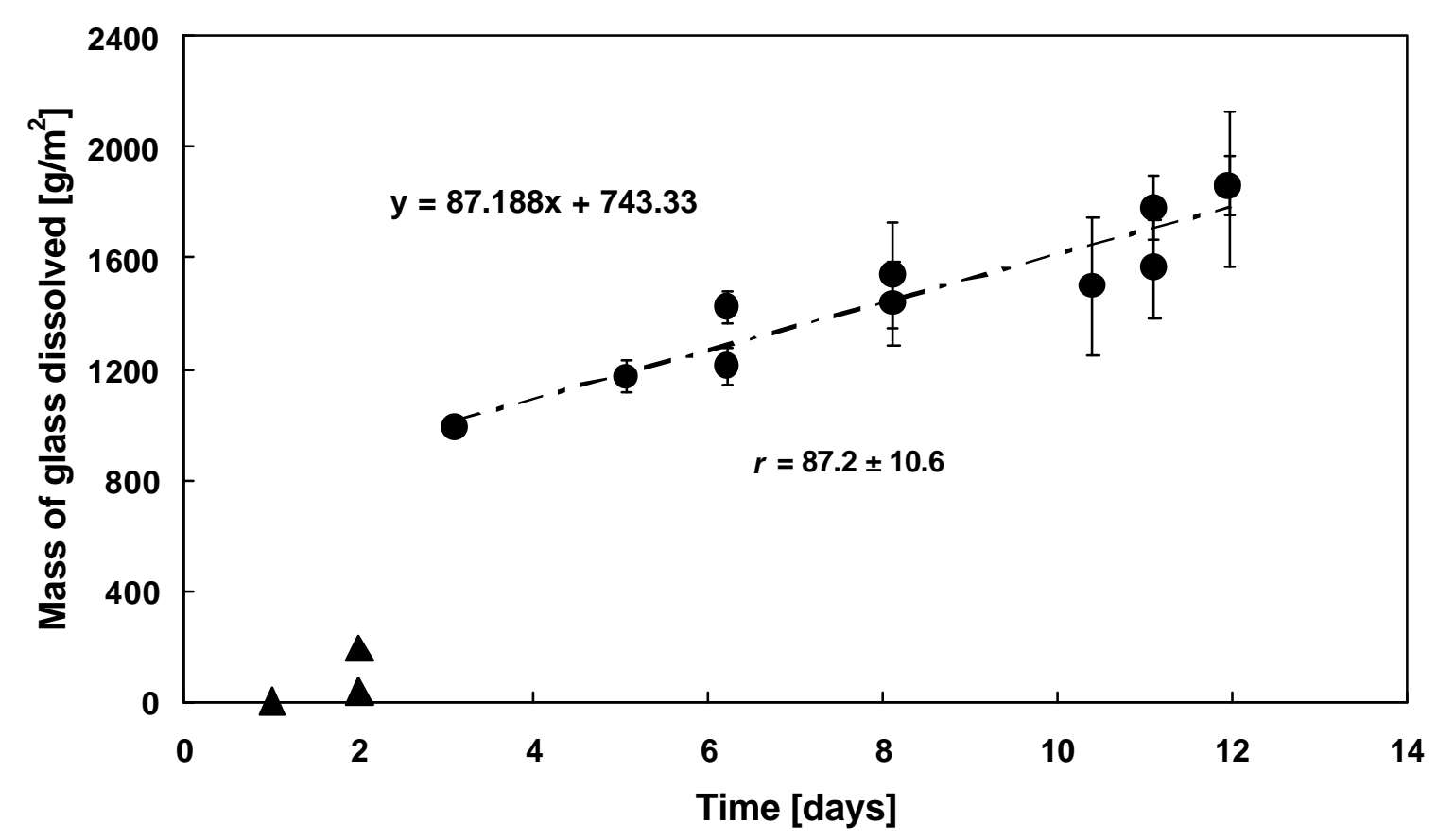

Figure 3-38. VHT Tests on HLP-46 Glass at $175^{\circ} \mathrm{C}$ up to 12 Days; Triangles Represent Data in the Incubation Time that Were Excluded from Linear Regression

An example of the progression through different reaction stages in duplicate samples of HLP-46 glass after 2 days of VHT at $175^{\circ} \mathrm{C}$ is displayed in Figure 3-39. Sample (A) has a thin, 30- $\mu$ m layer partially covering the glass surface, whereas the secondary phases start to precipitate in the form of white dots. Sample (B) has a continuous alteration layer roughly $100 \mu \mathrm{m}$ thick.

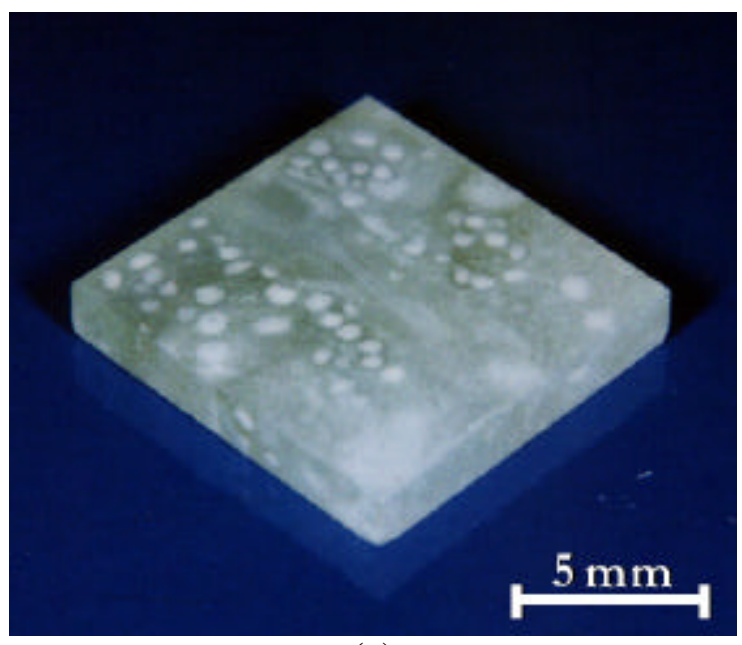

(a)

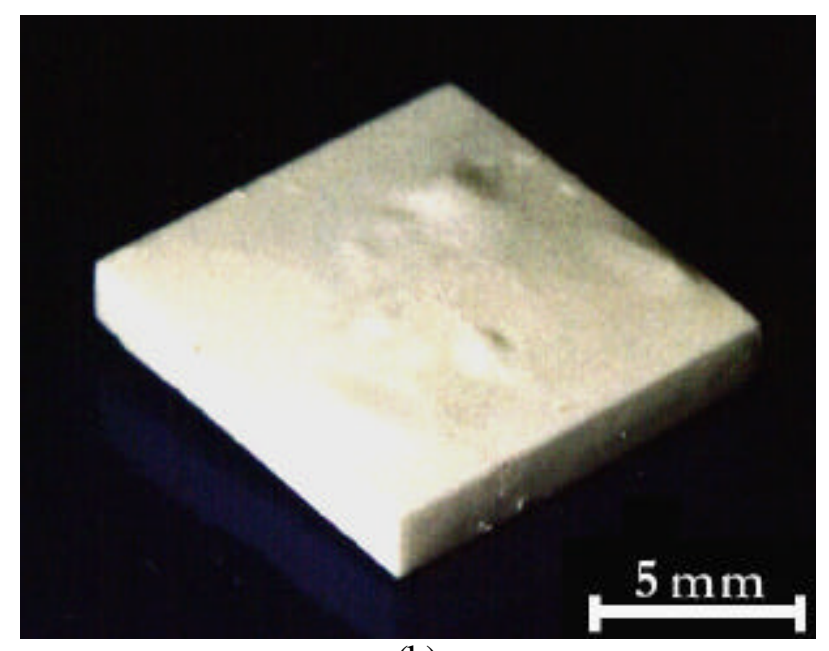

(b)

Figure 3-39. Duplicate Samples of HLP-46 Glass after 2 Days of VHT at $175^{\circ} \mathrm{C}$ 
A sample of HLP-46 glass after 3 days of VHT at $175^{\circ} \mathrm{C}$ is displayed in Figure 3-40. Although the test period was only 1 day longer, the sample shows a continuous layer of alteration products about $600 \mu \mathrm{m}$ thick, see cross section in Figure 3-40 (B). It can be concluded that rapid acceleration of dissolution occurred between the $2^{\text {nd }}$ and $3^{\text {rd }}$ day of the test. As shown in Figure 3-38, rate increases rapidly after alteration products begin to precipitate on the sample surface and becomes approximately constant after the alteration products form continuous layer/layers (i.e., after 3 days). Therefore, the rate for test glasses was determined by regression over the linear portion of the dissolution curve from 3 to 12 days.

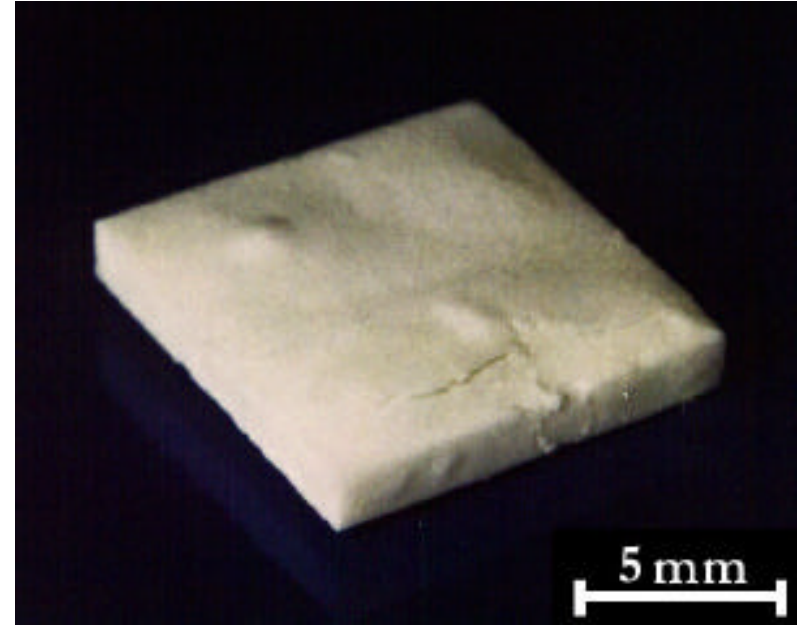

(a)

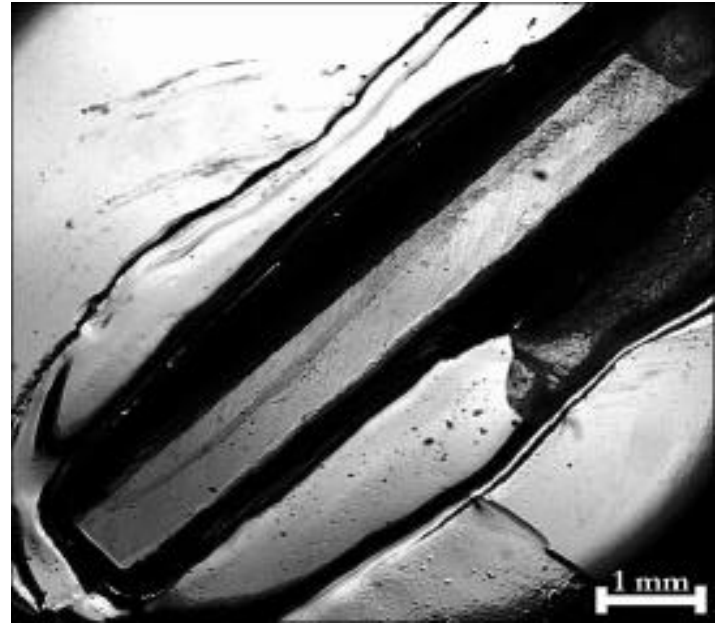

(b)

Figure 3-40. Photograph of a Sample of HLP-46 Glass after 3 days of VHT at $175^{\circ} \mathrm{C}$ (a) and Optical Micrograph of the Cross Section of the Same Sample (b)

\subsubsection{Alteration Rate at $200^{\circ} \mathrm{C}$}

The initial alteration rates of most glasses have been determined at $200^{\circ} \mathrm{C}$. These rates, listed in Table 3-11, are preliminary and are expected to change as further data are generated. ${ }^{\mathrm{a}}$ The glasses with high resistance to VHT (e.g., $r \leq 14 \mathrm{~g} / \mathrm{m}^{2} / \mathrm{d}$ ) b take long times to sufficiently corrode to accurately determine a rate; for example, Figure 3-41 shows $m_{d}$ as a function of time for HLP-03. The estimated rate is clearly subject to change as longer-term tests are completed. Conversely, Figure 3-42 shows $m_{d}$ as a function of time for HLP-29 for which the rate is well established.

\footnotetext{
${ }^{a}$ Considering the preliminary nature of the rates, uncertainties and intercepts were not estimated.

${ }^{b}$ The units of $\mathrm{g} / \mathrm{m}^{2} / \mathrm{d}$ are used in this report to allow direct comparison with existing data on glass alteration rates. To convert to the SI units of $\mathrm{kg} / \mathrm{m}^{2} / \mathrm{s}$, the reader can multiply reported values by $1.1574 \times 10^{-8}$.
} 
Table 3-11. Preliminary VHT Alteration Rates and Major Alteration Products at $200^{\circ} \mathrm{C}$

\begin{tabular}{lccccc}
\hline Glass ID $\mathbf{r}\left[\mathbf{g} / \mathbf{m}^{2} / \mathbf{d}\right]$ & Glass ID $\mathbf{r}\left[\mathbf{g} / \mathbf{m}^{\mathbf{2}} / \mathbf{d}\right]$ & Glass ID $\left.\mathbf{~} \mathbf{[ g} / \mathbf{m}^{2} / \mathbf{d}\right]$ \\
\hline HLP-01 & 4.3 & HLP-20 & 8.7 & HLP-39 & id \\
HLP-02 & 264.7 & HLP-21 & 4 & HLP-40 & 1 \\
HLP-03 & 1 & HLP-22 & 1.5 & HLP-41 & 14.1 \\
HLP-04 & 18.3 & HLP-23 & 15.9 & HLP-42 & 0.2 \\
HLP-05 & 2.5 & HLP-24 & 3.1 & HLP-43 & id \\
HLP-06 & 1.6 & HLP-25 & 5.7 & HLP-44 & id \\
HLP-07 & 13.8 & HLP-26 & 0.6 & HLP-45 & id \\
HLP-08 & 7.2 & HLP-27 & 84.2 & HLP-46 & 254.6 \\
HLP-09 & 0.9 & HLP-28 & 1.7 & HLP-47 & 36.4 \\
HLP-10 & 3.6 & HLP-29 & 55.4 & HLP-48 & 50.5 \\
HLP-11 & 5.4 & HLP-30 & 11.5 & HLP-49 & 0.6 \\
HLP-12 & 14.4 & HLP-31 & 78.3 & HLP-51 & 4.4 \\
HLP-13 & 1.3 & HLP-32 & 4.5 & HLP-52 & 1219.4 \\
HLP-14 & 13.2 & HLP-33 & 18.2 & HLP-53 & 552.6 \\
HLP-15 & 1.1 & HLP-34 & id & HLP-54 & 57 \\
HLP-16 & 1.4 & HLP-35 & 17.8 & HLP-55 & 24.7 \\
HLP-17 & 9.6 & HLP-36 & 13.5 & HLP-56 & id \\
HLP-18 & 16.1 & HLP-37 & 10.7 & & \\
HLP-19 & 0 & HLP-38 & 6.7 & & \\
\hline id = insufficient data & & & &
\end{tabular}

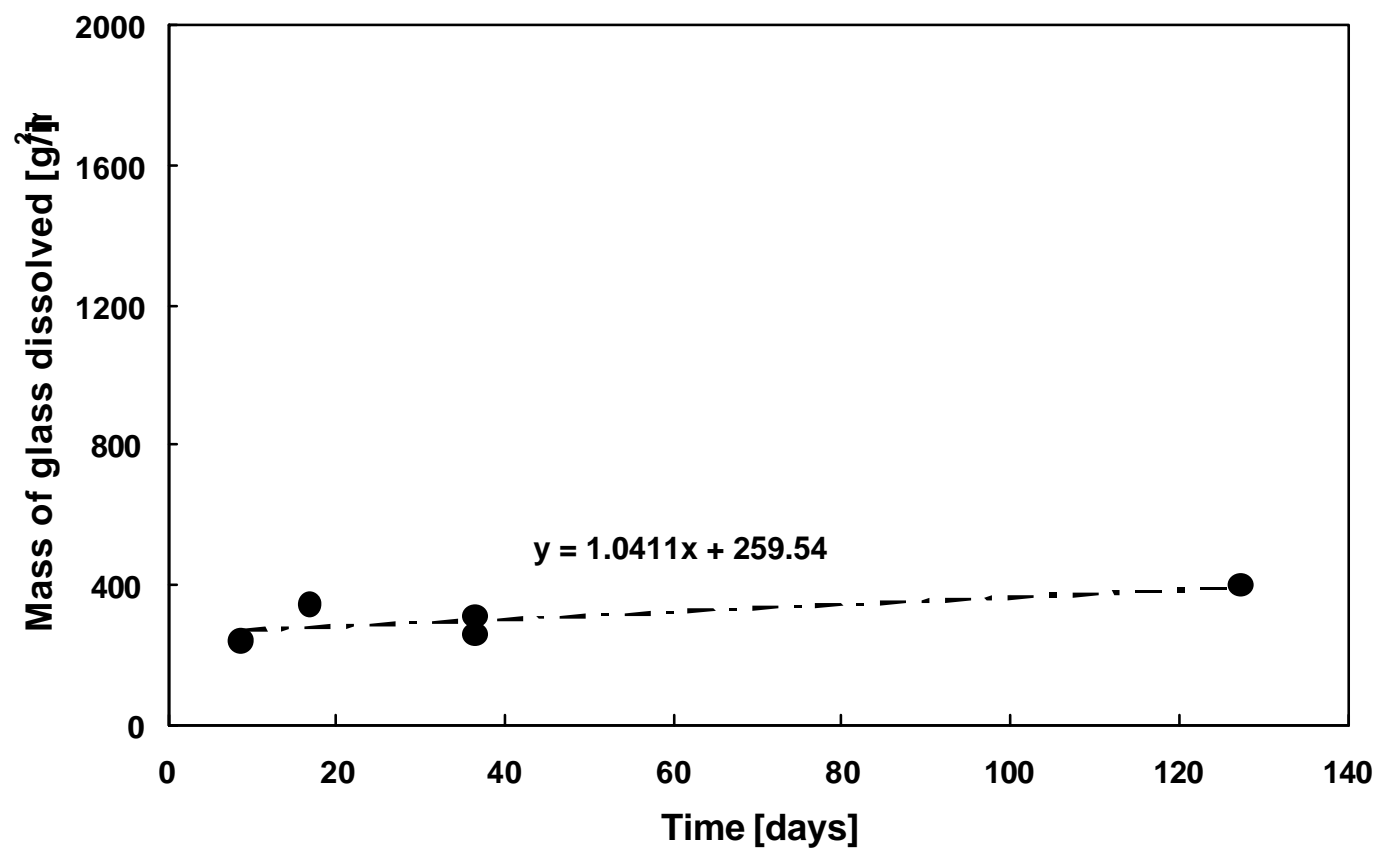

Figure 3-41. The $m_{d}$ as a Function of $t$ for HLP- 03 at $200^{\circ} \mathrm{C}$ 


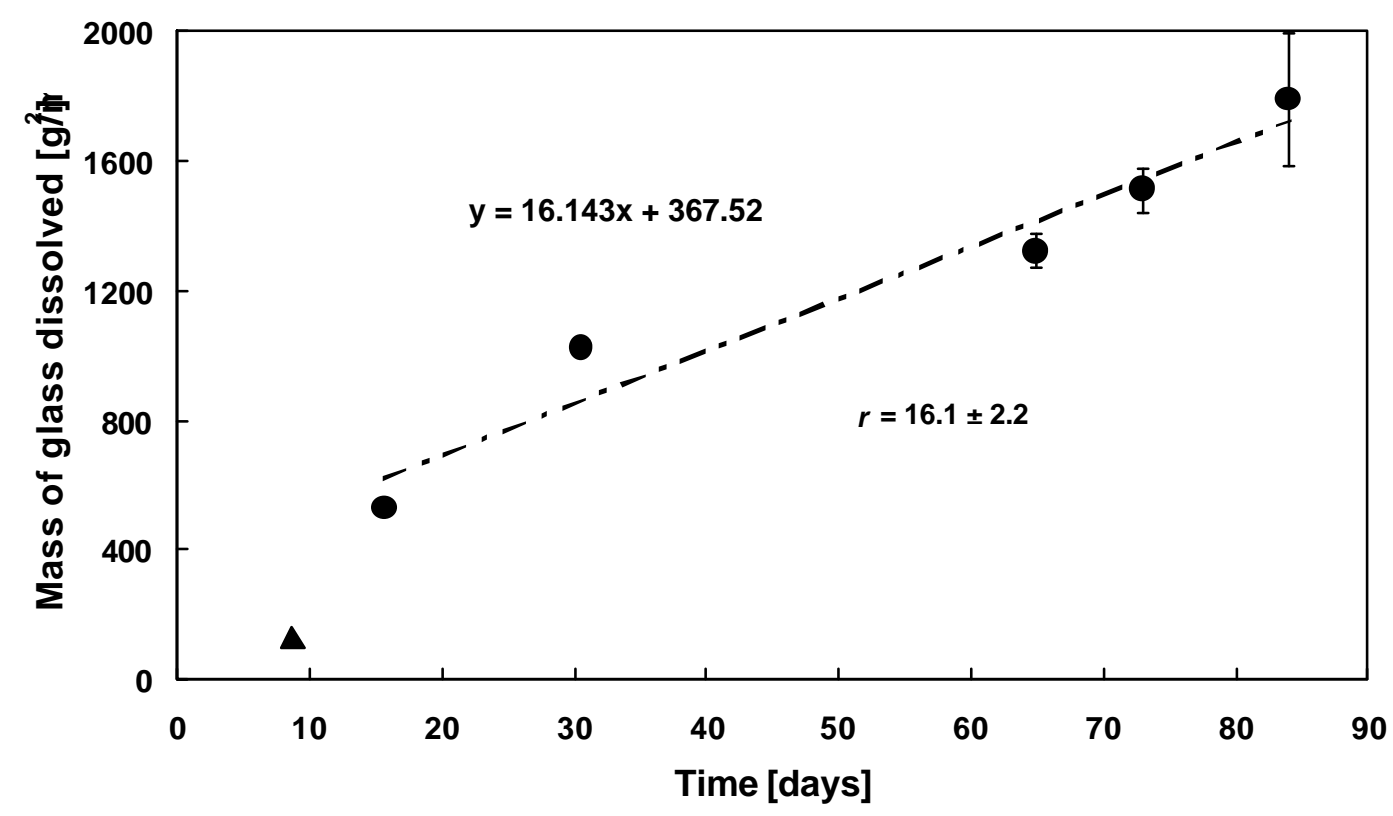

Figure 3-42. The $m_{d}$ as a Function of $t$ for HLP- 18 at $200^{\circ} \mathrm{C}$

The preliminary rates ranged from 0.0 to $1219 \mathrm{~g} / \mathrm{m}^{2} / \mathrm{d}$ and covered at least three orders of magnitude. The glasses can be categorized into four groups:

1. Glasses with low resistance to VHT - rate at $200^{\circ} \mathrm{C}$ between 14 and $1219 \mathrm{~g} / \mathrm{m}^{2} / \mathrm{d}$. For these glasses, we have good estimates of rate since the samples in this group are completely dissolved in roughly 100 days or less. This group contains 18 glasses, listed in Table 3-12.

2. Glasses with medium resistance to VHT - rate at $200^{\circ} \mathrm{C}$ between 6 and $14 \mathrm{~g} / \mathrm{m}^{2} / \mathrm{d}$. For these glasses, we have poor estimates of rate. The ranking of glasses within this category is likely to change; however, these glasses are clearly more resistant to VHT than glasses in Group 1 and less resistant to VHT than glasses in Group 3. This group has 9 glasses.

3. Glasses with high resistance to VHT - rate at $200^{\circ} \mathrm{C}$ less than $6 \mathrm{~g} / \mathrm{m}^{2} / \mathrm{d}$. For these glasses, we have poor estimates of rate. The ranking of glasses within this category is likely to change; however, these glasses are clearly more resistant to VHT than glasses in Groups 1 and 2. This group contains 22 glasses.

4. Glasses with insufficient data to estimate rate or, more generally, their resistance to VHT. This group has six glasses, not listed in Table 3-12.

The demarcation of these categories is largely arbitrary. The value of $14 \mathrm{~g} / \mathrm{m}^{2} / \mathrm{d}$ was selected because those glasses with rates higher than 14 are completely dissolved in roughly three months and therefore sufficient data to accurately measure the rate for these glasses were obtained. The value of $6 \mathrm{~g} / \mathrm{m}^{2} / \mathrm{d}$, separating Category 2 and 3 glasses, was selected after examination of $m_{d}$ vs. $t$ plots for glasses in each category. Those glasses with rates above $6 \mathrm{~g} / \mathrm{m}^{2} / \mathrm{d}$ could be clearly distinguished from those with rates below $6 \mathrm{~g} / \mathrm{m}^{2} / \mathrm{d}$. 
Table 3-12. HLP Glasses Listed in Order of rate and Grouped into Three Categories

\begin{tabular}{|c|c|c|c|c|c|c|c|c|}
\hline \multicolumn{3}{|c|}{ Group 1} & \multicolumn{3}{|c|}{ Group 2} & \multicolumn{3}{|c|}{ Group 3} \\
\hline Glass ID & Descr. & $r\left(g / \mathrm{m}^{2} / \mathrm{d}\right)$ & ) Glass ID & Descr. & $\mathbf{r}\left(\mathrm{g} / \mathrm{m}^{2} / \mathbf{d}\right)$ & ) Glass ID & Descr. & $r\left(g / m^{2} / d\right)$ \\
\hline HLP-52 & HAN 28 & 1219.4 & HLP-07 & I Al & 13.8 & HLP-25 & Center & 5.7 \\
\hline HLP-53* & LAW-A23 & 552.6 & HLP-36 ${ }^{*}$ & LHHL & 13.5 & HLP-11 & $\mathrm{LFe}$ & 5.4 \\
\hline HLP-02 & $\mathrm{L} \mathrm{Si}$ & 264.7 & HLP-14 & $\mathrm{L} \mathrm{Ti}$ & 13.2 & HLP-32 & HLHL & 4.5 \\
\hline HLP-46 & LD6-5412 & 254.6 & HLP-30 & HHLL & 11.5 & HLP-51 & LAW-ABP1 & 4.4 \\
\hline HLP-27 & НHНH & 84.2 & HLP-37* & LHLH & 10.7 & HLP-01 & Center & 4.3 \\
\hline HLP-31 & HLHH & 78.3 & HLP-17 & $\mathrm{HZn}$ & 9.6 & HLP-21 & $\mathrm{H} \mathrm{Mg}$ & 4.0 \\
\hline HLP-54 & L4-912 & 57.0 & HLP-20 & $\mathrm{L} \mathrm{Mg}$ & 8.7 & HLP-10 & I B & 3.6 \\
\hline HLP-29 & HHLH & 55.4 & HLP-08 & L B & 7.2 & HLP-24 & I Na & 3.1 \\
\hline HLP-48 & LAW-A33 & 50.5 & HLP- $38^{*}$ & LHLL & 6.7 & HLP-05 & $\mathrm{L} \mathrm{Al}$ & 2.5 \\
\hline HLP-47 & LRM-1 & 36.4 & & & & HLP-28 & HHHL & 1.7 \\
\hline HLP-55 & L4-99 & 24.7 & & & & HLP-06 & $\mathrm{H} \mathrm{Al}$ & 1.6 \\
\hline HLP-04 & I Si & 18.3 & & & & HLP-22 & $\mathrm{L} \mathrm{Na}$ & 1.5 \\
\hline HLP-33 & HLLH & 18.2 & & & & HLP-16 & $\mathrm{L} \mathrm{Zn}$ & 1.4 \\
\hline HLP-35 & LHHH & 17.8 & & & & HLP-13 & $\mathrm{IFe}$ & 1.3 \\
\hline HLP-18 & $\mathrm{L} \mathrm{Zr}$ & 16.1 & & & & HLP-15 & $\mathrm{H} \mathrm{Ti}$ & 1.1 \\
\hline HLP-23 & $\mathrm{H} \mathrm{Na}$ & 15.9 & & & & HLP-03 & $\mathrm{H} \mathrm{Si}$ & 1.0 \\
\hline HLP-12 & $\mathrm{H} \mathrm{Fe}$ & 14.4 & & & & HLP-40* & LLHL & 1.0 \\
\hline HLP- $41^{*}$ & LLLH & 14.1 & & & & HLP-09 & H B & 0.9 \\
\hline & & & & & & HLP-26 & Center & 0.6 \\
\hline & & & & & & HLP-49* & LAW-B29 & 0.6 \\
\hline & & & & & & HLP-42* & LLLL & 0.2 \\
\hline & & & & & & HLP-19 & $\mathrm{H} \mathrm{Zr}$ & 0 \\
\hline
\end{tabular}

(*) Crystallized glass

Since the rates of 37 out of 55 glasses are expected to change, it is premature to describe glasscomposition effects on VHT response. However, the following generalities can be made:

- Glasses with a high concentration of $\mathrm{Na}_{2} \mathrm{O}$ are more likely to have low resistance to VHT than those with lower concentrations.

- Those glasses with low concentrations of $\mathrm{SiO}_{2}, \mathrm{ZrO}_{2}$, or $\mathrm{TiO}_{2}$ are less resistant to VHT than those with high concentrations.

A more thorough evaluation of composition impacts on VHT resistance of matrix glasses will be made when the rates of more glasses become final.

\subsubsection{Alteration Products}

The alteration products formed during VHT of selected glasses were characterized with XRD and SEM/EDS. Table 3-14 lists the phases identified in VHT glasses and their content in mass percent. Most tested samples altered to form analcime and sodium aluminum silicate hydrate. Unlike in other tests, 
none of the glass components are removed to the solution, and therefore all elements are available for reaction. The typical soluble component used to characterize glass dissolution is boron. Although boron was expected to be found in crystalline alteration products, only two boron-containing phases were found (6, 12 in Table 3-13). Another boron-containing phase is sodium aluminum silicate boron hydroxide hydrate. However, its pattern is practically identical to sodium aluminum silicate hydrate, so its presence could not be confirmed yet.

Some selected minerals formed on the surface of VHT samples are shown in Figure 3-43 and Figure 3-44. Sodium Zinc Silicate is frequently was found in other test methods. Both minerals were not detected by XRD, probably because of their low content.

Table 3-13. Crystalline Phases Identified in VHT Samples with XRD

\begin{tabular}{|c|c|c|c|c|}
\hline$\#$ & Phase & Formula & JCPDF\# & \# Formed in Glasses \\
\hline 1 & Analcime-C & $\mathrm{Na}\left(\mathrm{Si}_{2} \mathrm{Al}\right) \mathrm{O}_{6} \cdot \mathrm{H}_{2} \mathrm{O}$ & $41-1478$ & All Except 52 and 53 \\
\hline 2 & Sodium Titanium silicate & $\mathrm{NaTiSi}_{2} \mathrm{O}_{6}$ & $29-1280$ & $\begin{array}{l}\text { All Except 06, 11, } \\
21,23,27,29,31 \\
35-38,46,48-55\end{array}$ \\
\hline 3 & Sodium Aluminum Silicate Hydrate & $\mathrm{Na}_{6}\left[\mathrm{AlSiO}_{4}\right]_{6} \cdot 4 \mathrm{H}_{2} \mathrm{O}$ & $42-216$ & $02,29,35,38,48,51$ \\
\hline & $\begin{array}{c}\text { Sodium Aluminum Silicate Boron } \\
\text { Hydroxide Hydrate }\end{array}$ & $\begin{array}{c}\mathrm{Na}_{7.55}\left(\mathrm{AlSiO}_{4}\right)_{6}\left(\mathrm{~B}(\mathrm{OH})_{4}\right)_{1.685^{-}} \\
\left(\mathrm{H}_{2} \mathrm{O}\right)_{1.97}\end{array}$ & $83-550$ & $53-55$ \\
\hline 4 & Sodium Aluminum Silicate Hydrate & $\mathrm{Na}_{6} \mathrm{Al}_{6} \mathrm{Si}_{10} \mathrm{O}_{32} \cdot 12 \mathrm{H}_{2} \mathrm{O}$ & $\begin{array}{l}39-219 \\
44-103\end{array}$ & 23,51 \\
\hline 5 & Sodium Aluminum Silicate Hydrate & $\mathrm{Na}_{5.7} \mathrm{Al}_{5.7} \mathrm{Si}_{10.3} \mathrm{O}_{32} \cdot 12 \mathrm{H}_{2} \mathrm{O}$ & $34-524$ & 27 \\
\hline 6 & Tincalconite & $\mathrm{Na}_{2} \mathrm{~B}_{4} \mathrm{O}_{7} \cdot 5 \mathrm{H}_{2} \mathrm{O}$ & $7-277$ & 30,36 \\
\hline 7 & Spinel & {$[\mathrm{Fe}, \mathrm{Zn}, \mathrm{Ni}][\mathrm{Fe}, \mathrm{Ti}, \mathrm{Cr}]_{2} \mathrm{O}_{4}$} & $86-509$ & 38,42 \\
\hline 8 & Gobbinsite & $\mathrm{Ca}_{0.6} \mathrm{Na}_{2.6} \mathrm{~K}_{2.2} \mathrm{Al}_{6} \mathrm{Si}_{10} \mathrm{O}_{32}\left(\mathrm{H}_{2} \mathrm{O}\right)_{12}$ & $75-1464$ & 46 \\
\hline 9 & Sodium Aluminum Silicate Hydrate & $\mathrm{Na}_{3} \mathrm{Al}_{3} \mathrm{Si}_{3} \mathrm{O} 12\left(\mathrm{H}_{2} \mathrm{O}\right)_{2}$ & $84-590$ & 09 \\
\hline 10 & Sodium aluminum silicon oxide & $\mathrm{Na}_{2.12} \mathrm{Al}_{2} \mathrm{Si}_{2} \mathrm{O}_{8.06}$ & $47-716$ & 56 \\
\hline 11 & Phillipsite & $(\mathrm{K}, \mathrm{Na})_{2}(\mathrm{Si}, \mathrm{Al})_{8} \mathrm{O}_{16} \cdot 4 \mathrm{H}_{2} \mathrm{O}$ & $46-1427$ & 51 \\
\hline 12 & $\begin{array}{l}\text { Pinakiolite } \\
\end{array}$ & $(\mathrm{Mg}, \mathrm{Mn})_{2} \mathrm{Mn}\left(\mathrm{BO}_{3}\right)_{2}$ & $36-413$ & $04,37,43,48$ \\
\hline 13 & Calcium silicate hydroxide hydrate & $\mathrm{Ca}_{4.5} \mathrm{Si}_{6} \mathrm{O}_{15}(\mathrm{OH})_{3} \cdot 2 \mathrm{H}_{2} \mathrm{O}$ & $43-1488$ & 53 \\
\hline 14 & Sodium Zirconium silicate & $\mathrm{Na}_{14} \mathrm{Zr}_{2} \mathrm{Si}_{10} \mathrm{O}_{31}$ & $29-1459$ & 52 \\
\hline 15 & Hydroxycancrinite & $\mathrm{Na}_{8} \mathrm{Al}_{6} \mathrm{Si}_{6} \mathrm{O}_{24}(\mathrm{OH})_{2} \cdot 2 \mathrm{H}_{2} \mathrm{O}$ & $46-1457$ & 52 \\
\hline 15 & Sodium aluminum silicate hydrate & $\mathrm{Na}_{14} \mathrm{Al}_{12} \mathrm{Si}_{13} \mathrm{O}_{51} \cdot 6 \mathrm{H}_{2} \mathrm{O}$ & $28-1036$ & 52 \\
\hline
\end{tabular}

Table 3-14. Crystalline Phases from Table 3-13 and Their Content (\%) in Analyzed VHT Samples

\begin{tabular}{|c|c|c|c|c|c|c|c|c|c|c|}
\hline \multirow[t]{2}{*}{ Sample ID } & \multicolumn{10}{|c|}{ Crystalline phase } \\
\hline & 1 & 2 & 3 & 4 & 5 & 6 & 7 & 8 & 9 & $\begin{array}{lllllll}10 & 11 & 12 & 13 & 14 & 15 & \text { (a) }\end{array}$ \\
\hline HLP-01-200-125-surface & 97 & 3 & & & & & & & & \\
\hline HLP-02-200-30 & 16 & 15 & 69 & & & & & & & \\
\hline HLP-03-200-125-surface & 90 & 10 & & & & & & & & \\
\hline HLP-04-200-016 & 46 & 44 & & & & & & & & 10 \\
\hline HLP-06-200-106-surface & 100 & & & & & & & & & \\
\hline HLP-07-200-100 & 94 & 6 & & & & & & & & \\
\hline HLP-08-200-100-surface & 95 & 5 & & & & & & & & \\
\hline HLP-09-300-005-surface & 93 & 4 & & & & & & & 3 & \\
\hline
\end{tabular}




\begin{tabular}{|c|c|c|c|c|c|c|c|c|c|c|c|c|c|c|}
\hline \multirow[t]{2}{*}{ Sample ID } & \multicolumn{13}{|c|}{ Crystalline phase } & \multirow[b]{2}{*}{15 (a) } \\
\hline & 1 & 2 & 3 & 4 & 5 & 6 & 7 & 8 & 9 & 10 & 11 & 1213 & 14 & \\
\hline HLP-10-200-129-surface & 98 & 2 & & & & & & & & & & & & \\
\hline HLP-11-200-068-surface & 100 & & & & & & & & & & & & & \\
\hline HLP-12-200-105 & 82 & 18 & & & & & & & & & & & & \\
\hline HLP-12-300-002 & 45 & 55 & & & & & & & & & & & & \\
\hline HLP-13-200-080-surface & 97 & 3 & & & & & & & & & & & & \\
\hline HLP-15-200-075-surface & 99 & 1 & & & & & & & & & & & & \\
\hline HLP-16-200-075-surface & 98 & 2 & & & & & & & & & & & & \\
\hline HLP-17-200-075-surface & 98 & 2 & & & & & & & & & & & & \\
\hline HLP-18-200-032 & 93 & 7 & & & & & & & & & & & & \\
\hline HLP-20-200-075-surface & 87 & 13 & & & & & & & & & & & & \\
\hline HLP-21-200-032-surface & 85 & & & & & & & & & & & & & 15 \\
\hline HLP-23-200-007-surface & 95 & & & 5 & & & & & & & & & & \\
\hline HLP-24-200-032-surface & 95 & 5 & & & & & & & & & & & & \\
\hline HLP-27-200-004 & 88 & & & & 12 & & & & & & & & & \\
\hline HLP-27-200-100 & 100 & & & & & & & & & & & & & \\
\hline HLP-29-200-013 & 39 & 60 & 1 & & & & & & & & & & & \\
\hline HLP-30-200-023-surface & 94 & & & & & 6 & & & & & & & & \\
\hline HLP-31-200-002-surface & 100 & & & & & & & & & & & & & \\
\hline HLP-31-200-010 & 68 & 32 & & & & & & & & & & & & \\
\hline HLP-32-200-024-surface & 85 & 15 & & & & & & & & & & & & \\
\hline HLP-33-200-129-surface & 93 & 7 & & & & & & & & & & & & \\
\hline HLP-33-300-005 & 29 & 71 & & & & & & & & & & & & \\
\hline HLP-35-200-021 & 61 & & 39 & & & & & & & & & & & \\
\hline HLP-36-200-032-surface & 86 & & & & & 14 & & & & & & & & \\
\hline HLP-37-200-024-surface & 76 & & & & & & & & & & & 24 & & \\
\hline HLP-38-200-024 & 38 & & 2 & & & & 60 & & & & & & & \\
\hline HLP-38-200-064 & 24 & & 10 & & & & 66 & & & & & & & \\
\hline HLP-41-200-120-surface & 90 & 10 & & & & & & & & & & & & \\
\hline HLP-42-200-068-surface & 33 & 5 & & & & & 62 & & & & & & & \\
\hline HLP-43-200-033 & 53 & 6 & & & & & & & & & & 41 & & \\
\hline HLP-46-200-001 & 97 & & & & & & & 3 & & & & & & \\
\hline HLP-46-200-004b & 95 & & & & & & & 5 & & & & & & \\
\hline HLP-47-200-024 & 97 & 3 & & & & & & & & & & & & \\
\hline HLP-48-200-020 & 41 & & 51 & & & & & & & & & 8 & & \\
\hline HLP-49-200-050-surface & 47 & & & & & & & & & & & & & 53 \\
\hline HLP-51-150-187-surface & 13 & & & & & & & & & & 87 & & & \\
\hline HLP-51-200-075 & 19 & & & 81 & & & & & & & & & & \\
\hline HLP-51-250-003b-surface & 70 & & 30 & & & & & & & & & & & \\
\hline HLP-52-200-013 & & & & & & & & & & & & & 38 & 62 \\
\hline HLP-53-200-003 & & & 94 & & & & & & & & & 6 & & \\
\hline HLP-54-200-041 & 65 & & 45 & & & & & & & & & & & \\
\hline HLP-55-200-014 & 40 & & 60 & & & & & & & & & & & \\
\hline HLP-56-250-005-surface & 96 & 4 & & & & & & & & & & & & \\
\hline HLP-56-300-003 & 21 & 72 & & & & & & & & 7 & & & & \\
\hline
\end{tabular}

(a) Unidentified crystalline phase 


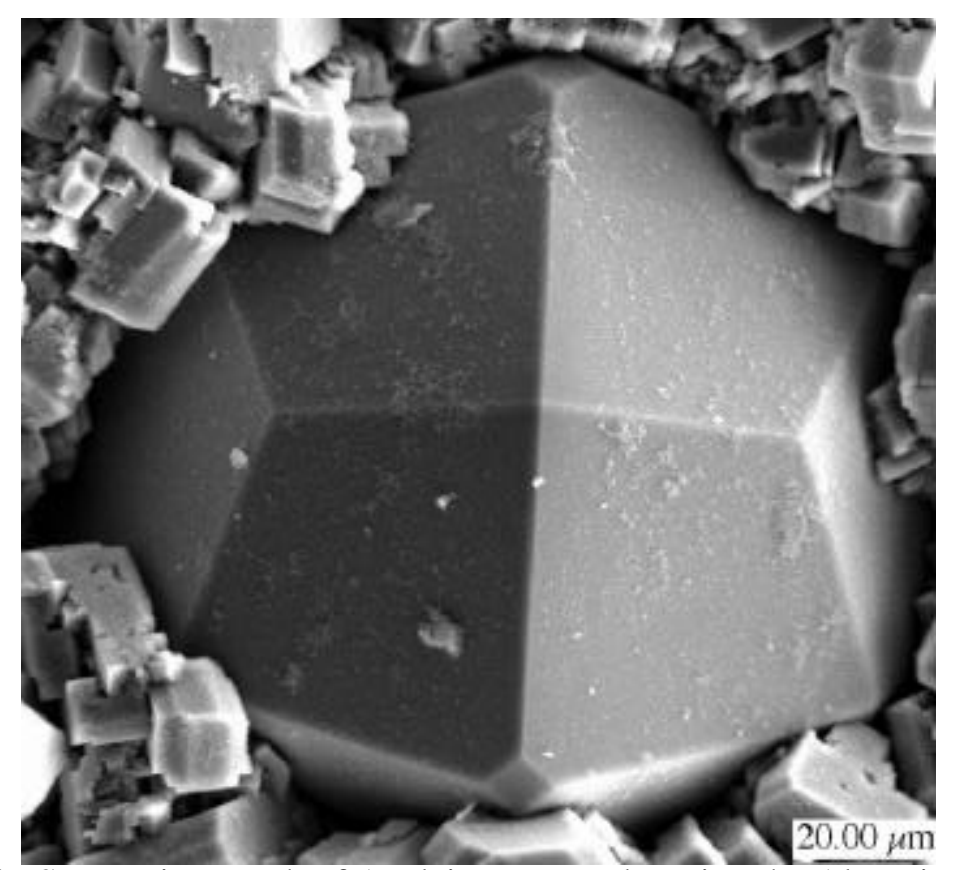

Figure 3-43. SEM Micrograph of Analcime Formed During the Alteration of HLP-48 at $175^{\circ} \mathrm{C}$ After 28 Days

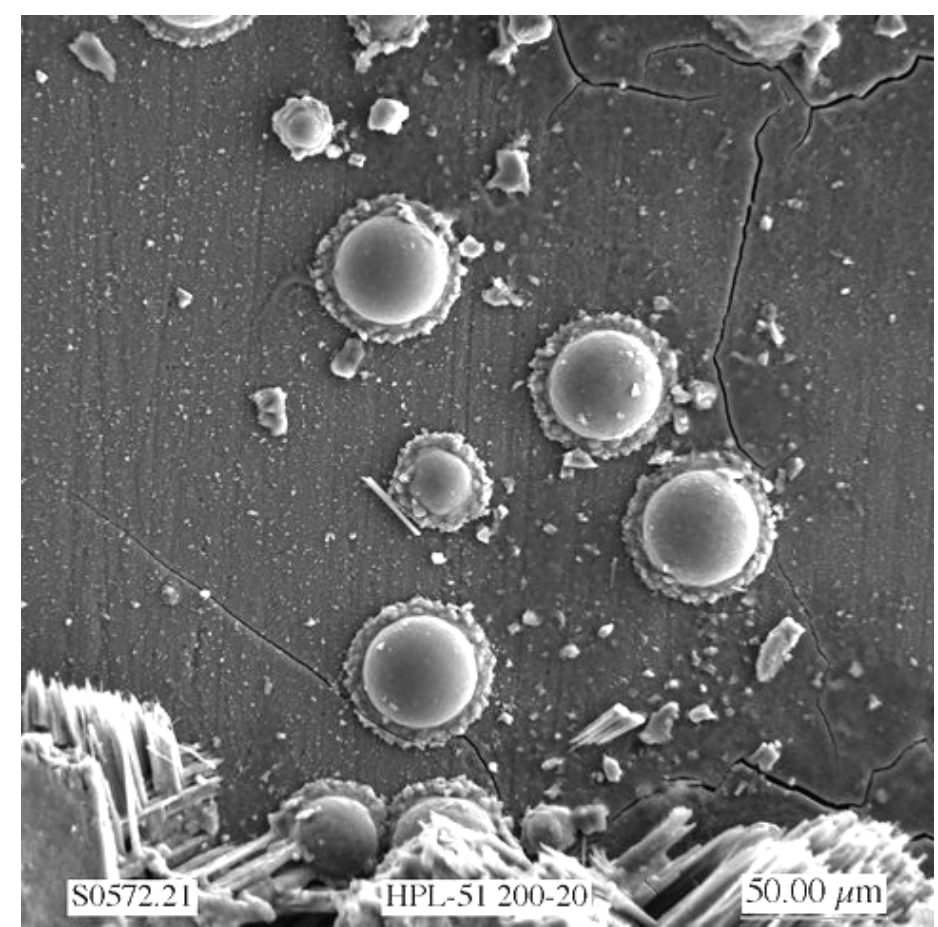

Figure 3-44. SEM Micrograph of Sodium Zinc Silicate - $\mathrm{Na}_{2} \mathrm{ZnSiO}_{4}$ Formed During the Alteration of HLP-51 at $200^{\circ} \mathrm{C}$ 


\subsubsection{Effects of Temperature}

VHT's were initiated over the temperature range from $90^{\circ} \mathrm{C}$ to $300^{\circ} \mathrm{C}$ for selected glasses to determine the impact of temperature on rate and the alteration products formed. However, only tests from $150^{\circ} \mathrm{C}$ to $300^{\circ} \mathrm{C}$ are sufficiently progressed to discuss their results. Table 3-15 lists the rates for glasses tested at multiple temperatures. Figure 3-45 through Figure 3-47 show the $m_{d}-t$ relationships for HLP$46,-48$, and -51 at various temperatures. There are insufficient data to examine the effects of temperature on rate of the remaining test-matrix glasses. Figure 3-48 shows the effect of temperature on rate for these glasses. The apparent activation energies $\left(E_{a}\right)$ for the rate of HLP-46, -48 , and -51 were $87.3 \mathrm{~kJ} / \mathrm{mol}, 94.2$ $\mathrm{kJ} / \mathrm{mol}$, and $97.6 \mathrm{~kJ} / \mathrm{mol}$, respectively. The term "apparent activation energy" is considered appropriate because the dissolution of even a simple mineral consists of several reaction steps (five steps in case of quartz) (Lasaga 1995); in VHT, we have changing solution chemistry with reaction extent, dissolution processes, and precipitation processes that must be considered. It should be noted that the validity of the Arrhenius empirical relationship does not imply that the mechanism is the same over the temperature interval in question and that the same alteration products are formed at high- and low-temperatures. These $E_{a}$ values are at the high end of the range commonly reported for glass corrosion by other test methods, which generally range from $32 \mathrm{~kJ} / \mathrm{mol}$ (for low $\mathrm{SiO}_{2}$ glasses) to $100 \mathrm{~kJ} / \mathrm{mol}$ (Lutze and Ewing 1988, Jercinovic and Ewing 1992, Westsik and Peters 1981, and Abraitis et al.1998). It is uncertain if our measured $E_{a}$ values will remain constant with decreasing temperature. Mazer (1991) suggests caution in use of temperature as an accelerating parameter until more is understood about the rate-determining mechanism at test and disposal-site temperatures.

Leturcq et al. (1998) summarized corrosion rate data for R7T7 glass within the temperature interval from $25^{\circ} \mathrm{C}$ to $300^{\circ} \mathrm{C}$ and confirmed the validity of Arrhenius behavior with a constant $\mathrm{E}_{\mathrm{a}}=60 \pm 5 \mathrm{~kJ} / \mathrm{mol}$. Likewise, Westsik and Peters (1981) showed that $\mathrm{E}_{\mathrm{a}}$ of 76-68 glass corrosion remained constant at $53 \mathrm{~kJ} / \mathrm{mol}$ over the temperature range from $50^{\circ} \mathrm{C}$ to $150^{\circ} \mathrm{C}$; however, the corrosion was found to change below $50^{\circ} \mathrm{C}$ and above $150^{\circ} \mathrm{C}$. A possible explanation for the change in corrosion behavior at the extreme temperature was a change in the stage of corrosion. In the initial stage of corrosion, ion exchange occurs and $\mathrm{pH}$ increases rapidly; Westsik and Peters (1981) found the normalized $\mathrm{Na}$ release was significantly higher than the normalized boron release for samples tested at temperatures below $50^{\circ} \mathrm{C}$. In the second stage, corrosion is roughly congruent, as was found by Westsik and Peters (1981) between $50^{\circ} \mathrm{C}$ and $150^{\circ} \mathrm{C}$, and the rate of corrosion drops as the concentration of aqueous species increases, decreasing the driving force for dissolution. In the third stage of corrosion, mineral phases precipitate from solution allowing the driving force for dissolution to increase and the dissolution rate to accelerate; we suspect that this stage was achieved in the Westsik and Peters (1981) tests at temperatures above $150^{\circ} \mathrm{C}$.

Insufficient data are available to determine if the mechanisms that determine rate at $200^{\circ} \mathrm{C}$ are similar to those that would determine rate at $15^{\circ} \mathrm{C}$. Therefore, we cannot predict $15^{\circ} \mathrm{C}$ rates for these glasses with the data generated at $200^{\circ} \mathrm{C}$, even with estimated $\mathrm{E}_{\mathrm{a}}$ values. 
Table 3-15. Preliminary $r$ s (in $\mathrm{g} / \mathrm{m}^{2} / \mathrm{d}$ ) of Test Glasses Subjected to VHT at Various Temperatures

\begin{tabular}{|c|c|c|c|c|c|c|}
\hline Glass ID & $300^{\circ} \mathrm{C}$ & $275^{\circ} \mathrm{C}$ & $250^{\circ} \mathrm{C}$ & $200^{\circ} \mathrm{C}$ & $175^{\circ} \mathrm{C}$ & $150^{\circ} \mathrm{C}$ \\
\hline HLP-01 & 505.0 & & & 4.3 & & \\
\hline HLP-09 & 409.3 & & & 0.9 & & \\
\hline HLP-10 & 541.8 & & & 3.6 & & \\
\hline HLP-12 & 1126.0 & & & 14.4 & & \\
\hline HLP-25 & 655.0 & & & 5.7 & & \\
\hline HLP-26 & 685.8 & & & 0.6 & & \\
\hline HLP-46 & & & & 254.6 & 87.2 & 18.6 \\
\hline HLP-48 & & & 522.2 & 50.5 & 13.7 & 3.1 \\
\hline HLP-51 & 336.4 & 129.3 & 42.3 & 4.4 & & \\
\hline HLP-56 & 603.0 & & 78.3 & & & \\
\hline
\end{tabular}

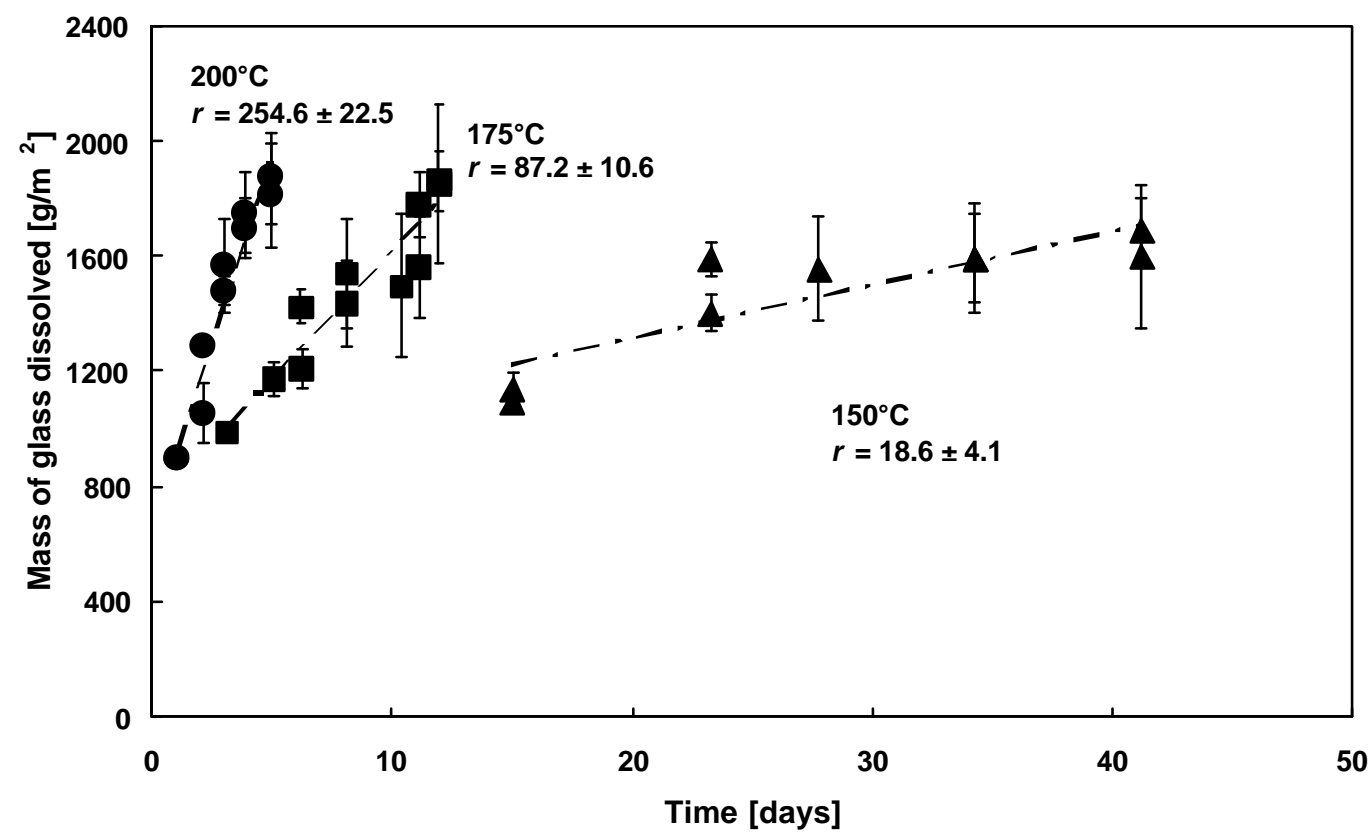

Figure 3-45. Amount of HLP-46 Dissolved in VHT at $150^{\circ} \mathrm{C}, 175^{\circ} \mathrm{C}$, and $200^{\circ} \mathrm{C}$ as Functions of $t$ 


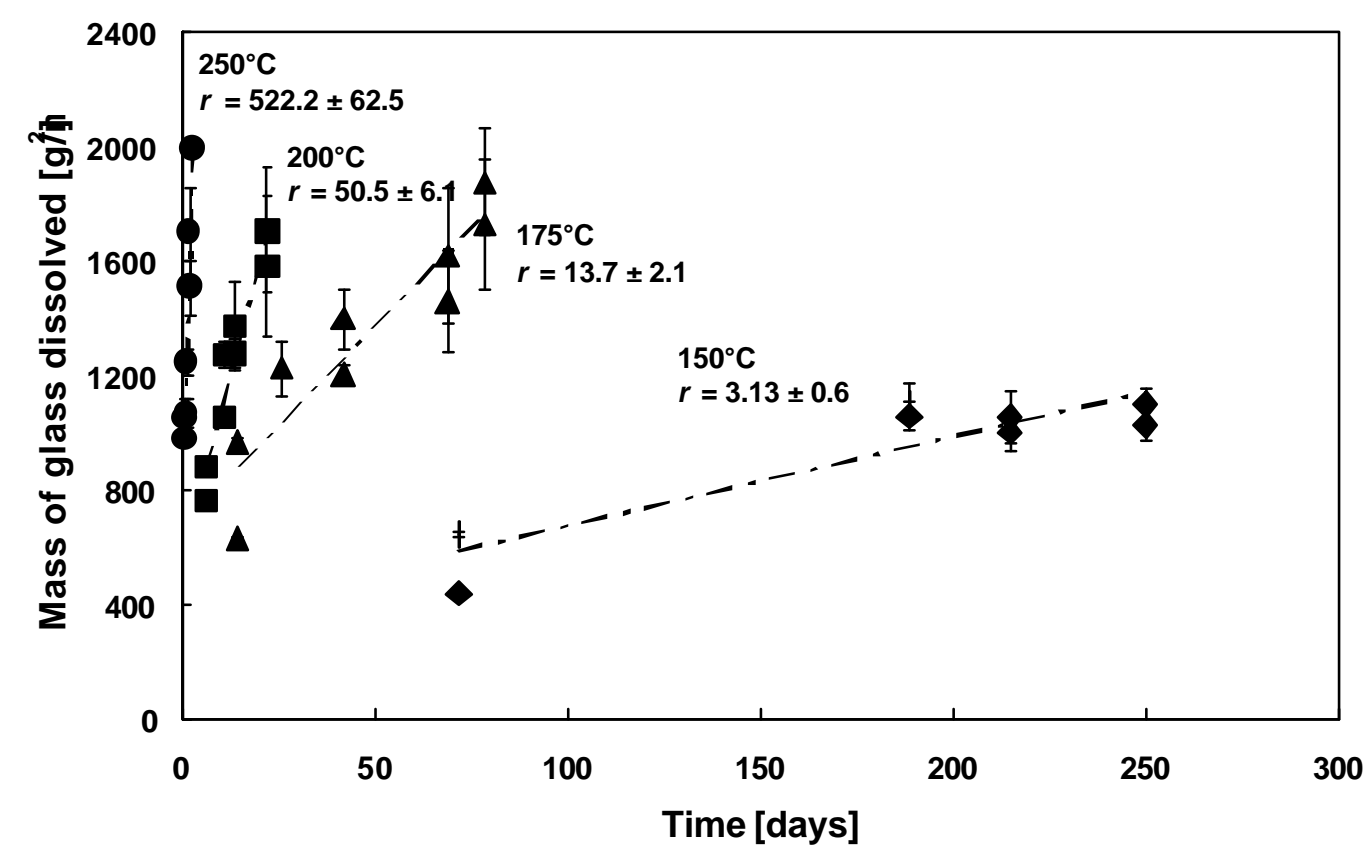

Figure 3-46. Amount of HLP-48 Dissolved in VHT at $150^{\circ} \mathrm{C}, 175^{\circ} \mathrm{C}, 200^{\circ} \mathrm{C}$, and $250^{\circ} \mathrm{C}$ as Functions of $t$

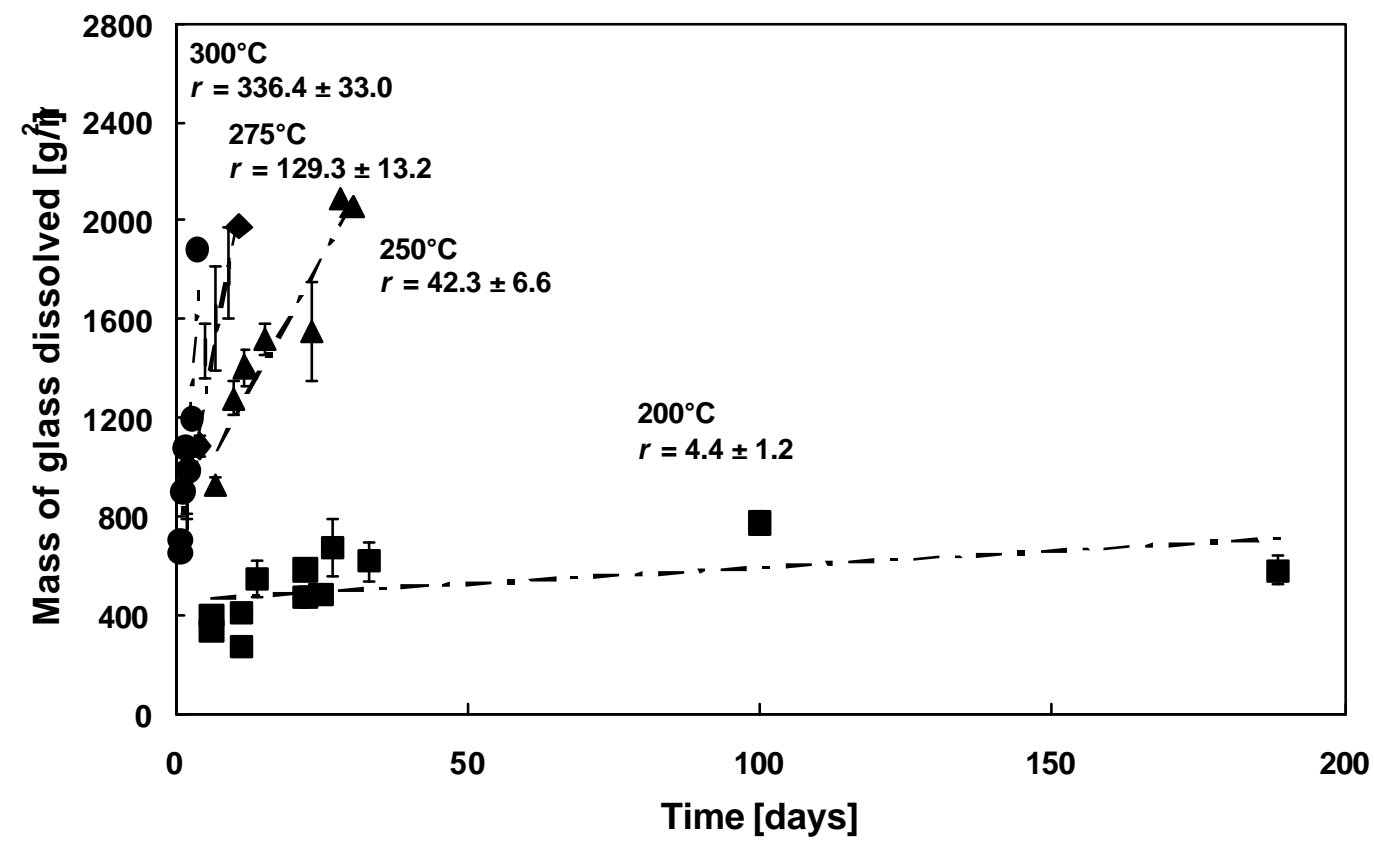

Figure 3-47. Amount of HLP-51 Dissolved in VHT at $200^{\circ} \mathrm{C}, 250^{\circ} \mathrm{C}, 275^{\circ} \mathrm{C}$, and $300^{\circ} \mathrm{C}$ as Functions of $t$ 


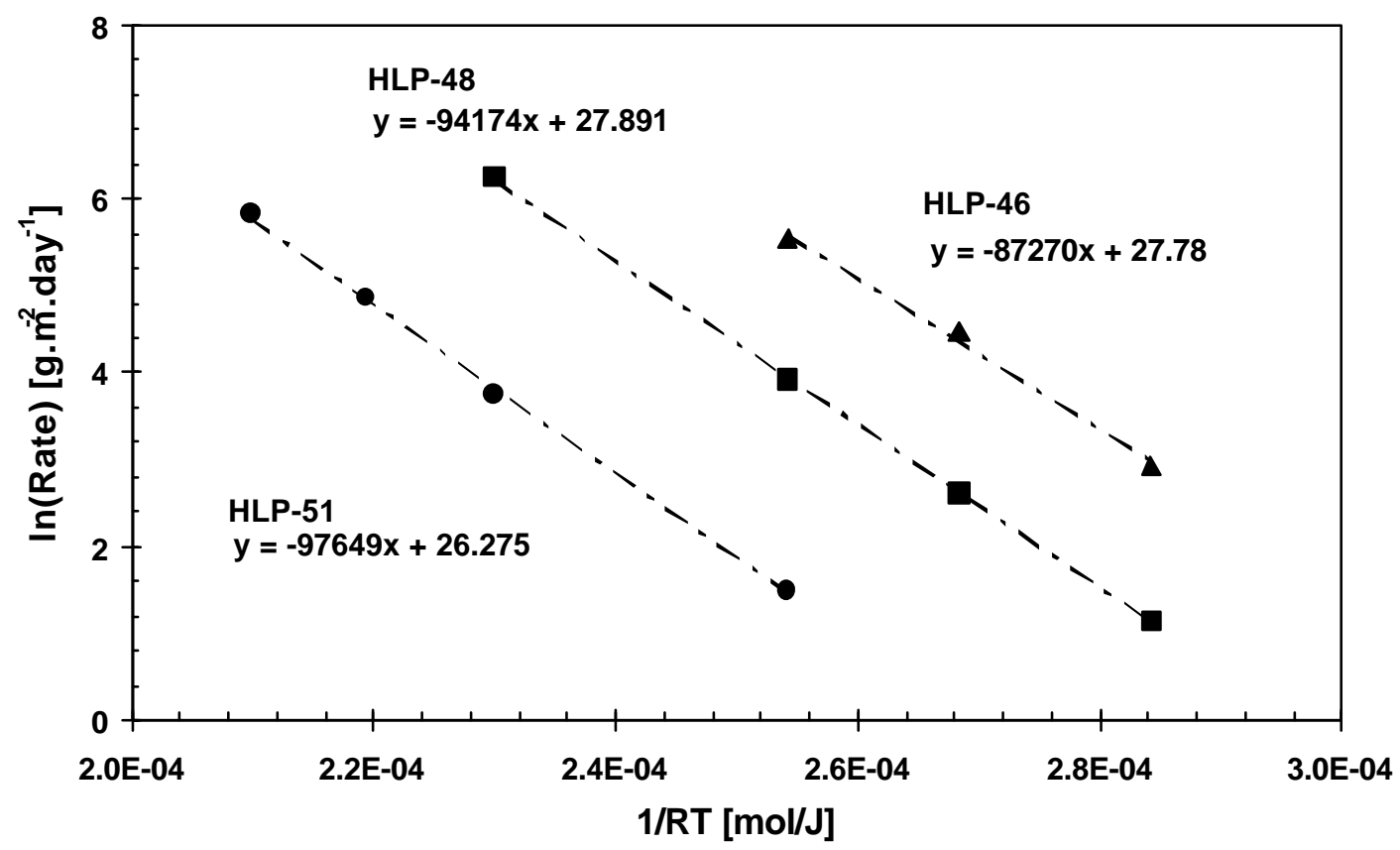

Figure 3-48. Effect of Temperature on rate for HLP-46, HLP-48, HLP-51

Jercinovic and Ewing (1992) found that different alteration products were formed on natural high silica glass at different temperatures of corrosion. Temperature was also found to affect the alteration products formed during VHT of selected HLP glasses. Figure 3-49 shows that the XRD pattern of HLP-46 reacted at increasing temperatures. While the location of major peaks does not change, it is clear that peaks 21.645 and 28.108 decrease while peaks 15.809 and 25.978 increase with increasing temperature. Since each of these has a different amount of alteration, we compare the XRD pattern of HLP- 46 at $200^{\circ} \mathrm{C}$ as a function of alteration time in Figure 3-50. The lack of change in relative peak heights with alteration extent suggests that the change in the XRD pattern in Figure 3-49 must be due to temperature. The peaks in these XRD patterns are identified in Figure 3-51. This identification led us to the conclusion that as temperature is increased, the concentration of analcime is increased relative to that of sodium aluminum silicate hydrate. 


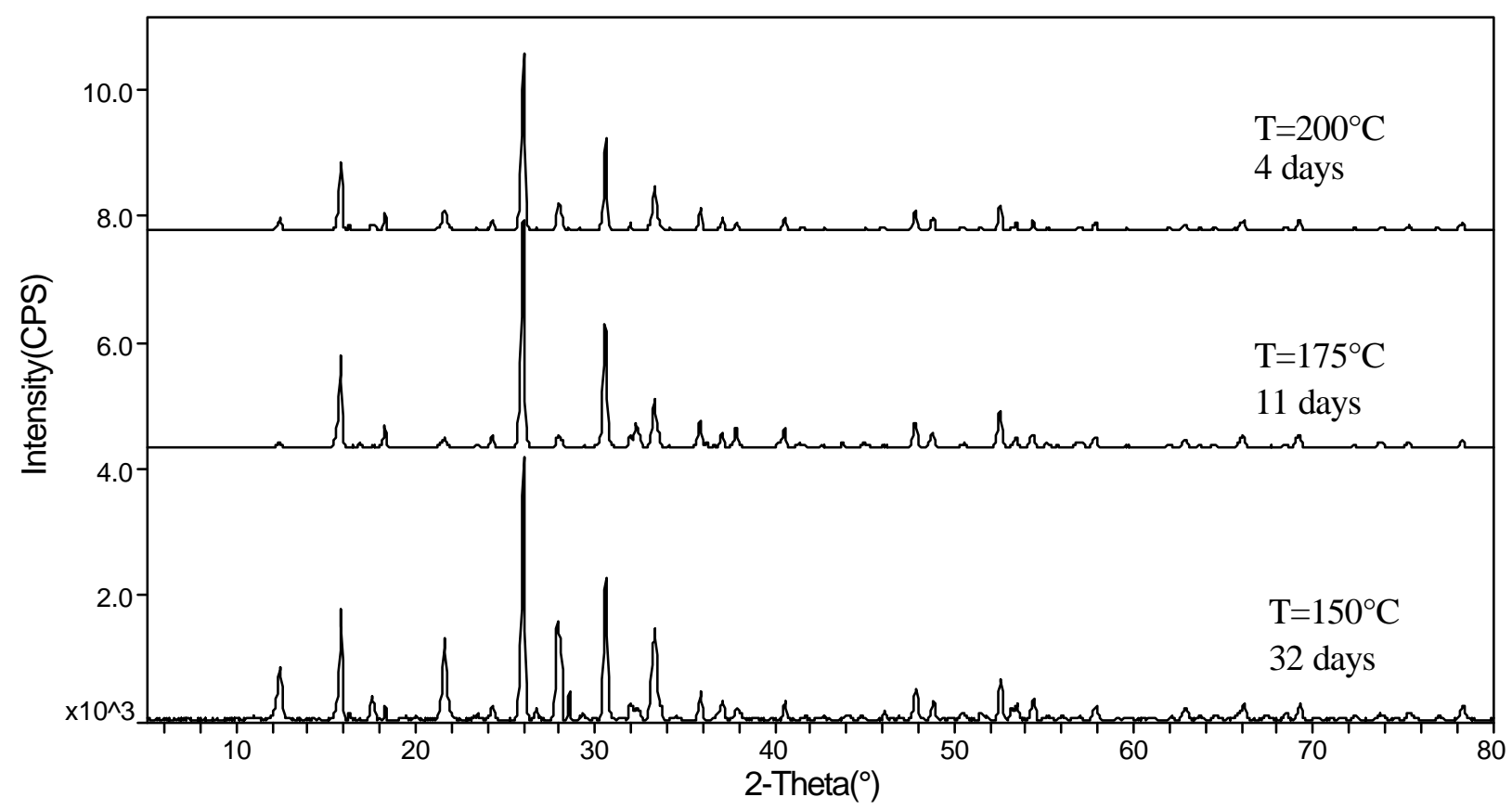

Figure 3-49. Comparison of XRD Patterns for HLP-46 Subjected to VHT at Different Temperatures

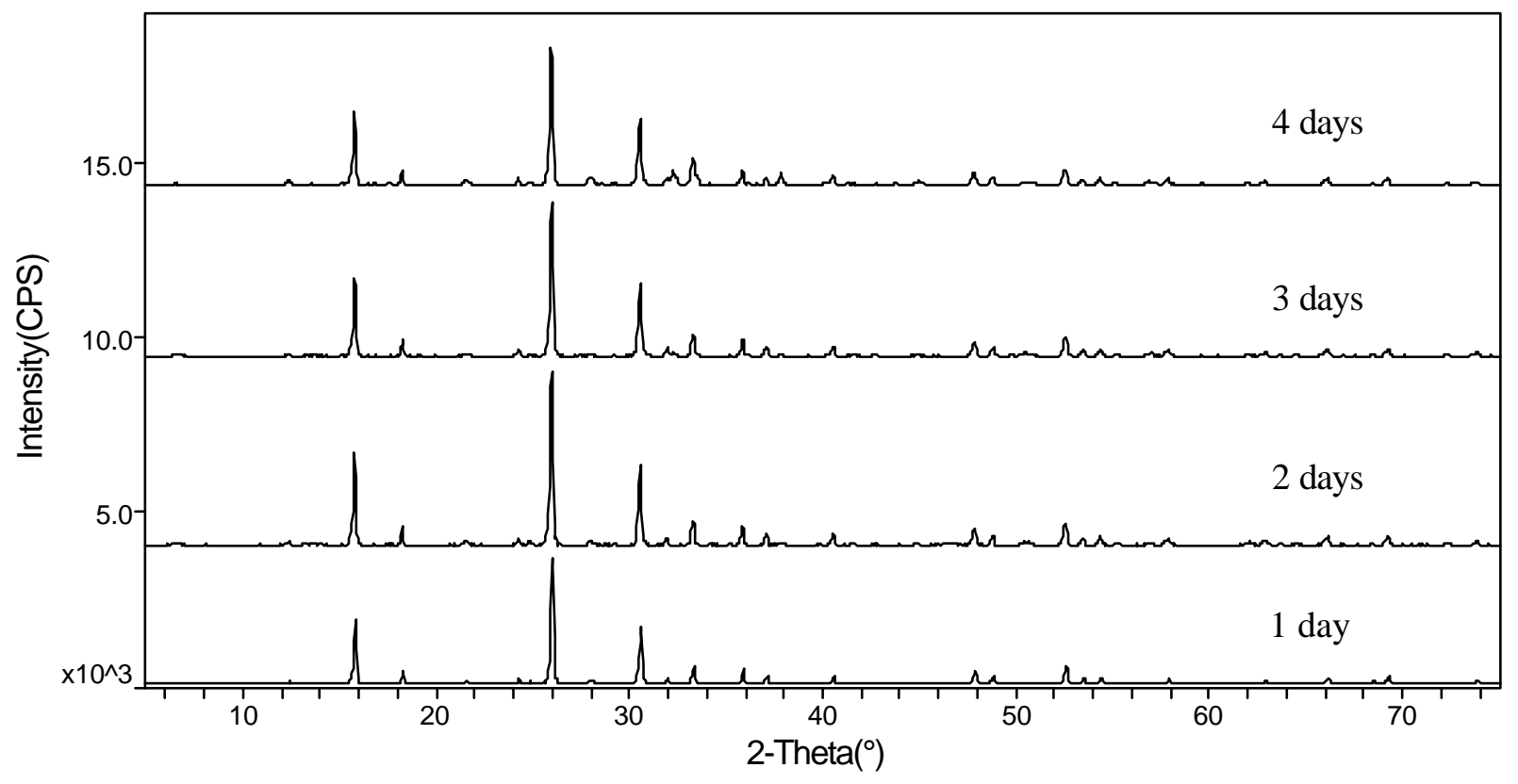

Figure 3-50. Comparison of XRD Patterns for HLP-46 Subjected to VHT at $200^{\circ} \mathrm{C}$ for 1,2 , 3, and 4 Days 


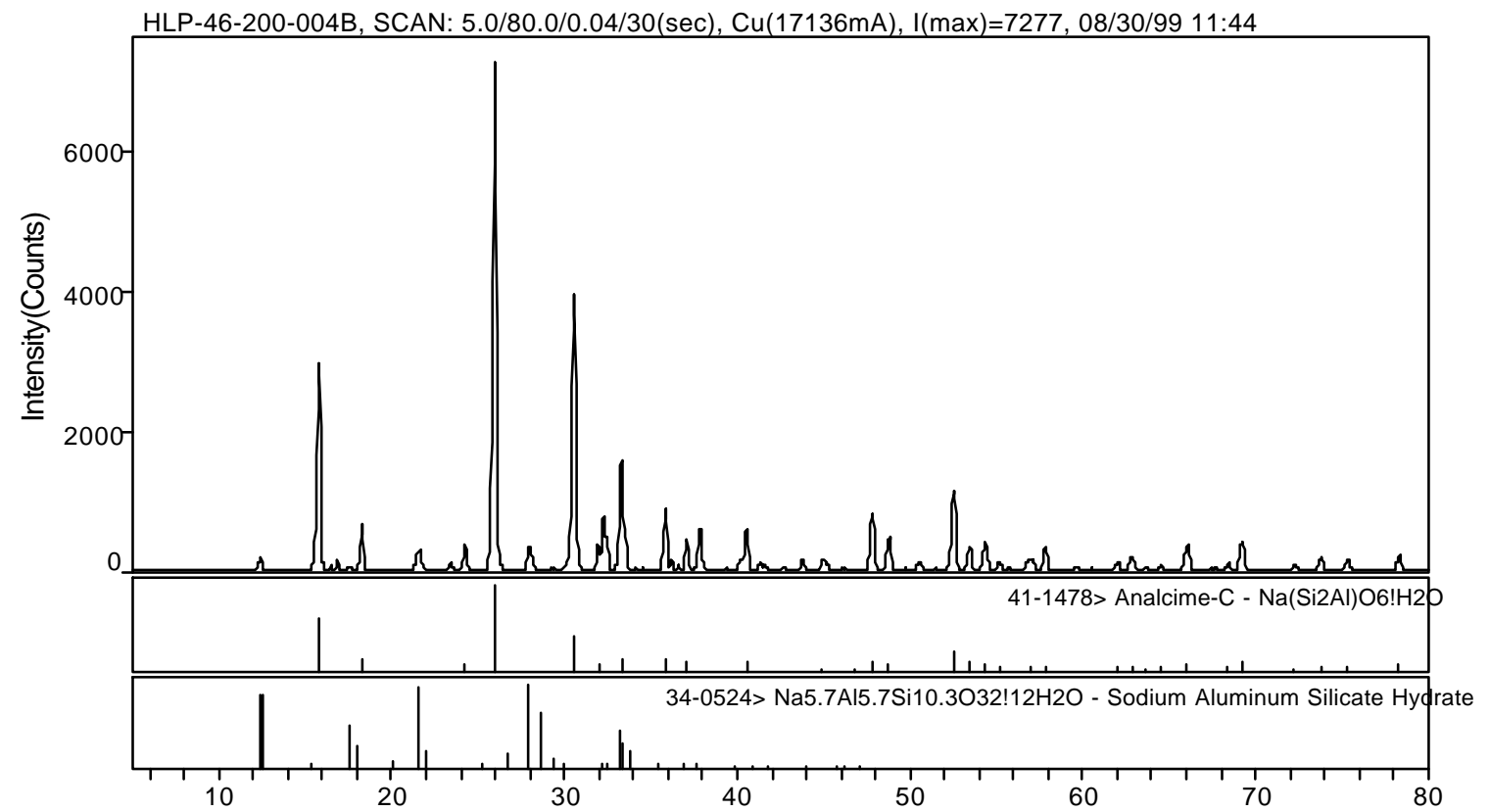

Figure 3-51. XRD Pattern of HLP-46 Subjected to VHT at $200^{\circ} \mathrm{C}$ for 4 Days

A similar analysis was performed on VHT samples of HLP-48. Figure 3-52 shows that the XRD pattern of HLP-46 reacted at increasing temperatures. While the location of major peaks does not change, it is clear that the peak at 25.865 decreases while the peak at 24.155 increases with increasing temperature. Since each of these has a different amount of alteration, we compare the XRD pattern of HLP-48 at $200^{\circ} \mathrm{C}$ as a function of alteration time in Figure 3-53. The lack of change in relative peak heights with alteration extent suggests that the change in XRD pattern in Figure 3-52 must be due to temperature. The peaks in these XRD patterns are identified in Figure 3-54. This identification led us to the conclusion that as temperature is increased, the concentration of sodium aluminum silicate boron hydroxide hydrate is increased relative to that of analcime. Surprisingly, the concentration of analcime increases with temperature in HLP-46 and decreases with temperature in HLP-48. A more thorough examination of the stability of alteration products as a function of temperature should be conducted when more data are available. 


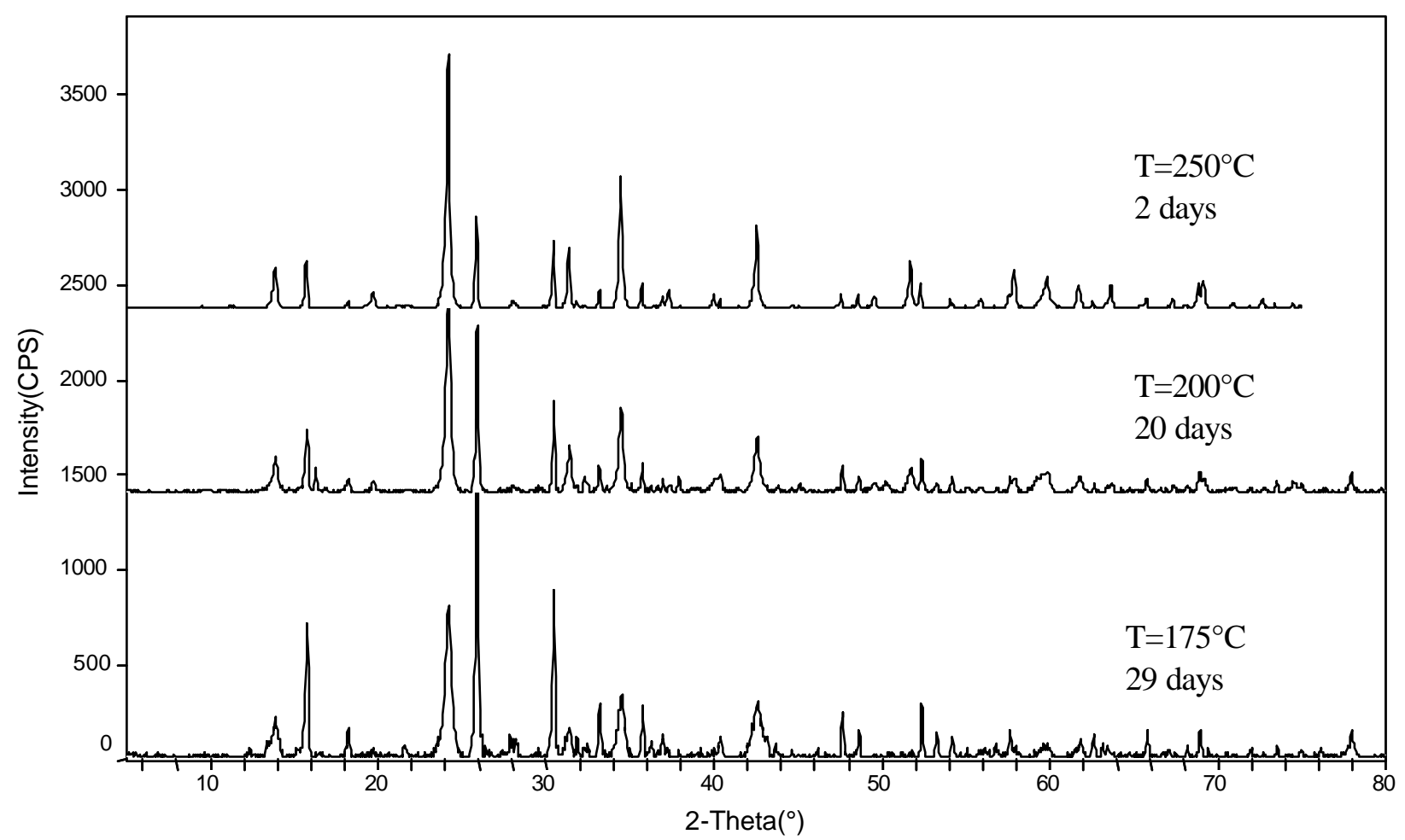

Figure 3-52. Comparison of XRD Patterns for HLP-48 Subjected to VHT at Different Temperatures

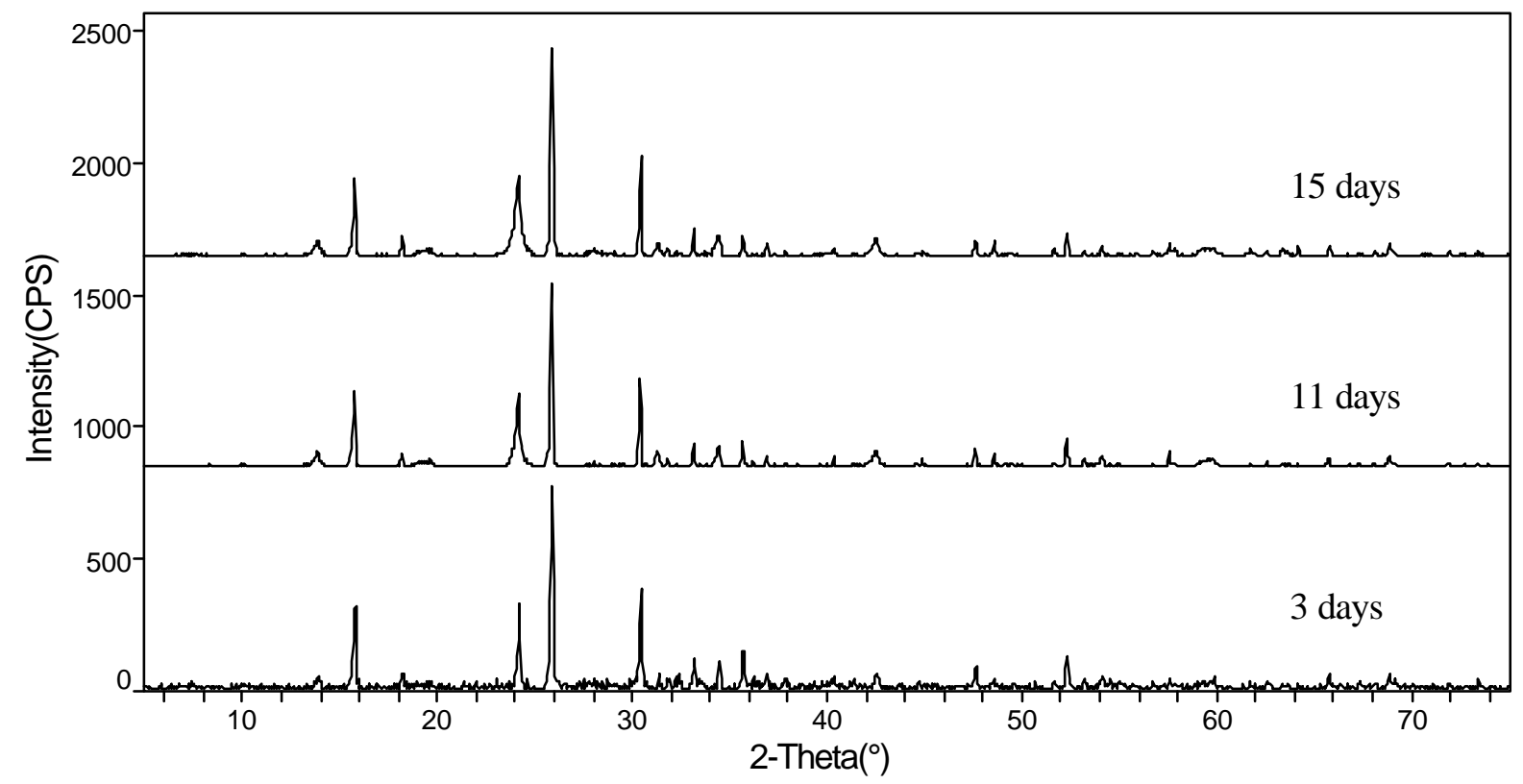

Figure 3-53. Comparison of XRD Patterns for HLP-48 Subjected to VHT at $200^{\circ} \mathrm{C}$ for 3,11 , and 15 Days 


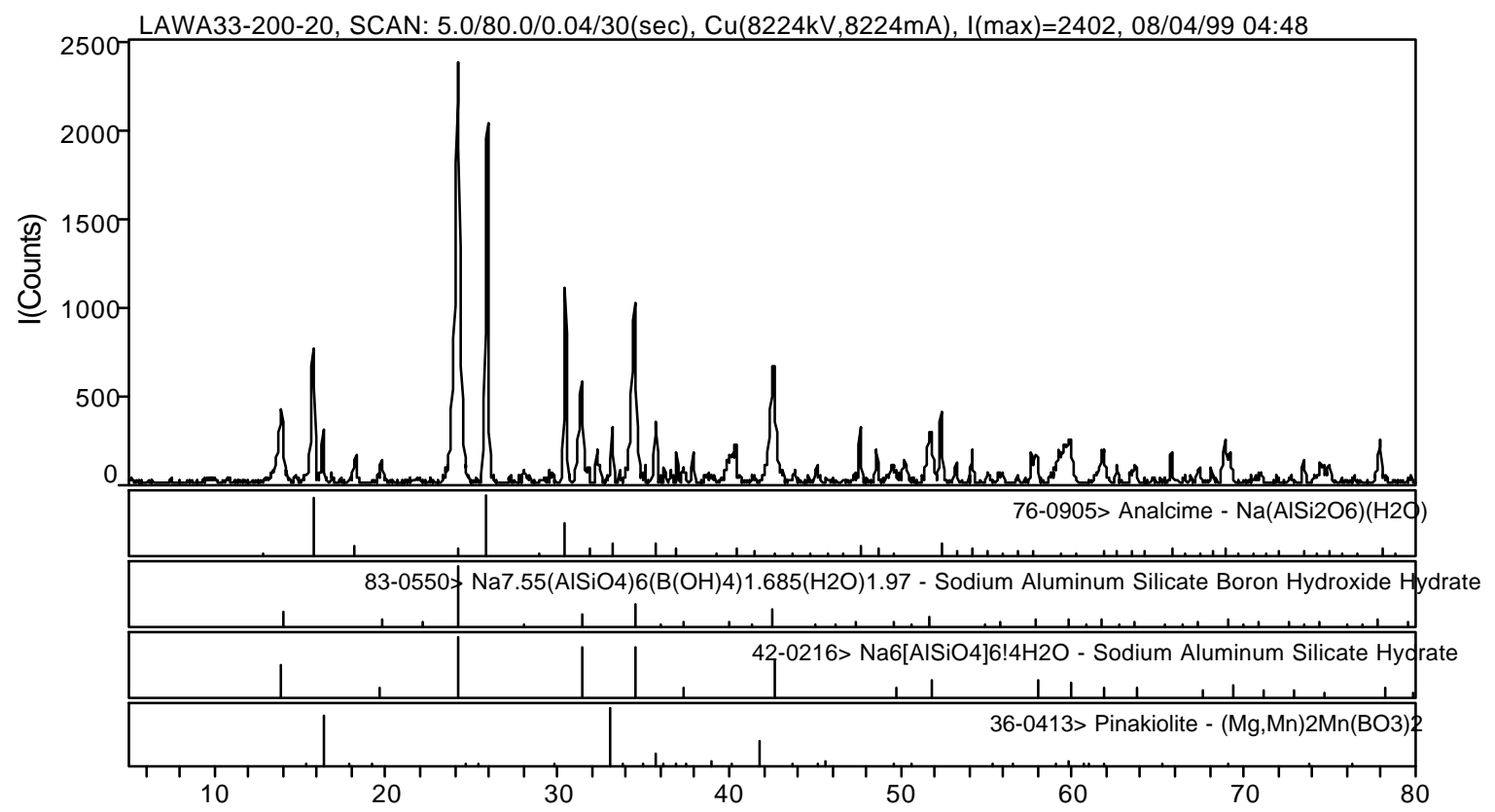

Figure 3-54. XRD Pattern of HLP-48 Subjected to VHT at $200^{\circ} \mathrm{C}$ for 20 Days 


\subsection{Data Reproducibility}

Results from repeated glass testing and property values of test-matrix glasses reported in the literature were compared to assess the reproducibility of the testing program employed in this study. The literature results compared to those in this study are presented in Section 4.1 for PCT and in Section 4.2 for VHT. The results from repeated test glasses are compared in Section 4.3.

\subsection{PCT Data}

As part of these research activities, PCT-A (i.e., $\mathrm{T}=90^{\circ} \mathrm{C}, \mathrm{S} / \mathrm{V} \approx 2000 \mathrm{~m}^{-1}$, and $\mathrm{t}=7$ days) and PCT-B (i.e., $\mathrm{T}=90^{\circ} \mathrm{C}, \mathrm{S} / \mathrm{V} \approx 20000 \mathrm{~m}^{-1}$, and $\mathrm{t}=10,100$, and $1000 \mathrm{~h}$ ) tests were run at SRTC on the HLP glasses whose compositions are provided in Table 2-1. However, a number of these glasses were previously fabricated and tested for the PCT at other laboratories. These historical data were examined to indicate whether they corroborated the SRTC data under the realization that these data were subject to laboratory-to-laboratory, glass-to-glass, and other variations that have not been characterized. Thus, results from these comparisons will be necessarily qualitative; however, work is planned to perform a more rigorous statistical evaluation of the data before the final Hanford ILAW data-package submission.

\subsubsection{HLP-46}

The first glass examined was HLP-46. A series of tests was run by PNNL on this glass to examine the potential effects of S/V and time on the PCT results. These results are summarized in Table 4-1. Argonne National Laboratory (ANL) also performed the PCT on this same glass. ${ }^{\text {a }}$ The SRTC, PNNL, and ANL boron and sodium releases, $\mathrm{NC}_{\mathrm{i}}$ in $\mathrm{g} / \mathrm{L}$, are plotted against the $(\mathrm{S} / \mathrm{V}) \mathrm{t}$ term on Figure 4-1. (This is a convenient way to plot results with different S/V values on the same graph.) The PNNL results also include historic PCT-A data (Kim et al. 1995). For the boron results, it is evident that corrosion has accelerated in the PCT experiments with $(\mathrm{S} / \mathrm{V}) \mathrm{t}$ values beginning at approximately $10^{8} \mathrm{~h} / \mathrm{m}$. Thus deviation of the long-term data from the least-squares fit to short-term PCT responses is not surprising and indicates that, under these conditions, the short-term data will not provide insight into the long-term data. Figure 4-1 indicates a similar short-term relationship for the sodium release (where no long-term ANL data were available). Additional examinations of these data will be made as long-term PCT-B data become available. However, the information in Figure 4-1 suggests that there is no reason to believe that the SRTC, ANL, or PNNL data are invalid for the HLP-46 glass.

\subsubsection{HLP-47}

Additional PCT data for the HLP-47 glass were previously collected from a round-robin study of this glass conducted by ANL (Ebert and Wolf 1999). Since these additional data were all from PCT-A on a single glass, only the test solution concentrations (in $\mathrm{mg} / \mathrm{L}$ ) were examined (as the glass-to-glass effects should have been insignificant). As illustrated in Figure 4-2, the individual PCT-A measurements from this study do not appear prone to either larger than expected random or systematic variation when compared to the results from the round-robin study. Additional work is planned to closely examine the appropriate components of variance to which these measurements are subject. This will allow more rigorous statistical methods to be used to provide more objective comparisons.

\footnotetext{
${ }^{a}$ W. L. Ebert, A. J. Bakel, D. M. Strachan, and S. F. Wolf. 1998. Laboratory Testing of LD6-5412 Glass, DRAFT, Argonne National Laboratory, Argonne, Illinois.
} 
Table 4-1. PNNL PCT-B Test Results for HLP-46

\begin{tabular}{crccccccc}
\hline $\begin{array}{c}\text { Glass } \\
(\mathbf{g})\end{array}$ & $\begin{array}{c}\mathbf{H}_{\mathbf{2}} \mathbf{O} \\
(\mathbf{m L})\end{array}$ & $\begin{array}{c}\mathbf{S} / \mathbf{V} \\
\left(\mathbf{m}^{-1}\right)\end{array}$ & $\begin{array}{c}\text { Time, } \mathbf{t} \\
(\mathbf{h})\end{array}$ & $\begin{array}{c}\mathbf{( S / V ) t} \\
(\mathbf{h} / \mathbf{m})\end{array}$ & $\begin{array}{c}\mathbf{B} \\
(\mathbf{m g} / \mathbf{L})\end{array}$ & $\begin{array}{c}\mathbf{N a} \\
(\mathbf{m g} / \mathbf{L})\end{array}$ & $\begin{array}{c}\mathbf{N C}_{\mathbf{B}} \\
(\mathbf{g} / \mathbf{L})\end{array}$ & $\begin{array}{c}\mathbf{N C}_{\mathbf{N a}} \\
(\mathbf{g} / \mathbf{L})\end{array}$ \\
\hline 0.1 & 100 & $2 \times 10^{1}$ & 1 & $2 \times 10^{1}$ & 0.073 & 0.35 & 0.0047 & 0.0023 \\
0.5 & 50 & $2 \times 10^{2}$ & 1 & $2 \times 10^{2}$ & 0.063 & 1.9 & 0.0040 & 0.012 \\
1 & 10 & $2 \times 10^{3}$ & 1 & $2 \times 10^{3}$ & 0.52 & 13.5 & 0.033 & 0.089 \\
10 & 10 & $2 \times 10^{4}$ & 1 & $2 \times 10^{4}$ & 2.5 & 57 & 0.16 & 0.38 \\
0.1 & 100 & $2 \times 10^{1}$ & 10 & $2 \times 10^{2}$ & 0.068 & 1.3 & 0.0043 & 0.0086 \\
0.5 & 50 & $2 \times 10^{2}$ & 10 & $2 \times 10^{3}$ & 0.72 & 8.9 & 0.046 & 0.059 \\
1 & 10 & $2 \times 10^{3}$ & 10 & $2 \times 10^{4}$ & 1.9 & 37 & 0.12 & 0.24 \\
10 & 10 & $2 \times 10^{4}$ & 10 & $2 \times 10^{5}$ & 5.0 & 150 & 0.32 & 0.99 \\
0.1 & 100 & $2 \times 10^{1}$ & 100 & $2 \times 10^{3}$ & $0.785^{(a)}$ & 7.4 & 0.050 & 0.049 \\
0.5 & 50 & $2 \times 10^{2}$ & 100 & $2 \times 10^{4}$ & 1.6 & 22 & 0.10 & 0.15 \\
1 & 10 & $2 \times 10^{3}$ & 100 & $2 \times 10^{5}$ & 3.3 & 88 & 0.21 & 0.58 \\
1 & 10 & $2 \times 10^{3}$ & 100 & $2 \times 10^{5}$ & 3.0 & 74 & 0.19 & 0.49 \\
10 & 10 & $2 \times 10^{4}$ & 100 & $2 \times 10^{6}$ & 13.0 & 120 & 0.83 & 0.79 \\
0.1 & 100 & $2 \times 10^{1}$ & 1000 & $2 \times 10^{4}$ & 1.4 & 14 & 0.089 & 0.092 \\
0.5 & 50 & $2 \times 10^{2}$ & 1000 & $2 \times 10^{5}$ & 2.4 & 35 & 0.15 & 0.23 \\
1 & 10 & $2 \times 10^{3}$ & 1000 & $2 \times 10^{6}$ & 5.4 & 171 & 0.34 & 1.1 \\
10 & 10 & $2 \times 10^{4}$ & 1000 & $2 \times 10^{7}$ & \multicolumn{5}{c}{ No analyses were available } \\
\hline
\end{tabular}

(a) The last digit was estimated.
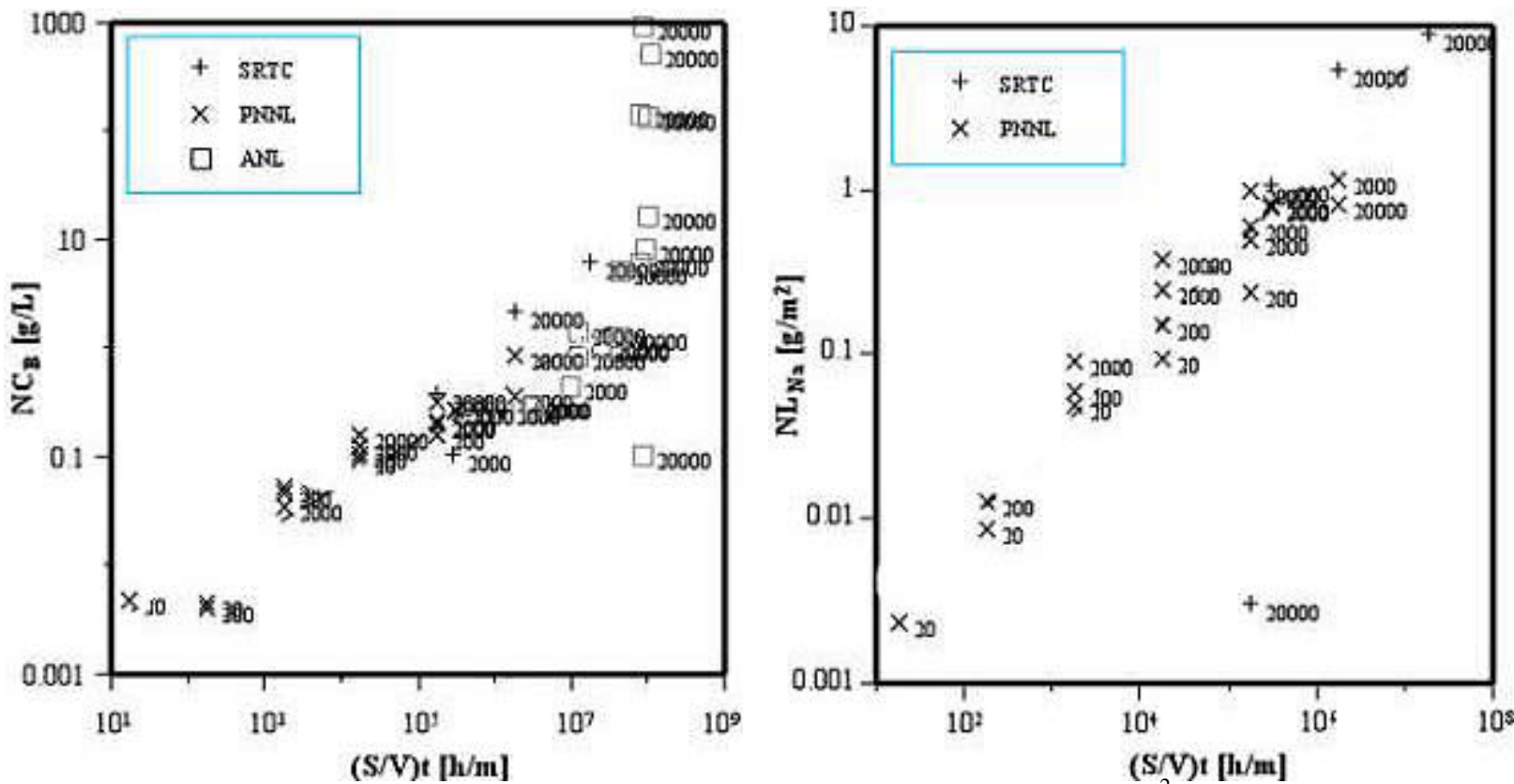

Figure 4-1. Relationships Between the Boron and Sodium Releases, $\mathrm{NL}_{\mathrm{i}}$ in $\mathrm{g} / \mathrm{m}^{2}$, and Time for HLP-46. The approximate $\mathrm{S} / \mathrm{V}$ value is shown for each sample. The dotted lines represent the leastsquares fits for the respective boron and sodium data with $(\mathrm{S} / \mathrm{V}) \mathrm{t}$ values up to approximately $10^{8} \mathrm{~h} / \mathrm{m}$. 

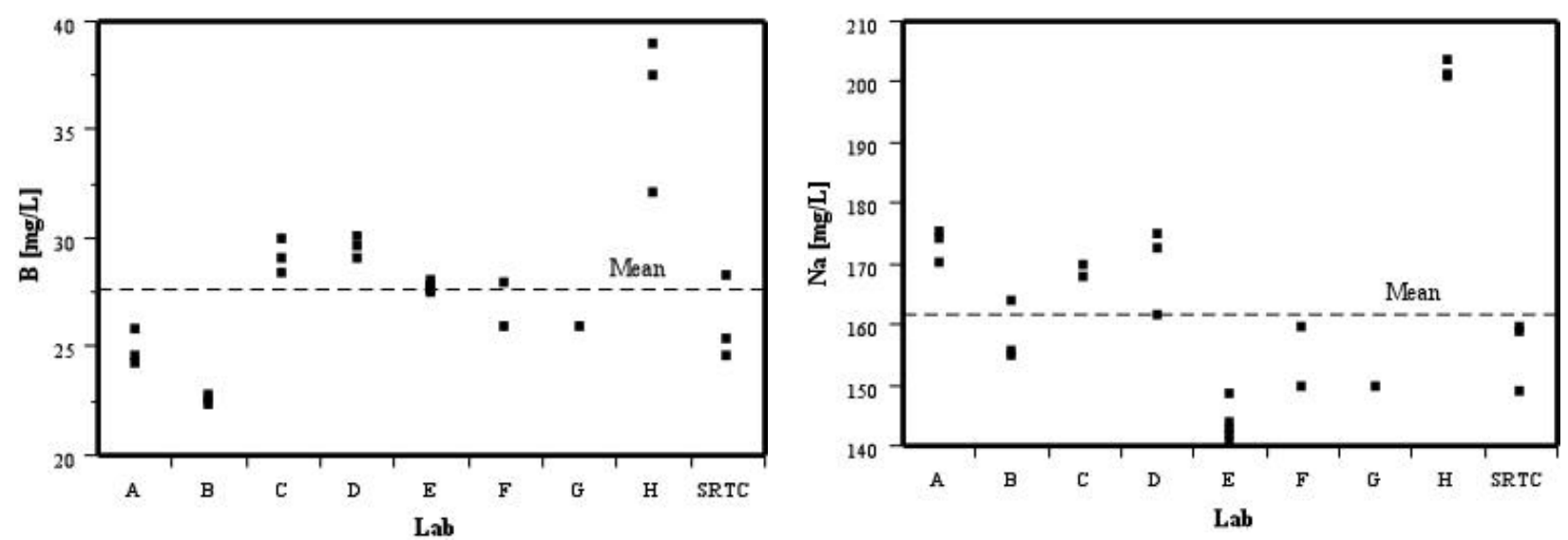

Figure 4-2. Boron (on the left) and Sodium (on the right) PCT-A Measurements for HLP-47 (or LRM-1). Data sets titled "A" through " $H$ " are from round-robin testing, and the set entitled "SRTC" represents the measurements taken as part of this study. The dotted lines represent overall mean concentrations.

\subsubsection{HLP-48}

Additional data for the HLP-48 glass were also previously collected by ANL (McGrail 1999). Figure 4-3 illustrates the relationships between normalized boron and sodium releases, $\mathrm{NC}_{\mathrm{i}}$, and $(\mathrm{S} / \mathrm{V}) \mathrm{t}$ for the SRTC and ANL data. This figure appears to indicate that the SRTC and ANL data agree fairly well, and thus there is no reason to believe that either set is invalid. Additional work is planned to more closely examine the appropriate components of variance to which these measurements are subject. This will allow more rigorous statistical methods to be used for future comparisons.

\subsubsection{HLP-54}

A series of tests was run at PNNL on the HLP-54 glass to examine the potential effects of S/V and time on PCT-B results. These results are summarized in Table 4-2. These PNNL data (including previously run PCT-A measurements [Kim et al. 1995]) and the SRTC data from this study are plotted on Figure 4-4. In this context, there is no reason to believe that either the SRTC data from this study or the previous PNNL results are invalid. 


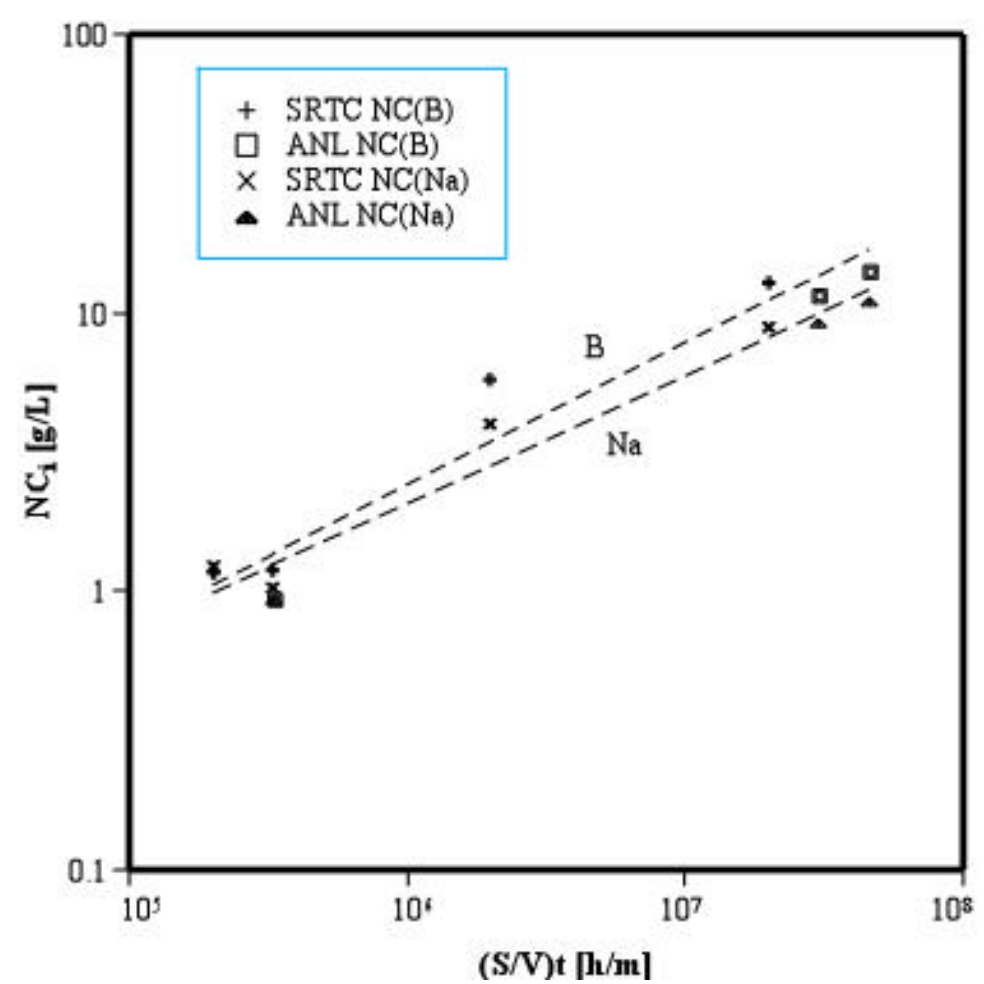

Figure 4-3. Relationships Between Normalized Boron and Sodium Releases, $\mathrm{NC}_{\mathrm{i}}$ in $\mathrm{g} / \mathrm{L}$, as Functions of (S/V)t in h/m for HLP-48 Glass. The dotted lines represent the least-squares fits through the respective boron and sodium data.

Table 4-2. PNNL PCT-B Test Results for HLP-54

\begin{tabular}{cccccccll}
\hline $\begin{array}{c}\text { Glass } \\
(\mathbf{g})\end{array}$ & $\begin{array}{c}\mathbf{H}_{\mathbf{2}} \mathbf{O} \\
(\mathbf{m L})\end{array}$ & $\begin{array}{c}\mathbf{S} / \mathbf{V} \\
\left(\mathbf{m}^{-1}\right)\end{array}$ & $\begin{array}{c}\text { Time, } \mathbf{t} \\
(\mathbf{h})\end{array}$ & $\begin{array}{c}\mathbf{( S / V ) t} \\
(\mathbf{h} / \mathbf{m})\end{array}$ & $\begin{array}{c}\mathbf{B} \\
(\mathbf{m g} / \mathbf{L})\end{array}$ & $\begin{array}{c}\mathbf{N a} \\
(\mathbf{m g} / \mathbf{L})\end{array}$ & $\begin{array}{c}\mathbf{N C}_{\mathbf{B}} \\
(\mathbf{g} / \mathbf{L})\end{array}$ & $\begin{array}{c}\mathbf{N C}_{\mathbf{N a}} \\
(\mathbf{g} / \mathbf{L})\end{array}$ \\
\hline 0.1 & 100 & $2 \times 10^{1}$ & 1 & $2 \times 10^{1}$ & 0.019 & 0.27 & 0.0007 & 0.0018 \\
0.5 & 50 & $2 \times 10^{2}$ & 1 & $2 \times 10^{2}$ & 0.12 & 1.1 & 0.0043 & 0.0074 \\
1 & 10 & $2 \times 10^{3}$ & 1 & $2 \times 10^{3}$ & 0.72 & 6.3 & 0.026 & 0.042 \\
10 & 10 & $2 \times 10^{4}$ & 1 & $2 \times 10^{4}$ & 4 & 30 & 0.14 & 0.20 \\
0.1 & 100 & $2 \times 10^{1}$ & 10 & $2 \times 10^{2}$ & 0.12 & 0.86 & 0.0043 & 0.0058 \\
0.5 & 50 & $2 \times 10^{2}$ & 10 & $2 \times 10^{3}$ & 0.47 & 3.4 & 0.017 & 0.023 \\
1 & 10 & $2 \times 10^{3}$ & 10 & $2 \times 10^{4}$ & 2.9 & 22 & 0.10 & 0.15 \\
10 & 10 & $2 \times 10^{4}$ & 10 & $2 \times 10^{5}$ & 11.5 & 80 & 0.412 & 0.54 \\
0.1 & 100 & $2 \times 10^{1}$ & 100 & $2 \times 10^{3}$ & $0.648^{(a)}$ & 3 & 0.023 & 0.020 \\
0.5 & 50 & $2 \times 10^{2}$ & 100 & $2 \times 10^{4}$ & 1.9 & 12 & 0.068 & 0.081 \\
1 & 10 & $2 \times 10^{3}$ & 100 & $2 \times 10^{5}$ & 9.7 & 64 & 0.35 & 0.43 \\
1 & 10 & $2 \times 10^{3}$ & 100 & $2 \times 10^{5}$ & 9.4 & 60 & 0.34 & 0.40 \\
10 & 10 & $2 \times 10^{4}$ & 100 & $2 \times 10^{6}$ & 55 & 312 & 1.97 & 2.10 \\
0.1 & 100 & $2 \times 10^{1}$ & 1000 & $2 \times 10^{4}$ & 2.3 & 10 & 0.082 & 0.067 \\
0.5 & 50 & $2 \times 10^{2}$ & 1000 & $2 \times 10^{5}$ & 8 & 38 & 0.29 & 0.26 \\
1 & 10 & $2 \times 10^{3}$ & 1000 & $2 \times 10^{6}$ & 37 & 160 & 1.32 & 1.08 \\
10 & 10 & $2 \times 10^{4}$ & 1000 & $2 \times 10^{7}$ & 207 & 742 & 7.41 & 5.00 \\
\hline
\end{tabular}

(a) The last digit was estimated. 


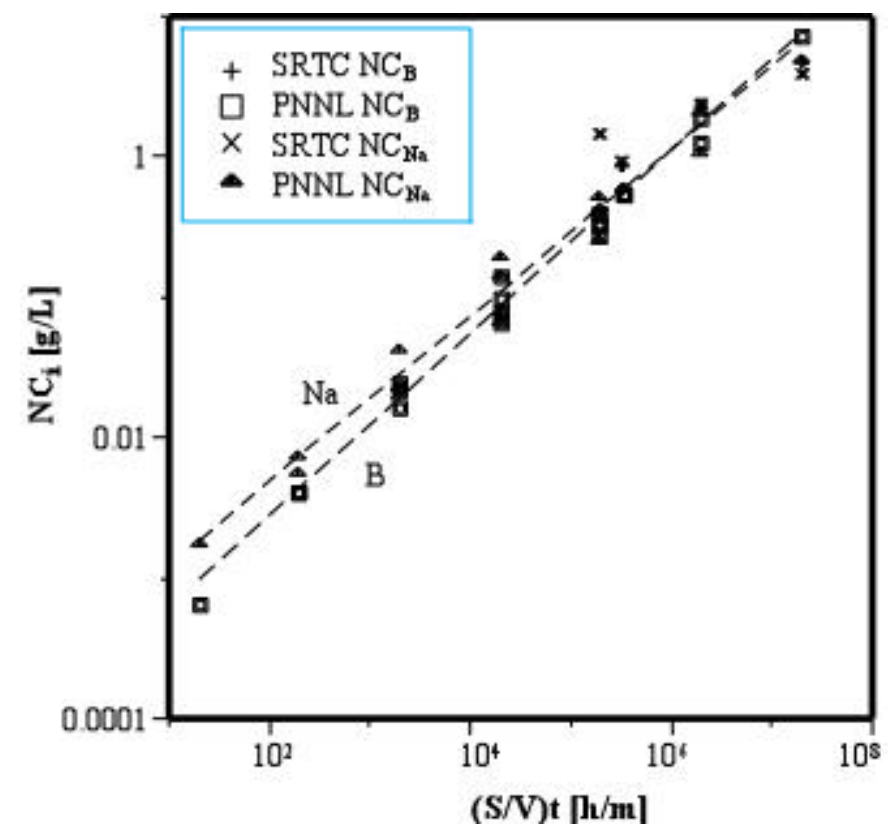

Figure 4-4. Relationships Between Normalized Boron and Sodium Releases, $\mathrm{NC}_{\mathrm{i}}$ in $\mathrm{g} / \mathrm{L}$, as Functions of $(\mathrm{S} / \mathrm{V}) \mathrm{t}$ in $\mathrm{h} / \mathrm{m}$ for HLP-54 Glass. The dotted lines represent the least-squares fits through the respective boron and sodium data.

\subsubsection{HLP-55}

A series of tests was also run at PNNL on the HLP-55 glass to examine the potential effects of S/V and time on PCT-B results. These results are summarized in Table 4-3. These PNNL data (including previously run PCT-A measurements [Kim et al. 1995]) and the SRTC data from this study are plotted on Figure 4-5. In this context, there is again no reason to believe that either the SRTC data from this study or the previous PNNL results are invalid. 
Table 4-3. PNNL PCT-B Test Results for HLP-55

\begin{tabular}{|c|c|c|c|c|c|c|c|c|}
\hline $\begin{array}{c}\text { Glass } \\
\text { (g) }\end{array}$ & $\begin{array}{c}\mathbf{H}_{2} \mathbf{O} \\
(\mathbf{m L})\end{array}$ & $\begin{array}{c}\mathbf{S} / \mathbf{V} \\
\left(\mathbf{m}^{-1}\right)\end{array}$ & $\begin{array}{c}\text { Time, } t \\
\text { (h) }\end{array}$ & $\begin{array}{l}(\mathrm{S} / \mathrm{V}) \mathbf{t} \\
(\mathbf{h} / \mathbf{m})\end{array}$ & $\begin{array}{c}\text { B } \\
(\mathrm{mg} / \mathrm{L})\end{array}$ & $\begin{array}{c}\mathrm{Na} \\
(\mathrm{mg} / \mathrm{L})\end{array}$ & $\begin{array}{l}N_{\mathbf{N}_{B}} \\
(\mathrm{~g} / \mathrm{L})\end{array}$ & $\begin{array}{l}N_{C_{N a}} \\
(g / L)\end{array}$ \\
\hline 0.1 & 100 & $2 \times 10^{1}$ & 1 & $2 \times 101$ & 0.024 & 0.33 & 0.0009 & 0.0022 \\
\hline 0.5 & 50 & $2 \times 10^{2}$ & 1 & $2 \times 10^{2}$ & 0.2 & 1.7 & 0.0072 & 0.012 \\
\hline 1 & 10 & $2 \times 10^{3}$ & 1 & $2 \times 10^{3}$ & 1.5 & 10.5 & 0.054 & 0.071 \\
\hline 10 & 10 & $2 \times 10^{4}$ & 1 & $2 \times 10^{4}$ & 11 & 57 & 0.39 & 0.38 \\
\hline 0.1 & 100 & $2 \times 10^{1}$ & 10 & $2 \times 10^{2}$ & 0.17 & 1.2 & 0.0061 & 0.0081 \\
\hline 0.5 & 50 & $2 \times 10^{2}$ & 10 & $2 \times 10^{3}$ & 0.65 & 4.2 & 0.023 & 0.028 \\
\hline 1 & 10 & $2 \times 10^{3}$ & 10 & $2 \times 10^{4}$ & 4.7 & 31 & 0.17 & 0.21 \\
\hline 10 & 10 & $2 \times 10^{4}$ & 10 & $2 \times 10^{5}$ & 49 & 220 & 1.75 & 1.48 \\
\hline 0.1 & 100 & $2 \times 10^{1}$ & 100 & $2 \times 10^{3}$ & $0.851^{\mathrm{i}}$ & 3.9 & 0.030 & 0.026 \\
\hline 0.5 & 50 & $2 \times 10^{2}$ & 100 & $2 \times 10^{4}$ & 2.8 & 16 & 0.10 & 0.11 \\
\hline 1 & 10 & $2 \times 10^{3}$ & 100 & $2 \times 10^{5}$ & 27 & 134 & 0.97 & 0.90 \\
\hline 1 & 10 & $2 \times 10^{3}$ & 100 & $2 \times 10^{5}$ & $23.2^{(\mathrm{a})}$ & 106 & 0.83 & 0.714 \\
\hline 10 & 10 & $2 \times 10^{4}$ & 100 & $2 \times 10^{6}$ & 166 & 708 & 5.94 & 4.77 \\
\hline 0.1 & 100 & $2 \times 10^{1}$ & 1000 & $2 \times 10^{4}$ & 3.2 & 14 & 0.11 & 0.094 \\
\hline 0.5 & 50 & $2 \times 10^{2}$ & 1000 & $2 \times 10^{5}$ & 12 & 53 & 0.43 & 0.36 \\
\hline 1 & 10 & $2 \times 10^{3}$ & 1000 & $2 \times 10^{6}$ & 74 & 277 & 2.65 & 1.87 \\
\hline 10 & 10 & $2 \times 10^{4}$ & 1000 & $2 \times 10^{7}$ & 474 & 1580 & 17.0 & 10.6 \\
\hline
\end{tabular}

(a) The last digit was estimated.

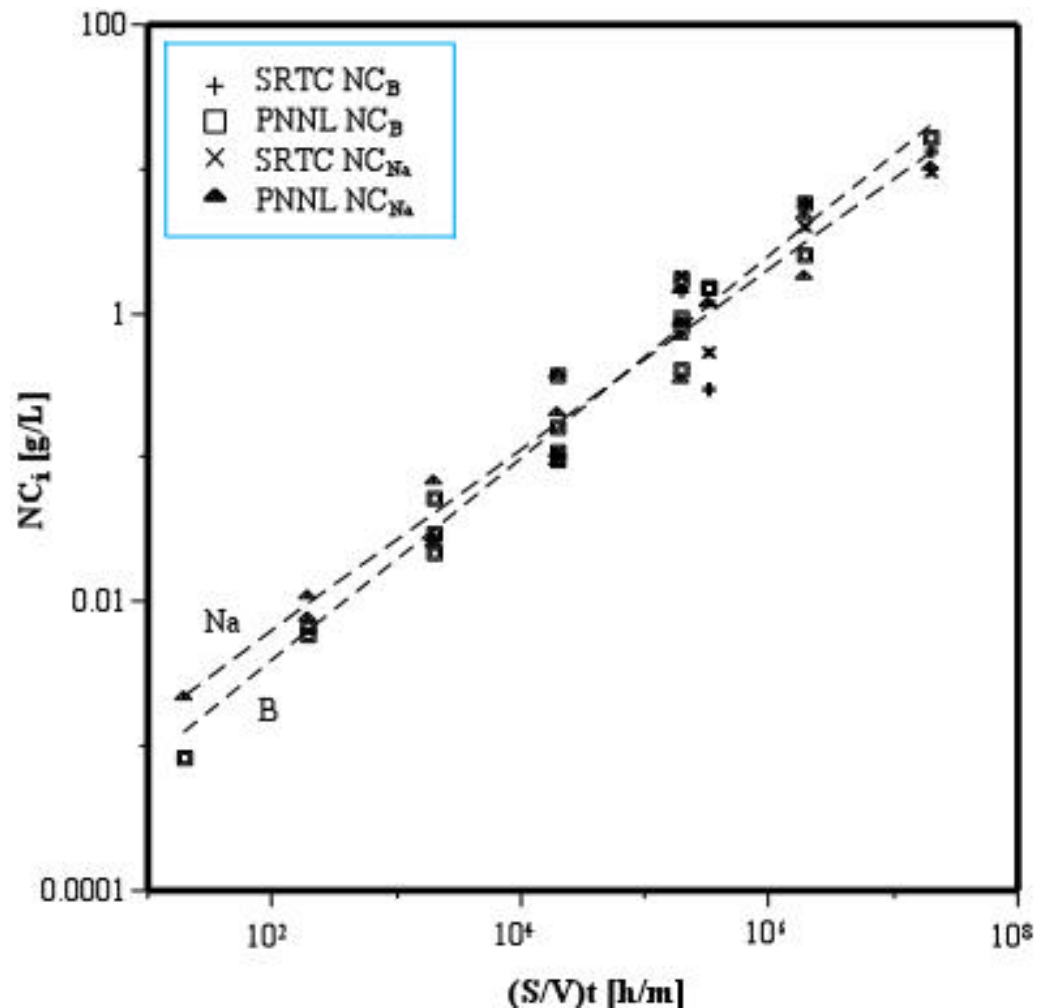

Figure 4-5. Relationships Between Normalized Boron and Sodium Releases, $\mathrm{NC}_{\mathrm{i}}$ in $\mathrm{g} / \mathrm{L}$, as Functions of $(\mathrm{S} / \mathrm{V}) \mathrm{t}$ in $\mathrm{h} / \mathrm{m}$ for HLP-55 Glass. The dotted lines represent the least-squares fits through the respective boron and sodium data. 


\subsection{VHT Data}

The response of HLP-46, -47 , and -48 to the VHT were measured at PNNL at the beginning of the test program (starting in April 1999) and again at the end of the program (January 2000). The response of HLP-46, $-47,-48,-54$, and -55 to the VHT were measured at Argonne National Laboratory (ANL). These data are compared in this section. However, to add the appropriate context under which the data can be compared, we first discuss some key parameters of the test.

The amount of water available in the VHT reaction vessel for glass corrosion was found to be very important to the $m_{d}$ of test samples. Tests with different amounts of water were conducted at $250^{\circ} \mathrm{C}$ and $300^{\circ} \mathrm{C}$ with the aim to determine the appropriate amount of water needed to conduct the test. The appropriate amount of water was defined as an amount of water that is

- $\quad$ sufficient to fully dissolve the amount of glass present during the test

- below the amount of water that would cause reflux and dripping of water from sample during the test (indicated by elevated $\mathrm{pH}$ in solution at the base of the vessel after test termination) ${ }^{\mathrm{a}}$.

Figure 4-6 shows the impact of water content on the $m_{d}$ of HLP-48 subjected to the VHT for 1, 1.5 , and 2 days at $250^{\circ} \mathrm{C}$. Tests were conducted with amount of water ranging from $0.4 \mathrm{~mL}$ to $0.6 \mathrm{~mL}$ ( $0.6 \mathrm{~mL}$ is the amount calculated from steam tables for $100 \% \mathrm{RH}$ plus $0.05 \mathrm{~mL}$ per sample in the vessel). There is an increase in $m_{d}$ as the amount of water increases until $0.45 \mathrm{~mL}$ and then a decrease. The amount, $0.45 \mathrm{~mL}$, was selected as the optimum amount of water for conducting the test at $250^{\circ} \mathrm{C}$ since it is the highest amount of water that did not show a $\mathrm{pH}$ rise. However, the rates were found to be relatively constant over a range of water contents from $0.45 \mathrm{~mL}$ to $0.6 \mathrm{~mL}$, as shown in Figure 4-7.

\footnotetext{
${ }^{\mathrm{a}} \mathrm{A} \mathrm{pH}$ rise in the solution at the bottom of the reaction vessel after termination of the VHT may indicate reflux has occurred during testing. However, there are other mechanisms that can cause a $\mathrm{pH}$ rise, such as a drop of $\mathrm{H}_{2} \mathrm{O}$ from the sample during or after test termination and particles falling from the sample during the test or after termination. Therefore, we cannot conclude that reflux has occurred without additional evidence.
} 


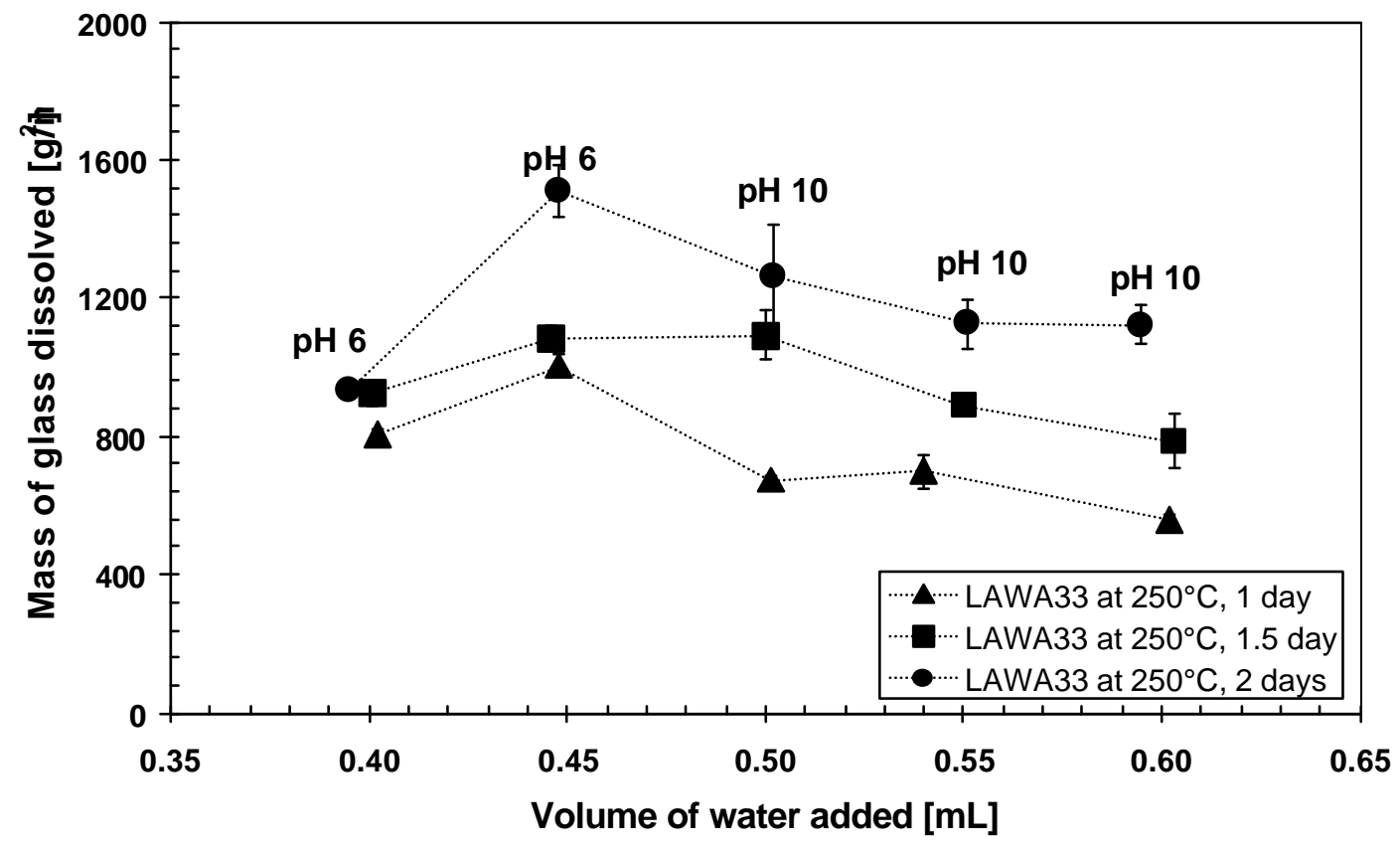

Figure 4-6. The $m_{d}$ of HLP-48 as a Function of Volume of Water in the Vessel

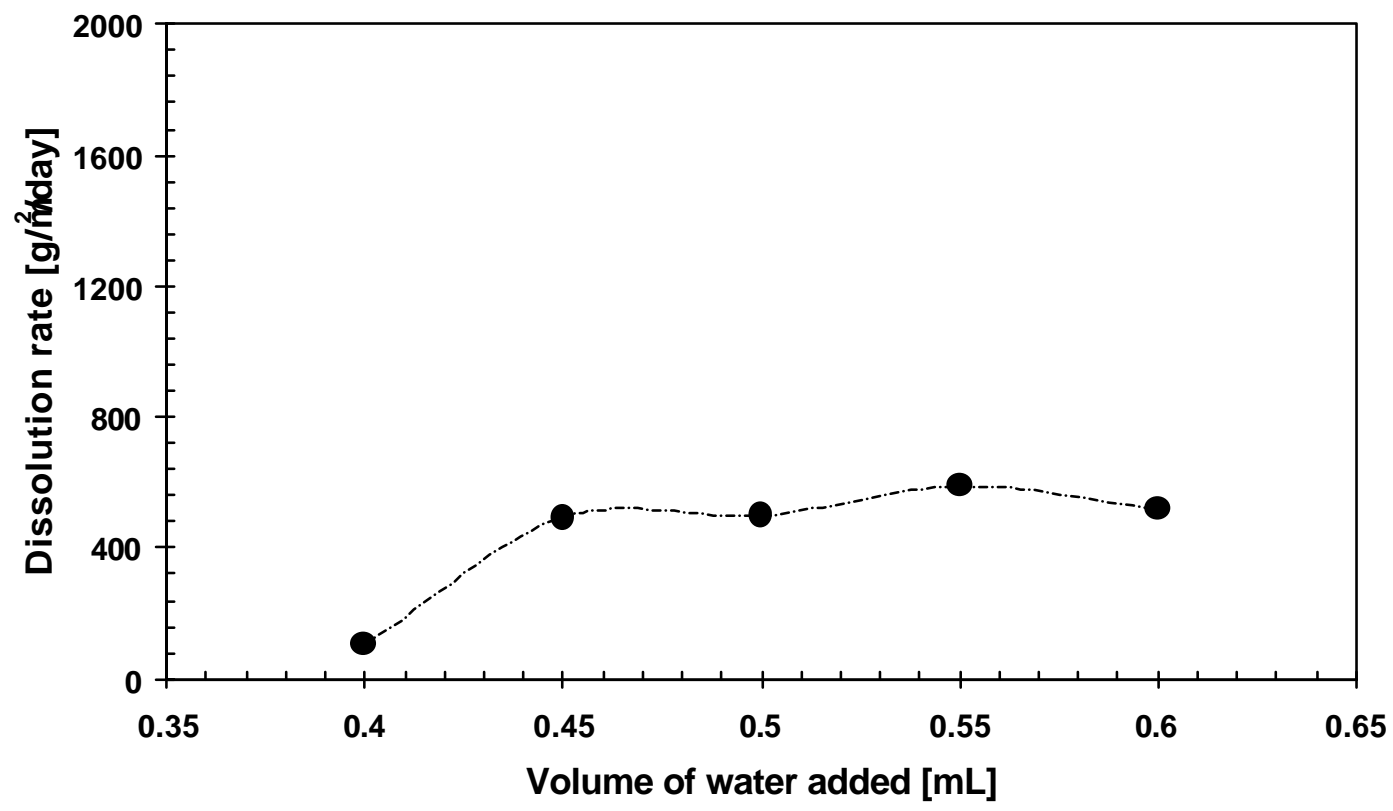

Figure 4-7. The rate of HLP-48 as a Function of Volume of Water in the Vessel 
Since the rate is almost independent of the amount of added water, the only variable that changed during the test is the incubation time, which resulted in a change of the intercept in $m_{d}$ vs. $t$, as shown in Figure 4-8. The intercept is decreased with increasing amount of water used in the test (except $0.4 \mathrm{~mL}$, which had a significantly different rate).

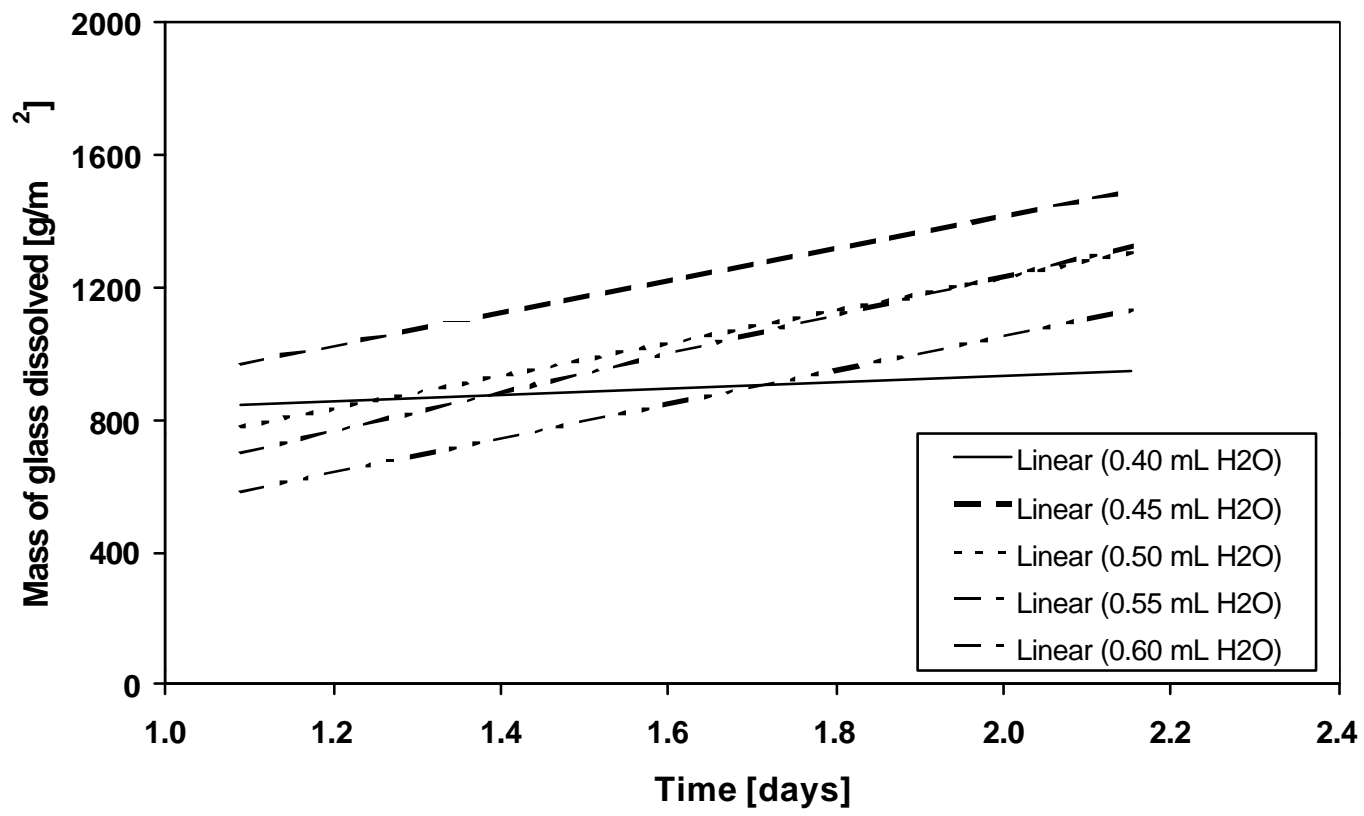

Figure 4-8. The $m_{d}$ of HLP-48 as a Function of $t$ for Different Volumes of Water

Figure 4-9 shows the impact of water content on the $m_{d}$ of HLP-51 subjected to the VHT for 2 days at $300^{\circ} \mathrm{C}$. Tests were conducted with the amount of water ranging from $0.7 \mathrm{~mL}$ to $1.5 \mathrm{~mL}(1.4 \mathrm{~mL}$ is the amount calculated from steam tables for $100 \% \mathrm{RH}$ plus $0.05 \mathrm{~mL}$ per sample).

There is an increase in $m_{d}$ as the amount of water increases towards $1 \mathrm{~mL}$ and then $m_{d}$ values are constant even with different reaction times. This may be caused by a change in dissolution mechanism because the alteration layers on samples from tests with greater than $1 \mathrm{~mL}$ of water flaked off during the test. The difference in reaction layers formed with $1.4 \mathrm{~mL}$ and $0.9 \mathrm{~mL}$ can be seen visually in Figure 4-10.

The amount of $0.8 \mathrm{~mL}$ was selected as the optimum amount of water for conducting the test at $300^{\circ} \mathrm{C}$ since it is the highest amount of water that did not have elevated $\mathrm{pH}$ in the post-test solution. Again, the rates were found to be relatively constant over a range of water contents (from $0.8 \mathrm{~mL}$ to 1.2 $\mathrm{mL}$ ), as shown in Figure 4-11. 


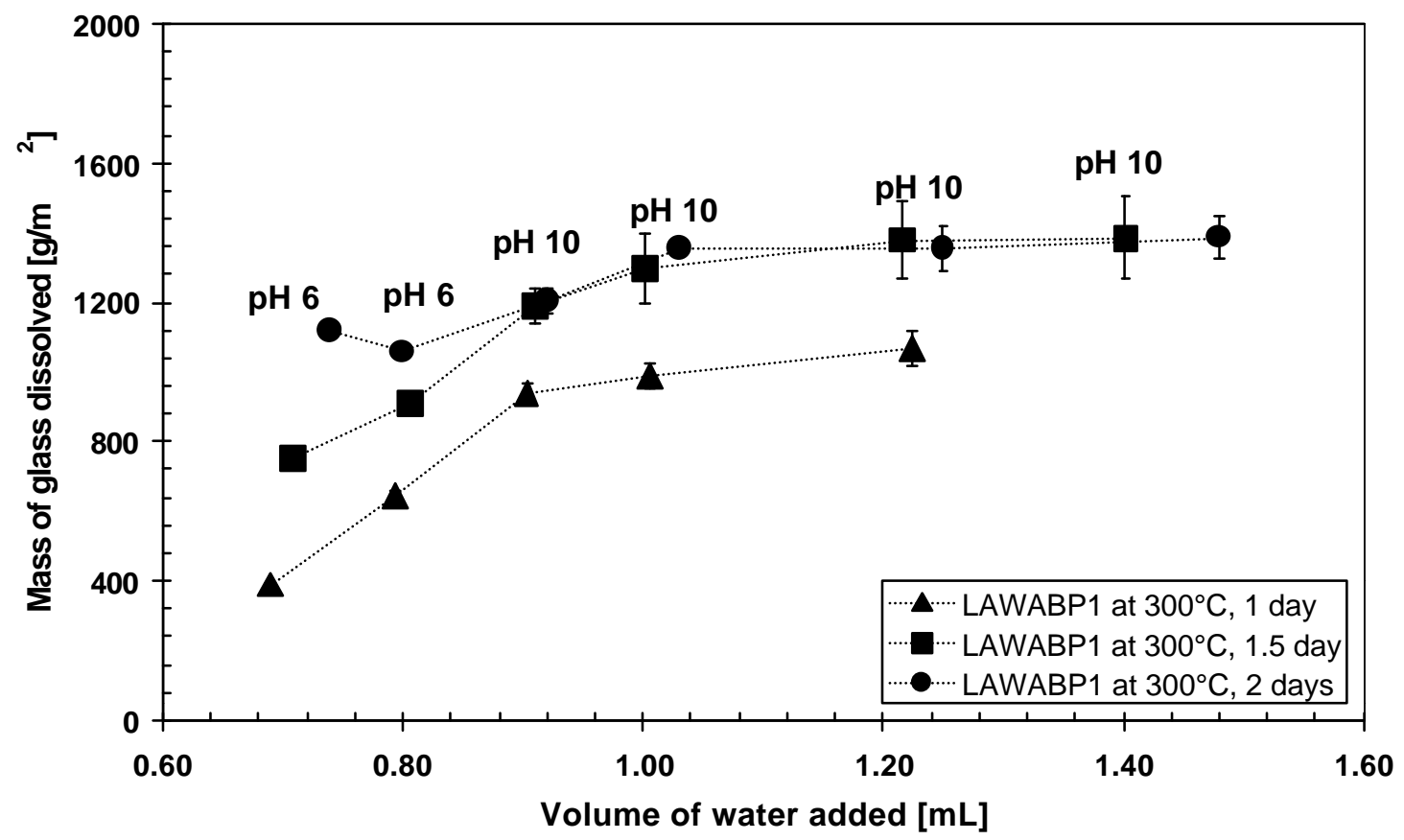

Figure 4-9. The $m_{d}$ of HLP-51 as a Function of Volume of Water in the Vessel

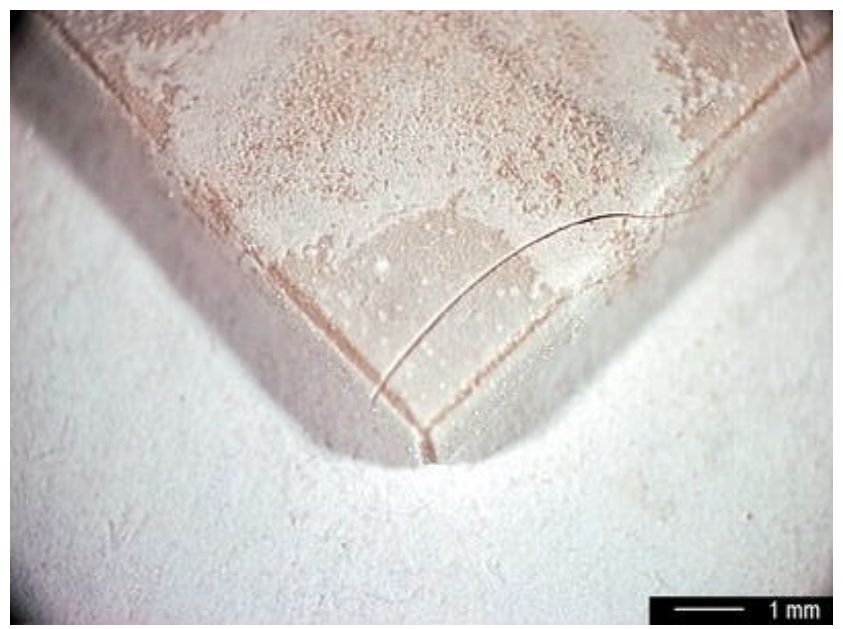

(a)

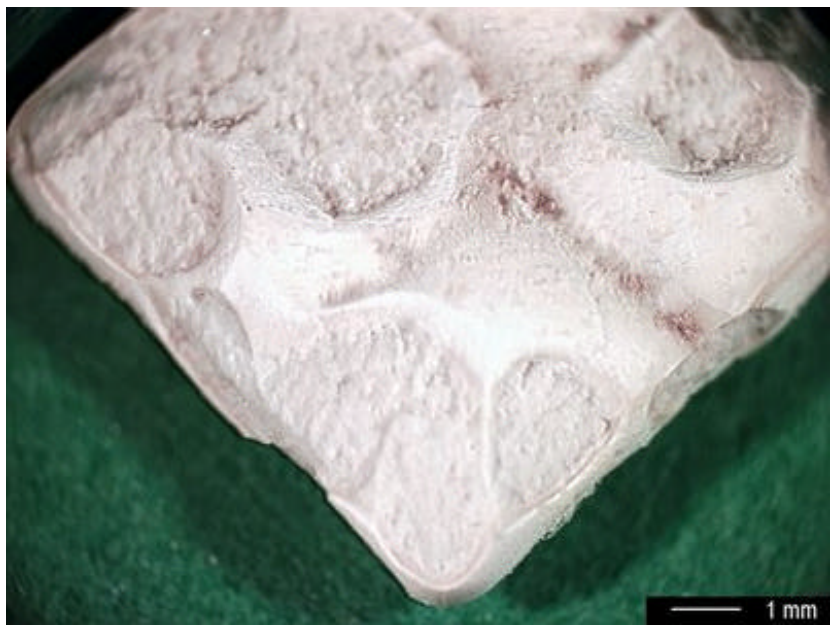

(b)

Figure 4-10. HLP-51 Glass after 1.5 Days at $300^{\circ} \mathrm{C}$ with (a) $0.9 \mathrm{~mL}$ and (b) $1.4 \mathrm{~mL}$ of Water 


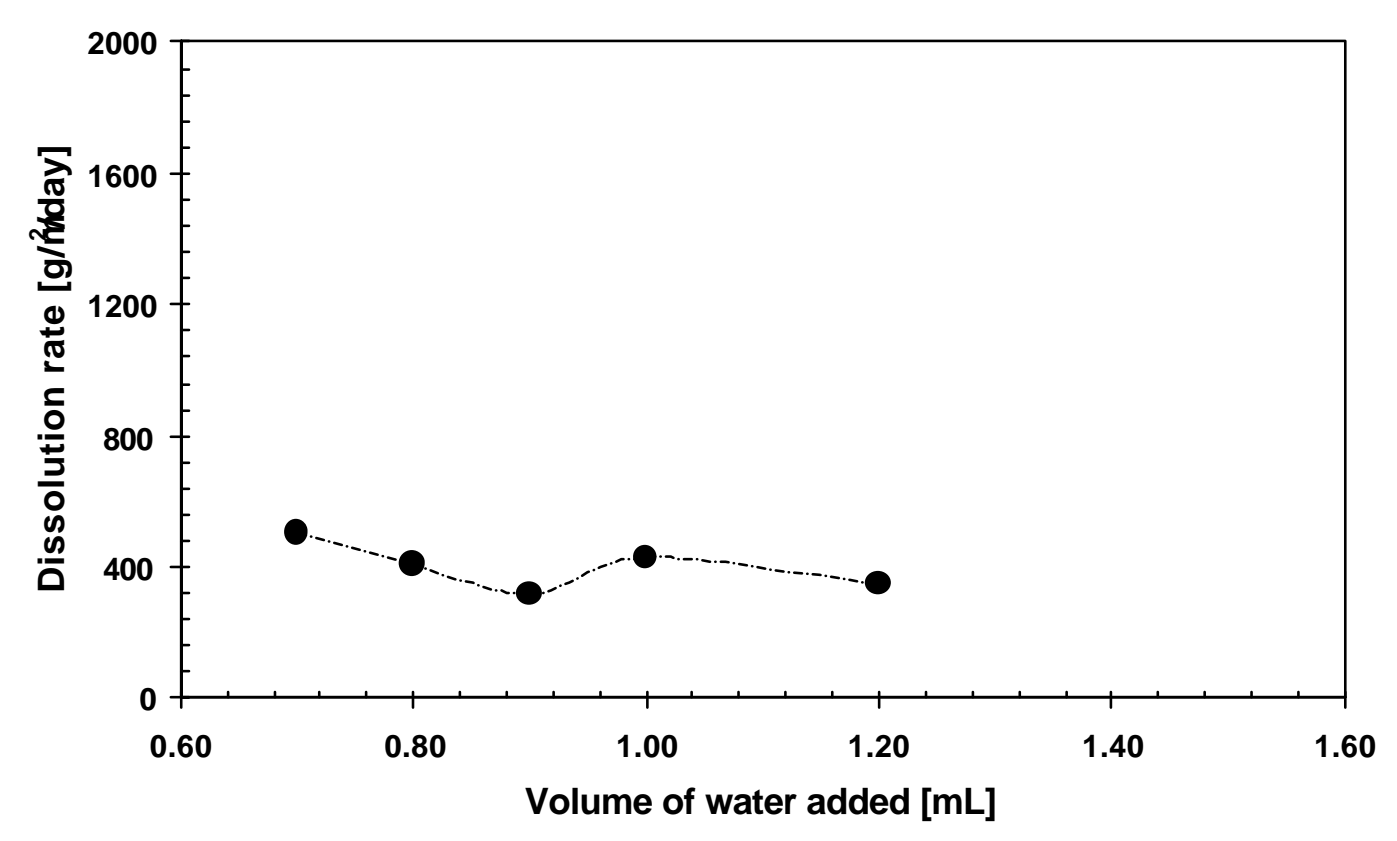

Figure 4-11. The rate of HLP-51 as a Function of Volume of Water in the Vessel

Unlike in tests at $250^{\circ} \mathrm{C}$, the intercept of $m_{d}$ - $t$ increased with decreasing amount of water used in the test (except $0.7 \mathrm{~mL}$, which showed a different rate), as shown in Figure 4-12.

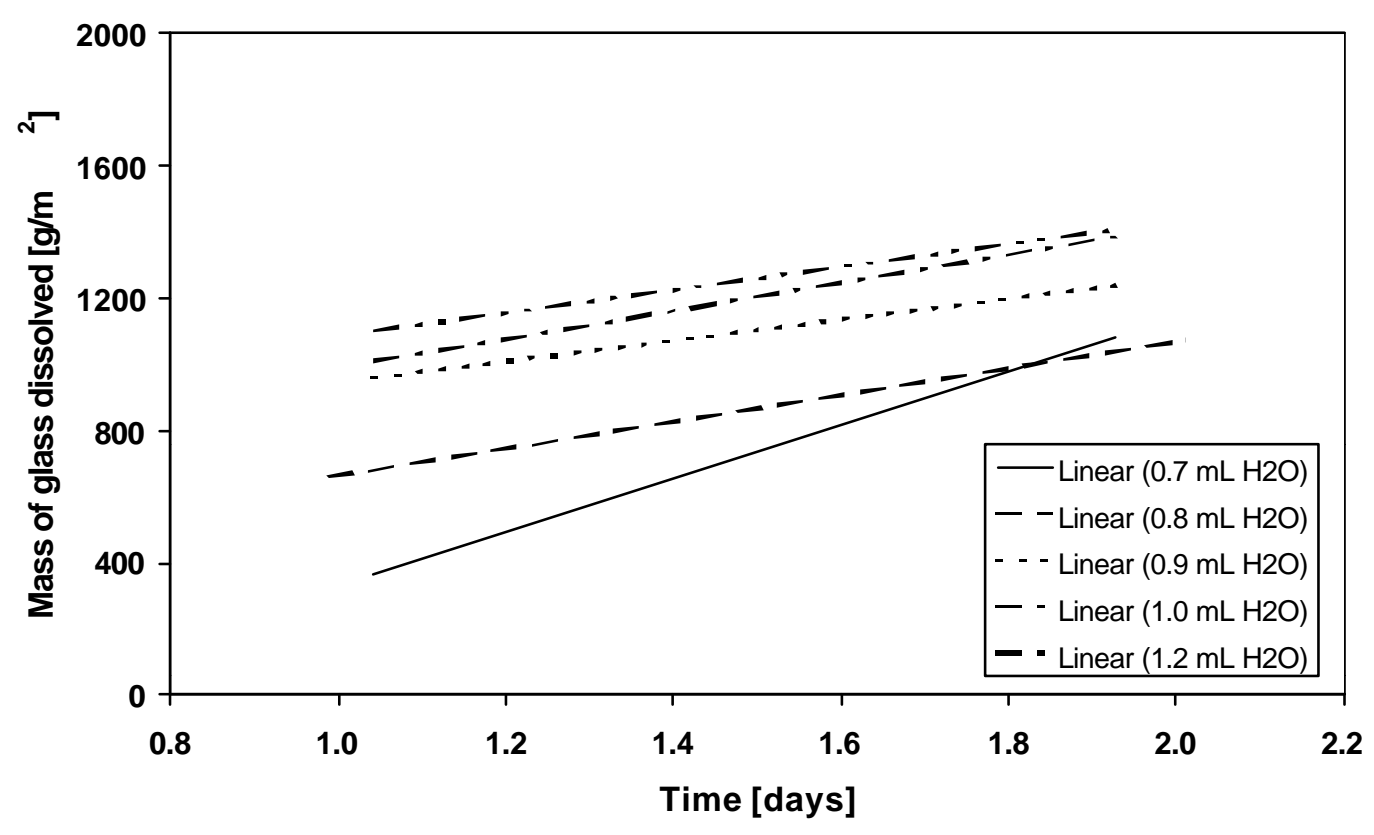

Figure 4-12. The $m_{d}$ of HLP-51 as a Function of $t$ for Different Volumes of Water 
It was shown that the amount of water used to conduct VHT affects the intercept of the $m_{d}$ vs. $t$ line and results in a difference in measured $m_{d}$ values. This observation plays an important role when combining results from different test, as will be shown later. However, because the amount of water showed the opposite effect on the intercept at $250^{\circ} \mathrm{C}$ and $300^{\circ} \mathrm{C}$, further research is required to identify the phenomenon(a) responsible for the difference. These tests are currently in progress.

HLP-46 was tested at $175^{\circ} \mathrm{C}$ in May 1999 and then again in January 2000 to ensure reproducibility. In both series of tests, one sample was loaded in each 22-mL reaction vessel with 0.14-mL of water. Figure 4-13 compares the $m_{d}$ of the samples as a function of time. Qualitatively, the results compare very well. As only two samples were measured in January, we do not make a quantitative comparison of the rate.

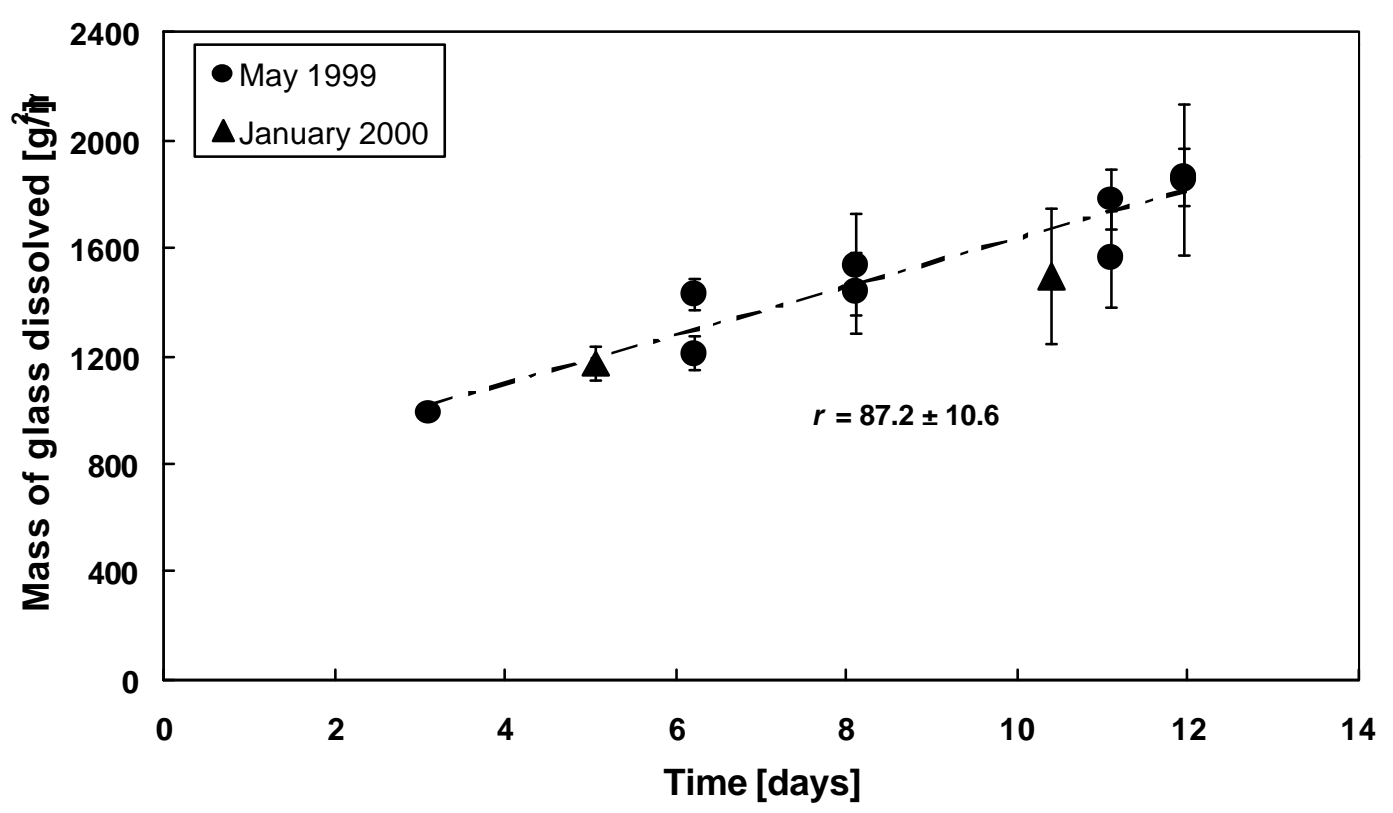

Figure 4-13. The $m_{d}$ as a Function of $t$ for HLP- 46 at $175^{\circ} \mathrm{C}$ Tested at PNNL in May 1999 and January 2000

The VHT response of HLP-47 at $200^{\circ} \mathrm{C}$ was measured in September 1999 and again in December 1999. In September, one sample of HLP-47 and one sample of HLP-53 were tested together in each vessel along with $0.25 \mathrm{~mL}$ of water. The resistance of HLP-53 to the VHT is low, and the samples were completely corroded after 3 days at $200^{\circ} \mathrm{C}$. As HLP- 47 is still within its incubation period at 3 days, the amount of water available to HLP-47 during this testing was reduced by absorption and alteration-product formation in the fully corroded HLP-53 sample. The tests performed in December 1999 contained only one sample per vessel with $0.20 \mathrm{~mL}$ of water. Figure 4-14 compares the $m_{d}$ for these different tests. The $m_{d}$ of those samples tested in September 1999 are clearly lower than those tested in December 1999. However, the rate is nearly identical (4.7\% difference). The difference in $m_{d}$ may be due to the difference in available water to corrode the HLP-47 samples. 


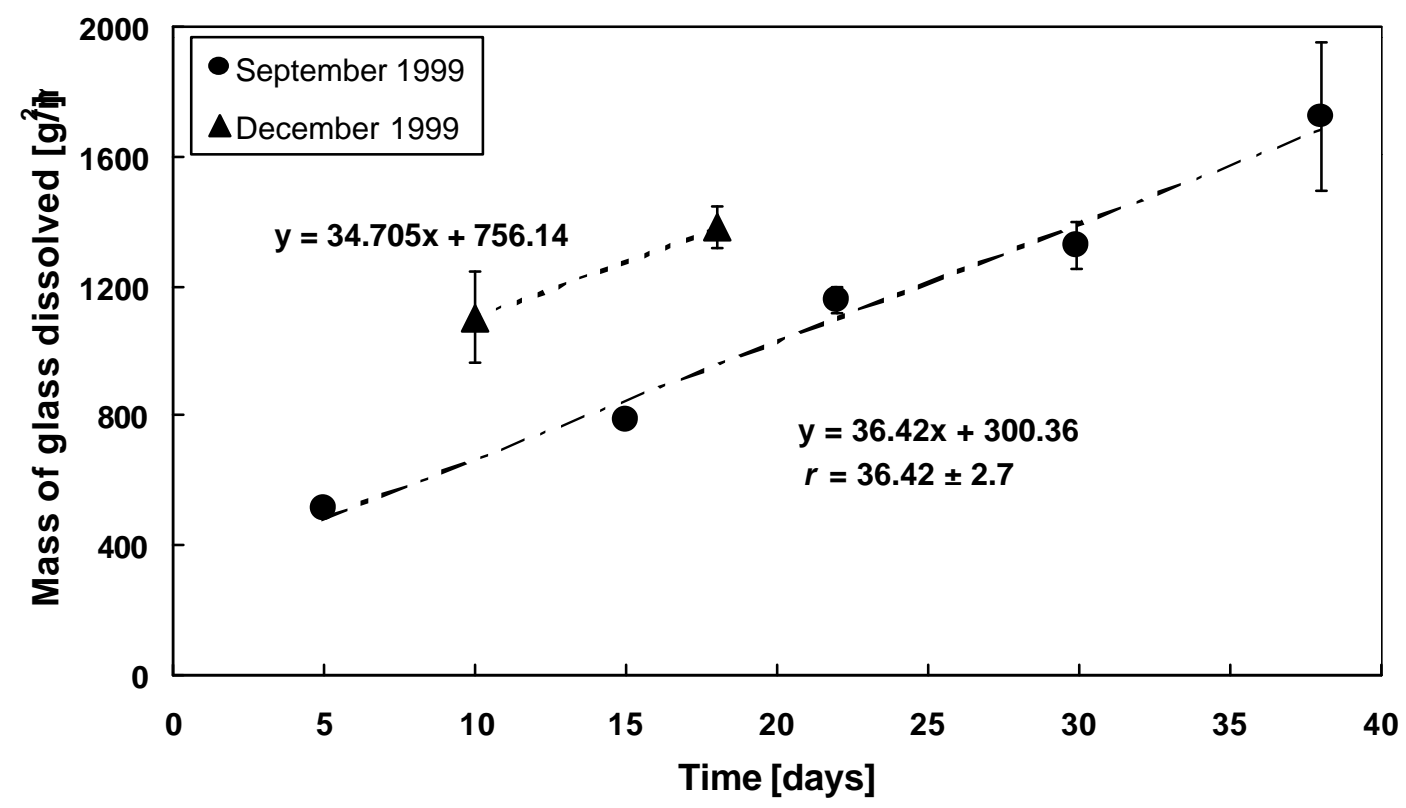

Figure 4-14. The $m_{d}$ as a Function of $t$ for HLP- 47 at $200^{\circ} \mathrm{C}$

The VHT response of HLP-48 at $200^{\circ} \mathrm{C}$ was measured in May 1999 and again in December 1999. In May, one sample of HLP-48 and one sample of HLP-51 were tested together in each vessel along with $0.25 \mathrm{~mL}$ of water. The rate of HLP-51 is roughly $10 \times$ lower that of HLP-48. After roughly 25 days, HLP-48 is completely corroded while HLP-51 is still within its incubation period. The amount of water available for corrosion of HLP-48 was much larger due to the low rate of HLP-51. The tests performed in December 1999 contained only one sample per vessel with $0.20 \mathrm{~mL}$ of water. Figure 4-15 compares the $m_{d}$ for these different tests. The $m_{d}$ of those samples tested in May 1999 are clearly higher than those tested in December 1999. However, the rate is nearly identical (1.2\% difference). The difference in $m_{d}$ is attributed to the difference in available water to corrode the HLP-48 samples.

Before comparing the VHT data generated by ANL (HLP-46, -48, -54, and -55), we have to evaluate the differences between experimental methods used. Table 4-4 summarizes the differences in test procedures. Two major differences between the two procedures are the manner in which alteration extent is measured and the sample size. 


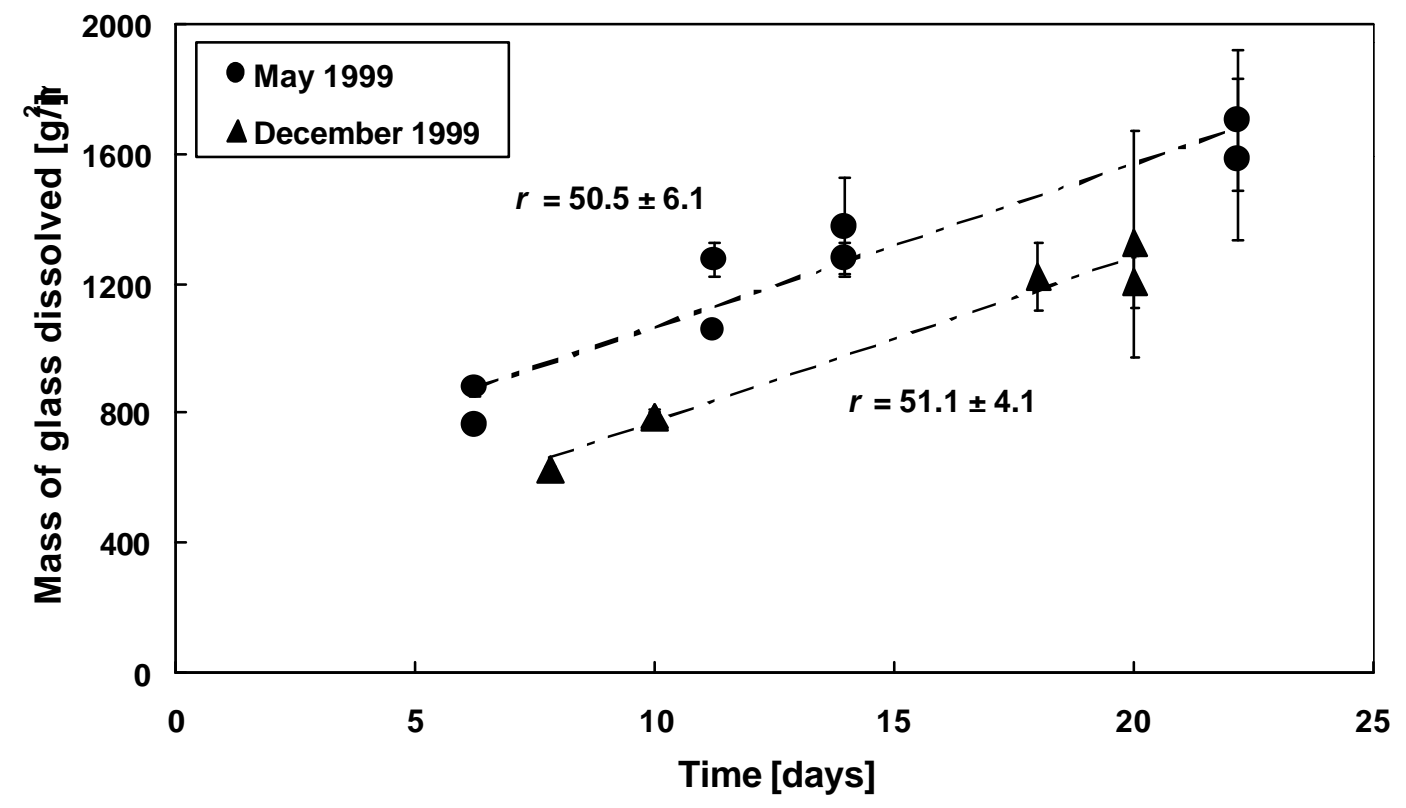

Figure 4-15. The $m_{d}$ as a Function of $t$ for HLP- 48 at $200^{\circ} \mathrm{C}$ Tested at PNNL in May 1999 and December 1999

Table 4-4. Comparison of Test Parameters

\begin{tabular}{|c|c|c|}
\hline & ANL & PNNL \\
\hline Sample dimensions & $\begin{array}{l}\text { Core drilled sample } \\
\text { diameter }=10 \mathrm{~mm} \\
\text { thickness }=1 \mathrm{~mm}\end{array}$ & $\begin{array}{c}\text { Square sample } \\
\text { width }=10 \mathrm{~mm} \\
\text { length }=10 \mathrm{~mm} \\
\text { thickness }=1.5 \mathrm{~mm}\end{array}$ \\
\hline Surface finish & One side polished to 600 grit & All sides polished to 600 grit \\
\hline $\begin{array}{l}\text { Mass of glass present } \\
\text { during the test [g] }\end{array}$ & 0.20 & 0.39 \\
\hline $\begin{array}{l}m_{d^{-}} \text {mass of glass per } \\
\text { unit surface area }\left[\mathrm{g} / \mathrm{m}^{2}\right] \\
\text { Mass of water added to } \\
22 \mathrm{~mL} \text { vessel with } \\
2 \text { samples at }\end{array}$ & 1300 & 1950 \\
\hline $\mathrm{T}=150^{\circ} \mathrm{C}$ & 0.15 & 0.15 \\
\hline $\mathrm{T}=175^{\circ} \mathrm{C}$ & 0.20 & 0.19 \\
\hline $\mathrm{T}=200^{\circ} \mathrm{C}$ & 0.25 & 0.25 \\
\hline Evaluation method & Thickness of alteration layer & Thickness of remaining glass layer \\
\hline
\end{tabular}


The results measured according to the ANL procedure were recalculated to yield the amount of glass dissolved in $\mathrm{g} / \mathrm{m}^{2}$ to be directly compared to PNNL results. Because the thickness of the sample before the test is $1000 \mu \mathrm{m}$, and the maximum amount of glass to be dissolved is $1300 \mathrm{~g} / \mathrm{m}^{2}$, we can assume that $0 \mu \mathrm{m}$ corresponds to $0 \mathrm{~g} / \mathrm{m}^{2}$ of dissolved glass and $1000 \mu \mathrm{m}$ thick alteration layer corresponds to $1300 \mathrm{~g} / \mathrm{m}^{2}$ of dissolved glass. This approximation enables direct comparison of the results.

Figure 4-16 compares the ANL and PNNL results for HLP-46 subjected to the VHT at $175^{\circ} \mathrm{C}$. The ANL tests were performed with two samples per vessel and $0.20 \mathrm{~mL}$ of water, and the PNNL tests were performed with one sample per vessel and $0.14 \mathrm{~mL}$ of water. Qualitatively, there is good agreement between the $m_{d}$ values. However, the calculated rate for the ANL data, $35.8 \mathrm{~g} / \mathrm{m}^{2} / \mathrm{d}$, is significantly lower than that for the PNNL data.

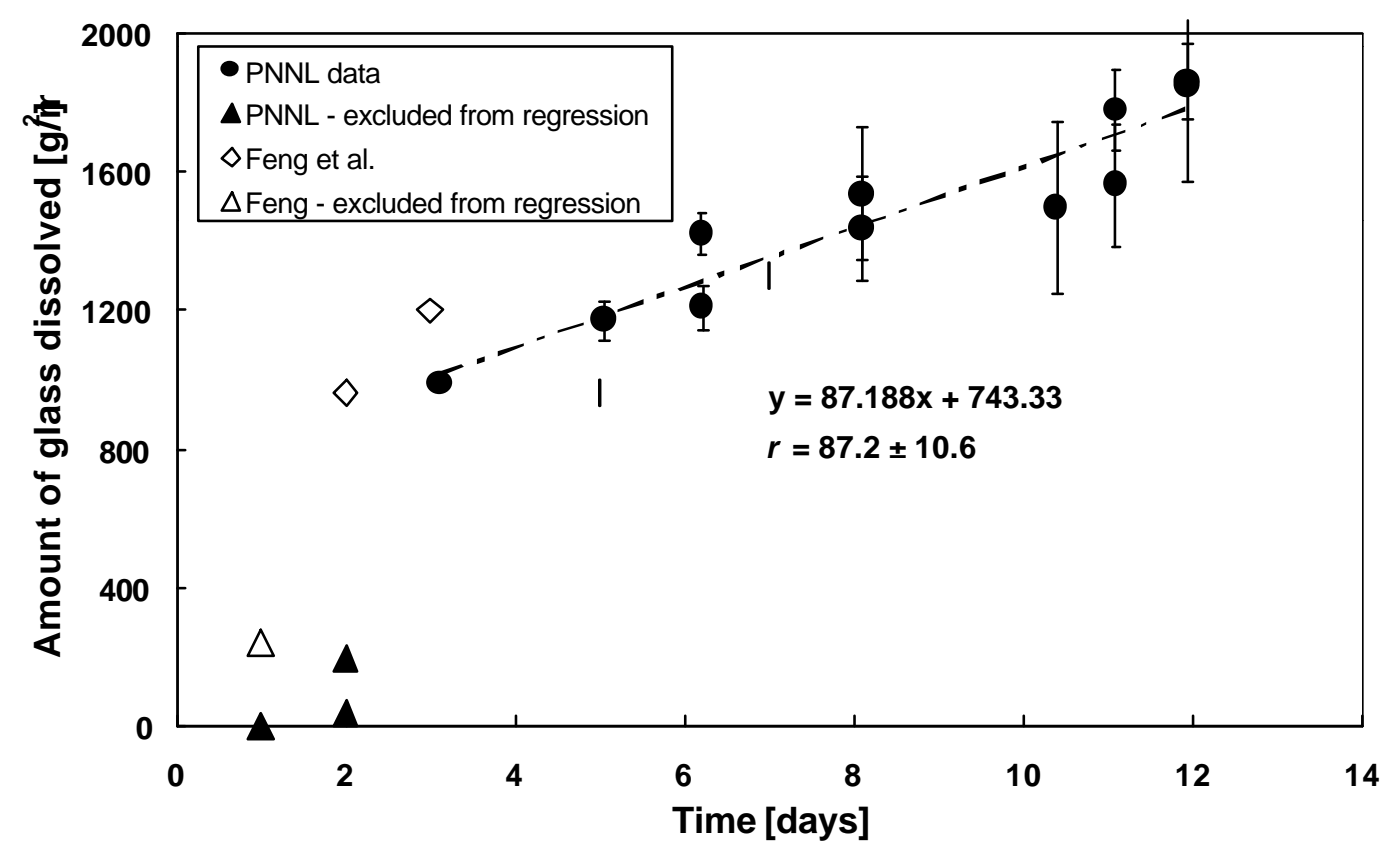

Figure 4-16. Comparison of VHT Results on HLP-46 at $175^{\circ} \mathrm{C}$

Figure 4-17 compares the ANL and PNNL results for HLP-48 subjected to the VHT at $150^{\circ} \mathrm{C}$. The ANL tests were performed with two samples per vessel and $0.15 \mathrm{~mL}$ of water, and the PNNL tests were performed with one sample per vessel and $0.10 \mathrm{~mL}$ of water. The $m_{d}$ values are in very good agreement and confirm the existence of the incubation time ending at roughly 70 days. Insufficient data were generated at ANL to estimate a rate.

${ }^{\text {a }}$ The rate value for ANL data was calculated by linear regression of the calculated $m_{d}$ vs. $t$ for the data taken at times of 2 days and longer. 


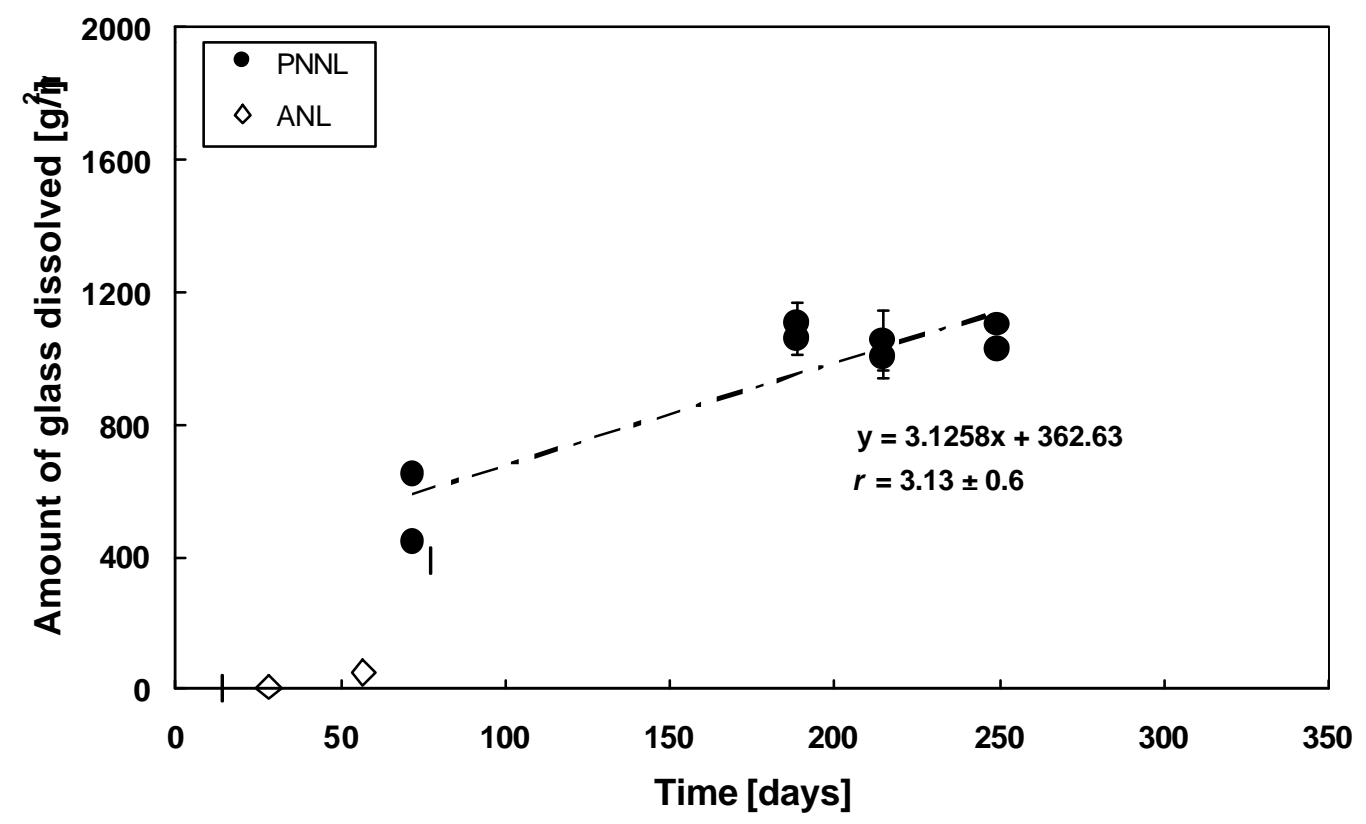

Figure 4-17. Comparison of VHT Results on HLP-48 Glass at $150^{\circ} \mathrm{C}$

Comparison of PNNL and ANL results on HLP-48 tested at $175^{\circ} \mathrm{C}$ is displayed in Figure 4-18. These results do not show very good agreement. The ANL tests were performed with two samples per vessel and $0.20 \mathrm{~mL}$ of water, and the PNNL tests were performed with one sample per vessel and $0.14 \mathrm{~mL}$ of water. The $m_{d}$ values determined from the ANL samples are significantly lower than those determined from the PNNL tests. The samples tested for less than 15 days are likely in the incubation stage of alteration (see Section 3.6.1 for discussion of the stages). There is no explanation for the differences in the results from the sample tested for 28 and 15 days. Insufficient data were generated at ANL to estimate a rate.

The alteration rates measured at multiple times within the same laboratory are similar (e.g., within 6.5\%). The measured $m_{d}$ values are dependent upon test conditions (such as the amount of water in the vessel and the presence and alteration rate of additional samples in the same vessel). Qualitative comparison between VHT results from ANL and PNNL show that the results are similar. Insufficient data exist to quantitate the similarity between the measurements at the two sites.

\subsection{Repeated Glasses}

Four glasses, HLP-01, $-25,-26$, and -43, with the same target compositions were included in the test matrix to give an indication of the reproducibility of the test methods involved. The variation in the property measurements of these glasses results from many sources, including batching, melting, and heat treating (at different sites) as well as property measurement. The PNNL replicate glasses were fabricated in the following order: HLP-26, HLP-43, and HLP-25. HLP-01 was the only glass fabricated at SRTC. The timing of the tests on these glasses is discussed below along with their properties. 


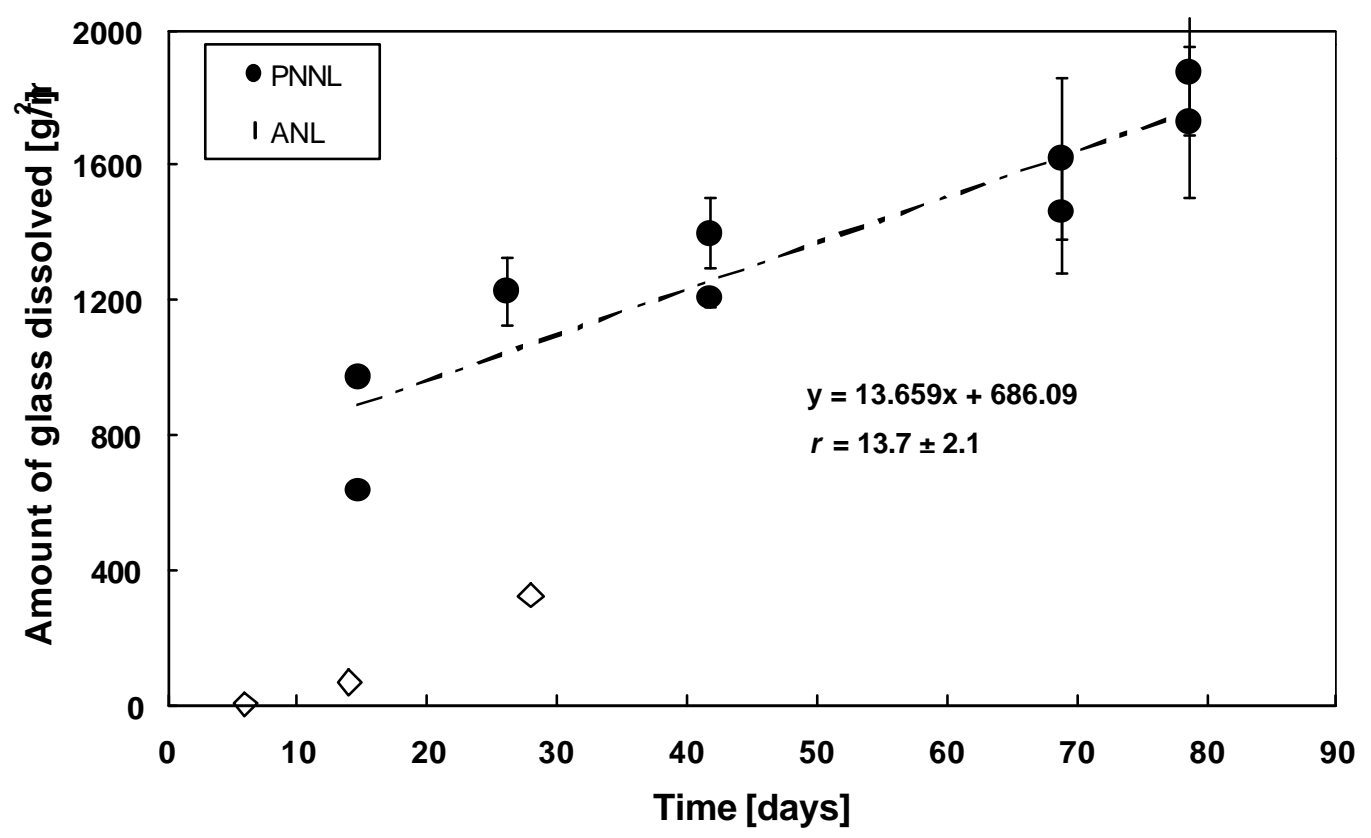

Figure 4-18. Comparison of VHT Results on HLP-48 Glass at $175^{\circ} \mathrm{C}$

\subsubsection{Composition}

The chemical compositions of the four repeated or "center" glasses (HLP-01, HLP-25, HLP-26 and HLP-43) were measured and are provided in Table 4-5. Analysis of the variance or standard deviation in the measured compositional values provides insight into reproducibility of the batching and analytical measurements. Comparisons among the mean measured compositional values to the targeted values provide an indication of how well the targeted composition was reproduced. Examination of the differences among component measurements and targeted concentrations (on a glass-by-glass basis) can provide some insight into the possibility of either gross batching or measurement errors.

The relative differences for the major oxide components presented in Table 4-5 indicate that reasonably good agreement between batching and chemical analysis was achieved. For the majority of the oxide components, the mean concentration was consistent with the targeted value (i.e., the relative difference was $5.33 \%$ or less). This was not the case with $\mathrm{Fe}_{2} \mathrm{O}_{3}$ and $\mathrm{Cr}_{2} \mathrm{O}_{3}$ where contamination from the grinding vessel was indicated, and the measured values were significantly higher than targeted. This was also not the case for $\mathrm{Na}_{2} \mathrm{O}$ where the relative difference between the mean measured and targeted concentrations was approximately $8 \%$. Further examination of this and the compositional data for the other glasses, however, indicates that the $\mathrm{Na}_{2} \mathrm{O}$ measurement values may be biased low since in almost all cases measured $\mathrm{Na}_{2} \mathrm{O}$ values were lower than targeted. The measured $\mathrm{SiO}_{2}$ concentrations were also consistently lower than the target values, although the difference (in means) was only approximately $2.6 \%$. A more detailed analysis of variance is planned for these "replicate" glasses.

An examination of the relative standard deviations for the major constituents of the four glasses represented in Table 4-5 indicates that there was good precision in the measured glass concentrations relative to the results from the LRM round-robin study (Ebert and Wolf 1999). That is, despite the fact that these batches were fabricated in separate batches in different laboratories, the relative standard deviations in the measured glass concentrations for these four glasses are generally lower than those from 
the LRM study. Considering the likely errors in the concentration measurements, it would be difficult to distinguish amongst these glasses based upon their measured compositions.

Table 4-5. Target Compositions (in mass \% of oxides) and Measured Compositions (in mass\% of oxides) for the Replicate Hanford LAW Product-Acceptance (HLP) "Center" Glasses $\left(\mathrm{Li}_{2} \mathrm{O}, \mathrm{Cl}, \mathrm{SO}_{3}\right.$, $\mathrm{P}_{2} \mathrm{O}_{5}, \mathrm{~F}, \mathrm{ReO}_{2}$, and $\mathrm{MoO}_{3}$, not included here, can be found in Table A-1)

\begin{tabular}{|c|c|c|c|c|c|c|c|c|c|c|c|c|c|c|}
\hline Glass ID & Description & $\mathrm{SiO}_{2}$ & $\mathrm{Al}_{2} \mathrm{O}_{3}$ & $\mathbf{B}_{2} \mathbf{O}_{3}$ & $\mathrm{Fe}_{2} \mathrm{O}_{3}$ & $\mathrm{TiO}_{2}$ & ZnO & $\mathrm{ZrO}_{2}$ & MgO & $\mathrm{Na}_{2} \mathrm{O}$ & $\mathrm{K}_{2} \mathrm{O}$ & $\mathrm{CaO}$ & $\mathrm{Cr}_{2} \mathrm{O}_{3}$ & $\mathrm{La}_{2} \mathrm{O}_{3}$ \\
\hline HLP-01 & Measured & 48.8 & 7.04 & 8.92 & 6.52 & 3.00 & 1.46 & 1.54 & 1.41 & 18.4 & 0.40 & 0.01 & 0.25 & 0.02 \\
\hline HLP-25 & Measured & 47.2 & 6.76 & 10.1 & 6.27 & 2.66 & 1.49 & 1.48 & 1.54 & 18.5 & 0.41 & 0.01 & 0.21 & 0.02 \\
\hline HLP-26 & Measured & 46.8 & 6.68 & 9.43 & 5.97 & 2.86 & 1.40 & 1.50 & 1.45 & 18.2 & 0.43 & $\mathrm{BD}$ & 0.21 & $\mathrm{BD}$ \\
\hline HLP-43 & Measured & 48.4 & 6.69 & 9.85 & 6.23 & 2.86 & 1.40 & 1.50 & 1.33 & 18.5 & 0.47 & 0.01 & 0.23 & $\mathrm{BD}$ \\
\hline Mean & Measured(M) & 47.8 & 6.79 & 9.58 & 6.25 & 2.84 & 1.44 & 1.50 & 1.43 & 18.4 & 0.43 & & 0.22 & \\
\hline Target & Center (C) & 49.07 & 7.00 & 10.00 & 5.50 & 3.00 & 1.50 & 1.50 & 1.50 & 20.00 & 0.41 & 0.01 & 0.08 & 0.00 \\
\hline Diff & $\Delta=\mathrm{C}-\mathrm{M}$ & 1.27 & 0.21 & 0.42 & -0.75 & 0.16 & 0.06 & 0 & 0.07 & 1.6 & -0.02 & 0.01 & -0.14 & \\
\hline $\operatorname{Diff}(\%)$ & $100 \%(\Delta / C)$ & 2.59 & 3.00 & 4.20 & -13.64 & 5.33 & 4.00 & 0 & 4.67 & 8.00 & -4.88 & & -175 & \\
\hline Std Dev & Measured & 0.82 & 0.15 & 0.45 & 0.20 & 0.12 & 0.04 & 0.02 & 0.08 & 0.12 & 0.03 & & 0.02 & \\
\hline Rel Std Dev (\%) & $\begin{array}{l}\text { Mean Measured } \\
\text { LRM }\end{array}$ & 1.7 & 2.2 & 4.7 & 3.2 & 4.2 & 2.8 & 1.3 & 5.3 & 0.65 & 6.3 & & 7.7 & \\
\hline \multicolumn{2}{|c|}{ Rel Std Dev (\%)(Ebert and Wolf 1999) } & 2.62 & 3.75 & 4.37 & 13.48 & 13.00 & $\mathrm{n} / \mathrm{a}$ & 6.99 & 9.00 & 6.07 & 33.04 & 15.93 & 11.58 & \\
\hline
\end{tabular}

$\mathrm{BD}$ - below detection limits

\subsubsection{Density}

Glass densities were measured in numerical order. The densities of repeated glasses are compared in Table 4-6. Figure 4-19 gives a comparison of the densities of repeated glasses with a twostandard-deviation range. The density of HLP-01 appears to be significantly above those of HLP-26 and HLP-43. The range of all other repeated glasses overlap.

Table 4-6. Density and Standard Deviation of Repeated Glasses in $\mathrm{g} / \mathrm{cm}^{3}$

\begin{tabular}{|c|c|}
\hline Glass & Density St.Dev. \\
\hline HLP-01 & $2.6493 \quad 0.0020$ \\
\hline HLP-25 & 2.6409 \\
\hline HLP-26 & 2.6418 \\
\hline HLP-43 & 2.6354 \\
\hline Min & 2.6354 \\
\hline $\max$ & 2.6493 \\
\hline St. Dev. & 0.0057 \\
\hline
\end{tabular}




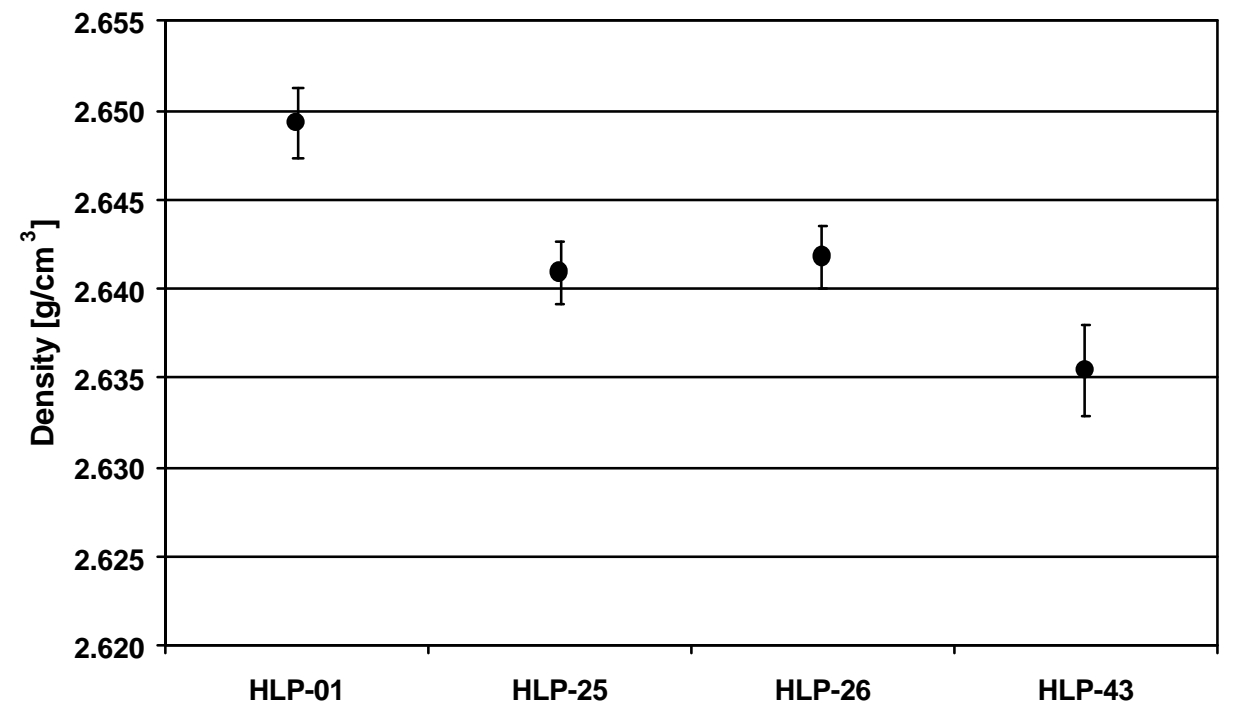

Figure 4-19. Density Range (2 standard deviations) for Repeated Glasses

\subsubsection{PCT}

Four of the HLP glasses (namely, HLP-01, -25, -26, and -43) were batched at either PNNL or SRTC to the same target composition. In each case, these glasses were only repeated in a very broad sense. HLP-25 was batched at SRTC, and the remaining three glasses (i.e., HLP-01, -26, and -43) were batched at PNNL. Both PCT-A (i.e., in triplicate for $165 \mathrm{~h}$ in stainless steel vessels) and PCT-B series (i.e., one per each glass at 10, 100, and $1000 \mathrm{~h}$ in Teflon ${ }^{\circledR}$ vessels) were conducted at SRTC for these glasses. Thus there were numerous effects (e.g., glass to glass, vessel type, etc.) that might have impacted the measured responses.

To simplify the analysis of such an unbalanced set of data (i.e., unbalanced in the sense of experimental design), the PCT-A results were initially examined as there is a wealth of information on the uncertainties involved with these tests. Furthermore, the possible impacts due to either vessel type (i.e., whether the system is "open" or "closed") or S/V can be assumed negligible for solely PCT-A. Because the differences among the boron and sodium concentrations for these four glasses are likely indistinguishable based upon Table 4-5, the PCT-A results for the four "replicate" glasses are illustrated in Figure 4-20. These results indicate significant differences in PCT responses from glass to glass (as evidenced by lack of overlap, differences in means, and Tukey-Kramer statistical comparisons ${ }^{\mathrm{a}}$ ) when the concentrations of boron and sodium expected in the test solutions are assumed to be the same. From a cursory examination of Figure 4-20, this effect appears to not be the result of laboratory-to-laboratory variations as the PCT responses for the single glass (i.e., HLP-25) batched at SRTC is well within the range of the responses for the three glasses (i.e., HLP-01, -26, and -43) batched at PNNL. (Note that the relative positions for the log-transformed boron and sodium concentrations from the four repeat glasses would be the same as those shown in Figure 4-20.) More data will be necessary to perform a more complete statistical examination of the components of variance for these glasses.

\footnotetext{
a JMP® Reference Guide: Statistics and Graphics Guide, Version 3.1. SAS Institute Inc., Cary, NC, USA.
} 

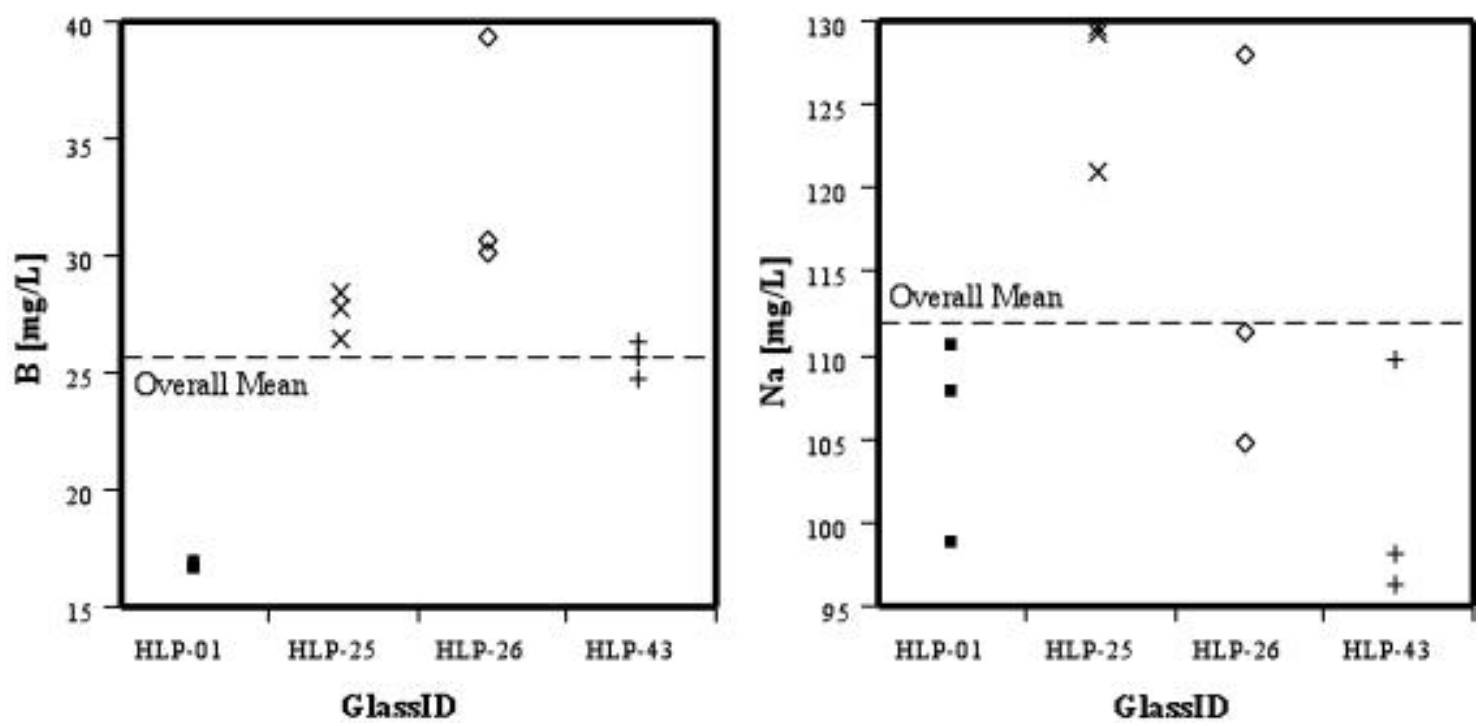

Figure 4-20. PCT-A Results for the Four HLP Glasses (i.e., HLP-01, -25, -26, and -43) Batched by PNNL and SRTC to the Same Target Composition. HLP-25 was fabricated at SRTC and the remaining three were prepared at PNNL. The dotted lines represent the overall means of the data.

However, even though the measured concentrations for $\mathrm{B}$ and $\mathrm{Na}$ for the four replicate glasses appear to be statistically indistinguishable; they do vary both from their corresponding targets and mean concentrations. However, as illustrated in Figure 4-21, accounting for these composition differences (by using normalizing releases) does not fully explain the differences noted previously. That is, there appear to be other differences between the PCT-A responses for these "replicate" glasses (indicated by lack of overlap, differences in means, and Tukey-Kramer comparisons) that cannot be explained by solely compositional differences. As expected, these same differences manifest themselves in the PCT-B data. Additional designed experiments can be performed to determine the probable sources of these differences.

The PCT-A data for the three glasses (i.e., HLP-01, -26, and -43) fabricated at PNNL can be examined to estimate glass-to-glass and within-glass (or residual) variance components. These are provided in Table 4-7. These results indicate that the variance structures for the boron and sodium data appear to be different for this very limited sample set. Also the residual errors for both the boron and sodium PCT-A data (i.e., 12.0 and $8.2 \%$, respectively) ${ }^{a}$ are somewhat larger than would be expected, based upon historical information for glasses measured by the same laboratory. (Note that the relative positions for the log-transformed $\mathrm{NL}_{\mathrm{B}}$ and $\mathrm{NL}_{\mathrm{Na}}$ values from the four repeat glasses would be the same as those shown in Figure 4-20.) Additional designed experiments can be performed to examine the cause of these larger than expected variance components.

\footnotetext{
${ }^{a}$ Note that these residual errors compare favorably to those (i.e., 17.5 and $8.7 \%$ for boron and sodium, respectively) presented in Section 3.5.3, which were necessary to describe the likely errors in corrosionrate estimates.
} 

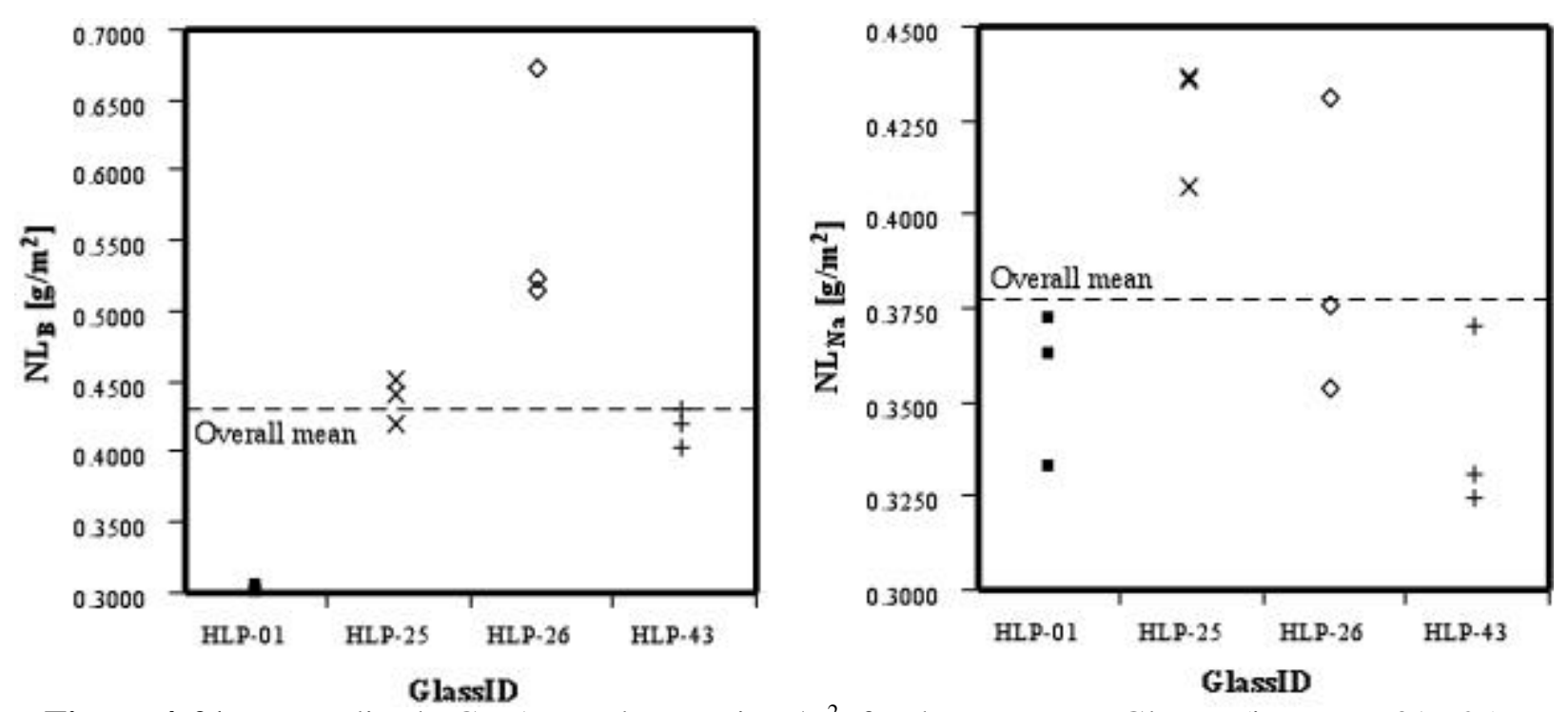

Figure 4-21. Normalized PCT-A Results, $\mathrm{NL}_{\mathrm{i}}$ in $\mathrm{g} / \mathrm{m}^{2}$, for the Four HLP Glasses (i.e., HLP-01, -25, -26 , and -43) Batched by PNNL and SRTC to the Same Target Composition. HLP-25 was fabricated by SRTC, and the remaining three were prepared by PNNL. The dotted line represents the overall mean of the data.

Table 4-7. PCT-A Variance Components Estimates for the PNNL "Replicate” Glasses

\begin{tabular}{cccccccrr}
\hline & & & \multicolumn{3}{c}{ Variance } & \multicolumn{3}{c}{ \% Rel. Standard Deviation } \\
& $\mathbf{N}$ & Mean & Glass & Residual & Total & Glass & Residual & Total \\
\hline $\mathrm{B}$ & 9 & 25.17 & 63.69 & 9.09 & 72.78 & 31.71 & 11.98 & 33.89 \\
$\mathrm{Na}$ & 9 & 107.15 & 19.73 & 77.72 & 97.45 & 4.15 & 8.23 & 9.21 \\
\hline
\end{tabular}

\subsubsection{VHT}

The rate measured by VHT is obtained from several samples tested at different times; therefore, measurements were not performed in a specific glass number order. However, an effort was made to stagger the testing of the repeated glasses. Table 4-8 lists the current VHT duration for repeated glasses, which ranges from 14 days for HLP-43 to 144 days for HLP-26. The measured rates for repeated glasses at $200^{\circ} \mathrm{C}$ and $300^{\circ} \mathrm{C}$ are compared in Table 4-8. Both sets of values are preliminary. As discussed in Section 3.6.2, the glasses with rates below 12 take very long to accurately measure and are currently uncertain. Figure 4-22 compares the $m_{d}$ of these glasses measured at $200^{\circ} \mathrm{C}$ as a function of time. Once the test enters the linear $m_{d}-t$, it is difficult to distinguish between the alteration of these glasses, despite the large difference in rates reported in Table 4-8. In addition, the time to fully corrode the repeated glass at $300^{\circ} \mathrm{C}$ is less than 2 days. For such short-term tests, the amount of time required for samples to heat up to test temperature and cool to room temperature after testing is thought to become a significant fraction of the total test time and introduces error in the measurement. Figure 4-23 compares the $m_{d}$ of these glasses measured at $300^{\circ} \mathrm{C}$ as a function of time. These glasses do not appear to have significant differences in their measured rates. 
Table 4-8. Comparison of Rates (in $\mathrm{g} / \mathrm{m}^{2} / \mathrm{d}$ ) and Test Durations for Repeated Glasses

\begin{tabular}{lccc}
\hline Glass ID & $\boldsymbol{r}$ at $\mathbf{3 0 0}^{\circ} \mathbf{C}$ & $\boldsymbol{r}$ at $\mathbf{2 0 0}^{\circ} \mathbf{C}$ & $\mathbf{2 0 0}^{\circ} \mathbf{C}$ Test Duration (days) \\
\hline HLP-01 & $505 \pm 80$ & $4.26 \pm 0.75$ & 117 \\
HLP-25 & $655 \pm 166$ & $5.7 \pm 0(2$ points) & 70 \\
HLP-26 & $686 \pm 94$ & $2.56 \pm 0.84$ & 144 \\
HLP-43 & id & id & 14 \\
\hline id = insufficient data & &
\end{tabular}

id = insufficient data

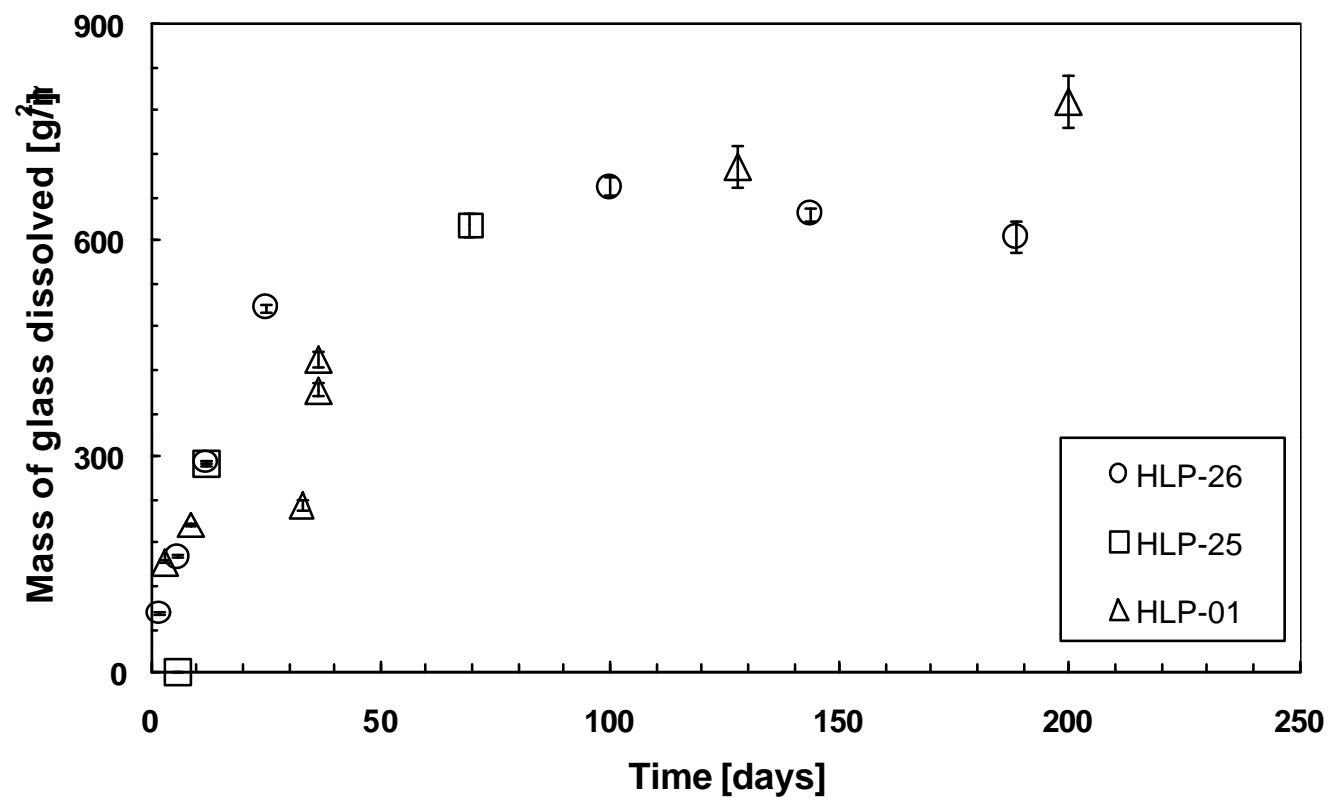

Figure 4-22. The $\mathrm{m}_{\mathrm{d}}$ as a Function of Time for Repeated Glasses at $200^{\circ} \mathrm{C}$ 


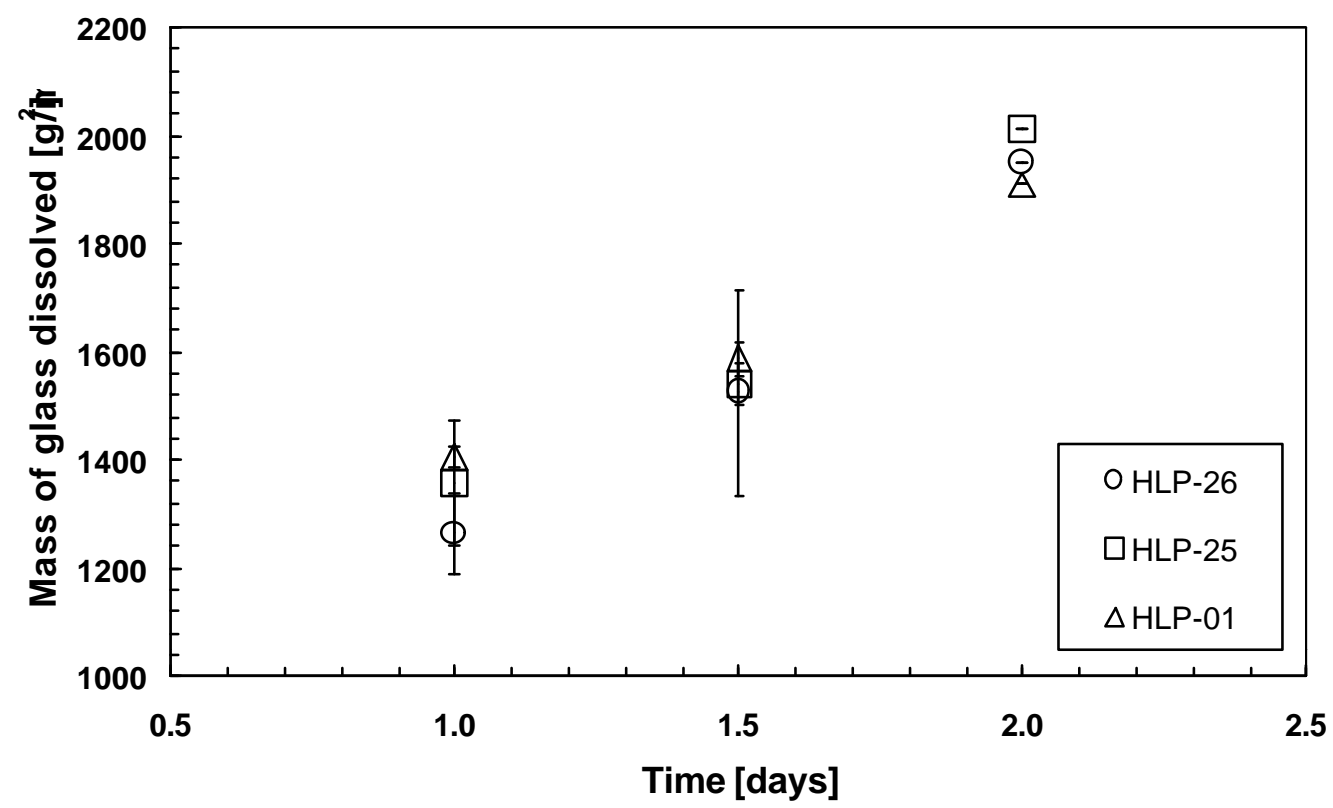

Figure 4-23. The $\mathrm{m}_{\mathrm{d}}$ as a Function of Time for Repeated Glasses at $300^{\circ} \mathrm{C}$ 


\subsection{Comparison Between Test Methods}

One of the goals of this task is to correlate the likely long-term durability of potential waste glasses, as measured with PCTs and VHTs, with the glass composition. Evaluation of the test results is in progress to identify correlations between the results of either PCTs or VHTs and the glass compositions. At this time, we can compare the PCT and VHT results directly to determine if the two data sets are correlated. The values of NL(B) and NL(Na) calculated from the results of PCT-B tests conducted at 20,000 m-1 for 10, 100, and 1000 hours and PCT-A tests conducted at $2000 \mathrm{~m}-1$ for 7 days with the suite of 56 glasses and the alteration rates determined from VHTs conducted at $200^{\circ} \mathrm{C}$ are summarized in Table 5-1. The logarithms of the values of NL(B) and NL(Na) for PCT-B tests conducted at 20,000 m-1 for and 1000 hours are plotted against the logarithms of the alteration rates that were determined from the VHTs in Figure 5-1. (Note that an average dissolution rate could be calculated for the PCTs by dividing NL(i) by 41.7 days (which is equivalent to 1000 hours) to directly compare rates. This would shift all the data equally and not affect the correlation.) No correlation is seen between the test results. This is probably because the alteration progress is much greater in the VHTs than in the PCTs. In the VHTs, alteration phases have formed that are believed to control the solution chemistry and the glass dissolution rate. Alteration phases have not yet formed in the PCTs conducted for 1000 hours. If PCTs are conducted for sufficiently long durations or at higher temperatures so that alteration phases form, we expect that those test results would be correlated with the VHT results. This is because the solution chemistry would be influenced by the same phases, although differences in test temperatures may result in differences in the phase assemblages.

Table 5-1. Summary of Results from PCT $\left(\mathrm{NL}_{\mathrm{i}}\right.$ in $\left.\mathrm{g} / \mathrm{m}^{2}\right)$ and VHT of Heat-Treated Glasses

\begin{tabular}{|c|c|c|c|c|c|c|c|c|c|c|}
\hline \multicolumn{2}{|c|}{ SampleID Description } & \multicolumn{2}{|c|}{ PCT-A } & \multicolumn{2}{|c|}{ 10-h PCT-B } & \multicolumn{2}{|c|}{ 100-h PCT-B } & \multicolumn{2}{|c|}{ 1000-h PCT-B } & \multirow{2}{*}{$\frac{200^{\circ} \mathrm{C} \text { VHT }}{r\left(\mathrm{~g} / \mathrm{m}^{2} / \mathrm{d}\right)}$} \\
\hline & & $\mathbf{N L}_{\mathbf{B}}$ & $\mathrm{NL}_{\mathrm{Na}}$ & $\mathbf{N L}_{\mathbf{B}}$ & $\mathrm{NL}_{\mathrm{Na}}$ & $\mathbf{N L}_{\mathbf{B}}$ & $\mathbf{N L}_{\mathrm{Na}}$ & $\mathbf{N L}_{\mathbf{B}}$ & $\mathbf{N L}_{\mathrm{Na}}$ & \\
\hline HLP-01 & Center & 0.27 & 0.36 & 0.04 & 0.05 & 0.16 & 0.14 & 0.37 & 0.28 & 4.3 \\
\hline HLP-02 & $\mathrm{L} \mathrm{Si}$ & 2.89 & 2.30 & 0.38 & 0.27 & 1.14 & 0.78 & 2.15 & 1.27 & 264.7 \\
\hline HLP-03 & $\mathrm{H} \mathrm{Si}$ & 0.29 & 0.32 & 0.03 & 0.05 & 0.14 & 0.13 & 0.31 & 0.22 & 1.0 \\
\hline HLP-04 & I Si & 1.95 & 1.18 & 0.14 & 0.01 & 0.77 & 0.49 & 1.56 & 0.90 & 18.3 \\
\hline HLP-05 & $\mathrm{L} A l$ & 1.28 & 0.85 & 0.09 & 0.09 & 1.36 & 0.85 & 3.09 & 1.74 & 2.5 \\
\hline HLP-06 & $\mathrm{H} \mathrm{Al}$ & 0.31 & 0.30 & 0.02 & 0.04 & 0.10 & 0.09 & 0.14 & 0.13 & 1.6 \\
\hline HLP-07 & $\mathrm{I} \mathrm{Al}$ & 0.31 & 0.32 & 0.03 & 0.05 & 0.12 & 0.11 & 0.25 & 0.20 & 13.8 \\
\hline HLP-08 & L B & 0.33 & 0.44 & 0.02 & 0.06 & 0.12 & 0.15 & 0.17 & 0.26 & 7.2 \\
\hline HLP-09 & H B & 0.51 & 0.47 & 0.04 & 0.05 & 0.24 & 0.16 & 0.81 & 0.45 & 0.9 \\
\hline HLP-10 & I B & 0.35 & 0.38 & 0.02 & 0.05 & 0.13 & 0.14 & 0.33 & 0.21 & 3.6 \\
\hline HLP-11 & $\mathrm{LFe}$ & 0.47 & 0.43 & 0.06 & 0.07 & 0.47 & 0.31 & 0.83 & 0.52 & 5.4 \\
\hline HLP-12 & $\mathrm{HFe}$ & 0.41 & 0.34 & 0.03 & 0.05 & 0.14 & 0.12 & 0.27 & 0.22 & 14.4 \\
\hline HLP-13 & I Fe & 0.46 & 0.44 & 0.03 & 0.06 & 0.23 & 0.18 & 0.50 & 0.33 & 1.3 \\
\hline HLP-14 & $\mathrm{L} \mathrm{Ti}$ & 0.72 & 0.56 & 0.05 & 0.07 & 0.39 & 0.27 & 0.72 & 0.41 & 13.2 \\
\hline HLP-15 & $\mathrm{H} \mathrm{Ti}$ & 0.35 & 0.36 & 0.02 & 0.05 & 0.13 & 0.14 & 0.27 & 0.21 & 1.1 \\
\hline HLP-16 & $\mathrm{L} \mathrm{Zn}$ & 0.37 & 0.37 & 0.04 & 0.06 & 0.20 & 0.16 & 0.39 & 0.28 & 1.4 \\
\hline HLP-17 & $\mathrm{H} \mathrm{Zn}$ & 0.45 & 0.42 & 0.03 & 0.05 & 0.18 & 0.16 & 0.39 & 0.25 & 9.6 \\
\hline HLP-18 & $\mathrm{L} \mathrm{Zr}$ & 0.52 & 0.47 & 0.04 & 0.06 & 0.24 & 0.19 & 0.53 & 0.33 & 16.1 \\
\hline HLP-19 & $\mathrm{H} \mathrm{Zr}$ & 0.28 & 0.30 & 0.02 & 0.04 & 0.11 & 0.11 & 0.20 & 0.17 & 0 \\
\hline
\end{tabular}




\begin{tabular}{|c|c|c|c|c|c|c|c|c|c|c|}
\hline \multicolumn{2}{|c|}{ SampleID Description } & \multicolumn{2}{|c|}{ PCT-A } & \multicolumn{2}{|c|}{ 10-h PCT-B } & \multicolumn{2}{|c|}{ 100-h PCT-B } & \multicolumn{2}{|c|}{ 1000-h PCT-B } & \multirow{2}{*}{$\begin{array}{c}200^{\circ} \mathrm{C} \text { VHT } \\
r\left(\mathrm{~g} / \mathrm{m}^{2} / \mathrm{d}\right) \\
\end{array}$} \\
\hline & & $\mathbf{N L}_{\mathbf{B}}$ & $\mathrm{NL}_{\mathrm{Na}}$ & $\mathbf{N L}_{\mathbf{B}}$ & $\mathbf{N L}_{\mathrm{Na}}$ & $\mathrm{NL}_{\mathrm{B}}$ & $\mathrm{NL}_{\mathrm{Na}}$ & $\mathbf{N L}_{\mathbf{B}}$ & $\mathrm{NL}_{\mathrm{Na}}$ & \\
\hline HLP-20 & $\mathrm{L} \mathrm{Mg}$ & 0.38 & 0.34 & 0.03 & 0.05 & 0.15 & 0.14 & 0.28 & 0.21 & 8.7 \\
\hline HLP-21 & $\mathrm{H} \mathrm{Mg}$ & 0.60 & 0.48 & 0.05 & 0.06 & 0.30 & 0.21 & 0.58 & 0.37 & 4 \\
\hline HLP-22 & $\mathrm{L} \mathrm{Na}$ & 0.25 & 0.24 & 0.01 & 0.03 & 0.10 & 0.08 & 0.20 & 0.13 & 1.5 \\
\hline HLP-23 & $\mathrm{H} \mathrm{Na}$ & 0.98 & 0.78 & 0.08 & 0.11 & 0.42 & 0.35 & 0.70 & 0.50 & 15.9 \\
\hline HLP-24 & $\mathrm{I} \mathrm{Na}$ & 0.34 & 0.36 & 0.02 & 0.04 & 0.14 & 0.12 & 0.30 & 0.20 & 3.1 \\
\hline HLP-25 & Center & 0.44 & 0.43 & 0.04 & 0.06 & 0.22 & 0.17 & 0.46 & 0.29 & 5.7 \\
\hline HLP-26 & Center & 0.53 & 0.38 & 0.04 & 0.06 & 0.21 & 0.16 & 0.41 & 0.29 & 0.6 \\
\hline HLP-27 & HHHH & 2.33 & 1.63 & 0.17 & 0.13 & 0.86 & 0.54 & 2.00 & 1.05 & 84.2 \\
\hline HLP-28 & HHHL & 0.27 & 0.21 & 0.02 & 0.03 & 0.10 & 0.07 & 0.21 & 0.11 & 1.7 \\
\hline HLP-29 & HHLH & 0.40 & 0.56 & 0.02 & 0.07 & 0.12 & 0.17 & 0.24 & 0.30 & 55.4 \\
\hline HLP-30 & HHLL & 0.16 & 0.24 & 0.00 & 0.03 & 0.05 & 0.06 & 0.11 & 0.10 & 11.5 \\
\hline HLP-31 & HLHH & 6.71 & 4.79 & 0.44 & 0.30 & 1.60 & 1.07 & 2.84 & 1.81 & 78.3 \\
\hline HLP-32 & HLHL & 0.48 & 0.35 & 0.04 & 0.04 & 0.23 & 0.14 & 0.61 & 0.28 & 4.5 \\
\hline HLP-33 & HLLH & 1.96 & 1.65 & 0.07 & 0.12 & 1.68 & 1.12 & 6.31 & 3.53 & 18.2 \\
\hline HLP-34 & HLLL & 0.38 & 0.36 & 0.01 & 0.04 & 0.14 & 0.11 & 0.29 & 0.17 & id \\
\hline HLP-35 & LHHH & 1.35 & 1.02 & 0.08 & 0.08 & 0.60 & 0.36 & 1.19 & 0.74 & 17.8 \\
\hline HLP-36 & LHHL & 0.43 & 0.34 & 0.03 & 0.04 & 0.19 & 0.12 & 0.73 & 0.39 & 13.5 \\
\hline HLP-37 & LHLH & 1.29 & 1.15 & 0.02 & 0.08 & 0.40 & 0.28 & - & - & 10.7 \\
\hline HLP-38 & LHLL & 0.40 & 0.36 & 0.02 & 0.05 & 0.12 & 0.10 & 0.19 & 0.18 & 6.7 \\
\hline HLP-39 & LLHH & 2.28 & 1.47 & 0.27 & 0.21 & 2.08 & 1.20 & 2.53 & 1.56 & id \\
\hline HLP-40 & LLHL & 0.90 & 0.69 & 0.06 & 0.07 & 0.81 & 0.46 & 1.58 & 0.93 & 1 \\
\hline HLP-41 & LLLH & 6.63 & 4.46 & 0.21 & 0.21 & 3.10 & 1.59 & 4.16 & 2.28 & 14.1 \\
\hline HLP-42 & LLLL & 0.68 & 0.54 & 0.03 & 0.06 & 0.56 & 0.33 & 3.73 & 2.11 & 0.2 \\
\hline HLP-43 & Center & 0.41 & 0.34 & 0.04 & 0.05 & 0.27 & 0.20 & 0.47 & 0.28 & id \\
\hline HLP-44 & reduced & 0.46 & 0.41 & 0.04 & 0.05 & 0.02 & 0.12 & 0.38 & 0.31 & id \\
\hline HLP-45 & reduced & 0.42 & 0.38 & 0.04 & 0.05 & 0.02 & 0.13 & 0.32 & 0.32 & id \\
\hline HLP-46 & LD6-5412 & 0.05 & 0.50 & 0.02 & 0.00 & 0.10 & 0.26 & 0.30 & 0.43 & 254.6 \\
\hline HLP-47 & LRM-1 & 0.53 & 0.53 & 0.06 & 0.08 & 0.32 & 0.26 & 0.92 & 0.61 & 36.4 \\
\hline HLP-48 & LAW-A33 & 0.61 & 0.52 & 0.06 & 0.06 & 0.30 & 0.20 & 0.65 & 0.45 & 50.5 \\
\hline HLP-49 & LAW-B & 0.30 & 0.28 & 0.03 & 0.04 & 0.11 & 0.09 & 0.15 & 0.15 & 0.6 \\
\hline HLP-51 & LAW-ABP1 & 0.34 & 0.38 & 0.04 & 0.06 & 0.04 & 0.13 & 0.33 & 0.32 & 4.4 \\
\hline HLP-52 & HAN-28 & - & 5.65 & - & 0.02 & - & 2.24 & - & 7.21 & 1219.4 \\
\hline HLP-53 & LAW-A23 & - & - & - & - & - & - & - & - & 552.6 \\
\hline HLP-54 & L4-912 & 0.46 & 0.48 & 0.02 & 0.08 & 0.12 & 0.12 & 0.25 & 0.20 & 57 \\
\hline HLP-55 & L4-99 & 0.16 & 0.28 & 0.07 & 0.09 & 0.30 & 0.21 & 0.70 & 0.48 & 24.7 \\
\hline
\end{tabular}




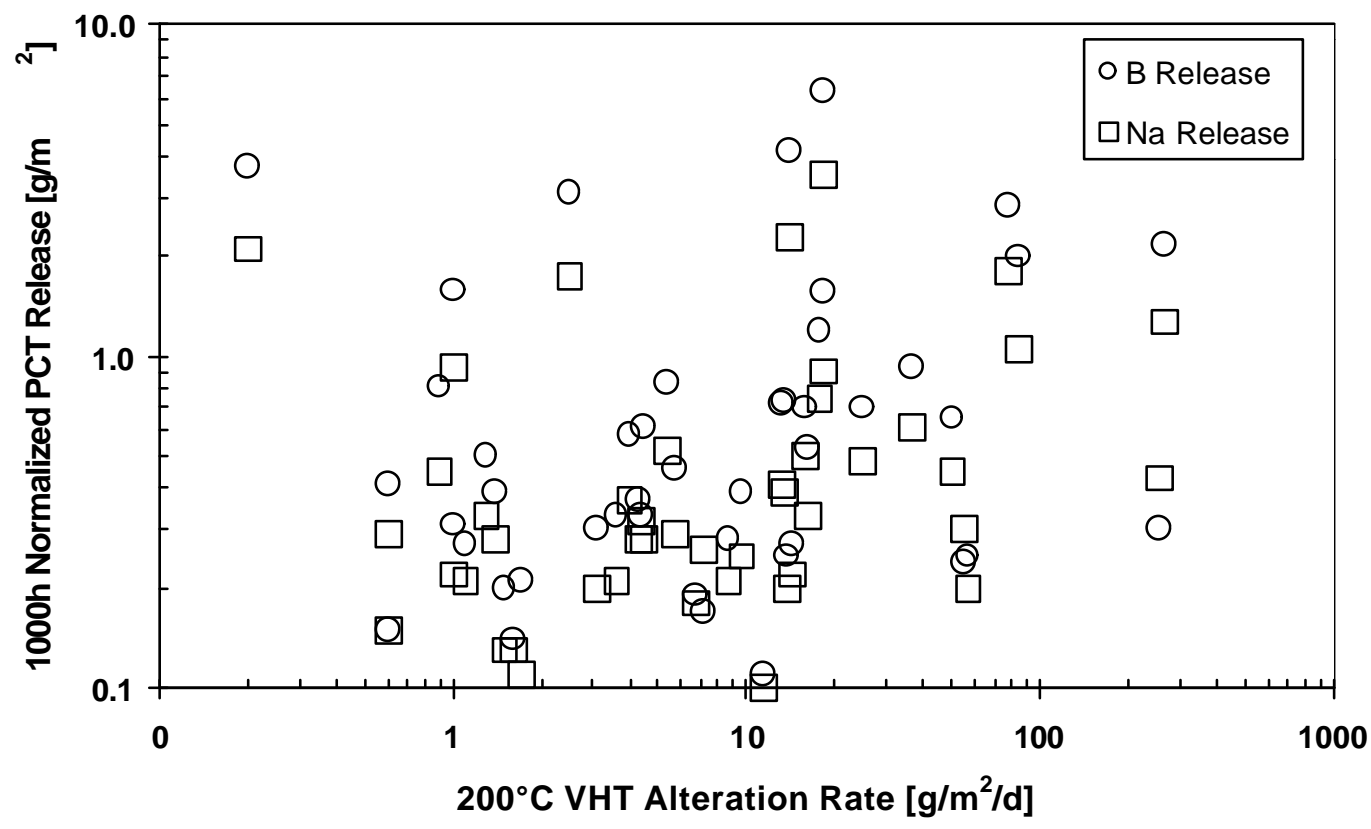

Figure 5-1. Comparison of 1000-h PCT Release to $200^{\circ} \mathrm{C}$ VHT Alteration Rate 


\subsection{Conclusions and Recommendations}

A voluminous database of corrosion characteristics is being developed on a systematically designed matrix of simulated LAW glasses. The data are being generated with two types of corrosion tests: the PCT and the VHT. Data from triplicate PCT-A performed in stainless steel at a temperature of $90^{\circ} \mathrm{C}$ and an S/V of $2000 \mathrm{~m}^{-1}$ have been completed. Data from the PCT-B were generated for times of 10 , 100 , and $1000 \mathrm{~h}$ performed in Teflon ${ }^{\circledR}$ at a temperature of $90^{\circ} \mathrm{C}$ and an $\mathrm{S} / \mathrm{V}$ of $20000 \mathrm{~m}^{-1}$. The shortterm PCT-B releases for many of the test matrix glasses appear to follow a power-law function. That is to say that no significant rate increase was detected in any of the matrix glasses for times up to $1000 \mathrm{~h}$. The ordering of glasses by PCT-B release data appears to be similar for times up to $1000 \mathrm{~h}$.

The normalized PCT releases for the 1000-h tests range from 0.1 to $6.3 \mathrm{~g} / \mathrm{m}^{2}$ for boron and from 0.1 to $7.2 \mathrm{~g} / \mathrm{m}^{2}$ for sodium. Based upon the boron releases, the estimated release rates for these glasses range up to 1.0 and $0.1 \mathrm{~g} / \mathrm{m}^{2} / \mathrm{d}$ for periods of 1 and $1000 \mathrm{~h}$, respectively. The glasses with the highest boron release rates were HLP-31, -02, -39, -41, and -27 at $10 \mathrm{~h}$ and HLP-51, $-41,-33$, and -39 , and -31 at $1000 \mathrm{~h}$. For the sodium data, the release rates range up to 0.7 and $0.2 \mathrm{~g} / \mathrm{m}^{2} / \mathrm{d}$ for periods of 1 and $1000 \mathrm{~h}$, respectively. The glasses with the highest sodium release rates were HLP-31, -02, -41, -39, and -27 at $1 \mathrm{~h}$ and HLP-52, -33, -41, -42, and -31 at $1000 \mathrm{~h}$. Insufficient information concerning the alteration products formed during PCT was available to make a comparison to the VHT or other data.

The VHT are still in progress. Preliminary rates have been determined for most glasses at $200^{\circ} \mathrm{C}$. These rates range from 0.0 to $1219 \mathrm{~g} / \mathrm{m}^{2} / \mathrm{d}$ and cover at least three orders of magnitude. The glasses are grouped into three categories based on their VHT rates at $200^{\circ} \mathrm{C}$.

1. Glasses with low resistance to VHT - rates between 14 and $1219 \mathrm{~g} / \mathrm{m}^{2} / \mathrm{d}$. For these glasses, we have good estimates of rate since the samples in this group are completely dissolved in roughly 100 days or less. This group contains 18 glasses, listed in Table 3-12.

2. Glasses with medium resistance to VHT - rates between 6 and $14 \mathrm{~g} / \mathrm{m}^{2} / \mathrm{d}$. For these glasses, we have poor estimates of rate. The ranking of glasses within this category is likely to change; however, these glasses are clearly more resistant to VHT than glasses in Group 1 and less resistant to VHT than glasses in Group 3. This group has 9 glasses.

3. Glasses with high resistance to VHT - rates between 0 and $6 \mathrm{~g} / \mathrm{m}^{2} / \mathrm{d}$. For these glasses, we have poor estimates of rate. The ranking of glasses within this category is likely to change; however, these glasses are clearly more resistant to VHT than glasses in Groups 1 and 2. This group contains 22 glasses.

Many alteration products were found to form on the matrix glasses during VHT. Analcime, sodium aluminum silicate hydrate, and sodium aluminum silicate boron hydroxide hydrate were the three most common major phases identified.

The effect of temperature on VHT response was investigated for selected glasses. The rate of alteration for HLP-46, -48, and -51 was found to follow the Arrhenius model with $E_{a}$ values ranging from $87 \mathrm{~kJ} / \mathrm{mol}$ to $98 \mathrm{~kJ} / \mathrm{mol}$. The assemblage of alteration phases was the same; however, the relative amount varied with temperature.

Little correlation was found between the release rates as measured by PCT and the alteration rates measured by VHT. This was expected since the stage of dissolution probed by VHT is much later than could be achieved with $\mathrm{PCT}$ at $90^{\circ} \mathrm{C}$ in $1000 \mathrm{~h}$. The results from the two tests are expected to become more comparable once the corrosion extent in PCT is sufficiently advanced. 
These data have led to three recommendations for future studies:

1. Data collection should continue on this program. The VHT rate should be determined for all matrix glasses at $200^{\circ} \mathrm{C}$. The VHT rate should be determined at a number of temperatures ranging from $90^{\circ} \mathrm{C}$ to $300^{\circ} \mathrm{C}$ for selected glasses. The major alteration products formed on VHT samples should be identified. The PCT should be completed for matrix glasses with times up to $10,000 \mathrm{~h}$. The alteration products formed on selected PCT samples should be identified and compared with those formed during VHT.

2. The PCT should be further accelerated by increasing test temperature. This will allow the similar reaction extents observed in VHT during similar time frames and potentially provide a link to lower temperature PCT data.

3. Further studies should be performed to determine the corrosion mechanisms that determine alteration rates by VHT and how they are impacted by temperature. The procedure for VHT should be further optimized and standardized.

4. The effect of composition on corrosion rate should be determined and modeled. It has been speculated that the glass stability with respect to conversion into key alteration products determines its long-term performance (McGrail et al. 1999). This data set, when sufficiently complete, can be used to test this theory. The impact of composition on the shorter-term PCT (up to $1000 \mathrm{~h}$ ) can be assessed immediately. The impact of composition on the VHT and longer-term PCT (> $1000 \mathrm{~h}$ ) can only be assessed once sufficient data are available. 


\subsection{References}

Abraitis, P. K., D. J. Vaugham, F. R. Livens, J. Monteith, D. P. Tivedi, and J. S. Small. 1998. "Dissolution of a Complex Borosilicate Glass at $60^{\circ} \mathrm{C}$ : The Influence of $\mathrm{pH}$ and Proton Adsorption on the Congruence of Short-term Leaching." In Material Research Society Symposium Proceedings Vol. 506, pp 47-54.

Baillie, W. L. 1921. "The Relation Between Density and the Composition of Glasses," J. Soc. Chem. Ind., 40 pp 141-148.

Cullity, B. D. 1978. Elements of X-Ray Diffraction, Addison-Wesley Pub., New York.

Ebert, W. L. and S. F. Wolf. 1999. Round-Robin Testing of a Reference Glass for Low-Activity Waste Forms, ANL-99/22, Argonne National Laboratory, Argonne, Illinois.

Feng, X., P.R. Hrma, J.H. Westsik, M.J. Schweiger, H. Li, J.D. Vienna, G. Chen, G.F. Piepel, D.K. Peeler, D.E. Smith, B.P. McGrail, S.E. Palmer, D. Kim, Y. Peng, W.K. Hahn, A.J. Bakel, and W.L. Ebert. 1996. Glass Optimization for Vitrification of Hanford Site Low-Level Tank Waste. PNNL-10918, Pacific Northwest National Laboratory, Richland, Washington.

Ferrara, D. M., C. L. Crawford, B. C. Ha, and N. E. Bibler. 1998. "Vitrification of Three LowActivity Radioactive Waste Streams From Hanford," Proceedings of the International Conference on Decommissioning and Decontamination and on Nuclear and Hazardous Waste Management, p. 706-713, ANS, La Grange, Illinois.

Hrma, P. R., G. F. Piepel, M. J. Schweiger, D. E. Smith, D. S. Kim, P. E. Redgate, J. D. Vienna, C. A. LoPresti, D. B. Simpson, D. K. Peeler, and M. H. Langowski. 1994.

Property/Composition Relationships for Hanford High-Level Waste Glasses Melting at $1150^{\circ} \mathrm{C}$, Volumes 1 and 2. PNL-10359, Pacific Northwest Laboratory, Richland, Washington.

Jercinovic, M.J., and R.C. Ewing. 1992. "Corrosion of Geological and Archeological Glasses." In Corrosion of Glass, Ceramics, and Ceramic Superconductors, eds. D.E. Clark and B. K. Zoitos. Noyes Publishing, Park Ridge, New Jersey.

Kim, D. S., P. Hrma, S. E. Palmer, D. E. Smith, and M. J. Schweiger. 1995. "Effect of $\mathrm{B}_{2} \mathrm{O}_{3}$, $\mathrm{CaO}$, and $\mathrm{Al}_{2} \mathrm{O}_{3}$ on the Chemical Durability of Silicate Glasses for Hanford Low-Level Waste Glass Immobilization," Ceram. Trans., 61, 531-538, American Ceramic Society, Westerville, Ohio.

Lasaga, A. C. 1995. "Fundamental Approaches in Describing Mineral Dissolution and Precipitation Rates." In Chemical Weathering Rates of Silicate Minerals,Vol. 31, eds. A.F. White and S.L. Bratley. Mineralogical Society of America pp. 22-86.

Leturcq G., G. Berger, T. Advocat, C. Fillet, O. Halgand, and E. Vernaz. 1998. "Chemical Durability of Aluminosilicate Glasses Containing Low Solubility Chemical Elements." Mat. Res. Soc. Symp. Proc. vol. 506, pp 199-214, Pittsburgh, Pennsylvania.

Lutze, W. and R. C. Ewing. 1988. Radioactive Waste Forms for the Future. North Holland, Amsterdam. 
Mann, F. M., R. J. Puish, P. D. Rittman, A. H. Lu, G. F. Williamson, N. R. Brown, P. E. LaMont, N. W. Kline, J. A. Voogd, Y. Chen, C. R. Eiholzer, C. T. Kincaid, and B. P. McGrail. 1998.

Hanford Immobilized Low-Activity Tank Waste Performance Assessment, DOE/RL-97-69, U.S. Department of Energy, Richland, Washington.

Mazer, J. J. 1991. Temperature Effects on Waste Glass Performance, ANL-91/17. Argonne National Laboratory, Argonne, Illinois.

McGrail, B. P., W. L. Ebert, A. J. Bakel, and D. K. Peeler. 1997a. "Measurement of Kinetic Rate Law Parameters on a Na-Ca-Al Borosilicate Glass for Low-Activity Waste," Journal of Nuclear Materials Vol. 249, p. 175-189.

McGrail, B. P., C. W. Lindenmeier, P. F. Martin, and G. W. Gee. 1997b. "The Pressurized Unsaturated Flow (PUF) Test: A New Method for Engineered-Barrier Materials Evaluation," Ceramic Transactions vol. 72, p. 317-329.

McGrail, B. P., W. L. Ebert, D. H. Bacon, and D. M. Strachan. 1998. A Strategy to Conduct an Analysis of the Long-Term Performance of Low-Activity Waste Glass in a Shallow Subsurface Disposal System at Hanford, PNNL-11834, Pacific Northwest National Laboratory, Richland, Washington.

McGrail, B. P., J. P. Icenhower, D. H. Bacon, J. D. Vienna, A. Jiricka, W. L. Ebert, P. F. Martin, H. T. Schaef, M. J. O'Hara, and E. A. Rodriguez. 1999. Waste Form Release Data Package for the 2001 Immobilized Low-Activity Waste Performance Assessment, PNNL-13043, Rev. 1, Pacific Northwest National Laboratory, Richland, Washington.

Scholes, S. R. 1975. Modern Glass Practice, CBI Publishing Co., Boston, Massachusetts.

Tri-Party Agreement, Washington State Department of Ecology, U.S. Environmental Protection Agency, and U.S. Department of Energy. 1994. Hanford Federal Facility Agreement and Consent Order, 89-10, Rev. 3, Fourth Amendment, Olympia, Washington.

Vienna, J. D., D. K. Peeler, and B. P. McGrail. 1999. Hanford Immobilized Low-Activity Waste Product Acceptance Test Plan (U), SRTC-RP-99-00288, Westinghouse Savannah River Company, Aiken, South Carolina.

Westsik, J. H., Jr. and R. D. Peters. 1981. "Time and Temperature Dependence of the Leaching of a Simulated High-Level Waste Glass," in Scientific Basis for Nuclear Waste Management, Vol. 3, Plenum Press, New York.

Winkelmann, A., and O. Schott. 1894. "Uber thermische Widerstandskoeffizienten verrschiedener Glaser in ihrer Abhangigkeit von chemischen Zusammensetzung," Ann. Physik, 51, pp. 730-746.

Wolf, S. F., W. L. Ebert, J. S. Luo, and D. M. Strachan. 1998. A Data Base and Standard Material for Use in Acceptance Testing of Low-Activity Waste Products, ANL-98/9, Argonne National Laboratory, Argonne, Illinois. 


\section{APPENDIX A \\ Target and Measured Composition Information for the HLP Glasses}


Table A-1. Target Compositions (in mass\% of oxides) and Measured Compositions (in mass\% of oxides) for the HLP Glasses

\begin{tabular}{|c|c|c|c|c|c|c|c|c|c|c|c|c|c|c|c|c|c|c|c|c|c|c|}
\hline & & $\mathrm{SiO}_{2}$ & $\mathbf{A l}_{2} \mathbf{O}_{3}$ & $\mathbf{B}_{2} \mathbf{O}_{3}$ & $\mathrm{Fe}_{2} \mathrm{O}_{3}$ & $\mathrm{TiO}_{2}$ & $\mathrm{ZnO}$ & $\mathrm{ZrO}$ & MgO & $\mathbf{L i}_{2} \mathbf{O}$ & $\mathrm{Na}_{2} \mathrm{O}$ & $\mathrm{K}_{\mathbf{2}} \mathrm{C}$ & $\mathrm{CaO}$ & $\mathrm{Cl}$ & $\mathrm{SO}_{3}$ & $\mathbf{P}_{2} \mathrm{O}_{5}$ & $\mathrm{Cr}_{2} \mathrm{O}_{3}$ & & $\mathbf{R e O}_{2}$ & $\mathrm{MoO}_{3}$ & $\mathrm{La}_{2} \mathrm{O}_{3}$ & Total \\
\hline \multirow[t]{2}{*}{ HLP-01 } & Center & 49.07 & 7.00 & 10.00 & 5.50 & 3.00 & 1.50 & 1.50 & 1.50 & 0.00 & 20.00 & & 0.01 & & 0.07 & 0.06 & & & 0.01 & & 0.00 & 100.00 \\
\hline & Measur & & & & & 3.00 & 1.46 & 1.54 & .41 & $\mathrm{BD}$ & & 0.40 & 0.01 & & & & 0.25 & & & & & \\
\hline \multirow[t]{2}{*}{ HLP-02 } & & & & & & & & & & 0.00 & & & & & & & & & & & & \\
\hline & & & & & .63 & 3.86 & .88 & 1.88 & .81 & $\mathrm{BD}$ & 25.80 & 0.59 & BD & & & & 0.22 & & & & & 99.22 \\
\hline \multirow[t]{2}{*}{ HLP-03 } & H Si & & & & & & & 1.41 & & 0.00 & & & 0.01 & & 0.07 & & & & 0.01 & & & \\
\hline & Meas & & .08 & 9.09 & 06 & 2.89 & 1.43 & 1.36 & .36 & $\mathrm{BD}$ & 7.90 & 0.41 & $\mathrm{BD}$ & & & & 0.19 & & & & & 99.27 \\
\hline \multirow[t]{2}{*}{ HLP-04 } & I Si & & 8.24 & 11.78 & .48 & 3.53 & 1.77 & 1.77 & .77 & 0.00 & 23.57 & & 0.01 & 0.33 & 0.09 & 0.07 & 0.09 & 0.01 & 0.01 & 0.00 & 0.00 & 100.01 \\
\hline & & & & & 7.72 & 3.56 & 1.74 & 1.74 & .68 & $\mathrm{BD}$ & 22.20 & 0.52 & $\mathrm{BD}$ & & & & 0.24 & & & & & 100.94 \\
\hline \multirow[t]{2}{*}{ HLP-05 } & $\mathrm{L} \mathrm{Al}$ & & 4.00 & 10.32 & 5.68 & 3.09 & 1.55 & 1.55 & .55 & 0.00 & 20.65 & & 0.01 & 0.29 & 0.08 & 0.06 & 0.08 & 0.01 & 0.01 & 0.00 & 0.00 & 100.01 \\
\hline & Meas & .30 & 4.24 & 10.30 & 6.80 & 3.17 & 1.56 & 1.45 & 1.45 & $\mathrm{BD}$ & 20.30 & 0.50 & BD & & & & 0.27 & & & & $\mathrm{BD}$ & 97.34 \\
\hline \multirow[t]{2}{*}{ HLP-06 } & & & 11.94 & & & & 1.42 & 1.42 & & 0.00 & & & 0.01 & 0.26 & 0.07 & 0.05 & & 0.01 & 0.01 & 0.00 & & \\
\hline & Mea & & 12.30 & 8.89 & 96 & .94 & 1.42 & 1.35 & .34 & $\mathrm{BD}$ & 19.10 & 0.42 & $\mathrm{BD}$ & & & & 0.14 & & & & $\mathrm{BD}$ & 98.46 \\
\hline \multirow[t]{2}{*}{ HLP-07 } & I Al & & & & & 93 & .47 & 1.47 & 47 & 0.00 & & 0 . & 0.01 & 0.27 & 0.07 & 0.05 & 0.07 & 0.01 & 0.01 & 0.00 & & \\
\hline & & & & & & & & 55 & & BD & & 0.43 & $\mathrm{BD}$ & & & & & & & & & .51 \\
\hline \multirow[t]{2}{*}{ HLP-08 } & & & & & & & & & & & & & & 0.29 & 0.08 & & & & & & & \\
\hline & Mea & & .06 & & 84 & .04 & 1.46 & 1.44 & .31 & $\mathrm{BD}$ & & 0.56 & $\mathrm{BD}$ & & & & 0.19 & & & & & \\
\hline \multirow[t]{2}{*}{ HLP-09 } & H B & & & & & & & 1.4 & & 0.00 & & & 0.01 & & 0.07 & & & & 0.01 & 0.00 & & \\
\hline & Mea & & & & 40 & 87 & .51 & 1.22 & 29 & $\mathrm{BD}$ & & 0.41 & $\mathrm{BD}$ & & & & & & & & & \\
\hline \multirow[t]{2}{*}{ HLP-10 } & I B & & & & & 3.06 & 1.53 & 1.53 & 53 & 0.00 & 20 & 0. & 0.01 & 0.28 & 0.07 & 0.06 & 8 & 0.01 & 0.01 & 0.00 & 0 & 99.98 \\
\hline & & & & & & 09 & 49 & (55 & 36 & $\mathrm{BD}$ & & 48 & $\mathrm{BD}$ & & & & & & & & & 79 \\
\hline \multirow[t]{2}{*}{ HLP-11 } & $\mathrm{L} \mathrm{I}$ & & & & & 17 & 59 & 1.59 & & 0.00 & & & 0.01 & 0.29 & 0.08 & 0.06 & 0.08 & 0.01 & 0.01 & 0.00 & & 100.01 \\
\hline & & & & & & & & 1.38 & & $\mathrm{BD}$ & & & BD & & & & & & & & & \\
\hline \multirow[t]{2}{*}{ HLP-12 } & & & & & 00 & 89 & .44 & 1.44 & 44 & 0.00 & & & 0.01 & 0.27 & 0.07 & 0.05 & & 0.01 & 0.01 & 0.00 & & \\
\hline & & & & & & & 1. & 1.3 & & $\mathrm{BD}$ & & & 0. & & & & & & & & & 15 \\
\hline \multirow[t]{2}{*}{ HLP-13 } & I Fe & & 18 & & 3.00 & 3.08 & 1.54 & 1.54 & 54 & 0.00 & & 0.42 & 0.01 & 0.28 & 0.08 & 0.06 & 0.08 & 0.01 & 0.01 & 0.00 & .00 & 0.00 \\
\hline & & & & & & & & & & & & & 0. & & & & & & & & & \\
\hline \multirow[t]{2}{*}{ HLP-14 } & & & & & & & & 1.55 & & 0.00 & & & & 0.29 & 0.08 & 0.06 & & 0.01 & 0.01 & 0.00 & & \\
\hline & & & & & & $\mathrm{BD}$ & 1.55 & 1.43 & & $\mathrm{BD}$ & & 0.45 & 0.06 & & & & & & & & & \\
\hline \multirow[t]{2}{*}{ HLP-15 } & & & & & & & & 1.4 & & 0.00 & & & 0.01 & 0.27 & 0.07 & 0.05 & & 0.01 & 0.01 & 0.00 & & \\
\hline & & & & & & 5.91 & 1.51 & 1.06 & 1.54 & $\mathrm{BD}$ & & 0.38 & 0.07 & & & & & & & & & 100.06 \\
\hline \multirow[t]{2}{*}{ HLP-16 } & $\mathrm{L} \mathrm{Zn}$ & & & & & 3.04 & 0.00 & 1.52 & & 0.00 & & 0.42 & 0.01 & 0.28 & 0.07 & 0.06 & 0.08 & 0.01 & 0.01 & 0.00 & & \\
\hline & $\mathrm{Me}$ & & 6.79 & & 6.84 & 3.18 & $\mathrm{BD}$ & 1.30 & 1.61 & $\mathrm{BD}$ & 19.00 & 0.41 & 0.08 & & & & 0.26 & & & & & 102.87 \\
\hline \multirow[t]{2}{*}{ HLP-17 } & $\mathrm{HZn}$ & & & & & 2.92 & 4.00 & 1.46 & 1.46 & 0.00 & & 0.40 & 0.01 & 0.27 & 0.07 & 0.05 & 0.07 & 0.01 & 0.01 & 0.00 & 0 . & \\
\hline & Meast & & & & 6.36 & 3.00 & 3.96 & 1.30 & 1.53 & BD & & 0.36 & BD & & & & 0.23 & & & & 0.05 & 100.19 \\
\hline \multirow[t]{2}{*}{ HLP-18 } & $\mathrm{L} \mathrm{Zr}$ & & 7.10 & 10.15 & 5.59 & 3.04 & 1.52 & 0.00 & 1.52 & 0.00 & 20.31 & 0.42 & 0.01 & 0.28 & 0.07 & 0.06 & 0.08 & 0.01 & 0.01 & 0.00 & 0.00 & 99.99 \\
\hline & & & & & & & 1.54 & $\mathrm{BD}$ & & & & & $\mathrm{BD}$ & & & & & & & & & \\
\hline HLP-19 & $\mathrm{H} \mathrm{Zr}$ & 46.83 & 6.68 & 9.55 & 5.25 & 2.86 & 1.43 & 6.00 & 1.43 & 0.00 & 19.09 & 0.39 & 0.01 & 0.26 & 0.07 & 0.05 & 0.07 & 0.01 & 0.01 & 0.00 & 0.00 & 99.99 \\
\hline & Measured & 48.20 & 6.94 & 9.63 & 6.40 & 2.98 & 1.50 & 5.64 & 1.47 & $\mathrm{BD}$ & 17.80 & 0.43 & $\mathrm{BD}$ & & & & 0.25 & & & & $\mathrm{BD}$ & 101.24 \\
\hline
\end{tabular}




\begin{tabular}{|c|c|c|c|c|c|c|c|c|c|c|c|c|c|c|c|c|c|c|c|c|c|c|}
\hline Glass ID & Description $^{(a)}$ & $\mathrm{SiO}_{2}$ & $\mathbf{A l}_{2} \mathbf{O}_{3}$ & $\mathbf{B}_{2} \mathbf{O}_{3}$ & $\mathrm{Fe}_{2} \mathrm{O}_{3}$ & $\mathrm{TiO}_{2}$ & $\mathrm{ZnO}$ & $\mathrm{ZrO}_{2}$ & $\mathrm{MgO}$ & $\mathbf{L i}_{2} \mathbf{O}$ & $\mathrm{Na}_{2} \mathrm{O}$ & $\mathbf{K}_{2} \mathbf{O}$ & $\mathrm{CaO}$ & $\mathrm{Cl}^{-}$ & $\mathrm{SO}_{3}$ & $\mathbf{P}_{2} \mathbf{O}_{5}$ & $\mathrm{Cr}_{2} \mathrm{O}_{3}$ & F & $\mathrm{ReO}_{2}$ & $\mathrm{MoO}_{3}$ & $\mathrm{La}_{2} \mathrm{O}_{3}$ & Total \\
\hline \multirow[t]{2}{*}{ HLP-20 } & $\mathrm{L} \mathrm{Mg}$ & 49.82 & 7.10 & 10.15 & 5.59 & 3.04 & 1.52 & 1.52 & 0.00 & 0.00 & 20.31 & 0.42 & 0.01 & 0.28 & 0.07 & 0.06 & 0.08 & 0.01 & 0.01 & 0.00 & 0.00 & 99.99 \\
\hline & Measured & 49.30 & 7.19 & 10.10 & 6.26 & 3.20 & 1.60 & 1.51 & $\mathrm{BD}$ & $\mathrm{BD}$ & 19.30 & 0.40 & $\mathrm{BD}$ & & & & 0.26 & & & & $\mathrm{BD}$ & 99.12 \\
\hline \multirow[t]{2}{*}{ HLP-21 } & $\mathrm{H} \mathrm{Mg}$ & 47.82 & 6.82 & 9.75 & 5.36 & 2.92 & 1.46 & 1.46 & 4.00 & 0.00 & 19.50 & 0.40 & 0.01 & 0.27 & 0.07 & 0.05 & 0.07 & 0.01 & 0.01 & 0.00 & 0.00 & 99.98 \\
\hline & Measured & 45.90 & 6.89 & 10.20 & 6.71 & 3.03 & 1.68 & 1.34 & 3.93 & $\mathrm{BD}$ & 18.30 & 0.37 & $\mathrm{BD}$ & & & & 0.25 & & & & $\mathrm{BD}$ & 98.60 \\
\hline \multirow[t]{2}{*}{ HLP-22 } & $\mathrm{L} \mathrm{Na}$ & 51.67 & 7.37 & 10.53 & 5.79 & 3.16 & 1.58 & 1.58 & 1.58 & 0.00 & 16.00 & 0.33 & 0.01 & 0.22 & 0.06 & 0.04 & 0.06 & 0.01 & 0.01 & 0.00 & 0.00 & 100.00 \\
\hline & Measured & 53.30 & 7.67 & 11.00 & 7.02 & 3.27 & 1.65 & 1.26 & 1.66 & $\mathrm{BD}$ & 15.40 & 0.30 & $\mathrm{BD}$ & & & & 0.27 & & & & $\mathrm{BD}$ & 102.80 \\
\hline \multirow[t]{2}{*}{ HLP-23 } & $\mathrm{H} \mathrm{Na}$ & 47.13 & 6.72 & 9.61 & 5.29 & 2.88 & 1.44 & 1.44 & 1.44 & 0.00 & 23.00 & 0.47 & 0.01 & 0.32 & 0.08 & 0.06 & 0.09 & 0.01 & 0.01 & 0.00 & 0.00 & 100.00 \\
\hline & Measured & 44.10 & 6.92 & 9.65 & 5.91 & 2.90 & 1.47 & 1.38 & 1.47 & $\mathrm{BD}$ & 21.50 & 0.42 & $\mathrm{BD}$ & & & & 0.27 & & & & $\mathrm{BD}$ & 95.99 \\
\hline \multirow[t]{2}{*}{ HLP-24 } & I Na & 50.37 & 7.18 & 10.27 & 5.65 & 3.08 & 1.54 & 1.54 & 1.54 & 0.00 & 18.00 & 0.37 & 0.01 & 0.25 & 0.07 & 0.05 & 0.07 & 0.01 & 0.01 & 0.00 & 0.00 & 100.01 \\
\hline & Measured & 48.90 & 7.44 & 10.00 & 6.59 & 3.24 & 1.60 & 1.51 & 1.63 & $\mathrm{BD}$ & 17.20 & 0.40 & $\mathrm{BD}$ & & & & 0.24 & & & & $\mathrm{BD}$ & 98.75 \\
\hline \multirow[t]{2}{*}{ HLP-25 } & Center & 49.07 & 7.00 & 10.00 & 5.50 & 3.00 & 1.50 & 1.50 & 1.50 & 0.00 & 20.00 & 0.41 & 0.01 & 0.28 & 0.07 & 0.06 & 0.08 & 0.01 & 0.01 & 0.00 & 0.00 & 100.00 \\
\hline & Measured & 47.20 & 6.76 & 10.10 & 6.27 & 2.66 & 1.49 & 1.48 & 1.54 & $\mathrm{BD}$ & 18.50 & 0.41 & 0.01 & & & & 0.21 & & & & 0.02 & 96.65 \\
\hline \multirow[t]{2}{*}{ HLP-26 } & Center & 49.07 & 7.00 & 10.00 & 5.50 & 3.00 & 1.50 & 1.50 & 1.50 & 0.00 & 20.00 & 0.41 & 0.01 & 0.28 & 0.07 & 0.06 & 0.08 & 0.01 & 0.01 & 0.00 & 0.00 & 100.00 \\
\hline & Measured & 46.80 & 6.68 & 9.43 & 5.97 & 2.86 & 1.40 & 1.50 & 1.45 & BD & 18.20 & 0.43 & $\mathrm{BD}$ & & & & 0.21 & & & & $\mathrm{BD}$ & 94.93 \\
\hline \multirow[t]{2}{*}{ HLP-27 } & НHНH & 52.00 & 11.94 & 12.00 & 0.00 & 0.00 & 0.00 & 0.00 & 0.00 & 0.00 & 23.00 & 0.47 & 0.01 & 0.32 & 0.08 & 0.06 & 0.09 & 0.01 & 0.01 & 0.00 & 0.00 & 99.99 \\
\hline & Measured & 50.40 & 12.00 & 12.30 & 0.60 & $\mathrm{BD}$ & $\mathrm{BD}$ & $\mathrm{BD}$ & $\mathrm{BD}$ & $\mathrm{BD}$ & 21.70 & 0.44 & $\mathrm{BD}$ & & & & 0.26 & & & & $\mathrm{BD}$ & 97.70 \\
\hline \multirow[t]{2}{*}{ HLP-28 } & HHHL & 52.00 & 11.94 & 12.00 & 3.10 & 1.69 & 0.84 & 0.84 & 0.84 & 0.00 & 16.00 & 0.33 & 0.01 & 0.22 & 0.06 & 0.04 & 0.06 & 0.01 & 0.01 & 0.00 & 0.00 & 99.99 \\
\hline & Measured & 51.80 & 12.10 & 13.00 & 3.82 & 1.74 & 0.92 & 0.75 & 0.80 & BD & 15.10 & & $\mathrm{BD}$ & & & & 0.22 & & & & $\mathrm{BD}$ & 100.25 \\
\hline \multirow[t]{2}{*}{ HLP-29 } & HHLH & 52.00 & 11.94 & 6.00 & 2.54 & 1.38 & 0.69 & 0.69 & 0.69 & 0.00 & 23.00 & 0.47 & 0.01 & 0.32 & 0.08 & 0.06 & 0.09 & 0.01 & 0.01 & 0.00 & 0.00 & 99.98 \\
\hline & Measured & 49.50 & 11.80 & 6.51 & 3.12 & 1.41 & 0.73 & 0.64 & 0.69 & $\mathrm{BD}$ & 21.50 & 0.42 & $\mathrm{BD}$ & & & & 0.25 & & & & $\mathrm{BD}$ & 96.57 \\
\hline \multirow[t]{2}{*}{ HLP-30 } & HHLL & 52.00 & 11.94 & 6.00 & 5.64 & 3.07 & 1.54 & 1.54 & 1.54 & 0.00 & 16.00 & 0.33 & 0.01 & 0.22 & 0.06 & 0.04 & 0.06 & 0.01 & 0.01 & 0.00 & 0.00 & 100.01 \\
\hline & Measured & 47.30 & 12.20 & 6.56 & 6.38 & 3.20 & 1.55 & 1.43 & 1.50 & BD & 15.40 & 0.29 & $\mathrm{BD}$ & & & & 0.23 & & & & $\mathrm{BD}$ & 96.04 \\
\hline \multirow[t]{2}{*}{ HLP-31 } & HLHH & 52.00 & 4.00 & 12.00 & 3.36 & 1.83 & 0.92 & 0.92 & 0.92 & 0.00 & 23.00 & 0.47 & 0.01 & 0.32 & 0.08 & 0.06 & 0.09 & 0.01 & 0.01 & 0.00 & 0.00 & 100.00 \\
\hline & Measured & 48.90 & 4.20 & 12.30 & 4.30 & 1.78 & 0.94 & 0.70 & 0.84 & $\mathrm{BD}$ & 22.00 & 0.40 & $\mathrm{BD}$ & & & & 0.24 & & & & $\mathrm{BD}$ & 96.60 \\
\hline \multirow[t]{2}{*}{ HLP-32 } & HLHL & 52.00 & 4.00 & 12.00 & 6.46 & 3.52 & 1.76 & 1.76 & 1.76 & 0.00 & 16.00 & 0.33 & 0.01 & 0.22 & 0.06 & 0.04 & 0.06 & 0.01 & 0.01 & 0.00 & 0.00 & 100.00 \\
\hline & Measured & 46.00 & 4.21 & 12.90 & 7.05 & 3.57 & 1.86 & 1.60 & 1.66 & $\mathrm{BD}$ & 15.70 & 0.31 & $\mathrm{BD}$ & & & & 0.25 & & & & $\mathrm{BD}$ & 95.11 \\
\hline \multirow[t]{2}{*}{ HLP-33 } & HLLH & 52.00 & 4.00 & 6.00 & 5.90 & 3.21 & 1.61 & 1.61 & 1.61 & 0.00 & 23.00 & 0.47 & 0.01 & 0.32 & 0.08 & 0.06 & 0.09 & 0.01 & 0.01 & 0.00 & 0.00 & 99.99 \\
\hline & Measured & 52.30 & 4.16 & 6.44 & 6.92 & 3.23 & 1.67 & 1.31 & 1.57 & $\mathrm{BD}$ & 22.00 & 0.45 & $\mathrm{BD}$ & & & & 0.30 & & & & $\mathrm{BD}$ & 100.35 \\
\hline \multirow[t]{2}{*}{ HLP-34 } & HLLL & 52.00 & 4.00 & 6.00 & 9.00 & 4.90 & 2.45 & 2.45 & 2.45 & 0.00 & 16.00 & 0.33 & 0.01 & 0.22 & 0.06 & 0.04 & 0.06 & 0.01 & 0.01 & 0.00 & 0.00 & 99.99 \\
\hline & Measured & 51.00 & 3.97 & 6.24 & 10.20 & 4.70 & 2.32 & 2.00 & 2.10 & $\mathrm{BD}$ & 14.30 & 0.30 & $\mathrm{BD}$ & & & & 0.20 & & & & $\mathrm{BD}$ & 97.33 \\
\hline \multirow[t]{2}{*}{ HLP-35 } & LHHH & 36.00 & 11.94 & 12.00 & 6.77 & 3.69 & 1.85 & 1.85 & 1.85 & 0.00 & 23.00 & 0.47 & 0.01 & 0.32 & 0.08 & 0.06 & 0.09 & 0.01 & 0.01 & 0.00 & 0.00 & 100.00 \\
\hline & Measured & 36.00 & 11.50 & 12.10 & 7.47 & 3.61 & 1.83 & 1.73 & 1.68 & $\mathrm{BD}$ & 21.60 & 0.50 & $\mathrm{BD}$ & & & & 0.22 & & & & $\mathrm{BD}$ & 98.24 \\
\hline \multirow[t]{2}{*}{ HLP-36 } & LHHL & 36.00 & 11.94 & 12.00 & 9.87 & 5.38 & 2.69 & 2.69 & 2.69 & 0.00 & 16.00 & 0.33 & 0.01 & 0.22 & 0.06 & 0.04 & 0.06 & 0.01 & 0.01 & 0.00 & 0.00 & 100.00 \\
\hline & Measured & 35.60 & 12.00 & 12.60 & 10.30 & 5.49 & 2.69 & 2.44 & 2.41 & $\mathrm{BD}$ & 15.50 & 0.27 & $\mathrm{BD}$ & & & & 0.17 & & & & $\mathrm{BD}$ & 99.47 \\
\hline \multirow[t]{2}{*}{ HLP-37 } & LHLH & 36.00 & 11.94 & 6.00 & 9.31 & 5.07 & 2.54 & 2.54 & 2.54 & 0.00 & 23.00 & 0.47 & 0.01 & 0.32 & 0.08 & 0.06 & 0.09 & 0.01 & 0.01 & 0.00 & 0.00 & 99.99 \\
\hline & Measured & 35.60 & 11.60 & 6.78 & 9.71 & 5.04 & 2.46 & 2.28 & 2.19 & $\mathrm{BD}$ & 21.80 & 0.40 & $\mathrm{BD}$ & & & & 0.19 & & & & $\mathrm{BD}$ & 98.05 \\
\hline HLP-38 & LHLL & 36.00 & 11.94 & 6.00 & 12.41 & 6.76 & 3.38 & 3.38 & 3.38 & 0.00 & 16.00 & 0.33 & 0.01 & 0.22 & 0.06 & 0.04 & 0.06 & 0.01 & 0.01 & 0.00 & 0.00 & 99.99 \\
\hline & Measured & 35.40 & 12.00 & 6.09 & 12.60 & 6.88 & 3.33 & 3.38 & 3.15 & BD & 15.30 & 0.30 & $\mathrm{BD}$ & & & & 0.17 & & & & $\mathrm{BD}$ & 98.60 \\
\hline HLP-39 & LLHH & 36.00 & 4.00 & 12.00 & 10.13 & 5.52 & 2.76 & 2.76 & 2.76 & 0.00 & 23.00 & 0.47 & 0.01 & 0.32 & 0.08 & 0.06 & 0.09 & 0.01 & 0.01 & 0.00 & 0.00 & 99.98 \\
\hline
\end{tabular}




\begin{tabular}{|c|c|c|c|c|c|c|c|c|c|c|c|c|c|c|c|c|c|c|c|c|c|c|}
\hline Glass ID & Description $^{(a)}$ & $\mathrm{SiO}_{2}$ & $\mathbf{A l}_{2} \mathbf{O}_{3}$ & $\mathrm{~B}_{2} \mathbf{O}_{3}$ & $\mathrm{Fe}_{2} \mathrm{O}_{3}$ & $\mathrm{TiO}_{2}$ & $\mathrm{ZnO}$ & $\mathrm{ZrO}$ & ${ }_{2} \mathrm{MgO}$ & $\mathbf{L i}_{2} \mathbf{O}$ & $\mathrm{Na}_{2} \mathrm{O}$ & $\mathbf{K}_{2} \mathrm{O}$ & $\mathrm{CaO}$ & $\mathrm{Cl}^{-}$ & $\mathrm{SO}_{3}$ & $\mathbf{P}_{2} \mathrm{O}_{5}$ & $\mathrm{Cr}_{2} \mathrm{O}_{3}$ & $\mathbf{F}$ & $\mathrm{ReO}_{2}$ & $\mathrm{MoO}_{3}$ & $\mathbf{L a}_{2} \mathbf{O}_{3}$ & Total \\
\hline & Measured & 34.40 & 3.99 & 12.60 & 10.40 & 5.50 & 2.72 & 2.62 & 2.59 & $\mathrm{BD}$ & 21.50 & 0.45 & $\mathrm{BD}$ & & & & 0.23 & & & & $\mathrm{BD}$ & 97.00 \\
\hline \multirow[t]{3}{*}{ HLP-40 } & LLHL & 36.00 & 4.00 & 12.00 & 13.23 & 7.21 & 3.61 & 3.61 & 3.61 & 0.00 & 16.00 & 0.33 & 0.01 & 0.22 & 0.06 & 0.04 & 0.06 & 0.01 & 0.01 & 0.00 & 0.00 & 100.01 \\
\hline & Measured Q & 34.10 & 4.01 & 12.70 & 13.40 & 7.28 & 3.62 & 3.16 & 3.46 & $\mathrm{BD}$ & 15.40 & 0.31 & $\mathrm{BD}$ & & & & 0.20 & & & & $\mathrm{BD}$ & 97.64 \\
\hline & Measured HT & 35.10 & 4.26 & 12.40 & 13.40 & 7.65 & 3.73 & 3.44 & 3.65 & $\mathrm{BD}$ & 16.30 & 0.31 & $\mathrm{BD}$ & & & & 0.18 & & & & $\mathrm{BD}$ & 100.42 \\
\hline \multirow[t]{2}{*}{ HLP-41 } & LLLH & 36.00 & 4.00 & 6.00 & 12.67 & 6.90 & 3.45 & 3.45 & 3.45 & 0.00 & 23.00 & 0.47 & 0.01 & 0.32 & 0.08 & 0.06 & 0.09 & 0.01 & 0.01 & 0.00 & 0.00 & 99.97 \\
\hline & Measured & 35.00 & 3.91 & 6.47 & 13.00 & 6.78 & 3.48 & 3.19 & 3.20 & $\mathrm{BD}$ & 21.60 & 0.43 & $\mathrm{BD}$ & & & & 0.22 & & & & $\mathrm{BD}$ & 97.28 \\
\hline \multirow[t]{3}{*}{ HLP-42 } & LLLL & 36.00 & 4.00 & 6.00 & 15.77 & 8.59 & 4.30 & 4.30 & 4.30 & 0.00 & 16.00 & 0.33 & 0.01 & 0.22 & 0.06 & 0.04 & 0.06 & 0.01 & 0.01 & 0.00 & 0.00 & 100.00 \\
\hline & Measured Q & 35.10 & 4.09 & 6.32 & 16.80 & 8.31 & 4.29 & 3.27 & 4.05 & $\mathrm{BD}$ & 15.50 & 0.37 & $\mathrm{BD}$ & & & & 0.19 & & & & 0.10 & 98.39 \\
\hline & Measured HT & 34.20 & 4.13 & 6.46 & 15.80 & 8.66 & 4.17 & 3.78 & 4.09 & $\mathrm{BD}$ & 15.60 & 0.42 & $\mathrm{BD}$ & & & & 0.17 & & & & $\mathrm{BD}$ & 97.48 \\
\hline \multirow[t]{2}{*}{ HLP-43 } & Center & 49.07 & 7.00 & 10.00 & 5.50 & 3.00 & 1.50 & 1.50 & 1.50 & 0.00 & 20.00 & 0.41 & 0.01 & 0.28 & 0.07 & 0.06 & 0.08 & 0.01 & 0.01 & 0.00 & 0.00 & 100.00 \\
\hline & Measured & 48.40 & 6.69 & 9.85 & 6.23 & 2.86 & 1.40 & 1.50 & 1.33 & $\mathrm{BD}$ & 18.50 & 0.47 & 0.01 & & & & 0.23 & & & & $\mathrm{BD}$ & 97.47 \\
\hline \multirow[t]{2}{*}{ HLP-44 } & Reduced & 49.07 & 7.00 & 10.00 & 5.50 & 3.00 & 1.50 & 1.50 & 1.50 & 0.00 & 20.00 & 0.41 & 0.01 & 0.28 & 0.07 & 0.06 & 0.08 & 0.01 & 0.01 & 0.00 & 0.00 & 100.00 \\
\hline & Measured & 48.30 & 6.93 & 9.97 & 6.07 & 3.12 & 1.51 & 1.22 & 1.46 & $\mathrm{BD}$ & 18.60 & 0.35 & BD & & & & 0.21 & & & & $\mathrm{BD}$ & 97.74 \\
\hline \multirow[t]{2}{*}{ HLP-45 } & Reduced & 49.07 & 7.00 & 10.00 & 5.50 & 3.00 & 1.50 & 1.50 & 1.50 & 0.00 & 20.00 & 0.41 & 0.01 & 0.28 & 0.07 & 0.06 & 0.08 & 0.01 & 0.01 & 0.00 & 0.00 & 100.00 \\
\hline & Measured & 48.60 & 7.10 & 10.10 & 6.06 & 2.93 & 1.46 & 1.34 & 1.55 & $\mathrm{BD}$ & 18.50 & 0.34 & BD & & & & 0.22 & & & & $\mathrm{BD}$ & 98.20 \\
\hline \multirow[t]{2}{*}{ HLP-46 } & LD6-5412 & 55.91 & 12.17 & 5.05 & 0.11 & 0.02 & 0.14 & 0.08 & 0.00 & 0.00 & 20.41 & 1.66 & 4.12 & 0.00 & 0.18 & 0.22 & 0.05 & 0.00 & 0.00 & 0.00 & 0.00 & 100.12 \\
\hline & Measured & 57.70 & 11.70 & 5.50 & 0.49 & $\mathrm{BD}$ & $\mathrm{BD}$ & $\mathrm{BD}$ & $\mathrm{BD}$ & $\mathrm{BD}$ & 18.00 & 0.28 & 3.92 & & & & 0.16 & & & & $\mathrm{BD}$ & 97.75 \\
\hline \multirow[t]{2}{*}{ HLP-47 } & LRM-1 & 54.37 & 10.00 & 8.00 & 1.00 & 0.10 & 0.00 & 1.00 & 0.10 & 0.10 & 20.00 & 1.50 & 0.50 & 0.80 & 0.20 & 0.50 & 0.20 & 1.00 & 0.00 & 0.00 & 0.01 & 99.38 \\
\hline & Measured & 55.10 & 9.42 & 7.64 & 2.04 & 0.09 & $\mathrm{BD}$ & 0.94 & 0.11 & 0.12 & 18.90 & 1.40 & 0.52 & & & & 0.32 & & & & $\mathrm{BD}$ & 96.60 \\
\hline \multirow[t]{2}{*}{ HLP-48 } & LAW-A $33^{(b)}$ & 38.25 & 11.97 & 8.85 & 5.77 & 2.49 & 4.27 & 2.49 & 1.99 & 0.00 & 20.00 & 3.10 & 0.00 & 0.58 & 0.10 & 0.08 & 0.02 & 0.04 & 0.00 & 0.00 & 0.00 & 100.00 \\
\hline & Measured & 36.40 & 11.50 & 8.93 & 6.37 & 2.45 & 4.10 & 2.04 & 1.83 & $\mathrm{BD}$ & 18.50 & 2.75 & $\mathrm{BD}$ & & & & 0.14 & & & & $\mathrm{BD}$ & 95.01 \\
\hline \multirow[t]{2}{*}{ HLP-49 } & LAW-B29 (b) & 43.93 & 8.03 & 8.07 & 8.03 & 0.00 & 3.99 & 3.04 & 3.00 & 4.08 & 10.00 & 0.36 & 7.03 & 0.29 & 0.02 & 0.01 & 0.10 & 0.00 & 0.00 & 0.00 & 0.00 & 99.98 \\
\hline & Measured & 41.10 & 7.76 & 8.74 & 8.71 & $\mathrm{BD}$ & 3.93 & 2.73 & 2.81 & 4.11 & 9.65 & 0.36 & 6.96 & & & & 0.24 & & & & $\mathrm{BD}$ & 97.10 \\
\hline \multirow[t]{2}{*}{ HLP-51 } & LAW-ABP1 & 41.89 & 10.00 & 9.25 & 2.50 & 2.49 & 2.60 & 5.25 & 1.00 & 0.00 & 20.00 & 2.20 & 0.00 & 0.58 & 0.10 & 0.08 & 0.02 & 0.04 & 0.00 & 0.00 & 2.00 & 100.00 \\
\hline & Measured & 41.20 & 9.68 & 9.26 & 2.94 & 2.37 & 2.51 & 3.90 & 0.92 & $\mathrm{BD}$ & 18.80 & 2.07 & $\mathrm{BD}$ & & & & 0.14 & & & & 1.94 & 95.73 \\
\hline \multirow[t]{2}{*}{ HLP-52 } & HAN- $28^{(\mathrm{b})}$ & 44.46 & 10.15 & 0.00 & 2.53 & 0.38 & 0.00 & 5.00 & 1.18 & 0.00 & 28.62 & 1.96 & 2.59 & 0.13 & 0.30 & 1.90 & 0.08 & 0.31 & 0.00 & 0.00 & 0.00 & 99.59 \\
\hline & Measured & 45.80 & 9.63 & 0.10 & 3.00 & 0.37 & $\mathrm{BD}$ & 2.54 & 1.08 & $\mathrm{BD}$ & 27.50 & 1.80 & 2.51 & & & & 0.21 & & & & $\mathrm{BD}$ & 94.54 \\
\hline \multirow[t]{5}{*}{ HLP-53 } & LAW-A $23^{(b)}$ & 40.15 & 9.86 & 4.23 & 7.30 & 0.00 & 3.28 & 2.99 & 2.04 & 2.04 & 20.00 & 3.10 & 4.38 & 0.36 & 0.04 & 0.08 & 0.01 & 0.12 & 0.00 & 0.00 & 0.00 & 99.98 \\
\hline & Measured Q & 40.80 & 9.79 & 4.54 & 7.52 & $\mathrm{BD}$ & 3.24 & 2.82 & 1.84 & 2.13 & 20.40 & 3.08 & 4.33 & & & & $\mathrm{BD}$ & & & & $\mathrm{BD}$ & 100.49 \\
\hline & Measured HT & 39.50 & 9.31 & 5.46 & 7.67 & $\mathrm{BD}$ & 3.09 & 2.76 & 1.93 & 2.29 & 18.60 & 2.75 & 4.21 & & & & 0.14 & & & & $\mathrm{BD}$ & 97.71 \\
\hline & Measured In & 42.20 & 9.59 & 4.34 & 7.99 & $\mathrm{BD}$ & 3.07 & 2.79 & 1.85 & 2.11 & 18.70 & 2.98 & 4.27 & & & & $\mathrm{BD}$ & & & & 0.30 & 100.19 \\
\hline & Measured Out & 43.50 & 9.49 & 4.26 & 8.12 & $\mathrm{BD}$ & 3.26 & 2.67 & 1.89 & 2.09 & 19.30 & 2.93 & 4.32 & & & & $\mathrm{BD}$ & & & & $\mathrm{BD}$ & 101.83 \\
\hline \multirow[t]{2}{*}{ HLP-54 } & L4-912 & 56.78 & 12.00 & 9.00 & 0.00 & 0.00 & 0.00 & 0.00 & 0.00 & 0.00 & 20.00 & 0.33 & 0.00 & 0.09 & 0.32 & 1.19 & 0.04 & 0.21 & 0.00 & 0.00 & 0.01 & 99.97 \\
\hline & Measured & 56.40 & 11.70 & 8.76 & 0.56 & $\mathrm{BD}$ & $\mathrm{BD}$ & 0.07 & $\mathrm{BD}$ & $\mathrm{BD}$ & 17.80 & 0.28 & $\mathrm{BD}$ & & & & 0.16 & & & & $\mathrm{BD}$ & 95.73 \\
\hline \multirow[t]{2}{*}{ HLP-55 } & L4-99 & 59.78 & 9.00 & 9.00 & 0.00 & 0.00 & 0.00 & 0.00 & 0.00 & 0.00 & 20.00 & 0.33 & 0.00 & 0.09 & 0.32 & 1.19 & 0.04 & 0.21 & 0.00 & 0.00 & 0.01 & 99.97 \\
\hline & $\begin{array}{l}\text { Measured } \\
\text { LAW-A44b, }{ }^{(\mathrm{c})}\end{array}$ & 60.60 & 8.87 & 8.92 & 0.58 & $\mathrm{BD}$ & $\mathrm{BD}$ & $\mathrm{BD}$ & $\mathrm{BD}$ & $\mathrm{BD}$ & 17.70 & 0.32 & $\mathrm{BD}$ & & & & 0.17 & & & & $\mathrm{BD}$ & 97.16 \\
\hline
\end{tabular}

(a) Levels of glass components are given as L - low, I - intermediate, and $\mathrm{H}$ - high for the components following the level; for four consecutive levels the components are $\mathrm{SiO}_{2}, \mathrm{Al}_{2} \mathrm{O}_{3}, \mathrm{~B}_{2} \mathrm{O}_{3}$, and $\mathrm{Na}_{2} \mathrm{O}$, respectively. 
(b) Preliminary Hanford LAW glasses developed by Catholic University of America for BNFL Inc. HT - heat treated glass, Q - quenched glass, In - inside area of HT glass, Out - outside area of HT glass.

$\mathrm{BD}$ - below detection limits.

(c) Composition of LAW-A44 is proprietary. 


\section{APPENDIX B \\ PCT-A, PCT-B, and Corrosion Information for the HLP Glasses}




\section{APPENDIX B Measured Concentrations in PCT-A Solutions}

Table B-1. SRTC Mobile Laboratory Results for the Measured $\mathrm{pH}$ and Concentrations for the Hanford PCT-A Series. Results Reported on 9/18/1999, Test Temperature $=90^{\circ} \mathrm{C}$, Test Duration $=$ $165 \mathrm{~h},(\mathrm{~S} / \mathrm{V}) \approx 2000 / \mathrm{m}$, and Dilution Factor $=5 / 3$.

\begin{tabular}{|c|c|c|c|c|c|c|c|c|c|c|}
\hline \multirow[b]{2}{*}{ SampleID } & \multirow[b]{2}{*}{ pH } & \multicolumn{9}{|c|}{ Diluted Concentration, $p_{1}$, in Test Solution $(\mathrm{mg} / \mathrm{L})$} \\
\hline & & Zn & Fe & B & $\mathrm{Si}$ & Mg & $\mathbf{T i}$ & $\mathbf{Z r}$ & Al & $\mathbf{N a}$ \\
\hline Blank & 6.67 & $<0.040$ & 0.025 & $<0.180$ & $<0.180$ & $<0.010$ & $<0.010$ & $<0.010$ & $<0.200$ & $<0.530$ \\
\hline HLP-01 & 10.31 & 0.920 & 4.09 & 10.1 & 47.6 & 0.500 & 1.68 & 0.600 & 6.62 & 64.8 \\
\hline HLP-01 & 10.31 & 0.830 & 3.73 & 10.2 & 47.6 & 0.440 & 1.63 & 0.550 & 7.24 & 66.4 \\
\hline HLP-01 & 10.32 & 0.780 & 4.17 & 10.1 & 47.0 & 0.440 & 1.62 & 0.430 & 6.91 & 59.4 \\
\hline HLP-02 & 11.69 & 0.370 & 2.14 & 144 & 69.1 & 0.300 & 0.280 & $<0.100$ & 16.1 & 499 \\
\hline HLP-02 & 11.68 & 0.260 & 1.53 & 130 & 64.0 & 0.260 & 0.320 & $<0.100$ & 15.8 & 520 \\
\hline HLP-02 & 11.67 & 0.250 & 1.95 & 132 & 69.0 & 0.240 & 0.320 & $<0.100$ & 16.4 & 525 \\
\hline HLP-03 & 10.23 & 1.04 & 4.49 & 11.2 & 54.0 & 0.550 & 1.88 & 0.760 & 6.73 & 60.4 \\
\hline HLP-03 & 10.21 & 0.830 & 4.20 & 9.39 & 50.4 & 0.510 & 1.77 & 0.620 & 5.98 & 53.5 \\
\hline HLP-03 & 10.22 & 1.09 & 4.70 & 9.96 & 53.3 & 0.590 & 1.92 & 0.720 & 6.65 & 49.4 \\
\hline HLP-04 & 11.3 & 1.08 & 3.94 & 87.9 & 69.6 & 0.860 & 1.46 & 0.600 & 13.3 & 244 \\
\hline HLP-04 & 11.29 & 1.30 & 4.41 & 82.3 & 67.1 & 0.850 & 1.67 & 0.790 & 12.2 & 252 \\
\hline HLP-04 & 11.29 & 1.26 & 4.39 & 86.5 & 70.2 & 0.910 & 1.53 & 0.610 & 12.9 & 245 \\
\hline HLP-05 & 10.31 & 0.580 & 2.82 & 47.9 & 117 & 0.390 & 0.890 & 0.380 & $<2.00$ & 144 \\
\hline HLP-05 & 10.36 & 0.750 & 2.78 & 51.3 & 121 & 0.500 & 0.650 & $<0.100$ & $<2.00$ & 163 \\
\hline HLP-05 & 10.38 & 0.740 & 2.69 & 48.9 & 120 & 0.490 & 0.650 & $<0.100$ & $<2.00$ & 162 \\
\hline Blank & 6.81 & $<0.040$ & 0.022 & $<0.180$ & $<0.180$ & $<0.010$ & $<0.010$ & $<0.010$ & $<0.200$ & $<0.530$ \\
\hline STD & $\mathrm{n} / \mathrm{a}$ & $<0.040$ & 4.08 & 20.7 & 52.4 & $<0.010$ & $<0.010$ & $<0.010$ & 3.98 & 87.3 \\
\hline HLP-06 & 10.21 & 0.860 & 3.88 & 11.8 & 47.9 & 0.470 & 1.55 & 0.590 & 13.2 & 53.8 \\
\hline HLP-06 & 10.31 & 0.820 & 3.92 & 10.6 & 47.2 & 0.420 & 1.49 & 0.490 & 13.0 & 49.0 \\
\hline HLP-06 & 10.3 & 0.900 & 4.27 & 10.7 & 51.5 & 0.510 & 1.65 & 0.710 & 13.7 & 47.9 \\
\hline HLP-07 & 10.28 & 0.850 & 3.84 & 11.6 & 47.8 & 0.490 & 1.52 & 0.600 & 8.87 & 54.9 \\
\hline HLP-07 & 10.29 & 0.930 & 4.08 & 11.4 & 49.8 & 0.510 & 1.64 & 0.620 & 9.60 & 57.1 \\
\hline HLP-07 & 10.3 & 1.00 & 4.43 & 11.4 & 49.7 & 0.520 & 1.78 & 0.660 & 9.98 & 54.1 \\
\hline HLP-08 & 10.85 & 1.10 & 4.79 & 7.43 & 61.8 & 0.690 & 1.93 & 0.800 & 8.44 & 81.5 \\
\hline HLP-08 & & & & Result & are missi & $\mathrm{ng}$ for th & sample & & & \\
\hline HLP-08 & 10.83 & 1.17 & 5.02 & 7.14 & 62.4 & 0.730 & 1.96 & 0.690 & 8.78 & 80.6 \\
\hline HLP-09 & 10.24 & 0.990 & 4.00 & 23.1 & 46.1 & 0.480 & 1.43 & 0.450 & 9.24 & 82.9 \\
\hline HLP-09 & 10.31 & 0.770 & 3.70 & 23.2 & 43.6 & 0.430 & 0.122 & 0.430 & 8.58 & 81.8 \\
\hline HLP-09 & 10.33 & 0.870 & 3.90 & 22.6 & 45.8 & 0.430 & 1.39 & 0.550 & 8.79 & 80.4 \\
\hline HLP-10 & 10.61 & 1.12 & 4.41 & 10.7 & 57.1 & 0.600 & 1.80 & 0.790 & 8.23 & 68.8 \\
\hline HLP-10 & 10.59 & 0.990 & 4.41 & 10.1 & 54.8 & 0.570 & 1.75 & 0.740 & 7.76 & 69.3 \\
\hline HLP-10 & 10.61 & 1.08 & 4.78 & 10.6 & 58.6 & 0.630 & 1.82 & 0.710 & 8.42 & 70.3 \\
\hline HLP-11 & 10.6 & 0.780 & 0.220 & 16.7 & 57.4 & 0.590 & 3.69 & 2.53 & 7.22 & 81.4 \\
\hline HLP-11 & 10.56 & 0.800 & 0.100 & 17.5 & 56.5 & 0.630 & 1.44 & 0.800 & 6.73 & 80.2 \\
\hline HLP-11 & 10.54 & 1.12 & 0.220 & 21.3 & 66.5 & 0.820 & 1.99 & 1.04 & 7.80 & 82.2 \\
\hline HLP-12 & 10.31 & 0.630 & 4.75 & 13.9 & 59.7 & 0.380 & 0.970 & 0.300 & 8.25 & 55.4 \\
\hline HLP-12 & 10.33 & 0.490 & 4.39 & 14.1 & 56.1 & 0.340 & 0.910 & 0.350 & 7.83 & 57.1 \\
\hline HLP-12 & 10.32 & 0.440 & 4.55 & 15.9 & 61.4 & 0.340 & 0.940 & 0.250 & 8.00 & 62.4 \\
\hline Blank & 6.48 & $<0.040$ & $<0.020$ & $<0.180$ & $<0.180$ & $<0.010$ & $<0.010$ & $<0.010$ & $<0.200$ & $<0.530$ \\
\hline STD & $\mathrm{n} / \mathrm{a}$ & $<0.040$ & 4.13 & 20.9 & 50.7 & $<0.010$ & $<0.010$ & $<0.010$ & 4.04 & 84.9 \\
\hline HLP-13 & 10.5 & 1.20 & 2.75 & 18.4 & 59.3 & 0.870 & 1.87 & 0.580 & 7.14 & 86.2 \\
\hline HLP-13 & 10.56 & 1.18 & 2.53 & 17.4 & 56.1 & 0.830 & 1.87 & 0.850 & 7.17 & 77.0 \\
\hline HLP-13 & 10.5 & 1.13 & 2.43 & 17.4 & 57.5 & 0.830 & 1.69 & 0.620 & 7.52 & 80.7 \\
\hline HLP-14 & 10.61 & 0.460 & 2.30 & 25.2 & 53.2 & 0.350 & $<0.100$ & 0.190 & 6.43 & 100 \\
\hline HLP-14 & 10.65 & 0.460 & 2.29 & 26.8 & 54.1 & 0.300 & $<0.100$ & 0.240 & 6.25 & 108 \\
\hline
\end{tabular}

B. 1 


\begin{tabular}{|c|c|c|c|c|c|c|c|c|c|c|}
\hline \multirow[b]{2}{*}{ SampleID } & \multirow[b]{2}{*}{ pH } & \multicolumn{9}{|c|}{ Diluted Concentration, $p_{1}$, in Test Solution (mg/L) } \\
\hline & & Zn & $\mathbf{F e}$ & B & $\mathbf{S i}$ & Mg & Ti & $\mathbf{Z r}$ & Al & $\mathbf{N a}$ \\
\hline HLP-14 & 10.65 & 0.650 & 2.55 & 31.1 & 62.8 & 0.470 & $<0.100$ & 0.280 & 7.34 & 100 \\
\hline HLP-15 & 10.47 & 1.40 & 5.45 & 13.8 & 65.1 & 0.940 & 4.42 & 0.920 & 9.04 & 60.2 \\
\hline HLP-15 & 10.43 & 1.04 & 4.46 & 13.2 & 59.6 & 0.750 & 3.73 & 0.680 & 8.24 & 61.2 \\
\hline HLP-15 & 10.42 & 0.890 & 4.01 & 11.0 & 55.1 & 0.720 & 3.58 & 0.710 & 7.49 & 62.9 \\
\hline HLP-16 & 10.57 & $<0.400$ & 6.04 & 14.5 & 58.6 & 1.03 & 2.31 & 0.700 & 8.25 & 67.1 \\
\hline HLP-16 & 10.54 & $<0.400$ & 5.84 & 13.5 & 57.8 & 0.980 & 2.31 & 0.850 & 8.08 & 68.8 \\
\hline HLP-16 & 10.54 & $<0.400$ & 6.11 & 14.2 & 57.7 & 1.01 & 2.30 & 0.460 & 8.35 & 66.4 \\
\hline HLP-17 & 10.45 & 0.830 & 1.20 & 17.4 & 55.7 & $<0.100$ & 0.400 & $<0.100$ & 5.94 & 75.2 \\
\hline HLP-17 & 10.47 & 0.560 & 0.970 & 16.0 & 50.7 & $<0.100$ & 0.320 & $<0.100$ & 5.47 & 73.9 \\
\hline HLP-17 & 10.45 & 0.690 & 1.09 & 15.3 & 52.8 & $<0.100$ & 0.360 & $<0.100$ & 6.34 & 72.2 \\
\hline HLP-18 & 10.63 & 2.71 & 8.21 & 19.6 & 71.1 & 1.83 & 3.53 & $<0.100$ & 9.48 & 87.0 \\
\hline HLP-18 & 10.61 & 2.57 & 8.80 & 19.7 & 70.3 & 1.72 & 3.63 & $<0.100$ & 8.88 & 82.1 \\
\hline HLP-18 & 10.6 & 2.65 & 8.58 & 20.2 & 68.6 & 1.79 & 3.45 & $<0.100$ & 9.52 & 84.8 \\
\hline HLP-19 & 10.6 & $<0.400$ & 0.580 & 8.90 & 42.5 & $<0.100$ & $<0.100$ & $<0.100$ & 6.18 & 54.3 \\
\hline HLP-19 & 10.54 & $<0.400$ & 0.450 & 11.6 & 44.0 & $<0.100$ & $<0.100$ & $<0.100$ & 6.03 & 48.9 \\
\hline HLP-19 & 10.52 & $<0.400$ & 0.480 & 9.21 & 43.3 & $<0.100$ & $<0.100$ & $<0.100$ & 6.23 & 50.2 \\
\hline Blank & 6.79 & $<0.040$ & $<0.020$ & 0.214 & $<0.180$ & $<0.010$ & $<0.010$ & $<0.010$ & $<0.200$ & $<0.530$ \\
\hline STD & $\mathrm{n} / \mathrm{a}$ & $<0.040$ & 4.65 & 22.2 & 55.0 & $<0.010$ & $<0.010$ & $<0.010$ & 4.34 & 82.6 \\
\hline HLP-20 & 10.57 & 1.72 & 7.69 & 15.8 & 61.7 & $<0.100$ & 3.20 & 1.14 & 9.33 & 59.1 \\
\hline HLP-20 & 10.52 & 1.22 & 6.13 & 12.2 & 50.6 & $<0.100$ & 2.70 & 1.24 & 7.14 & 63.8 \\
\hline HLP-20 & 10.52 & 1.58 & 7.18 & 14.9 & 60.2 & $<0.100$ & 2.98 & 1.05 & 8.18 & 62.4 \\
\hline HLP-21 & 10.59 & $<0.400$ & 0.820 & 20.8 & 58.9 & 0.240 & 0.220 & $<0.100$ & 5.10 & 83.6 \\
\hline HLP-21 & 10.55 & $<0.400$ & 1.55 & 22.8 & 67.0 & 0.470 & 0.340 & $<0.100$ & 6.22 & 80.0 \\
\hline HLP-21 & 10.55 & $<0.400$ & 0.840 & 22.0 & 63.2 & 0.260 & 0.240 & $<0.100$ & 5.10 & 85.6 \\
\hline HLP-22 & 9.8 & 0.110 & 2.11 & 9.76 & 50.7 & 0.160 & 0.610 & $<0.100$ & 6.02 & 36.4 \\
\hline HLP-22 & 9.82 & 0.280 & 2.18 & 10.4 & 57.1 & 0.240 & 0.790 & 0.250 & 7.18 & 31.8 \\
\hline HLP-22 & 9.79 & $<0.400$ & 1.68 & 9.02 & 45.6 & 0.160 & 0.620 & 0.150 & 5.90 & 32.9 \\
\hline HLP-23 & 11.15 & 2.26 & 7.85 & 30.5 & 77.3 & 1.76 & 3.03 & 1.01 & 9.70 & 145 \\
\hline HLP-23 & 11.17 & 1.91 & 7.17 & 34.5 & 77.0 & 1.55 & 2.60 & 0.660 & 9.09 & 167 \\
\hline HLP-23 & 11.18 & 2.14 & 7.63 & 41.0 & 88.2 & 1.80 & 2.82 & 0.550 & 10.2 & 169 \\
\hline HLP-24 & 10.11 & 0.410 & 2.78 & 13.0 & 53.5 & 0.360 & 1.00 & 0.350 & 7.12 & 59.2 \\
\hline HLP-24 & 10.17 & 0.470 & 2.94 & 12.7 & 55.4 & 0.360 & 1.14 & 0.370 & 7.30 & 55.0 \\
\hline HLP-24 & 10.13 & 0.460 & 2.89 & 13.2 & 55.8 & 0.350 & 1.12 & 0.210 & 7.42 & 58.7 \\
\hline HLP-25 & 10.54 & 0.580 & 3.55 & 17.0 & 56.6 & 0.430 & 1.07 & 0.150 & 9.92 & 77.7 \\
\hline HLP-25 & 10.51 & 0.590 & 3.66 & 16.6 & 58.2 & 0.400 & 1.06 & 0.110 & 7.14 & 72.5 \\
\hline HLP-25 & 10.46 & 0.570 & 2.99 & 15.8 & 55.6 & 0.430 & 1.03 & 0.370 & 7.37 & 77.5 \\
\hline Blank & 6.34 & $<0.040$ & $<0.020$ & $<0.180$ & $<0.180$ & $<0.010$ & $<0.010$ & $<0.010$ & $<0.200$ & $<0.530$ \\
\hline STD & $\mathrm{n} / \mathrm{a}$ & $<0.040$ & 4.49 & 23.9 & 55.8 & $<0.010$ & $<0.010$ & $<0.010$ & 4.29 & 86.9 \\
\hline HLP-26 & 10.47 & 1.51 & 6.21 & 23.5 & 76.4 & 0.870 & 2.08 & 0.380 & 9.85 & 62.7 \\
\hline HLP-26 & 10.44 & 1.04 & 4.19 & 18.3 & 57.2 & 0.630 & 1.59 & 0.440 & 7.43 & 66.7 \\
\hline HLP-26 & 10.45 & 1.14 & 4.32 & 18.0 & 56.7 & 0.650 & 1.79 & 0.710 & 8.09 & 76.6 \\
\hline HLP-27 & 11.36 & $<0.400$ & $<0.200$ & 99.7 & 70.7 & $<0.100$ & $<0.100$ & $<0.100$ & 16.5 & 325 \\
\hline HLP-27 & 11.36 & $<0.400$ & 0.220 & 106 & 70.9 & $<0.100$ & $<0.100$ & $<0.100$ & 16.6 & 329 \\
\hline HLP-27 & 11.35 & $<0.400$ & 0.480 & 107 & 73.2 & $<0.100$ & $<0.100$ & $<0.100$ & 17.0 & 347 \\
\hline HLP-28 & 9.65 & $<0.400$ & 2.63 & 11.8 & 73.1 & $<0.100$ & 0.950 & 0.100 & 10.5 & 33.7 \\
\hline HLP-28 & 9.57 & 0.400 & 3.15 & 12.1 & 49.0 & $<0.100$ & 1.11 & 0.160 & 12.3 & 28.7 \\
\hline HLP-28 & 9.54 & 0.350 & 2.83 & 11.9 & 48.8 & $<0.100$ & 1.09 & 0.190 & 12.1 & 26.6 \\
\hline HLP-29 & 11.05 & 0.860 & 3.77 & 8.03 & 62.2 & 0.550 & 1.57 & 0.280 & 15.4 & 90.9 \\
\hline HLP-29 & 11.07 & 1.02 & 4.69 & 8.74 & 67.1 & 0.680 & 1.74 & 0.440 & 17.8 & 104 \\
\hline HLP-29 & 11.08 & 2.37 & 5.08 & 10.2 & 114 & 1.03 & 2.55 & 1.51 & 27.1 & 159 \\
\hline HLP-30 & 10.14 & 1.04 & 1.73 & 3.76 & 46.2 & 0.210 & 0.890 & $<0.100$ & 12.0 & 35.4 \\
\hline HLP-30 & 10.19 & 0.960 & 1.55 & 3.36 & 46.2 & 0.180 & 0.870 & $<0.100$ & 11.8 & 36.8 \\
\hline HLP-30 & 10.19 & 0.890 & 1.30 & 3.42 & 45.2 & 0.170 & 0.850 & 0.140 & 11.1 & 32.5 \\
\hline Blank & 5.61 & 0.109 & 0.077 & $<0.180$ & $<0.180$ & $<0.010$ & $<0.010$ & $<0.010$ & 0.234 & $<0.530$ \\
\hline
\end{tabular}




\begin{tabular}{|c|c|c|c|c|c|c|c|c|c|c|}
\hline \multirow[b]{2}{*}{ SampleID } & \multirow[b]{2}{*}{ pH } & \multicolumn{9}{|c|}{ Diluted Concentration, $p$, in Test Solution $(\mathrm{mg} / \mathrm{L})$} \\
\hline & & Zn & $\mathrm{Fe}$ & B & Si & Mg & $\mathbf{T i}$ & $\mathbf{Z r}$ & Al & $\mathbf{N a}$ \\
\hline HLP-31 & 11.4 & 0.940 & $<0.200$ & 297 & 457 & 0.290 & 0.140 & $<0.100$ & $<2.00$ & 985 \\
\hline HLP-31 & 11.4 & 0.190 & $<0.200$ & 307 & 456 & $<0.100$ & $<0.100$ & $<0.100$ & $<2.00$ & 1000 \\
\hline HLP-31 & 11.4 & 0.920 & $<0.200$ & 296 & 418 & 0.280 & 0.140 & $<0.100$ & $<2.00$ & 958 \\
\hline HLP-32 & 9.88 & 0.540 & $<0.200$ & 21.0 & 49.1 & $<0.100$ & $<0.100$ & $<0.100$ & 3.35 & 49.7 \\
\hline HLP-32 & 9.81 & 0.660 & $<0.200$ & 23.3 & 60.0 & $<0.100$ & $<0.100$ & $<0.100$ & 3.83 & 48.9 \\
\hline HLP-32 & 9.83 & 0.600 & $<0.200$ & 19.7 & 53.0 & $<0.100$ & $<0.100$ & $<0.100$ & 3.21 & 50.0 \\
\hline HLP-33 & 11.36 & 3.39 & 7.94 & 38.7 & 211 & 1.63 & 2.07 & 0.900 & 2.04 & 223 \\
\hline HLP-33 & 11.35 & 5.09 & 11.7 & 59.2 & 332 & 2.65 & 3.79 & 1.98 & 2.94 & 422 \\
\hline HLP-33 & 11.34 & 3.41 & 6.53 & 36.9 & 197 & 1.74 & 2.78 & 0.710 & 2.19 & 408 \\
\hline HLP-34 & 10.22 & 0.450 & $<0.200$ & 8.95 & 53.8 & $<0.100$ & $<0.100$ & $<0.100$ & 3.59 & 57.8 \\
\hline HLP-34 & 10.2 & 0.470 & $<0.200$ & 8.47 & 57.9 & $<0.100$ & $<0.100$ & $<0.100$ & 4.09 & 50.2 \\
\hline HLP-34 & 10.19 & 0.530 & $<0.200$ & 8.07 & 56.1 & $<0.100$ & $<0.100$ & $<0.100$ & 3.85 & 46.9 \\
\hline HLP-35 & 11.21 & 1.03 & $<0.200$ & 63.6 & 43.7 & 0.320 & 0.260 & $<0.100$ & 15.5 & 242 \\
\hline HLP-35 & 11.14 & 0.900 & 0.590 & 56.4 & 44.7 & 0.110 & 0.170 & $<0.100$ & 15.3 & 211 \\
\hline HLP-35 & 11.12 & 0.940 & $<0.200$ & 61.0 & 43.6 & 0.130 & 0.240 & $<0.100$ & 16.0 & 178 \\
\hline HLP-36 & 9.92 & 0.530 & $<0.200$ & 20.0 & 32.4 & $<0.100$ & $<0.100$ & $<0.100$ & 12.2 & 47.8 \\
\hline HLP-36 & 9.86 & 0.580 & $<0.200$ & 18.5 & $<0.100$ & $<0.100$ & $<0.100$ & $<0.100$ & 12.7 & 47.6 \\
\hline HLP-36 & 9.83 & 0.580 & $<0.200$ & 18.6 & 31.0 & $<0.100$ & $<0.100$ & $<0.100$ & 11.6 & 51.2 \\
\hline HLP-37 & 11.61 & 7.99 & 14.0 & 28.7 & 77.5 & 4.34 & $<0.100$ & $<0.100$ & 50.5 & 222 \\
\hline HLP-37 & 11.6 & 8.14 & 14.2 & 29.1 & 80.3 & 4.71 & $<0.100$ & $<0.100$ & 49.8 & 235 \\
\hline HLP-37 & 11.58 & 8.67 & 14.9 & 28.9 & 85.7 & 4.84 & $<0.100$ & $<0.100$ & 49.5 & 248 \\
\hline Blank & 5.39 & 0.106 & $<0.020$ & 0.343 & $<0.180$ & $<0.010$ & $<0.010$ & $<0.100$ & $<0.200$ & $<0.530$ \\
\hline STD & $\mathrm{n} / \mathrm{a}$ & $<0.040$ & 4.04 & 20.8 & 53.3 & $<0.010$ & $<0.010$ & $<0.010$ & 3.78 & 83.3 \\
\hline HLP-37Q & 11.47 & 0.610 & $<0.200$ & 14.3 & 61.6 & $<0.100$ & $<0.100$ & $<0.100$ & 22.1 & 158 \\
\hline HLP-37Q & 11.43 & 0.510 & $<0.200$ & 14.1 & 61.0 & $<0.100$ & $<0.100$ & $<0.100$ & 23.0 & 150 \\
\hline HLP-37Q & 11.44 & 0.670 & $<0.200$ & 13.9 & 57.9 & $<0.100$ & $<0.100$ & $<0.100$ & 21.7 & 148 \\
\hline HLP-38 & 10.55 & 0.350 & $<0.200$ & 9.00 & 36.8 & $<0.100$ & $<0.100$ & $<0.100$ & 14.4 & 62.4 \\
\hline HLP-38 & 10.54 & 0.320 & $<0.200$ & 9.00 & 36.2 & $<0.100$ & $<0.100$ & $<0.100$ & 14.6 & 43.1 \\
\hline HLP-38 & 10.54 & 0.330 & $<0.200$ & 8.65 & 38.4 & $<0.100$ & $<0.100$ & $<0.100$ & 14.1 & 49.3 \\
\hline HLP-38Q & 10.61 & 0.310 & $<0.200$ & 8.64 & 34.6 & $<0.100$ & $<0.100$ & $<0.100$ & 13.6 & 49.0 \\
\hline HLP-38Q & 10.57 & 0.260 & $<0.200$ & 8.26 & 34.5 & $<0.100$ & $<0.100$ & $<0.100$ & 13.6 & 49.6 \\
\hline HLP-38Q & 10.57 & 0.350 & $<0.200$ & 8.77 & 35.2 & $<0.100$ & $<0.100$ & $<0.100$ & 13.9 & 54.1 \\
\hline HLP-39 & 11.48 & 0.460 & $<0.200$ & 106 & 83.2 & $<0.100$ & $<0.100$ & $<0.100$ & 4.53 & 306 \\
\hline HLP-39 & 11.45 & 0.450 & $<0.200$ & 102 & 78.2 & $<0.100$ & $<0.100$ & $<0.100$ & 4.04 & 283 \\
\hline HLP-39 & 11.44 & 0.380 & $<0.200$ & 97.8 & 74.9 & $<0.100$ & $<0.100$ & $<0.100$ & 3.71 & 312 \\
\hline HLP-40 & 10.05 & 0.370 & $<0.200$ & 39.8 & 38.6 & $<0.100$ & $<0.100$ & $<0.100$ & 2.06 & 100 \\
\hline HLP-40 & 10.05 & 0.320 & $<0.200$ & 38.9 & 40.0 & $<0.100$ & $<0.100$ & $<0.100$ & 2.03 & 96.2 \\
\hline HLP-40 & 10.06 & 0.350 & $<0.200$ & 42.0 & 40.7 & $<0.100$ & $<0.100$ & $<0.100$ & 2.48 & 100 \\
\hline HLP-40Q & 10.02 & 0.270 & $<0.200$ & 34.7 & 40.0 & $<0.100$ & $<0.100$ & $<0.100$ & 2.53 & 85.8 \\
\hline HLP-40Q & 10.03 & 0.310 & $<0.200$ & 34.8 & 40.3 & $<0.100$ & $<0.100$ & $<0.100$ & 2.53 & 84.8 \\
\hline HLP-40Q & 10.04 & 0.210 & $<0.200$ & 33.7 & 38.8 & $<0.100$ & $<0.100$ & $<0.100$ & 2.16 & 88.2 \\
\hline Blank & 5.62 & 0.083 & $<0.020$ & 0.263 & $<0.180$ & $<0.010$ & $<0.010$ & $<0.010$ & $<0.200$ & $<0.530$ \\
\hline HLP-41 & 12.17 & 2.93 & 3.31 & 152 & 223 & 2.58 & $<0.100$ & $<0.100$ & 4.15 & 915 \\
\hline HLP-41 & 12.22 & 1.33 & 0.710 & 148 & 210 & 0.780 & $<0.100$ & $<0.100$ & 3.51 & 876 \\
\hline HLP-41 & 12.22 & 1.51 & 0.960 & 145 & 211 & 0.970 & $<0.100$ & $<0.100$ & 3.18 & 950 \\
\hline HLP-42 & 10.85 & 0.200 & $<0.200$ & 16.6 & 50.1 & $<0.100$ & $<0.100$ & $<0.100$ & 4.20 & 81.6 \\
\hline HLP-42 & 10.86 & 0.200 & $<0.200$ & 14.7 & 47.4 & $<0.100$ & $<0.100$ & $<0.100$ & 4.01 & 73.1 \\
\hline HLP-42 & 10.89 & 0.290 & $<0.200$ & 14.3 & 46.4 & $<0.100$ & $<0.100$ & $<0.100$ & 4.03 & 76.6 \\
\hline HLP-42Q & 11.01 & 0.250 & $<0.200$ & 20.4 & 50.7 & $<0.100$ & $<0.100$ & $<0.100$ & 2.93 & 93.8 \\
\hline HLP-42Q & 10.98 & 0.210 & $<0.200$ & 19.1 & 47.7 & $<0.100$ & $<0.100$ & $<0.100$ & 2.68 & 91.2 \\
\hline HLP-42Q & 10.98 & 0.250 & $<0.200$ & 19.8 & 48.5 & $<0.100$ & $<0.100$ & $<0.100$ & 2.69 & 92.7 \\
\hline HLP-43 & 10.54 & 1.87 & 4.12 & 14.7 & 50.0 & 0.630 & 1.89 & 0.570 & 7.54 & 65.7 \\
\hline HLP-43 & 10.47 & 2.05 & 4.77 & 15.3 & 51.7 & 0.550 & 1.90 & 0.560 & 7.54 & 58.7 \\
\hline HLP-43 & 10.47 & 1.82 & 3.70 & 15.7 & 52.2 & 0.480 & 1.84 & 0.590 & 7.65 & 57.6 \\
\hline
\end{tabular}




\begin{tabular}{|c|c|c|c|c|c|c|c|c|c|c|}
\hline \multirow[b]{2}{*}{ SampleID } & \multirow[b]{2}{*}{ pH } & \multicolumn{9}{|c|}{ Diluted Concentration, $p$, in Test Solution $(\mathrm{mg} / \mathrm{L})$} \\
\hline & & $\mathbf{Z n}$ & $\mathbf{F e}$ & B & $\mathbf{S i}$ & Mg & $\mathbf{T i}$ & $\mathbf{Z r}$ & Al & $\mathbf{N a}$ \\
\hline STD & $\mathrm{n} / \mathrm{a}$ & $<0.040$ & 3.78 & 20.9 & 49.4 & $<0.010$ & $<0.010$ & $<0.010$ & 3.95 & 84.0 \\
\hline HLP-44 & 10.49 & 1.11 & 1.41 & 18.5 & 50.7 & 0.220 & 0.800 & 0.220 & 6.64 & 81.5 \\
\hline HLP-44 & 10.47 & 1.15 & 1.45 & 17.1 & 49.4 & 0.280 & 0.890 & 0.250 & 6.81 & 68.3 \\
\hline HLP-44 & 10.48 & 1.03 & 1.72 & 16.1 & 45.2 & 0.260 & 0.870 & 0.100 & 7.08 & 68.9 \\
\hline HLP-45 & 10.47 & 1.12 & 1.99 & 15.4 & 48.2 & 0.390 & 1.08 & 0.280 & 7.29 & 69.8 \\
\hline HLP-45 & 10.46 & 1.19 & 2.31 & 16.5 & 49.4 & 0.380 & 1.02 & 0.370 & 7.16 & 68.8 \\
\hline HLP-45 & 10.46 & 1.13 & 1.78 & 15.6 & 47.4 & 0.360 & 0.990 & 0.390 & 6.99 & 65.5 \\
\hline HLP-47 & 10.94 & 0.100 & $<0.200$ & 17.0 & 48.8 & $<0.100$ & $<0.100$ & 0.490 & 8.66 & 95.9 \\
\hline HLP-47 & 10.88 & 0.310 & 0.130 & 14.8 & 45.6 & $<0.100$ & $<0.100$ & 0.540 & 8.34 & 89.5 \\
\hline HLP-47 & 10.89 & 0.150 & $<0.200$ & 15.3 & 44.5 & $<0.100$ & $<0.100$ & 0.540 & 7.90 & 95.5 \\
\hline HLP-48 & 10.93 & 1.11 & $<0.200$ & 19.4 & 36.0 & $<0.100$ & $<0.100$ & $<0.100$ & 11.1 & 89.7 \\
\hline HLP-48 & 10.93 & 1.20 & $<0.200$ & 20.5 & 36.7 & $<0.100$ & $<0.100$ & $<0.200$ & 11.4 & 91.7 \\
\hline HLP-48 & 10.93 & 1.11 & $<0.200$ & 20.8 & 37.3 & $<0.100$ & $<0.100$ & $<0.100$ & 11.4 & 95.5 \\
\hline Blank & 5.46 & 0.090 & $<0.020$ & 0.431 & $<0.180$ & $<0.010$ & $<0.010$ & $<0.100$ & $<0.200$ & $<0.530$ \\
\hline STD & $\mathrm{n} / \mathrm{a}$ & $<0.040$ & 4.08 & 21.0 & 51.6 & $<0.100$ & $<0.100$ & $<0.010$ & 4.08 & 84.1 \\
\hline HLP-49 & 10.57 & $<0.400$ & $<0.200$ & 9.08 & 21.4 & $<0.100$ & $<0.100$ & $<0.100$ & 3.88 & 26.3 \\
\hline HLP-49 & 10.59 & $<0.400$ & $<0.200$ & 9.03 & 22.5 & $<0.100$ & $<0.100$ & $<0.100$ & 4.21 & 24.5 \\
\hline HLP-49 & 10.54 & $<0.400$ & $<0.200$ & 8.75 & 22.0 & $<0.100$ & $<0.100$ & $<0.100$ & 4.04 & 23.6 \\
\hline HLP-51 & 10.86 & 0.460 & $<0.200$ & 11.0 & 33.5 & $<0.100$ & $<0.100$ & $<0.100$ & 8.82 & 64.2 \\
\hline HLP-51 & 10.89 & 0.490 & $<0.200$ & 12.1 & 35.7 & $<0.100$ & $<0.100$ & $<0.100$ & 9.24 & 66.2 \\
\hline HLP-51 & 10.86 & 0.430 & $<0.200$ & 11.6 & 34.5 & $<0.100$ & $<0.100$ & $<0.100$ & 9.08 & 71.0 \\
\hline HLP-52 & 12.66 & 0.450 & 1.30 & $<1.80$ & 153 & $<0.100$ & $<0.100$ & $<0.100$ & 40.6 & 1490 \\
\hline HLP-52 & 12.68 & 0.700 & 1.09 & $<1.80$ & 177 & $<0.100$ & $<0.100$ & $<0.100$ & 43.9 & 1420 \\
\hline HLP-52 & 12.7 & 0.460 & 1.38 & $<1.80$ & 165 & $<0.100$ & $<0.100$ & $<0.100$ & 42.2 & 1410 \\
\hline HLP-54 & 10.41 & 0.390 & $<0.200$ & 15.8 & 64.5 & $<0.100$ & $<0.100$ & $<0.100$ & 5.46 & 92.2 \\
\hline HLP-54 & 10.31 & 0.510 & $<0.200$ & 16.6 & 66.5 & $<0.100$ & $<0.100$ & $<0.100$ & 5.69 & 80.2 \\
\hline HLP-54 & 10.27 & 0.410 & $<0.200$ & 14.4 & 63.4 & $<0.100$ & $<0.100$ & $<0.100$ & 5.85 & 85.8 \\
\hline HLP-55 & 10.36 & 0.400 & $<0.200$ & 5.43 & 42.1 & $<0.100$ & $<0.100$ & $<0.100$ & 11.2 & 53.4 \\
\hline HLP-55 & 10.31 & 0.350 & $<0.200$ & 5.17 & 42.0 & $<0.100$ & $<0.100$ & $<0.100$ & 10.1 & 47.3 \\
\hline HLP-55 & 10.3 & 0.420 & $<0.200$ & 5.07 & 42.1 & $<0.100$ & $<0.100$ & $<0.100$ & 10.5 & 47.5 \\
\hline HLP-46 & 11.39 & 0.410 & $<0.200$ & $<1.80$ & 37.8 & $<0.100$ & $<0.100$ & $<0.100$ & 9.41 & 91.3 \\
\hline HLP-46 & 11.37 & 0.400 & $<0.200$ & $<1.80$ & 37.9 & $<0.100$ & $<0.100$ & $<0.100$ & 8.36 & 91.6 \\
\hline HLP-46 & 11.33 & 0.390 & $<0.200$ & $<1.80$ & 37.0 & $<0.100$ & $<0.100$ & $<0.100$ & 8.31 & 89.7 \\
\hline Blank & 5.35 & 0.088 & $<0.020$ & 0.318 & 0.070 & $<0.100$ & $<0.100$ & $<0.010$ & $<0.200$ & $<0.530$ \\
\hline STD & $\mathrm{n} / \mathrm{a}$ & $<0.040$ & 4.03 & 21.0 & 50.1 & 0.021 & $<0.010$ & $<0.010$ & 3.84 & 82.9 \\
\hline
\end{tabular}




\section{Measured Concentrations in 10-h PCT-B Solutions}

Table B-2. SRTC Mobile Laboratory Results for the Measured Concentrations for the 10-h Hanford PCT-B Series. Results Reported on 9/10/1999 and 9/13/1999, Test Temperature $=90^{\circ} \mathrm{C}$, Test Duration $=10 \mathrm{~h},(\mathrm{~S} / \mathrm{V}) \approx 20,000 / \mathrm{m}$, and Dilution Factor $=5 / 3$.

\begin{tabular}{|c|c|c|c|c|c|c|c|c|c|c|}
\hline \multirow[b]{2}{*}{ SampleID } & \multirow[b]{2}{*}{ pH } & \multicolumn{9}{|c|}{ Diluted Concentration, $p_{1}$, in Test Solution $(\mathrm{mg} / \mathrm{L})$} \\
\hline & & B & $\mathbf{S i}$ & Al & $\mathbf{Z n}$ & $\mathbf{F e}$ & Mg & $\mathbf{T i}$ & $\mathbf{Z r}$ & $\mathbf{N a}$ \\
\hline STD & $\mathrm{n} / \mathrm{a}$ & 20.1 & 55.3 & 4.18 & $<0.200$ & 4.50 & $<0.200$ & $<0.200$ & $<0.100$ & 82.7 \\
\hline HLP-01 & 10.19 & 13.3 & 46.7 & 5.27 & 0.583 & 1.51 & 0.367 & 0.608 & 0.317 & 93.6 \\
\hline HLP-02 & 11.41 & 178 & 70.6 & 15.1 & 2.39 & 2.18 & 1.85 & 1.13 & $<0.100$ & 615 \\
\hline HLP-03 & 10.27 & 10.1 & 48.5 & 4.23 & 0.667 & 1.74 & 0.383 & 0.703 & 0.348 & 75.9 \\
\hline HLP-04 & 11.07 & 60.0 & 57.8 & 9.85 & 2.48 & 2.56 & 1.97 & 1.29 & $<0.100$ & 26.9 \\
\hline HLP-05 & 10.57 & 34.1 & 90.0 & 1.55 & 0.249 & 0.234 & $<0.200$ & $<0.200$ & $<0.100$ & 160 \\
\hline HLP-06 & 10.35 & 6.00 & 37.9 & 9.95 & 0.743 & 1.72 & 0.387 & 0.750 & 0.390 & 62.1 \\
\hline HLP-07 & 10.44 & 9.15 & 51.3 & 9.09 & 1.15 & 3.16 & 0.667 & 1.38 & 0.491 & 79.3 \\
\hline HLP-08 & 10.92 & 4.12 & 63.5 & 7.71 & 1.23 & 3.39 & 0.857 & 1.36 & 0.642 & 115 \\
\hline HLP-09 & 10.38 & 17.3 & 44.7 & 5.11 & 0.653 & 1.67 & 0.351 & 0.672 & 0.351 & 90.6 \\
\hline HLP-10 & 10.74 & 5.99 & 54.1 & 7.13 & 0.850 & 2.29 & 0.531 & 0.967 & 0.466 & 94.1 \\
\hline Blank & 7.03 & $<1.80$ & $<1.80$ & $<2.00$ & 0.252 & 0.235 & $<0.200$ & $<0.200$ & 0.101 & $<0.530$ \\
\hline HLP-11 & 10.63 & 23.2 & 70.0 & 4.54 & 0.973 & 0.224 & 0.897 & 1.24 & 0.535 & 134 \\
\hline HLP-12 & 10.5 & 9.57 & 50.0 & 5.78 & 0.648 & 2.39 & 0.349 & 0.629 & 0.331 & 80.9 \\
\hline HLP-13 & 10.66 & 11.7 & 57.7 & 5.37 & 0.920 & 1.63 & 0.695 & 1.10 & 0.503 & 102 \\
\hline HLP-14 & 10.71 & 19.5 & 60.4 & 4.89 & 0.913 & 2.19 & 0.887 & $<0.200$ & 0.315 & 125 \\
\hline HLP-15 & 10.59 & 8.79 & 52.5 & 5.46 & 0.923 & 2.44 & 0.609 & 2.08 & 0.548 & 88.4 \\
\hline HLP-16 & 10.67 & 13.5 & 58.2 & 6.05 & 0.278 & 2.06 & 0.520 & 0.819 & 0.423 & 107 \\
\hline HLP-17 & 10.68 & 9.35 & 55.1 & 5.64 & 1.14 & 1.29 & 0.486 & 0.468 & 0.244 & 91.5 \\
\hline HLP-18 & 10.67 & 13.3 & 66.3 & 6.69 & 1.92 & 5.86 & 1.42 & 2.51 & $<0.100$ & 107 \\
\hline HLP-19 & 10.7 & 6.07 & 37.8 & 4.72 & 0.330 & 0.438 & 0.222 & $<0.200$ & 0.224 & 74.2 \\
\hline HLP-20 & 10.65 & 12.6 & 56.8 & 5.39 & 1.28 & 3.88 & $<0.200$ & 1.69 & 0.711 & 96.8 \\
\hline Blank & 7.04 & $<1.80$ & $<1.80$ & $<2.00$ & 0.247 & 0.183 & $<0.200$ & $<0.200$ & $<0.100$ & $<0.530$ \\
\hline STD & $\mathrm{n} / \mathrm{a}$ & 20.2 & 55.0 & 4.10 & $<0.200$ & 4.60 & $<0.200$ & $<0.200$ & $<0.100$ & 85.0 \\
\hline HLP-21 & 10.63 & 17.1 & 58.7 & 3.88 & 0.668 & 1.26 & 1.20 & 0.436 & 0.179 & 107 \\
\hline HLP-22 & 10.15 & 3.66 & 36.7 & 4.02 & 0.417 & 0.759 & 0.259 & 0.320 & 0.193 & 37.6 \\
\hline HLP-23 & 11.24 & 29.2 & 88.8 & 7.06 & 1.36 & 4.02 & 1.54 & 1.39 & 0.517 & 226 \\
\hline HLP-24 & 10.4 & 8.49 & 47.6 & 4.97 & 0.606 & 1.35 & 0.395 & 0.587 & 0.290 & 67.3 \\
\hline HLP-25 & 10.68 & 13.2 & 58.3 & 5.06 & 0.809 & 2.09 & 0.647 & 0.764 & 0.386 & 112 \\
\hline HLP-26 & 10.7 & 14.8 & 56.9 & 5.51 & 0.820 & 2.23 & 0.545 & 0.912 & 0.437 & 106 \\
\hline HLP-27 & 11.05 & 74.1 & 67.8 & 8.28 & 2.15 & 1.52 & 1.72 & 1.04 & $<1.00$ & 265 \\
\hline HLP-28 & 9.71 & 9.18 & 28.5 & 6.15 & 0.483 & 0.982 & 0.219 & 0.389 & 0.204 & 39.4 \\
\hline HLP-29 & 11.21 & 3.74 & 60.7 & 13.3 & 0.938 & 2.42 & 0.638 & 1.06 & 0.434 & 150 \\
\hline HLP-30 & 10.28 & $<1.80$ & 33.3 & 7.75 & 0.449 & 1.00 & 0.279 & 0.362 & 0.207 & 41.6 \\
\hline Blank & 6.74 & $<1.80$ & $<1.80$ & $<2.00$ & 0.245 & 0.144 & $<0.200$ & $<0.200$ & $<0.100$ & $<0.530$ \\
\hline STD & $\mathrm{n} / \mathrm{a}$ & 19.9 & 54.9 & 4.16 & 0.208 & 4.62 & $<0.200$ & $<0.200$ & $<0.100$ & 84.1 \\
\hline HLP-31 & 10.94 & 195 & 296 & $<2.00$ & 2.31 & 1.79 & 2.01 & 1.26 & $<1.00$ & 604 \\
\hline HLP-32 & 9.88 & 18.3 & 51.8 & $<2.00$ & 0.422 & 0.667 & 0.270 & 0.311 & 0.184 & 62.7 \\
\hline HLP-33 & 11.34 & 16.4 & 138 & 3.72 & 1.14 & 3.38 & 1.26 & 1.14 & 0.380 & 243 \\
\hline HLP-34 & 10.43 & 2.67 & 46.7 & 2.23 & 0.373 & 0.533 & 0.279 & 0.227 & 0.149 & 57.1 \\
\hline HLP-35 & 10.91 & 37.2 & 44.0 & 17.7 & 0.502 & 0.956 & 0.322 & 0.351 & 0.228 & 169 \\
\hline HLP-36 & 10.19 & 12.9 & 26.2 & 9.86 & 0.333 & 0.321 & 0.253 & $<0.200$ & 0.140 & 58.4 \\
\hline HLP-37 & 11.32 & 4.44 & 47.7 & 30.5 & 2.59 & 5.17 & 1.82 & $<0.200$ & 0.101 & 160 \\
\hline HLP-37Q & 11.41 & 7.16 & 44.8 & 19.4 & 0.468 & 0.815 & 0.277 & 0.217 & 0.117 & 181 \\
\hline HLP-38 & 10.67 & 4.14 & 29.6 & 13.6 & 0.335 & 0.410 & 0.316 & $<0.200$ & 0.176 & 66.1 \\
\hline HLP-38Q & 10.73 & $<1.80$ & 26.0 & 11.1 & 0.327 & 0.321 & 0.226 & $<0.200$ & 0.134 & 52.9 \\
\hline Blank & 6.75 & $<1.80$ & $<1.80$ & $<2.00$ & 0.247 & 0.144 & $<0.200$ & $<0.200$ & $<0.100$ & 47.2 \\
\hline
\end{tabular}




\begin{tabular}{ccccccccccc}
\hline & \multicolumn{8}{c}{ Diluted Concentration, $\mathbf{p}$, in Test Solution (mg/L) } \\
SampleID & $\mathbf{p H}$ & $\mathbf{B}$ & $\mathbf{S i}$ & $\mathbf{A l}$ & $\mathbf{Z n}$ & $\mathbf{F e}$ & $\mathbf{M g}$ & $\mathbf{T i}$ & $\mathbf{Z r}$ & $\mathbf{N a}$ \\
\hline HLP-39 & 11.49 & 120 & 72.9 & 3.21 & 2.40 & 2.94 & 2.03 & 1.14 & $<1.00$ & 433 \\
HLP-40 & 10.38 & 26.3 & 39.1 & 2.15 & 0.391 & 0.419 & 0.331 & $<0.200$ & 0.112 & 92.7 \\
HLP-40Q & 10.36 & 19.6 & 34.4 & 2.68 & 0.292 & 0.309 & 0.251 & $<0.200$ & $<0.100$ & 80.4 \\
HLP-41 & 11.77 & 47.82 & 94.4 & 4.59 & 2.45 & 2.42 & 1.84 & 1.14 & $<1.00$ & 435 \\
HLP-42 & 11.03 & 6.75 & 40.9 & 3.61 & 0.394 & 0.469 & 0.344 & $<0.200$ & 0.100 & 91.6 \\
HLP-42Q & 10.95 & 7.96 & 32.7 & 3.88 & 0.376 & 0.436 & 0.301 & $<0.200$ & 0.103 & 81.3 \\
HLP-43 & 10.74 & 13.3 & 45.8 & 4.80 & 0.710 & 2.04 & 0.393 & 0.823 & 0.389 & 88.6 \\
HLP-47 & 11.04 & 16.7 & 57.8 & 5.50 & 0.292 & 0.941 & $<0.200$ & $<0.200$ & 0.355 & 144 \\
HLP-48 & 11.07 & 19.8 & 42.5 & 14.8 & 0.824 & 0.686 & 0.383 & $<0.200$ & 0.143 & 112 \\
HLP-49 & 10.68 & 9.13 & 26.8 & 4.32 & 0.365 & 0.310 & 0.223 & $<0.200$ & $<0.100$ & 34.4 \\
STD & n/a & 20.9 & 54.5 & 4.01 & 0.210 & 4.78 & $<0.200$ & $<0.200$ & $<0.100$ & 80.4 \\
HLP-52 & 12.49 & $<1.80$ & 116 & 24.7 & 2.84 & 2.00 & 1.78 & 1.06 & $<1.00$ & 59.0 \\
HLP-54 & 11.01 & 7.39 & 34.2 & 6.24 & 0.301 & 0.199 & $<0.200$ & $<0.200$ & $<0.100$ & 134 \\
HLP-55 & 10.49 & 25.1 & 74.3 & 2.38 & 0.303 & 0.198 & $<0.200$ & $<0.200$ & $<0.100$ & 163 \\
HLP-46 & 11.42 & 3.32 & 54.2 & 8.86 & 0.246 & 0.141 & $<0.200$ & $<0.200$ & $<0.100$ & $<0.530$ \\
HLP-44 & 10.5 & 15.5 & 49.5 & 5.58 & 0.522 & 5.70 & 0.252 & 0.651 & 0.150 & 87.8 \\
HLP-45 & 10.59 & 16.1 & 50.4 & 5.33 & 0.523 & 1.80 & 0.309 & 0.613 & 0.213 & 95.6 \\
HLP-51 & 10.8 & 13.2 & 34.1 & 8.80 & 0.361 & 1.13 & $<0.100$ & $<0.100$ & $<0.100$ & 99.9 \\
Blank & 6.21 & $<1.80$ & $<1.80$ & $<2.00$ & 0.223 & 0.274 & $<0.200$ & $<0.200$ & $<0.100$ & $<0.530$ \\
Blank & 6.30 & $<1.80$ & $<1.80$ & $<2.00$ & 0.241 & 0.148 & $<0.200$ & $<0.200$ & $<0.100$ & $<0.530$ \\
Blank & 6.25 & $<1.80$ & $<1.80$ & $<2.00$ & 0.250 & 0.187 & $<0.200$ & $<0.200$ & $<0.100$ & $<0.530$ \\
Blank & 6.08 & $<1.80$ & $<1.80$ & $<2.00$ & 0.238 & 0.143 & $<0.200$ & $<0.200$ & $<0.100$ & $<0.530$ \\
Blank & 6.01 & $<1.80$ & $<1.80$ & $<2.00$ & 0.263 & 0.141 & $<0.200$ & $<0.200$ & $<0.100$ & $<0.530$ \\
Blank & 6.02 & $<1.80$ & $<1.80$ & $<2.00$ & 0.243 & 0.141 & $<0.200$ & $<0.200$ & $<0.100$ & $<0.530$ \\
\hline
\end{tabular}

B.6 


\section{Measured Concentrations in 100-h PCT-B Solutions}

Table B-3. SRTC Mobile Laboratory Results for the Measured Concentrations for the 100-h Hanford PCT-B Series. Results Reported on 9/13/1999, Test Temperature $=90^{\circ} \mathrm{C}$, Test Duration $=$ $100 \mathrm{~h},(\mathrm{~S} / \mathrm{V}) \approx 20000 / \mathrm{m}$, and Dilution Factor $=5 / 3$.

\begin{tabular}{|c|c|c|c|c|c|c|c|c|c|c|}
\hline \multirow[b]{2}{*}{ SampleID } & \multirow[b]{2}{*}{ pH } & \multicolumn{9}{|c|}{ Diluted Concentration, $p$, in Test Solution $(\mathrm{mg} / \mathrm{L})$} \\
\hline & & B & $\mathbf{S i}$ & Al & Zn & $\mathbf{F e}$ & Mg & $\mathbf{T i}$ & $\mathbf{Z r}$ & $\mathbf{N a}$ \\
\hline STD & $\mathrm{n} / \mathrm{a}$ & 21.7 & 53.5 & 4.10 & $<0.040$ & 4.24 & $<0.100$ & $<0.100$ & $<0.100$ & 87.0 \\
\hline HLP-01 & 10.95 & 60.8 & 92.8 & 6.39 & 2.79 & 4.86 & 2.79 & 2.69 & 1.27 & 258 \\
\hline HLP-02 & 12.09 & 532 & 114 & 18.6 & 0.530 & $<0.200$ & 0.680 & $<1.00$ & $<1.00$ & 1740 \\
\hline HLP-03 & 10.92 & 49.3 & 99.2 & 4.63 & 2.58 & 5.29 & 2.41 & 2.80 & 1.28 & 221 \\
\hline HLP-04 & 11.84 & 338 & 110 & 11.8 & 0.710 & 0.740 & 0.950 & 1.08 & $<1.00$ & 1020 \\
\hline HLP-05 & 11.56 & 524 & 528 & $<2.00$ & 0.420 & $<0.200$ & 0.670 & 1.00 & $<1.00$ & 1560 \\
\hline HLP-06 & 10.98 & 33.7 & 54.7 & 15.8 & 2.53 & 4.65 & 2.11 & 2.79 & 1.21 & 148 \\
\hline HLP-07 & 11.09 & 45.5 & 78.8 & 11.6 & 3.32 & 5.83 & 2.93 & 3.13 & 1.32 & 188 \\
\hline HLP-08 & 11.63 & 26.4 & 125 & 12.5 & 3.83 & 8.10 & 3.22 & 3.66 & 1.19 & 275 \\
\hline HLP-09 & 10.92 & 106 & 73.6 & 6.45 & 3.58 & 5.05 & 4.03 & 2.20 & 1.08 & 286 \\
\hline HLP-10 & 11.44 & 38.7 & 109 & 9.44 & 2.96 & 6.27 & 2.57 & 3.22 & 1.26 & 250 \\
\hline Blank & 6.76 & 0.369 & $<0.180$ & 0.202 & 0.109 & $<0.020$ & $<0.100$ & $<0.100$ & $<0.100$ & $<0.530$ \\
\hline HLP-11 & 11.3 & 185 & 226 & 1.82 & 4.34 & $<0.200$ & 4.49 & 1.85 & 1.10 & 589 \\
\hline HLP-12 & 11.17 & 50.7 & 88.0 & 7.41 & 2.38 & 6.51 & 2.23 & 2.18 & 1.04 & 214 \\
\hline HLP-13 & 11.33 & 89.7 & 130 & 4.58 & 3.66 & 3.92 & 4.11 & 3.09 & 1.45 & 336 \\
\hline HLP-14 & 11.47 & 149 & 151 & 4.41 & 4.76 & 7.41 & 4.94 & $<1.00$ & 1.28 & 487 \\
\hline HLP-15 & 11.28 & 48.3 & 103 & 8.31 & 2.75 & 5.74 & 2.67 & 5.03 & 1.27 & 236 \\
\hline HLP-16 & 11.36 & 75.3 & 111 & 6.85 & $<0.400$ & 7.11 & 4.15 & 3.14 & 1.41 & 291 \\
\hline HLP-17 & 11.29 & 66.7 & 109 & 6.23 & 8.30 & 5.57 & 3.18 & 2.72 & 1.15 & 282 \\
\hline HLP-18 & 11.34 & 92.1 & 147 & 8.62 & 7.36 & 13.1 & 7.14 & 5.74 & $<1.00$ & 335 \\
\hline HLP-19 & 11.29 & 38.9 & 72.3 & 5.83 & 1.22 & 1.81 & 1.53 & 1.40 & 1.24 & 185 \\
\hline HLP-20 & 11.33 & 56.4 & 96.0 & 6.70 & 2.20 & 7.22 & 0.670 & 3.84 & 1.53 & 250 \\
\hline Blank & 7.11 & 0.370 & $<0.180$ & $<0.200$ & 0.090 & $<0.200$ & $<0.100$ & $<0.100$ & 0.112 & $<0.530$ \\
\hline STD & $\mathrm{n} / \mathrm{a}$ & 21.6 & 51.4 & 4.00 & $<0.040$ & 4.38 & $<0.100$ & $<0.100$ & $<0.100$ & 83.6 \\
\hline HLP-21 & 11.33 & 110 & 121 & 7.82 & 2.55 & 3.27 & 4.94 & 1.82 & 1.18 & 373 \\
\hline HLP-22 & 10.34 & 37.9 & 66.2 & 4.79 & 2.02 & 3.50 & 2.09 & 2.16 & 1.08 & 119 \\
\hline HLP-23 & 11.92 & 152 & 187 & 6.72 & 2.31 & 4.65 & 2.79 & 2.06 & 1.09 & 726 \\
\hline HLP-24 & 10.89 & 54.0 & 86.3 & 5.40 & 2.63 & 4.74 & 2.67 & 2.75 & 1.32 & 186 \\
\hline HLP-25 & 11.36 & 80.5 & 113 & 6.29 & 3.64 & 5.90 & 3.74 & 2.71 & 1.22 & 309 \\
\hline HLP-26 & 11.33 & 78.0 & 111 & 6.67 & 3.35 & 5.90 & 3.43 & 2.87 & 1.40 & 282 \\
\hline HLP-27 & 12.01 & 384 & 138 & 16.6 & $<0.400$ & 0.300 & $<1.00$ & $<1.00$ & $<1.00$ & 1110 \\
\hline HLP-28 & 10.04 & 42.5 & 46.8 & 10.0 & 0.990 & 2.01 & $<1.00$ & 1.62 & $<1.00$ & 94.3 \\
\hline HLP-29 & 11.87 & 27.0 & 126 & 25.8 & 2.02 & 4.44 & 1.91 & 2.53 & 1.16 & 340 \\
\hline HLP-30 & 10.95 & 12.0 & 60.8 & 14.0 & 1.42 & 3.28 & 1.39 & 2.18 & 1.09 & 88.4 \\
\hline Blank & 5.17 & 0.409 & $<0.180$ & $<0.200$ & 0.103 & $<0.200$ & $<0.100$ & $<0.100$ & $<0.100$ & $<0.530$ \\
\hline STD & $\mathrm{n} / \mathrm{a}$ & 21.7 & 52.2 & 3.99 & $<0.040$ & 4.42 & $<0.100$ & $<0.100$ & $<0.100$ & 85.4 \\
\hline HLP-31 & 11.71 & 714 & 804 & $<2.00$ & 0.500 & $<0.200$ & $<1.00$ & $<1.00$ & $<1.00$ & 2200 \\
\hline HLP-32 & 9.96 & 101 & 95.9 & $<2.00$ & 1.49 & 2.18 & 1.73 & 1.72 & $<1.00$ & 206 \\
\hline HLP-33 & 12.34 & 376 & 1270 & $<2.00$ & 0.790 & 0.470 & $<1.00$ & 1.00 & $<1.00$ & 2300 \\
\hline HLP-34 & 11 & 31.9 & 122 & 2.31 & 1.79 & 3.56 & 1.82 & 2.18 & 1.12 & 163 \\
\hline HLP-35 & 11.76 & 270 & 65.5 & 20.0 & 0.950 & 1.09 & 1.06 & 1.17 & $<1.00$ & 739 \\
\hline HLP-36 & 10.22 & 82.8 & 35.2 & 12.0 & 2.05 & 1.16 & 1.86 & 1.22 & 1.07 & 174 \\
\hline HLP-37 & 12.06 & 89.0 & 97.2 & 62.2 & 4.74 & 7.68 & 2.69 & 1.07 & $<1.00$ & 580 \\
\hline HLP-37Q & 12.08 & 38.9 & 106 & 40.9 & 0.780 & 1.06 & $<1.00$ & 1.08 & $<1.00$ & 502 \\
\hline HLP-38 & 11.3 & 26.3 & 52.2 & 22.2 & 0.990 & 1.18 & 1.51 & 1.35 & $<1.00$ & 143 \\
\hline HLP-38Q & 11.35 & 19.9 & 54.9 & 21.2 & 1.10 & 1.45 & 1.28 & 1.49 & 1.15 & 144 \\
\hline Blank & 5.15 & 0.523 & $<0.180$ & $<0.200$ & $<0.040$ & $<0.200$ & $<0.100$ & $<0.100$ & $<0.100$ & $<0.530$ \\
\hline
\end{tabular}

B.7 


\begin{tabular}{|c|c|c|c|c|c|c|c|c|c|c|}
\hline \multirow[b]{2}{*}{ SampleID } & \multirow[b]{2}{*}{ pH } & \multicolumn{9}{|c|}{ Diluted Concentration, $p$, in Test Solution $(\mathrm{mg} / \mathrm{L})$} \\
\hline & & B & $\mathbf{S i}$ & Al & Zn & $\mathrm{Fe}$ & Mg & $\mathbf{T i}$ & $\mathbf{Z r}$ & $\mathbf{N a}$ \\
\hline HLP-39 & 12.2 & 931 & 312 & $<2.00$ & 0.540 & $<0.200$ & $<1.00$ & $<1.00$ & $<1.00$ & 2460 \\
\hline HLP-40 & 10.18 & 361 & 66.0 & $<2.00$ & 1.51 & 1.41 & 1.82 & 1.11 & $<1.00$ & 655 \\
\hline HLP-40Q & 10.1 & 378 & 46.2 & $<2.00$ & 0.410 & 0.260 & $<1.00$ & $<1.00$ & $<1.00$ & 660 \\
\hline HLP-41 & 12.72 & 694 & 55.1 & 6.21 & 2.24 & 1.16 & $<1.00$ & $<1.00$ & $<1.00$ & 3260 \\
\hline HLP-42 & 11.75 & 125 & 176 & 2.35 & 2.28 & 3.17 & 2.25 & 1.36 & $<1.00$ & 463 \\
\hline HLP-42Q & 11.67 & 120 & 127 & 2.93 & 2.43 & 4.66 & 2.40 & 1.62 & $<1.00$ & 395 \\
\hline HLP-43 & 11.32 & 99.5 & 124 & 36.4 & 15.3 & 42.4 & 9.87 & 17.9 & 1.18 & 350 \\
\hline HLP-47 & 10.67 & 96.8 & 147 & 8.60 & $<0.040$ & 1.54 & $<1.00$ & $<1.00$ & 1.34 & 459 \\
\hline HLP-48 & 11.74 & 97.6 & 70.6 & 20.1 & 4.46 & 2.46 & 1.59 & 1.51 & 1.16 & 361 \\
\hline HLP-49 & 11.32 & 33.8 & 56.1 & 9.19 & 0.560 & 0.220 & $<1.00$ & $<1.00$ & $<1.00$ & 80.3 \\
\hline STD & $\mathrm{n} / \mathrm{a}$ & 23.2 & 53.6 & 4.14 & $<0.040$ & 4.54 & $<0.100$ & $<0.100$ & $<0.100$ & 83.6 \\
\hline HLP-52 & 13.19 & 15.2 & 367 & 36.7 & 0.400 & 1.42 & $<1.00$ & $<1.00$ & $<1.00$ & 5700 \\
\hline HLP-54 & 11.29 & 40.7 & 78.2 & 11.2 & 0.320 & $<0.200$ & $<1.00$ & $<1.00$ & $<1.00$ & 214 \\
\hline HLP-55 & 11.26 & 102 & 196 & $<2.00$ & 0.330 & $<0.200$ & $<1.00$ & $<1.00$ & $<1.00$ & 368 \\
\hline HLP-46 & 12.1 & 18.6 & 142 & 26.1 & 0.310 & $<0.200$ & $<1.00$ & $<1.00$ & $<1.00$ & 470 \\
\hline Blank & 5.43 & 0.805 & $<0.180$ & $<0.200$ & 0.105 & 0.028 & $<0.100$ & $<0.100$ & $<0.100$ & $<0.530$ \\
\hline Blank & 5.52 & 0.773 & $<0.180$ & $<0.200$ & 0.127 & 0.035 & $<0.100$ & 0.101 & $<0.100$ & $<0.530$ \\
\hline Blank & 5.29 & 0.713 & $<0.180$ & $<0.200$ & 0.107 & 0.026 & $<0.100$ & $<0.100$ & $<0.100$ & $<0.530$ \\
\hline Blank & 5.22 & 0.632 & $<0.180$ & $<0.200$ & 0.095 & $<0.020$ & $<0.100$ & $<0.100$ & $<0.100$ & $<0.530$ \\
\hline Blank & 5.10 & $<0.180$ & $<0.180$ & $<0.200$ & 0.179 & 0.084 & $<0.100$ & $<0.100$ & $<0.100$ & $<0.530$ \\
\hline Blank & 5.10 & $<0.180$ & $<0.180$ & $<0.200$ & 0.164 & 0.174 & $<0.100$ & $<0.100$ & $<0.100$ & $<0.530$ \\
\hline Blank & 6.68 & 0.595 & $<0.180$ & $<0.200$ & 0.168 & 0.059 & $<0.100$ & $<0.100$ & $<0.100$ & $<0.530$ \\
\hline HLP-44 & 10.97 & 53.7 & 86.0 & 5.80 & 2.14 & 3.72 & 2.25 & 2.21 & 1.13 & 205 \\
\hline HLP-45 & 11.13 & 57.0 & 99.0 & 6.57 & 2.37 & 4.94 & 2.38 & 2.48 & 1.14 & 238 \\
\hline HLP-51 & 11.48 & 45.9 & 65.7 & 13.8 & 1.68 & 0.650 & 1.06 & 1.05 & $<1.00$ & 232 \\
\hline STD & $\mathrm{n} / \mathrm{a}$ & 21.8 & 55.2 & 4.01 & $<0.040$ & 4.62 & $<0.100$ & $<0.100$ & $<0.100$ & 82.2 \\
\hline
\end{tabular}




\section{Measured Concentrations in 1000-h PCT-B Solutions}

Table B-4. SRTC Mobile Laboratory Results for the Measured $\mathrm{pH}$ and Concentrations for the 1000-h Hanford PCT-B Series. Results Reported on 9/19/1999, 9/29/1999, and 10/20/19999, Test Temperature $=90^{\circ} \mathrm{C}$, Test Duration $=1000 \mathrm{~h}$, and $(\mathrm{S} / \mathrm{V}) \approx 20000 / \mathrm{m}$. Dilution factors are also provided.

\begin{tabular}{|c|c|c|c|c|c|c|c|c|c|c|c|}
\hline \multirow[b]{2}{*}{ SampleID } & \multicolumn{3}{|c|}{ Dilution } & \multicolumn{7}{|c|}{ Diluted Concentration, $p$, in Test Solution $(\mathrm{mg} / \mathrm{L})$} & \multirow[b]{2}{*}{ Na } \\
\hline & pH & Factor & $\mathbf{Z n}$ & $\mathrm{Fe}$ & B & $\mathbf{S i}$ & Mg & $\mathbf{T i}$ & $\mathbf{Z r}$ & Al & \\
\hline Blank & 6.72 & $5 / 3$ & 0.115 & 0.020 & $<0.180$ & 0.308 & $<0.010$ & $<0.060$ & $<0.060$ & $<0.200$ & $<0.530$ \\
\hline HLP-47 & 12.13 & $5 / 3$ & $<0.400$ & 0.340 & 273 & 215 & $<0.100$ & $<0.600$ & $<0.600$ & 11.4 & 1080 \\
\hline HLP-02 & 12.51 & $5 / 3$ & 0.410 & 0.250 & 1007 & 162 & $<0.100$ & $<0.600$ & $<0.600$ & 21.9 & 2850 \\
\hline HLP-03 & 11.11 & $5 / 3$ & 3.95 & 5.27 & 110 & 133 & 2.83 & 2.36 & 1.14 & 3.53 & 371 \\
\hline HLP-04 & 12.22 & $9 / 5$ & $<0.400$ & $<0.200$ & 634 & 139 & $<0.100$ & $<0.600$ & $<0.600$ & 11.2 & 1740 \\
\hline HLP-05 & 11.86 & $9 / 5$ & 0.300 & $<0.200$ & 1102 & 875 & $<0.100$ & $<0.600$ & $<0.600$ & $<2.00$ & 2960 \\
\hline HLP-09 & 11.05 & $5 / 3$ & 1.25 & 1.67 & 361 & 80.5 & $<0.100$ & 0.900 & $<0.600$ & $<2.00$ & 781 \\
\hline HLP-11 & 11.73 & $5 / 3$ & 1.50 & $<0.200$ & 329 & 247 & 1.18 & 0.880 & $<0.600$ & 1.57 & 986 \\
\hline HLP-13 & 11.51 & $5 / 3$ & 3.41 & 2.45 & 190 & 160 & 3.69 & 1.82 & 0.840 & 3.56 & 611 \\
\hline HLP-14 & 11.74 & $5 / 3$ & 0.620 & 0.740 & 275 & 182 & 0.210 & $<0.600$ & $<0.600$ & 2.55 & 755 \\
\hline HLP-15 & 11.33 & $5 / 3$ & 2.37 & 3.64 & 96.7 & 116 & 1.82 & 2.98 & 1.03 & 6.39 & 367 \\
\hline HLP-16 & 11.58 & $5 / 3$ & $<0.400$ & 3.51 & 147 & 125 & 2.45 & 1.64 & 0.890 & 5.29 & 513 \\
\hline HLP-17 & 11.45 & $5 / 3$ & 7.64 & 4.08 & 140 & 130 & 2.09 & 1.93 & 0.880 & 4.82 & 438 \\
\hline HLP-18 & 11.61 & $5 / 3$ & 0.440 & 0.630 & 200 & 165 & $<0.100$ & 0.750 & $<0.600$ & 3.85 & 602 \\
\hline HLP-19 & 11.35 & $5 / 3$ & 1.91 & 3.05 & 71.3 & 83.9 & 1.44 & 1.30 & 1.22 & 5.77 & 282 \\
\hline HLP-20 & 11.38 & $5 / 3$ & 2.85 & 7.57 & 107 & 116 & $<0.100$ & 3.46 & 1.51 & 6.44 & 377 \\
\hline HLP-21 & 11.64 & $5 / 3$ & 2.04 & 2.79 & 211 & 157 & 3.78 & 1.21 & 0.860 & 4.47 & 638 \\
\hline HLP-22 & 10.16 & $5 / 3$ & 2.97 & 4.29 & 77.0 & 71.2 & 1.96 & 2.34 & 1.16 & 3.87 & 183 \\
\hline HLP-23 & 12.18 & $5 / 3$ & $<0.400$ & 0.520 & 252 & 223 & $<0.100$ & 0.650 & 0.640 & 7.01 & 1030 \\
\hline HLP-24 & 10.83 & $5 / 3$ & 3.81 & 4.87 & 116 & 9.89 & 3.07 & 2.43 & 1.30 & 4.35 & 318 \\
\hline HLP-25 & 11.57 & $5 / 3$ & 3.88 & 5.29 & 172 & 146 & 3.61 & 1.87 & 1.01 & 5.64 & 515 \\
\hline STD & $\mathrm{n} / \mathrm{a}$ & $5 / 3$ & $<0.040$ & 3.96 & 21.4 & 49.3 & $<0.010$ & $<0.060$ & $<0.060$ & 3.87 & 78.8 \\
\hline Blank & 6.46 & $5 / 3$ & 0.099 & $<0.020$ & 1.41 & $<0.180$ & $<0.060$ & $<0.060$ & $<0.200$ & $<0.530$ & 0.745 \\
\hline HLP-26 & 11.49 & $5 / 3$ & 4.21 & 5.46 & 152 & 142 & 4.05 & 2.31 & 2.07 & 5.31 & 518 \\
\hline HLP-27 & 12.34 & $5 / 3$ & $<0.400$ & $<0.200$ & 893 & 181 & $<0.100$ & $<0.600$ & $<0.600$ & 22.1 & 2140 \\
\hline HLP-28 & 9.57 & $5 / 3$ & 1.61 & 1.52 & 92.6 & 38.7 & 0.570 & 1.09 & 0.660 & 6.25 & 151 \\
\hline HLP-29 & 12.18 & $9 / 5$ & $<0.400$ & 0.670 & 50.2 & 152 & $<0.100$ & 0.700 & $<0.600$ & 30.4 & 572 \\
\hline HLP-30 & 10.94 & $9 / 5$ & 1.56 & 3.48 & 21.9 & 64.3 & 0.740 & 1.97 & 0.870 & 13.6 & 134 \\
\hline HLP-31 & 11.99 & $5 / 3$ & $<0.400$ & $<0.200$ & 1270 & 1150 & $<0.100$ & $<0.600$ & $<0.600$ & $<2.00$ & 3700 \\
\hline HLP-32 & 9.85 & $5 / 3$ & 8.33 & 9.54 & 275 & 123 & 6.67 & 3.11 & 1.11 & $<2.00$ & 405 \\
\hline HLP-33 & 12.65 & $5 / 3$ & $<0.400$ & $<0.200$ & 1410 & 485 & $<0.100$ & $<0.600$ & $<0.600$ & $<2.00$ & 7230 \\
\hline HLP-34 & 11.28 & $5 / 3$ & 5.60 & 11.2 & 64.9 & 188 & 3.87 & 3.29 & 1.29 & 2.86 & 244 \\
\hline HLP-35 & 12.09 & $5 / 3$ & $<0.400$ & $<0.200$ & 530 & 68.8 & $<0.100$ & $<0.600$ & $<0.600$ & 20.6 & 1520 \\
\hline HLP-36 & 9.72 & $5 / 3$ & 7.13 & 3.09 & 328 & 29.8 & 5.03 & 1.35 & 0.980 & 8.79 & 551 \\
\hline HLP-37 & 12.42 & $5 / 3$ & & & & & ost sample & & & & \\
\hline HLP-37Q & 11.66 & $5 / 3$ & $<0.400$ & 0.400 & 76.0 & 134 & $<0.100$ & $<0.600$ & $<0.600$ & 49.4 & 854 \\
\hline HLP-38Q & 11.67 & $5 / 3$ & & 3.77 & 43.4 & 72.7 & 1.59 & 1.54 & 1.07 & 25.0 & 248 \\
\hline HLP-39 & 12.39 & $5 / 3$ & $<0.400$ & $<0.200$ & 1130 & 421 & $<0.100$ & $<0.600$ & $<0.600$ & 1.27 & 3190 \\
\hline HLP-40Q & 10.1 & $5 / 3$ & $<0.400$ & $<0.200$ & 706 & 54.1 & $<0.100$ & $<0.600$ & $<0.600$ & $<2.00$ & 1320 \\
\hline HLP-40 & 10.04 & $9 / 5$ & $<0.400$ & $<0.200$ & 675 & 53.2 & $<0.100$ & $<0.600$ & $<0.600$ & $<2.00$ & 1300 \\
\hline HLP-41 & 12.99 & $5 / 3$ & 2.44 & 1.00 & 930 & 867 & $<0.100$ & $<0.600$ & $<0.600$ & 4.82 & 4660 \\
\hline HLP-42Q & 12.34 & $5 / 3$ & $<0.400$ & $<0.200$ & 880 & 270 & $<0.100$ & $<0.600$ & $<0.600$ & 1.38 & 2440 \\
\hline HLP-43 & 11.6 & $5 / 3$ & 5.26 & 7.22 & 174 & 148 & 4.59 & 2.54 & 1.58 & 5.44 & 498 \\
\hline HLP-46 & 12.37 & $5 / 3$ & $<0.400$ & $<0.200$ & 55.7 & 252 & $<0.100$ & $<0.600$ & $<0.600$ & 16.3 & 778 \\
\hline STD & $\mathrm{n} / \mathrm{a}$ & $5 / 3$ & $<0.040$ & 4.28 & 20.7 & 49.6 & 0.035 & $<0.010$ & $<0.080$ & 3.93 & $<0.530$ \\
\hline HLP-01 & 11.47 & $5 / 3$ & 4.73 & 5.54 & 139 & 126 & 4.44 & 0.730 & $<0.800$ & 6.02 & 505 \\
\hline
\end{tabular}




\begin{tabular}{cccccccccccc}
\hline & & Dilution & \multicolumn{8}{c}{ Diluted Concentration, $\mathbf{p}$, in Test Solution $\mathbf{( m g / L )}$} \\
SampleID & $\mathbf{p H}$ & Factor & $\mathbf{Z n}$ & $\mathbf{F e}$ & $\mathbf{B}$ & $\mathbf{S i}$ & $\mathbf{M g}$ & $\mathbf{T i}$ & $\mathbf{Z r}$ & $\mathbf{A l}$ & $\mathbf{N a}$ \\
\hline HLP-06 & 11.29 & $5 / 3$ & 4.11 & 4.82 & 50.7 & 67.2 & 2.73 & 0.870 & $<0.800$ & 15.8 & 227 \\
HLP-07 & 11.5 & $5 / 3$ & 5.00 & 5.93 & 89.6 & 92.8 & 3.79 & 1.22 & $<0.800$ & 11.7 & 353 \\
HLP-08 & 12.05 & $5 / 3$ & 2.22 & 3.49 & 37.1 & 168 & 1.63 & $<0.100$ & $<0.800$ & 14.3 & 485 \\
HLP-10 & 11.85 & $5 / 3$ & 4.40 & 6.47 & 63.8 & 153 & 3.58 & 1.00 & $<0.800$ & 11.2 & 419 \\
HLP-12 & 11.59 & $5 / 3$ & 4.74 & 10.7 & 98.0 & 114 & 3.70 & 1.04 & $<0.800$ & 7.47 & 377 \\
STD & n/a & $5 / 3$ & $<0.040$ & 4.40 & 21.0 & 51.4 & 0.032 & $<0.010$ & $<0.080$ & 3.96 & 81.0 \\
HLP-38 & 11.66 & $5 / 3$ & 3.86 & 3.29 & 41.6 & 70.0 & 4.05 & $<0.100$ & $<0.800$ & 28.8 & 252 \\
HLP-42 & 12.42 & $5 / 3$ & 0.680 & $<0.200$ & 835 & 509 & 0.310 & $<0.100$ & $<0.800$ & $<2.00$ & 3000 \\
HLP-48 & 11.87 & $9 / 5$ & 1.68 & $<0.200$ & 200 & 86.5 & 0.570 & $<0.100$ & $<0.800$ & 22.6 & 744 \\
HLP-49 & 11.41 & $5 / 3$ & 0.630 & $<0.200$ & 45.8 & 78.8 & 0.380 & $<0.100$ & $<0.800$ & 13.4 & 137 \\
HLP-52 & 13.57 & $9 / 5$ & $<0.400$ & 4.80 & 12.4 & 4900 & 0.300 & $<0.100$ & 1.91 & 64.7 & 17000 \\
HLP-54 & 11.52 & $5 / 3$ & $<0.400$ & $<0.200$ & 82.4 & 92.6 & 0.330 & $<0.100$ & $<0.800$ & 9.97 & 360 \\
HLP-55 & 11.73 & $5 / 3$ & $<0.400$ & $<0.200$ & 235 & 265 & 0.300 & $<0.100$ & $<0.800$ & 2.85 & 851 \\
STD & n/a & $5 / 3$ & 21.4 & 50.3 & 3.98 & 0.114 & 4.28 & 0.051 & 0.129 & $<0.080$ & 85.0 \\
Blank & 5.61 & $5 / 3$ & 0.279 & 0.308 & 0.629 & 0.279 & $<0.020$ & 0.077 & $<0.100$ & $<0.080$ & 0.902 \\
HLP-44 & 11.34 & $5 / 3$ & 142 & 132 & 6.53 & 4.65 & 3.08 & 3.95 & 1.87 & 0.690 & 543 \\
HLP-45 & 11.45 & $5 / 3$ & 119 & 136 & 7.50 & 3.82 & 2.76 & 3.04 & 1.77 & 0.790 & 567 \\
HLP-51 & 11.48 & $5 / 3$ & 114 & 80.6 & 15.6 & 2.81 & $<0.200$ & 1.04 & $<0.100$ & 0.510 & 577 \\
STD & n/a & $5 / 3$ & 22.2 & 49.8 & 3.99 & 0.114 & 3.99 & 0.050 & $<0.100$ & $<0.080$ & 78.8 \\
Blank & 5.90 & $5 / 3$ & 0.317 & 0.285 & 0.208 & 0.186 & $<0.020$ & 0.060 & $<0.100$ & $<0.080$ & 0.927 \\
Blank & 7.0 & $5 / 3$ & 0.243 & 0.243 & $<0.200$ & 0.166 & $<0.020$ & 0.056 & $<0.100$ & $<0.080$ & 0.774 \\
\hline
\end{tabular}




\section{PCT-A Normalized Release Information}

Table B-5. Dilution Adjusted Release Values for the PCT-A Boron, Sodium, and Silicon Results for the Hanford Glasses. Test Temperature $=90^{\circ} \mathrm{C}$, Test Duration $=165 \mathrm{~h},(\mathrm{~S} / \mathrm{V}) \approx 2000 / \mathrm{m}$, and Dilution Factor $=5 / 3$. For these glasses, $(\mathrm{S} / \mathrm{V}) \mathrm{t}$ is approximately $330000 \mathrm{~h} / \mathrm{m}$.

\begin{tabular}{|c|c|c|c|c|c|c|c|c|c|}
\hline \multirow[b]{2}{*}{ SampleID } & \multicolumn{3}{|c|}{$\operatorname{Mean} \ln \left[p_{1}(m g / L)\right]$} & \multicolumn{3}{|c|}{$N C_{i}(g / L)$} & \multicolumn{3}{|c|}{$N_{i}\left(g / m^{2}\right)$} \\
\hline & B & $\mathrm{Na}$ & $\mathbf{S i}$ & B & $\mathrm{Na}$ & $\mathbf{S i}$ & B & $\mathrm{Na}$ & $\mathbf{S i}$ \\
\hline HLP-01 & 2.83 & 4.66 & 4.37 & 0.54 & 0.71 & 0.34 & 0.27 & 0.36 & 0.17 \\
\hline HLP-02 & 5.42 & 6.75 & 4.72 & 5.77 & 4.60 & 0.67 & 2.89 & 2.30 & 0.33 \\
\hline HLP-03 & 2.83 & 4.50 & 4.47 & 0.58 & 0.65 & 0.36 & 0.29 & 0.32 & 0.18 \\
\hline HLP-04 & 4.96 & 6.02 & 4.74 & 3.90 & 2.35 & 0.61 & 1.95 & 1.18 & 0.31 \\
\hline HLP-05 & 4.41 & 5.56 & 5.29 & 2.57 & 1.70 & 0.84 & 1.28 & 0.85 & 0.42 \\
\hline HLP-06 & 2.91 & 4.43 & 4.40 & 0.62 & 0.60 & 0.37 & 0.31 & 0.30 & 0.19 \\
\hline HLP-07 & 2.95 & 4.52 & 4.40 & 0.63 & 0.64 & 0.36 & 0.31 & 0.32 & 0.18 \\
\hline HLP-08 & 2.50 & 4.91 & 4.64 & 0.65 & 0.87 & 0.43 & 0.33 & 0.44 & 0.22 \\
\hline HLP-09 & 3.64 & 4.91 & 4.32 & 1.03 & 0.94 & 0.34 & 0.51 & 0.47 & 0.17 \\
\hline HLP-10 & 2.86 & 4.75 & 4.55 & 0.70 & 0.76 & 0.40 & 0.35 & 0.38 & 0.20 \\
\hline HLP-11 & 3.42 & 4.91 & 4.60 & 0.93 & 0.86 & 0.41 & 0.47 & 0.43 & 0.21 \\
\hline HLP-12 & 3.19 & 4.58 & 4.59 & 0.81 & 0.68 & 0.45 & 0.41 & 0.34 & 0.22 \\
\hline HLP-13 & 3.39 & 4.91 & 4.56 & 0.93 & 0.89 & 0.41 & 0.46 & 0.44 & 0.20 \\
\hline HLP-14 & 3.83 & 5.14 & 4.55 & 1.44 & 1.12 & 0.40 & 0.72 & 0.56 & 0.20 \\
\hline HLP-15 & 3.05 & 4.63 & 4.60 & 0.70 & 0.71 & 0.45 & 0.35 & 0.36 & 0.22 \\
\hline HLP-16 & 3.15 & 4.72 & 4.57 & 0.74 & 0.75 & 0.42 & 0.37 & 0.37 & 0.21 \\
\hline HLP-17 & 3.30 & 4.81 & 4.48 & 0.89 & 0.85 & 0.40 & 0.45 & 0.42 & 0.20 \\
\hline HLP-18 & 3.50 & 4.95 & 4.76 & 1.05 & 0.94 & 0.50 & 0.52 & 0.47 & 0.25 \\
\hline HLP-19 & 2.80 & 4.44 & 4.28 & 0.55 & 0.60 & 0.33 & 0.28 & 0.30 & 0.16 \\
\hline HLP-20 & 3.17 & 4.63 & 4.56 & 0.75 & 0.68 & 0.41 & 0.38 & 0.34 & 0.20 \\
\hline HLP-21 & 3.60 & 4.93 & 4.65 & 1.20 & 0.96 & 0.47 & 0.60 & 0.48 & 0.23 \\
\hline HLP-22 & 2.78 & 4.03 & 4.44 & 0.49 & 0.47 & 0.35 & 0.25 & 0.24 & 0.18 \\
\hline HLP-23 & 4.07 & 5.59 & 4.90 & 1.96 & 1.56 & 0.61 & 0.98 & 0.78 & 0.31 \\
\hline HLP-24 & 3.07 & 4.56 & 4.52 & 0.68 & 0.72 & 0.39 & 0.34 & 0.36 & 0.19 \\
\hline HLP-25 & 3.31 & 4.84 & 4.55 & 0.88 & 0.85 & 0.41 & 0.44 & 0.43 & 0.21 \\
\hline HLP-26 & 3.50 & 4.74 & 4.65 & 1.06 & 0.77 & 0.46 & 0.53 & 0.38 & 0.23 \\
\hline HLP-27 & 5.16 & 6.32 & 4.78 & 4.66 & 3.26 & 0.49 & 2.33 & 1.63 & 0.25 \\
\hline HLP-28 & 2.99 & 3.90 & 4.53 & 0.53 & 0.41 & 0.38 & 0.27 & 0.21 & 0.19 \\
\hline HLP-29 & 2.70 & 5.25 & 4.87 & 0.80 & 1.12 & 0.54 & 0.40 & 0.56 & 0.27 \\
\hline HLP-30 & 1.77 & 4.06 & 4.34 & 0.31 & 0.49 & 0.31 & 0.16 & 0.24 & 0.16 \\
\hline HLP-31 & 6.21 & 7.40 & 6.61 & 13.42 & 9.58 & 3.04 & 6.71 & 4.79 & 1.52 \\
\hline HLP-32 & 3.57 & 4.41 & 4.50 & 0.95 & 0.70 & 0.37 & 0.48 & 0.35 & 0.18 \\
\hline HLP-33 & 4.29 & 6.33 & 5.99 & 3.93 & 3.30 & 1.64 & 1.96 & 1.65 & 0.82 \\
\hline HLP-34 & 2.65 & 4.45 & 4.53 & 0.76 & 0.72 & 0.38 & 0.38 & 0.36 & 0.19 \\
\hline HLP-35 & 4.61 & 5.85 & 4.29 & 2.70 & 2.04 & 0.44 & 1.35 & 1.02 & 0.22 \\
\hline HLP-36 & 3.46 & 4.40 & 3.97 & 0.85 & 0.69 & 0.31 & 0.43 & 0.34 & 0.16 \\
\hline HLP-37 & 3.87 & 5.97 & 4.91 & 2.59 & 2.29 & 0.80 & 1.29 & 1.15 & 0.40 \\
\hline HLP-37Q ${ }^{(a)}$ & 3.16 & 5.53 & 4.61 & 1.26 & 1.48 & 0.60 & 0.63 & 0.74 & 0.30 \\
\hline HLP-38 & 2.69 & 4.44 & 4.13 & 0.79 & 0.72 & 0.37 & 0.40 & 0.36 & 0.18 \\
\hline HLP-38Q ${ }^{(a)}$ & 2.66 & 4.44 & 4.06 & 0.77 & 0.71 & 0.34 & 0.38 & 0.36 & 0.17 \\
\hline HLP-39 & 5.13 & 6.21 & 4.88 & 4.56 & 2.93 & 0.78 & 2.28 & 1.47 & 0.39 \\
\hline HLP-40 & 4.21 & 5.10 & 4.19 & 1.80 & 1.39 & 0.39 & 0.90 & 0.69 & 0.20 \\
\hline HLP-40Q ${ }^{(a)}$ & 4.05 & 4.97 & 4.19 & 1.54 & 1.21 & 0.39 & 0.77 & 0.61 & 0.20 \\
\hline HLP-41 & 5.51 & 7.33 & 5.88 & 13.27 & 8.92 & 2.13 & 6.63 & 4.46 & 1.06 \\
\hline HLP-42 & 3.23 & 4.85 & 4.38 & 1.36 & 1.08 & 0.47 & 0.68 & 0.54 & 0.24 \\
\hline HLP-42Q ${ }^{(a)}$ & 3.49 & 5.04 & 4.40 & 1.77 & 1.30 & 0.48 & 0.88 & 0.65 & 0.24 \\
\hline HLP-43 & 3.23 & 4.61 & 4.45 & 0.82 & 0.68 & 0.37 & 0.41 & 0.34 & 0.19 \\
\hline
\end{tabular}




\begin{tabular}{|c|c|c|c|c|c|c|c|c|c|}
\hline \multirow[b]{2}{*}{ SampleID } & \multicolumn{3}{|c|}{$\operatorname{Mean} \ln \left[p_{1}(\mathrm{mg} / \mathrm{L})\right]$} & \multicolumn{3}{|c|}{$\mathrm{NC}_{\mathrm{i}}(\mathrm{g} / \mathrm{L})$} & \multicolumn{3}{|c|}{$\mathrm{NL}_{\mathbf{i}}\left(\mathrm{g} / \mathrm{m}^{2}\right)$} \\
\hline & B & $\mathbf{N a}$ & $\mathbf{S i}$ & B & $\mathbf{N a}$ & $\mathbf{S i}$ & B & $\mathbf{N a}$ & Si \\
\hline HLP-44 & 3.36 & 4.80 & 5.16 & 0.92 & 0.82 & 0.35 & 0.46 & 0.41 & 0.18 \\
\hline HLP-45 & 3.27 & 4.73 & 4.39 & 0.85 & 0.76 & 0.35 & 0.42 & 0.38 & 0.18 \\
\hline HLP-46 & $0.41^{(b)}$ & 5.02 & 4.14 & 0.096 & 1.00 & 0.24 & 0.048 & 0.50 & 0.12 \\
\hline HLP-47 & 3.26 & 5.05 & 4.35 & 1.05 & 1.05 & 0.30 & 0.53 & 0.53 & 0.15 \\
\hline HLP-48 & 3.52 & 5.04 & 4.11 & 1.23 & 1.04 & 0.34 & 0.61 & 0.52 & 0.17 \\
\hline HLP-49 & 2.70 & 3.72 & 3.60 & 0.60 & 0.56 & 0.18 & 0.30 & 0.28 & 0.09 \\
\hline HLP-50 & \multicolumn{9}{|c|}{ No results for this glass } \\
\hline HLP-51 & 2.96 & 4.72 & 4.05 & 0.67 & 0.75 & 0.29 & 0.34 & 0.38 & 0.15 \\
\hline HLP-52 & $--(c)$ & 7.78 & 5.62 & $--(c)$ & 11.3 & 1.32 & $--(c)$ & 5.65 & 0.66 \\
\hline HLP-53 & \multicolumn{9}{|c|}{ No results for this glass } \\
\hline HLP-54 & 3.26 & 4.96 & 4.68 & 0.93 & 0.97 & 0.41 & 0.46 & 0.48 & 0.20 \\
\hline HLP-55 & 2.16 & 4.41 & 4.25 & 0.31 & 0.55 & 0.25 & 0.16 & 0.28 & 0.13 \\
\hline
\end{tabular}

(a) This indicates that this glass was quenched because the heat-treated glass exhibited crystalline material.

(b) The measured boron release for HLP-46 was less than $1.80 \mathrm{mg} / \mathrm{L}$. A value of one-half this concentration was used for the B concentration for this glass.

(c) As indicated in Table 2-1, Glass HLP-52 contained no boron so the test solution concentration cannot be normalized using the concentration in the glass. 


\section{PCT-B Normalized Release Information}

Table B-6. Normalized Release Values for the PCT-B Boron, Sodium, and Silicon Results for the Hanford Glasses. Test Temperature $=90^{\circ} \mathrm{C}$; Test Duration $=10,100$, and $1000 \mathrm{~h}$; and $(\mathrm{S} / \mathrm{V}) \approx 20,000 / \mathrm{m}$.

\begin{tabular}{|c|c|c|c|c|c|c|c|c|}
\hline \multirow[b]{2}{*}{ SampleID } & \multirow{2}{*}{$\begin{array}{l}\text { Time, t } \\
\text { (hours) }\end{array}$} & \multirow{2}{*}{$\begin{array}{l}(\mathrm{S} / \mathrm{V}) \mathbf{t} \\
(\mathbf{h} / \mathbf{m})\end{array}$} & \multicolumn{3}{|c|}{$N C_{i}(g / L)$} & \multicolumn{3}{|c|}{$N_{i}\left(g / m^{2}\right)$} \\
\hline & & & B & $\mathrm{Na}$ & Si & B & Na & $\mathbf{S i}$ \\
\hline HLP-01 & 10 & $2 \times 10^{5}$ & 0.71 & 1.05 & 1.25 & 0.036 & 0.053 & 0.062 \\
\hline HLP-01 & 100 & $2 \times 10^{6}$ & 3.26 & 2.90 & 2.48 & 0.16 & 0.14 & 0.12 \\
\hline HLP-01 & 1000 & $2 \times 10^{7}$ & 7.46 & 5.67 & 3.37 & 0.37 & 0.28 & 0.17 \\
\hline HLP-02 & 10 & $2 \times 10^{5}$ & 7.60 & 5.50 & 2.57 & 0.38 & 0.27 & 0.13 \\
\hline HLP-02 & 100 & $2 \times 10^{6}$ & 22.71 & 15.55 & 4.15 & 1.14 & 0.78 & 0.21 \\
\hline HLP-02 & 1000 & $2 \times 10^{7}$ & 42.99 & 25.47 & 5.90 & 2.15 & 1.27 & 0.30 \\
\hline HLP-03 & 10 & $2 \times 10^{5}$ & 0.57 & 0.90 & 1.22 & 0.029 & 0.045 & 0.061 \\
\hline HLP-03 & 100 & $2 \times 10^{6}$ & 2.81 & 2.63 & 2.50 & 0.14 & 0.13 & 0.12 \\
\hline HLP-03 & 1000 & $2 \times 10^{7}$ & 6.26 & 4.42 & 3.35 & 0.31 & 0.22 & 0.17 \\
\hline HLP-04 & 10 & $2 \times 10^{5}$ & 2.73 & 0.26 & 1.90 & 0.14 & 0.01 & 0.095 \\
\hline HLP-04 & 100 & $2 \times 10^{6}$ & 15.40 & 9.72 & 3.61 & 0.77 & 0.49 & 0.18 \\
\hline HLP-04 & 1000 & $2 \times 10^{7}$ & 31.20 & 17.91 & 4.92 & 1.56 & 0.90 & 0.25 \\
\hline HLP-05 & 10 & $2 \times 10^{5}$ & 1.77 & 1.74 & 2.33 & 0.09 & 0.09 & 0.12 \\
\hline HLP-05 & 100 & $2 \times 10^{6}$ & 27.25 & 16.97 & 13.7 & 1.36 & 0.85 & 0.68 \\
\hline HLP-05 & 1000 & $2 \times 10^{7}$ & 61.89 & 34.78 & 24.5 & 3.09 & 1.74 & 1.22 \\
\hline HLP-06 & 10 & $2 \times 10^{5}$ & 0.34 & 0.74 & 1.07 & 0.017 & 0.037 & 0.054 \\
\hline HLP-06 & 100 & $2 \times 10^{6}$ & 1.91 & 1.76 & 1.54 & 0.10 & 0.09 & 0.077 \\
\hline HLP-06 & 1000 & $2 \times 10^{7}$ & 2.87 & 2.69 & 1.90 & 0.14 & 0.13 & 0.095 \\
\hline HLP-07 & 10 & $2 \times 10^{5}$ & 0.50 & 0.91 & 1.40 & 0.03 & 0.05 & 0.070 \\
\hline HLP-07 & 100 & $2 \times 10^{6}$ & 2.49 & 2.16 & 2.15 & 0.12 & 0.11 & 0.11 \\
\hline HLP-07 & 1000 & $2 \times 10^{7}$ & 4.91 & 4.05 & 2.54 & 0.25 & 0.20 & 0.13 \\
\hline HLP-08 & 10 & $2 \times 10^{5}$ & 0.37 & 1.24 & 1.63 & 0.018 & 0.062 & 0.081 \\
\hline HLP-08 & 100 & $2 \times 10^{6}$ & 2.36 & 2.96 & 3.20 & 0.12 & 0.15 & 0.16 \\
\hline HLP-08 & 1000 & $2 \times 10^{7}$ & 3.32 & 5.22 & 4.30 & 0.17 & 0.26 & 0.22 \\
\hline HLP-09 & 10 & $2 \times 10^{5}$ & 0.77 & 1.04 & 1.22 & 0.039 & 0.052 & 0.061 \\
\hline HLP-09 & 100 & $2 \times 10^{6}$ & 4.74 & 3.29 & 2.01 & 0.24 & 0.16 & 0.10 \\
\hline HLP-09 & 1000 & $2 \times 10^{7}$ & 16.15 & 8.97 & 2.20 & 0.81 & 0.45 & 0.11 \\
\hline HLP-10 & 10 & $2 \times 10^{5}$ & 0.40 & 1.03 & 1.41 & 0.020 & 0.052 & 0.071 \\
\hline HLP-10 & 100 & $2 \times 10^{6}$ & 2.60 & 2.75 & 2.85 & 0.13 & 0.14 & 0.14 \\
\hline HLP-10 & 1000 & $2 \times 10^{7}$ & 6.57 & 4.14 & 2.98 & 0.33 & 0.21 & 0.15 \\
\hline HLP-11 & 10 & $2 \times 10^{5}$ & 1.18 & 1.42 & 1.77 & 0.06 & 0.07 & 0.088 \\
\hline HLP-11 & 100 & $2 \times 10^{6}$ & 9.38 & 6.25 & 5.71 & 0.47 & 0.31 & 0.28 \\
\hline HLP-11 & 1000 & $2 \times 10^{7}$ & 16.69 & 10.46 & 6.24 & 0.83 & 0.52 & 0.31 \\
\hline HLP-12 & 10 & $2 \times 10^{5}$ & 0.53 & 0.94 & 1.39 & 0.027 & 0.047 & 0.069 \\
\hline HLP-12 & 100 & $2 \times 10^{6}$ & 2.83 & 2.50 & 2.44 & 0.14 & 0.12 & 0.12 \\
\hline HLP-12 & 1000 & $2 \times 10^{7}$ & 5.46 & 4.40 & 3.16 & 0.27 & 0.22 & 0.16 \\
\hline HLP-13 & 10 & $2 \times 10^{5}$ & 0.61 & 1.12 & 1.50 & 0.031 & 0.056 & 0.075 \\
\hline HLP-13 & 100 & $2 \times 10^{6}$ & 4.69 & 3.68 & 3.39 & 0.23 & 0.18 & 0.17 \\
\hline HLP-13 & 1000 & $2 \times 10^{7}$ & 9.93 & 6.69 & 4.17 & 0.50 & 0.33 & 0.21 \\
\hline HLP-14 & 10 & $2 \times 10^{5}$ & 1.02 & 1.36 & 1.57 & 0.051 & 0.068 & 0.078 \\
\hline HLP-14 & 100 & $2 \times 10^{6}$ & 7.76 & 5.31 & 3.92 & 0.39 & 0.27 & 0.20 \\
\hline HLP-14 & 1000 & $2 \times 10^{7}$ & 14.32 & 8.23 & 4.72 & 0.72 & 0.41 & 0.24 \\
\hline HLP-15 & 10 & $2 \times 10^{5}$ & 0.49 & 1.02 & 1.45 & 0.024 & 0.051 & 0.072 \\
\hline HLP-15 & 100 & $2 \times 10^{6}$ & 2.68 & 2.73 & 2.84 & 0.13 & 0.14 & 0.14 \\
\hline
\end{tabular}




\begin{tabular}{|c|c|c|c|c|c|c|c|c|}
\hline \multirow[b]{2}{*}{ SampleID } & \multirow{2}{*}{$\begin{array}{l}\text { Time, } t \\
\text { (hours) }\end{array}$} & \multirow{2}{*}{$\begin{array}{l}(\mathbf{S} / \mathrm{V}) \mathbf{t} \\
(\mathbf{h} / \mathbf{m})\end{array}$} & \multicolumn{3}{|c|}{$\mathrm{NC}_{\mathrm{i}}(\mathrm{g} / \mathrm{L})$} & \multicolumn{3}{|c|}{$\mathrm{NL}_{\mathrm{i}}\left(\mathrm{g} / \mathrm{m}^{2}\right)$} \\
\hline & & & B & $\mathrm{Na}$ & Si & B & Na & $\mathbf{S i}$ \\
\hline HLP-15 & 1000 & $2 \times 10^{7}$ & 5.36 & 4.25 & 3.20 & 0.27 & 0.21 & 0.16 \\
\hline HLP-16 & 10 & $2 \times 10^{5}$ & 0.71 & 1.18 & 1.53 & 0.036 & 0.059 & 0.077 \\
\hline HLP-16 & 100 & $2 \times 10^{6}$ & 3.98 & 3.22 & 2.92 & 0.20 & 0.16 & 0.15 \\
\hline HLP-16 & 1000 & $2 \times 10^{7}$ & 7.77 & 5.67 & 3.29 & 0.39 & 0.28 & 0.16 \\
\hline HLP-17 & 10 & $2 \times 10^{5}$ & 0.51 & 1.05 & 1.51 & 0.026 & 0.053 & 0.076 \\
\hline HLP-17 & 100 & $2 \times 10^{6}$ & 3.67 & 3.25 & 2.99 & 0.18 & 0.16 & 0.15 \\
\hline HLP-17 & 1000 & $2 \times 10^{7}$ & 7.71 & 5.05 & 3.57 & 0.39 & 0.25 & 0.18 \\
\hline HLP-18 & 10 & $2 \times 10^{5}$ & 0.70 & 1.18 & 1.75 & 0.035 & 0.059 & 0.087 \\
\hline HLP-18 & 100 & $2 \times 10^{6}$ & 4.87 & 3.71 & 3.87 & 0.24 & 0.19 & 0.19 \\
\hline HLP-18 & 1000 & $2 \times 10^{7}$ & 10.58 & 6.66 & 4.34 & 0.53 & 0.33 & 0.22 \\
\hline HLP-19 & 10 & $2 \times 10^{5}$ & 0.34 & 0.87 & 1.06 & 0.017 & 0.044 & 0.053 \\
\hline HLP-19 & 100 & $2 \times 10^{6}$ & 2.19 & 2.18 & 2.03 & 0.11 & 0.11 & 0.10 \\
\hline HLP-19 & 1000 & $2 \times 10^{7}$ & 4.01 & 3.32 & 2.35 & 0.20 & 0.17 & 0.12 \\
\hline HLP-20 & 10 & $2 \times 10^{5}$ & 0.67 & 1.07 & 1.50 & 0.033 & 0.054 & 0.075 \\
\hline HLP-20 & 100 & $2 \times 10^{6}$ & 2.98 & 2.77 & 2.53 & 0.15 & 0.14 & 0.13 \\
\hline HLP-20 & 1000 & $2 \times 10^{7}$ & 5.66 & 4.17 & 3.05 & 0.28 & 0.21 & 0.15 \\
\hline HLP-21 & 10 & $2 \times 10^{5}$ & 0.94 & 1.23 & 1.61 & 0.047 & 0.062 & 0.081 \\
\hline HLP-21 & 100 & $2 \times 10^{6}$ & 6.05 & 4.30 & 3.32 & 0.30 & 0.21 & 0.17 \\
\hline HLP-21 & 1000 & $2 \times 10^{7}$ & 11.61 & 7.35 & 4.31 & 0.58 & 0.37 & 0.22 \\
\hline HLP-22 & 10 & $2 \times 10^{5}$ & 0.19 & 0.53 & 0.93 & 0.009 & 0.026 & 0.047 \\
\hline HLP-22 & 100 & $2 \times 10^{6}$ & 1.93 & 1.67 & 1.68 & 0.10 & 0.084 & 0.084 \\
\hline HLP-22 & 1000 & $2 \times 10^{7}$ & 3.92 & 2.57 & 1.81 & 0.20 & 0.13 & 0.090 \\
\hline HLP-23 & 10 & $2 \times 10^{5}$ & 1.63 & 2.21 & 2.47 & 0.082 & 0.11 & 0.12 \\
\hline HLP-23 & 100 & $2 \times 10^{6}$ & 8.49 & 7.09 & 5.20 & 0.42 & 0.35 & 0.26 \\
\hline HLP-23 & 1000 & $2 \times 10^{7}$ & 14.07 & 10.06 & 6.21 & 0.70 & 0.50 & 0.31 \\
\hline HLP-24 & 10 & $2 \times 10^{5}$ & 0.44 & 0.84 & 1.24 & 0.022 & 0.042 & 0.062 \\
\hline HLP-24 & 100 & $2 \times 10^{6}$ & 2.82 & 2.32 & 2.25 & 0.14 & 0.12 & 0.11 \\
\hline HLP-24 & 1000 & $2 \times 10^{7}$ & 6.06 & 3.97 & 0.26 & 0.30 & 0.20 & 0.013 \\
\hline HLP-25 & 10 & $2 \times 10^{5}$ & 0.71 & 1.26 & 1.56 & 0.035 & 0.063 & 0.078 \\
\hline HLP-25 & 100 & $2 \times 10^{6}$ & 4.32 & 3.47 & 3.02 & 0.22 & 0.17 & 0.15 \\
\hline HLP-25 & 1000 & $2 \times 10^{7}$ & 9.23 & 5.79 & 3.90 & 0.46 & 0.29 & 0.20 \\
\hline HLP-26 & 10 & $2 \times 10^{5}$ & 0.79 & 1.19 & 1.52 & 0.040 & 0.060 & 0.076 \\
\hline HLP-26 & 100 & $2 \times 10^{6}$ & 4.19 & 3.17 & 2.97 & 0.21 & 0.16 & 0.15 \\
\hline HLP-26 & 1000 & $2 \times 10^{7}$ & 8.16 & 5.82 & 3.80 & 0.41 & 0.29 & 0.19 \\
\hline HLP-27 & 10 & $2 \times 10^{5}$ & 3.31 & 2.59 & 1.71 & 0.166 & 0.129 & 0.086 \\
\hline HLP-27 & 100 & $2 \times 10^{6}$ & 17.17 & 10.84 & 3.48 & 0.86 & 0.54 & 0.17 \\
\hline HLP-27 & 1000 & $2 \times 10^{7}$ & 39.94 & 20.90 & 4.57 & 2.00 & 1.05 & 0.23 \\
\hline HLP-28 & 10 & $2 \times 10^{5}$ & 0.41 & 0.55 & 0.72 & 0.021 & 0.028 & 0.036 \\
\hline HLP-28 & 100 & $2 \times 10^{6}$ & 1.90 & 1.32 & 1.18 & 0.10 & 0.07 & 0.059 \\
\hline HLP-28 & 1000 & $2 \times 10^{7}$ & 4.14 & 2.12 & 0.98 & 0.21 & 0.11 & 0.049 \\
\hline HLP-29 & 10 & $2 \times 10^{5}$ & 0.33 & 1.47 & 1.53 & 0.017 & 0.073 & 0.077 \\
\hline HLP-29 & 100 & $2 \times 10^{6}$ & 2.42 & 3.32 & 3.18 & 0.12 & 0.17 & 0.16 \\
\hline HLP-29 & 1000 & $2 \times 10^{7}$ & 4.85 & 6.03 & 4.14 & 0.24 & 0.30 & 0.21 \\
\hline HLP-30 & 10 & $2 \times 10^{5}$ & 0.08 & 0.58 & 0.84 & 0.004 & 0.029 & 0.042 \\
\hline HLP-30 & 100 & $2 \times 10^{6}$ & 1.07 & 1.24 & 1.53 & 0.054 & 0.062 & 0.077 \\
\hline HLP-30 & 1000 & $2 \times 10^{7}$ & 2.12 & 2.03 & 1.75 & 0.11 & 0.10 & 0.088 \\
\hline HLP-31 & 10 & $2 \times 10^{5}$ & 8.72 & 5.90 & 7.47 & 0.436 & 0.295 & 0.37 \\
\hline HLP-31 & 100 & $2 \times 10^{6}$ & 31.93 & 21.49 & 20.3 & 1.60 & 1.07 & 1.01 \\
\hline HLP-31 & 1000 & $2 \times 10^{7}$ & 56.80 & 36.14 & 29.0 & 2.84 & 1.81 & 1.45 \\
\hline HLP-32 & 10 & $2 \times 10^{5}$ & 0.82 & 0.88 & 1.31 & 0.041 & 0.044 & 0.065 \\
\hline
\end{tabular}




\begin{tabular}{|c|c|c|c|c|c|c|c|c|}
\hline \multirow[b]{2}{*}{ SampleID } & \multirow{2}{*}{$\begin{array}{l}\text { Time, t } \\
\text { (hours) }\end{array}$} & \multirow{2}{*}{$\begin{array}{l}(\mathrm{S} / \mathrm{V}) \mathrm{t} \\
(\mathrm{h} / \mathrm{m})\end{array}$} & \multicolumn{3}{|c|}{$\mathrm{NC}_{\mathrm{i}}(\mathrm{g} / \mathrm{L})$} & \multicolumn{3}{|c|}{$\mathrm{NL}_{\mathrm{i}}\left(\mathrm{g} / \mathrm{m}^{2}\right)$} \\
\hline & & & B & $\mathrm{Na}$ & $\mathbf{S i}$ & B & $\mathbf{N a}$ & Si \\
\hline HLP-32 & 100 & $2 \times 10^{6}$ & 4.52 & 2.89 & 2.42 & 0.23 & 0.14 & 0.12 \\
\hline HLP-32 & 1000 & $2 \times 10^{7}$ & 12.30 & 5.69 & 3.10 & 0.61 & 0.28 & 0.16 \\
\hline HLP-33 & 10 & $2 \times 10^{5}$ & 1.47 & 2.37 & 3.48 & 0.073 & 0.119 & 0.17 \\
\hline HLP-33 & 100 & $2 \times 10^{6}$ & 33.63 & 22.47 & 32.0 & 1.68 & 1.12 & 1.60 \\
\hline HLP-33 & 1000 & $2 \times 10^{7}$ & 126.12 & 70.62 & 12.2 & 6.31 & 3.53 & 0.61 \\
\hline HLP-34 & 10 & $2 \times 10^{5}$ & 0.24 & 0.80 & 1.18 & 0.012 & 0.040 & 0.059 \\
\hline HLP-34 & 100 & $2 \times 10^{6}$ & 2.85 & 2.29 & 3.08 & 0.14 & 0.11 & 0.15 \\
\hline HLP-34 & 1000 & $2 \times 10^{7}$ & 5.81 & 3.43 & 4.74 & 0.29 & 0.17 & 0.24 \\
\hline HLP-35 & 10 & $2 \times 10^{5}$ & 1.66 & 1.65 & 1.60 & 0.083 & 0.083 & 0.080 \\
\hline HLP-35 & 100 & $2 \times 10^{6}$ & 12.08 & 7.22 & 2.39 & 0.60 & 0.36 & 0.12 \\
\hline HLP-35 & 1000 & $2 \times 10^{7}$ & 23.70 & 14.85 & 2.51 & 1.19 & 0.74 & 0.13 \\
\hline HLP-36 & 10 & $2 \times 10^{5}$ & 0.58 & 0.82 & 0.95 & 0.029 & 0.041 & 0.048 \\
\hline HLP-36 & 100 & $2 \times 10^{6}$ & 3.70 & 2.44 & 1.28 & 0.19 & 0.12 & 0.064 \\
\hline HLP-36 & 1000 & $2 \times 10^{7}$ & 14.67 & 7.74 & 1.09 & 0.73 & 0.39 & 0.054 \\
\hline HLP-37 & 10 & $2 \times 10^{5}$ & 0.40 & 1.56 & 1.74 & 0.020 & 0.078 & 0.087 \\
\hline HLP-37 & 100 & $2 \times 10^{6}$ & 7.96 & 5.67 & 3.54 & 0.40 & 0.28 & 0.18 \\
\hline HLP-37 & 1000 & $2 \times 10^{7}$ & & & Sam & as lost & & \\
\hline HLP-37Q & 10 & $2 \times 10^{5}$ & 0.64 & 1.77 & 1.63 & 0.032 & 0.088 & 0.082 \\
\hline HLP-37Q & 100 & $2 \times 10^{6}$ & 3.48 & 4.90 & 3.86 & 0.17 & 0.25 & 0.19 \\
\hline HLP-37Q & 1000 & $2 \times 10^{7}$ & 6.80 & 8.34 & 4.88 & 0.34 & 0.42 & 0.24 \\
\hline HLP-38 & 10 & $2 \times 10^{5}$ & 0.37 & 0.93 & 1.08 & 0.019 & 0.046 & 0.054 \\
\hline HLP-38 & 100 & $2 \times 10^{6}$ & 2.35 & 2.01 & 1.90 & 0.12 & 0.10 & 0.095 \\
\hline HLP-38 & 1000 & $2 \times 10^{7}$ & 3.72 & 3.54 & 2.55 & 0.19 & 0.18 & 0.13 \\
\hline HLP-38Q & 10 & $2 \times 10^{5}$ & 0.081 & 0.74 & 0.95 & 0.0040 & 0.037 & 0.047 \\
\hline HLP-38Q & 100 & $2 \times 10^{6}$ & 1.78 & 2.02 & 2.00 & 0.089 & 0.10 & 0.10 \\
\hline HLP-38Q & 1000 & $2 \times 10^{7}$ & 3.88 & 3.48 & 2.65 & 0.19 & 0.17 & 0.13 \\
\hline HLP-39 & 10 & $2 \times 10^{5}$ & 5.37 & 4.23 & 2.66 & 0.27 & 0.21 & 0.13 \\
\hline HLP-39 & 100 & $2 \times 10^{6}$ & 41.64 & 24.03 & 11.37 & 2.08 & 1.20 & 0.57 \\
\hline HLP-39 & 1000 & $2 \times 10^{7}$ & 50.54 & 31.16 & 15.34 & 2.53 & 1.56 & 0.77 \\
\hline HLP-40 & 10 & $2 \times 10^{5}$ & 1.18 & 1.30 & 1.42 & 0.059 & 0.065 & 0.071 \\
\hline HLP-40 & 100 & $2 \times 10^{6}$ & 16.15 & 9.20 & 2.40 & 0.81 & 0.46 & 0.12 \\
\hline HLP-40 & 1000 & $2 \times 10^{7}$ & 31.57 & 18.54 & 1.97 & 1.58 & 0.93 & 0.099 \\
\hline HLP-40Q & 10 & $2 \times 10^{5}$ & 0.88 & 1.13 & 1.25 & 0.044 & 0.056 & 0.063 \\
\hline HLP-40Q & 100 & $2 \times 10^{6}$ & 16.91 & 9.27 & 1.68 & 0.85 & 0.46 & 0.084 \\
\hline HLP-40Q & 1000 & $2 \times 10^{7}$ & 32.60 & 19.71 & 2.09 & 1.63 & 0.986 & 0.10 \\
\hline HLP-41 & 10 & $2 \times 10^{5}$ & 4.28 & 4.25 & 3.44 & 0.21 & 0.21 & 0.17 \\
\hline HLP-41 & 100 & $2 \times 10^{6}$ & 62.08 & 31.84 & 2.01 & 3.104 & 1.59 & 0.10 \\
\hline HLP-41 & 1000 & $2 \times 10^{7}$ & 83.19 & 45.52 & 31.59 & 4.16 & 2.28 & 1.58 \\
\hline HLP-42 & 10 & $2 \times 10^{5}$ & 0.60 & 1.29 & 1.49 & 0.030 & 0.064 & 0.075 \\
\hline HLP-42 & 100 & $2 \times 10^{6}$ & 11.18 & 6.50 & 6.41 & 0.56 & 0.33 & 0.32 \\
\hline HLP-42 & 1000 & $2 \times 10^{7}$ & 74.69 & 42.13 & 18.55 & 3.73 & 2.11 & 0.93 \\
\hline HLP-42Q & 10 & $2 \times 10^{5}$ & 0.71 & 1.14 & 1.19 & 0.036 & 0.057 & 0.060 \\
\hline HLP-42Q & 100 & $2 \times 10^{6}$ & 10.73 & 5.55 & 4.63 & 0.54 & 0.28 & 0.23 \\
\hline HLP-42Q & 1000 & $2 \times 10^{7}$ & 78.71 & 34.26 & 9.84 & 3.94 & 1.71 & 0.49 \\
\hline HLP-43 & 10 & $2 \times 10^{5}$ & 0.71 & 1.00 & 1.22 & 0.036 & 0.050 & 0.061 \\
\hline HLP-43 & 100 & $2 \times 10^{6}$ & 5.34 & 3.93 & 3.31 & 0.27 & 0.20 & 0.17 \\
\hline HLP-43 & 1000 & $2 \times 10^{7}$ & 9.34 & 5.59 & 3.96 & 0.47 & 0.28 & 0.20 \\
\hline HLP-44 & 10 & $2 \times 10^{5}$ & 0.83 & 0.99 & 1.32 & 0.042 & 0.049 & 0.066 \\
\hline HLP-44 & 100 & $2 \times 10^{6}$ & 0.31 & 2.30 & 0.06 & 0.016 & 0.12 & $2.9 \mathrm{E}-3$ \\
\hline HLP-44 & 1000 & $2 \times 10^{7}$ & 7.62 & 6.10 & 3.53 & 0.38 & 0.31 & 0.18 \\
\hline
\end{tabular}




\begin{tabular}{|c|c|c|c|c|c|c|c|c|}
\hline \multirow[b]{2}{*}{ SampleID } & \multirow{2}{*}{$\begin{array}{l}\text { Time, } t \\
\text { (hours) }\end{array}$} & \multirow{2}{*}{$\begin{array}{l}(\mathbf{S} / \mathbf{V}) \mathbf{t} \\
(\mathbf{h} / \mathbf{m})\end{array}$} & \multicolumn{3}{|c|}{$N_{i}(g / L)$} & \multicolumn{3}{|c|}{$N_{i}\left(g / m^{2}\right)$} \\
\hline & & & B & $\mathrm{Na}$ & $\mathbf{S i}$ & B & $\mathrm{Na}$ & $\mathbf{S i}$ \\
\hline HLP-45 & 10 & $2 \times 10^{5}$ & 0.86 & 1.07 & 1.35 & 0.043 & 0.054 & 0.067 \\
\hline HLP-45 & 100 & $2 \times 10^{6}$ & 0.35 & 2.67 & 0.063 & 0.018 & 0.13 & $3.2 \mathrm{E}-3$ \\
\hline HLP-45 & 1000 & $2 \times 10^{7}$ & 6.39 & 6.37 & 3.64 & 0.32 & 0.32 & 0.18 \\
\hline HLP-46 & 10 & $2 \times 10^{5}$ & 0.35 & $2.9 \mathrm{E}-03$ & 1.27 & 0.018 & $1.0 \mathrm{E}-04$ & 0.064 \\
\hline HLP-46 & 100 & $2 \times 10^{6}$ & 1.98 & 5.17 & 3.33 & 0.10 & 0.26 & 0.17 \\
\hline HLP-46 & 1000 & $2 \times 10^{7}$ & 5.92 & 8.56 & 5.91 & 0.30 & 0.43 & 0.30 \\
\hline HLP-47 & 10 & $2 \times 10^{5}$ & 1.12 & 1.62 & 1.39 & 0.056 & 0.081 & 0.070 \\
\hline HLP-47 & 100 & $2 \times 10^{6}$ & 6.49 & 5.16 & 3.55 & 0.32 & 0.26 & 0.18 \\
\hline HLP-47 & 1000 & $2 \times 10^{7}$ & 18.31 & 12.13 & 5.19 & 0.92 & 0.61 & 0.26 \\
\hline HLP-48 & 10 & $2 \times 10^{5}$ & 1.20 & 1.26 & 1.46 & 0.060 & 0.063 & 0.073 \\
\hline HLP-48 & 100 & $2 \times 10^{6}$ & 5.92 & 4.06 & 2.42 & 0.30 & 0.20 & 0.12 \\
\hline HLP-48 & 1000 & $2 \times 10^{7}$ & 13.10 & 9.03 & 3.20 & 0.65 & 0.45 & 0.16 \\
\hline HLP-49 & 10 & $2 \times 10^{5}$ & 0.61 & 0.77 & 0.80 & 0.030 & 0.039 & 0.040 \\
\hline HLP-49 & 100 & $2 \times 10^{6}$ & 2.25 & 1.80 & 1.68 & 0.11 & 0.09 & 0.084 \\
\hline HLP-49 & 1000 & $2 \times 10^{7}$ & 3.05 & 3.08 & 2.35 & 0.15 & 0.15 & 0.12 \\
\hline HLP-50 & 10 & $2 \times 10^{5}$ & \multicolumn{6}{|c|}{ No results for this sample } \\
\hline HLP-50 & 100 & $2 \times 10^{6}$ & \multicolumn{6}{|c|}{ No results for this sample } \\
\hline HLP-50 & 1000 & $2 \times 10^{7}$ & \multicolumn{6}{|c|}{ No results for this sample } \\
\hline HLP-51 & 10 & $2 \times 10^{5}$ & 0.77 & 1.12 & 1.07 & 0.038 & 0.056 & 0.053 \\
\hline HLP-51 & 100 & $2 \times 10^{6}$ & 0.80 & 2.61 & 0.053 & 0.04 & 0.13 & $2.6 \mathrm{E}-3$ \\
\hline HLP-51 & 1000 & $2 \times 10^{7}$ & 6.61 & 6.48 & 2.52 & 0.33 & 0.32 & 0.13 \\
\hline HLP-52 & 10 & $2 \times 10^{5}$ & -_(a) & 0.46 & 3.42 & -(a) & 0.023 & 0.17 \\
\hline HLP-52 & 100 & $2 \times 10^{6}$ & $--^{(a)}$ & 44.74 & 10.8 & $--^{(a)}$ & 2.24 & 0.54 \\
\hline HLP-52 & 1000 & $2 \times 10^{7}$ & $--^{\text {(a) }}$ & 144.1 & 56 & $--^{(a)}$ & 7.21 & 7.81 \\
\hline HLP-53 & 10 & $2 \times 10^{5}$ & \multicolumn{6}{|c|}{ No results for this sample } \\
\hline HLP-53 & 100 & $2 \times 10^{6}$ & \multicolumn{6}{|c|}{ No results for this sample } \\
\hline HLP-53 & 1000 & $2 \times 10^{7}$ & \multicolumn{6}{|c|}{ No results for this sample } \\
\hline HLP-54 & 10 & $2 \times 10^{5}$ & 0.44 & 1.51 & 0.79 & 0.022 & 0.075 & 0.040 \\
\hline HLP-54 & 100 & $2 \times 10^{6}$ & 2.43 & 2.40 & 1.81 & 0.12 & 0.12 & 0.090 \\
\hline HLP-54 & 1000 & $2 \times 10^{7}$ & 4.91 & 4.04 & 2.14 & 0.25 & 0.20 & 0.11 \\
\hline HLP-55 & 10 & $2 \times 10^{5}$ & 1.50 & 1.83 & 1.63 & 0.075 & 0.092 & 0.082 \\
\hline HLP-55 & 100 & $2 \times 10^{6}$ & 6.08 & 4.13 & 4.30 & 0.30 & 0.21 & 0.22 \\
\hline HLP-55 & 1000 & $2 \times 10^{7}$ & 14.01 & 9.56 & 5.82 & 0.70 & 0.48 & 0.29 \\
\hline
\end{tabular}

a As indicated in Table 2-1, glass HLP-52 contained no boron, so the test solution concentration cannot be normalized using the concentration in the glass. 


\section{Short-term Release Rates Based Upon PCT-B Results}

Table B-7. Short-term Boron Release Rates Based Upon Measured $\mathrm{NL}_{\mathrm{B}}$

\begin{tabular}{|c|c|c|c|c|c|}
\hline \multirow[b]{2}{*}{ Glass } & \multicolumn{3}{|c|}{ Release Rate, $r$, in $\mathrm{g} / \mathrm{m}^{2}$-Day } & \multicolumn{2}{|c|}{ Release Rate, $r_{\Delta}{ }^{(a)}$} \\
\hline & 10 hours & 100 hours & 1000 hours & 100 hours & 1000 hours \\
\hline HLP-01 & $8.57 \mathrm{E}-02$ & $3.92 \mathrm{E}-02$ & $8.95 \mathrm{E}-03$ & 3.40E-02 & $5.60 \mathrm{E}-03$ \\
\hline HLP-02 & $9.12 \mathrm{E}-01$ & 2.73E-01 & $5.16 \mathrm{E}-02$ & $2.02 \mathrm{E}-01$ & $2.70 \mathrm{E}-02$ \\
\hline HLP-03 & $6.90 \mathrm{E}-02$ & 3.37E-02 & $7.51 \mathrm{E}-03$ & 2.97E-02 & $4.61 \mathrm{E}-03$ \\
\hline HLP-04 & $3.28 \mathrm{E}-01$ & $1.85 \mathrm{E}-01$ & 3.74E-02 & $1.69 \mathrm{E}-01$ & $2.11 \mathrm{E}-02$ \\
\hline HLP-05 & 2.13E-01 & $3.27 \mathrm{E}-01$ & 7.43E-02 & $3.40 \mathrm{E}-01$ & $4.62 \mathrm{E}-02$ \\
\hline HLP-06 & 4.08E-02 & 2.29E-02 & $3.45 \mathrm{E}-03$ & 2.09E-02 & $1.28 \mathrm{E}-03$ \\
\hline HLP-07 & $6.02 \mathrm{E}-02$ & 2.99E-02 & 5.89E-03 & $2.66 \mathrm{E}-02$ & $3.22 \mathrm{E}-03$ \\
\hline HLP-08 & 4.42E-02 & 2.83E-02 & 3.98E-03 & $2.66 \mathrm{E}-02$ & $1.28 \mathrm{E}-03$ \\
\hline HLP-09 & $9.28 \mathrm{E}-02$ & 5.69E-02 & $1.94 \mathrm{E}-02$ & $5.29 \mathrm{E}-02$ & $1.52 \mathrm{E}-02$ \\
\hline HLP-10 & 4.82E-02 & $3.12 \mathrm{E}-02$ & 7.89E-03 & $2.93 \mathrm{E}-02$ & $5.30 \mathrm{E}-03$ \\
\hline HLP-11 & $1.41 \mathrm{E}-01$ & $1.13 \mathrm{E}-01$ & 2.00E-02 & $1.09 \mathrm{E}-01$ & $9.74 \mathrm{E}-03$ \\
\hline HLP-12 & $6.40 \mathrm{E}-02$ & 3.39E-02 & $6.55 \mathrm{E}-03$ & $3.06 \mathrm{E}-02$ & $3.51 \mathrm{E}-03$ \\
\hline HLP-13 & 7.34E-02 & $5.62 \mathrm{E}-02$ & 1.19E-02 & $5.43 \mathrm{E}-02$ & $6.99 \mathrm{E}-03$ \\
\hline HLP-14 & $1.22 \mathrm{E}-01$ & 9.31E-02 & $1.72 \mathrm{E}-02$ & 8.99E-02 & $8.75 \mathrm{E}-03$ \\
\hline HLP-15 & $5.84 \mathrm{E}-02$ & $3.21 \mathrm{E}-02$ & $6.43 \mathrm{E}-03$ & $2.92 \mathrm{E}-02$ & $3.57 \mathrm{E}-03$ \\
\hline HLP-16 & 8.57E-02 & 4.78E-02 & 9.33E-03 & $4.36 \mathrm{E}-02$ & $5.05 \mathrm{E}-03$ \\
\hline HLP-17 & $6.18 \mathrm{E}-02$ & 4.41E-02 & $9.25 \mathrm{E}-03$ & 4.21E-02 & 5.38E-03 \\
\hline HLP-18 & 8.44E-02 & 5.84E-02 & $1.27 \mathrm{E}-02$ & $5.56 \mathrm{E}-02$ & 7.61E-03 \\
\hline HLP-19 & 4.09E-02 & 2.62E-02 & 4.81E-03 & $2.46 \mathrm{E}-02$ & $2.43 \mathrm{E}-03$ \\
\hline HLP-20 & 7.99E-02 & $3.58 \mathrm{E}-02$ & 6.79E-03 & $3.09 \mathrm{E}-02$ & $3.57 \mathrm{E}-03$ \\
\hline HLP-21 & $1.13 \mathrm{E}-01$ & 7.27E-02 & 1.39E-02 & $6.82 \mathrm{E}-02$ & $7.41 \mathrm{E}-03$ \\
\hline HLP-22 & $2.24 \mathrm{E}-02$ & 2.32E-02 & 4.71E-03 & 2.33E-02 & $2.66 \mathrm{E}-03$ \\
\hline HLP-23 & $1.96 \mathrm{E}-01$ & $1.02 \mathrm{E}-01$ & 1.69E-02 & $9.14 \mathrm{E}-02$ & $7.45 \mathrm{E}-03$ \\
\hline HLP-24 & $5.32 \mathrm{E}-02$ & 3.39E-02 & 7.27E-03 & $3.17 \mathrm{E}-02$ & 4.32E-03 \\
\hline HLP-25 & $8.50 \mathrm{E}-02$ & $5.18 \mathrm{E}-02$ & $1.11 \mathrm{E}-02$ & $4.82 \mathrm{E}-02$ & $6.55 \mathrm{E}-03$ \\
\hline HLP-26 & $9.53 \mathrm{E}-02$ & $5.02 \mathrm{E}-02$ & 9.79E-03 & $4.52 \mathrm{E}-02$ & $5.30 \mathrm{E}-03$ \\
\hline HLP-27 & $3.98 \mathrm{E}-01$ & 2.06E-01 & 4.79E-02 & $1.85 \mathrm{E}-01$ & $3.04 \mathrm{E}-02$ \\
\hline HLP-28 & 4.93E-02 & $2.28 \mathrm{E}-02$ & 4.97E-03 & $1.99 \mathrm{E}-02$ & $2.99 \mathrm{E}-03$ \\
\hline HLP-29 & 4.01E-02 & $2.90 \mathrm{E}-02$ & $5.82 \mathrm{E}-03$ & $2.77 \mathrm{E}-02$ & $3.25 \mathrm{E}-03$ \\
\hline HLP-30 & $9.66 \mathrm{E}-03$ & $1.29 \mathrm{E}-02$ & $2.54 \mathrm{E}-03$ & $1.32 \mathrm{E}-02$ & $1.39 \mathrm{E}-03$ \\
\hline HLP-31 & $1.05 \mathrm{E}+00$ & 3.83E-01 & 6.82E-02 & 3.09E-01 & $3.32 \mathrm{E}-02$ \\
\hline HLP-32 & $9.82 \mathrm{E}-02$ & $5.42 \mathrm{E}-02$ & $1.48 \mathrm{E}-02$ & 4.93E-02 & $1.04 \mathrm{E}-02$ \\
\hline HLP-33 & $1.76 \mathrm{E}-01$ & 4.04E-01 & $1.51 \mathrm{E}-01$ & 4.29E-01 & $1.23 \mathrm{E}-01$ \\
\hline HLP-34 & $2.87 \mathrm{E}-02$ & $3.42 \mathrm{E}-02$ & 6.97E-03 & $3.49 \mathrm{E}-02$ & $3.94 \mathrm{E}-03$ \\
\hline HLP-35 & $2.00 \mathrm{E}-01$ & $1.45 \mathrm{E}-01$ & 2.84E-02 & $1.39 \mathrm{E}-01$ & $1.55 \mathrm{E}-02$ \\
\hline HLP-36 & $6.92 \mathrm{E}-02$ & 4.44E-02 & $1.76 \mathrm{E}-02$ & 4.17E-02 & $1.46 \mathrm{E}-02$ \\
\hline HLP-37 & 4.77E-02 & $9.55 \mathrm{E}-02$ & $\mathrm{n} / \mathrm{a}$ & $1.01 \mathrm{E}-01$ & $\mathrm{n} / \mathrm{a}$ \\
\hline HLP-37Q & 7.69E-02 & 4.18E-02 & $8.16 \mathrm{E}-03$ & 3.79E-02 & $4.42 \mathrm{E}-03$ \\
\hline HLP-38 & 4.44E-02 & $2.82 \mathrm{E}-02$ & 4.47E-03 & 2.64E-02 & $1.82 \mathrm{E}-03$ \\
\hline HLP-38Q & $9.66 \mathrm{E}-03$ & 2.14E-02 & $4.66 \mathrm{E}-03$ & $2.27 \mathrm{E}-02$ & $2.80 \mathrm{E}-03$ \\
\hline HLP-39 & $6.44 \mathrm{E}-01$ & $5.00 \mathrm{E}-01$ & $6.06 \mathrm{E}-02$ & 4.84E-01 & $1.19 \mathrm{E}-02$ \\
\hline HLP-40 & $1.41 \mathrm{E}-01$ & $1.94 \mathrm{E}-01$ & $3.79 \mathrm{E}-02$ & $2.00 \mathrm{E}-01$ & $2.06 \mathrm{E}-02$ \\
\hline HLP-40Q & $1.05 \mathrm{E}-01$ & 2.03E-01 & $3.91 \mathrm{E}-02$ & $2.14 \mathrm{E}-01$ & $2.09 \mathrm{E}-02$ \\
\hline HLP-41 & $5.13 \mathrm{E}-01$ & 7.45E-01 & $9.98 \mathrm{E}-02$ & 7.71E-01 & 2.81E-02 \\
\hline HLP-42 & $7.25 \mathrm{E}-02$ & $1.34 \mathrm{E}-01$ & $8.96 \mathrm{E}-02$ & $1.41 \mathrm{E}-01$ & 8.47E-02 \\
\hline
\end{tabular}




\begin{tabular}{|c|c|c|c|c|c|}
\hline \multirow[b]{2}{*}{ Glass } & \multicolumn{3}{|c|}{ Release Rate, $r$, in $\mathbf{g} / \mathrm{m}^{2}$-Day } & \multicolumn{2}{|c|}{ Release Rate, $r_{\Delta}{ }^{(a)}$} \\
\hline & 10 hours & 100 hours & 1000 hours & 100 hours & 1000 hours \\
\hline HLP-42Q & $8.54 \mathrm{E}-02$ & $1.29 \mathrm{E}-01$ & $9.45 \mathrm{E}-02$ & $1.34 \mathrm{E}-01$ & $9.06 \mathrm{E}-02$ \\
\hline HLP-43 & $8.57 \mathrm{E}-02$ & $6.41 \mathrm{E}-02$ & $1.12 \mathrm{E}-02$ & $6.17 \mathrm{E}-02$ & $5.33 \mathrm{E}-03$ \\
\hline HLP-44 & 9.98E-02 & $3.74 \mathrm{E}-03$ & $9.15 \mathrm{E}-03$ & $-6.94 \mathrm{E}-03$ & $9.75 \mathrm{E}-03$ \\
\hline HLP-45 & $1.04 \mathrm{E}-01$ & 4.23E-03 & $7.66 \mathrm{E}-03$ & $-6.82 \mathrm{E}-03$ & $8.05 \mathrm{E}-03$ \\
\hline HLP-46 & 4.23E-02 & $2.37 \mathrm{E}-02$ & $7.10 \mathrm{E}-03$ & 2.17E-02 & $5.26 \mathrm{E}-03$ \\
\hline HLP-47 & $1.34 \mathrm{E}-01$ & $7.79 \mathrm{E}-02$ & $2.20 \mathrm{E}-02$ & $7.16 \mathrm{E}-02$ & $1.58 \mathrm{E}-02$ \\
\hline HLP-48 & $1.44 \mathrm{E}-01$ & $7.10 \mathrm{E}-02$ & $1.57 \mathrm{E}-02$ & 6.29E-02 & $9.57 \mathrm{E}-03$ \\
\hline HLP-49 & 7.29E-02 & 2.70E-02 & $3.66 \mathrm{E}-03$ & $2.19 \mathrm{E}-02$ & $1.06 \mathrm{E}-03$ \\
\hline HLP-50 & \multicolumn{5}{|c|}{ No results for this glass } \\
\hline HLP-51 & $9.19 \mathrm{E}-02$ & $9.61 \mathrm{E}-03$ & 7.94E-03 & 4.64E-04 & $7.75 \mathrm{E}-03$ \\
\hline HLP-52 & \multicolumn{5}{|c|}{ This glass contains no boron } \\
\hline HLP-53 & & No & sults for this & & \\
\hline HLP-54 & $5.29 \mathrm{E}-02$ & 2.91E-02 & $5.90 \mathrm{E}-03$ & $2.65 \mathrm{E}-02$ & $3.32 \mathrm{E}-03$ \\
\hline HLP-55 & $1.80 \mathrm{E}-01$ & 7.30E-02 & $1.68 \mathrm{E}-02$ & $6.11 \mathrm{E}-02$ & $1.06 \mathrm{E}-02$ \\
\hline
\end{tabular}

(a) The release rates, $r$ and $r_{\Delta}$, are the same at 10 hours. 
Table B-8. Short-term Sodium Release Rates Based Upon Measured NL $L_{\mathrm{Na}}$

\begin{tabular}{|c|c|c|c|c|c|}
\hline \multirow[b]{2}{*}{ Glass } & \multicolumn{3}{|c|}{ Release Rate, $r$, in $\mathrm{g} / \mathrm{m}^{2}$-Day } & \multicolumn{2}{|c|}{ Release Rate, $r_{\Delta}{ }^{(a)}$} \\
\hline & 10 hours & 100 hours & 1000 hours & 100 hours & 1000 hours \\
\hline HLP-01 & $1.26 \mathrm{E}-01$ & $3.48 \mathrm{E}-02$ & $6.81 \mathrm{E}-03$ & $2.46 \mathrm{E}-02$ & $3.70 \mathrm{E}-03$ \\
\hline HLP-02 & $6.60 \mathrm{E}-01$ & $1.87 \mathrm{E}-01$ & $3.06 \mathrm{E}-02$ & $1.34 \mathrm{E}-01$ & $1.32 \mathrm{E}-02$ \\
\hline HLP-03 & $1.09 \mathrm{E}-01$ & $3.16 \mathrm{E}-02$ & $5.31 \mathrm{E}-03$ & 2.31E-02 & 2.38E-03 \\
\hline HLP-04 & $3.08 \mathrm{E}-02$ & $1.17 \mathrm{E}-01$ & $2.15 \mathrm{E}-02$ & $1.26 \mathrm{E}-01$ & $1.09 \mathrm{E}-02$ \\
\hline HLP-05 & $2.09 \mathrm{E}-01$ & 2.04E-01 & 4.17E-02 & 2.03E-01 & 2.37E-02 \\
\hline HLP-06 & $8.84 \mathrm{E}-02$ & $2.11 \mathrm{E}-02$ & $3.23 \mathrm{E}-03$ & $1.36 \mathrm{E}-02$ & $1.25 \mathrm{E}-03$ \\
\hline HLP-07 & $1.09 \mathrm{E}-01$ & $2.59 \mathrm{E}-02$ & $4.86 \mathrm{E}-03$ & $1.66 \mathrm{E}-02$ & $2.53 \mathrm{E}-03$ \\
\hline HLP-08 & $1.48 \mathrm{E}-01$ & $3.55 \mathrm{E}-02$ & $6.26 \mathrm{E}-03$ & 2.29E-02 & $3.01 \mathrm{E}-03$ \\
\hline HLP-09 & $1.25 \mathrm{E}-01$ & 3.94E-02 & $1.08 \mathrm{E}-02$ & 2.99E-02 & $7.58 \mathrm{E}-03$ \\
\hline HLP-10 & $1.24 \mathrm{E}-01$ & $3.30 \mathrm{E}-02$ & 4.97E-03 & $2.28 \mathrm{E}-02$ & $1.86 \mathrm{E}-03$ \\
\hline HLP-11 & $1.71 \mathrm{E}-01$ & 7.50E-02 & $1.26 \mathrm{E}-02$ & $6.44 \mathrm{E}-02$ & $5.62 \mathrm{E}-03$ \\
\hline HLP-12 & $1.13 \mathrm{E}-01$ & $3.00 \mathrm{E}-02$ & $5.28 \mathrm{E}-03$ & $2.07 \mathrm{E}-02$ & $2.54 \mathrm{E}-03$ \\
\hline HLP-13 & $1.34 \mathrm{E}-01$ & 4.41E-02 & 8.02E-03 & $3.41 \mathrm{E}-02$ & $4.01 \mathrm{E}-03$ \\
\hline HLP-14 & $1.63 \mathrm{E}-01$ & 6.37E-02 & 9.87E-03 & $5.26 \mathrm{E}-02$ & $3.89 \mathrm{E}-03$ \\
\hline HLP-15 & $1.23 \mathrm{E}-01$ & $3.28 \mathrm{E}-02$ & $5.10 \mathrm{E}-03$ & $2.28 \mathrm{E}-02$ & $2.02 \mathrm{E}-03$ \\
\hline HLP-16 & $1.42 \mathrm{E}-01$ & $3.86 \mathrm{E}-02$ & $6.81 \mathrm{E}-03$ & 2.71E-02 & 3.27E-03 \\
\hline HLP-17 & $1.27 \mathrm{E}-01$ & 3.90E-02 & $6.06 \mathrm{E}-03$ & $2.93 \mathrm{E}-02$ & $2.40 \mathrm{E}-03$ \\
\hline HLP-18 & $1.42 \mathrm{E}-01$ & 4.45E-02 & 7.99E-03 & $3.36 \mathrm{E}-02$ & $3.94 \mathrm{E}-03$ \\
\hline HLP-19 & $1.05 \mathrm{E}-01$ & $2.61 \mathrm{E}-02$ & $3.98 \mathrm{E}-03$ & $1.74 \mathrm{E}-02$ & $1.52 \mathrm{E}-03$ \\
\hline HLP-20 & $1.28 \mathrm{E}-01$ & 3.32E-02 & $5.00 \mathrm{E}-03$ & $2.26 \mathrm{E}-02$ & $1.87 \mathrm{E}-03$ \\
\hline HLP-21 & $1.48 \mathrm{E}-01$ & $5.16 \mathrm{E}-02$ & 8.82E-03 & 4.09E-02 & $4.07 \mathrm{E}-03$ \\
\hline HLP-22 & $6.34 \mathrm{E}-02$ & 2.01E-02 & $3.08 \mathrm{E}-03$ & $1.52 \mathrm{E}-02$ & $1.20 \mathrm{E}-03$ \\
\hline HLP-23 & $2.65 \mathrm{E}-01$ & $8.51 \mathrm{E}-02$ & $1.21 \mathrm{E}-02$ & $6.51 \mathrm{E}-02$ & $3.96 \mathrm{E}-03$ \\
\hline HLP-24 & $1.01 \mathrm{E}-01$ & 2.79E-02 & 4.76E-03 & $1.98 \mathrm{E}-02$ & $2.20 \mathrm{E}-03$ \\
\hline HLP-25 & $1.51 \mathrm{E}-01$ & 4.17E-02 & 6.94E-03 & $2.95 \mathrm{E}-02$ & $3.09 \mathrm{E}-03$ \\
\hline HLP-26 & $1.43 \mathrm{E}-01$ & $3.80 \mathrm{E}-02$ & 6.98E-03 & 2.64E-02 & $3.53 \mathrm{E}-03$ \\
\hline HLP-27 & $3.11 \mathrm{E}-01$ & $1.30 \mathrm{E}-01$ & $2.51 \mathrm{E}-02$ & $1.10 \mathrm{E}-01$ & $1.34 \mathrm{E}-02$ \\
\hline HLP-28 & $6.64 \mathrm{E}-02$ & $1.59 \mathrm{E}-02$ & $2.54 \mathrm{E}-03$ & $1.03 \mathrm{E}-02$ & $1.06 \mathrm{E}-03$ \\
\hline HLP-29 & $1.76 \mathrm{E}-01$ & 3.99E-02 & 7.24E-03 & $2.47 \mathrm{E}-02$ & $3.62 \mathrm{E}-03$ \\
\hline HLP-30 & 7.01E-02 & $1.49 \mathrm{E}-02$ & 2.44E-03 & 8.76E-03 & $1.05 \mathrm{E}-03$ \\
\hline HLP-31 & 7.08E-01 & $2.58 \mathrm{E}-01$ & 4.34E-02 & 2.08E-01 & $1.95 \mathrm{E}-02$ \\
\hline HLP-32 & $1.06 \mathrm{E}-01$ & $3.47 \mathrm{E}-02$ & $6.82 \mathrm{E}-03$ & 2.68E-02 & $3.73 \mathrm{E}-03$ \\
\hline HLP-33 & $2.85 \mathrm{E}-01$ & $2.70 \mathrm{E}-01$ & $8.47 \mathrm{E}-02$ & 2.68E-01 & $6.42 \mathrm{E}-02$ \\
\hline HLP-34 & $9.62 \mathrm{E}-02$ & $2.75 \mathrm{E}-02$ & $4.11 \mathrm{E}-03$ & $1.98 \mathrm{E}-02$ & $1.52 \mathrm{E}-03$ \\
\hline HLP-35 & $1.98 \mathrm{E}-01$ & $8.66 \mathrm{E}-02$ & $1.78 \mathrm{E}-02$ & $7.42 \mathrm{E}-02$ & $1.02 \mathrm{E}-02$ \\
\hline HLP-36 & $9.84 \mathrm{E}-02$ & $2.93 \mathrm{E}-02$ & 9.28E-03 & $2.16 \mathrm{E}-02$ & $7.06 \mathrm{E}-03$ \\
\hline HLP-37 & $1.88 \mathrm{E}-01$ & $6.80 \mathrm{E}-02$ & $\mathrm{n} / \mathrm{a}$ & $5.47 \mathrm{E}-02$ & $\mathrm{n} / \mathrm{a}$ \\
\hline HLP-37Q & $2.12 \mathrm{E}-01$ & $5.88 \mathrm{E}-02$ & $1.00 \mathrm{E}-02$ & 4.18E-02 & $4.58 \mathrm{E}-03$ \\
\hline HLP-38 & $1.11 \mathrm{E}-01$ & $2.41 \mathrm{E}-02$ & $4.25 \mathrm{E}-03$ & $1.44 \mathrm{E}-02$ & $2.04 \mathrm{E}-03$ \\
\hline HLP-38Q & 8.91E-02 & $2.43 \mathrm{E}-02$ & 4.18E-03 & $1.71 \mathrm{E}-02$ & $1.95 \mathrm{E}-03$ \\
\hline HLP-39 & $5.08 \mathrm{E}-01$ & $2.88 \mathrm{E}-01$ & 3.74E-02 & $2.64 \mathrm{E}-01$ & $9.51 \mathrm{E}-03$ \\
\hline HLP-40 & $1.56 \mathrm{E}-01$ & $1.10 \mathrm{E}-01$ & 2.22E-02 & $1.05 \mathrm{E}-01$ & $1.25 \mathrm{E}-02$ \\
\hline HLP-40Q & $1.35 \mathrm{E}-01$ & $1.11 \mathrm{E}-01$ & 2.37E-02 & $1.09 \mathrm{E}-01$ & $1.39 \mathrm{E}-02$ \\
\hline HLP-41 & $5.10 \mathrm{E}-01$ & $3.82 \mathrm{E}-01$ & $5.46 \mathrm{E}-02$ & $3.68 \mathrm{E}-01$ & $1.82 \mathrm{E}-02$ \\
\hline HLP-42 & $1.54 \mathrm{E}-01$ & $7.80 \mathrm{E}-02$ & $5.06 \mathrm{E}-02$ & $6.95 \mathrm{E}-02$ & $4.75 \mathrm{E}-02$ \\
\hline HLP-42Q & $1.37 \mathrm{E}-01$ & $6.66 \mathrm{E}-02$ & $4.11 \mathrm{E}-02$ & 5.87E-02 & $3.83 \mathrm{E}-02$ \\
\hline HLP-43 & 1.19E-01 & 4.72E-02 & $6.71 \mathrm{E}-03$ & 3.92E-02 & $2.22 \mathrm{E}-03$ \\
\hline
\end{tabular}




\begin{tabular}{lcrrrr}
\hline \multicolumn{3}{c}{ Release Rate, $\boldsymbol{r}$, in $\mathbf{g} / \mathbf{m}^{2}$-Day } & \multicolumn{2}{c}{ Release Rate, $\boldsymbol{r}_{\mathbf{\Delta}}{ }^{(\mathbf{a})}$} \\
Glass & $\mathbf{1 0}$ hours & $\mathbf{1 0 0}$ hours & $\mathbf{1 0 0 0}$ hours & $\mathbf{1 0 0}$ hours & $\mathbf{1 0 0 0}$ hours \\
\hline HLP-44 & $1.18 \mathrm{E}-01$ & $2.76 \mathrm{E}-02$ & $7.32 \mathrm{E}-03$ & $1.76 \mathrm{E}-02$ & $5.06 \mathrm{E}-03$ \\
HLP-45 & $1.29 \mathrm{E}-01$ & $3.21 \mathrm{E}-02$ & $7.64 \mathrm{E}-03$ & $2.13 \mathrm{E}-02$ & $4.93 \mathrm{E}-03$ \\
HLP-46 & $3.50 \mathrm{E}-04$ & $6.21 \mathrm{E}-02$ & $1.03 \mathrm{E}-02$ & $6.89 \mathrm{E}-02$ & $4.52 \mathrm{E}-03$ \\
HLP-47 & $1.94 \mathrm{E}-01$ & $6.19 \mathrm{E}-02$ & $1.46 \mathrm{E}-02$ & $4.72 \mathrm{E}-02$ & $9.30 \mathrm{E}-03$ \\
HLP-48 & $1.51 \mathrm{E}-01$ & $4.87 \mathrm{E}-02$ & $1.08 \mathrm{E}-02$ & $3.73 \mathrm{E}-02$ & $6.63 \mathrm{E}-03$ \\
HLP-49 & $9.27 \mathrm{E}-02$ & $2.16 \mathrm{E}-02$ & $3.69 \mathrm{E}-03$ & $1.37 \mathrm{E}-02$ & $1.70 \mathrm{E}-03$ \\
HLP-50 & \multicolumn{5}{c}{ No results for this glass } \\
HLP-51 & $1.35 \mathrm{E}-01$ & $3.13 \mathrm{E}-02$ & $7.78 \mathrm{E}-03$ & $1.98 \mathrm{E}-02$ & $5.17 \mathrm{E}-03$ \\
HLP-52 & $5.56 \mathrm{E}-02$ & $5.37 \mathrm{E}-01$ & $1.73 \mathrm{E}-01$ & $5.90 \mathrm{E}-01$ & $1.33 \mathrm{E}-01$ \\
HLP-53 & \multicolumn{5}{c}{ No results for this glass } \\
HLP-54 & $1.81 \mathrm{E}-01$ & $2.88 \mathrm{E}-02$ & $4.85 \mathrm{E}-03$ & $1.20 \mathrm{E}-02$ & $2.19 \mathrm{E}-03$ \\
HLP-55 & $2.20 \mathrm{E}-01$ & $4.96 \mathrm{E}-02$ & $1.15 \mathrm{E}-02$ & $3.07 \mathrm{E}-02$ & $7.23 \mathrm{E}-03$ \\
\hline
\end{tabular}

(a) The release rates, $r$ and $r_{\Delta}$, are the same at 10 hours. 


\section{Relationship Between Standard Deviations and Means from PCT-A Data}

Exhibit B-1. Relationship Between Standard Deviations and Means for Boron and Sodium
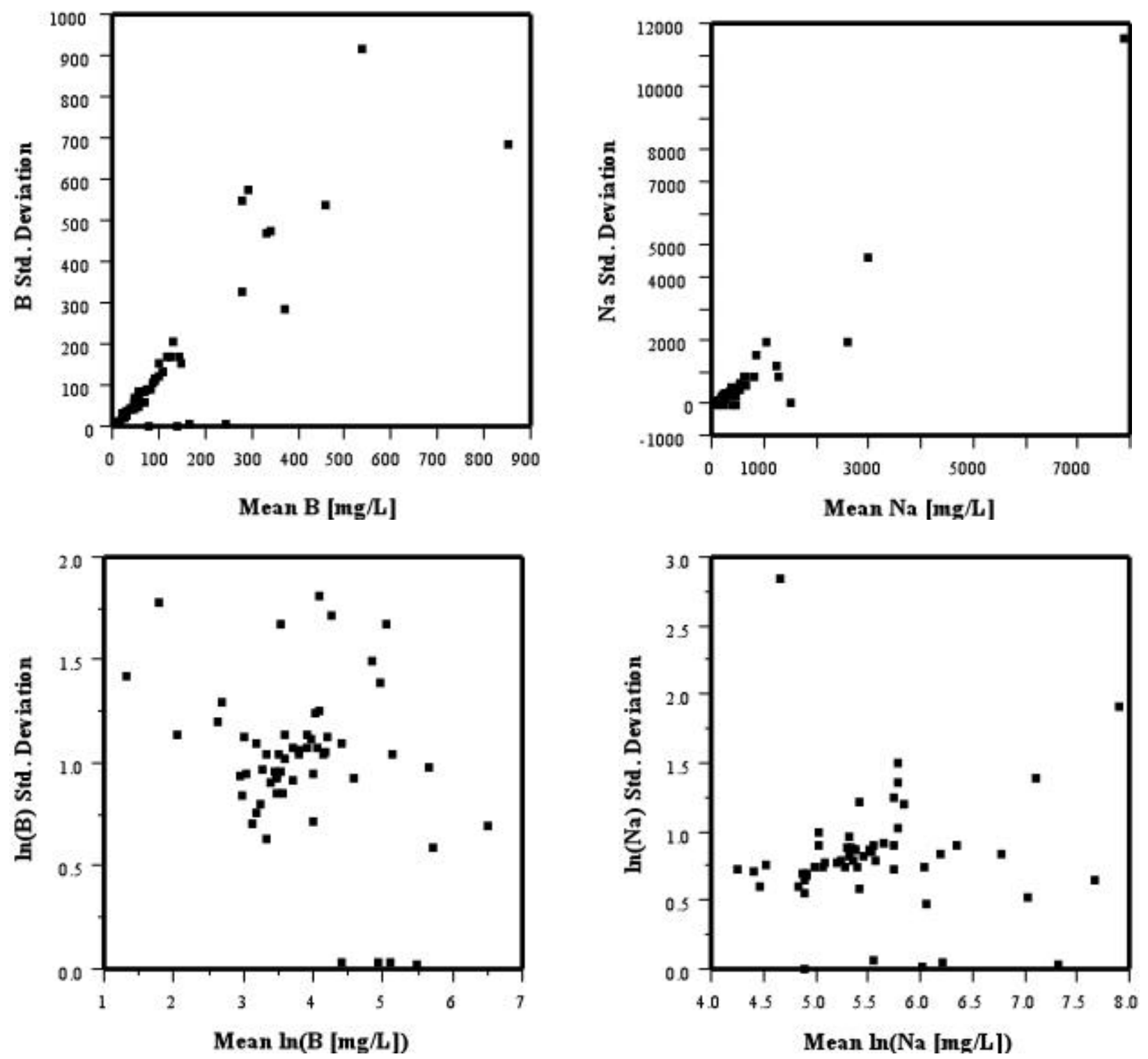


\section{APPENDIX C}

\section{VHT Corrosion Extents}




\section{APPENDIX C VHT Alteration Extents}

Table C-1. Results from Terminated VHT Tests

\begin{tabular}{|c|c|c|c|c|c|c|c|c|c|c|c|c|}
\hline $\begin{array}{l}n \\
\frac{\omega}{\omega}\end{array}$ & 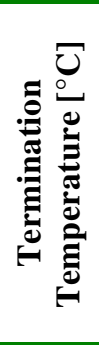 & 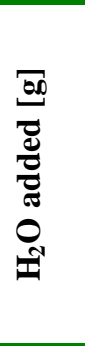 & 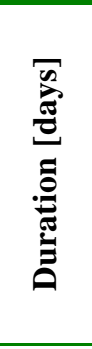 & 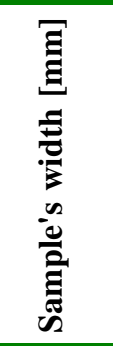 & 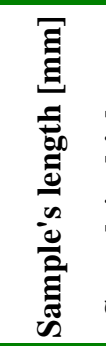 & 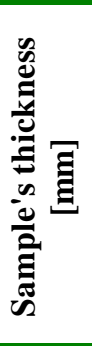 & 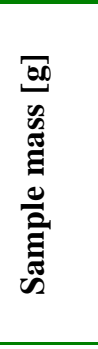 & 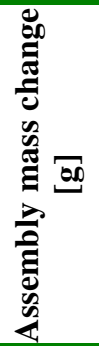 & 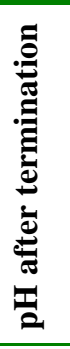 & 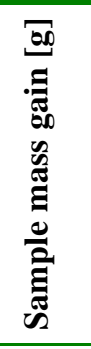 & 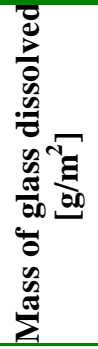 & 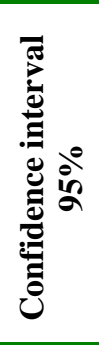 \\
\hline HLP-01 & 199.7 & 0.26 & 3.0 & 10.17 & 9.72 & $1.5 !$ & 0.401 & -0.03 & 10 & 0.00 & 153 & 1.5 \\
\hline HLP-01 & 199.8 & 0.26 & 8.8 & 9.74 & 10.04 & 1.5: & 0.383 & -0.04 & 10 & 0.00 & 205 & 1.1 \\
\hline HLP-01 & 200.7 & 0.27 & 36.6 & 9.71 & 10.38 & 1.5 & 0.373 & -0.06 & 8 & 0.03 & 392 & 9.5 \\
\hline HLP-01 & 200.7 & 0.26 & 32.8 & 9.67 & 10.17 & 1.6 & 0.413 & -0.07 & 6 & 0.01 & 232 & 8.1 \\
\hline HLP-01 & 200.7 & 0.25 & 36.5 & 9.74 & 10.30 & 1.6 & 0.412 & -0.06 & 10 & 0.02 & 434 & 9.8 \\
\hline HLP-02 & 199.8 & 0.26 & 8.8 & 9.64 & 10.27 & 1.4 & 0.373 & -0.04 & 10 & 0.07 & 1884 & - \\
\hline HLP-02 & 200.5 & 0.25 & 3.0 & 10.30 & 9.76 & $1.3^{\prime}$ & 0.363 & -0.02 & 8 & 0.04 & 778 & 122.0 \\
\hline HLP-02 & 200.5 & 0.25 & 5.0 & 10.17 & 9.73 & 1.5 & 0.399 & -0.02 & 8 & 0.04 & 1423 & 227.7 \\
\hline HLP-02 & 200.5 & 0.25 & 3.0 & 10.17 & 9.73 & 1.5 & 0.399 & -0.02 & 8 & 0.04 & 857 & 70.1 \\
\hline HLP-02 & 200.5 & 0.25 & 1.6 & 10.39 & 9.80 & $1.4 !$ & 0.393 & -0.01 & 10 & 0.03 & 557 & 49.2 \\
\hline HLP-02 & 200.5 & 0.25 & 1.0 & 10.29 & 9.70 & 1.5 & 0.400 & -0.02 & - & - & 351 & 21.9 \\
\hline HLP-02 & 200.5 & 0.25 & 0.5 & 10.24 & 9.72 & $1.5 !$ & 0.402 & -0.02 & 10 & 0.03 & 207 & 2.1 \\
\hline HLP-03 & 199.7 & 0.26 & 3.0 & 10.06 & 9.92 & 1.5 & 0.397 & -0.03 & 10 & 0.00 & 153 & 1.5 \\
\hline HLP-03 & 199.8 & 0.25 & 8.8 & 9.59 & 9.90 & 1.4 & 0.383 & -0.03 & 10 & 0.06 & 235 & 3.9 \\
\hline HLP-03 & 200.4 & 0.26 & 17.0 & 10.07 & 10.13 & $1.4^{\prime}$ & 0.367 & -0.04 & 10 & 0.01 & 343 & 6.2 \\
\hline HLP-03 & 200.7 & 0.27 & 36.6 & 10.15 & 10.12 & 1.4 & 0.373 & -0.06 & 8 & 0.02 & 254 & 3.0 \\
\hline HLP-03 & 200.7 & 0.25 & 36.5 & 10.01 & 10.04 & 1.5 & 0.392 & -0.06 & 10 & 0.02 & 306 & 1.7 \\
\hline HLP-04 & 199.7 & 0.26 & 3.0 & 9.94 & 9.96 & 1.5 & 0.394 & -0.03 & 10 & 0.01 & 377 & 2.2 \\
\hline HLP-04 & 199.8 & 0.25 & 8.8 & 9.83 & 9.98 & 1.5 & 0.402 & -0.03 & 10 & -0.05 & 854 & 47.3 \\
\hline HLP-04 & 199.9 & 0.25 & 41.0 & 10.05 & 10.01 & 1.5 & 0.388 & -0.03 & 10 & 0.06 & 1775 & 319.5 \\
\hline HLP-04 & 200.4 & 0.26 & 17.0 & 12.26 & 9.84 & 1.5 & 0.401 & -0.04 & 10 & 0.04 & 879 & 34.7 \\
\hline HLP-04 & 200.4 & 0.26 & 16.0 & 9.96 & 9.91 & 1.4 & 0.372 & -0.03 & 10 & 0.05 & 904 & 202.9 \\
\hline HLP-04 & 200.4 & 0.25 & 16.0 & 9.90 & 9.93 & 1.5 & 0.396 & -0.02 & 6 & 0.04 & 931 & 204.9 \\
\hline HLP-04 & 200.6 & 0.25 & 65.0 & 10.11 & 9.93 & 1.5 & 0.391 & -0.05 & 8.5 & 0.12 & 1947 & - \\
\hline HLP-04 & 200.7 & 0.25 & 83.1 & 9.96 & 10.05 & $1.5 !$ & 0.407 & -0.08 & 7 & 0.06 & 2033 & - \\
\hline HLP-05 & 199.7 & 0.26 & 3.0 & 10.14 & 9.70 & 1.6 & 0.411 & -0.02 & 8 & 0.00 & 0 & - \\
\hline HLP-05 & 199.8 & 0.25 & 8.8 & 9.88 & 10.21 & 1.4 & 0.379 & -0.03 & $5 . \varepsilon$ & 0.01 & 444 & 5.8 \\
\hline HLP-05 & 200.3 & 0.26 & 23.7 & 10.23 & 9.89 & 1.61 & 0.405 & -0.03 & 6 & 0.01 & 188 & 1.9 \\
\hline HLP-05 & 200.3 & 0.26 & 23.7 & 9.96 & 10.18 & 1.6 & 0.409 & -0.05 & 6 & 0.01 & 237 & 2.4 \\
\hline HLP-05 & 200.4 & 0.27 & 12.0 & 9.90 & 10.16 & $1.5^{\prime}$ & 0.395 & -0.03 & $5 . \varepsilon$ & 0.00 & 125 & 1.2 \\
\hline HLP-05 & 200.4 & 0.26 & 13.9 & 9.89 & 10.20 & 1.5 & 0.408 & -0.03 & 8 & 0.01 & 480 & 14.5 \\
\hline HLP-05 & 200.6 & 0.26 & 12.9 & 9.88 & 10.23 & $1.5 i$ & 0.405 & -0.03 & 6 & 0.01 & 190 & 1.9 \\
\hline HLP-05 & 200.7 & 0.30 & 8.8 & 9.96 & 10.27 & 1.5 & 0.404 & -0.08 & 6 & 0.01 & 127 & 0.6 \\
\hline HLP-05 & 200.8 & 0.25 & 41.0 & 10.46 & 10.63 & 1.41 & 0.420 & -0.06 & 8.5 & 0.02 & 207 & 3.4 \\
\hline HLP-06 & 199.7 & 0.26 & 3.0 & 9.91 & 10.18 & 1.61 & 0.408 & -0.02 & 8 & 0.00 & 278 & 2.9 \\
\hline HLP-06 & 199.8 & 0.25 & 8.8 & 10.00 & 10.00 & 1.5 & 0.394 & -0.03 & $5 . \varepsilon$ & 0.01 & 811 & 26.0 \\
\hline HLP-06 & 200.4 & 0.26 & 13.9 & 10.03 & 10.00 & 1.6 & 0.409 & -0.03 & 8 & 0.04 & 1178 & 62.4 \\
\hline
\end{tabular}

C. 1 


\begin{tabular}{|c|c|c|c|c|c|c|c|c|c|c|c|c|}
\hline$\frac{\tilde{E}}{\tilde{E}}$ & 岂 & 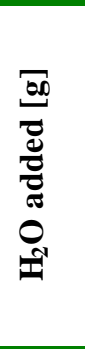 & 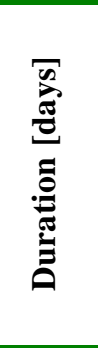 & 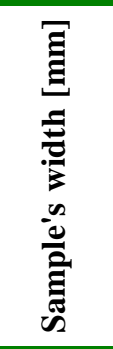 & 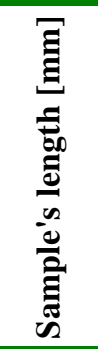 & 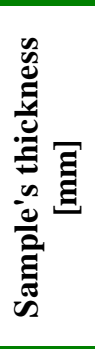 & 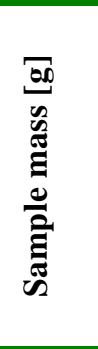 & 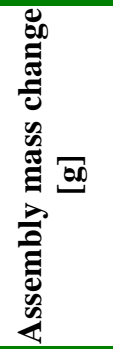 & 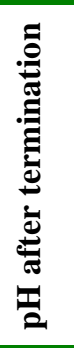 & 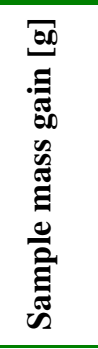 & 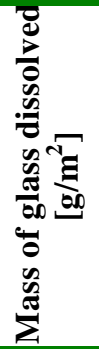 & 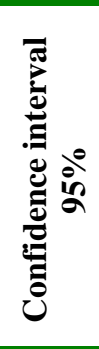 \\
\hline HLP-06 & 200.4 & 0.25 & 16.0 & 10.02 & 10.03 & $1.5 !$ & 0.399 & -0.03 & 10 & 0.01 & 424 & 12.2 \\
\hline HLP-06 & 200.6 & 0.25 & 5.1 & 10.04 & 10.15 & 1.61 & 0.415 & -0.02 & 10 & 0.00 & 395 & 13.2 \\
\hline HLP-06 & 200.6 & 0.25 & 21.7 & 10.09 & 10.05 & 1.5 & 0.381 & -0.04 & 10 & 0.02 & 427 & 7.7 \\
\hline HLP-06 & 200.6 & 0.25 & 32.8 & 10.16 & 10.05 & 1.5 & 0.393 & -0.04 & 8 & 0.01 & 525 & 13.5 \\
\hline HLP-06 & 200.7 & 0.25 & 108.7 & 10.20 & 10.03 & 1.5 & 0.395 & -0.09 & 10 & 0.02 & 569 & 7.5 \\
\hline HLP-07 & 199.7 & 0.25 & 108.7 & 10.11 & 10.00 & 1.5 & 0.399 & -0.08 & 8.5 & 0.03 & 1847 & 398.9 \\
\hline HLP-07 & 200.2 & 0.26 & 12.9 & 10.09 & 10.12 & 1.5 & 0.405 & -0.03 & $5 . \varepsilon$ & 0.01 & 326 & 3.6 \\
\hline HLP-07 & 200.2 & 0.25 & 44.9 & 9.99 & 10.10 & $1.5^{\prime}$ & 0.407 & -0.02 & 10 & 0.02 & 1118 & 80.5 \\
\hline HLP-07 & 200.4 & 0.25 & 16.0 & 10.01 & 10.03 & 1.5 & 0.389 & -0.03 & 6 & 0.02 & 329 & 3.7 \\
\hline HLP-07 & 200.5 & 0.25 & 77.9 & 10.03 & 10.06 & $1.5 !$ & 0.401 & 0.00 & 9 & 0.02 & 1350 & 155.5 \\
\hline HLP-07 & 200.6 & 0.26 & 21.7 & 10.07 & 10.03 & 1.61 & 0.415 & -0.03 & 10 & 0.01 & 552 & 10.2 \\
\hline HLP-08 & 199.7 & 0.25 & 108.7 & 10.24 & 10.07 & 1.6 & 0.428 & -0.08 & 8.5 & 0.04 & 1063 & 38.8 \\
\hline HLP-08 & 200.2 & 0.26 & 12.9 & 10.09 & 10.17 & $1.5^{\prime}$ & 0.409 & -0.03 & $5 . \varepsilon$ & 0.01 & 267 & 4.2 \\
\hline HLP-08 & 200.2 & 0.25 & 44.9 & 10.05 & 10.07 & 1.5. & 0.402 & -0.02 & 10 & 0.02 & 532 & 10.3 \\
\hline HLP-08 & 200.4 & 0.25 & 16.0 & 10.09 & 10.10 & 1.6 & 0.423 & -0.03 & 6 & 0.01 & 168 & 2.4 \\
\hline HLP-08 & 200.5 & 0.25 & 77.9 & 10.13 & 10.16 & 1.61 & 0.451 & 0.00 & 9 & 0.01 & 794 & 28.0 \\
\hline HLP-08 & 200.6 & 0.26 & 21.7 & 10.13 & 10.12 & $1.5 !$ & 0.410 & -0.03 & 10 & 0.01 & 308 & 8.4 \\
\hline HLP-09 & 199.7 & 0.27 & 3.0 & 9.84 & 10.04 & 1.4 & 0.365 & -0.03 & $5 . \varepsilon$ & 0.00 & 103 & 1.1 \\
\hline HLP-09 & 199.8 & 0.26 & 8.8 & 9.90 & 10.09 & 1.5 & 0.396 & -0.04 & 6 & 0.00 & 343 & 3.8 \\
\hline HLP-09 & 200.4 & 0.26 & 12.0 & 9.86 & 10.22 & 1.6 & 0.409 & -0.02 & 6 & 0.00 & 88 & 0.8 \\
\hline HLP-09 & 200.6 & 0.25 & 19.0 & 9.85 & 10.30 & 1.5 & 0.390 & -0.04 & 6 & -0.01 & 49 & 0.2 \\
\hline HLP-09 & 200.6 & 0.24 & 19.0 & 10.10 & 10.00 & 1.6. & 0.401 & -0.04 & 6 & 0.00 & 304 & 3.2 \\
\hline HLP-09 & 200.7 & 0.26 & 26.7 & 9.93 & 10.29 & 1.5 & 0.392 & -0.06 & 6 & 0.01 & 201 & 4.2 \\
\hline HLP-09 & 200.7 & 0.26 & 32.8 & 10.22 & 9.76 & 1.5 & 0.394 & -0.07 & 6 & 0.01 & 494 & 6.1 \\
\hline HLP-09 & 200.7 & 0.25 & 26.7 & 9.95 & 10.16 & 1.5 & 0.402 & -0.06 & 6 & 0.01 & 214 & 1.1 \\
\hline HLP-09 & 299.6 & 0.80 & 2.0 & 10.15 & 10.08 & 1.5: & 0.408 & -0.05 & 5.5 & 0.03 & 1248 & 31.0 \\
\hline HLP-09 & 299.6 & 0.79 & 3.0 & 10.05 & 10.15 & 1.5 & 0.401 & -0.20 & 6 & 0.03 & 1053 & 42.7 \\
\hline HLP-09 & 299.7 & 0.79 & 1.0 & 10.10 & 10.08 & 1.5 & 0.405 & -0.02 & $5 . \varepsilon$ & 0.03 & 827 & 13.2 \\
\hline HLP-09 & 299.9 & 0.80 & 3.0 & 9.87 & 9.95 & 1.41 & 0.348 & -0.04 & 5 & 0.04 & 1645 & 236.9 \\
\hline HLP-10 & 199.7 & 0.27 & 3.0 & 10.11 & 10.10 & 1.5 & 0.421 & -0.03 & $5 . \varepsilon$ & 0.00 & 117 & 0.6 \\
\hline HLP-10 & 199.8 & 0.26 & 8.8 & 9.09 & 10.02 & 1.4 & 0.372 & -0.04 & 6 & 0.00 & 138 & 1.4 \\
\hline HLP-10 & 200.7 & 0.26 & 32.8 & 9.98 & 10.13 & $1.5 !$ & 0.425 & -0.07 & 6 & 0.02 & 238 & 2.4 \\
\hline HLP-10 & 299.9 & 0.80 & 1.0 & 9.91 & 9.98 & 1.4 & 0.352 & -0.03 & 7.5 & 0.04 & 1416 & 70.3 \\
\hline HLP-10 & 300.0 & 0.80 & 2.0 & 9.79 & 9.86 & 1.5 & 0.378 & -0.05 & 8 & 0.04 & 1958 & - \\
\hline HLP-11 & 199.8 & 0.26 & 7.3 & 10.20 & 10.11 & 1.5 & 0.412 & -0.03 & 6 & 0.00 & 101 & 1.9 \\
\hline HLP-11 & 200.1 & 0.26 & 12.9 & 9.90 & 10.09 & 1.5 & 0.396 & 0.06 & 6 & 0.02 & 114 & 1.7 \\
\hline HLP-11 & 200.6 & 0.25 & 88.0 & 10.08 & 10.15 & $1.5^{\prime}$ & 0.403 & -0.10 & 6.5 & 0.04 & 1267 & 16.3 \\
\hline HLP-11 & 200.7 & 0.25 & 70.0 & 10.10 & 10.13 & 1.5 & 0.399 & -0.09 & 8 & - & 1170 & 27.2 \\
\hline HLP-12 & 199.8 & 0.26 & 7.3 & 9.86 & 10.36 & 1.5 & 0.402 & -0.03 & 6 & 0.00 & 180 & 2.8 \\
\hline HLP-12 & 199.9 & 0.25 & 41.0 & 10.06 & 10.08 & 1.5. & 0.406 & -0.03 & 10 & 0.03 & 837 & 13.5 \\
\hline HLP-12 & 200.1 & 0.26 & 12.9 & 10.22 & 9.76 & 1.5 & 0.394 & -0.01 & 6 & 0.01 & 405 & 9.4 \\
\hline HLP-12 & 200.4 & 0.26 & 16.0 & 10.24 & 10.96 & 1.71 & 0.450 & -0.03 & 10 & 0.03 & 484 & 8.1 \\
\hline
\end{tabular}




\begin{tabular}{|c|c|c|c|c|c|c|c|c|c|c|c|c|}
\hline$\frac{\tilde{E}}{\tilde{E}}$ & 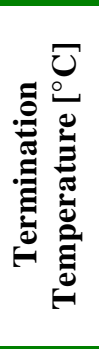 & 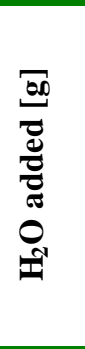 & 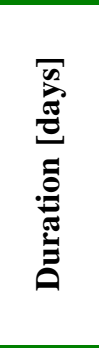 & 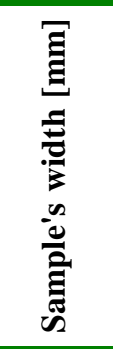 & 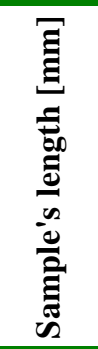 & 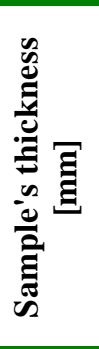 & 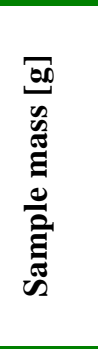 & 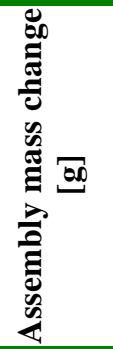 & 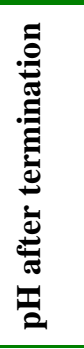 & 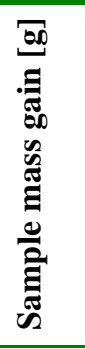 & 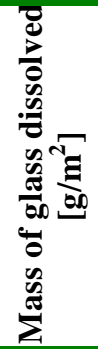 & 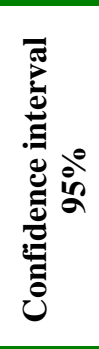 \\
\hline HLP-12 & 200.4 & 0.25 & 16.0 & 10.28 & 9.94 & 1.5 & 0.415 & -0.02 & 6 & 0.03 & 553 & 10.4 \\
\hline HLP-12 & 200.6 & 0.25 & 65.0 & 9.90 & 9.96 & 1.5 & 0.386 & -0.05 & 8.5 & 0.03 & 1043 & 42.3 \\
\hline HLP-12 & 200.7 & 0.26 & 96.7 & 9.93 & 10.26 & 1.6: & 0.422 & -0.08 & 10 & 0.04 & 1677 & 155.8 \\
\hline HLP-12 & 200.7 & 0.25 & 83.1 & 9.98 & 10.16 & 1.5 & 0.389 & -0.08 & 7 & 0.08 & 1348 & 82.6 \\
\hline HLP-12 & 300.0 & 0.80 & 1.5 & 9.93 & 10.34 & 1.5. & 0.408 & -0.06 & 6 & 0.04 & 1584 & 184.0 \\
\hline HLP-12 & 300.0 & 0.80 & 0.5 & 10.04 & 10.08 & $1.5 !$ & 0.401 & -0.03 & 6 & 0.03 & 508 & 15.8 \\
\hline HLP-12 & 300.0 & 0.79 & 1.0 & 10.11 & 10.04 & 1.4 & 0.384 & -0.05 & 6 & 0.03 & 895 & 24.8 \\
\hline HLP-13 & 200.5 & 0.24 & 150.0 & 9.79 & 10.26 & 1.5 & 0.395 & -0.11 & 6 & 0.01 & 706 & 5.1 \\
\hline HLP-13 & 200.7 & 0.25 & 30.6 & 10.09 & 9.76 & 1.5 & 0.393 & -0.09 & 5 & 0.02 & 518 & 6.5 \\
\hline HLP-13 & 200.7 & 0.25 & 8.7 & 9.73 & 10.24 & 1.4 & 0.368 & -0.03 & 6 & 0.01 & 0 & - \\
\hline HLP-13 & 200.7 & 0.25 & 97.9 & 9.87 & 10.33 & 1.61 & 0.427 & -0.07 & 8 & 0.04 & 782 & 10.8 \\
\hline HLP-13 & 200.7 & 0.25 & 15.6 & 10.10 & 9.81 & 1.5 & 0.405 & -0.02 & 6 & 0.01 & 279 & 31.7 \\
\hline HLP-13 & 200.7 & 0.22 & 79.9 & 9.83 & 10.20 & 1.5 & 0.404 & -0.07 & 5.5 & 0.03 & 944 & 40.4 \\
\hline HLP-14 & 199.9 & 0.20 & 20.9 & 10.03 & 10.07 & 1.5: & 0.403 & -0.04 & 5 & 0.04 & 656 & 9.1 \\
\hline HLP-14 & 200.5 & 0.24 & 150.0 & 9.94 & 9.98 & 1.5 & 0.380 & -0.11 & 6 & 0.03 & 1915 & - \\
\hline HLP-14 & 200.7 & 0.25 & 30.6 & 9.95 & 9.80 & $1.4^{\prime}$ & 0.372 & -0.09 & 5 & 0.04 & 1324 & 21.2 \\
\hline HLP-14 & 200.7 & 0.25 & 8.7 & 10.09 & 9.93 & 1.4 & 0.376 & -0.03 & 6 & 0.01 & 13 & 0.1 \\
\hline HLP-14 & 200.7 & 0.25 & 97.9 & 10.02 & 10.01 & 1.4 & 0.374 & -0.07 & 8 & 0.05 & 1864 & - \\
\hline HLP-14 & 200.7 & 0.25 & 15.6 & 9.87 & 9.97 & 1.4 & 0.363 & -0.02 & 6 & 0.06 & 392 & 28.0 \\
\hline HLP-14 & 200.7 & 0.22 & 79.9 & 9.93 & 9.88 & 1.5. & 0.380 & -0.07 & 5.5 & 0.05 & 1810 & 130.3 \\
\hline HLP-14 & 200.7 & 0.21 & 24.9 & 10.03 & 10.07 & 1.5: & 0.403 & -0.04 & 9.5 & 0.04 & 1055 & 52.0 \\
\hline HLP-15 & 200.7 & 0.25 & 30.6 & 10.06 & 9.89 & $1.4^{\prime}$ & 0.382 & -0.07 & 6 & 0.01 & 144 & 1.5 \\
\hline HLP-15 & 200.7 & 0.25 & 8.7 & 10.08 & 10.14 & 1.5 & 0.409 & -0.07 & 10 & 0.00 & 0 & - \\
\hline HLP-15 & 200.7 & 0.25 & 15.6 & 9.93 & 10.04 & 1.5 & 0.400 & -0.04 & 6 & 0.02 & 119 & 0.6 \\
\hline HLP-15 & 200.7 & 0.23 & 76.9 & 10.09 & 9.96 & 1.5 & 0.396 & -0.11 & 8 & 0.00 & 326 & 1.9 \\
\hline HLP-16 & 200.7 & 0.25 & 30.6 & 8.29 & 11.62 & 1.4: & 0.358 & -0.07 & 5 & 0.01 & 484 & 13.3 \\
\hline HLP-16 & 200.7 & 0.25 & 8.7 & 11.76 & 8.08 & 1.51 & 0.366 & -0.07 & 10 & 0.00 & 0 & - \\
\hline HLP-16 & 200.7 & 0.25 & 15.6 & 8.25 & 11.42 & 1.5. & 0.372 & -0.04 & 6 & 0.02 & 310 & 5.2 \\
\hline HLP-16 & 200.7 & 0.23 & 76.9 & 8.74 & 11.30 & 1.5. & 0.386 & -0.11 & 8 & 0.01 & 792 & 18.8 \\
\hline HLP-17 & 200.7 & 0.25 & 8.7 & 9.95 & 9.90 & 1.4 & 0.376 & -0.05 & 6 & 0.00 & 0 & 0.0 \\
\hline HLP-17 & 200.7 & 0.25 & 30.6 & 9.77 & 9.99 & $1.4 !$ & 0.390 & -0.06 & 5 & 0.01 & 416 & 5.1 \\
\hline HLP-17 & 200.7 & 0.25 & 76.9 & 10.02 & 9.89 & $1.4 !$ & 0.381 & -0.09 & 10 & 0.03 & 903 & 49.4 \\
\hline HLP-17 & 200.7 & 0.25 & 15.6 & 9.94 & 9.85 & 1.5 & 0.380 & -0.04 & 6 & 0.01 & 334 & 9.6 \\
\hline HLP-18 & 200.1 & 0.25 & 84.1 & 9.90 & 10.09 & 1.5 & 0.396 & -0.10 & 10 & 0.05 & 1789 & 257.6 \\
\hline HLP-18 & 200.2 & 0.26 & 73.0 & 9.97 & 10.16 & $1.5^{\prime}$ & 0.400 & -0.07 & 10 & 0.04 & 1509 & 205.6 \\
\hline HLP-18 & 200.7 & 0.25 & 8.7 & 10.08 & 10.02 & 1.4 & 0.384 & -0.06 & 6 & 0.01 & 128 & 0.7 \\
\hline HLP-18 & 200.7 & 0.25 & 30.6 & 10.00 & 10.04 & $1.3 !$ & 0.352 & -0.06 & 5 & 0.05 & 1022 & 50.7 \\
\hline HLP-18 & 200.7 & 0.25 & 15.6 & 9.71 & 9.76 & 1.5 & 0.368 & -0.04 & 6 & 0.02 & 527 & 3.5 \\
\hline HLP-19 & 200.7 & 0.31 & 30.6 & 9.99 & 9.72 & 1.4 & 0.361 & -0.07 & 5 & 0.01 & 0 & - \\
\hline HLP-19 & 200.7 & 0.25 & 15.6 & 10.35 & 9.70 & 1.4: & 0.389 & -0.04 & 7 & 0.01 & 0 & - \\
\hline HLP-20 & 200.7 & 0.31 & 30.6 & 11.42 & 8.33 & 1.5 & 0.372 & -0.07 & 5 & 0.02 & 142 & 2.2 \\
\hline HLP-20 & 200.7 & 0.25 & 15.6 & 8.64 & 11.51 & 1.5 & 0.398 & -0.04 & 7 & 0.00 & 142 & 0.7 \\
\hline
\end{tabular}




\begin{tabular}{|c|c|c|c|c|c|c|c|c|c|c|c|c|}
\hline$\frac{\tilde{E}}{\tilde{E}}$ & 岂 & 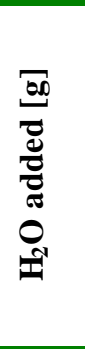 & 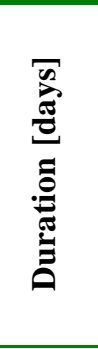 & 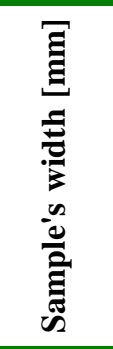 & 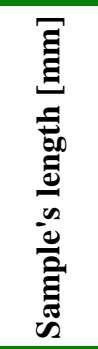 & 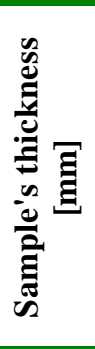 & 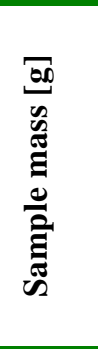 & 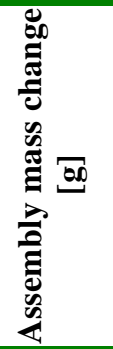 & 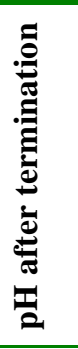 & 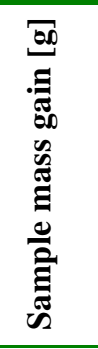 & 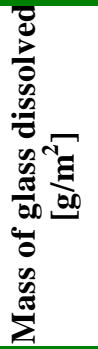 & 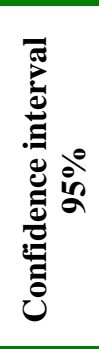 \\
\hline HLP-20 & 200.7 & 0.25 & 76.9 & 8.65 & 11.54 & 1.5: & 0.392 & -0.09 & 10 & 0.02 & 646 & 8.9 \\
\hline HLP-21 & 199.6 & 0.25 & 92.0 & 10.03 & 10.02 & $1.4 !$ & 0.380 & -0.10 & 5.5 & 0.02 & 723 & 17.0 \\
\hline HLP-21 & 200.3 & 0.25 & 85.0 & 10.06 & 9.96 & $1.4 !$ & 0.382 & -0.08 & 7.5 & 0.02 & 627 & 9.0 \\
\hline HLP-21 & 200.4 & 0.25 & 77.0 & 10.05 & 10.00 & 1.5 & 0.391 & -0.10 & 8 & 0.01 & 819 & 26.8 \\
\hline HLP-21 & 200.7 & 0.25 & 30.6 & 9.97 & 9.89 & 1.5 & 0.391 & -0.05 & 10 & 0.01 & 248 & 1.3 \\
\hline HLP-21 & 200.7 & 0.25 & 15.6 & 10.09 & 10.12 & 1.51 & 0.397 & -0.04 & 6 & 0.00 & 26 & 0.3 \\
\hline HLP-21 & 200.7 & 0.25 & 8.7 & 9.99 & 10.13 & 1.51 & 0.401 & -0.02 & 6 & 0.00 & 0 & - \\
\hline HLP-22 & 200.7 & 0.25 & 30.6 & 10.07 & 9.89 & $1.3 !$ & 0.356 & -0.05 & 10 & 0.04 & 90 & 1.0 \\
\hline HLP-22 & 200.7 & 0.25 & 15.6 & 9.77 & 10.25 & 1.5: & 0.393 & -0.04 & 6 & 0.00 & 0 & - \\
\hline HLP-22 & 200.7 & 0.25 & 8.7 & 9.78 & 10.32 & 1.4 & 0.361 & -0.02 & 6 & 0.00 & 0 & - \\
\hline HLP-23 & 198.3 & 0.20 & 51.8 & 9.99 & 10.01 & $1.4 !$ & 0.384 & -0.05 & 8.5 & 0.05 & 1920 & - \\
\hline HLP-23 & 199.6 & 0.25 & 92.0 & 10.09 & 9.95 & 1.5 & 0.401 & -0.10 & 5.5 & 0.06 & 1997 & - \\
\hline HLP-23 & 200.0 & 0.25 & 69.6 & 9.88 & 9.91 & $1.5^{\prime}$ & 0.397 & -0.10 & 6 & 0.04 & 1911 & 152.9 \\
\hline HLP-23 & 200.0 & 0.20 & 16.8 & 9.93 & 10.04 & 1.51 & 0.388 & -0.04 & 9 & 0.05 & 1077 & 92.6 \\
\hline HLP-23 & 200.3 & 0.25 & 85.0 & 9.95 & 9.96 & 1.6 & 0.416 & -0.08 & 7.5 & 0.06 & 2099 & - \\
\hline HLP-23 & 200.5 & 0.20 & 34.9 & 10.00 & 10.04 & $1.5^{\prime}$ & 0.408 & -0.06 & 8.5 & 0.05 & 1229 & 42.8 \\
\hline HLP-23 & 200.7 & 0.25 & 5.8 & 10.02 & 9.82 & 1.5 & 0.394 & -0.03 & 10 & 0.02 & 92 & 0.9 \\
\hline HLP-24 & 200.7 & 0.26 & 8.7 & 10.28 & 9.72 & 1.5. & 0.388 & -0.06 & 6 & 0.00 & 51 & - \\
\hline HLP-24 & 200.7 & 0.25 & 30.6 & 9.42 & 10.50 & 1.5 & 0.390 & -0.08 & 8 & 0.01 & 128 & 1.3 \\
\hline HLP-25 & 200.0 & 0.25 & 69.6 & 8.58 & 11.29 & 1.5 & 0.394 & -0.10 & 6 & 0.00 & 621 & 16.7 \\
\hline HLP-25 & 200.7 & 0.25 & 5.8 & 8.30 & 11.41 & 1.5 & 0.375 & -0.03 & 10 & 0.01 & 0 & - \\
\hline HLP-25 & 299.8 & 0.85 & 1.5 & 8.05 & 11.96 & 1.4 & 0.366 & -0.04 & 9 & 0.03 & 1541 & 39.6 \\
\hline HLP-25 & 299.9 & 0.85 & 3.1 & 9.23 & 11.84 & $1.5 !$ & 0.441 & -0.27 & 10 & - & 1916 & 344.9 \\
\hline HLP-25 & 299.9 & 0.85 & 2.5 & 8.47 & 11.62 & 1.5: & 0.385 & -0.04 & 8.5 & 0.02 & 1956 & - \\
\hline HLP-25 & 299.9 & 0.85 & 1.0 & 9.03 & 11.84 & $1.4 !$ & 0.408 & -0.03 & 8 & 0.04 & 1357 & 113.6 \\
\hline HLP-25 & 300.0 & 0.85 & 2.0 & 8.88 & 11.22 & 1.5 & 0.401 & -0.04 & 9 & 0.05 & 2012 & - \\
\hline HLP-26 & 199.3 & 0.25 & 5.8 & 9.96 & 9.96 & 1.6 & 0.408 & -0.01 & 10 & 0.03 & 161 & 2.3 \\
\hline HLP-26 & 199.8 & 0.25 & 1.9 & 10.04 & 9.98 & $1.5 !$ & 0.422 & -0.02 & 10 & 0.00 & 82 & 0.8 \\
\hline HLP-26 & 200.1 & 0.25 & 11.9 & 10.08 & 10.07 & $1.5^{\prime}$ & 0.410 & -0.02 & 10 & 0.02 & 292 & 3.1 \\
\hline HLP-26 & 200.6 & 0.25 & 24.9 & 10.06 & 10.06 & 1.6 & 0.412 & -0.05 & 6 & 0.02 & 506 & 6.0 \\
\hline HLP-26 & 299.9 & 0.85 & 1.0 & 10.03 & 10.09 & $1.4 !$ & 0.385 & -0.03 & 8 & 0.03 & 1264 & 72.8 \\
\hline HLP-26 & 299.9 & 0.85 & 1.5 & 10.03 & 10.06 & 1.4 & 0.384 & -0.04 & 9 & 0.04 & 1525 & 189.3 \\
\hline HLP-26 & 299.9 & 0.85 & 2.5 & 10.02 & 10.04 & 1.5 & 0.396 & -0.03 & 8 & 0.04 & 1968 & - \\
\hline HLP-26 & 300.0 & 0.85 & 2.0 & 10.06 & 10.07 & 1.51 & 0.395 & -0.03 & 9 & 0.05 & 1950 & - \\
\hline HLP-27 & 199.3 & 0.25 & 5.8 & 9.97 & 10.07 & 1.6 & 0.401 & -0.01 & 10 & -0.08 & 1459 & 193.6 \\
\hline HLP-27 & 199.8 & 0.25 & 1.9 & 10.04 & 9.96 & $1.5 !$ & 0.401 & -0.02 & 10 & 0.05 & 1132 & 58.9 \\
\hline HLP-27 & 200.1 & 0.25 & 11.9 & 10.06 & 10.05 & 1.6 & 0.404 & -0.02 & 10 & - & 1998 & - \\
\hline HLP-27 & 200.3 & 0.20 & 2.3 & 10.08 & 10.16 & $1.5 !$ & 0.409 & -0.03 & 10 & 0.10 & 1557 & 288.3 \\
\hline HLP-27 & 200.3 & 0.20 & 1.0 & 10.05 & 10.09 & 1.4 & 0.366 & -0.02 & - & -0.05 & 236 & 1.4 \\
\hline HLP-27 & 200.4 & 0.25 & 16.0 & 10.10 & 10.16 & 1.61 & 0.405 & -0.03 & 10 & - & 1973 & - \\
\hline HLP-27 & 200.4 & 0.20 & 8.0 & 10.06 & 10.16 & 1.6 & 0.413 & -0.02 & - & - & 1154 & 216.8 \\
\hline HLP-27 & 200.6 & 0.25 & 5.1 & 10.18 & 10.08 & 1.5 & 0.395 & -0.02 & 10 & - & 1511 & 255.9 \\
\hline
\end{tabular}




\begin{tabular}{|c|c|c|c|c|c|c|c|c|c|c|c|c|}
\hline$\frac{\tilde{E}}{\tilde{E}}$ & 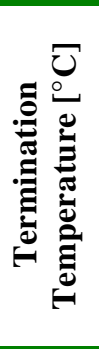 & 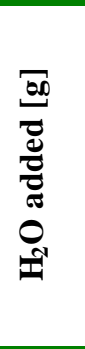 & 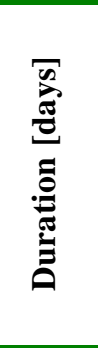 & 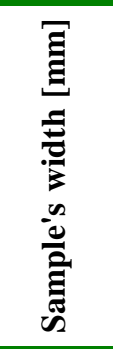 & 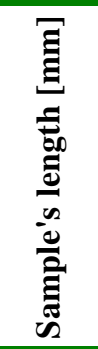 & 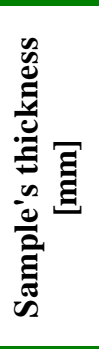 & 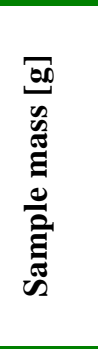 & 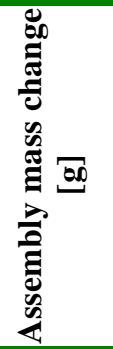 & 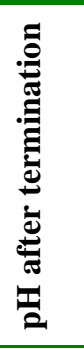 & 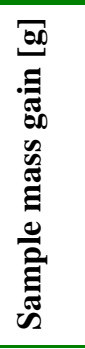 & 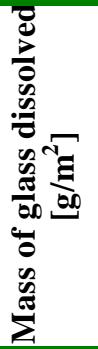 & 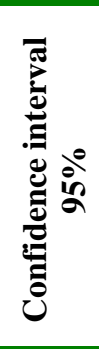 \\
\hline HLP-27 & 200.6 & 0.25 & 21.7 & 10.16 & 10.05 & 1.6: & 0.415 & -0.04 & 10 & 0.07 & 2032 & - \\
\hline HLP-28 & 200.1 & 0.26 & 5.8 & 10.04 & 9.94 & 1.5 & 0.383 & -0.02 & 10 & 0.02 & 493 & 6.2 \\
\hline HLP-28 & 200.1 & 0.25 & 1.8 & 9.99 & 9.90 & 1.5 & 0.395 & -0.02 & 10 & 0.01 & 68 & 0.7 \\
\hline HLP-28 & 200.1 & 0.15 & 11.9 & 9.99 & 10.08 & 1.5 & 0.389 & -0.03 & 10 & 0.01 & 525 & 6.7 \\
\hline HLP-28 & 200.4 & 0.26 & 12.0 & 10.00 & 9.98 & $1.5 !$ & 0.390 & -0.02 & 6 & 0.02 & 283 & 7.5 \\
\hline HLP-28 & 200.6 & 0.25 & 19.0 & 10.05 & 10.08 & 1.61 & 0.393 & -0.04 & 6 & 0.01 & 352 & 5.8 \\
\hline HLP-28 & 200.6 & 0.24 & 19.0 & 10.13 & 10.08 & $1.5^{\prime}$ & 0.380 & -0.04 & 6 & 0.01 & 261 & 5.6 \\
\hline HLP-28 & 200.7 & 0.26 & 26.7 & 10.06 & 10.09 & 1.5 & 0.390 & -0.06 & 6 & 0.02 & 280 & 7.5 \\
\hline HLP-28 & 200.7 & 0.25 & 26.7 & 10.15 & 10.07 & $1.5 !$ & 0.390 & -0.06 & 6 & 0.00 & 288 & 7.7 \\
\hline HLP-29 & 200.3 & 0.25 & 13.2 & 10.14 & 10.08 & 1.6 & 0.410 & -0.01 & 10 & 0.05 & 990 & 43.5 \\
\hline HLP-29 & 200.4 & 0.25 & 7.1 & 10.08 & 10.12 & 1.6 & 0.408 & -0.02 & 6 & 0.03 & 683 & 13.9 \\
\hline HLP-29 & 200.6 & 0.25 & 7.8 & 9.94 & 10.12 & $1.5 !$ & 0.395 & -0.04 & 6 & 0.05 & 1395 & 109.2 \\
\hline HLP-29 & 200.6 & 0.25 & 20.8 & 10.09 & 10.02 & 1.61 & 0.405 & -0.04 & 5 & 0.06 & 1853 & 333.5 \\
\hline HLP-29 & 200.6 & 0.25 & 3.4 & 9.85 & 10.07 & 1.61 & 0.403 & -0.03 & 6 & 0.03 & 813 & 12.2 \\
\hline HLP-29 & 200.6 & 0.25 & 5.7 & 10.08 & 10.11 & 1.61 & 0.407 & -0.03 & 5 & 0.04 & 1036 & 38.7 \\
\hline HLP-30 & 200.1 & 0.55 & 5.8 & 10.00 & 10.11 & 1.61 & 0.416 & -0.02 & 10 & 0.01 & 464 & 10.8 \\
\hline HLP-30 & 200.1 & 0.25 & 1.8 & 10.09 & 10.06 & 1.5 & 0.415 & -0.02 & 10 & 0.00 & 113 & 1.1 \\
\hline HLP-30 & 200.1 & 0.25 & 11.9 & 10.09 & 10.08 & 1.4: & 0.377 & -0.02 & 10 & 0.00 & 768 & 19.5 \\
\hline HLP-30 & 200.3 & 0.26 & 23.7 & 10.10 & 10.03 & 1.6 & 0.409 & -0.03 & 6 & 0.02 & 263 & 8.1 \\
\hline HLP-30 & 200.3 & 0.26 & 23.7 & 10.21 & 10.18 & 1.6 & 0.425 & -0.05 & 6 & 0.01 & 568 & 17.5 \\
\hline HLP-30 & 200.4 & 0.27 & 12.0 & 10.21 & 10.17 & 1.5 & 0.414 & -0.03 & $5 . \varepsilon$ & 0.02 & 404 & 4.6 \\
\hline HLP-30 & 200.6 & 0.26 & 12.9 & 10.11 & 10.11 & 1.61 & 0.427 & -0.03 & 6 & 0.01 & 617 & 7.6 \\
\hline HLP-30 & 200.7 & 0.25 & 8.8 & 10.08 & 10.08 & 1.6 & 0.427 & -0.03 & 6 & 0.01 & 315 & 3.2 \\
\hline HLP-30 & 200.8 & 0.25 & 41.0 & 9.96 & 10.00 & $1.4^{\prime}$ & 0.370 & -0.06 & 8.5 & 0.02 & 821 & 86.5 \\
\hline HLP-31 & 200.1 & 0.26 & 5.8 & 10.10 & 10.11 & $1.5^{\prime}$ & 0.418 & -0.02 & 10 & 0.06 & 1137 & 11.7 \\
\hline HLP-31 & 200.1 & 0.25 & 1.8 & 10.12 & 10.12 & 1.61 & 0.422 & -0.02 & 10 & 0.04 & 336 & 5.4 \\
\hline HLP-31 & 200.1 & 0.25 & 11.9 & 10.10 & 10.04 & 1.5 & 0.412 & -0.03 & 10 & 0.08 & 1899 & 265.5 \\
\hline HLP-31 & 200.3 & 0.25 & 6.8 & 10.22 & 10.16 & 1.61 & 0.422 & -0.02 & 6 & 0.06 & 1537 & 198.6 \\
\hline HLP-31 & 200.6 & 0.26 & 3.0 & 10.14 & 10.15 & 1.6 & 0.420 & -0.02 & 6 & 0.06 & 1209 & 26.4 \\
\hline HLP-31 & 200.6 & 0.25 & 5.1 & 10.13 & 10.08 & 1.6 & 0.421 & -0.02 & 6 & 0.06 & 1502 & 24.6 \\
\hline HLP-31 & 200.6 & 0.25 & 21.7 & 10.18 & 10.16 & 1.6 & 0.425 & -0.03 & 6 & 0.07 & 1826 & 146.1 \\
\hline HLP-32 & 200.3 & 0.25 & 13.2 & 10.10 & 10.06 & 1.5. & 0.391 & -0.02 & 10 & 0.00 & 50 & 0.7 \\
\hline HLP-32 & 200.4 & 0.26 & 7.1 & 10.20 & 10.13 & 1.6 & 0.423 & -0.02 & 6 & 0.00 & 25 & 0.2 \\
\hline HLP-32 & 200.6 & 0.26 & 24.0 & 10.05 & 10.17 & $1.5 !$ & 0.413 & -0.03 & 6 & 0.00 & 102 & 1.9 \\
\hline HLP-33 & 200.1 & 0.25 & 1.8 & 10.02 & 10.09 & 1.4: & 0.351 & -0.02 & 10 & 0.03 & 137 & 2.3 \\
\hline HLP-33 & 200.1 & 0.25 & 5.8 & 10.09 & 10.07 & $1.5^{\prime}$ & 0.419 & -0.02 & 10 & 0.01 & 180 & 1.8 \\
\hline HLP-33 & 200.1 & 0.25 & 11.9 & 10.10 & 10.11 & $1.5 !$ & 0.424 & -0.02 & 10 & 0.00 & 113 & 2.2 \\
\hline HLP-33 & 200.2 & 0.20 & 30.0 & 10.05 & 10.06 & 1.5 & 0.420 & -0.04 & 8.5 & 0.06 & 1656 & 0.0 \\
\hline HLP-33 & 200.7 & 0.20 & 50.0 & 10.04 & 10.08 & 1.5 & 0.401 & -0.06 & 7 & 0.05 & 1981 & - \\
\hline HLP-33 & 200.8 & 0.20 & 45.0 & 9.99 & 10.03 & 1.5. & 0.406 & -0.06 & 8.5 & 0.05 & 2026 & - \\
\hline HLP-34 & 200.4 & 0.25 & 7.1 & 10.18 & 10.09 & 1.41 & 0.438 & -0.02 & 10 & 0.00 & 152 & 0.8 \\
\hline HLP-34 & 200.6 & 0.25 & 24.0 & 10.18 & 10.13 & 1.2 & 0.425 & -0.03 & 6 & 0.00 & 102 & 3.2 \\
\hline
\end{tabular}




\begin{tabular}{|c|c|c|c|c|c|c|c|c|c|c|c|c|}
\hline$\frac{\tilde{E}}{\tilde{E}}$ & 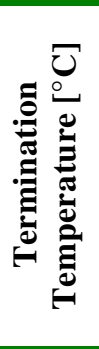 & 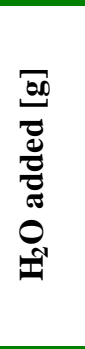 & 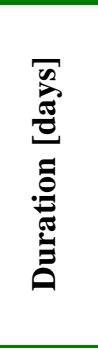 & 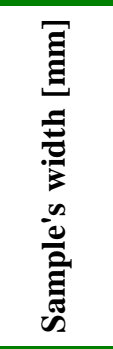 & 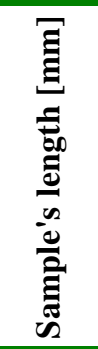 & 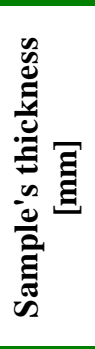 & 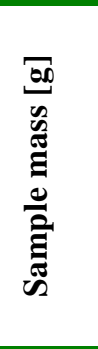 & 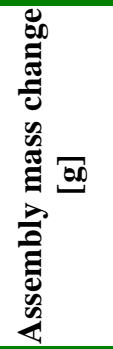 & 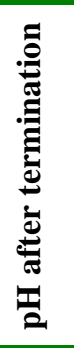 & 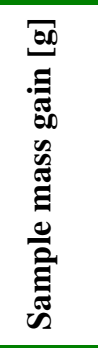 & 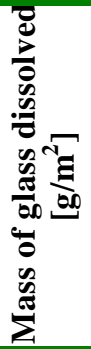 & 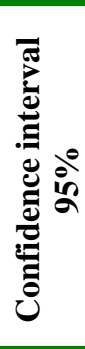 \\
\hline HLP-35 & 198.3 & 0.20 & 46.8 & 10.04 & 10.09 & 1.5 & 0.408 & -0.04 & 8 & 0.05 & 1575 & 133.4 \\
\hline HLP-35 & 200.1 & 0.25 & 5.8 & 9.94 & 10.01 & 1.5 & 0.390 & -0.02 & 10 & -0.01 & 1166 & 107.6 \\
\hline HLP-35 & 200.1 & 0.25 & 2.0 & 10.01 & 9.93 & 1.5. & 0.400 & -0.02 & 10 & 0.01 & 460 & 22.5 \\
\hline HLP-35 & 200.3 & 0.25 & 6.8 & 10.12 & 10.07 & $1.5 !$ & 0.412 & -0.02 & 6 & 0.03 & 966 & 117.3 \\
\hline HLP-35 & 200.4 & 0.25 & 16.0 & 9.98 & 9.91 & 1.51 & 0.391 & -0.01 & 6 & 0.06 & 1178 & 175.1 \\
\hline HLP-35 & 200.5 & 0.20 & 29.9 & 10.05 & 10.05 & 1.5 & 0.400 & -0.04 & 9.5 & 0.07 & 1376 & 63.2 \\
\hline HLP-35 & 200.6 & 0.26 & 3.0 & 10.02 & 10.05 & $1.5^{\prime}$ & 0.405 & -0.02 & 6 & 0.03 & 653 & 39.9 \\
\hline HLP-35 & 200.6 & 0.25 & 5.1 & 10.09 & 9.89 & 1.5 & 0.405 & -0.02 & 6 & 0.03 & 976 & 120.0 \\
\hline HLP-35 & 200.6 & 0.25 & 21.7 & 10.06 & 10.12 & 1.61 & 0.417 & -0.03 & 6 & 0.04 & 1165 & 85.1 \\
\hline HLP-35 & 201.0 & 0.20 & 60.8 & 9.18 & 10.91 & $1.5 !$ & 0.405 & -0.06 & 9 & 0.05 & 1594 & 139.1 \\
\hline HLP-36 & 200.6 & 0.25 & 50.0 & 9.55 & 10.37 & 1.5 & 0.400 & -0.06 & 10 & 0.00 & 575 & 7.7 \\
\hline HLP-36 & 200.7 & 0.26 & 8.7 & 9.62 & 10.35 & $1.4 !$ & 0.395 & -0.06 & 6 & 0.01 & 27 & 0.1 \\
\hline HLP-36 & 200.7 & 0.25 & 30.6 & 9.76 & 10.35 & 1.5 & 0.420 & -0.08 & 8 & 0.02 & 697 & 33.5 \\
\hline HLP-37 & 200.4 & 0.25 & 7.1 & 10.14 & 10.09 & 1.21 & 0.402 & -0.02 & 10 & 0.00 & 16 & 0.2 \\
\hline HLP-37 & 200.6 & 0.25 & 24.0 & 10.21 & 10.16 & 1.5 & 0.412 & -0.03 & 6 & 0.01 & 101 & 1.9 \\
\hline HLP-37 & 200.6 & 0.25 & 50.0 & 10.09 & 10.11 & 1.5 & 0.421 & -0.06 & 10 & 0.02 & 463 & 16.5 \\
\hline HLP-38 & 200.1 & 0.25 & 84.1 & 10.09 & 10.08 & 1.5 & 0.436 & -0.09 & 10 & -0.07 & 1030 & 55.6 \\
\hline HLP-38 & 200.2 & 0.26 & 73.0 & 10.04 & 10.11 & $1.5 !$ & 0.438 & -0.07 & 10 & 0.00 & 802 & 41.3 \\
\hline HLP-38 & 200.3 & 0.25 & 13.2 & 10.10 & 10.13 & 1.4: & 0.410 & -0.02 & 10 & 0.01 & 470 & 18.3 \\
\hline HLP-38 & 200.4 & 0.26 & 7.1 & 10.16 & 10.10 & 1.6: & 0.456 & -0.02 & 6 & 0.01 & 27 & 0.4 \\
\hline HLP-38 & 200.6 & 0.26 & 24.0 & 10.18 & 10.16 & 1.31 & 0.394 & -0.03 & 6 & 0.04 & 602 & 55.9 \\
\hline HLP-39 & 200.1 & 0.25 & 5.3 & 9.95 & 9.88 & 1.5 & 0.416 & -0.02 & 10 & 0.00 & 14 & 0.6 \\
\hline HLP-39 & 200.1 & 0.25 & 2.0 & 9.96 & 9.99 & $1.5 !$ & 0.428 & -0.02 & 10 & 0.01 & 195 & 8.7 \\
\hline HLP-39 & 200.6 & 0.25 & 3.9 & 9.98 & 9.95 & 1.5 & 0.396 & -0.03 & 6 & 0.02 & 13 & 0.3 \\
\hline HLP-40 & 199.5 & 0.25 & 51.1 & 9.94 & 10.04 & 1.5 & 0.415 & -0.10 & 8 & 0.01 & 179 & 6.5 \\
\hline HLP-40 & 199.7 & 0.25 & 88.0 & 9.96 & 9.85 & $1.3 !$ & 0.363 & -0.11 & 10 & 0.01 & 200 & 8.1 \\
\hline HLP-41 & 200.1 & 0.25 & 5.3 & 10.00 & 10.11 & 1.5 & 0.448 & -0.02 & 10 & 0.00 & 280 & 13.2 \\
\hline HLP-41 & 200.1 & 0.25 & 11.9 & 9.95 & 10.07 & 1.5 & 0.435 & -0.03 & 10 & 0.01 & 474 & 17.0 \\
\hline HLP-41 & 200.1 & 0.25 & 2.0 & 10.07 & 10.10 & 1.5 & 0.448 & -0.02 & 10 & 0.00 & 209 & 5.3 \\
\hline HLP-41 & 200.4 & 0.26 & 29.9 & 10.15 & 10.05 & $1.5 !$ & 0.420 & -0.06 & 6 & 0.00 & 350 & 15.3 \\
\hline HLP-41 & 200.4 & 0.26 & 29.9 & 10.10 & 10.16 & $1.5 !$ & 0.434 & -0.04 & 6 & 0.01 & 293 & 6.2 \\
\hline HLP-41 & 200.6 & 0.26 & 35.6 & 10.01 & 10.12 & 1.6: & 0.449 & -0.08 & 6 & 0.02 & 322 & 8.2 \\
\hline HLP-41 & 200.6 & 0.26 & 50.8 & 10.05 & 9.80 & 1.6 & 0.434 & -0.09 & 6 & 0.02 & 356 & 11.4 \\
\hline HLP-41 & 200.6 & 0.25 & 35.6 & 10.10 & 10.10 & $1.5^{\prime}$ & 0.439 & -0.07 & 8 & 0.03 & 206 & 4.2 \\
\hline HLP-42 & 200.3 & 0.25 & 13.2 & 10.07 & 10.07 & $1.5 !$ & 0.462 & -0.02 & 6 & 0.00 & 143 & 2.1 \\
\hline HLP-42 & 200.4 & 0.25 & 7.1 & 10.03 & 10.42 & $1.5 !$ & 0.471 & -0.01 & 6 & 0.00 & 0 & - \\
\hline HLP-42 & 200.6 & 0.25 & 88.0 & 10.06 & 10.12 & 1.5: & 0.459 & -0.10 & 6.5 & 0.00 & 102 & 1.0 \\
\hline HLP-42 & 200.6 & 0.25 & 24.0 & 10.11 & 10.08 & 1.5: & 0.450 & -0.04 & 6 & 0.00 & 142 & 0.7 \\
\hline HLP-42 & 200.7 & 0.25 & 70.0 & 10.07 & 10.07 & $1.5^{\prime}$ & 0.462 & -0.09 & 8 & 0.00 & 131 & 0.6 \\
\hline HLP-43 & 200.1 & 0.25 & 5.8 & 10.02 & 9.90 & 1.61 & 0.422 & -0.02 & 10 & 0.01 & 283 & 2.8 \\
\hline HLP-43 & 200.1 & 0.25 & 2.0 & 9.94 & 10.00 & $1.5 !$ & 0.414 & -0.02 & 10 & 0.00 & 134 & 2.6 \\
\hline HLP-43 & 200.1 & 0.25 & 11.9 & 10.01 & 9.98 & 1.5 & 0.412 & -0.03 & 10 & 0.02 & 425 & 9.8 \\
\hline
\end{tabular}




\begin{tabular}{|c|c|c|c|c|c|c|c|c|c|c|c|c|}
\hline$\frac{\tilde{E}}{\tilde{E}}$ & 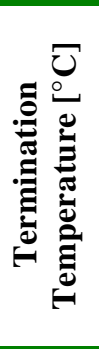 & 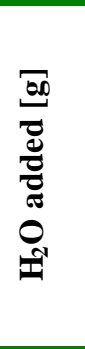 & 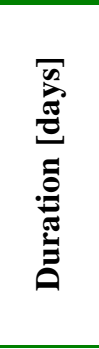 & 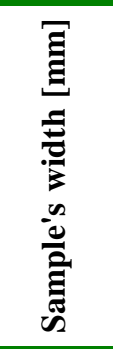 & 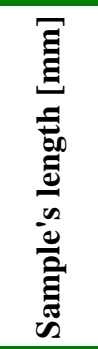 & 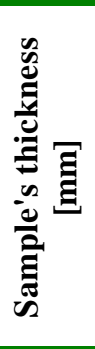 & 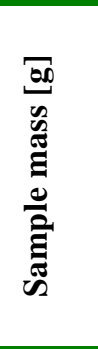 & 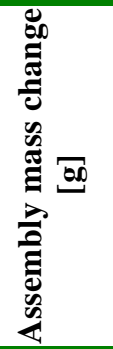 & 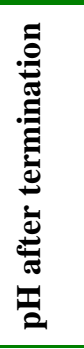 & 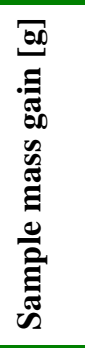 & 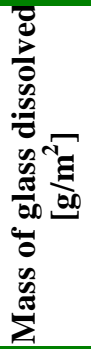 & 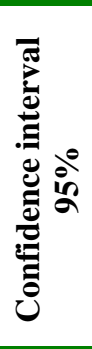 \\
\hline HLP-43 & 299.8 & 0.85 & 1.5 & 9.94 & 10.03 & 1.5 & 0.390 & -0.04 & 9 & 0.03 & 1535 & 97.5 \\
\hline HLP-43 & 299.9 & 0.85 & 1.0 & 9.90 & 10.01 & $1.5^{\prime}$ & 0.401 & -0.03 & 8 & 0.03 & 1302 & 50.2 \\
\hline HLP-43 & 300.0 & 0.85 & 2.0 & 9.90 & 9.99 & 1.5 & 0.400 & -0.03 & 9 & 0.04 & 2022 & - \\
\hline HLP-44 & 200.4 & 0.24 & 120.0 & 9.99 & 10.08 & 1.5 & 0.400 & -0.05 & 8.5 & 0.02 & 1019 & 29.3 \\
\hline HLP-45 & 200.4 & 0.24 & 120.0 & 9.93 & 10.00 & 1.4 & 0.371 & -0.05 & 8.5 & 0.04 & 1310 & 65.8 \\
\hline HLP-46 & 149.7 & 0.10 & 41.2 & 10.01 & 10.06 & 1.4 & 0.372 & -0.02 & 5.5 & 0.07 & 1597 & 222 \\
\hline HLP-46 & 149.7 & 0.10 & 41.2 & 10.13 & 10.12 & 1.5: & 0.39 & -0.02 & $5 . \varepsilon$ & 0.07 & 1685 & 262 \\
\hline HLP-46 & 149.8 & 0.10 & 34.3 & 10.02 & 10.08 & 1.6 & 0.396 & -0.02 & - & 0.10 & 1593 & 201 \\
\hline HLP-46 & 149.8 & 0.10 & 34.3 & 10.15 & 10.03 & $1.5 !$ & 0.399 & -0.02 & - & 0.09 & 1592 & 117 \\
\hline HLP-46 & 150.1 & 0.10 & 23.3 & 10.08 & 9.98 & 1.6 & 0.406 & -0.01 & 6.1 & 0.07 & 1403 & 76 \\
\hline HLP-46 & 150.1 & 0.10 & 23.3 & 10.09 & 10.02 & 1.61 & 0.406 & -0.01 & 6.1 & 0.06 & 1585 & 128 \\
\hline HLP-46 & 150.2 & 0.10 & 15.0 & 10.02 & 10.08 & $1.5 !$ & 0.408 & -0.02 & $5 . \varepsilon$ & 0.07 & 1138 & 44 \\
\hline HLP-46 & 150.2 & 0.10 & 15.0 & 9.99 & 10.03 & 1.5 & 0.392 & -0.01 & $5 . \varepsilon$ & 0.06 & 1089 & 27 \\
\hline HLP-46 & 150.4 & 0.10 & 7.3 & 10.07 & 10.10 & $1.5 !$ & 0.407 & -0.07 & 5.5 & 0.00 & 176 & 2 \\
\hline HLP-46 & 150.4 & 0.10 & 7.3 & 10.01 & 10.01 & 1.6 & 0.424 & -0.01 & 5.5 & 0.02 & 378 & 5 \\
\hline HLP-46 & 175.2 & 0.15 & 6.2 & 10.00 & 10.01 & 1.4 & 0.362 & -0.02 & 5.5 & 0.06 & 1208 & 64 \\
\hline HLP-46 & 175.2 & 0.15 & 6.2 & 9.92 & 9.99 & $1.5^{\prime}$ & 0.378 & -0.02 & 5.5 & 0.05 & 1424 & 59 \\
\hline HLP-46 & 175.3 & 0.15 & 11.1 & 10.01 & 10.08 & 1.6? & 0.412 & -0.03 & 5 & 0.06 & 1779 & 115 \\
\hline HLP-46 & 175.3 & 0.14 & 11.1 & 9.99 & 10.05 & 1.5 & 0.388 & -0.03 & 5 & 0.06 & 1562 & 178 \\
\hline HLP-46 & 175.4 & 0.15 & 8.1 & 9.98 & 10.11 & 1.4 & 0.375 & -0.02 & 10 & 0.07 & 1537 & 190 \\
\hline HLP-46 & 175.4 & 0.15 & 8.1 & 9.98 & 10.11 & 1.6? & 0.407 & -0.03 & 5 & 0.07 & 1435 & 151 \\
\hline HLP-46 & 175.4 & 0.15 & 3.1 & 10.05 & 9.90 & 1.6 & 0.399 & -0.02 & 4.7 & 0.05 & 989 & 18 \\
\hline HLP-46 & 175.4 & 0.14 & 12.0 & 10.01 & 10.09 & 1.6 & 0.401 & -0.02 & 5 & 0.08 & 1851 & 278 \\
\hline HLP-46 & 175.4 & 0.14 & 12.0 & 10.00 & 10.05 & $1.5^{\prime}$ & 0.391 & -0.01 & 10 & 0.08 & 1862 & 107 \\
\hline HLP-46 & 199.9 & 0.20 & 4.9 & 9.95 & 9.95 & $1.4 !$ & 0.365 & -0.03 & 5 & 0.06 & 1809 & 179 \\
\hline HLP-46 & 199.9 & 0.20 & 4.9 & 10.16 & 10.08 & 1.5 & 0.4 & -0.03 & 5 & 0.06 & 1871 & 156 \\
\hline HLP-46 & 200.0 & 0.20 & 1.1 & 10.09 & 10.03 & 1.61 & 0.401 & -0.03 & 5 & 0.05 & 892 & 19 \\
\hline HLP-46 & 200.0 & 0.20 & 3.9 & 10.05 & 10.08 & 1.6 & 0.409 & -0.03 & 5 & 0.06 & 1694 & 103 \\
\hline HLP-46 & 200.0 & 0.20 & 3.9 & 10.06 & 10.09 & $1.5 !$ & 0.398 & -0.03 & 5 & 0.06 & 1748 & 139 \\
\hline HLP-46 & 200.0 & 0.20 & 1.1 & 10.20 & 9.97 & 1.6 & 0.403 & -0.02 & 5 & 0.05 & 898 & 22 \\
\hline HLP-46 & 200.1 & 0.20 & 2.1 & 10.13 & 10.01 & 1.51 & 0.373 & -0.02 & 5 & 0.05 & 1053 & 105 \\
\hline HLP-46 & 200.1 & 0.20 & 2.1 & 10.03 & 10.10 & 1.6 & 0.403 & -0.02 & 5 & 0.05 & 1289 & 33 \\
\hline HLP-46 & 200.2 & 0.20 & 3.0 & 10.06 & 10.01 & 1.51 & 0.375 & -0.02 & 5 & 0.06 & 1568 & 161 \\
\hline HLP-46 & 200.2 & 0.20 & 3.0 & 10.07 & 9.95 & 1.5 & 0.38 & -0.02 & 5.2 & 0.05 & 1476 & 50 \\
\hline HLP-47 & 200.0 & 0.20 & 18.0 & 9.93 & 10.00 & 1.5 & 0.390 & -0.03 & 9 & 0.04 & 1381 & 64.8 \\
\hline HLP-47 & 200.0 & 0.20 & 10.0 & 10.00 & 10.06 & 1.5: & 0.391 & -0.02 & 8 & 0.04 & 1103 & 142.3 \\
\hline HLP-47 & 200.0 & 0.20 & 29.9 & 10.04 & 10.05 & 1.5 & 0.406 & -0.03 & 8 & 0.03 & 1324 & 70.6 \\
\hline HLP-47 & 200.2 & 0.20 & 38.0 & 10.00 & 10.06 & 1.4 & 0.390 & -0.05 & 10 & 0.05 & 1724 & 232.8 \\
\hline HLP-47 & 200.6 & 0.25 & 5.0 & 9.92 & 10.01 & 1.4 & 0.368 & -0.02 & 10 & 0.04 & 513 & 6.9 \\
\hline HLP-47 & 200.6 & 0.25 & 22.0 & 10.11 & 10.05 & 1.5. & 0.387 & -0.02 & 6 & 0.02 & 1158 & 41.7 \\
\hline HLP-47 & 200.6 & 0.25 & 15.0 & 9.91 & 10.04 & 1.5 & 0.389 & -0.03 & 8 & 0.03 & 785 & 18.6 \\
\hline HLP-48 & 150.6 & 0.16 & 214.7 & 9.91 & 10.05 & 1.51 & 0.375 & -0.10 & 10 & 0.03 & 1004 & 64 \\
\hline
\end{tabular}

C. 7 


\begin{tabular}{|c|c|c|c|c|c|c|c|c|c|c|c|c|}
\hline $\begin{array}{l}\tilde{n} \\
\frac{\tilde{\sigma}}{U}\end{array}$ & ل & 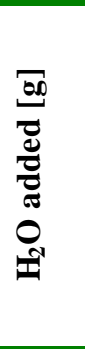 & 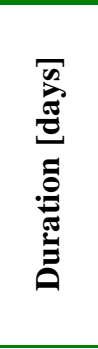 & 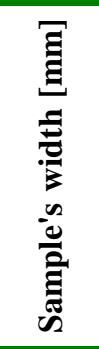 & 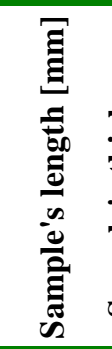 & 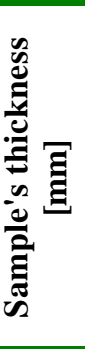 & 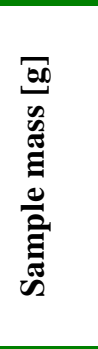 & 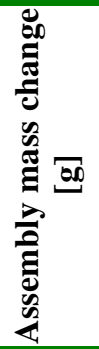 & 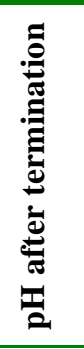 & 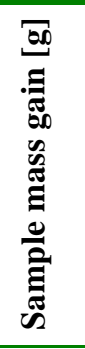 & 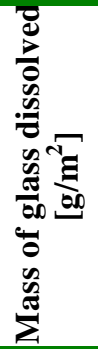 & 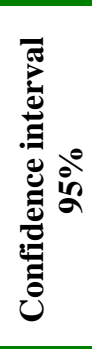 \\
\hline HLP-48 & 150.6 & 0.15 & 214.7 & 9.93 & 10.07 & $1.4 !$ & 0.383 & -0.04 & 10 & 0.03 & 1054 & 87 \\
\hline HLP-48 & 150.7 & 0.16 & 188.6 & 10.09 & 9.94 & 1.6 & 0.417 & -0.04 & - & 0.01 & 1059 & 51 \\
\hline HLP-48 & 150.7 & 0.16 & 72.0 & 9.95 & 9.96 & 1.51 & 0.386 & -0.02 & 6.2 & 0.01 & 441 & 6 \\
\hline HLP-48 & 150.7 & 0.15 & 188.6 & 9.98 & 10.18 & $1.5^{\prime}$ & 0.409 & -0.05 & - & 0.04 & 1103 & 68 \\
\hline HLP-48 & 150.7 & 0.15 & 72.0 & 9.99 & 10.08 & 1.6: & 0.401 & -0.04 & 10 & 0.02 & 647 & 10 \\
\hline HLP-48 & 174.8 & 0.15 & 41.9 & 10.02 & 9.80 & 1.6 & 0.418 & -0.03 & 6.1 & 0.06 & 1205 & 28 \\
\hline HLP-48 & 174.8 & 0.15 & 41.9 & 10.04 & 10.07 & 1.61 & 0.418 & -0.03 & $5 . \varepsilon$ & 0.06 & 1397 & 103 \\
\hline HLP-48 & 175.2 & 0.15 & 78.6 & 10.18 & 10.00 & 1.6 & 0.44 & -0.05 & $5 . \varepsilon$ & 0.05 & 1875 & 185 \\
\hline HLP-48 & 175.2 & 0.15 & 78.6 & 9.96 & 9.99 & 1.5: & 0.386 & -0.05 & $5 . \varepsilon$ & 0.05 & 1727 & 223 \\
\hline HLP-48 & 175.3 & 0.15 & 68.9 & 10.24 & 10.07 & $1.5 !$ & 0.42 & -0.05 & 6.1 & 0.07 & 1460 & 178 \\
\hline HLP-48 & 175.3 & 0.14 & 68.9 & 10.10 & 10.17 & 1.5: & 0.412 & -0.04 & 6.1 & 0.05 & 1617 & 238 \\
\hline HLP-48 & 175.4 & 0.15 & 14.7 & 9.97 & 9.97 & 1.6 & 0.427 & -0.03 & 5.2 & 0.07 & 634 & 8 \\
\hline HLP-48 & 175.4 & 0.14 & 14.7 & 10.01 & 10.20 & 1.61 & 0.422 & -0.02 & 6.1 & 0.08 & 969 & 16 \\
\hline HLP-48 & 199.6 & 0.26 & 14.0 & 9.95 & 10.01 & 1.4 & 0.377 & -0.04 & $5 . \varepsilon$ & 0.04 & 1278 & 47 \\
\hline HLP-48 & 199.6 & 0.25 & 14.0 & 10.02 & 10.08 & $1.4^{\prime}$ & 0.389 & -0.04 & $5 . \varepsilon$ & 0.03 & 1372 & 154 \\
\hline HLP-48 & 199.8 & 0.25 & 22.2 & 10.11 & 9.95 & 1.51 & 0.381 & -0.06 & $5 . S$ & 0.02 & 1582 & 248 \\
\hline HLP-48 & 199.8 & 0.25 & 22.2 & 10.05 & 10.02 & 1.4 & 0.389 & -0.06 & $5 . \varepsilon$ & 0.05 & 1704 & 218 \\
\hline HLP-48 & 199.9 & 0.25 & 11.2 & 10.01 & 10.13 & 1.6 & 0.422 & -0.04 & $5 . \varepsilon$ & 0.06 & 1057 & 10 \\
\hline HLP-48 & 199.9 & 0.25 & 11.2 & 10.01 & 10.03 & 1.6 & 0.422 & -0.03 & 6.1 & 0.05 & 1273 & 49 \\
\hline HLP-48 & 200.1 & 0.25 & 6.2 & 10.17 & 9.98 & 1.61 & 0.415 & -0.03 & 5.5 & 0.03 & 762 & 9 \\
\hline HLP-48 & 200.1 & 0.25 & 6.2 & 10.05 & 10.04 & 1.51 & 0.392 & -0.03 & $5 . \varepsilon$ & 0.04 & 881 & 26 \\
\hline HLP-49 & 199.5 & 0.25 & 51.1 & 9.95 & 10.06 & 1.5 & 0.424 & -0.10 & 8 & 0.03 & 617 & 31.7 \\
\hline HLP-49 & 199.7 & 0.25 & 88.0 & 10.13 & 10.12 & 1.4 & 0.409 & -0.11 & 10 & 0.04 & 714 & 32.5 \\
\hline HLP-49 & 200.3 & 0.25 & 13.2 & 9.94 & 10.30 & 1.4 & 0.384 & -0.02 & 6 & 0.01 & 200 & 2.3 \\
\hline HLP-49 & 200.4 & 0.25 & 7.1 & 10.02 & 10.03 & 1.51 & 0.407 & -0.01 & 6 & 0.02 & 135 & 1.4 \\
\hline HLP-49 & 200.6 & 0.25 & 24.0 & 10.27 & 9.90 & 1.5: & 0.407 & -0.04 & 6 & 0.03 & 527 & 6.8 \\
\hline HLP-51 & 150.6 & 0.16 & 214.7 & 9.84 & 10.09 & $1.3 !$ & 0.359 & -0.10 & 10 & 0.03 & 624 & 46 \\
\hline HLP-51 & 150.6 & 0.15 & 214.7 & 10.14 & 10.04 & $1.5 !$ & 0.421 & -0.04 & 10 & 0.03 & 468 & 31 \\
\hline HLP-51 & 150.7 & 0.15 & 188.6 & 10.10 & 10.00 & $1.5 !$ & 0.421 & -0.05 & - & 0.02 & 367 & 6 \\
\hline HLP-51 & 199.1 & 0.25 & 27.0 & 9.99 & 9.98 & 1.4 & 0.384 & -0.05 & 10 & 0.04 & 671 & 116 \\
\hline HLP-51 & 199.6 & 0.25 & 14.0 & 10.05 & 10.00 & 1.5 & 0.411 & -0.04 & $5 . \varepsilon$ & 0.00 & 547 & 75 \\
\hline HLP-51 & 199.8 & 0.25 & 22.2 & 10.03 & 10.07 & 1.5: & 0.412 & -0.06 & 5.5 & 0.04 & 586 & 29 \\
\hline HLP-51 & 199.8 & 0.25 & 22.2 & 10.07 & 10.01 & 1.51 & 0.395 & -0.06 & 5.5 & 0.02 & 472 & 44 \\
\hline HLP-51 & 199.9 & 0.25 & 11.2 & 10.01 & 9.96 & 1.6: & 0.418 & -0.04 & $5 . \varepsilon$ & 0.01 & 274 & 14 \\
\hline HLP-51 & 199.9 & 0.25 & 11.2 & 10.08 & 10.05 & 1.51 & 0.393 & -0.03 & 6.1 & 0.02 & 407 & 31 \\
\hline HLP-51 & 200.1 & 0.25 & 33.2 & 9.96 & 10.05 & 1.51 & 0.391 & -0.05 & 10 & 0.05 & 618 & 80 \\
\hline HLP-51 & 200.1 & 0.25 & 6.2 & 10.11 & 10.07 & 1.51 & 0.393 & -0.03 & $5 . \varepsilon$ & 0.02 & 335 & 19 \\
\hline HLP-51 & 200.1 & 0.25 & 6.2 & 10.14 & 9.96 & 1.61 & 0.42 & -0.03 & $5 . \varepsilon$ & 0.00 & 403 & 21 \\
\hline HLP-51 & 200.6 & 0.25 & 24.9 & 9.93 & 9.81 & 1.4 & 0.350 & -0.05 & 6 & 0.02 & 484 & 2.7 \\
\hline HLP-52 & 200.5 & 0.25 & 3.0 & 10.11 & 10.08 & $1.5^{\prime}$ & 0.419 & -0.02 & 8 & 0.07 & 2056 & - \\
\hline HLP-52 & 200.5 & 0.25 & 1.6 & 10.06 & 10.10 & 1.51 & 0.390 & -0.01 & 10 & 0.10 & 1791 & 129.0 \\
\hline HLP-52 & 200.5 & 0.25 & 1.0 & 10.06 & 10.06 & $1.4 !$ & 0.400 & -0.02 & - & - & 1512 & 124.4 \\
\hline
\end{tabular}




\begin{tabular}{|c|c|c|c|c|c|c|c|c|c|c|c|c|}
\hline $\begin{array}{l}\frac{n}{n} \\
\frac{\tilde{v}}{v}\end{array}$ & 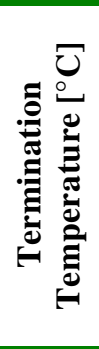 & 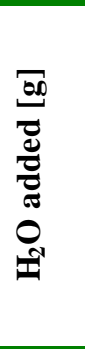 & 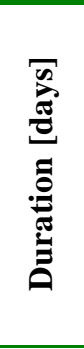 & 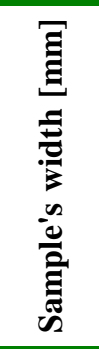 & 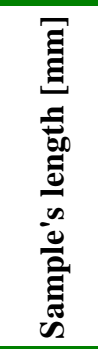 & 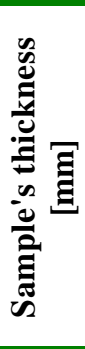 & 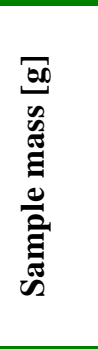 & 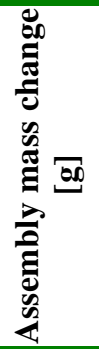 & 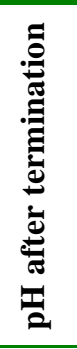 & 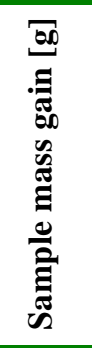 & 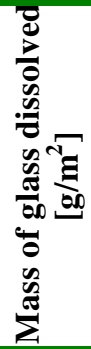 & 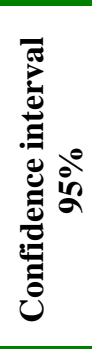 \\
\hline HLP-52 & 200.5 & 0.25 & 0.5 & 10.15 & 10.04 & 1.5 & 0.398 & -0.02 & 10 & 0.06 & 485 & 6.1 \\
\hline HLP-53 & 200.0 & 0.20 & 2.9 & 9.99 & 10.05 & 1.5: & 0.413 & -0.02 & 10 & 0.06 & 1892 & 0.0 \\
\hline HLP-53 & 200.0 & 0.20 & 0.9 & 10.02 & 10.03 & 1.4 & 0.374 & -0.07 & 10 & 0.00 & 185 & 3.1 \\
\hline HLP-53 & 200.0 & 0.20 & 2.0 & 9.86 & 10.06 & 1.4i & 0.390 & -0.03 & 10 & 0.03 & 1376 & 89.3 \\
\hline HLP-53 & 200.3 & 0.20 & 1.5 & 10.05 & 9.98 & 1.5 & 0.424 & -0.01 & 10 & 0.00 & 149 & 0.7 \\
\hline HLP-54 & 200.5 & 0.24 & 6.9 & 9.96 & 9.92 & 1.4: & 0.340 & -0.02 & 6 & 0.03 & 537 & 7.9 \\
\hline HLP-54 & 200.6 & 0.24 & 14.0 & 9.98 & 10.13 & 1.5 & 0.380 & -0.03 & 5 & 0.04 & 1103 & 49.3 \\
\hline HLP-54 & 200.6 & 0.24 & 10.1 & 9.92 & 10.01 & $1.4^{\prime}$ & 0.349 & -0.03 & 6 & 0.04 & 951 & 50.7 \\
\hline HLP-54 & 200.7 & 0.25 & 28.6 & 10.03 & 9.89 & 1.5: & 0.379 & -0.06 & 10 & 0.02 & 1373 & 272.1 \\
\hline HLP-54 & 200.7 & 0.24 & 15.6 & 10.04 & 10.03 & 1.5 & 0.379 & -0.05 & 8 & 0.03 & 1133 & 149.4 \\
\hline HLP-55 & 200.4 & 0.25 & 41.2 & 9.92 & 9.83 & 1.5 & 0.360 & -0.07 & 6 & -0.01 & 1433 & 151.7 \\
\hline HLP-55 & 200.5 & 0.24 & 6.9 & 9.97 & 9.98 & 1.51 & 0.360 & -0.02 & 6 & 0.04 & 458 & 11.8 \\
\hline HLP-55 & 200.6 & 0.24 & 14.0 & 9.94 & 9.94 & 1.61 & 0.380 & -0.03 & 5 & 0.02 & 733 & 32.0 \\
\hline HLP-55 & 200.6 & 0.23 & 33.9 & 9.78 & 9.92 & 1.51 & 0.364 & -0.04 & 8 & 0.04 & 1101 & 89.5 \\
\hline HLP-55 & 200.7 & 0.24 & 8.1 & 9.82 & 9.87 & 1.4i & 0.341 & -0.03 & 6 & 0.04 & 606 & 31.5 \\
\hline HLP-56 & 200.4 & 0.20 & 49.8 & 10.54 & 9.71 & 1.5 & 0.429 & -0.07 & 7 & 0.00 & 199 & 2.0 \\
\hline HLP-56 & 200.5 & 0.20 & 34.8 & 10.36 & 9.64 & $1.4^{\prime}$ & 0.382 & -0.05 & 5.5 & 0.00 & 169 & 5.5 \\
\hline HLP-56 & 200.8 & 0.20 & 69.0 & 10.60 & 9.41 & 1.5 & 0.407 & -0.07 & 9 & 0.00 & 121 & 1.8 \\
\hline HLP-56 & 249.6 & 0.45 & 9.9 & 10.54 & 9.55 & 1.5 & 0.416 & -0.07 & 6 & 0.05 & 1298 & 96.7 \\
\hline HLP-56 & 249.6 & 0.45 & 12.1 & 10.39 & 9.55 & 1.51 & 0.392 & -0.09 & 6 & 0.03 & 1409 & 94.4 \\
\hline HLP-56 & 249.7 & 0.45 & 7.8 & 10.54 & 9.42 & 1.5 & 0.406 & -0.06 & 7 & 0.05 & 1148 & 72.9 \\
\hline HLP-56 & 249.7 & 0.45 & 5.3 & 10.58 & 9.58 & 1.5 & 0.416 & -0.05 & 10 & 0.02 & 813 & 6.3 \\
\hline HLP-56 & 299.3 & 0.80 & 2.5 & 9.58 & 10.50 & 1.5 & 0.418 & -0.06 & 5.5 & 0.05 & 1878 & 90.1 \\
\hline HLP-56 & 299.7 & 0.80 & 1.5 & 10.05 & 9.98 & $1.4 !$ & 0.408 & -0.04 & 6 & 0.04 & 1256 & 31.7 \\
\hline HLP-56 & 299.8 & 0.80 & 1.0 & 10.04 & 9.97 & 1.5. & 0.406 & -0.03 & 8 & 0.04 & 981 & 17.9 \\
\hline HLP-56 & 299.8 & 0.80 & 2.0 & 10.07 & 9.93 & 1.3. & 0.342 & -0.04 & 5.5 & 0.06 & 1582 & - \\
\hline
\end{tabular}

C. 9 


\section{APPENDIX D}

\section{VHT Alteration Extent as a Function of Time (plots)}


APPENDIX D

VHT Alteration Extent as a Function of Time (plots)

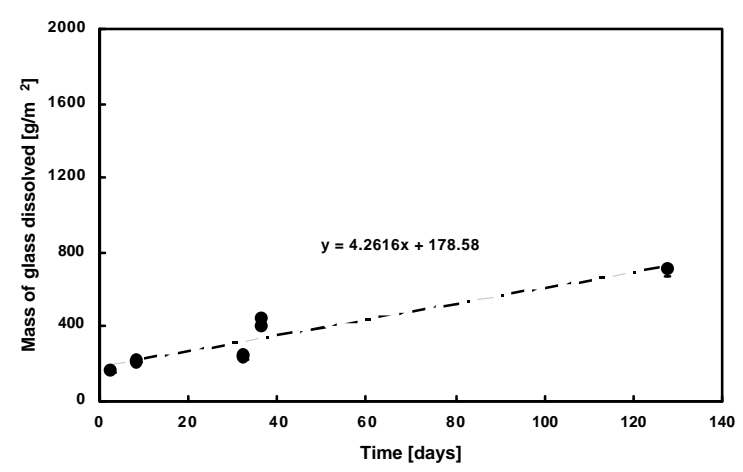

HLP- $01,200^{\circ} \mathrm{C}$

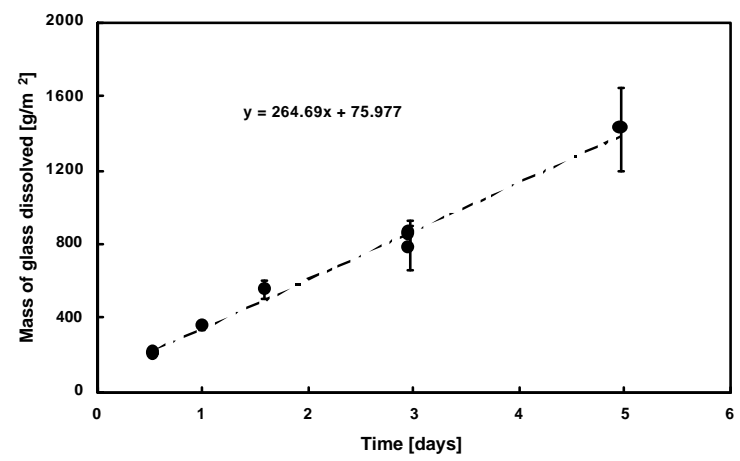

HLP- $02,200^{\circ} \mathrm{C}$

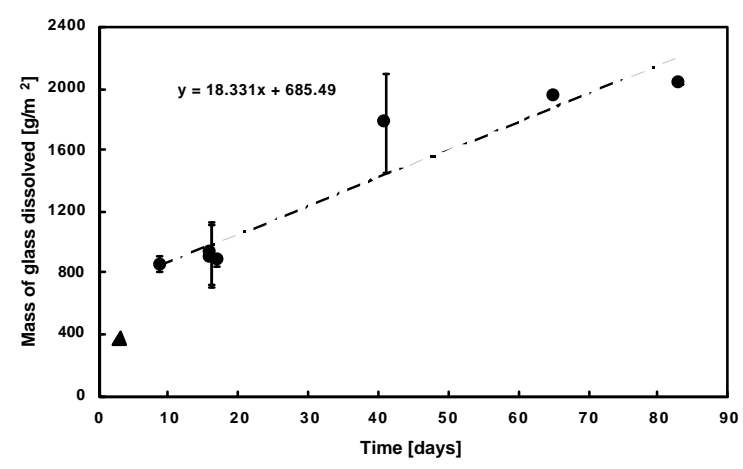

HLP- $04,200^{\circ} \mathrm{C}$

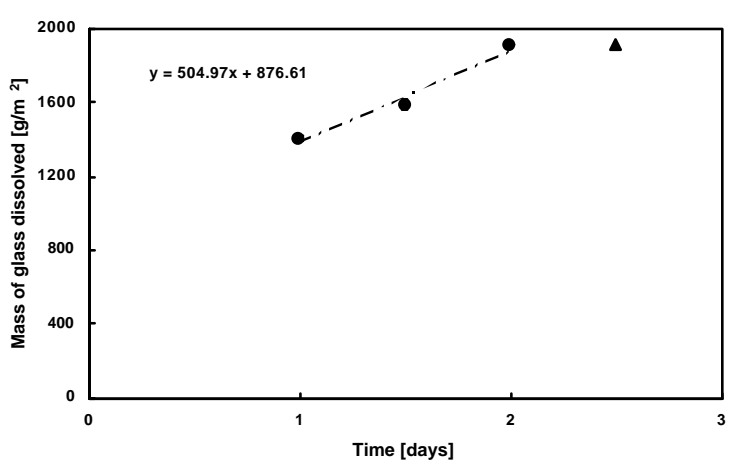

HLP- $01,300^{\circ} \mathrm{C}$

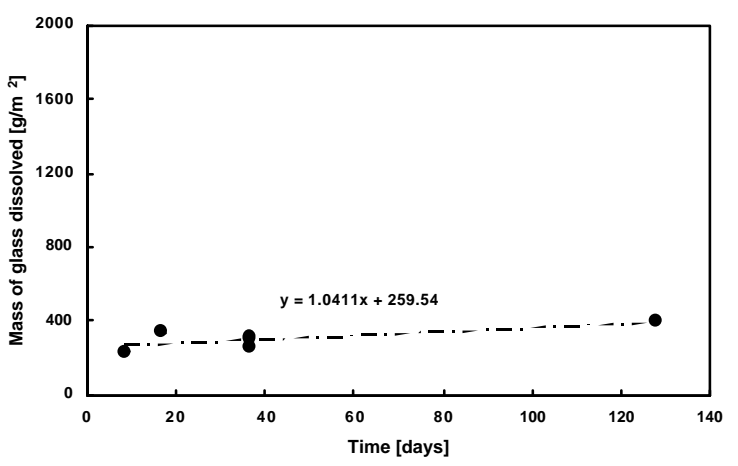

HLP- $03,200^{\circ} \mathrm{C}$

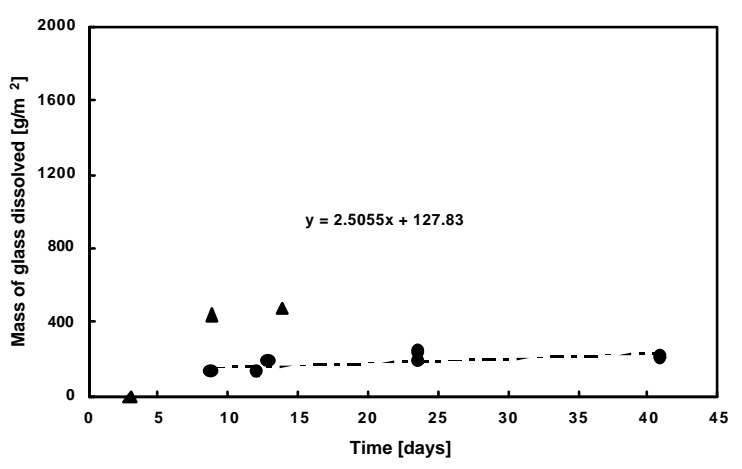

HLP- $05,200^{\circ} \mathrm{C}$ 


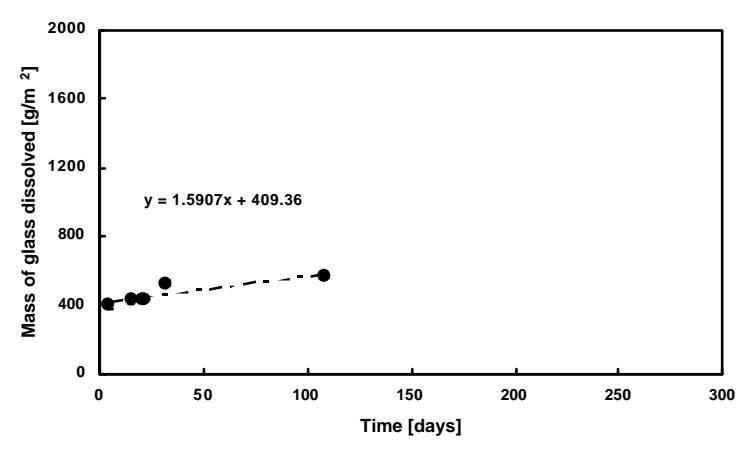

HLP-06, $200^{\circ} \mathrm{C}$

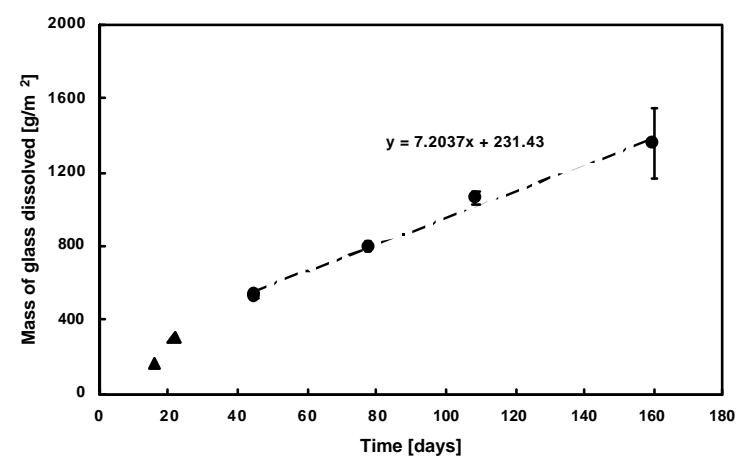

HLP-08, $200^{\circ} \mathrm{C}$

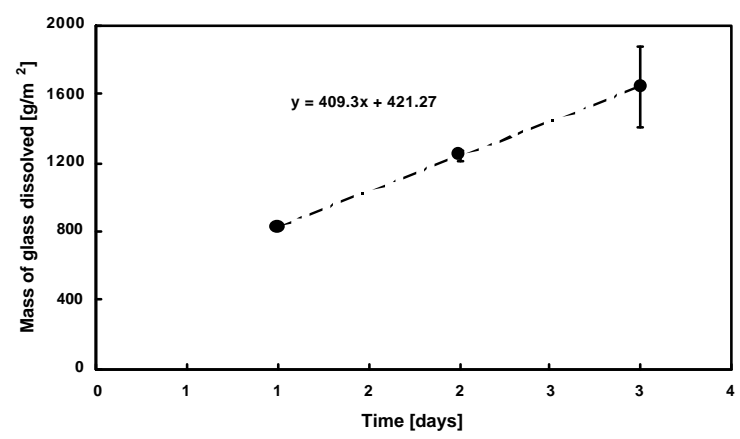

HLP-09, $300^{\circ} \mathrm{C}$

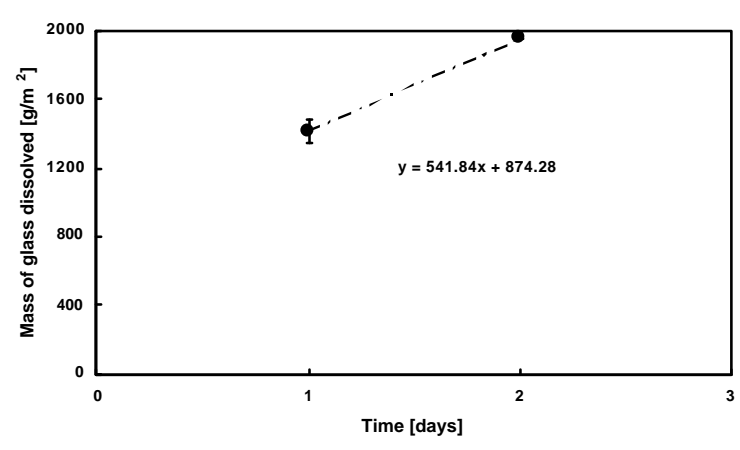

HLP- $10,300^{\circ} \mathrm{C}$

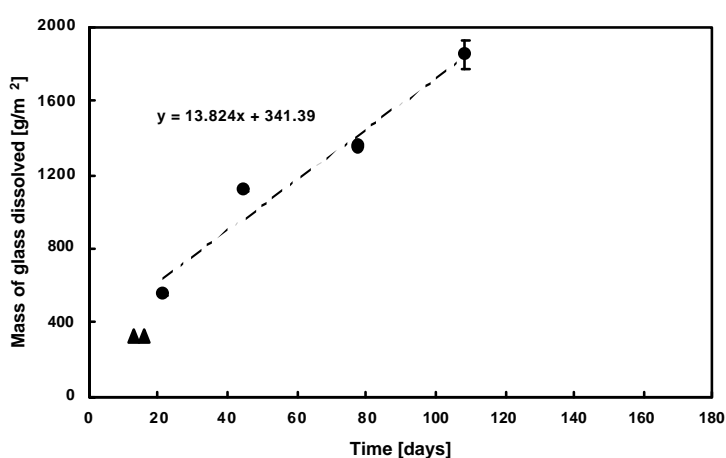

HLP-07, $200^{\circ} \mathrm{C}$

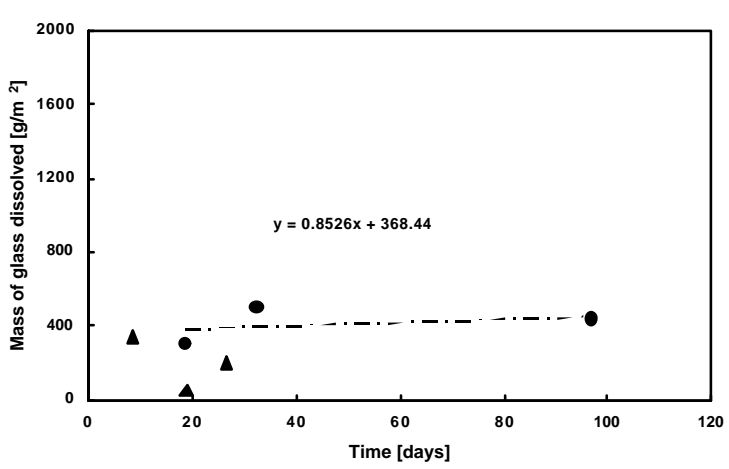

HLP-09, $200^{\circ} \mathrm{C}$

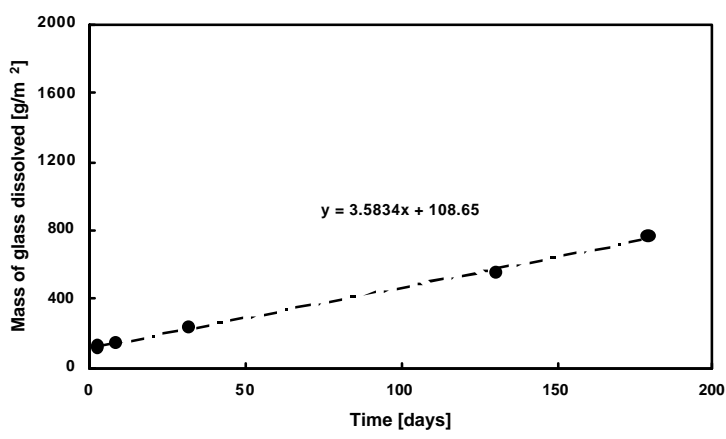

HLP- $10,200^{\circ} \mathrm{C}$

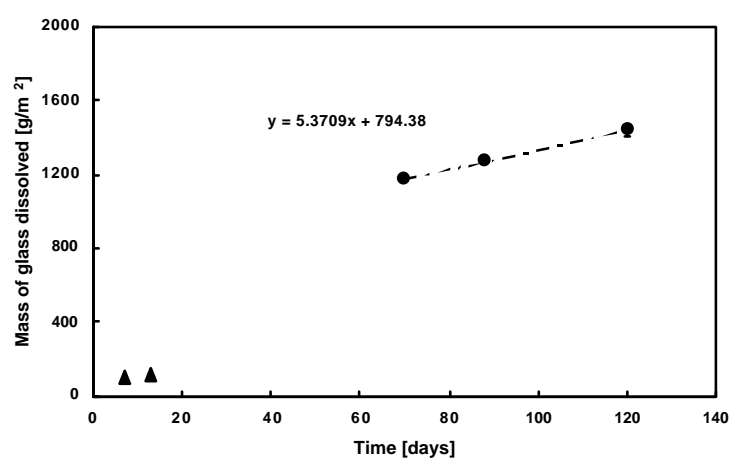

HLP- $11,200^{\circ} \mathrm{C}$ 


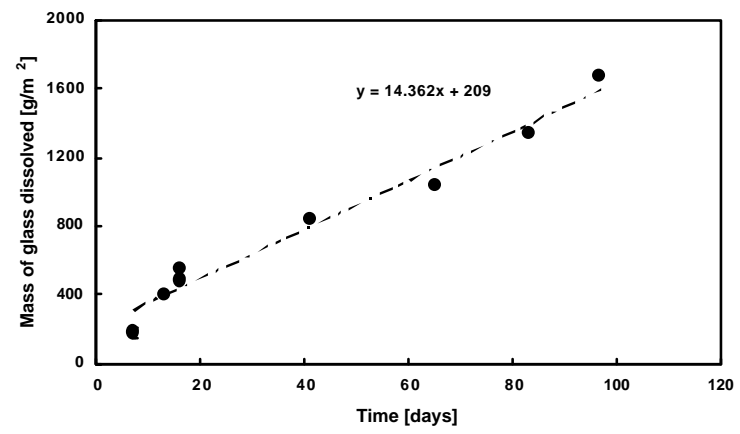

HLP- $12,200^{\circ} \mathrm{C}$

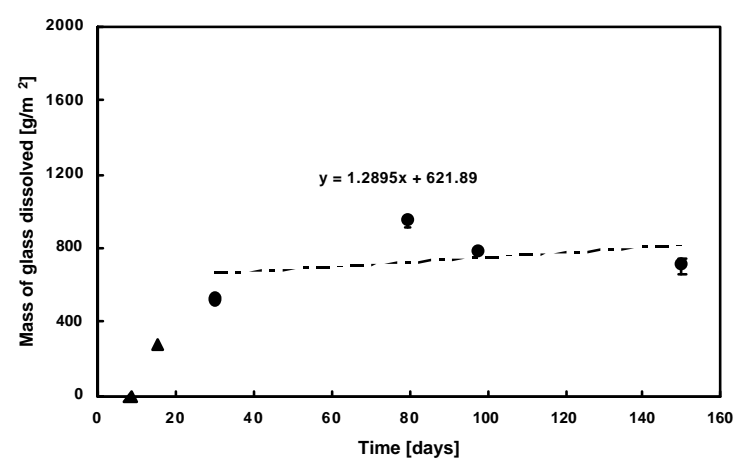

HLP- $13,200^{\circ} \mathrm{C}$

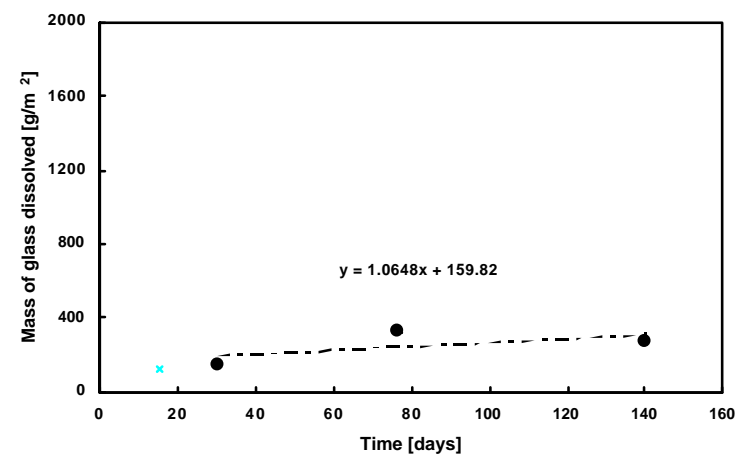

HLP- $15,200^{\circ} \mathrm{C}$

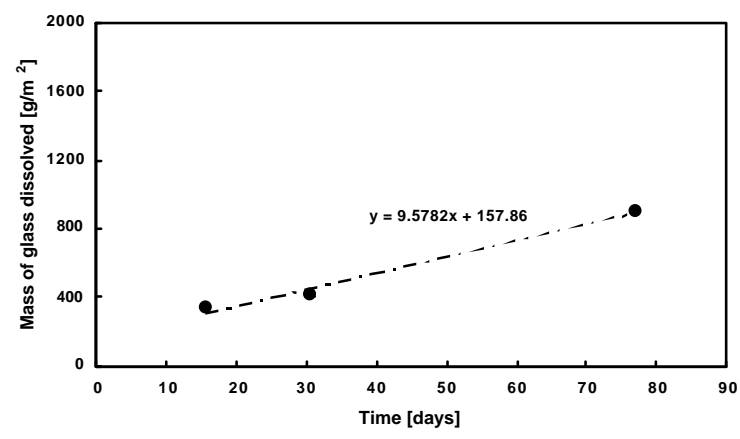

HLP- $17,200^{\circ} \mathrm{C}$

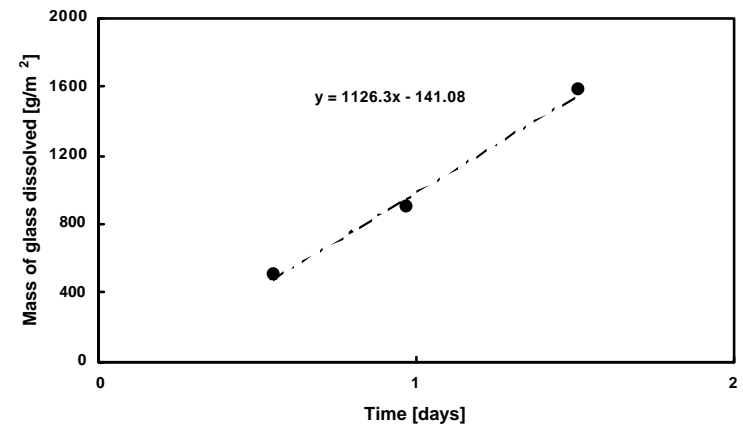

HLP- $12,300^{\circ} \mathrm{C}$

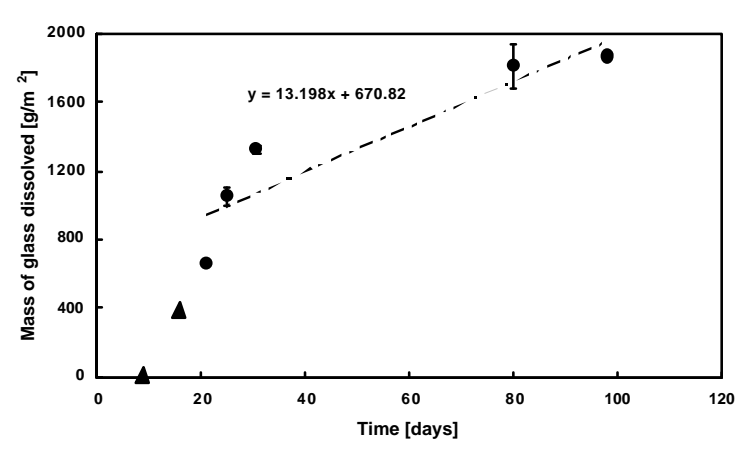

HLP- $14,200^{\circ} \mathrm{C}$

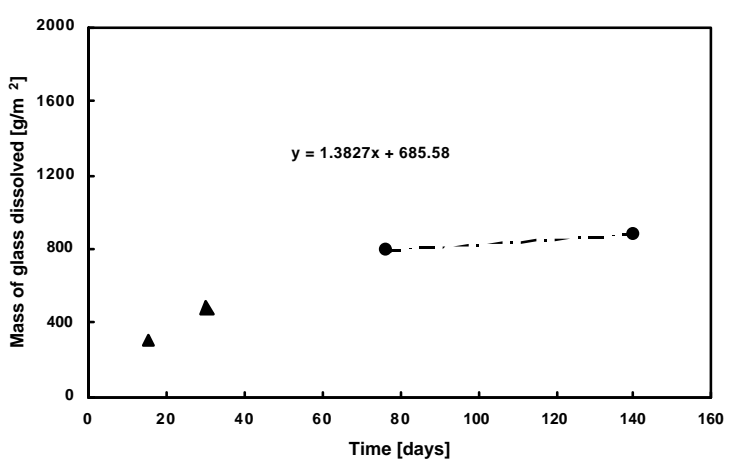

HLP-16, $200^{\circ} \mathrm{C}$

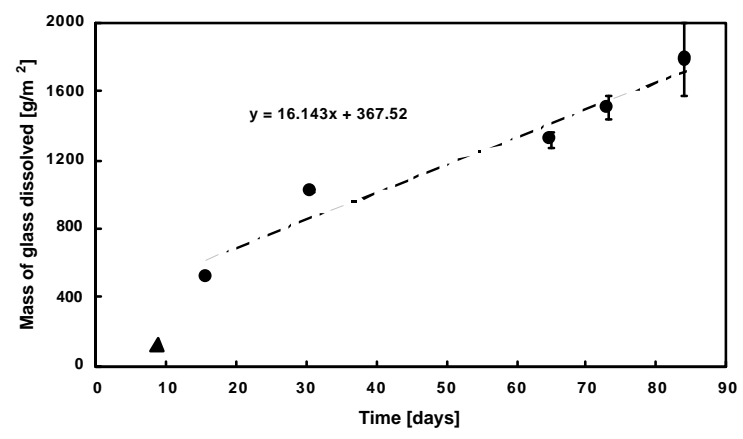

HLP- $18,200^{\circ} \mathrm{C}$ 


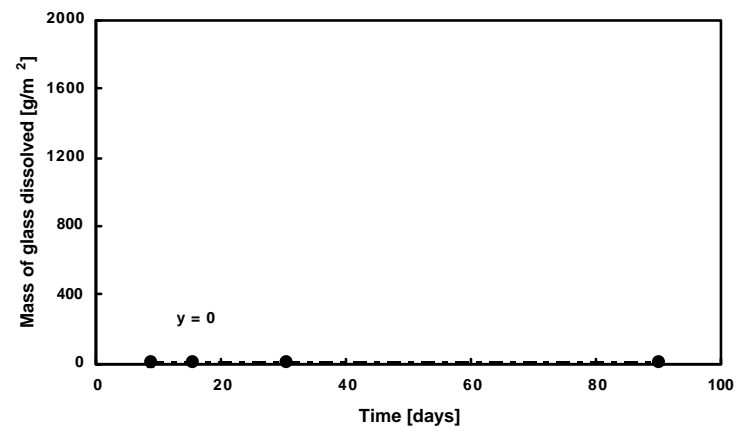

HLP- $19,200^{\circ} \mathrm{C}$

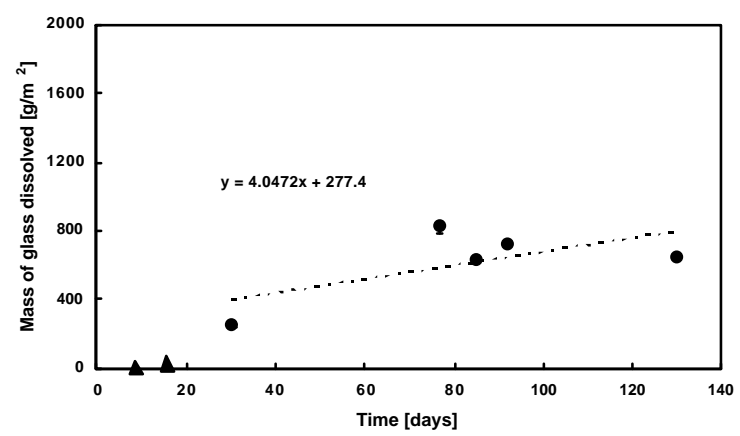

HLP-21, $200^{\circ} \mathrm{C}$

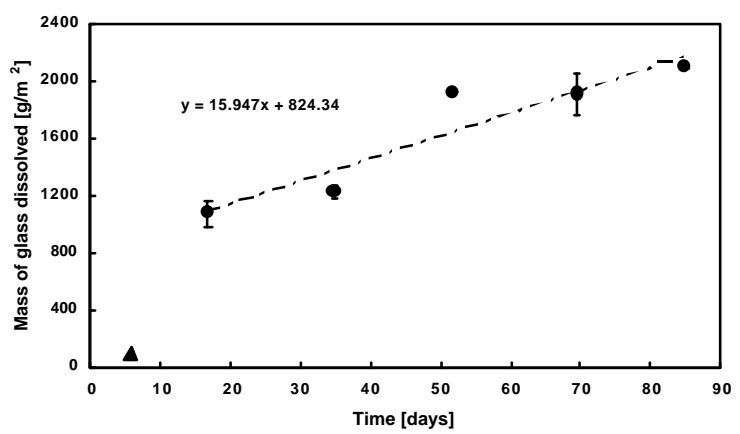

HLP-23, $200^{\circ} \mathrm{C}$

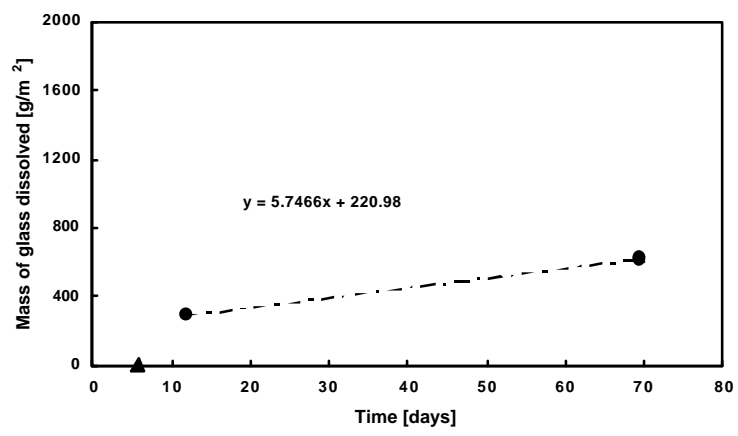

HLP- $25,200^{\circ} \mathrm{C}$

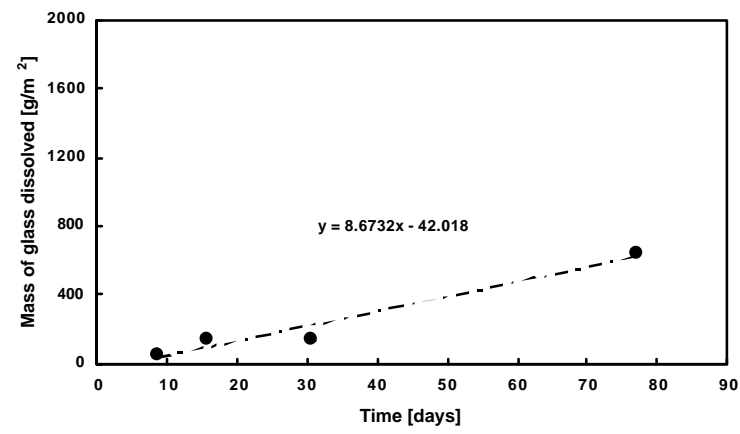

HLP-20, $200^{\circ} \mathrm{C}$

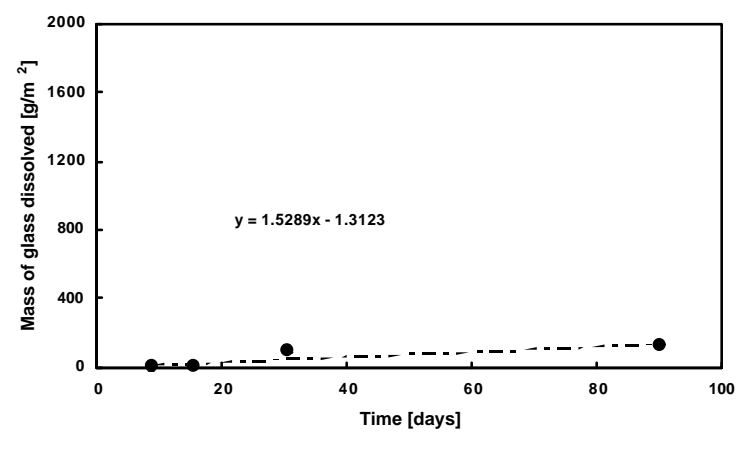

HLP- $22,200^{\circ} \mathrm{C}$

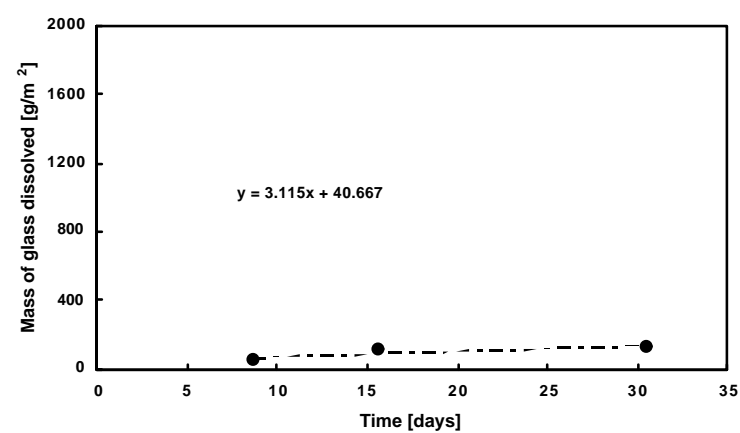

HLP- $24,200^{\circ} \mathrm{C}$

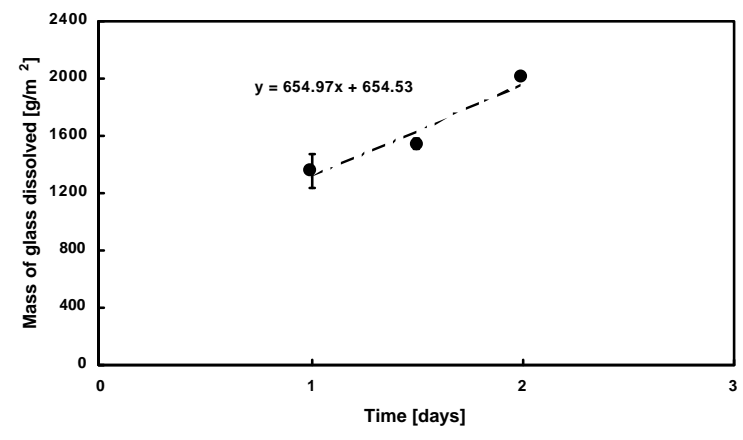

HLP- $25,300^{\circ} \mathrm{C}$ 


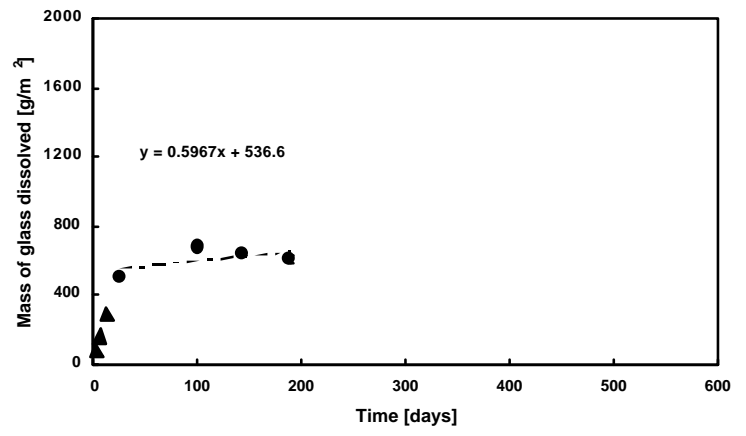

HLP-26, $200^{\circ} \mathrm{C}$

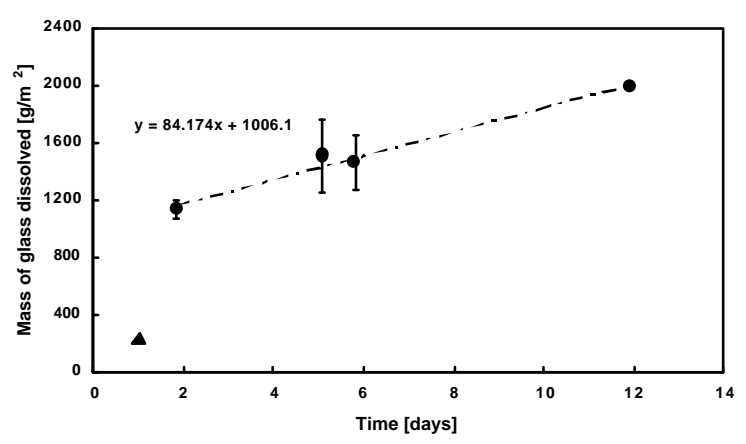

HLP-27, $200^{\circ} \mathrm{C}$

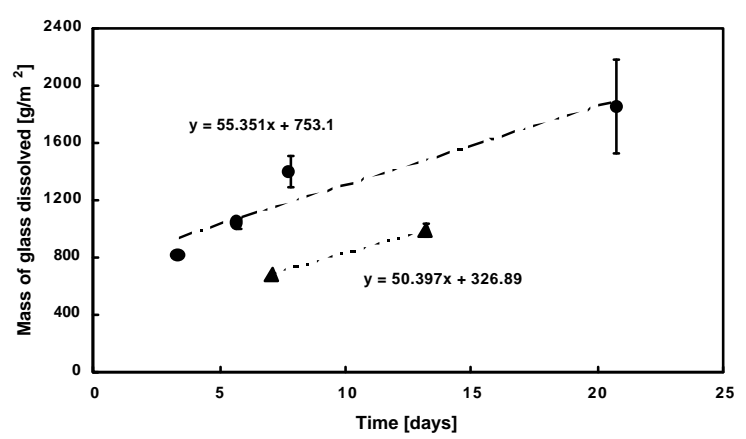

HLP- $29,200^{\circ} \mathrm{C}$

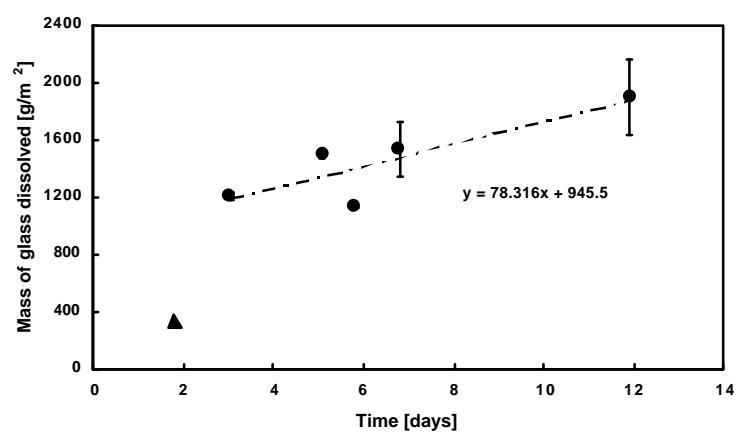

HLP- $31,200^{\circ} \mathrm{C}$

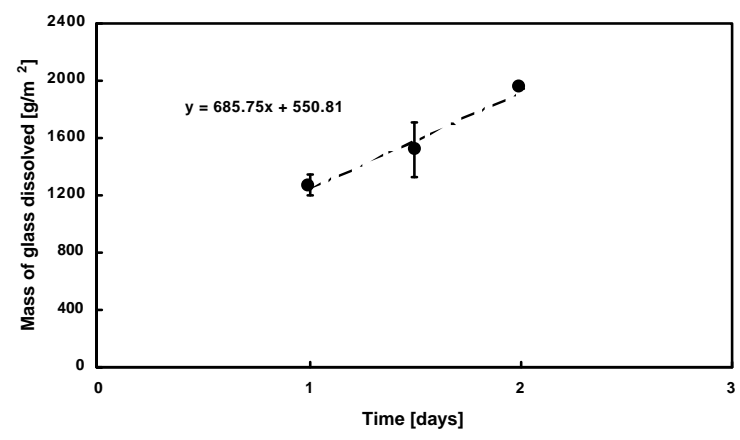

HLP-26, $300^{\circ} \mathrm{C}$

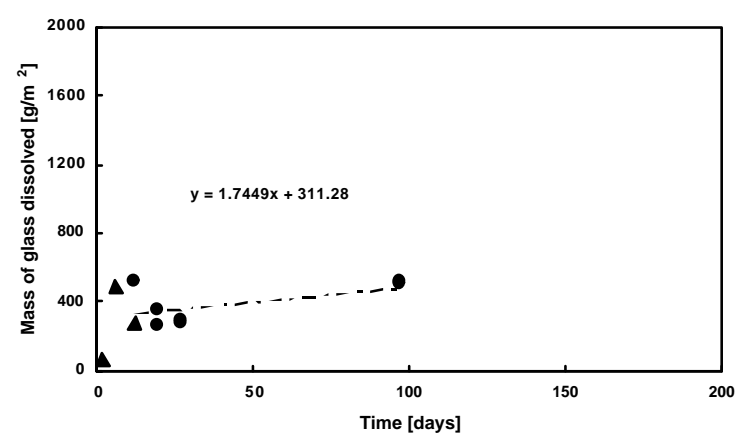

HLP- $28,200^{\circ} \mathrm{C}$

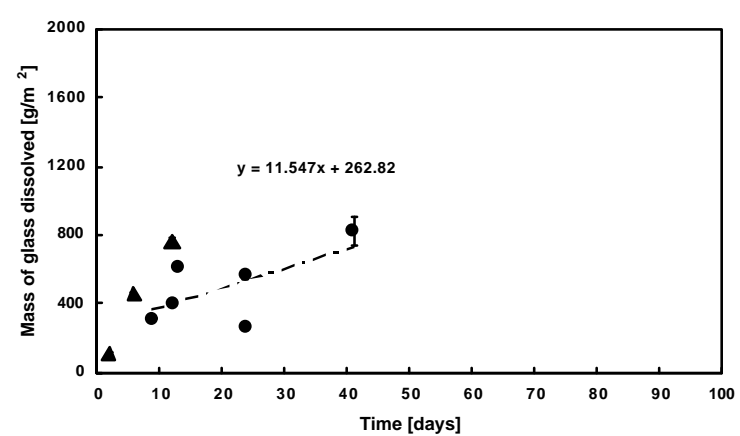

HLP-30, $200^{\circ} \mathrm{C}$

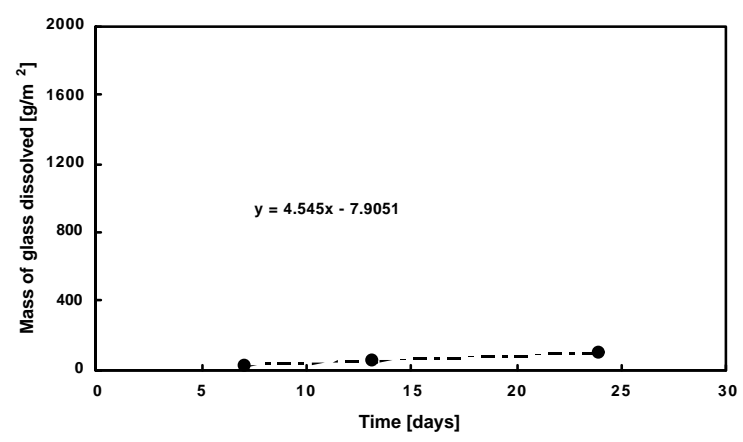

HLP-32, $200^{\circ} \mathrm{C}$ 


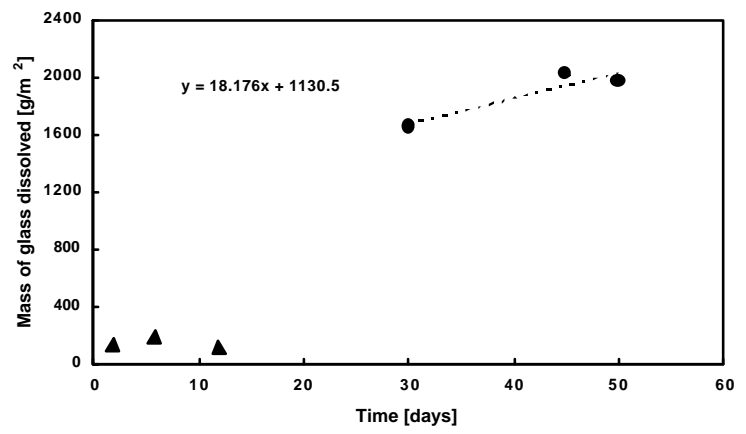

HLP-33, $200^{\circ} \mathrm{C}$

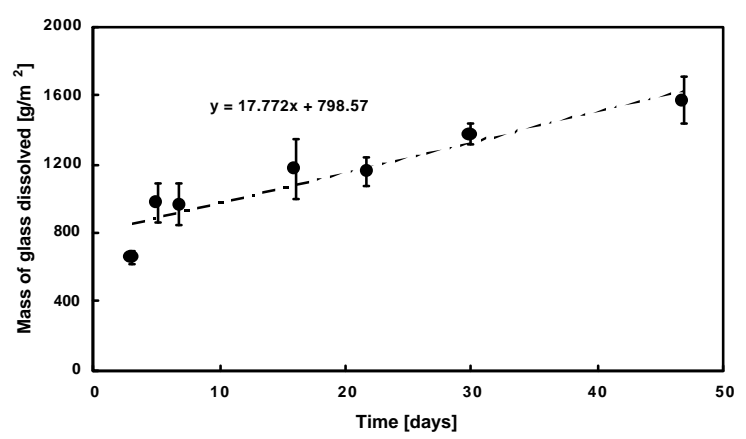

HLP- $35,200^{\circ} \mathrm{C}$

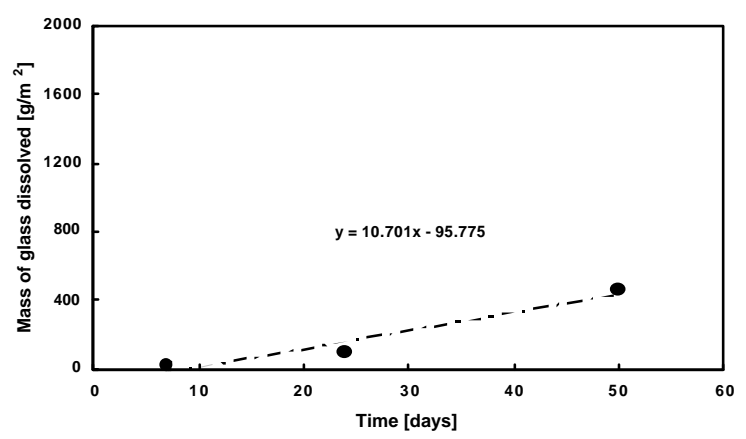

HLP-37, $200^{\circ} \mathrm{C}$

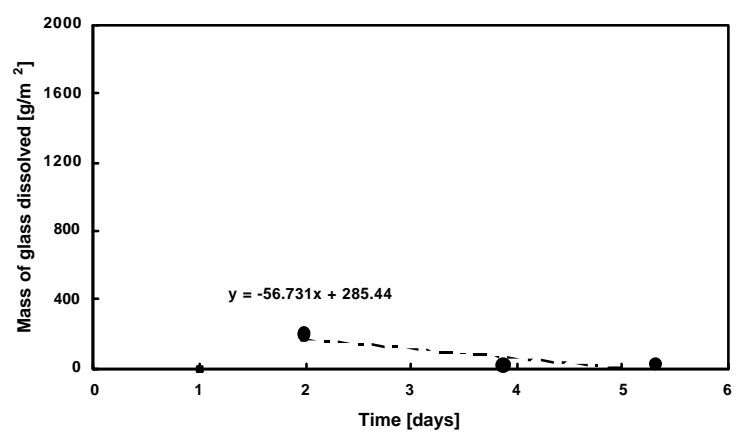

HLP- $39,200^{\circ} \mathrm{C}$

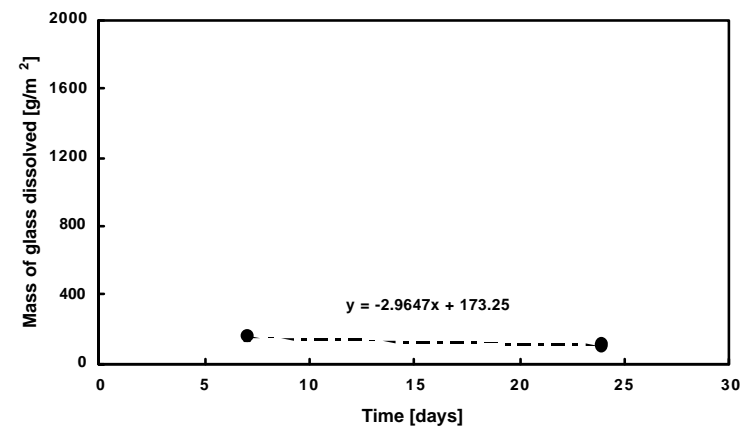

HLP-34, $200^{\circ} \mathrm{C}$

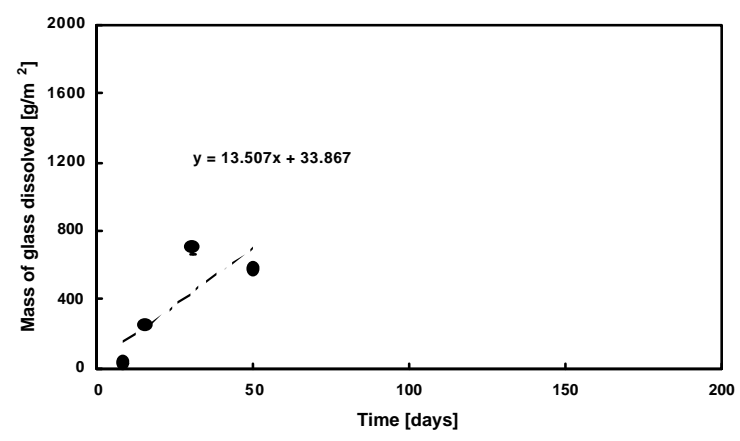

HLP-36, $200^{\circ} \mathrm{C}$

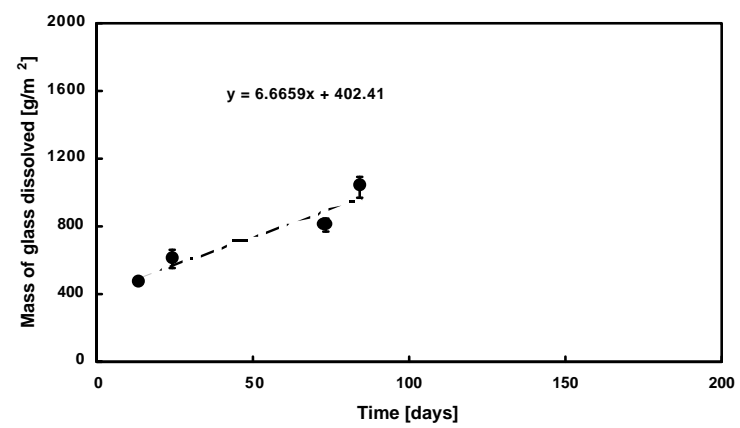

HLP- $38,200^{\circ} \mathrm{C}$

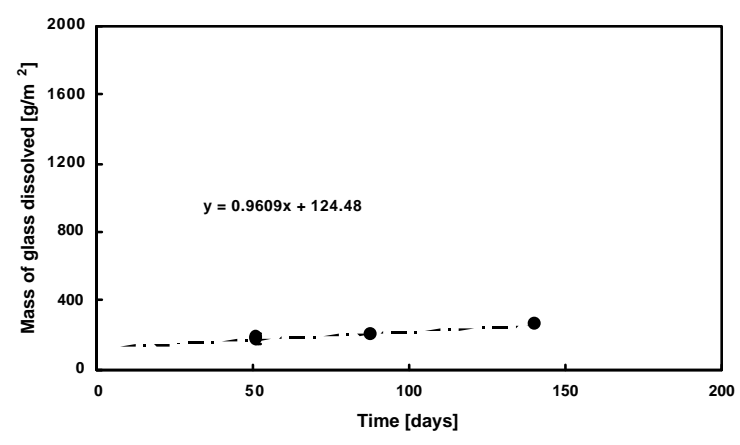

HLP- $40,200^{\circ} \mathrm{C}$ 


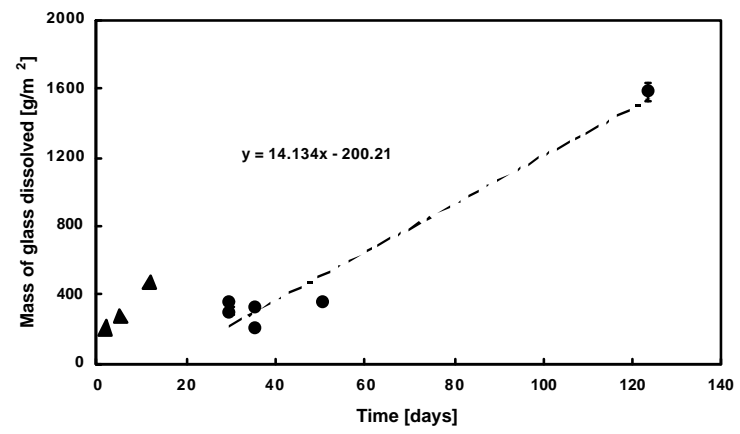

HLP-41, $200^{\circ} \mathrm{C}$

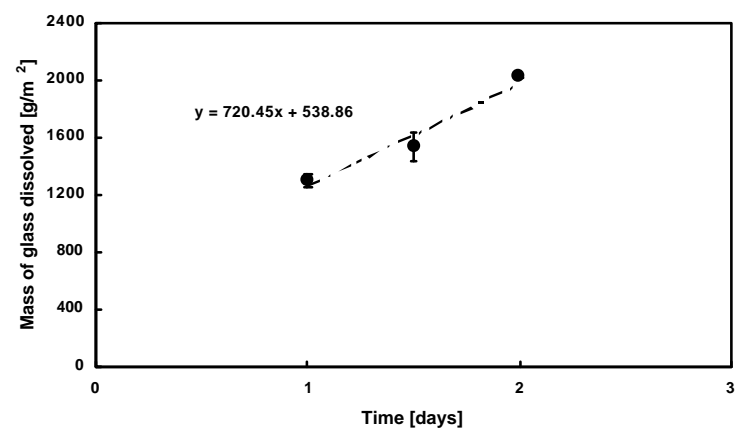

HLP- $43,300^{\circ} \mathrm{C}$

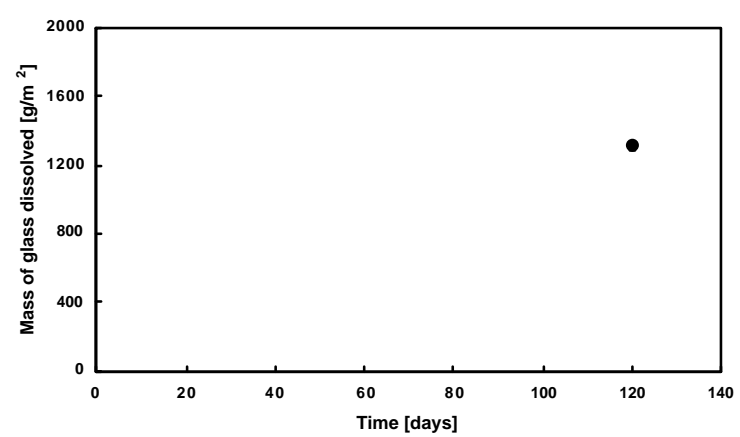

HLP- $45,200^{\circ} \mathrm{C}$

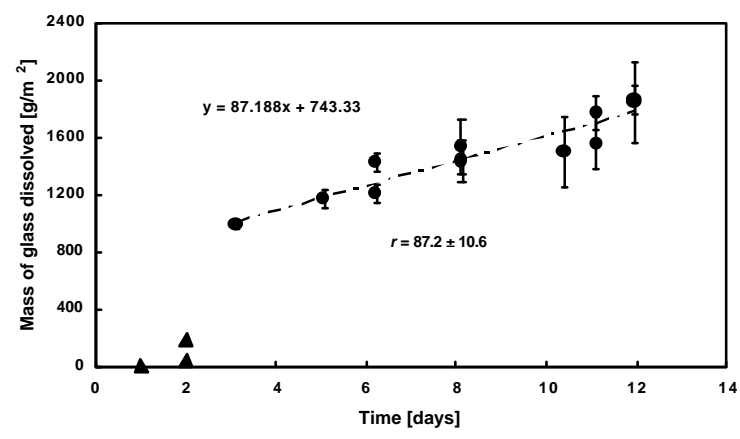

HLP-46, $175^{\circ} \mathrm{C}$

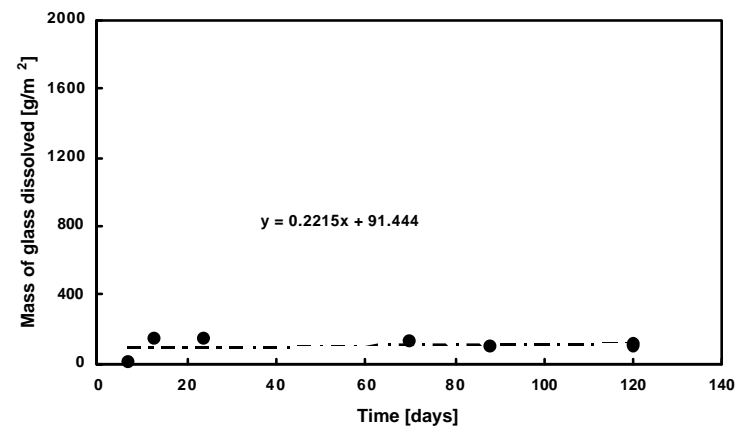

HLP-42, $200^{\circ} \mathrm{C}$

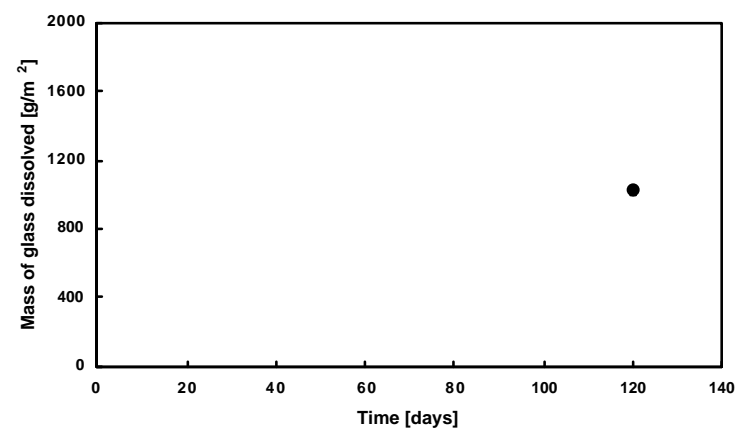

HLP-44, $200^{\circ} \mathrm{C}$

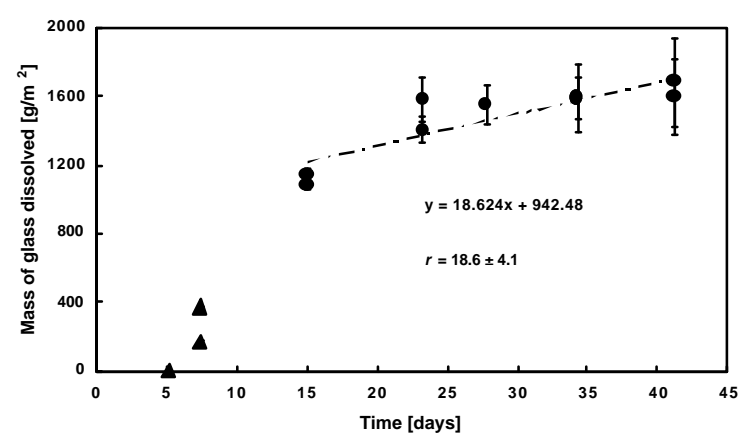

HLP-46, $150^{\circ} \mathrm{C}$

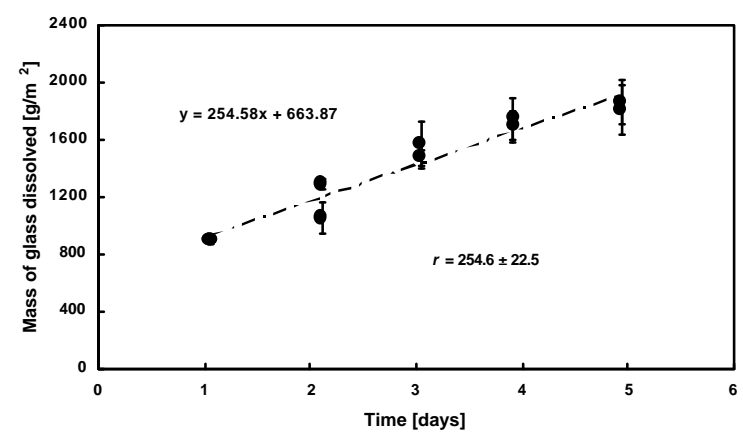

HLP- $46,200^{\circ} \mathrm{C}$ 


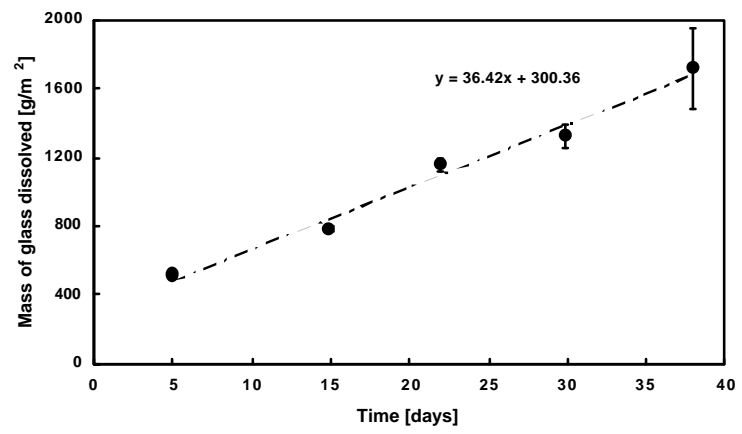

HLP- $47,200^{\circ} \mathrm{C}$

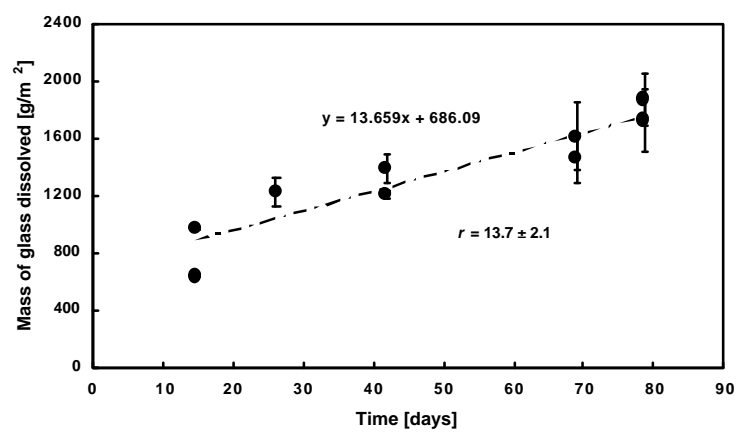

HLP- $48,175^{\circ} \mathrm{C}$

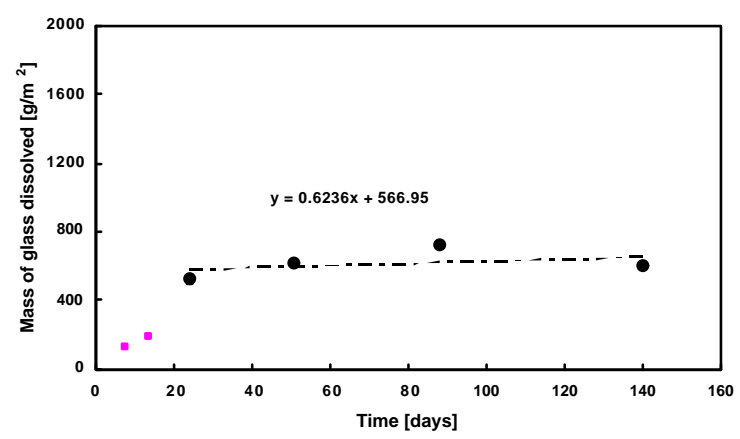

HLP- $49,200^{\circ} \mathrm{C}$

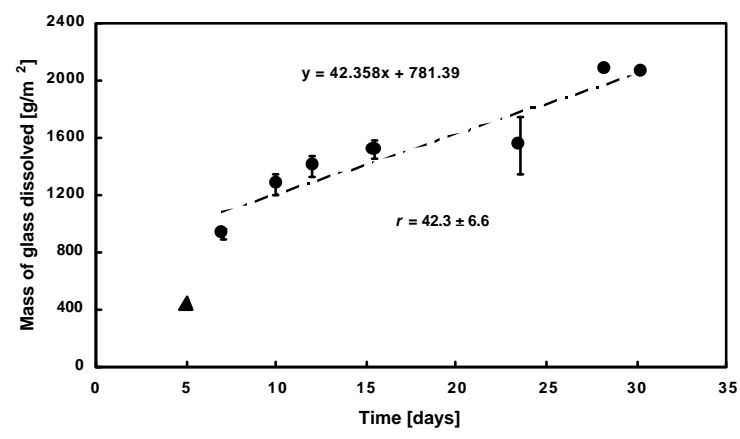

HLP-51, $250^{\circ} \mathrm{C}$

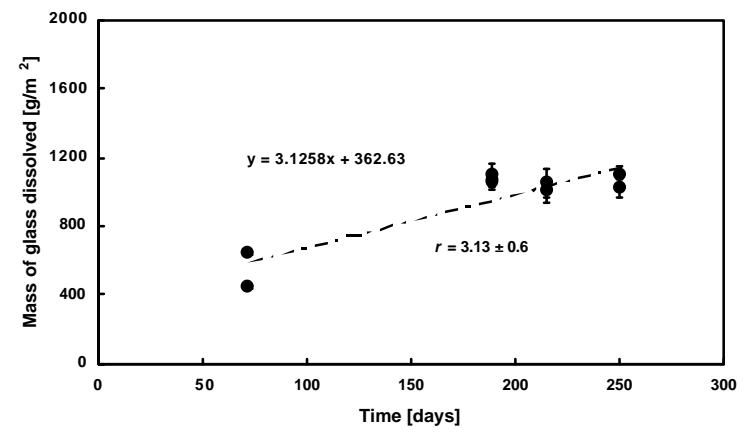

HLP- $48,150^{\circ} \mathrm{C}$

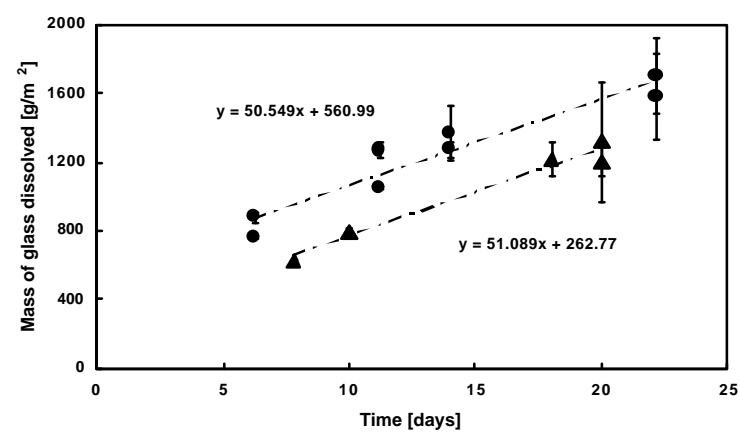

HLP- $48,200^{\circ} \mathrm{C}$

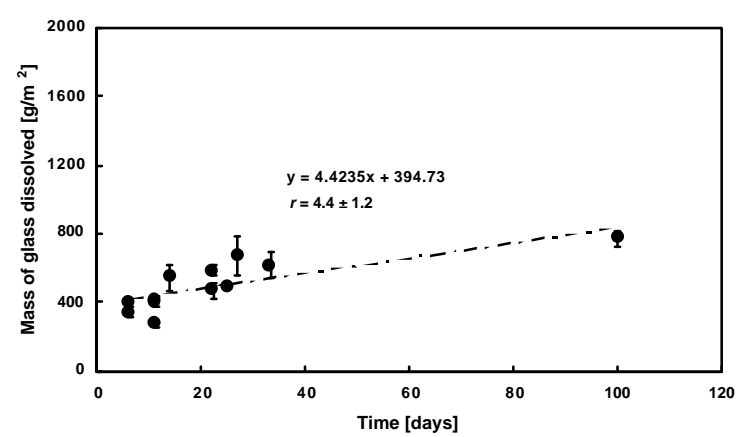

HLP- $51,200^{\circ} \mathrm{C}$

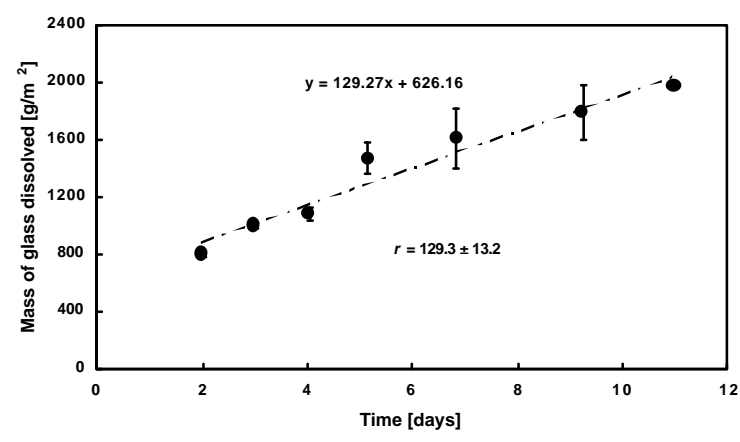

HLP-51, $275^{\circ} \mathrm{C}$ 


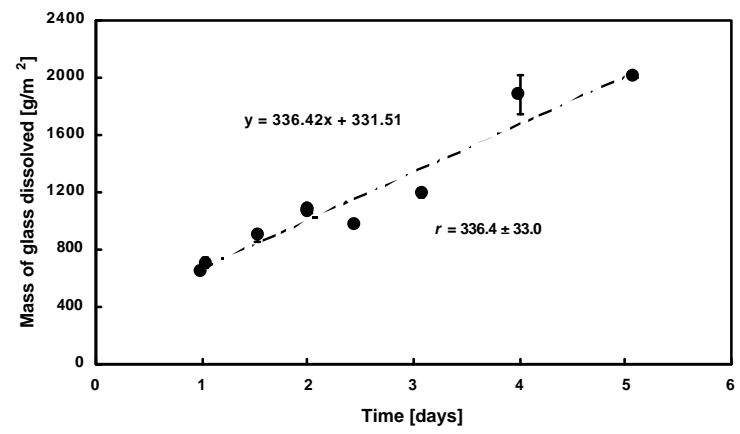

HLP-51, $300^{\circ} \mathrm{C}$

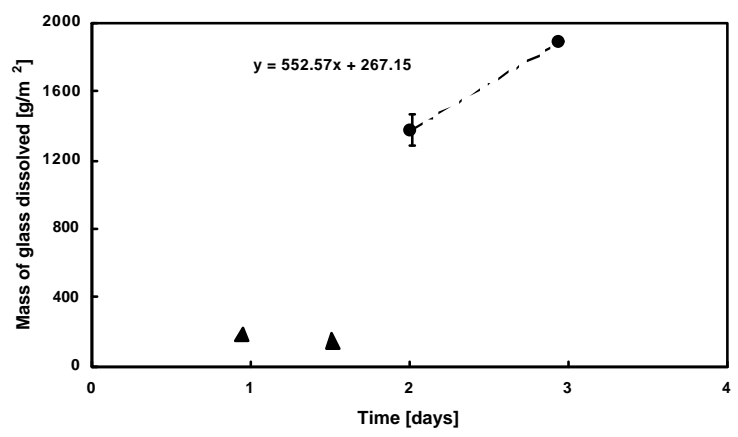

HLP-53, $200^{\circ} \mathrm{C}$

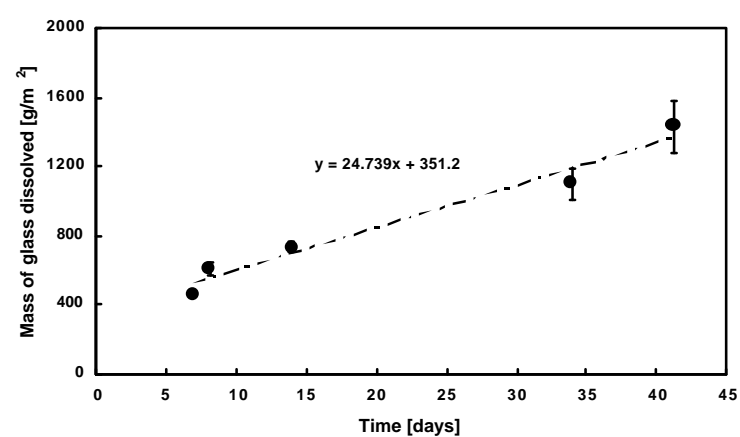

HLP- $55,200^{\circ} \mathrm{C}$

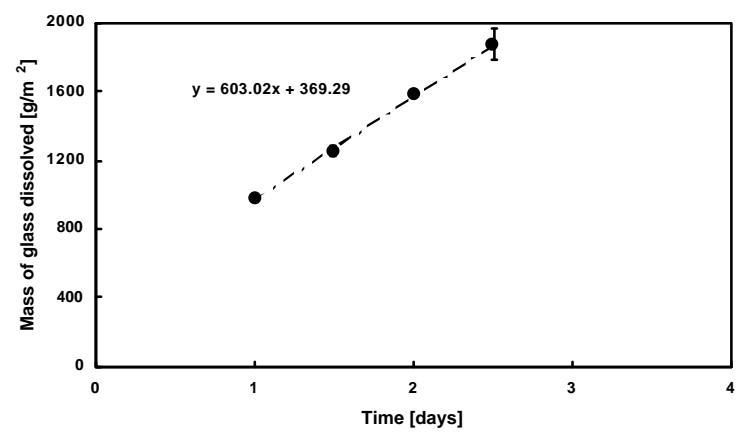

HLP-56, $300^{\circ} \mathrm{C}$

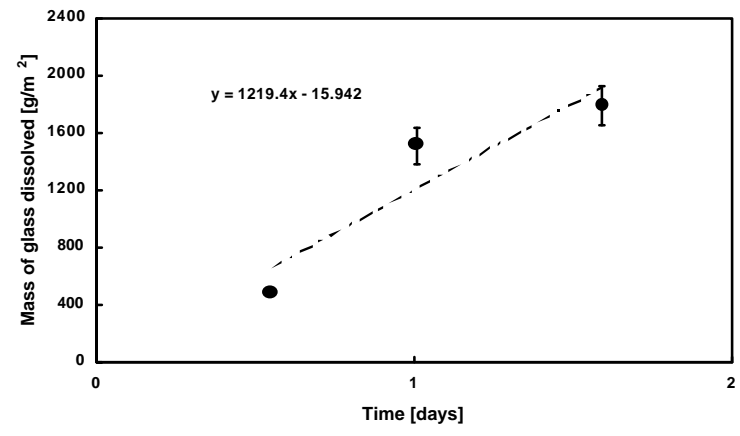

HLP-52, $200^{\circ} \mathrm{C}$

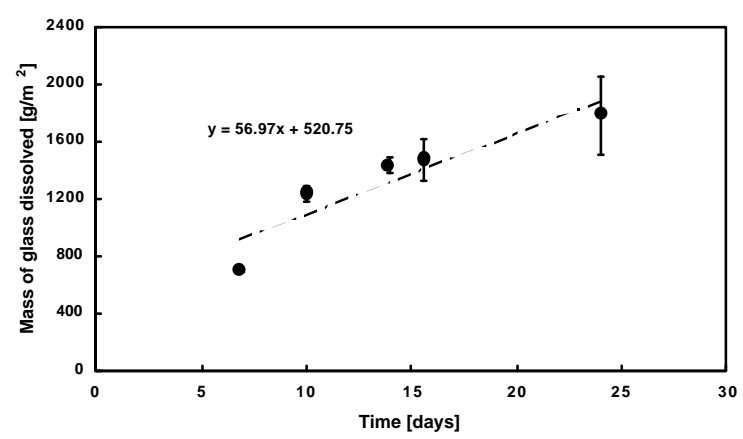

HLP-54, $200^{\circ} \mathrm{C}$

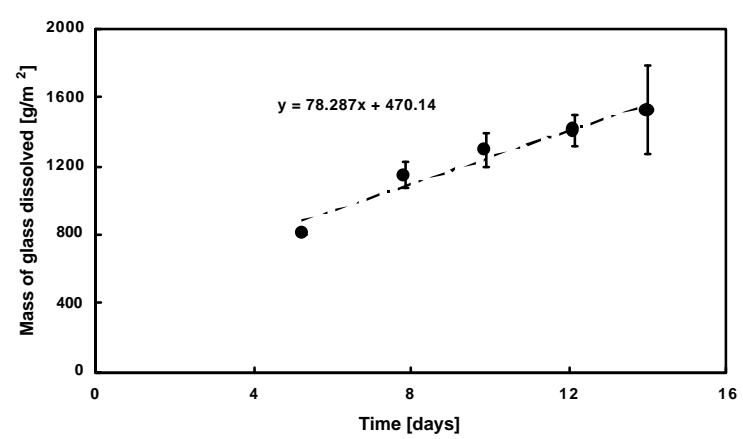

HLP-56, $250^{\circ} \mathrm{C}$ 


\section{APPENDIX E}

\section{VHT Alteration from Literature}




\section{APPENDIX E \\ VHT Alteration from Literature}

Results on HLP-46, HLP-55, and HLP-54 published by Feng et al. (1996) are summarized in Table E-1 together with results on HLP-48 are published in McGrail et al. (1999). All tests were conducted according to the Argonne National Laboratory vapor hydration test (VHT) procedure.

Table E-1. VHT Results Published in Literature

\begin{tabular}{clccc}
\hline Glass ID & Description & Temperature $\left[{ }^{\circ} \mathbf{C}\right]$ & Duration [days] & Alteration layer thickness [ $\boldsymbol{\mu m}$ ] \\
\hline HLP-46 & LD6-5412 & 70 & 56 & 0 \\
HLP-46 & LD6-5412 & 120 & 28 & 0 \\
HLP-46 & LD6-5412 & 120 & 56 & 0 \\
HLP-46 & LD6-5412 & 150 & 3 & 0 \\
HLP-46 & LD6-5412 & 150 & 7 & 200 \\
HLP-46 & LD6-5412 & 150 & 11 & 200 \\
HLP-46 & LD6-5412 & 150 & 14 & Completely altered \\
HLP-46 & LD6-5412 & 150 & 18 & Completely altered \\
HLP-46 & LD6-5412 & 150 & 21 & 200 \\
HLP-46 & LD6-5412 & 175 & 1 & 800 \\
HLP-46 & LD6-5412 & 175 & 2 & 1000 \\
HLP-46 & LD6-5412 & 175 & 3 & 800 \\
HLP-46 & LD6-5412 & 175 & 5 & Completely reacted \\
HLP-46 & LD6-5412 & 175 & 7 & Completely reacted \\
HLP-46 & LD6-5412 & 200 & 3 & Completely reacted \\
HLP-46 & LD6-5412 & 200 & 7 & 0 \\
HLP-48 & LAWA33 & 150 & 14 & 5 \\
HLP-48 & LAWA33 & 150 & 28 & 40 \\
HLP-48 & LAWA33 & 150 & 57 & 300 \\
HLP-48 & LAWA33 & 150 & 77 & 1 \\
HLP-48 & LAWA33 & 175 & 6 & 50 \\
HLP-48 & LAWA33 & 175 & 14 & 250 \\
HLP-48 & LAWA33 & 175 & 28 & 0 \\
HLP-54 & L4-912 & 150 & 7 & 0 \\
HLP-54 & L4-912 & 150 & 14 & 0 \\
HLP-54 & L4-912 & 150 & 28 & 0 \\
HLP-55 & L4-99 & 150 & 7 & 0 \\
HLP-55 & L4-99 & 150 & 14 & 0 \\
HLP-55 & L4-99 & 150 & 28 & \\
\hline
\end{tabular}




\section{APPENDIX F}

\section{XRD Scans from VHT Samples}




\section{APPENDIX F XRD Scans from VHT Samples}

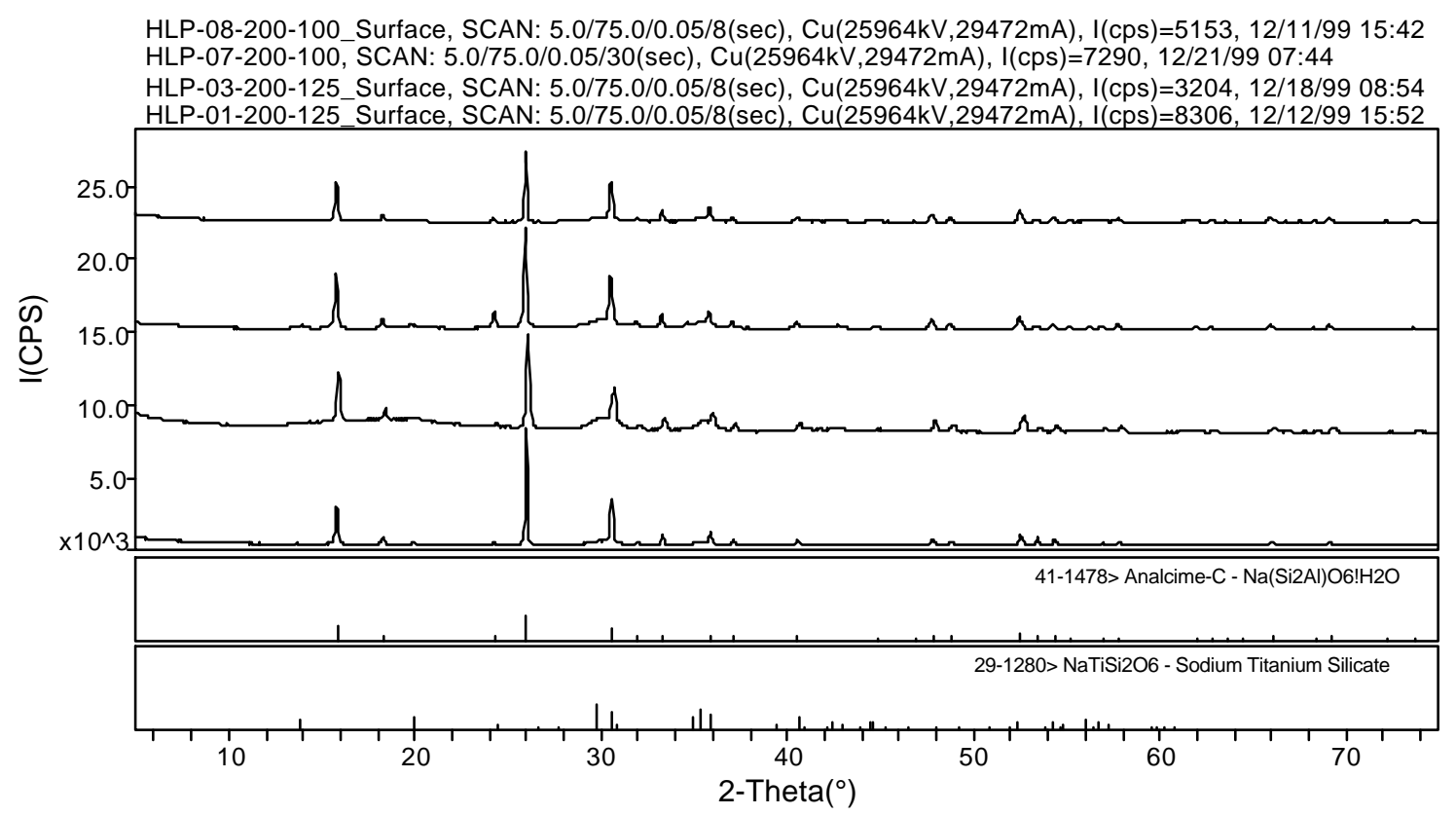

HLP-55-200-014, SCAN: 5.0/75.0/0.05/8(sec), Cu(25964kV,29472mA), I(cps)=2076, 11/01/99 13:01 HLP-54-200-041, SCAN: 5.0/75.0/0.05/8(sec), Cu(25964kV,29472mA), I(cps)=4338, 11/01/99 16:07 HLP-51-250-003B_Surface, SCAN: 5.0/75.0/0.05/8(sec), Cu(25964kV,29472mA), I(cps)=1153, 12/07/99 06:02 HLP-35-200-021, SCAN: 5.0/75.0/0.05/1(sec), Cu(25964kV,29472mA), I(cps)=3299, 09/20/99 16:52 HLP-29-200-013, SCAN: 5.0/75.0/0.05/30(sec), Cu(25964kV,29472mA), I(cps)=12833, 09/03/99 18:36 HLP-02-200-030, SCAN: 5.0/75.0/0.05/30(sec), Cu(25964kV,29472mA), I(cps)=8885, 08/29/99 07:56
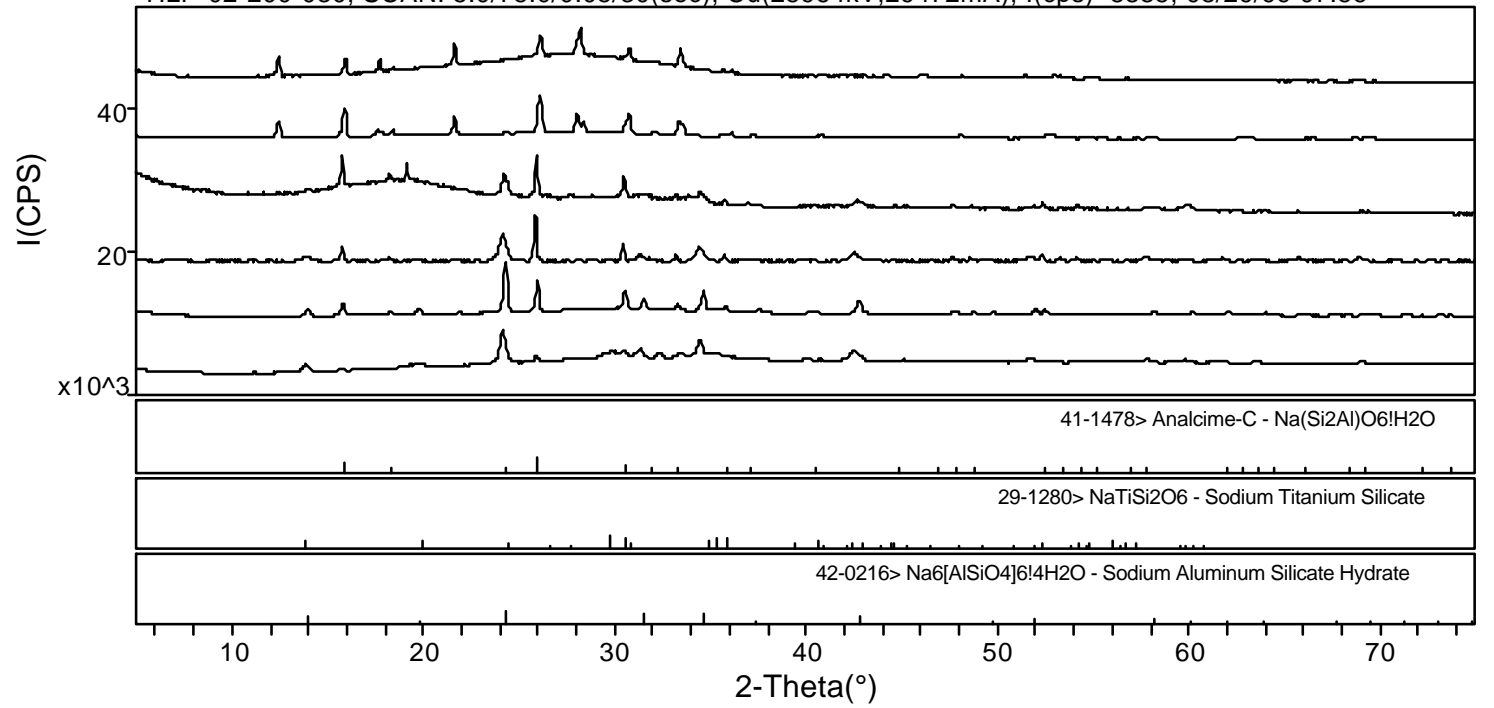

F. 1 


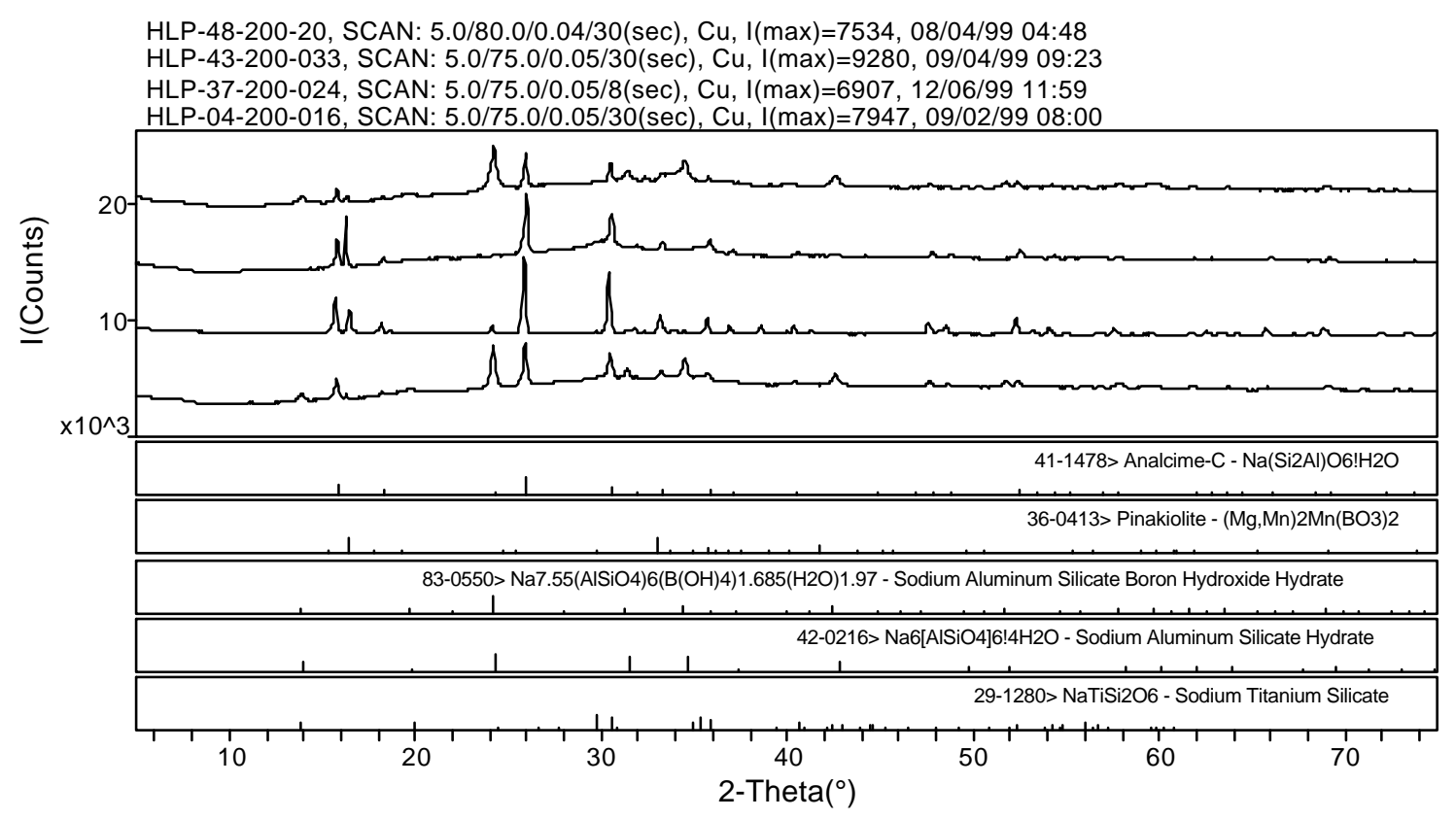

HLP-53-300-003, SCAN: 5.0/75.0/0.05/8(sec), Cu, I(cps)=1494, 11/27/99 14:28

HLP-51-150-187_Surface, SCAN: 5.0/75.0/0.05/8(sec), Cu, I(cps)=5280, 11/29/99 11:17

HLP-09-300-005, SCAN: 5.0/75.0/0.05/8(sec), Cu, I(cps)=4380, 11/25/99 16:13

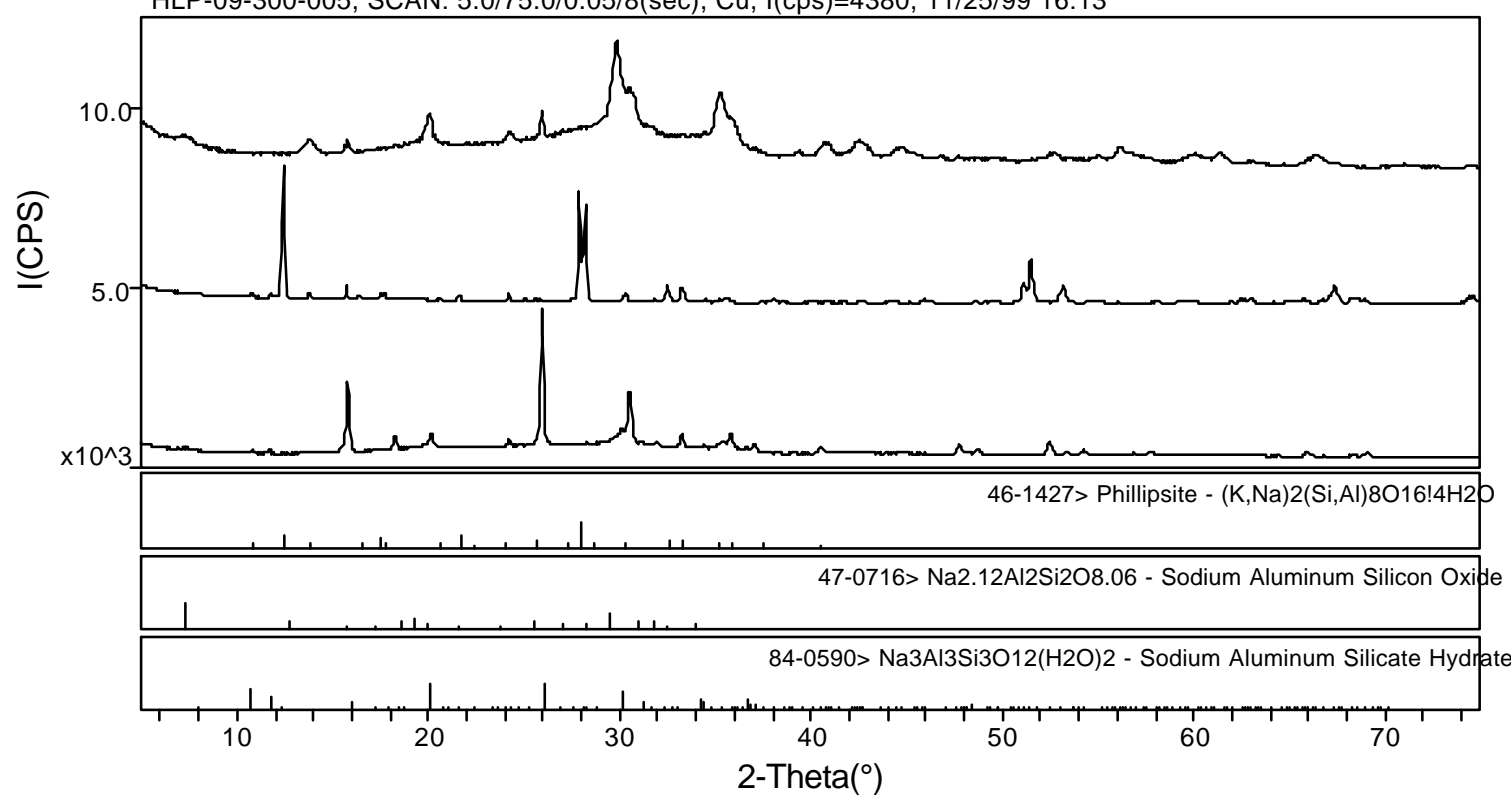


HLP-13-200-080 Surface, SCAN: 5.0/75.0/0.05/8(sec), Cu(25964kV,29472mA), I(cps)=6152, 12/21/99 18:33

HLP-12-300-002, SCAN: 5.0/75.0/0.05/8(sec), Cu(25964kV,29472mA), I(cps)=1944, 11/26/99 08:18

HLP-12-200-105, SCAN: 5.0/75.0/0.05/8(sec), Cu(25964kV,29472mA), I(cps)=3268, 11/28/99 15:42

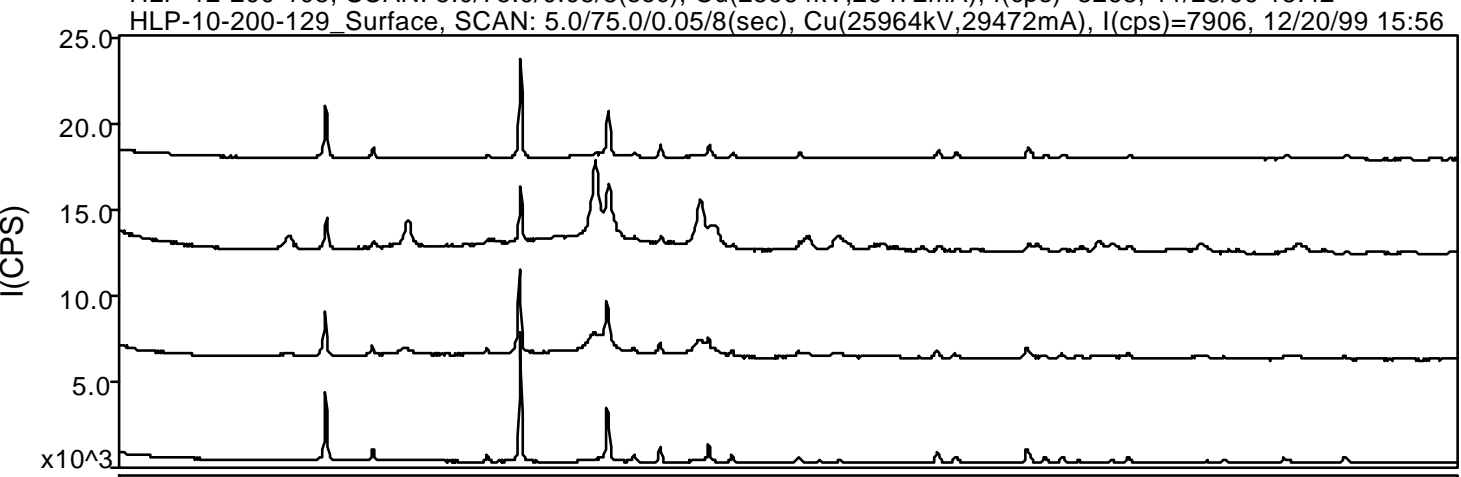

41-1478> Analcime-C - Na(Si2Al)O6!H2O

29-1280> NaTiSi2O6 - Sodium Titanium Silicate

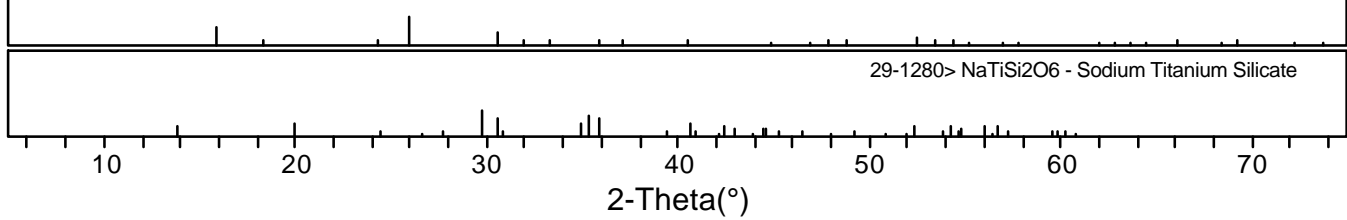

HL-18-200-032-103199c, SCAN: 5.0/75.0/0.05/8(sec), Cu(25964kV 29472mA), I(cps)=4542, 10/31/99 21:20

HLP-17-200-075_Surface, SCAN: 5.0/75.0/0.05/8(sec), Cu(25964kV,29472mA), I(cps)=5559, 12/18/99 15:41

HLP-16-200-075_Surface, SCAN: 5.0/75.0/0.05/8(sec), Cu(25964kV,29472mA), I(cps)=8646, 12/11/99 18:57

HLP-15-200-075 Surface, SCAN: 5.0/75.0/0.05/8(sec), Cu(25964kV,29472mA), I(cps)=13877, 12/17/99 12:55

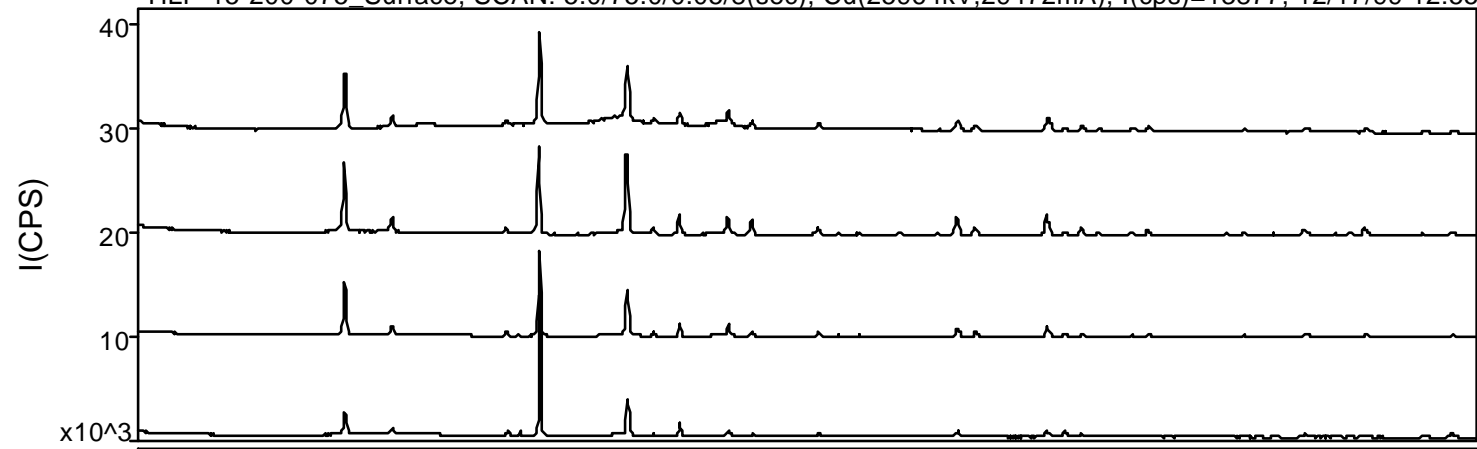

41-1478> Analcime-C - Na(Si2Al)O6!H2O

29-1280> NaTiSi2O6 - Sodium Titanium Silicate

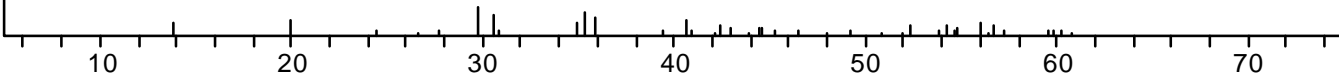

2-Theta $\left({ }^{\circ}\right)$ 

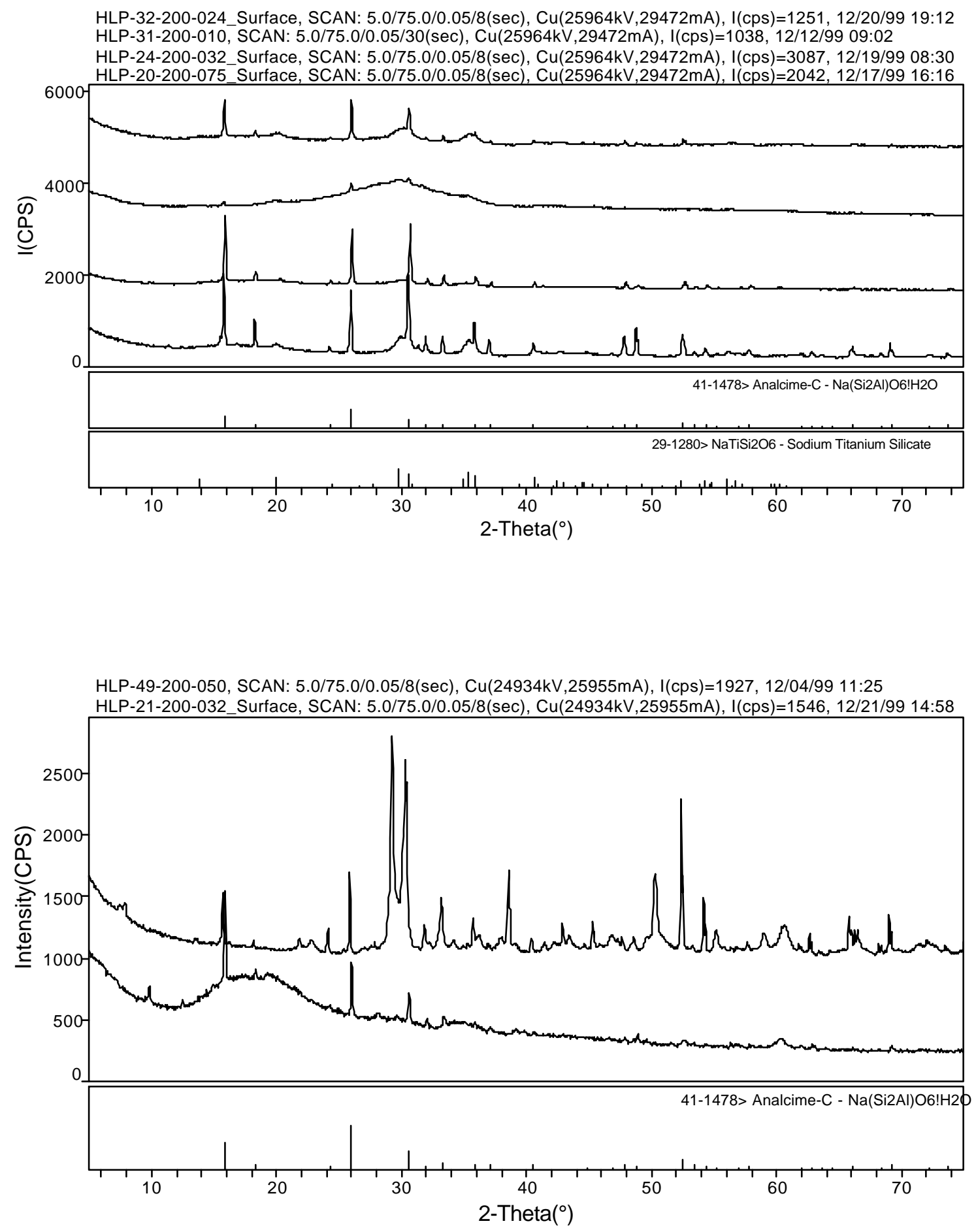

F.4 


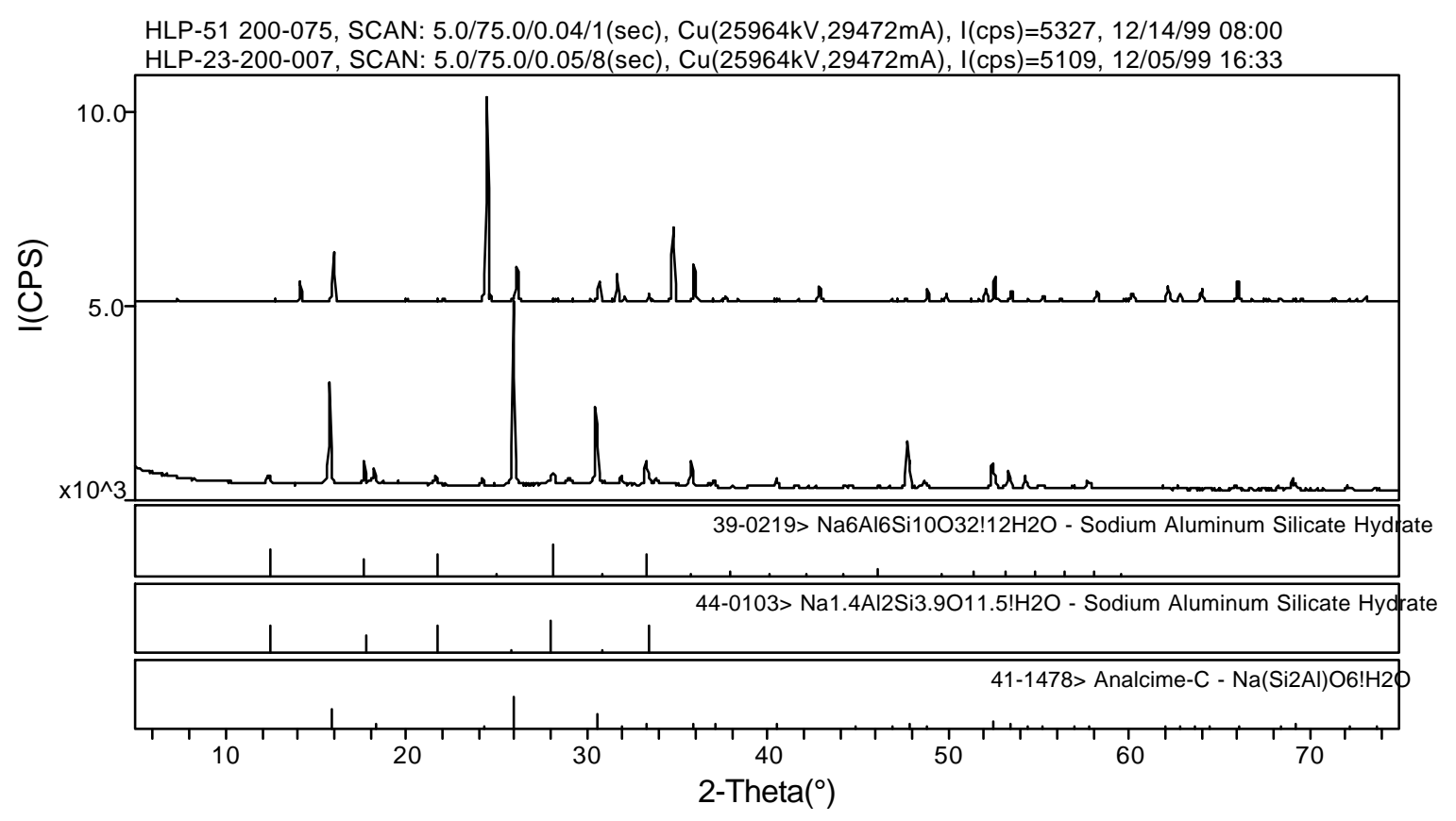

HLP-27-200-100, SCAN: 5.0/75.0/0.05/8(sec), Cu(25964kV,29472mA), I(cps)=11810, 12/05/99 12:41

HLP-36-200-032_Whole sample, SCAN: 5.0/75.0/0.05/8(sec), Cu(25964kV,29472mA), I(cps)=5523, 11/29/99 18:31 HLP-30-200-023_Surface, SCAN: 5.0/75.0/0.05/8(sec), Cu(16896mA), I(cps)=9359, 12/12/99 19:55

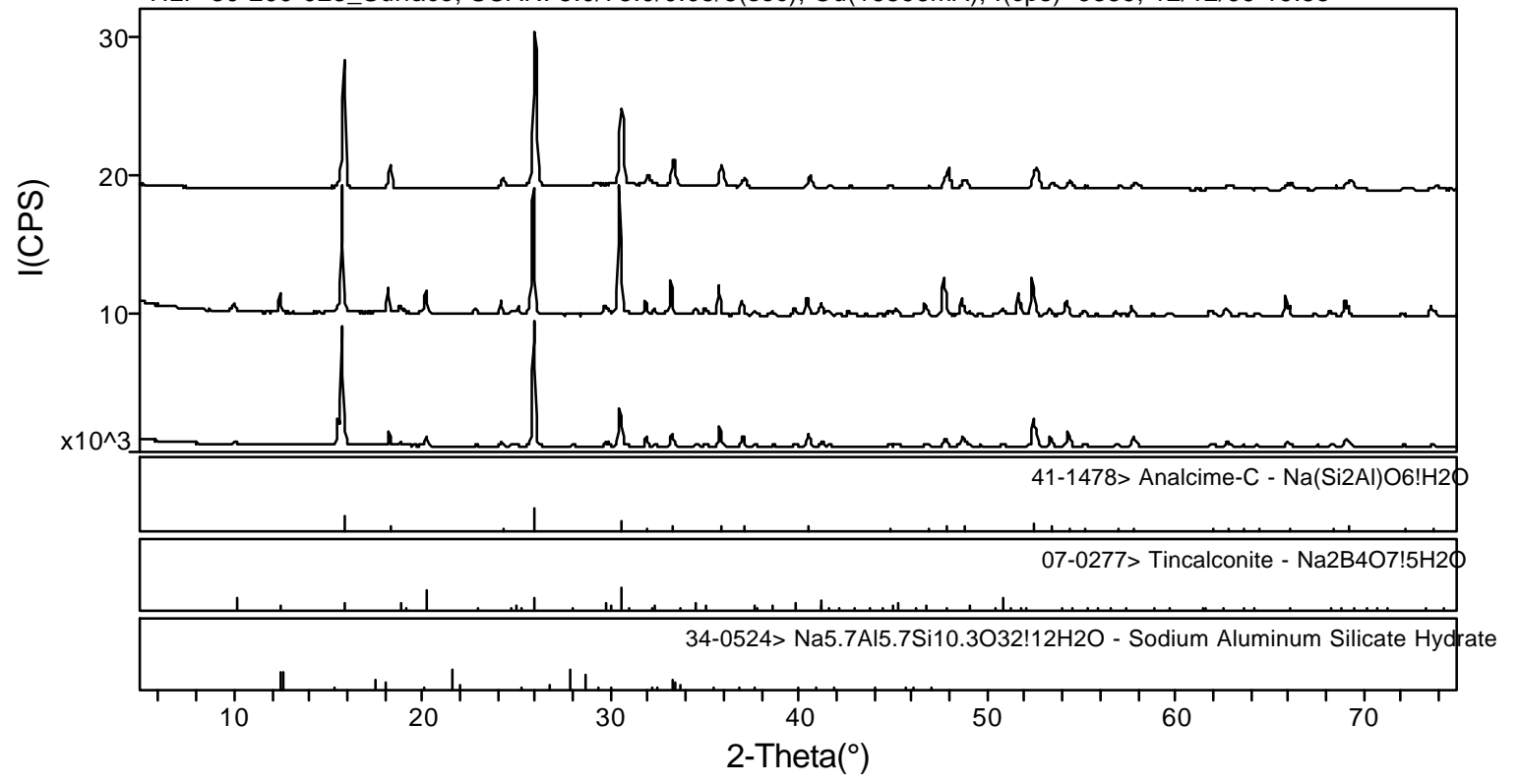




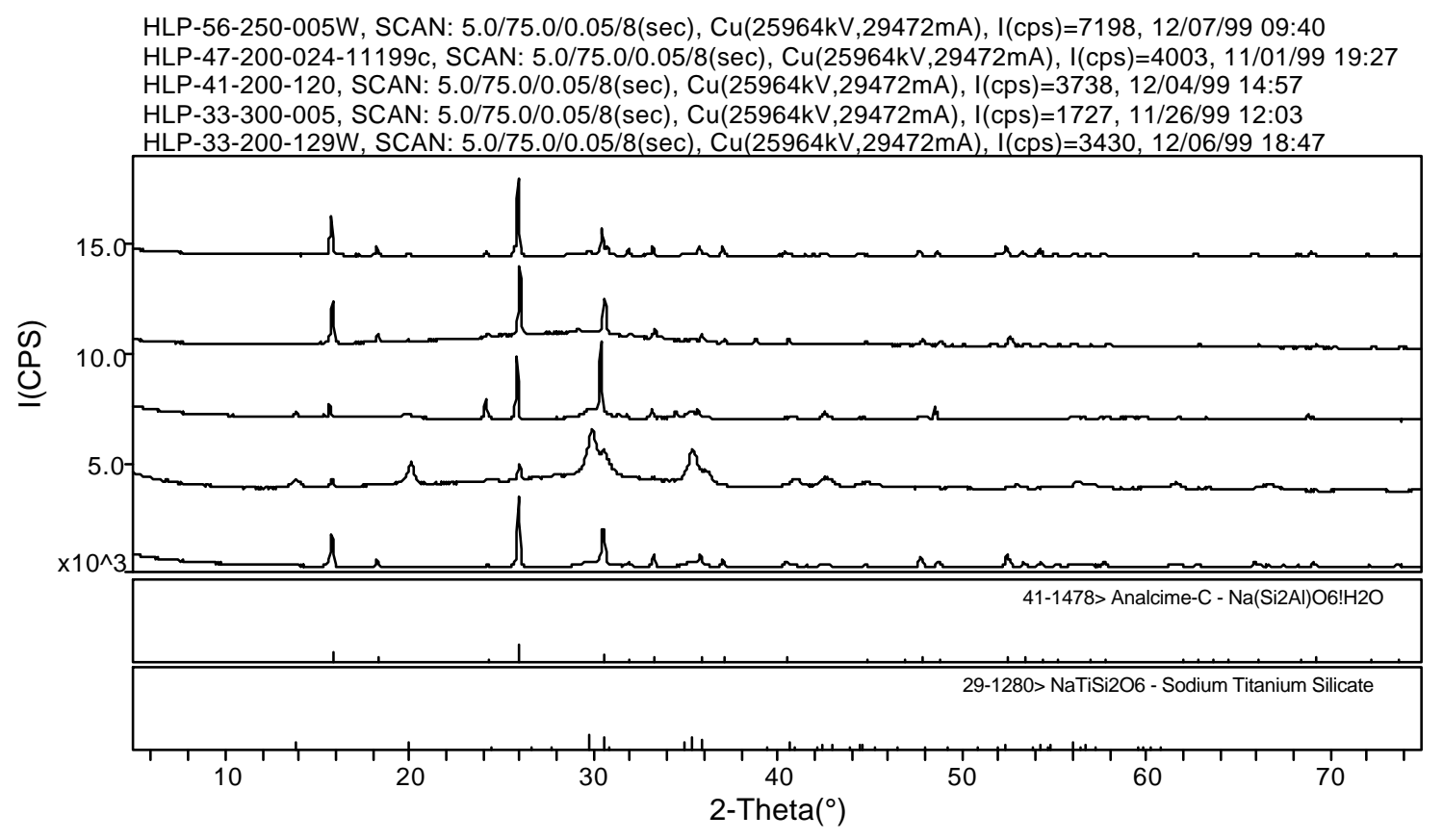

HLP-42-200-068_Surface, SCAN: 5.0/75.0/0.05/8(sec), Cu, I(cps)=2979, 12/21/99 11:01 HLP-38-200-064, SCAN: 5.0/75.0/0.05/8(sec), Cu, I(cps)=3794, 11/27/99 21:28 HLP-38-200-024, SCAN: 5.0/75.0/0.05/30(sec), Cu, I(cps) =12597, 09/06/99 20:05
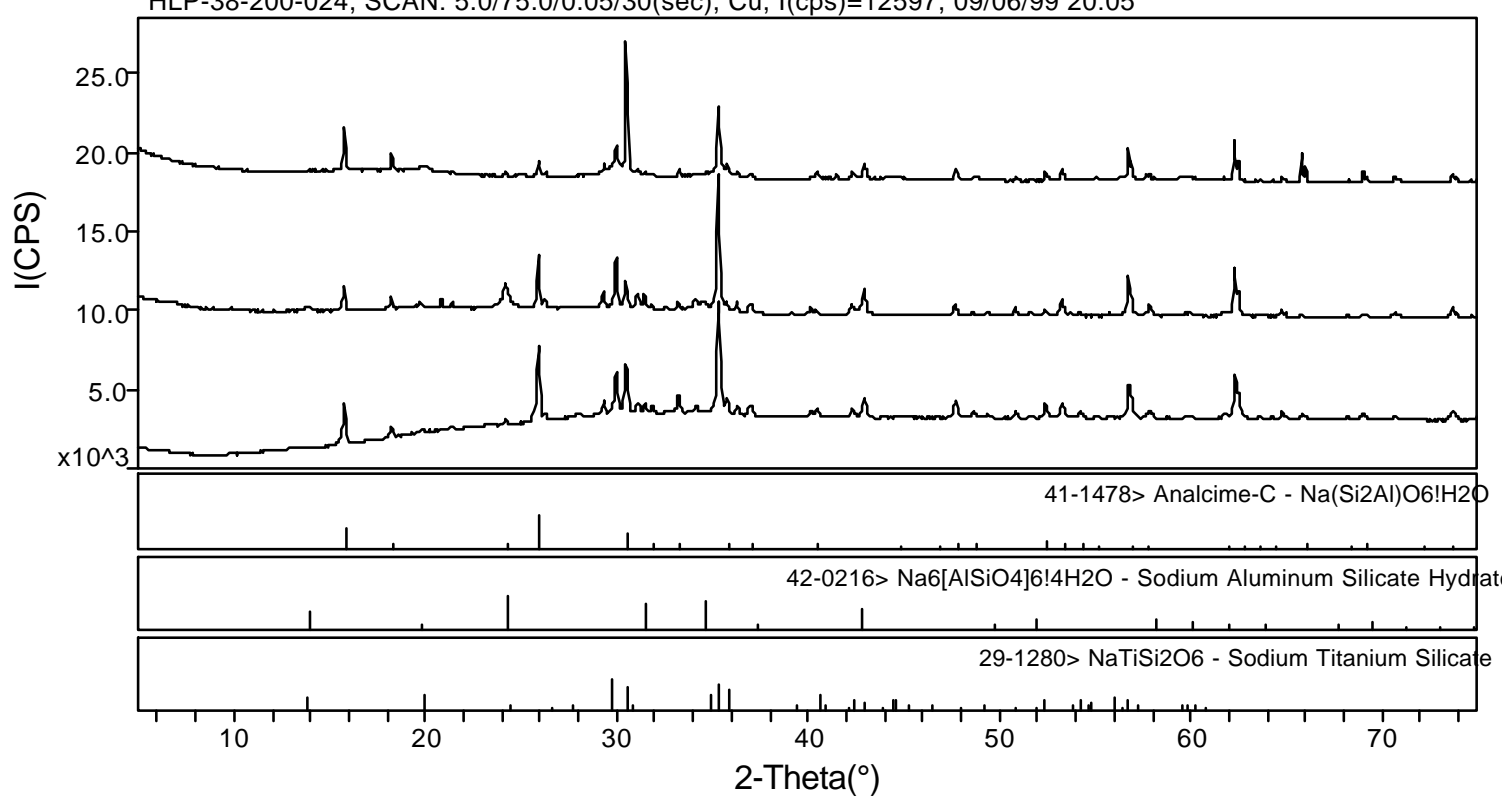

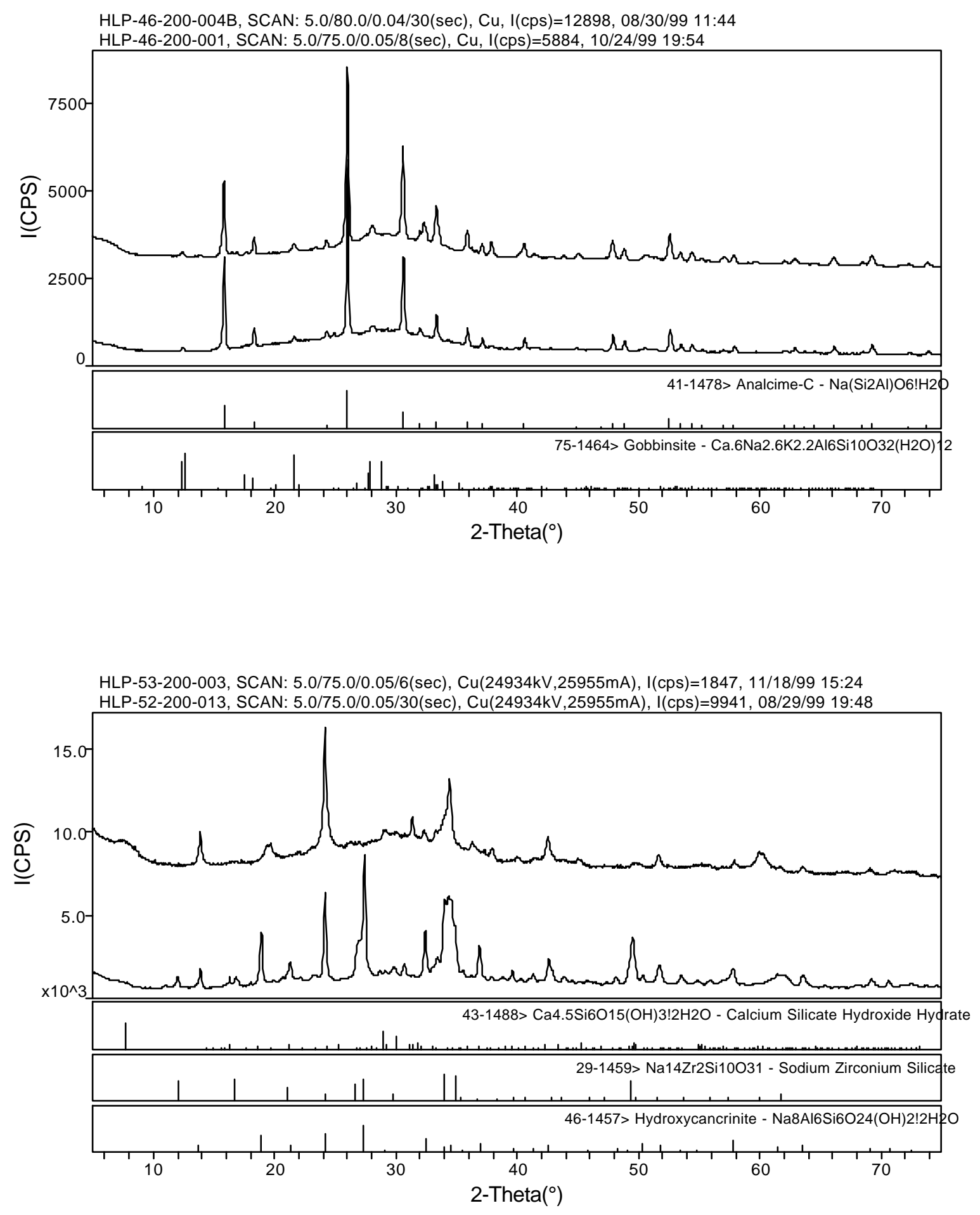


\section{Distribution}

No. of

Copies

\section{OFFSITE}

2 DOE/Office of Scientific and Technical Information

2 Argonne National Laboratory Argonne, IL 60439, Attn:

W. L. Ebert (2)

2 Catholic University of America

Vitreous State Laboratory 620 Michigan Ave., N. E. Washington, D. C. 20064, Attn:

A. C. Buechele

I. Pegg

2 VSCHT

Ustav Skla a Keramiky

Technicka 5

16628 Praha 6

Czech Republic, Attn:

Ales Helebrant (2)

14 Westinghouse Savannah River Company Aiken, SC 29808, Attn:

K. G. Brown (5)

D. A. Crowley

J. R. Harbour

E. W. Holtzscheiter

C. M. Jantzen

J. C. Marra

S. L. Marra

D. K. Peeler

I. A. Reamer

G. W. Wicks
No. of

Copies

\section{ONSITE}

10 DOE/Office of River Protection

N. R. Brown

H6-60

P. E. Lamont

H6-60

C. A. Babel (8)

H6-60

CMT/205 2 DOE/Richland Operations Office

T. E. Pietrok

K8-50

D. A. Brown

$\mathrm{K} 8-50$

2 BNFL Inc.

N. Lockwood

D. Swanberg

BN-FL

BN-FL

1 CH2M Hill Hanford Group

J. O. Honeyman

H6-62

2 Fluor Daniel Northwest

F. M. Mann (2)

H0-22

53 Pacific Northwest National Laboratory

B. R. Allen

K6-24

W. F. Bonner (5)

K9-14

W. C. Cosby

K7-62

P. R. Hrma

K6-24

L. K. Holton

H6-61

A. Jiricka

K6-24

B. M. Jorgensen

K6-24

B. P. McGrail (3)

K6-81

L. R. Pederson

K2-44

J. M. Perez

H6-61

L. M. Peurrung

K6-24

D. E. Smith

K6-24

D. M. Strachan

K6-24

J. D. Vienna (20)

K6-24

J. H. Westsik

K9-91

B. J. Williams -- TFA (8)

K9-69

Technical Report Files (5)

P8-55 